\title{
Selected Papers from the 13th Estuarine and Coastal Modeling Conference
}

Edited by

Richard P. Signell and Henry J. Bokuniewicz

Printed Edition of the Special Issue Published in JMSE

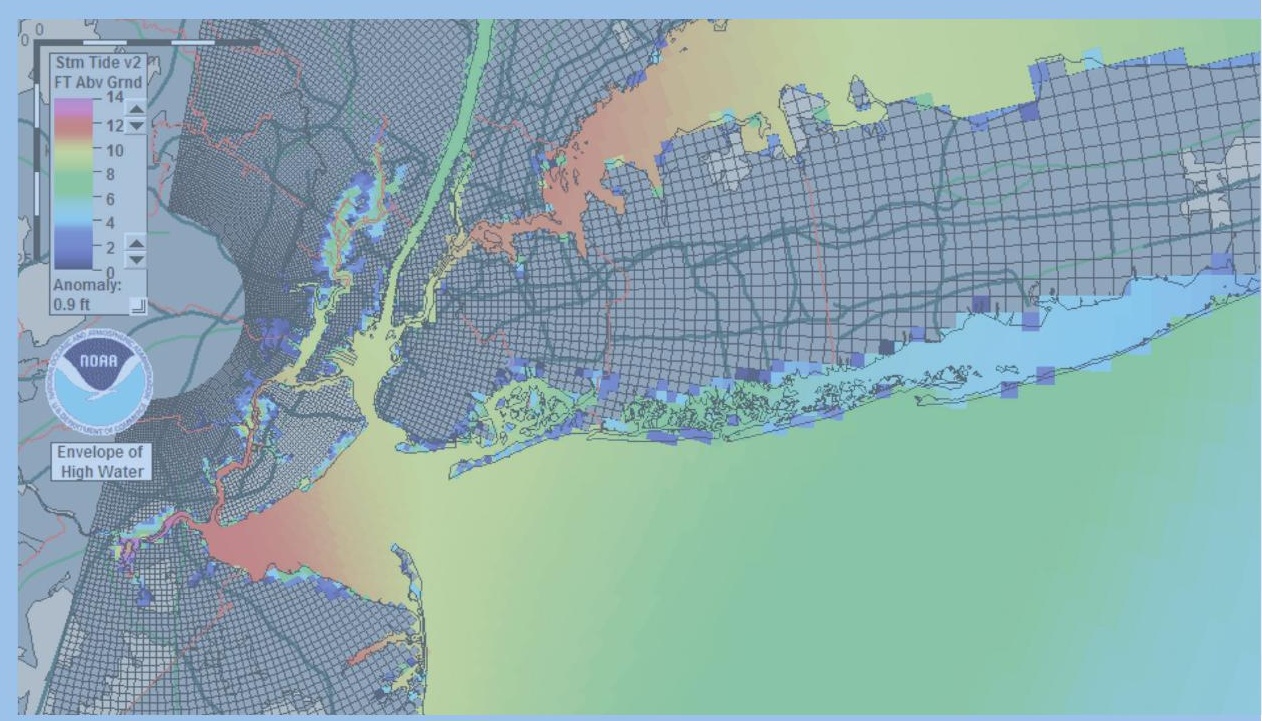

www.mdpi.com/journal/jmse 
Richard P. Signell and Henry J. Bokuniewicz (Eds.)

\section{Selected Papers from the 13th Estuarine and Coastal Modeling Conference}


This book is a reprint of the special issue that appeared in the online open access

Journal of Marine Science and Engineering (ISSN 2077-1312) in 2014 (available at:

http://www.mdpi.com/journal/jmse/special_issues/estuarine-coastal-modeling-conference).

\section{Guest Editors}

Richard P. Signell

United States Geological Survey

Woods Hole

MA 02543-1523, USA

Henry J. Bokuniewicz

School of Marine and Atmospheric Sciences

Stony Brook University

Stony Brook

NY 11794-5000, USA

\section{Editorial Office}

MDPI AG

Klybeckstrasse 64

Basel, Switzerland

Publisher

Shu-Kun Lin

Assistant Editor

Yueyue Zhang

\section{Edition 2015}

MDPI • Basel • Beijing • Wuhan

ISBN 978-3-03842-047-7 (PDF)

ISBN 978-3-03842-046-0 (Hbk)

(C) 2015 by the authors; licensee MDPI, Basel, Switzerland. All articles in this volume are Open Access distributed under the Creative Commons Attribution 4.0 license (http://creativecommons.org/licenses/by/4.0/), which allows users to download, copy and build upon published articles even for commercial purposes, as long as the author and publisher are properly credited, which ensures maximum dissemination and a wider impact of our publications. However, the dissemination and distribution of copies of this book as a whole is restricted to MDPI, Basel, Switzerland. 


\section{Table of Contents}

About the Guest Editors

VI

Preface

VII

Julia M. Moriarty, Courtney K. Harris and Mark G. Hadfield

A Hydrodynamic and Sediment Transport Model for the Waipaoa Shelf, New Zealand:

Sensitivity of Fluxes to Spatially-Varying Erodibility and Model Nesting

Reprinted from: J. Mar. Sci. Eng. 2014, 2(2), 336-369. 1

http://www.mdpi.com/2077-1312/2/2/336

\section{Kelsey A. Fall, Courtney K. Harris, Carl T. Friedrichs, J. Paul Rinehimer and \\ Christopher R. Sherwood}

Model Behavior and Sensitivity in an Application of the Cohesive Bed Component of the

Community Sediment Transport Modeling System for the York River Estuary, VA, USA

Reprinted from: J. Mar. Sci. Eng. 2014, 2(2), 413-436.

http://www.mdpi.com/2077-1312/2/2/413

\section{Cristina Forbes, Jamie Rhome, Craig Mattocks and Arthur Taylor}

Predicting the Storm Surge Threat of Hurricane Sandy with the National Weather Service SLOSH Model

Reprinted from: J. Mar. Sci. Eng. 2014, 2(2), 437-476

http://www.mdpi.com/2077-1312/2/2/437

Eugene Wei, Aijun Zhang, Zizang Yang, Yi Chen, John G.W. Kelley, Frank Aikman and Degui Cao

NOAA's Nested Northern Gulf of Mexico Operational Forecast Systems Development Reprinted from: J. Mar. Sci. Eng. 2014, 2(1), 1-17

http://www.mdpi.com/2077-1312/2/1/1

\section{Zhaoqing Yang, Taiping Wang, Dave Cline and Brian Williams}

Hydrodynamic Modeling Analysis to Support Nearshore Restoration Projects in a Changing Climate

Reprinted from: J. Mar. Sci. Eng. 2014, 2(1), 18-32 114 http://www.mdpi.com/2077-1312/2/1/18

\section{XinJian Chen}

Estimate Submarine Groundwater Discharge to Crystal River/Kings Bay in Florida with the Help of a Hydrodynamic Model 


\section{Taiping Wang, Tarang Khangaonkar, Wen Long and Gary Gill}

Development of a Kelp-Type Structure Module in a Coastal Ocean Model to Assess the Hydrodynamic Impact of Seawater Uranium Extraction Technology

Reprinted from: J. Mar. Sci. Eng. 2014, 2(1), 81-92 144

http://www.mdpi.com/2077-1312/2/1/81

Parmeshwar L. Shrestha, Steave H. Su, Scott C. James, Philip J. Shaller, Macan Doroudian, Clifford E. Firstenberg and Carlie T. Thompson

Conceptual Site Model for Newark Bay-Hydrodynamics and Sediment Transport

Reprinted from: J. Mar. Sci. Eng. 2014, 2(1), 123-139. 156 http://www.mdpi.com/2077-1312/2/1/123

\section{Justin R. Davis, Alex Sheremet, Miao Tian and Saurabh Saxena}

A Numerical Implementation of a Nonlinear Mild Slope Model for Shoaling Directional Waves

Reprinted from: J. Mar. Sci. Eng. 2014, 2(1), 140-158.

http://www.mdpi.com/2077-1312/2/1/140

Peter Bacopoulos, James David Lambert, Mary Hertz, Luis Montoya and Terry Smith

Field and Model Study to Define Baseline Conditions of Beached Oil Tar Balls along

Florida's First Coast

Reprinted from: J. Mar. Sci. Eng. 2014, 2(1), 160-170. 192

http://www.mdpi.com/2077-1312/2/1/160

\section{Lei Shi, Jindong Wang, Edward Myers and Lijuan Huang}

Development and Use of Tide Models in Alaska Supporting VDatum and Hydrographic

Surveying

Reprinted from: J. Mar. Sci. Eng. 2014, 2(1), 171-193

http://www.mdpi.com/2077-1312/2/1/171

\section{Richard P. Signell and Derrick P. Snowden}

Advances in a Distributed Approach for Ocean Model Data Interoperability

Reprinted from: J. Mar. Sci. Eng. 2014, 2(1), 194-208.

http://www.mdpi.com/2077-1312/2/1/194

\section{Yuehua Lin and David B. Fissel}

High Resolution 3-D Finite-Volume Coastal Ocean Modeling in Lower Campbell River and Discovery Passage, British Columbia, Canada

Reprinted from: J. Mar. Sci. Eng. 2014, 2(1), 209-225.

http://www.mdpi.com/2077-1312/2/1/209

\section{Harry V. Wang, Jon Derek Loftis, Zhuo Liu, David Forrest and Joseph Zhang}

The Storm Surge and Sub-Grid Inundation Modeling in New York City during Hurricane

Sandy

Reprinted from: J. Mar. Sci. Eng. 2014, 2(1), 226-246. 


\section{Machuan Peng, Richard A. Schmalz Jr., Aijun Zhang and Frank Aikman III}

Towards the Development of the National Ocean Service San Francisco Bay Operational

Forecast System

Reprinted from: J. Mar. Sci. Eng. 2014, 2(1), 247-286.

.275

http://www.mdpi.com/2077-1312/2/1/247

Justin R. Davis, Vladimir A. Paramygin, Chrysafis Vogiatzis, Y. Peter Sheng,

Panos M. Pardalos and Renato J. Figueiredo

Strengthening the Resiliency of a Coastal Transportation System through Integrated

Simulation of Storm Surge, Inundation, and Nonrecurrent Congestion in Northeast Florida

Reprinted from: J. Mar. Sci. Eng. 2014, 2(2), 287-305.

http://www.mdpi.com/2077-1312/2/2/287

\section{Shwet Prakash, Venkat Kolluru and Carol Young}

Evaluation of the Zone of Influence and Entrainment Impacts for an Intake Using a 3-

Dimensional Hydrodynamic and Transport Model

Reprinted from: J. Mar. Sci. Eng. 2014, 2(2), 306-325

http://www.mdpi.com/2077-1312/2/2/306

\section{Michail Manolidis and Nikolaos Katopodes}

Bed Scouring During the Release of an Ice Jam

Reprinted from: J. Mar. Sci. Eng. 2014, 2(2), 370-385.

http://www.mdpi.com/2077-1312/2/2/370

\section{Ramona Stammermann and Philip Duzinski}

Exploring Localized Mixing Dynamics during Wet Weather in a Tidal Fresh Water System Reprinted from: J. Mar. Sci. Eng. 2014, 2(2), 386-399...................................................... 368

http://www.mdpi.com/2077-1312/2/2/386

\section{Mustafa Samad and Karim El-Kheiashy}

Effluent Mixing Modeling for Liquefied Natural Gas Outfalls in a Coastal Ecosystem

Reprinted from: J. Mar. Sci. Eng. 2014, 2(2), 493-505

http://www.mdpi.com/2077-1312/2/2/493

James D. Bowen, David N. Perry and Colin D. Bell

Hydrologic and Water Quality Model Development Using Simulink

Reprinted from: J. Mar. Sci. Eng. 2014, 2(4), 616-632.

http://www.mdpi.com/2077-1312/2/4/616

\section{Alfred M. Klausmann \\ Analysis of Hurricane Irene's Wind Field Using the Advanced Research Weather Research and Forecast (WRF-ARW) Model}

Reprinted from: J. Mar. Sci. Eng. 2014, 2(1), 33-45 


\section{About the Guest Editors}

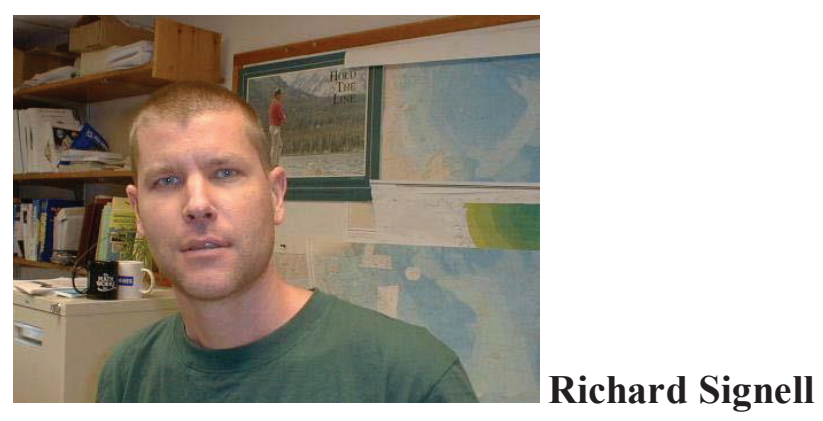

Dr. Signell is a research oceanographer at the US Geological Survey in Woods Hole, MA, USA. He holds his doctorate in physical oceanography from the MIT/Woods Hole Oceanographic Institution Joint Program (1989). He has over 25 years experience in coastal ocean modeling and geoinformatics. He is author or co-author of 97 refereed articles, was the Chair of the 2011 Gordon Research Conference on Coastal Ocean Modeling and was the Chair of the 13th International Estuarine and Coastal Modeling Conference.

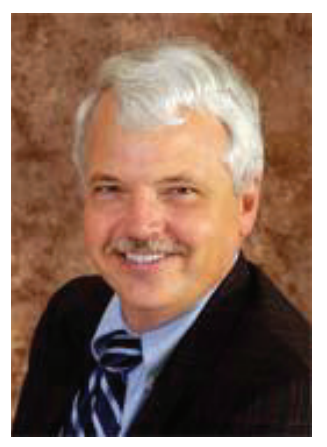

\section{Henry Bokuniewicz}

Dr. Bokuniewicz is a Distinguished-Service Professor of Oceanography at the School of Marine and Atmospheric Sciences of Stony Brook University. He holds his doctorate in Geophysics from Yale University (1976). He has over 30 years' research experience in the dynamics of coastal and estuarine processes. He is author or co-author of 130 refereed articles and over 100 other articles and reports. 


\section{Preface}

This special issue contains selected papers from the $13^{\text {th }}$ International Conference on Estuarine and Coastal Modeling (ECM13), held Nov 4-6, 2013. The conference brings modelers from academic institutions, government and private industry together to present and discuss the latest developments in the field of marine environmental modeling. Begun in 1989 by Dr. Malcolm Spaulding, the conference is held every other year in a retreat-like setting with a maximum of about 125 people to encourage interaction and help strengthen ties between modeling communities. A wide range of modeling issues are encouraged, including advances in physical understanding, numerical algorithm development, model applications, and better tools. A wide range of modeling topics are encouraged as well, including storm surge, eutrophication, larval transport, search and rescue, oil spills, fisheries issues, coastal erosion and contaminated sediment transport. Many conferences also have special themes. The special theme of ECM13 was modeling related to Hurricane Sandy which in late October 2012 devastated the Caribbean and the US East Coast, including record flooding in New York City.

The 22 papers presented here cover a broad spectrum of topics, including simulations of cohesive sediment, inundation, effluent mixing, shoaling waves, and water quality and with modeling applications from Alaska to New Zealand.

Richard Signell and Henry Bokuniewicz

Guest Editors 



\title{
A Hydrodynamic and Sediment Transport Model for the Waipaoa Shelf, New Zealand: Sensitivity of Fluxes to Spatially-Varying Erodibility and Model Nesting
}

\author{
Julia M. Moriarty, Courtney K. Harris and Mark G. Hadfield
}

\begin{abstract}
Numerical models can complement observations in investigations of marine sediment transport and depositional processes. A coupled hydrodynamic and sediment transport model was implemented for the Waipaoa River continental shelf offshore of the North Island of New Zealand, to complement a 13-month field campaign that collected seabed and hydrodynamic measurements. This paper described the formulations used within the model, and analyzed the sensitivity of sediment flux estimates to model nesting and seabed erodibility. Calculations were based on the Regional Ocean Modeling System-Community Sediment Transport Modeling System (ROMS-CSTMS), a primitive equation model using a finite difference solution to the equations for momentum and water mass conservation, and transport of salinity, temperature, and multiple classes of suspended sediment. The three-dimensional model resolved the complex bathymetry, bottom boundary layer, and river plume that impact sediment dispersal on this shelf, and accounted for processes including fluvial input, winds, waves, tides, and sediment resuspension. Nesting within a larger-scale, lower resolution hydrodynamic model stabilized model behavior during river floods and allowed large-scale shelf currents to impact sediment dispersal. To better represent observations showing that sediment erodibility decreased away from the river mouth, the seabed erosion rate parameter was reduced with water depth. This allowed the model to account for the observed spatial pattern of erodibility, though the model held the critical shear stress for erosion constant. Although the model neglected consolidation and swelling processes, use of a spatially-varying erodibility parameter significantly increased export of fluvial sediment from Poverty Bay to deeper areas of the shelf.
\end{abstract}

Reprinted from J. Mar. Sci. Eng. Cite as: Moriarty, J.M.; Harris, C.K.; Hadfield, M.G. A Hydrodynamic and Sediment Transport Model for the Waipaoa Shelf, New Zealand: Sensitivity of Fluxes to Spatially-Varying Erodibility and Model Nesting. J. Mar. Sci. Eng. 2014, 2, 336-369.

\section{Background}

\subsection{Sediment Transport Models}

Field experiments carry a high cost and are hampered by difficulties of observing water column sediment fluxes during energetic conditions such as floods and storms, except at discrete points served by deployed instruments. Numerical models based on the relevant processes for transport can be used to extrapolate point observations to continuous spatial scales, beyond the spatial and temporal coverage of field experiments. Here, we present a numerical model that complements a 13-month field campaign on the Waipaoa shelf, New Zealand. 
Three-dimensional circulation and sediment transport models, such as the Community Sediment Transport Modeling System (CSTMS; [1]) resolve horizontal and vertical gradients, all of which can be important in the coastal ocean. The CSTMS has been implemented within the numerical hydrodynamic model ROMS (the Regional Ocean Modeling System; [2-5]). Although increased model complexity and resolution carries a heavier computational load, a three dimensional model was necessary to represent the complex bathymetry, bottom boundary layer processes, and river plume dynamics on the Waipaoa River continental shelf, New Zealand.

Many three-dimensional coastal sediment transport models have either neglected larger-scale currents or simplified them by using temporal and/or spatial averages to specify currents at the model's boundary, e.g., [6-10]. For example, a numerical model for Poverty Bay, the coastal portion of the Waipaoa Sedimentary System, which accounted for wind, wave, tidal, and river plume processes was developed by [6]. At the open boundaries, [6] accounted for tides and allowed disturbances to propagate through the boundary by using Chapman [11], Flather [12], radiation [13], and no-gradient boundary conditions for the free surface, two and three dimensional currents, and tracers, respectively. Recently, however, numerical models of continental shelf sediment transport have specified conditions along open boundaries based on estimates of coastal currents, temperature, and salinity from larger-scale, lower resolution models [14,15]. Like these examples, we build on previous efforts by nesting a finer-scale grid within a larger-scale hydrodynamic model, thereby accounting for larger-scale circulation patterns. For the event-driven Waipaoa shelf model, nesting not only allowed us to account for larger-scale currents, but was necessary to increase the stability of the model by reducing the reflection at the open boundary of sediment and freshwater from the river plume.

In many coastal environments, sediment fluxes are also affected by seabed erodibility, which can be defined as the amount of sediment available for entrainment into the water column at a given bed shear stress (see [16]). The treatment of erodibility is a distinguishing characteristic of cohesive and non-cohesive models (see [17,18]). For models of muddy cohesive seabeds, erosion typically depends on the seabed's critical shear stress, $\tau_{c r i t}$, and an erosion rate parameter, $M$, which regulates the rate of sediment resuspension (e.g., [1,17]; see section 2.4). Observations show that both parameters may vary with seabed porosity, the depositional history of the seabed, biological processes and other factors, e.g., [19-21]. For instance, recently-deposited sediments were easier to erode than material from consolidated, older seabeds in the York River estuary [16]. Based on seabed erodibility experiments, a bed consolidation scheme in which critical shear stress varied in time, space, and with depth into the seabed, depending on depositional history of the seabed, has been developed and implemented within numerical models $[18,22]$. Here, we developed a simpler parameterization that modified the erosion rate parameter to account for spatial variations in erodibility, based on seabed microcosm erodibility experiments (see section 3.6).

\subsection{Study Site: Waipaoa River Continental Shelf, New Zealand}

Located on an active tectonic margin and draining a small mountainous catchment, the Waipaoa River delivers material to the ocean primarily during floods [23,24]. The Waipaoa exports about 15 million tons of sediment annually, primarily through either gullying or landsliding, depending 
on riverine conditions [24]. This material is primarily mud, with a median grain diameter of $8.5 \mu \mathrm{m}$ during flood conditions, and approximately $1 \%$ of the load is sandy bedload [23,25]. Because of the river's small catchment, rain storms induce flooding throughout the drainage basin, and delivery of sediment to the coastal zone typically coincides with energetic oceanic conditions [23].

Riverine sediments are delivered to Poverty Bay, an about $50 \mathrm{~km}^{2}$ embayment that opens onto the continental shelf through a 10-km wide mouth (see Figure 1A). A counter-clockwise gyre driven by river discharge and the Coriolis force typically dominates currents in Poverty Bay [26-28]. On the shelf, water velocities during January 2010-February 2011 were primarily along-shore, but switched direction often, with an average current of $1.6 \mathrm{~cm} \mathrm{~s}^{-1}$ to the NE and a mean speed of $26.3 \mathrm{~cm} \mathrm{~s}^{-1}$ (data obtained from Hale, R. and Ogston, A., University of Washington (UW) [29]; tripod set-up described in [30]). Local winds, as well as larger-scale wind driven currents, southward travelling eddies, and coastally trapped waves likely drive water velocities [26,31-33]. Surface wind and swell waves on the shelf have average periods of 9-10 seconds and significant wave heights of $0.8-0.9 \mathrm{~m}$, although longer-period waves can reach the shelf from the Southern Ocean [28,34]. Wave-induced motion dominated bed shear stress calculations by an order of magnitude compared to current-induced stress [30,35]. During 2010 at a tripod deployed in $50 \mathrm{~m}$ of water near the Southern depocenter, bed stresses exceeded $0.15 \mathrm{~Pa}$, a threshold for fine-sediment resuspension, for $46 \%$ of the deployment period (data from [30]).

Over decadal and Holocene timescales, sediment accumulation on the shelf has occurred in two bathymetric lows to either side of Poverty Bay, but deposition is more variable over day- to month-long periods. Tripod observations and model estimates indicated that material is temporarily deposited in Poverty Bay following floods, and then, in the subsequent days to weeks, waves resuspend sediment and currents carry it to the shelf $[6,28,35]$. Observations of ${ }^{7} \mathrm{Be}$ activities also indicate that deposition over month-long timescales varies, depending on weather conditions [36,37]. For instance, ${ }^{7} \mathrm{Be}$ inventories from successive research cruises indicated that both erosion and deposition of terrestrial sediments occurred over different parts of the shelf during the January 2010 flood [37]. Over longer timescales, seismic profiles and ${ }^{210} \mathrm{~Pb}$ radioisotopes (22.3 year half life) indicated two depocenters with maximum accumulation rates of $\sim 1 \mathrm{~cm}$ year ${ }^{-1}$ occur located in bathymetric lows to either side of Poverty Bay, bordered by the coast and offshore anticlines (Figure 1; [38,39]).

\subsection{Objective}

Though both seabed and water column data have been collected for the Waipaoa River continental shelf, knowledge of sediment transport mechanisms is benefited by development of a three dimensional hydrodynamic-sediment transport numerical model providing spatial coverage unattained by observational efforts. This paper describes the implementation of the ROMS-CSTMS numerical model for the Waipaoa continental shelf and examines the sensitivity of sediment flux estimates to model nesting and seabed erodibility parameterizations. 
Figure 1. Study site on North Island, New Zealand. (A) Waipaoa Shelf map showing locations of Poverty Bay, Poverty Gap, shelf depocenters (Dep), and the Lachlan and Ariel Anticlines (L.A. and A.A., respectively). Red arrow indicates river mouth. Grey bathymetric contours drawn every $10 \mathrm{~m}$ up to $70 \mathrm{~m}$ depth, while dashed grey line indicates shelf break at $150 \mathrm{~m}$. Inset shows location of study site within the larger-scale model. (B) Waipaoa Shelf map showing shelf bathymetry up to $80 \mathrm{~m}$ water depth (shading; in meters), tripod locations (brown dots) and multi-core stations (black dots) from the January 2010 research cruise. Grey and black bathymetric contours drawn every $10 \mathrm{~m}$ to $100 \mathrm{~m}$ depth, then at $150 \mathrm{~m}$ depth. (C) Waipaoa model grid showing bathymetry, where each box shown encompasses 25 model cells. Model boundaries labeled "NW", "SW", "SE", "NE". (D) Bathymetric map of larger-scale model Regional Ocean Modeling System (ROMS)-NZ covering the eastern half of the North Island, New Zealand. Black box indicates location of Waipaoa shelf model.

(A)

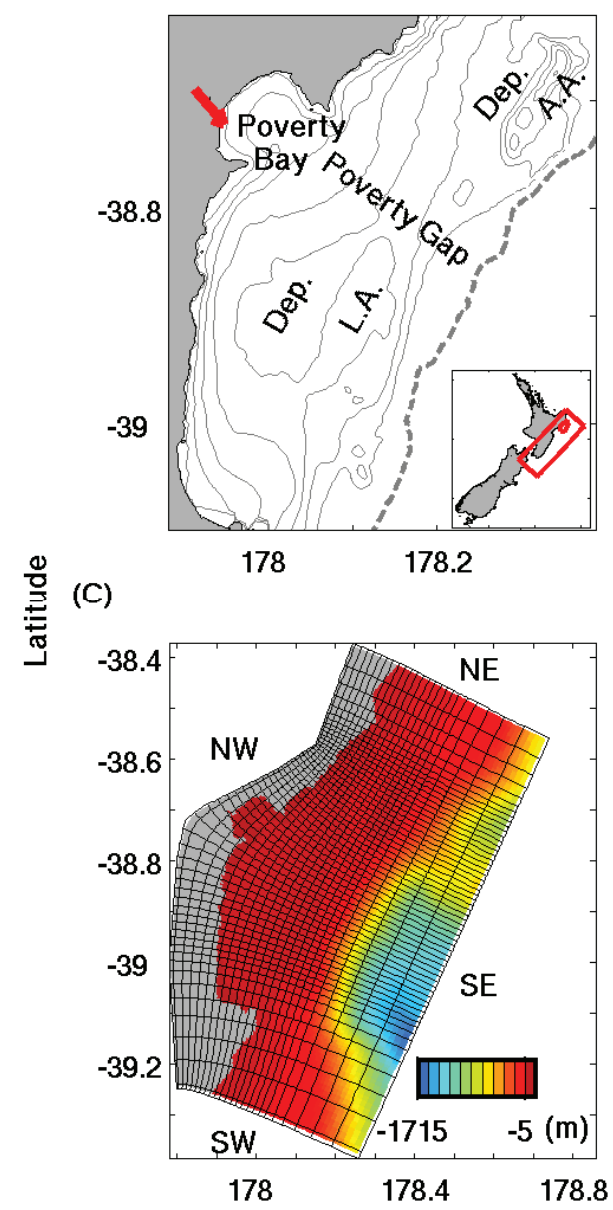

(B)

$-38.8$

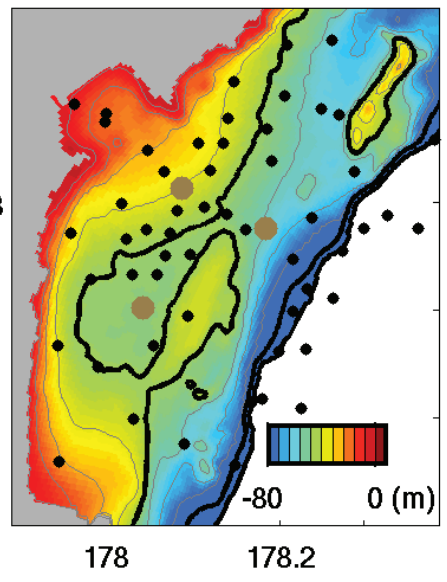

(D)

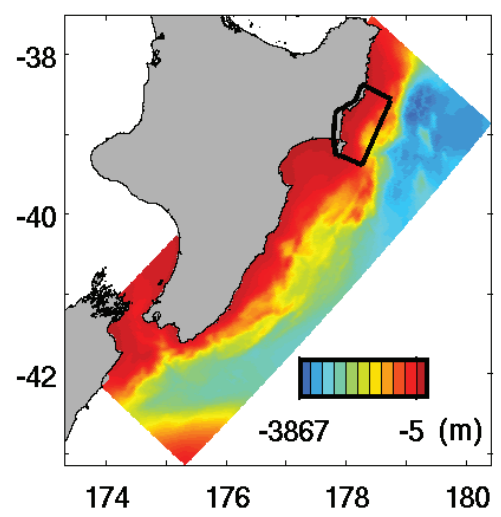




\section{Model Development}

This section describes the equations and numerical schemes used to specify hydrodynamic and sediment transport processes within the model and at the boundaries of the grid. Table 1 lists symbols for all equations.

\subsection{Hydrodynamic Model and Numerical Schemes}

ROMS-CSTMS, a community-developed numerical circulation and sediment transport model, solves the equations for Reynolds-averaged Navier-Stokes, tracer advection-diffusion, and continuity using the hydrostatic and Boussinesq assumptions as described in [3]. Tracer concentrations could represent an array of different tracers, which included temperature, salinity, and seven sediment classes. River discharge was treated as a point source for momentum, temperature, salinity and suspended sediment. Sources and sinks within the governing equations included, but were not limited to, bottom friction, wind stress, and nudging to match the regional grid (see section 2.5). The density equation of state accounted for temperature, salinity, and sediment concentrations $[1,40]$.

ROMS distinguishes itself from other community hydrodynamic models by its model grid, and time-stepping and advective schemes. It uses a curvilinear orthogonal grid in the horizontal and a stretched, terrain-following grid in the vertical which allows it to carry high resolution in both the surface and bottom boundary layers [2]. The numerical schemes in ROMS include split barotropic-baroclinic modes (Leap-Frog-Adams-Moulton predictor-corrector scheme; [2-5]) and reduce the pressure-gradient truncation error [41-44] by redefining the pressure-gradient term $[3,45,46]$. ROMS also provides high-order schemes for estimating both vertical and horizontal advection $[3,47]$. For advection of sediment and other tracers, ROMS provides the MP-DATA scheme (Multidimensional Positive Definite Advection Transport Algorithm; [48]) to avoid numerical oscillations and negative concentrations, and reduce numerical dispersion, e.g., [1,49]. For vertical advection of sediment, the ROMS framework implemented the PPM (Piecewise Parabolic Method) so that relatively large timesteps can be used for faster settling sands without the introduction of instabilities [1,50,51]. These numerical schemes and reasonably high spatial resolution are important for representing the high gradients typical of coastal and estuarine settings without sacrificing computational efficiency, e.g., [49]. For application of ROMS to the Waipaoa shelf, numerical schemes and the model grid (Figure 1) were chosen to reduce error in numerical computations without sacrificing model efficiency. A timestep of $15 \mathrm{~s}$, and the numerical schemes listed in Table 2 were used.

\subsection{Surface Boundary Formulation}

The surface boundary formulation in ROMS was adopted from the physically-based COARE (Coupled Ocean Atmosphere Response Experiment) framework [52,53]. In this one layer boundary model, wind and rain transfer momentum from the atmosphere to the ocean. 
Table 1. Model parameters as described in this paper.

\begin{tabular}{|c|c|c|}
\hline Parameter & Meaning & Unit \\
\hline $\mathrm{C}_{\mathrm{s}, 1, \text { ised }}$ & Suspended concentration of sediment class ised in bottom water grid cell per unit area & $\mathrm{kg} \mathrm{m}^{-2}$ \\
\hline $\mathrm{c}_{\mathrm{x}}, \mathrm{c}_{\mathrm{y}}$ & Phase speeds for oblique radiation boundary condition & $\mathrm{m} \mathrm{s}^{-1}$ \\
\hline $\mathrm{D}_{50}$ & Median grain diameter & M \\
\hline Eised & Erosion for sediment class ised & $\mathrm{kg} \mathrm{m}^{-2} \mathrm{~s}^{-1}$ \\
\hline$F_{c s, i s e d}$ & Source of sediment class ised to the water column due to seabed deposition and erosion & $\mathrm{kg} \mathrm{m}^{-2} \mathrm{~s}^{-1}$ \\
\hline F grid & Parameter specifying spatially-variable nudging at open boundaries & non-dimensional \\
\hline $\mathrm{FOBC}_{\mathrm{OBC}}$ & Parameter specifying changes to nudging at open boundaries based on current direction & non-dimensional \\
\hline $\mathrm{h}$ & Water depth & $\mathrm{m}$ \\
\hline$h_{\text {transition }}$ & Transitional water depth for erosion rate parameter parameterization & $\mathrm{m}$ \\
\hline I & Number of grid cells in NW-SE direction & non-dimensional \\
\hline $\mathrm{i}$ & Index for model grid in NW-SE direction & non-dimensional \\
\hline ised & Index for modeled sediment classes & non-dimensional \\
\hline $\mathrm{J}$ & Number of grid cells in SW-NE direction & non-dimensional \\
\hline $\mathrm{j}$ & Index for model grid in SW-NE direction & non-dimensional \\
\hline $\mathrm{k}_{1}, \mathrm{k}_{2}$ & Coefficients for active layer formulation & $\mathrm{m}^{2} \mathrm{~s}^{2} \mathrm{~kg}^{-1}$; non-dimensional \\
\hline $\mathrm{M}$ & Erosion rate parameter & $\mathrm{kg} \mathrm{m}^{-2} \mathrm{~s}^{-1}$ \\
\hline $\mathrm{M}_{\min }$ & Minimum erosion rate parameter & $\mathrm{kg} \mathrm{m}^{-2} \mathrm{~s}^{-1}$ \\
\hline $\mathrm{M}_{\max }$ & Maximum erosion rate parameter & $\mathrm{kg} \mathrm{m}^{-2} \mathrm{~s}^{-1}$ \\
\hline$\hat{n}$ & Unit vector perpendicular to open boundary & \\
\hline $\mathrm{p}$ & Seabed porosity & non-dimensional \\
\hline $\mathrm{S}$ & Salinity & psu \\
\hline $\mathrm{S}_{0}$ & Background salinity & psu \\
\hline $\mathrm{S}_{\mathrm{OBC}}$ & Flux of freshwater through the open boundaries & $\mathrm{m}^{3}$ \\
\hline$T_{R, b}$ & Relaxation timescale for nudging at open boundaries & s \\
\hline $\mathrm{T}_{\mathrm{R}, \mathrm{i}}$ & Relaxation timescale for nudging within model interior & s \\
\hline $\mathrm{T}_{\mathrm{RO}}$ & Relaxation constant for nudging at open boundaries & non-dimensional \\
\hline $\mathrm{t}$ & Time & $\mathrm{s}$ \\
\hline$u$ & Current velocity & $\mathrm{m} \mathrm{s}^{-1}$ \\
\hline $\mathrm{W}_{\mathrm{s}, \mathrm{ised}}$ & Settling velocity for sediment class ised & $\mathrm{m} \mathrm{s}^{-1}$ \\
\hline $\mathrm{x}, \mathrm{y}$ & Horizontal coordinates & non-dimensional \\
\hline $\mathrm{z}$ & Vertical coordinate in water column & non-dimensional \\
\hline $\mathrm{z}_{\mathrm{a}}$ & Thickness of seabed active layer & $\mathrm{m}$ \\
\hline $\mathrm{z}_{\mathrm{s}}$ & Vertical coordinate in seabed & $\mathrm{m}$ \\
\hline$\zeta$ & Variable of interest in boundary condition equations & $\begin{array}{l}\text { Same units as velocity, } \\
\text { temperature, salinity, or } \\
\text { sediment concentrations }\end{array}$ \\
\hline$\zeta^{\prime}$ & Variable of interest in boundary condition equations before nudging & Same as above \\
\hline$\zeta_{\mathrm{obc}}$ & Prescribed value for variable of interest in open boundary condition equations & Same as above \\
\hline$\tau_{c w, \max }$ & Maximum wave-current induced bed shear stress over a wave period & $\mathrm{Pa}$ \\
\hline$\left|\tau_{c w, \max }\right|$ & Magnitude of maximum wave-current induced bed shear stress over a wave period & $\mathrm{Pa}$ \\
\hline$\tau_{\text {crit }}$ & Critical shear stress for the seabed & $\mathrm{Pa}$ \\
\hline
\end{tabular}


Table 2. Numerical Schemes for Waipaoa Shelf model.

\begin{tabular}{cc}
\hline Process & Numerical Scheme \\
\hline Advection of momentum (Vertical, 3D) & 4th order, centered \\
Advection of momentum (Horizontal, 3D) & 3rd order, upstream \\
Advection of tracers & MPData \\
Vertical Sediment Settling & PPM \\
\hline
\end{tabular}

\subsection{Bottom Boundary Layer Formulation}

This implementation of ROMS used the Sherwood, Signell and Warner [1] bottom boundary layer parameterization, a physics-based approach that could account for form drag and ripples. This formulation, defined as "SSW" within ROMS, was based on [54] that divided the bottom boundary layer into two sections: a thin combined wave-current boundary layer, and a current boundary layer. For this study, the hydraulic roughness represented the grain size roughness, which was set equal to $0.30 \mathrm{~mm}$ based on estimates of bed shear stress from acoustic Doppler velocimeters (ADVs) provided by [30]. The model used the bottom roughness, the eddy viscosity profiles, wave orbital velocities provided by input files, and currents $20 \mathrm{~cm}$ above the bed, estimated by the hydrodynamic model, to calculate the total maximum current-wave-induced bed shear stresses, $\tau_{c w, \max }$, following [54].

\subsection{Seabed Model}

As summarized in section 2.1, the model accounted for suspended transport, erosion and deposition. Both fluvial discharge and seabed erosion provided sediment to the water column. To calculate erosion and deposition, Equations (1) and (2) were calculated for multiple sediment types, each having assigned values for settling velocity and diameter. Other values (e.g., erosion rate parameter, critical shear stress, and seabed porosity) were identical for all sediment classes. Processes not explicitly represented in the model include flocculation [55], seabed consolidation [56], and bioturbation [57].

Erosion was calculated following the Ariathurai and Arulanandan formulation [58] for each sediment class with index ised:

$$
\begin{aligned}
& F_{c s, \text { ised }}=E_{i s e d}-\frac{\partial w_{s, i s e d} C_{s, 1, \text { ised }}}{\partial z_{s}} \\
& E_{i s e d}=\left\{\begin{array}{ll}
M(1-p) f_{i s e d} \frac{\left|\tau_{c w, \max }^{\mathrm{r}}\right|-\tau_{c r i t}}{\tau_{c r i t}} & \text { when }\left|\tau_{c w, \max }^{\mathrm{r}}\right|>\tau_{c r i t} \\
0 & \text { when }\left|\frac{\tau_{c w, \max }}{\mathrm{r}}\right|<\tau_{c r i t}
\end{array}\right\}
\end{aligned}
$$

As indicated in Equation (1), the model assumed continuous deposition so that $F_{c s, \text { ised, the net }}$ entrainment of suspended sediment for each class, was calculated as the difference between the erosion of each sediment class, $E_{i s e d}$, and estimated settling to the bed based on settling velocity of 


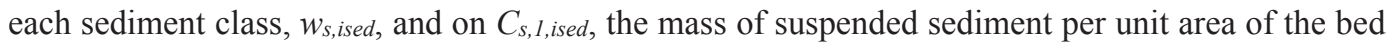
in the bottommost grid cell for each sediment class. In Equation (2), $p$ was porosity, or void fraction of the seabed, $f_{\text {ised }}$ was the fraction of the seabed composed of sediment class ised, $\left|\tau_{c w, \max }^{\mathrm{r}}\right|$ was the magnitude of the total wave-current-bed shear stress, and $\tau_{c r i t}$ was a constant critical bed shear stress. Erosion during any time step was limited to the amount of each size class available within a thin active layer whose thickness, $z_{a}$, was specified as:

$$
z_{a}=\max \left[k_{1}\left(\left|\tau_{c w, \max }^{\mathrm{r}}\right|-\tau_{c r i t}\right), 0\right]+k_{2} D_{50}
$$

where $k_{1}$ and $k_{2}$ were constants set equal to $0.007 \mathrm{~m}^{2} \mathrm{~s}^{2} \mathrm{~kg}^{-1}$ and 6.0 , respectively, and $D_{50}$ was the median grain size on the seabed [59]. As implemented for the Waipaoa shelf, active layer thicknesses on the mid-shelf rarely exceeded $\sim-10 \mathrm{~mm}$ and increased in shallow areas and near the anticlines due to the relatively high bed stress and the larger sediment grains found there (Figure 2).

Consistent with observations of erodibility on the Waipaoa shelf, the model formulation was modified to encourage erosion of sediment from shallow areas by varying the erosion rate parameter, $M$, with water depth, $h$. Choice of $M$ used for a given water depth depended on parameters including the maximum and minimum erosion rate parameters $\left(M_{\max }\right.$ and $\left.M_{\min }\right)$, and a transitional water depth $\left(h_{\text {transition})}\right.$ :

$$
M=\left\{\left[\left(M_{\min }-M_{\max }\right) /\left(1+\exp \left(0.2 \bullet\left(h-h_{\text {transition }}\right)\right)\right)\right]+M_{\min }\right\}
$$

Based on observations, $M_{\max }, M_{\min }$, and $h_{\text {transition, }}$, were set to $4.5 \times 10^{-4} \mathrm{~kg} \mathrm{~m}^{-2} \mathrm{~s}^{-1}, 0.1 \times 10^{-4} \mathrm{~kg} \mathrm{~m}^{-2}$ $\mathrm{s}^{-1}$, and $30 \mathrm{~m}$, respectively (see section 3.6; [36]). Sections 4.1 and 4.3 evaluate the erodibility parameterization by comparing model results that used Equation (4) with two cases that used spatially-uniform $M$ (see section 3.7). Both the active layer thickness and spatial variation in the erosion rate parameter influenced seabed erodibility. Other parameters such as critical shear stress likely also varied spatially and affected erodibility. However, estimations of parameters from erodibility experiments and tripod data can carry substantial uncertainty, and so this paper focused on a single variable, the erosion rate parameter, because it required no additional information about the seabed critical stress profiles and was computationally efficient. Use of a spatially-varying critical shear stress would likely also encourage erosion of sediment from shallow areas, similar to the parameterization used here. Alternate parameterizations from the literature are discussed in section 4.3.

Sediment bed properties such as grain size distribution were stored for eight seabed layers that each initially represented $20 \mathrm{~cm}$ of sediment. Erosion and deposition of multiple sediment classes modified the thickness of seabed layers and the grain size distributions stored for the sediment bed, as described in [1]. These changes impacted the upper few layers of the sediment bed, while the deeper layers served as a repository of sediment. The surficial seabed layer was $\sim 1 \mathrm{~cm}$ across the shelf on average, but was thinner in areas of low deposition and where the active layer was thin (Figure 2). 
Figure 2. Shows (a) time-averaged active layer thickness in the standard model, and (b) the spatially-varying erosion rate parameter, $M$, from Equation (4).

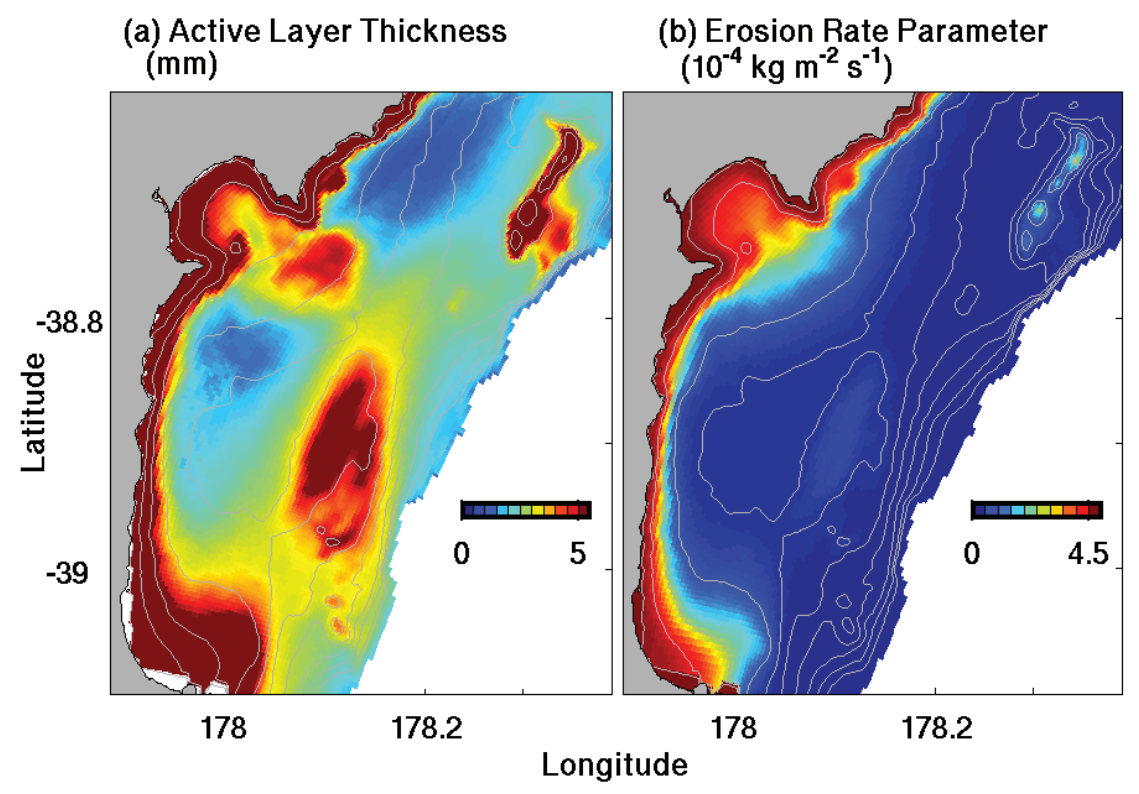

\subsection{Open Boundary Conditions}

The Waipaoa shelf model grid was bounded by land on the northwestern side (Figure 1), so a free-slip wall condition was used there which specified a zero gradient condition for tracers and sea surface elevation, set water velocities normal to land equal to zero, and used a free-slip condition for tangential velocities. Along the other three edges, open boundary conditions (OBCs) for sea surface height, barotropic and baroclinic velocities, and tracer concentrations accounted for tides, shelf waves, and the transient behavior of the river plume. Radiation conditions along the southwest, southeast, and northeast boundaries allowed waves to propagate through them without reflecting. Specifically, the Chapman [11] and Flather [60,61] conditions were applied there for the free surface and barotropic momentum, respectively, to account for tides [62-64]. Velocity and sea surface height at the boundary were required as input and were specified using data from ROMS-NZ, a larger-scale hydrodynamic model ([65]; model used a similar setup to [66]; see Figure 1; section 3.5). Sediment concentrations, which were not provided by ROMS-NZ, were nudged toward zero at the boundaries. This parameterization implied that external sediment sources were negligible, a common assumption in sediment budget calculations, e.g., [38,39], and in many models of riverine-dominated systems, e.g., [6,15]. Nudging sediment concentrations toward zero also assumed that material leaving the grid did not reenter the model domain, which was a reasonable expectation because the largest fluxes occurred during floods, when the river plume carried sediment off of the proximal 
shelf $[30,35]$. Using the oblique radiation condition for baroclinic velocities and tracer concentrations reduced artificial reflections at the boundaries $[11,13,67]$.

Similar to other studies $[13,68]$, we nudged baroclinic current velocities, salinity, temperature, and suspended sediment concentrations within 30 grid cells of the open boundaries toward values specified from ROMS-NZ, or zero, as described above:

Nudging, evaluated within grid interior:

$$
\xi=\xi^{\prime}+\frac{F_{g r i d}}{T_{R, i}}\left(\xi_{o b c}-\xi^{\prime}\right) \Delta t
$$

Nudging-Radiation $\mathrm{OBC}$, evaluated at model boundary:

$$
\begin{aligned}
& \frac{\partial \xi}{\partial t}+c_{x} \frac{\partial \xi}{\partial x}+c_{y} \frac{\partial \xi}{\partial y}=\left(\frac{1}{\mathrm{~T}_{R, b}}\right) \xi_{o b c}(t) \\
& c_{x}=-\frac{\partial \xi}{\partial t} \frac{\partial \xi / \partial x}{(\partial \xi / \partial x)^{2}+(\partial \xi / \partial y)^{2}} \\
& c_{y}=-\frac{\partial \xi}{\partial t} \frac{\partial \xi / \partial y}{(\partial \xi / \partial x)^{2}+(\partial \xi / \partial y)^{2}} \\
& T_{R, b}=\left\{\begin{array}{lllll}
T_{R O} & \text { current } & \text { velocities } & \text { directed out of } & \text { grid } \\
T_{R O} / F_{O B C} & \text { current } & \text { velocities } & \text { directed in to grid }
\end{array}\right\}
\end{aligned}
$$

Here, $\zeta^{\prime}$ was the variable of interest (e.g., velocity or tracer concentrations) before nudging, $T_{R, i}$ and $T_{R, b}$ were the relaxation timescales in the interior of the grid and at the open boundaries, and $\Delta t$ was the timestep. The larger-scale model, ROMS-NZ provided $\zeta_{o b c}(t)$. The open boundary relaxation timescale, $T_{R, b}$, decreased with decreasing $T_{R O}$ and increasing $F_{O B C}$, enhancing nudging when currents flowed into the model grid. Based on sensitivity tests, $T_{R, i}, T_{R O}$ and $F_{O B C}$ were set to 2.5 days, 2.5 days and 2.5. Section 4.2 presents results for "moderately-nudged" and "weakly-nudged" sensitivity tests where $T_{R, i}$ and $T_{R 0}$ were doubled and multiplied by a factor of 10 , respectively, increasing the influence of larger-scale currents. The parameter $F_{\text {grid }}$ specified spatial variability for nudging so that it was non-zero only for locations within 30 grid cells of open boundaries, and weakened sinusoidally with distance from the open boundary:

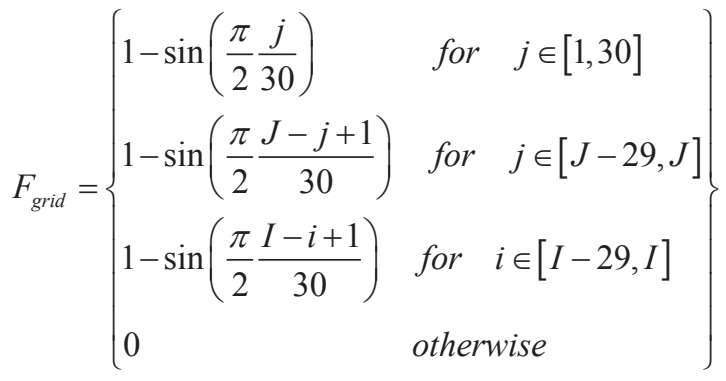


where $I$ and $J$ were the total number of grid cells in the NW-SE and SW-NE directions and coordinates $(i, j)$ indicate location within the grid. Note that since ROMS-NZ did not include sediment, this meant that suspended sediment concentrations within 30 grid cells of the boundaries were nudged toward zero. Nesting not only enabled the model to account for larger-scale currents, but also reduced reflections of river plume salinity and suspended sediment concentrations at the boundary, which increased model stability.

\section{Model Initialization and Forcing}

Observed and modeled datasets used to initialize and force the model are listed in Table 3 and discussed in this section. All interpolations used linear Delaunay triangulation, unless specified below.

\subsection{Model Grid Construction and Bathymetry}

Designed to include the river mouth, Poverty Bay, and the proximal continental shelf, the model grid (Figure 1) also encompassed the three depocenters identified by [23,38,39]. Use of a curvilinear horizontal grid and a stretched terrain-following vertical grid allowed the model to resolve regions of interest (e.g., two depocenters landward of shelf anticlines) and the near-bed and near-surface areas that have high vertical gradients in sediment concentration or velocity. While our model achieved lower horizontal resolution within Poverty Bay than that used by [6], it included more of the proximal continental shelf, allowing us to focus on shelf transport mechanisms.

The model grid had a horizontal resolution of about $450 \mathrm{~m}$ on the mid-shelf and was curved to reduce the number of terrestrial grid cells and to approximately parallel bathymetry (Figure 1). This facilitated post-processing of data (i.e., across-shelf fluxes), and reduced model errors associated with nesting and along-isobath flow. In the unmasked (water) section of the grid, the angles of grid corners deviated from perpendicular by a maximum of $1.4^{\circ}$ and a mean of $0.13^{\circ}$. Vertical resolution varied with depth, and was about $0.40 \mathrm{~m}, 2.0 \mathrm{~m}$, and $0.40 \mathrm{~m}$ near the surface, mid water-column, and seabed at $24 \mathrm{~m}$ water depth at the entrance to Poverty Bay. In deeper areas, resolution decreased so that, for example, surface, mid-water column and near-bed layers were $0.84 \mathrm{~m}, 5.3 \mathrm{~m}$, and $0.84 \mathrm{~m}$ thick at $50 \mathrm{~m}$ depth.

Four datasets that each had a different focus provided the basis for the model's bathymetry. Multibeam was used to map Poverty Bay in 2005 and 2006 by J. McNinch (now at USACoE; see [69]), while S. Kuehl (Virginia Institute of Marine Science; VIMS) provided multibeam data of the continental shelf and slope that had been obtained in 2005 on the R/V Kilo Moana [39]. S. Stephens (National Institute of Water and Atmosphere (NIWA), New Zealand) provided complete, though low resolution, $10 \mathrm{~m}$ bathymetric contours of the continental shelf and slope [70]. Finally, the historical gridded bathymetry from NIWA [71] provided the only data coverage near the entrance of Poverty Bay. The datasets were all referenced with respect to the WGS 84 datum and the universal transverse Mercator horizontal projection, except for the historical gridded dataset, for which the projection was unknown. 
Table 3. Datasets used for model initialization and forcing.

\begin{tabular}{|c|c|}
\hline Type of Data & Data Description and Source \\
\hline Bathymetry to construct model grid & $\begin{array}{l}\text { - } \text { Multibeam surveys }[39,69] \\
\text { - } \quad \text { Bathymetric contours provided by S. Stephens (NIWA) [70] } \\
\text { - } \text { Historical gridded bathymetry [71] } \\
\text { - } \quad \text { Modeled bathymetry of New Zealand ROMS model (ROMS-NZ) }\end{array}$ \\
\hline $\begin{array}{l}\text { Currents, temperature and salinity at } \\
\text { open boundaries, and for model } \\
\text { initialization }\end{array}$ & - Baroclinic version of ROMS-NZ ([65]; model used a similar setup to [66]; see Figure 1) \\
\hline Wave height, direction, and period & $\begin{array}{l}\text { - NIWA's New Zealand Wave (NZWAVE) model (NZWAVE, an implementation of } \\
\text { NOAA's Wave Watch III model; [72]) }\end{array}$ \\
\hline Wind stress & $\begin{array}{l}\text { - NIWA's New Zealand Limited Area Model (NZLAM, an implementation of the UK Met } \\
\text { Office's Unified Model; [73]) }\end{array}$ \\
\hline $\begin{array}{l}\text { Tidal components: open boundary sea } \\
\text { surface height and tidal velocities }\end{array}$ & $\begin{array}{l}\text { - Tidal velocities, amplitudes and phase components from the Oregon State Tidal } \\
\text { Prediction Software TPX07.1 global solution (OTPS; }[74,75] \text { ) }\end{array}$ \\
\hline Meteorological data & $\begin{array}{l}\text { - Air pressure, cloud cover, precipitation, relative humidity, shortwave radiation, air } \\
\text { temperature from NIWA's National Climate Database web system [76] at Gisborne } \\
\text { airport }\end{array}$ \\
\hline $\begin{array}{l}\text { River discharge of freshwater and } \\
\text { sediment }\end{array}$ & $\begin{array}{l}\text { - River gauge measurements provided by G. Hall and D. Peacock (Gisborne District } \\
\text { Council, New Zealand) [77] }\end{array}$ \\
\hline $\begin{array}{l}\text { Sediment properties of fluvial and } \\
\text { seabed material (diameter, settling } \\
\text { velocity, critical stress for erosion, } \\
\text { erosion rate parameter) }\end{array}$ & $\begin{array}{ll}\text { - } & \text { River observations }[25] \\
\text { - } & \text { Observed seabed properties }[78] \\
\text { - } & \text { ADV and OBS data }[30] \\
\text { - } & \text { Gust microcosm erodibility experimental data }[36]\end{array}$ \\
\hline $\begin{array}{l}\text { Seabed characteristics for comparison } \\
\text { to model estimates }\end{array}$ & - Radiometric and X-ray analysis of cores $[36,37]$ \\
\hline
\end{tabular}

Comparisons revealed systematic offsets between the bathymetric datasets. In areas that overlapped (see Figure 3), the NIWA contours and Kuehl water depths were $\sim 3 \mathrm{~m}$ and $\sim 2 \mathrm{~m}$ shallower, respectively, than those from J. McNinch. The offsets were removed by adding 3 and 2 $\mathrm{m}$ to the NIWA contours and Kuehl data, which aligned them with the McNinch data from Poverty Bay. The deeper-water datasets were referenced to the McNinch data because bed stresses were most sensitive to bathymetry in shallow water and because 2-3 $\mathrm{m}$ was a smaller percentage of water column height in deeper areas compared to shallow areas. These three data sets were then combined for interpolation. Note that because the NIWA $10 \mathrm{~m}$ contours had lower resolution for much of the shelf, this dataset was relatively sparse compared to the gridded products. Thus, the gridded multibeam datasets dominated the model bathymetry where they provided coverage, while the NIWA contours filled in areas that were sparsely covered, primarily near the coastline and in the southwest and northeast portions of the grid.

After gridding, the model bathymetry was smoothed with a Shapiro (1975) filter to improve model stability $[41,42,79]$. Finally, water depths near the open boundaries of the model grid were adjusted to match the lower resolution ROMS-NZ bathymetry to facilitate model nesting. Both water depth and land-ocean masking were identical to ROMS-NZ over the region where nudging occurred. This methodology avoided noticeable seams where the datasets abutted, and the bathymetry, slope and curvature of the model grid was consistent with those of each individual 
dataset. The greatest uncertainty in bathymetry unfortunately lay at the entrance of Poverty Bay, where recent datasets on known projections did not provide much coverage.

Figure 3. Coverage of bathymetric datasets near Poverty Bay mouth. Datasets are labeled by source (see Table 3). The National Institute of Water and Atmosphere (NIWA) contours also act as $10 \mathrm{~m}$ bathymetric contours. Note that the NIWA contours and multibeam data provided by S. Kuehl extend onto the continental shelf and slope.

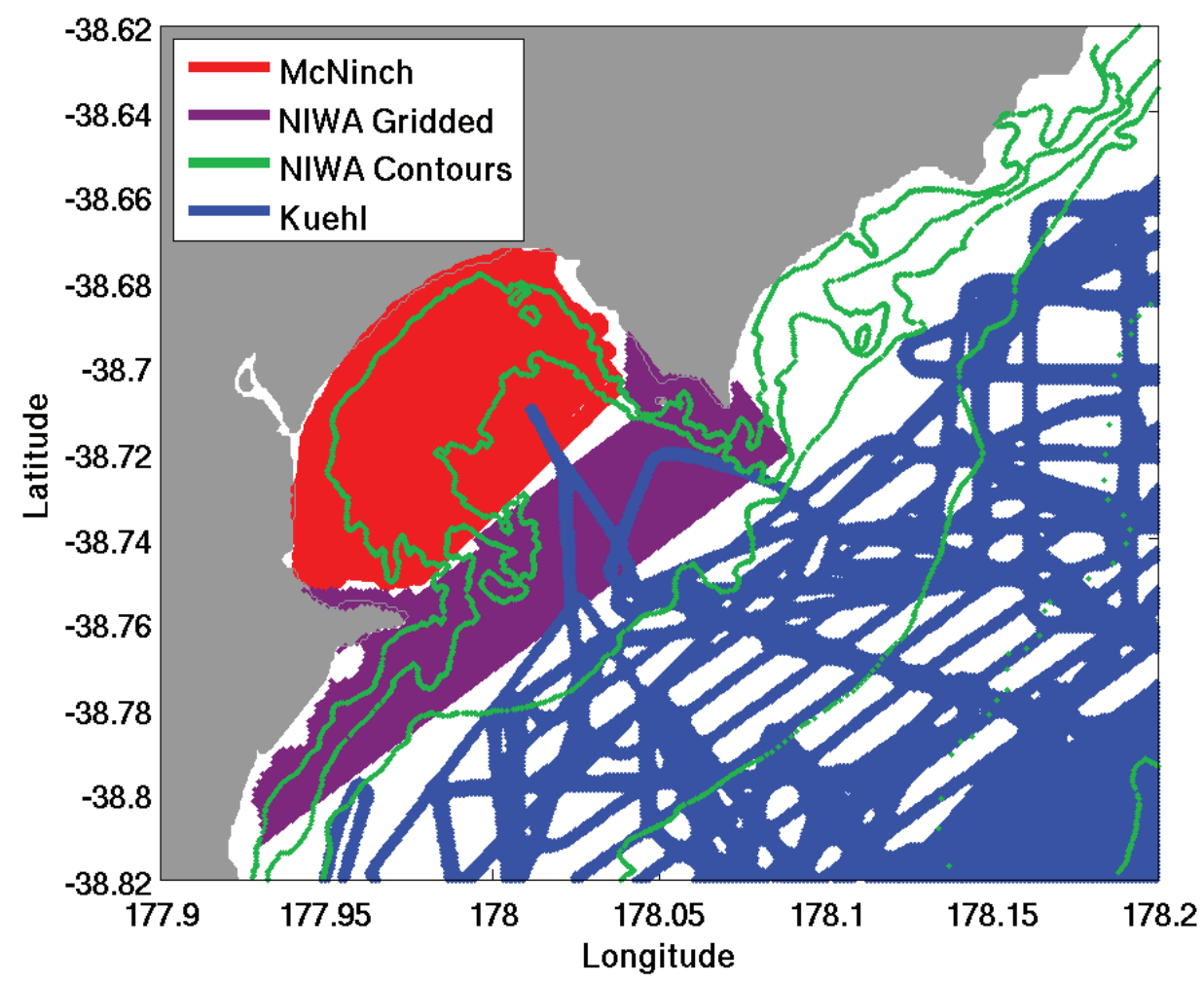

\subsection{Atmospheric Forcing and Waves}

Modeled data were used as input to account for spatial and temporal variability in the wind and wave fields. Estimates from NZLAM and NZWAVE (described below; Figure 4c,e-f) were used for these because they had relatively fine resolution and were calibrated against local as opposed to global data. Values from these models, including wind velocities and wave estimates (significant wave height, mean wave direction, wave length, and mean wave period) were interpolated to the ROMS grid. 
Figure 4. Time series of observed and estimated weather conditions on Waipaoa Shelf. (a) River and (b) sediment discharge from Gisborne District Council, New Zealand; modeled wind speed from New Zealand Limited Area Model (NZLAM) (c) and current speed from ROMS-NZ (d) averaged over the model domain; (e) significant wave height; (f) bottom wave period; (g) wave orbital velocity; (h) total wave- and current-induced bed shear stress; and (i) suspended sediment concentrations. For panels (e)-(i), black lines indicate model estimates made for the grid cell nearest the tripod site (see Figure 1b), and grey lines indicate acoustic Doppler velocimeter (ADV) (wave height; bed shear stress) and optical backscatter sensor (OBS) (suspended sediment concentration) observations provided by Hale, R. and Ogston, A. (University of Washington; [30]) from the tripod at $40 \mathrm{~m}$ water depth.
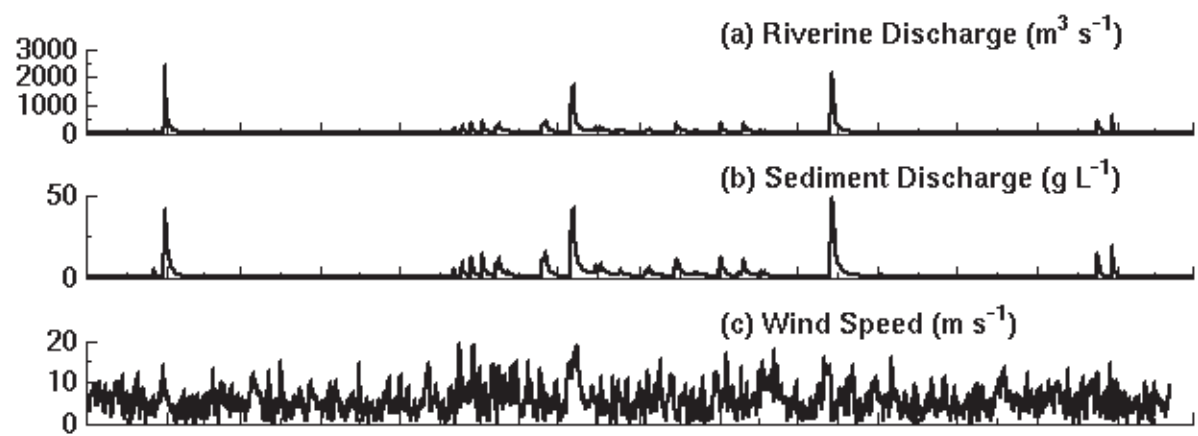

(d) Current Speed $\left(\mathrm{m} \mathrm{s}^{-1}\right)$

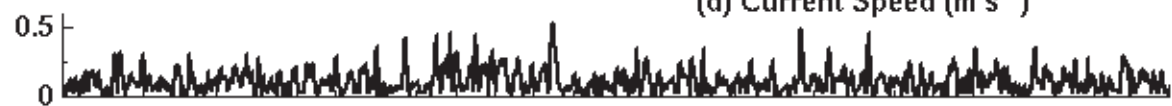

(e) Wave Height (m)

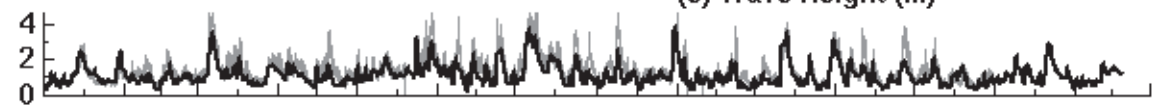

(f) Wave Period (s)

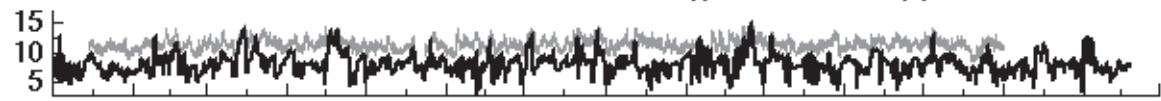

(g) Wave Orbital Velocity ( $\mathrm{m} \mathrm{s}^{-1}$ )

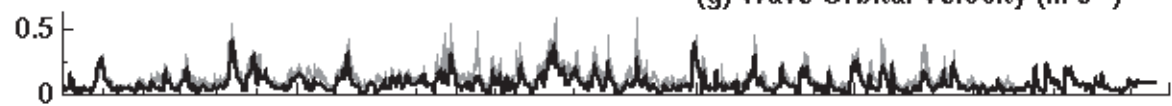

(h) Total Bed Shear Stress (Pa)

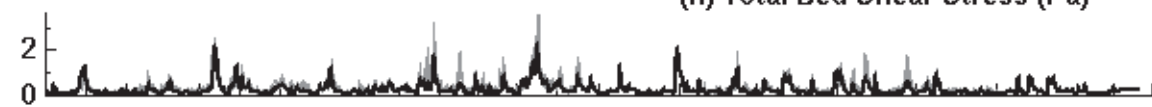

(i) Suspended Sediment ( $\left.\mathrm{g} \mathrm{L}^{-1}\right)$

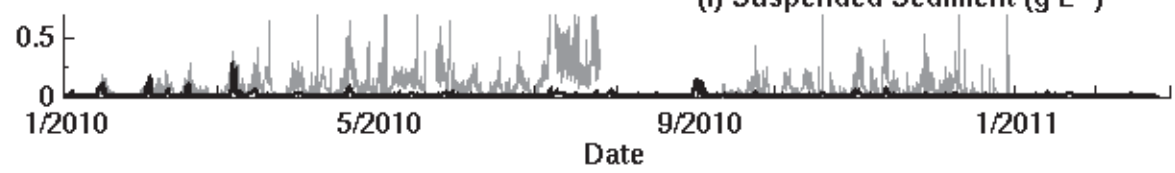


A local implementation of NOAA's Wave Watch 3 model [72], NZWAVE produced output every three hours on a $12 \mathrm{~km}$ resolution grid. Since NZWAVE did not provide wave spectra, the bottom wave period was assumed to be equal to the surface average period. This assumption resulted in underestimations of bottom wave period, because high frequency waves within a wave spectrum decay with water depth so that only the longer-period waves are felt at depth. Wave orbital velocities were calculated using linear wave theory and the interpolated NZWAVE data and bathymetry from the model grid. Linear wave theory was used instead of methods presented in [80] because estimates of wave orbital velocity based on this theory best matched tripod data.

Both model estimates and observed datasets provided atmospheric input. NZLAM, an implementation of the UK Meteorological (Met) Office's Unified Model [73], provided hourly estimates of wind velocity on a $12 \mathrm{~km}$ resolution grid. ROMS also required values for air pressure, cloud cover, precipitation, relative humidity, shortwave radiation, and air temperature as input. Hourly records of these meteorological data from the Gisborne, NZ airport were obtained from NIWA's National Climate Database web system [76] and applied uniformly across the Waipaoa shelf.

\subsection{River Discharge}

Waipaoa River water and sediment discharges were represented as a point-source entering Poverty Bay at a grid cell located at the river mouth. Observations of river stage were collected hourly at Kanakania Bridge, $\sim 80 \mathrm{~km}$ upriver, above tidal influences, by G. Hall and D. Peacock at the Gisborne District Council (GDC) [77]. For water and sediment input, recently-calibrated rating curves provided by the GDC were applied to the river stage and water discharge, respectively (see Figure $4 a, b)$. ROMS required that the vertical profile of the freshwater and sediment flux be specified at the point source. For the Waipaoa River, the profile was configured so that the freshwater and river sediment was delivered in the top half of the water column (Figure 5).

\subsection{Tides}

Tidal velocities, amplitudes and phase components extracted from the Oregon State Tidal Prediction Software (OTPS) TPX07.1 global solution [74,75] were used to estimate tidal currents and sea surface height. OTPS accounted for eleven ocean tidal constituents, and was driven by satellite altimeter data (i.e., TOPEX/Poseidon and Jason). The sum of the OTPS estimates and values of water velocities and elevation from ROMS-NZ, which did not account for tides, were imposed at the model open boundaries. 
Figure 5. Vertical profile of river input showing the partitioning of momentum, fresh water, and river sediment at the river mouth.

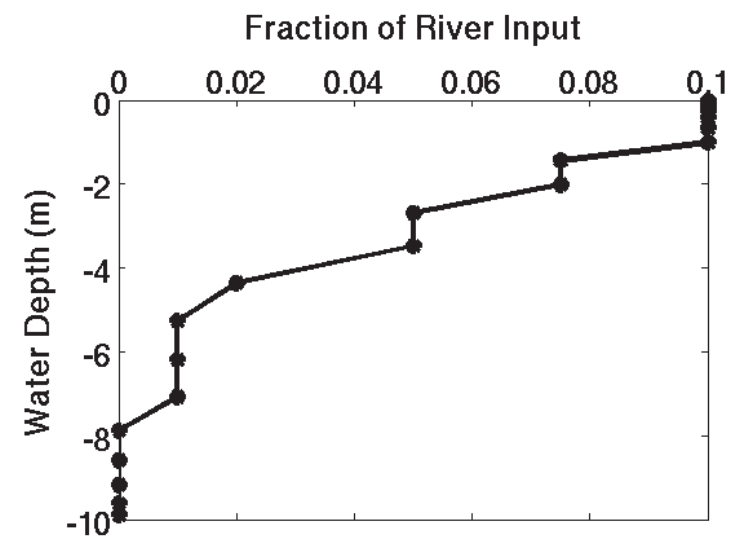

\subsection{Baroclinic Currents, Temperature and Salinity}

Current velocities, temperature and salinity at and near open boundaries of the Waipaoa grid were nudged toward values from ROMS-NZ, a larger-scale baroclinic model adapted for northern New Zealand ([65]; model used a similar model setup to [66]; see Figures 1 and 4d). ROMS-NZ provided estimates of current velocity, temperature and salinity every three hours on a two kilometer grid. This one-way nesting of the Waipaoa shelf model within the lower resolution hydrodynamic model allowed larger-scale circulation (i.e., shelf waves and offshore eddies) to influence modeled Waipaoa shelf hydrodynamics.

Three-dimensional, time dependent current velocities, temperature and salinity estimates from ROMS-NZ were linearly interpolated to the Waipaoa shelf grid and used for model initialization and nudging at model boundaries. ROMS-NZ estimates were unavailable for some grid cells near the coast in the interior of the grid where the land-ocean masking differed between the two models. At these sites, current velocities were initialized to zero, and initial temperature and salinity estimates were set equal to values from adjacent grid cells. Since land-ocean masking was identical between model grids near the open boundaries, these approximations only affected model initialization and not nudging near the open boundaries (see section 2.5).

\subsection{Sediment Characteristics}

Model calculations included a total of seven sediment types and eight seabed layers (Table 4). Different sediment classes were used to store fluvial and bed sediment so that model analysis could differentiate between materials from these two sources. Sediment classes were primarily distinguished based on their settling velocity, a primary control on transport in hydrodynamic-sediment transport models, e.g., [81], with nominal $\mathrm{D}_{50}$ values provided based on observations from the river and seabed [25,78], and unpublished data [82] from the January 2010 cruise described in [36].

Estimates of effective settling velocity based on tripod measurements from the field site (obtained from A. Ogston and R. Hale, UW [29]; see [30]) informed our choice of settling velocities, while 
the initial seabed sediment distributions were based on sediment texture from Poverty Bay and shelf $[36,69,78]$ (Figure 6). Observed grain size data were converted to percent sand and percent mud for all sites, and then spatially interpolated. Grain size data were unavailable for locations near the model open boundaries, so grid cells with water depth exceeding $300 \mathrm{~m}$ or near the northeastern and southwestern boundaries were assumed to be mud (sediment class 1). For the purpose of interpolation, grid cells at the coastline were assumed to be composed of sand (sediment class 2). Tripod-based estimates of effective settling velocities on the shelf ranged from $<0.1$ to $\sim 1 \mathrm{~mm} \mathrm{~s}^{-1}$, with a mode of $\sim 0.1 \mathrm{~mm} \mathrm{~s}^{-1}$ during energetic shelf conditions at $40 \mathrm{~m}$ water depth, and were used to set the settling velocities of these two classes. Finally, the grain size distribution was constrained so that at least $10 \%$ of the seabed was composed of fast-settling material (sediment class 3 ) to enhance bed armoring, consistent with previous modeling efforts [6].

Table 4. Sediment classes and their characteristics

\begin{tabular}{ccccc}
\hline Sediment Class & Source & \% of Riverine Load & Settling Velocity $\left(\mathbf{m m ~ s}^{\mathbf{- 1}}\right)$ & $\mathbf{D}_{\mathbf{5 0}}(\boldsymbol{\mu m})$ \\
\hline 1 & Seabed & - & 0.1 & 63 \\
2 & Seabed & - & 0.5 & 500 \\
3 & Seabed & - & 125.0 & 1000 \\
4 & River & 53 & 0.15 & 16 \\
5 & River & 27 & 0.3 & 22 \\
6 & River & 13 & 0.5 & 30 \\
7 & River & 7 & 1.0 & 40 \\
\hline
\end{tabular}

For all sediment classes: Critical Shear Stress: 0.15 Pa; Sediment Density: $2650 \mathrm{~kg} \mathrm{~m}^{-3}$; Porosity: 0.6.

Figure 6. Initial distribution of seabed sediment classes showing fraction of (a) mud and (b) sand.

(a) Mud Fraction

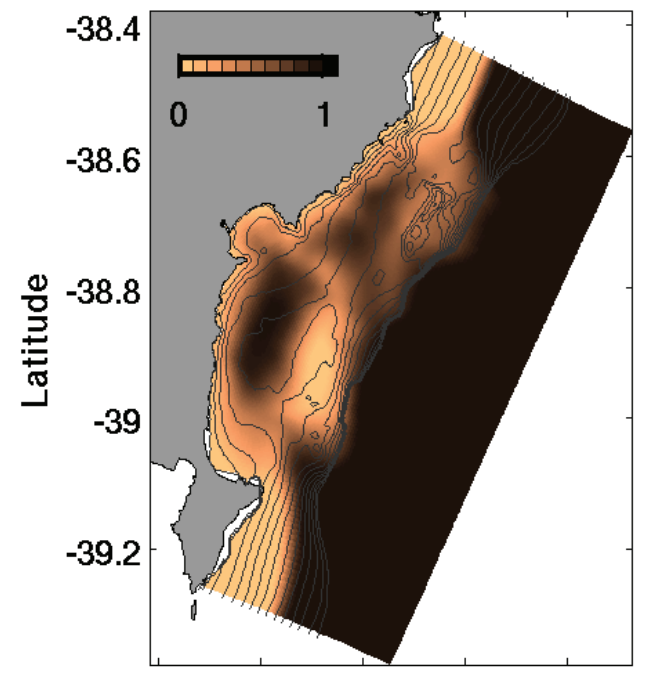

$\begin{array}{lllll}177.8 & 178 & 178.2 & 178.4 & 178.6\end{array}$ (b) Sand Fraction

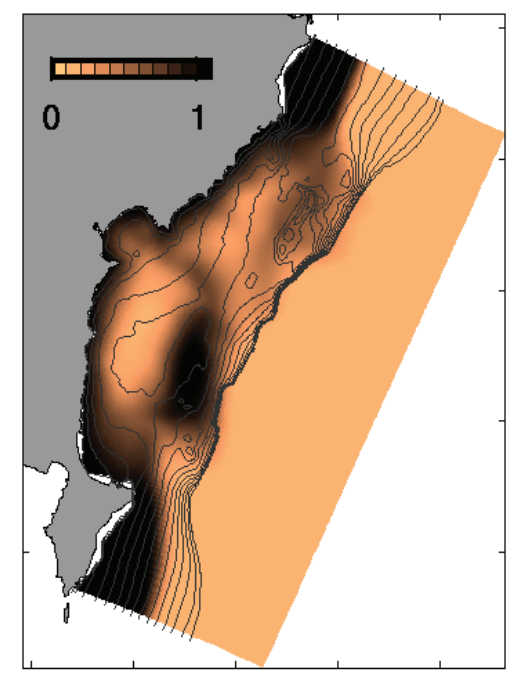

$\begin{array}{lllll}177.8 & 178 & 178.2 & 178.4 & 178.6\end{array}$

\section{Longitude}


Four classes were used to represent sediment delivered fluvially. Their properties were informed by observations that estimated a median grain diameter of $8.5 \mu \mathrm{m}$ in the Waipaoa River during floods [25], sediment budgets for the shelf, as well as the tripod estimates from the Waipaoa shelf (see above paragraph). Since information regarding the distribution of sediment settling velocity in the river plume was unavailable, a range of reasonable sediment settling velocities $\left(0.15-1 \mathrm{~mm} \mathrm{~s}^{-1}\right)$ was chosen. River mud was assumed to be flocculated because salinity profiles from research cruises in 2010-2011 [82] and results from other model runs [35] indicated that freshwater mixes quickly with ocean water, and very little stratification is observed in Poverty Bay. The fluvial sediment was logarithmically partitioned into these classes following sensitivity tests that considered the sediment budgets for Poverty Bay and the continental shelf following a three month model run representing early 2010. During this procedure, different settling velocities were prescribed for the slowest settling fluvial and seabed classes, $0.15 \mathrm{~mm} / \mathrm{s}$ and $0.1 \mathrm{~mm} / \mathrm{s}$, respectively. This was not surprising, as the choice of fluvial settling velocities relied on an integrative view of sediment dispersal, i.e., the overall shelf sediment budget, while seabed settling velocities were selected based on local tripod observations on the mid-shelf $\sim 10$ 's of $\mathrm{cm}$ above the bed. Further study would be required to reconcile these, perhaps involving a model that includes particle aggregation and breakup.

Parameters related to erodibility (critical shear stress, erosion rate parameter) were informed by ADV and OBS (Optical Backscatter Sensor) measurements from the first two months of the tripod deployment (data from [30]) and Gust erosion chamber experiments conducted at the field site [36]. Critical shear stress for all sediment was set to $0.15 \mathrm{~Pa}$, consistent with time series of tripod-based estimates of bed shear stress and sediment concentration, and Gust chamber erodibility experiments. For fast-settling grains (i.e., sediment classes 1 and 2), this critical shear stress was low compared to values based on the Shields parameter for the nominal grain diameters. However, in the absence of observations from which to specify various critical shear stress estimates for different classes of sediment, we used a uniform value. Note that calculated sediment fluxes were insensitive to the critical stress for fast-settling grains which settled to the bed quickly. Porosity was assumed constant across the shelf and set equal to 0.6 based on water content measurements [36]. Maximum and minimum erosion rate parameters in Equation (4) were assigned values of $4.5 \times 10^{-4} \mathrm{~kg} \mathrm{~m}^{-2} \mathrm{~s}^{-1}$, and $1.0 \times 10^{-5} \mathrm{~kg} \mathrm{~m}^{-2} \mathrm{~s}^{-1}$ based on estimates from the Gust microcosm erodibility experiments [36]. Although the model neglected the role of depositional history and biology on seabed consolidation and erodibility, spatially-variable bed stresses and erosion rate parameters created a gradient of high to low seabed erodibility as discussed in section 4.1.

\subsection{Sensitivity Tests}

The Waipaoa shelf model described above, called the "standard model", was implemented for 15 January 2010-27 August 2010. Sections 4.2 and 4.3 evaluated the effect of model nesting and spatially-varying erodibility on model estimates using four sensitivity tests listed below. First, "moderately nudged" and "weakly nudged" test cases were run by increasing nudging timescales $T_{R, I}$ and $T_{R 0}$ from 2.5 days to 5 and 25 days to relax the degree to which larger-scale currents influenced model estimates. Second, "low $M$ " and "high $M$ " test cases applied spatially-uniform 
erosion rate parameters where $M$ in Equation 4 was set equal to $M_{\min }$ and $M_{\max }$ instead of the spatially varying $M$ used in the standard model. All sensitivity tests were run for the same seven month period as the standard model, except for the weakly-nudged simulation which became unsteady after about 20 March 2010. Sensitivity tests for other parameters were considered, but we chose to focus on this subset to demonstrate the importance of nesting for model stability, and because use of a spatially-varying erodibility has not been previously used with the CSTMS, yet provided a straightforward way to improve the agreement between modeled and observed patterns of erodibility and sediment retention.

\section{Results and Discussion}

Results for the standard model are evaluated, and then the sensitivity of estimates to model nesting and seabed erodibility parameterization is discussed.

Figure 7. Time series of tidally- and depth-averaged water velocities from the Poverty Gap tripod in $40 \mathrm{~m}$ water depth. Observations (grey) and model estimates, including the standard model (thick red line), moderately-nudged (maroon), and weakly-nudged sensitivity tests (black).
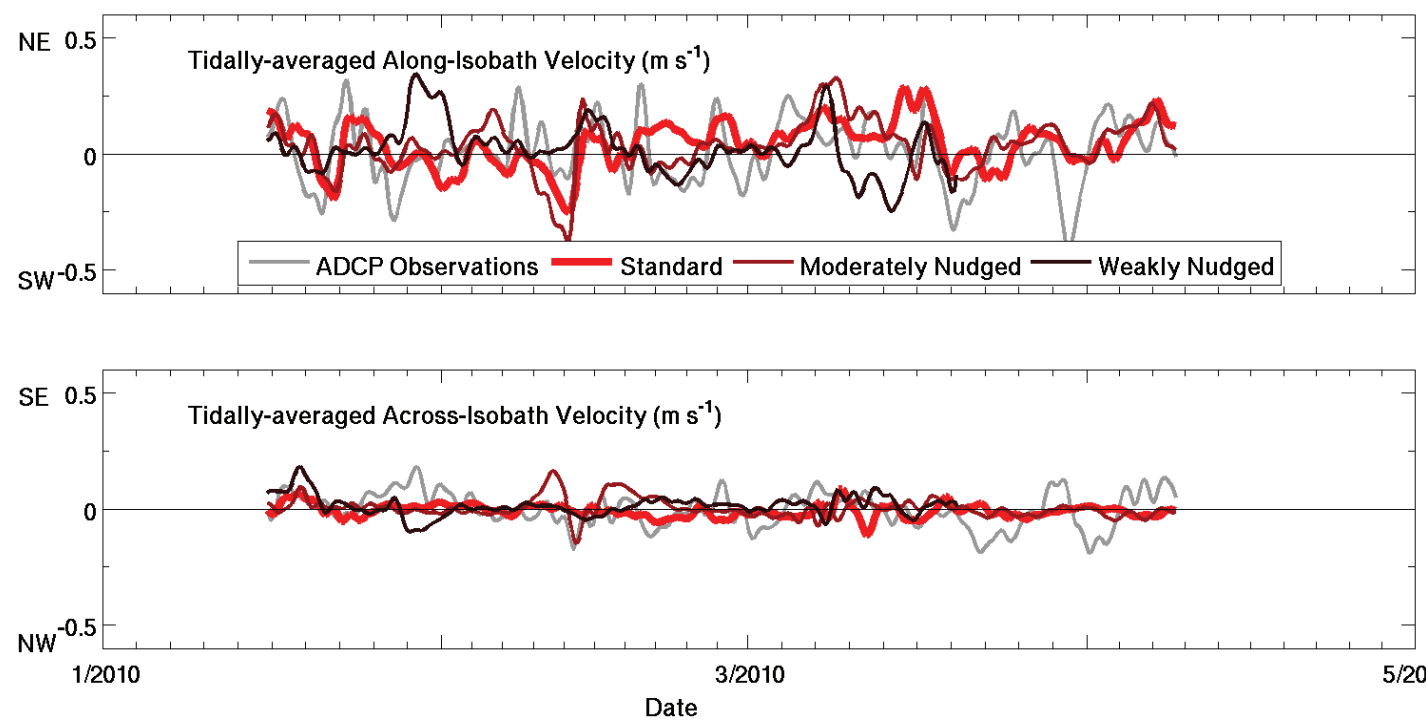

\subsection{Model Evaluation}

Both the modeled and observed currents varied spatially and frequently reversed direction (Figure 7). For the most part, depth- and time-averaged current velocities on the shelf had a northeastward orientation, although the modeled and observed currents often had an offset in direction. At the $40 \mathrm{~m}$ deep tripod location, for example, velocities in the model were directed 15 degrees east of north, shoreward of measured velocities that were oriented 54 degrees east of north. Although the model underestimated peak water speeds at the three tripod locations, it replicated the 
spatial patterns of the tripod-observed time- and depth-averaged current speeds, which increased from the depocenter to the shallow site to the deep tripod (Figure 8). Modeled velocities along the shelf-slope break were particularly fast, with the strongest shelf currents traveling along the shelf break and along isobaths, passing seaward of the southern anticline, through Poverty Gap, and inshore of the northern anticline. Lower current speeds were estimated in the lee of Mahia Peninsula, over the southern depocenter and in Poverty Bay. While shelf currents were generally to the northeast, a counterclockwise eddy formed within Poverty Bay, as seen in observations $[21,27,28]$ and a previous model [6]. A persistent eddy also developed in the model over the southern depocenter, consistent with local tripod observations where depth-averaged currents fluctuated, but were primarily directed to the northwest or south. The modeled currents frequently reversed direction in response to boundary forcing from the larger-scale model. The reversals occurred on a timescale of days, similar to temporal behavior seen in measured currents (Figure 7). Discrepancies between the modeled and observed currents did occur, however. Factors that likely contributed to these include issues with the skill or resolution of the wind model; use of climatological temperature and salinity fields to force ROMS-NZ, which could affect the timing of large-scale eddies propagating southward along the shelf break; imperfect or smoothed bathymetric data; grid discretization; or choice of mixing schemes.

Figure 8. Map of estimated time-averaged depth-averaged current speed (shading; $\mathrm{m} \mathrm{s}^{-1}$ ) and direction (black arrows). Long white arrows with blue outlines indicate observed current direction for tripod deployments. Black bathymetric contours indicate every $10 \mathrm{~m}$.

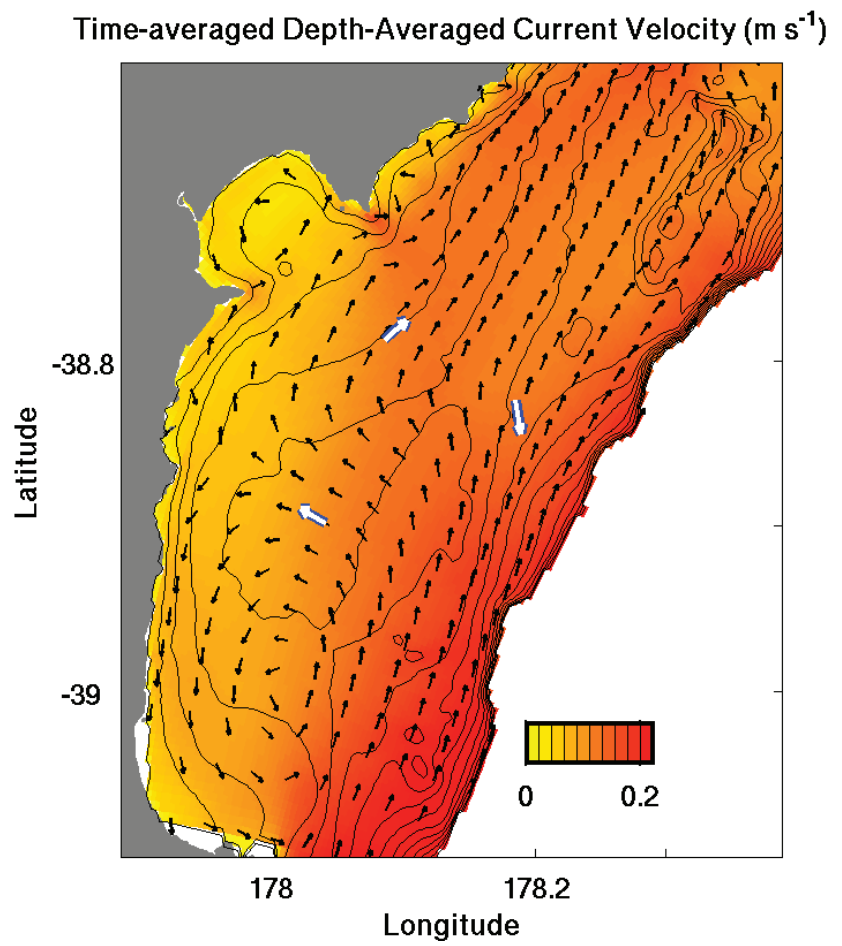


Model estimates of waves, bed shear stresses, and sediment concentrations also captured the timing of observed episodic events (see [30]). Although wave periods were underestimated in the model, wave orbital velocities were comparable to values derived from tripod data (Figure 4f,g). Peaks in bed shear stress estimates occurred during the observed wave events, with a correlation coefficient of 0.72 and a bias of -0.20 to $0.02 \mathrm{~Pa}$ (Table 5; Figure 4h). Although time-averaged bed shear stresses were underestimated by about $17 \%$ for tripod deployments, the bias improved during periods of energetic waves and in the shallow area of Poverty Gap, where the largest sediment fluxes occurred. Modeled stresses were underestimated by about 5\% at the $40 \mathrm{~m}$ deep tripod for time periods when ADV-derived data exceeded 0.15 Pa. For suspended sediment, we compared point measurements from a small sampling volume located 17-100 cmab, depending on tripod location and deployment, to estimates from the model's bottom grid cell, which represented a vertically-averaged value over the thickness of that layer ( $0.84 \mathrm{~m}$ at $50 \mathrm{~m}$ water depth). For these, the model underestimated near-bed concentrations from the tripod by more than $80 \%$. Since the model cannot capture near-bed gradients in turbidity, the lower estimates for suspended sediment concentrations were not surprising. Consistent with observations, suspended sediment concentrations peaked during observed wave events (Figure 4i).

Table 5. Model evaluation statistics calculated (A) for the standard model for all tripod deployments with available observations; and (B) for depth-averaged currents from all three tripods' first deployments for all nesting sensitivity tests. This was the only time period when all models ran stably.

\begin{tabular}{|c|c|c|c|c|}
\hline \multicolumn{5}{|c|}{$(\mathbf{A})$} \\
\hline \multicolumn{2}{|c|}{ Parameter } & $\mathbf{R}^{1}$ & $\sigma_{\text {model }} / \sigma_{\text {observations }}{ }^{2}$ & Bias $^{3}$ \\
\hline \multicolumn{2}{|c|}{ Wave Orbital Velocity } & $0.63-0.85$ & $0.84-1.35$ & $-6.4-1.4 \mathrm{~cm} / \mathrm{s}$ \\
\hline \multicolumn{2}{|c|}{ Bed Shear Stress } & $0.60-0.82$ & $0.72-1.79$ & $-0.20-0.02 \mathrm{~Pa}$ \\
\hline \multicolumn{2}{|c|}{ Depth-Averaged Currents (Along-Shelf) } & $0.33-0.79$ & $0.59-0.93$ & $-4.7-10.4 \mathrm{~cm} / \mathrm{s}$ \\
\hline \multicolumn{2}{|c|}{ Depth-Averaged Currents (Across-Shelf) } & $0.01-0.24$ & $0.34-1.52$ & $-2.1-7.0 \mathrm{~cm} / \mathrm{s}$ \\
\hline \multicolumn{2}{|c|}{ Suspended Sediment Concentrations } & $0.27-0.52$ & $0.03-0.28$ & $-0.22-0.01 \mathrm{~g} / \mathrm{L}$ \\
\hline \multicolumn{5}{|c|}{ (B) } \\
\hline \multicolumn{2}{|c|}{ Parameter } & $\mathbf{R}^{1}$ & $\sigma_{\text {model }} / \sigma_{\text {observations }}{ }^{2}$ & Bias $^{3}$ \\
\hline Depth-Averaged Currents & Standard & $0.33-0.45$ & $0.59-0.74$ & $8.0-10.4 \mathrm{~cm} / \mathrm{s}$ \\
\hline \multirow[t]{2}{*}{ (Along-Shelf) } & Moderate Nudging & $0.40-0.41$ & $0.47-0.79$ & $1.2-10.0 \mathrm{~cm} / \mathrm{s}$ \\
\hline & Weak Nudging & $0.14-0.23$ & $0.65-0.84$ & $-1.0-13.6 \mathrm{~cm} / \mathrm{s}$ \\
\hline \multirow{3}{*}{$\begin{array}{l}\text { Depth-Averaged Currents } \\
\text { (Across-Shelf) }\end{array}$} & Standard & $0.01-0.12$ & $0.35-1.23$ & $-0.8-0.65 \mathrm{~cm} / \mathrm{s}$ \\
\hline & Moderate Nudging & $0.02-0.07$ & $0.44-1.25$ & $-0.64-1.0 \mathrm{~cm} / \mathrm{s}$ \\
\hline & Weak Nudging & $0.09-0.30$ & $0.59-1.11$ & $-4.7-1.7 \mathrm{~cm} / \mathrm{s}$ \\
\hline
\end{tabular}

${ }^{1}$ Correlation Coefficient; ${ }^{2}$ Ratio of the standard deviation of the model estimates to that of the observations; ${ }^{3}$ Difference between the mean of the model estimates and mean of the observations.

Erodibility in the model was evaluated by comparing estimates of seabed level variability to observations of eroded mass from Gust microcosm experiments (observations provided by [36]). Seabed level variability for each grid cell was calculated by taking the standard deviation of the time series of modeled seabed elevation (Figure 9). At each grid cell, seabed level variability 
depended on the erosion rate parameter, local sediment supply, and on active layer thickness (Equation (3); Figure 2) which varied with bed stress and grain size. Seabed level variability, as defined by the standard deviation, included both the net trend of erosion and deposition for a grid cell, as well as shorter-timescale fluctuations from individual floods and storms. For example, locations in Poverty Bay experienced relatively high rates of deposition that contributed to the high variability calculated there. Overall, seabed level variability was highest in areas shallower than $\sim 30 \mathrm{~m}$ depth and where fluvial deposition occurred. The decrease in seabed level variability from Poverty Bay to the depocenters was consistent with estimates of eroded mass from Gust microcosm experiments (data provided by [36]), which indicated that the most erodible sediments were also found in Poverty Bay and the mouth of the bay $\left(R^{2}=0.4\right.$; Figures 10 and 11). Differences between the model and observations could occur because Gust microcosm experiments were instantaneous measurements, while seabed variability was time-averaged, or because the model neglected processes such as bioturbation, and variations in parameters including critical shear stress (see section 4.3).

Figure 9. Modeled seabed level variability. Shading indicates $\log _{10}$ of the modeled seabed level variability, equal to the standard deviation of seabed thickness $(\mathrm{cm})$ for each grid cell.

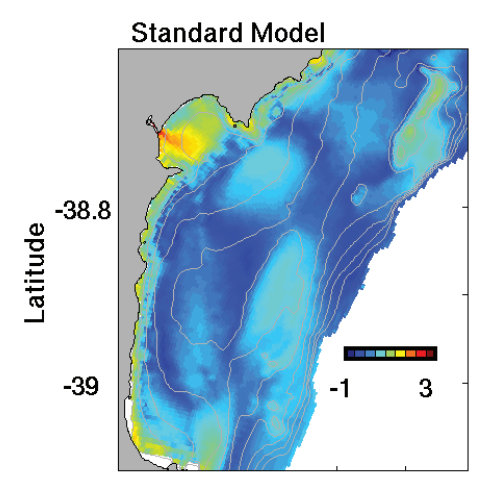

178

178.2

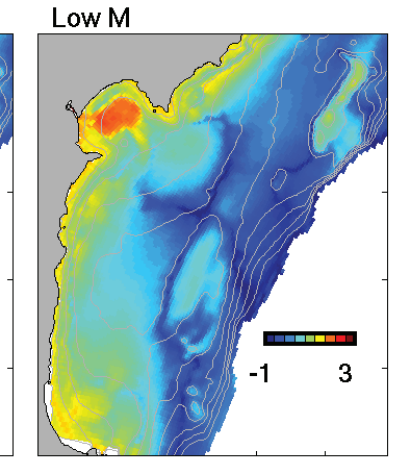

178

\section{Seabed Variability $\left(\log _{10}(\mathrm{~cm})\right)$}

\section{High M}

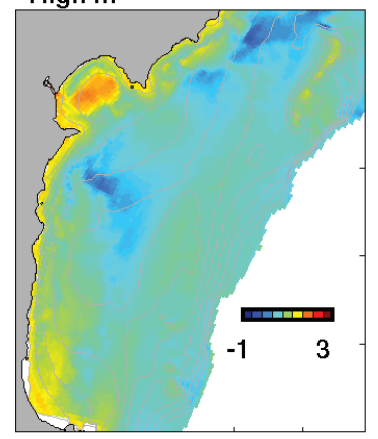

178

178.2

Longitude

Patterns of erosion and deposition estimated by the model have been evaluated using seabed observations of ${ }^{7} \mathrm{Be}$ inventories that indicate recent deposition of terrestrially derived material ([36,37]; Figures 12 and 13). Overall, both the observations and model estimates exhibited high spatial and temporal variability [35-37]. Areas of deposition often occurred in close proximity to areas where little or no sedimentation was detected or estimated, and the shape of the footprint of recent terrestrial deposition changed between each research cruise. Both observations and model estimates generally showed enhanced deposition to either side of Poverty Gap, landward of shelf anticlines, although model estimates of deposition were located in shallower water than observed high ${ }^{7} \mathrm{Be}$ inventories. During every research cruise, radioisotope signatures were also high in some part of Poverty Gap, consistent with model estimates that showed sediment deposits there, 
particularly following periods of high discharge. Often, these high radioisotope signatures and model estimates of deposition were observed at $\sim 40 \mathrm{~m}$ and $\sim 30 \mathrm{~m}$ in Poverty Gap, respectively.

Figure 10. Observations of eroded mass from [36] for Gust microcosm erodibility experiments from January 2010 (C1), May 2010 (C2), September 2010 (C3), and February 2011 (C4). Grey bathymetric contours are every $10 \mathrm{~m}$ until $100 \mathrm{~m}$ water depth. Figure reproduced with permission from [36], copyright (C) Kiker, 2014.

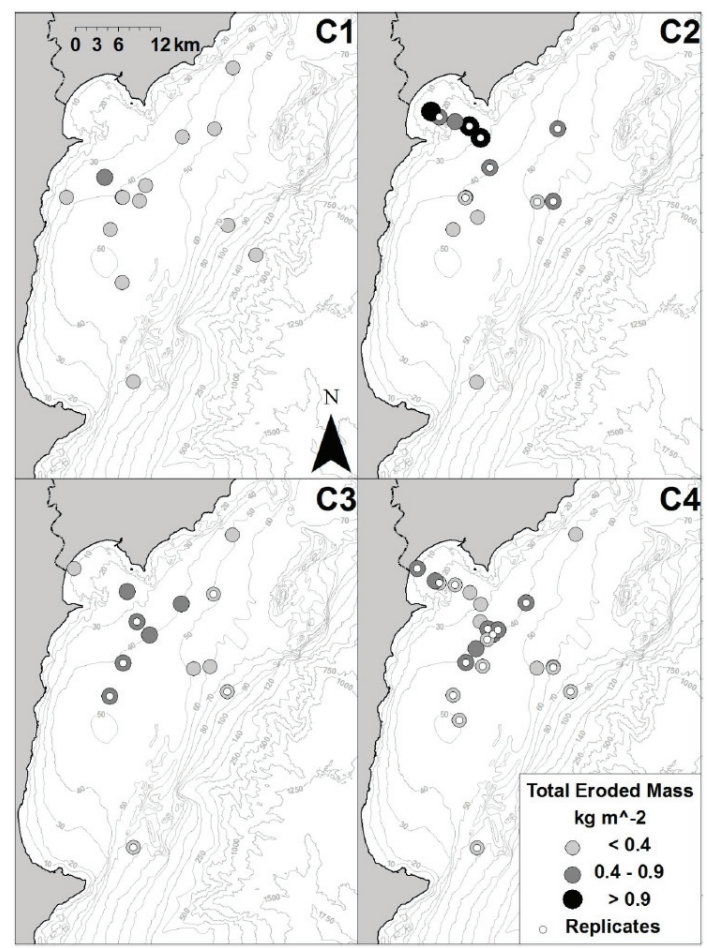

Figure 11. Comparison of seabed level variability to observations of eroded mass from [36] for Gust microcosm erodibility experiments for specific sites. Multiple observations at a single site from were averaged.

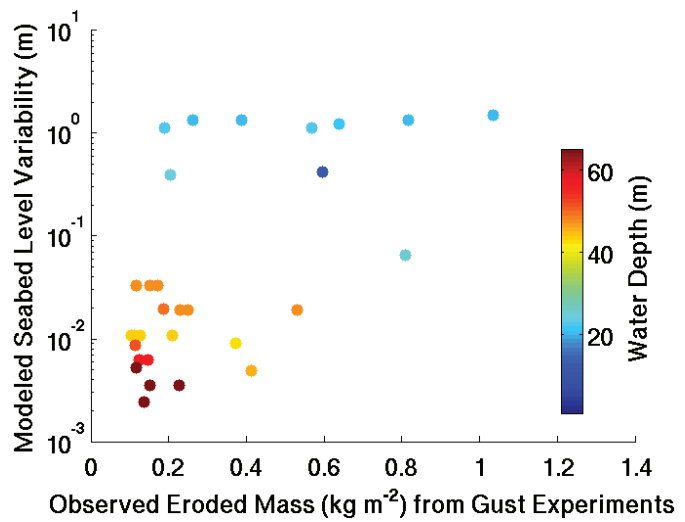


Figure 12. Deposition per percent of riverine load following the March wave event for standard, moderately-nudged, low $M$ and high $M$ cases.

\section{Deposit Thickness per \% Riverine Load: 15-Mar-2010}

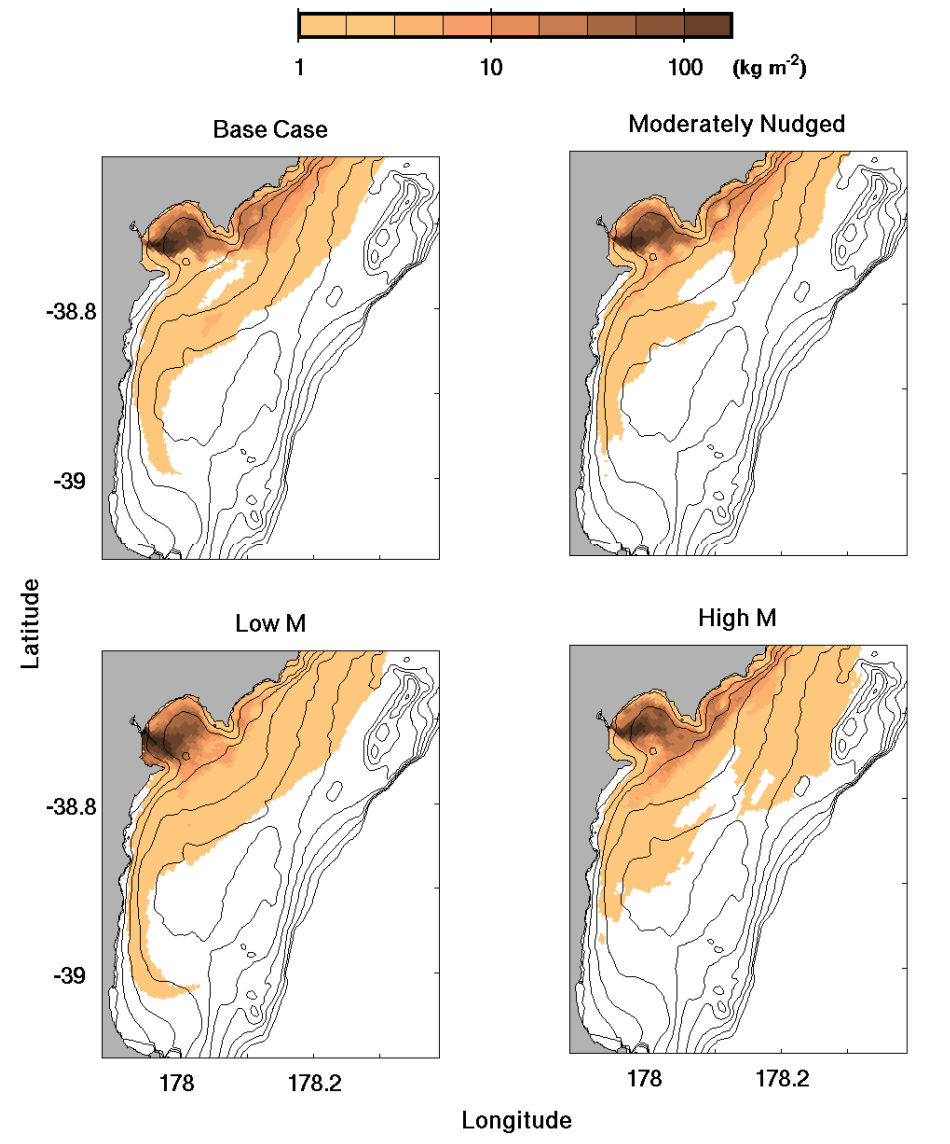

Overall, sediment fluxes were likely underestimated, but patterns of transport and deposition were consistent with observations. For instance, episodic and energetic waves dominated bed shear stress calculations and determined the timing of seabed resuspension, as seen in observations and other modeling studies (see above, section 1.2). Relatively slow water speeds and low sediment concentrations compared to observations would cause sediment fluxes to be underestimated, especially in the on- and off-shore directions. However, the model captured the spatial pattern of velocities, the frequent reversals of current direction, and the time-averaged currents; also, changes to open boundary conditions, as presented in this paper and during early model runs, affected the shape and location of the flood deposit for individual events, but had little effect over the entire 13month model run, suggesting that time-averaged fluxes were consistent with observations. Finally, the skill of this model was comparable to others for the region. For the Poverty Bay model [6], the authors calculated biases and correlation coefficients of -5 to $0 \mathrm{~cm} \mathrm{~s}^{-1}$ and $\sim 0.75$ for wave orbital velocity, and -11 to $-5 \mathrm{~cm} \mathrm{~s}^{-1}$ and -0.33 to 0.67 for current velocities, comparable to values in Table 5 for the shelf environment. 
Figure 13. Observed ${ }^{7} \mathrm{Be}$ inventories from (A) January, and (B) May 2010 research cruise. Figure reproduced with permission from [36], copyright (C) Kiker, 2014.

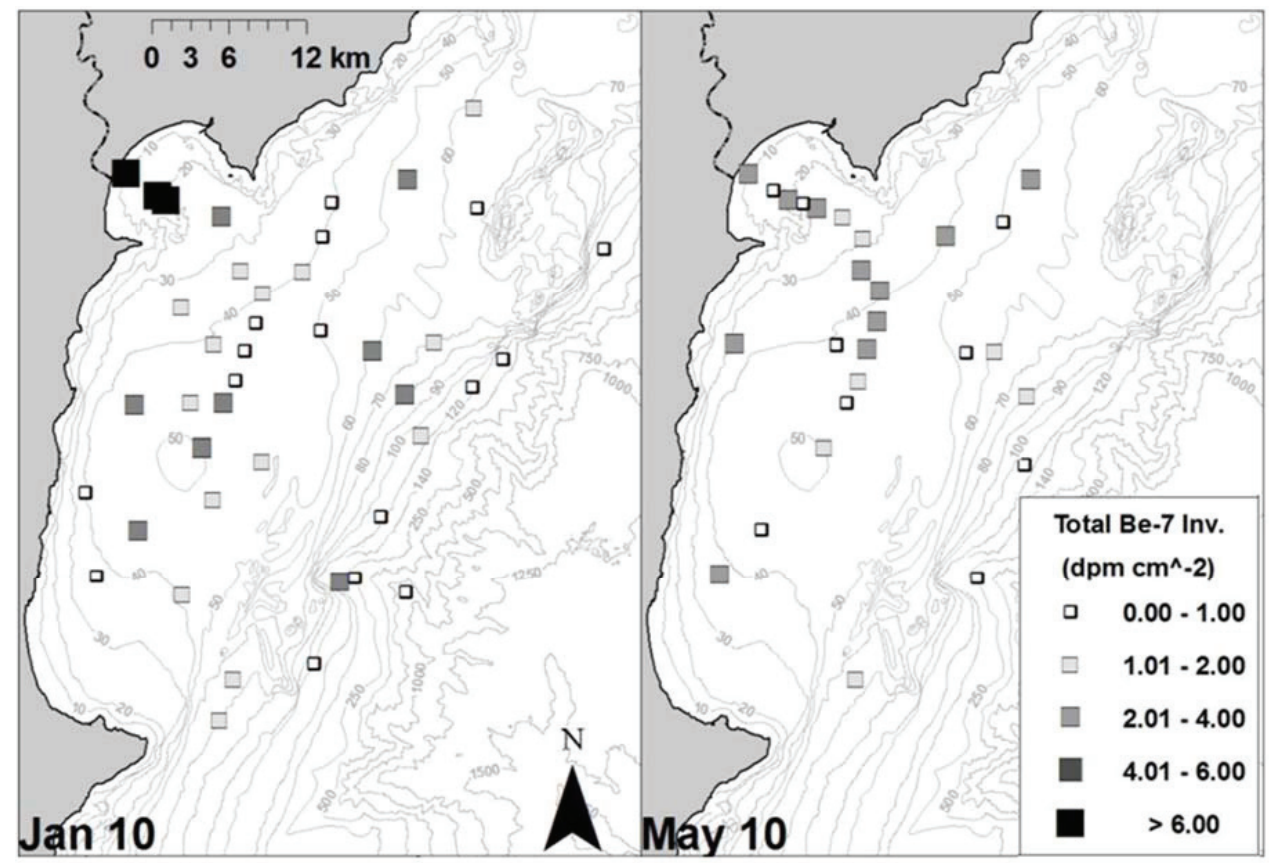

\subsection{Model Nesting}

Comparing behavior of the standard model to ones that used less rigid relaxation timescales showed that model nesting helped account for larger-scale currents, improved current velocity skill, and increased stability. Evaluations of model performance for this study considered water velocities because currents are important for sediment fluxes. A. Ogston and R. Hale, UW, provided time series of acoustic Doppler current profiler (ADCP) data from three locations ([29]; see [30], Figures 1 and 7). Overall, stronger nudging to regional circulation did not significantly affect the mean current speeds (Table 5, Figure 7). At the $40 \mathrm{~m}$ tripod, time- and depth-averaged current speeds and associated standard deviations for 15 January 2010-20 March 2010 were $10.4 \pm 6.3 \mathrm{~cm} \mathrm{~s}^{-1}, 10.3 \pm 8.3 \mathrm{~cm} \mathrm{~s}^{-1}$ and $9.3 \pm 7.7 \mathrm{~cm} \mathrm{~s}^{-1}$ in the standard, moderately-nudged and weakly-nudged cases, respectively. However, stronger nudging near the open boundaries increased the frequency with which along-shore currents switched direction, better matching observations (Figure 7). At the $50 \mathrm{~m}$ tripod in Poverty Gap, correlation coefficients between model estimates and observed depth-averaged along-shore velocities increased from 0.21 to 0.42 to 0.47 as the intensity of nesting increased from the weakly-nudged to moderately-nudged to the standard implementation (Table 5).

Model nesting also stabilized currents in areas near the open boundaries, reducing the reflection of the river plume at the grid's edge. Without nudging, the model failed within a couple of days because of excessively high water velocities (over $2 \mathrm{~m} \mathrm{~s}^{-1}$ ) at the boundaries near Mahia peninsula 
and the northeast coast as the river plume reflected off of the open boundaries creating a gyre within the domain. As expected, stronger nudging limited both the formation of the gyre and reflection at the open boundaries. To evaluate model behavior, the flux of freshwater through the open boundaries was estimated as:

$$
S_{o b c}=\iint \mathcal{\imath} \bullet \hat{n} \max \left\{0,\left(S_{0}-S / S_{0}\right)\right\} d x d z
$$

where $\tilde{u} \bullet \hat{n}$ was the velocity perpendicular to an open boundary, $S$ was salinity, and $S_{0}$ was the background salinity of $35.1 \mathrm{psu}$. During the January 2010 river flood (28 January-15 February 2010), the cumulative freshwater flux through the open boundaries increased from $0.12 \times 10^{6} \mathrm{~m}^{3}$ to $0.23 \times 10^{6} \mathrm{~m}^{3}$ to $1.12 \times 10^{6} \mathrm{~m}^{3}$ when the nudging relaxation timescales, $T_{R, i}$ and $T_{R 0}$, decreased from 25 days to 5 days to 2.5 days. These fluxes of water were equivalent to about $1 \%, 2 \%$, and $11 \%$ of the freshwater discharge into the grid. Note that the nudging of tracers from cells near the open boundary but within the grid (Equation (5)) removed freshwater from the grid, removing more freshwater for shorter relaxation timescales. Therefore, the estimates of freshwater flux through the boundaries represent low estimates which removed approximately double the volume of freshwater from the standard model compared to the weakly-nudged simulation.

Mean current velocities were sensitive to the strength of nudging. During the first tripod deployment, for instance, mean currents in Poverty Gap at $40 \mathrm{~m}$ water depth changed from 2.1 to 3.4 to $4.1 \mathrm{~cm} \mathrm{~s}^{-1}$, and the direction of mean water velocity changed from 104 to 72 to 54 degrees counter clockwise from east for the weakly-nudged, moderately-nudged and standard simulations. Current direction fluctuated frequently, however, so sediment dispersal remained relatively consistent among the different model runs, especially over timescales of months.

Therefore, the partitioning of sediment among different areas of the system (e.g., Poverty Bay $v s$. the rest of the shelf $v s$. off the proximal shelf) was relatively insensitive to the nesting scheme. Over the nine months of the model run, from 15 January to 25 August 2010, there was a 6\% decrease in the sediment escaping the proximal shelf, a $6 \%$ decrease in sediment on the shelf, and a $13 \%$ increase in sediment in the bay for the weakly-nudged test case compared to the standard simulation. Similarly, a numerical modeling study [15] found that nesting increased sediment export from the Mekong delta front by $<5 \%$.

\subsection{Sediment Erodibility}

Choice of seabed erosion rate parameter ( $M$ in Equation (4)) influenced the amount of, and location of deposition on the shelf. In general, estimates of resuspension and sediment export from Poverty Bay to the shelf increased with the erosion rate parameter (Figure 12). Sediment fluxes in shallow areas were particularly sensitive to the choice of $M$ due to increased sediment resuspension where bed stresses were high. Dispersal of slow settling material that remained suspended for relatively long times was also sensitive to $M$. In contrast, dispersal of sediment settling at $1.0 \mathrm{~mm} \mathrm{~s}^{-1}$ was relatively insensitive to $M$; differences in estimated sediment budgets were within $2 \%$ of each other for the cases of low, to spatially-variable, to high erosion rate parameters. For sediment settling at $0.15 \mathrm{~mm} \mathrm{~s}^{-1}$, however, sediment export from Poverty Bay between 15 January and 7 August 2010 increased from $26 \%$ to $44 \%$ to $50 \%$ for the three cases. Despite the increased influx 
of sediment onto the shelf during the high $M$ test case, however, less sediment was retained on the shelf because the high erosion rate parameter encouraged resuspension and resulted in more sediment export from the shelf compared to the standard model (Figure 14). For the low, spatially-varying, and high $M$ test cases, $7 \%, 14 \%$, and $9 \%$ of sediment settling at $0.15 \mathrm{~mm} \mathrm{~s}^{-1}$ remained on the shelf, excluding Poverty Bay. Overall, spatially-varying erodibility increased deposition on the shelf relative to Poverty Bay, consistent with radioisotope-derived estimates of deposition on month long timescales [36]. Results from the standard model were most consistent with studies indicating that about a quarter of riverine material has remained on the shelf over decadal to century-long timescales [38].

Figure 14. Sediment Budget. (a) Time series of cumulative sediment input, mass of sediment in Poverty Bay (B in (b)), and mass of sediment on the shelf ( $\mathrm{S}$ in (b)). Colors indicate sensitivity test. Line style indicates area of model grid included in calculations, as shown in (b). "Shelf" includes all areas up to $150 \mathrm{~m}$ water depth where no model nudging occurred, excluding Poverty Bay. Model grid boundaries were indicated by dashed line. Bathymetric contours were drawn every $50 \mathrm{~m}$ up to $150 \mathrm{~m}$ depth.

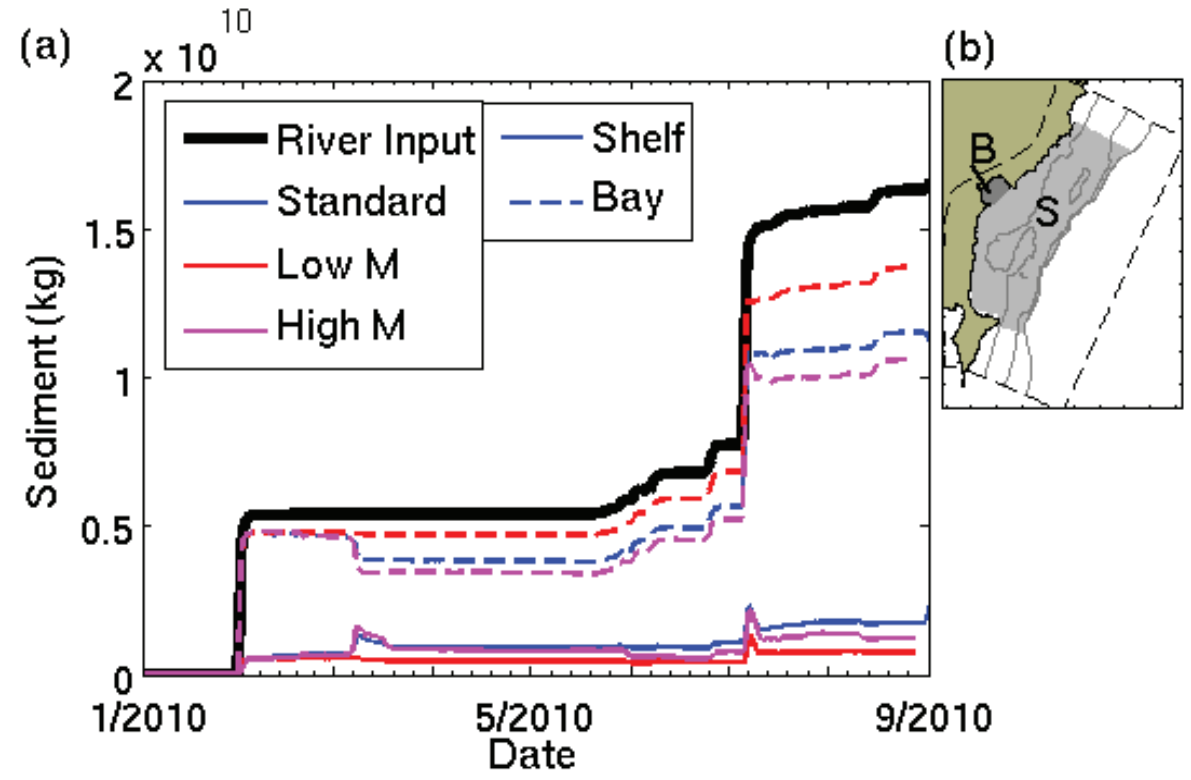

Use of other seabed parameterizations for erodibility that account for bed consolidation and variations in critical shear stress, e.g., [18,22], could further increase sediment export from Poverty Bay following floods, and further strengthen the spatial trend of decreased seabed level variability in deeper areas of the shelf. For instance, some models account for the dependence of seabed erodibility of muds on depositional history such that the seabed's critical shear stress increase and decrease following erosional and depositional time periods, respectively [22]. Utilizing this type of seabed scheme would likely create areas of low critical stress in depositional areas following floods, such as Poverty Bay, enhancing sediment export in the days following high discharge 
events. However, this erodibility parameterization requires additional information about observed seabed critical stress profiles, is more computationally expensive, and has not yet been used for many realistically implemented sediment models (e.g., [83]).

\subsection{Computational Concerns}

Many decisions in the implementation of this three-dimensional numerical model required tradeoffs between desired accuracy and spatial resolution, and computational limits. The model had a total of $118 \times 287$ horizontal grid cells, each with 20 vertical water column layers and 8 vertical sediment bed layers. A total of nine tracer variables were included (salinity, temperature, and seven sediment classes), in addition to the momentum state variables. To provide estimates that overlapped with the Poverty Shelf field experiment, the modeled time period needed to span 13 months, from January 2010-February 2011, and provide estimates of state variables, including velocities, tracer concentrations, and sediment bed characteristics, every three hours for each grid point. ROMS has been parallelized using MPI (Message Passing Interface), which allowed us to run the model on VIMS' High Performance Computing (HPC) cluster using 48 nodes. The full 13-month model run required 9 days to run to completion. Some choices of model implementation significantly slowed the computations, including the MPData algorithm for horizontal advection of tracers, and the nudging of currents and tracers near the open boundaries. These components of the model were, however, important for model stability.

\section{Summary}

This project built on previous efforts by using a nested hydrodynamic-sediment transport model with spatially-variable erodibility to examine sediment fluxes on the Waipaoa Shelf. A three-dimensional sediment transport model accounting for a river plume, winds, waves, largerscale currents, and tides was developed and implemented for the Waipaoa Shelf, New Zealand. These processes were represented using the ROMS-CSTMS framework in conjunction with locally-validated observed and modeled datasets described above. By varying horizontal and vertical resolution in the model, we focused on the area of interest and boundary layer processes while maintaining sufficient model efficiency. Sensitivity tests indicated that nesting helped to stabilize currents near the open boundaries, reducing the reflection of the river plume there, but variations in nudging did not notably affect sediment budgets for this implementation of the model. In contrast, a spatially-variable erosion rate parameter was needed to increase the export of material from Poverty Bay and retention of material on the shelf.

\section{Acknowledgments}

Funding was provided by NSF MARGINS grant 0841092 (Moriarty and Harris), a VIMS student fellowship (Moriarty), and NIWA as part of its government-funded, core research (Hadfield). Many datasets were useful during development and testing of the model, and these were provided by personnel from NIWA (M. Uddstrom, S. Stephens, A. Orpin), VIMS (S. Kuehl, T. Kniskern), the USACoE (J. McNinch), GDC (G. Hall, D. Peacock), East Carolina University (J.P. 
Walsh, R. Corbett, J. Kiker), and UW (A. Ogston, R. Hale). Thank you to persons who provided technical assistance, including A. Bever (now at Delta Modeling Associates), A. Miller, M.A. Bynum, and D. Weiss (all from VIMS/William \& Mary). Computational facilities at VIMS, the SciClone cluster at the College of William \& Mary, and the CSDMS computing cluster at the University of Colorado were supported by the NSF, VA Port Authority, Sun Microsystems, and Virginia's Commonwealth Technology Research Fund. High-performance computing facilities at NIWA were supported by the NZ eScience Infrastructure (NESI) and funded by NESI's collaborator institutions and through the Ministry of Business, Innovation \& Employment's Research Infrastructure programme. Comments from 3 anonymous reviewers, C. Friedrichs, S. Kuehl, and L. Schaffner (all at VIMS) benefitted the manuscript's development. This paper is Contribution No. 3356 of the Virginia Institute of Marine Science, College of William \& Mary.

\section{Author Contributions}

The authors collaborated closely on this work. J.M. Moriarty did the bulk of the development and analysis of the model as part of her M.S. thesis research, and wrote the manuscript. C.K. Harris designed the model experiments, served as co-PI on the project, edited the manuscript, and supervised Moriarty's M.S. program. M.G. Hadfield provided guidance in model development and data analysis, especially for the open boundary conditions and NIWA data products. He also edited the manuscript.

\section{Conflicts of Interest}

The authors declare no conflict of interest.

\section{References}

1. Warner, J.C.; Sherwood, C.R.; Signell, R.P.; Harris, C.K.; Arango, H.G. Development of a three-dimensional, regional, coupled wave, current, and sediment-transport model. Comput. Geosci. 2008, 34, 1284-1306.

2. Haidvogel, D.B.; Arango, H.G.; Hedstrom, K.; Beckmann, A.; Malanotte-Rizzoli, P.; Shchepetkin, A.F. Model evaluation experiments in the North Atlantic Basin: simulations in nonlinear terrain-following coordinates. Dyn. Atmos. Ocean. 2000, 32, 239-281.

3. Haidvogel, D.B.; Arango, H.; Budgell, W.P.; Cornuelle, B.D.; Curchitser, E.; Di Lorenzo, E.; Fennel, K.; Geyer, W.R.; Hermann, A.J.; Lanerolle, L.; et al. Ocean forecasting in terrain-following coordinates: Formulation and skill assessment of the Regional Ocean Modeling System. J. Comput. Phys. 2008, 227, 3595-3624.

4. Shchepetkin, A.F.; McWilliams, J.C. The Regional Oceanic Modeling System (ROMS): A split-explicit, free-surface, topography-following-coordinate oceanic model. Ocean Model. 2005, 9, 347-404. 
5. Shchepetkin, A.F.; McWilliams, J.C. Correction and commentary for "Ocean forecasting in terrain-following coordinates: Formulation and skill assessment of the regional ocean modeling system" by Haidvogel et al., J. Comp. Phys. 227, pp. 3595-3624. J. Comput. Phys. 2009, 24, 8985-9000.

6. Bever, A.J.; Harris, C.K. Storm and fair-weather driven sediment-transport within Poverty Bay, New Zealand, evaluated using coupled numerical models. Cont. Shelf Res. 2013, in press.

7. Ralston, D.K.; Geyer, W.R.; Traykovski, P.A.; Nidzieko, N.J. Effects of estuarine and fluvial processes on sediment transport over deltaic tidal flats. Cont. Shelf Res. 2013, 60, S40-S57.

8. Xu, K.; Harris, C.K.; Hetland, R.D.; Kaihatu, J.M. Dispersal of Mississippi and Atchafalaya sediment on the Texas-Louisiana shelf: Model estimates for the year 1993. Cont. Shelf Res. 2011, 31, 1558-1575.

9. Ganju, N.K.; Schoellhamer, D.H. Decadal-timescale estuarine geomorphic change under future scenarios of climate and sediment supply. Estuar. Coasts 2010, 33, 15-29.

10. Chen, S.; Sanford, L.P.; Ralston, D.K. Lateral circulation and sediment transport driven by axial winds in an idealized, partially mixed estuary. J. Geophys. Res. 2009, 114, doi:10.1029/ 2008JC005014.

11. Chapman, D.C. Numerical treatment of cross-shelf open boundaries in a barotropic coastal ocean model. J. Phys. Oceanogr. 1985, 15, 1060-1075.

12. Flather, R.; Proctor, R. Prediction of North Sea storm surges using numerical models: Recent developments in UK. In North Sea Dynamics; Sündermann, J., Lenz, W., Eds.; Springer: New York, NY, USA, 1983; pp. 299-317.

13. Marchesiello, P.; McWilliams, J.C.; Shchepetkin, A. Open boundary conditions for long-term integration of regional oceanic models. Ocean Model. 2001, 3, 1-20.

14. Blaas, M.; Dong, C.; Marchesiello, P.; McWilliams, J.C.; Stolzenbach, K.D. Sediment-transport modeling on Southern Californian shelves: A ROMS case study. Cont. Shelf Res. 2007, 27, $832-853$.

15. Xue, Z. Modeling transport and deposition of the Mekong River sediment. Cont. Shelf Res. 2012, 37, 66-78.

16. Dickhudt, P.J.; Friedrichs, C.T.; Schaffner, L.C.; Sanford, L.P. Spatial and temporal variation in cohesive sediment erodibility in the York River estuary, eastern USA: A biologically influenced equilibrium modified by seasonal deposition. Mar. Geol. 2009, 267, 128-140.

17. Sanford, L.P.; Maa, J.P. A unified erosion formulation for fine sediments. Mar. Geol. 2001, 179, 9-23.

18. Sanford, L.P. Modeling a dynamically varying mixed sediment bed with erosion, deposition, bioturbation, consolidation, and armoring. Comput. Geosci. 2008, 34, 1263-1283.

19. Amos, C.; Feeney, T.; Sutherland, T.; Luternauer, J. The stability of fine-grained sediments from the Fraser River Delta. Estuar. Coast. Shelf Sci. 1997, 45, 507-524.

20. Wright, L.D. Sediment transport and deposition at river mouths: A synthesis. Geol. Soc. Am. Bull. 1977, 88, 857-868.

21. Stevens, A.; Wheatcroft, R.; Wiberg, P. Seabed properties and sediment erodibility along the western Adriatic margin, Italy. Cont. Shelf Res. 2007, 27, 400-416. 
22. Rinehimer, J.P.; HARRIS, C.K.; Sherwood, C.R.; Sanford, L.P. Estimating cohesive sediment erosion and consolidation in a muddy, tidally-dominated environment: Model behavior and sensitivity. In Proceedings of the 10th International Estuarine and Coastal Modeling Conference, Newport, RI, USA, 5-7 November 2007; Spaulding, M.L., Ed.; American Society of Civil Engineers: Reston, VA, USA, 2008; pp. 819-838.

23. Orpin, A.R.; Alexander, C.R.; Carter, L.; Kuehl, S.; Walsh, J.P. Temporal and spatial complexity in post-glacial sedimentation on the tectonically active, Poverty Bay continental margin of New Zealand. Cont. Shelf Res. 2006, 26, 2205-2224.

24. Hicks, D.M.; Gomez, B.; Trustrum, N.A. Erosion thresholds and suspended sediment yields, Waipaoa River Basin, New Zealand. Water Resour. Res. 2000, 36, 1129-1142.

25. Hicks, D.M.; Gomez, B.; Trustrum, N.A. Event suspended sediment characteristics and the generation of hyperpycnal plumes at river mouths: East Coast continental margin, North Island, New Zealand. J. Geol. 2004, 112, 471-485.

26. Stephens, S.A.; Bell, R.G.; Black, K.P. Complex circulation in a coastal embayment: Shelf-current, wind and density-driven circulation in Poverty Bay, New Zealand. J. Coast. Res. 2001, 17 (Special issue 34), 45-59.

27. Healy, T.; Stephens, S.; Black, K.; Gorman, R.; Beamsley, B. Numerical and physical process studies for Port of Gisborne redesign for the 21st century. J. Coast. Res. 1998, 15 (Special issue 26), 304-311.

28. Bever, A.J.; McNinch, J.E.; Harris, C.K. Hydrodynamics and sediment-transport in the nearshore of Poverty Bay, New Zealand: Observations of nearshore sediment segregation and oceanic storms. Cont. Shelf Res. 2011, 31, 507-526.

29. Ogston, A.; Hale, R. University of Washington, Seattle, WA, USA. Unpublished data from Waipaoa shelf tripod deployments, 2013.

30. Hale, R.; Ogston, A.S.; Walsh, J.P.; Orpin, A.R. Sediment transport and event deposition on the Waipaoa River Shelf, New Zealand. Cont. Shelf Res.2014, in press.

31. Chiswell, S.M. The Wairarapa Coastal Current. N. Z. J. Mar. Freshw. Res. 2000, 34, 303-315.

32. Chiswell, S.M.; Roemmich, D. The East Cape Current and two eddies: A mechanism for larval retention? N. Z. J. Mar. Freshw. Res. 1998, 32, 385-397.

33. Chiswell, S.M. Mean and variability in the Wairarapa and Hikurangi Eddies, New Zealand. N. Z. J. Mar. Freshw. Res. 2005, 39, 121-134.

34. Smith, R.K. Poverty Bay, New Zealand: A case of coastal accretion 1886-1975. N. Z. J. Mar. Freshw. Res. 1988, 22, 135-142.

35. Moriarty, J.M. Event-to-Seasonal Sediment Dispersal on the Waipaoa River Shelf, New Zealand: A Numerical Modeling Study. In Transport and Fate of Sediment on the Waipaoa River Continental Shelf: Implications for the Formation and Reworking of Flood Deposits; The Faculty of the School of Marine Science, the College of William and Mary in Virginia: Williamsburg, VA, USA, 2012.

36. Kiker, J.M. Spatial and Temporal Variability in Surficial Seabed Character, Waipaoa River Margin, New Zealand. Master's Thesis, East Carolina University, Greenville, NC, USA, 2012. 
37. Kniskern, T.A.; Mitra, S.; Orpin, A.R.; Harris, C.K. Characterization of flood deposition on the Waipaoa River shelf using radioisotopes and terrigenous organic matter abundance and composition. Cont. Shelf Res. 2014, submitted for publication.

38. Miller, A.J.; Kuehl, S.A. Shelf sedimentation on a tectonically active margin: A modern sediment budget for Poverty continental shelf, New Zealand. Mar. Geol. 2010, 270, 175-187.

39. Gerber, T.P.; Pratson, L.F.; Kuehl, S.; Walsh, J.P.; Alexander, C.; Palmer, A. The influence of sea level and tectonics on Late Pleistocene through Holocene sediment storage along the high-sediment supply Waipaoa continental shelf. Mar. Geol. 2010, 270, 139-159.

40. Jackett, D.R.; McDougall, T.J. Minimal adjustment of hydrographic profiles to achieve static stability. J. Atmos. Ocean. Technol. 1995, 2, 381-389.

41. Haney, R. L. On the pressure gradient force over steep topography in sigma coordinate ocean models. J. Phys. Oceanogr. 1991, 21, 610-619.

42. Beckmann, A.; Haidvogel, D.B. Numerical simulation of flow around a tall isolated seamount. Part I: Formulation and model accuracy. J. Phys. Oceanogr. 1993, 23, 1736-1753.

43. Mellor, G.; Ezer, T.; Oey, L. The pressure gradient conundrum of sigma coordinate ocean models. J. Atmos. Ocean. Technol. 1994, 11, 1126-1134.

44. Mellor, G.; Oey, L.; Ezer, T. Sigma coordinate pressure gradient errors and the seamount problem. J. Atmos. Ocean. Technol. 1998, 15, 1122-1131.

45. Ezer, T.; Arango, H.; Shchepetkin, A.F. Developments in terrain-following ocean models: intercomparisons of numerical aspects. Ocean Model. 2002, 4, 249-267.

46. Shchepetkin, A.F.; McWilliams, J.C. A method for computing horizontal pressure-gradient force in an oceanic model with a nonaligned vertical coordinate. J. Geophys. Res. 2003, 108, doi:10.1029/2001JC001047.

47. Huang, H.; Chen, C.; Cowles, G.W.; Winant, C.D.; Beardsley, R.C.; Hedstrom, K.S.; Haidvogel, D.B. FVCOM validation experiments: Comparisons with ROMS for three idealized barotropic test problems. J. Geophys. Res. 2008, 113, doi:10.1029/2007JC004557.

48. Smolarkiewicz, P.K.; Margolin, L.G. MPDATA: A finite-difference solver for geophysical flows. J. Comput Phys. 1998, 140, 459-480.

49. Hyatt, J.; Signell, R.P. Modeling Surface Trapped River Plumes: A sensitivity study. In Proceedings of the 6th International Estuarine and Coastal Modelling Conference, New Orleans, LA, USA, 3-5 November 1999; Spaulding, M.L., Blumberg, A.F., Eds.; American Society of Civil Engineers: Reston, VA, USA, 2000.

50. Colella, P.; Woodward, P.R. The piecewise parabolic method (PPM) for gas-dynamical simulations. J. Comput. Phys. 1984, 54, 174-201.

51. Liu, X.; Osher, S.; Chan, T. Weighted essentially non-oscillatory schemes. J. Comput. Phys. 1994, 115, 200-212.

52. Fairall, C.W.; Bradley, E.F.; Rogers, D.P.; Edson, J.B.; Young, G.S. Bulk parameterization of air-sea fluxes for tropical ocean-global atmosphere coupled-ocean atmosphere response experiment. J. Geophys. Res. 1996, 101, 3747-3764.

53. Fairall, C.; Bradley, E.F.; Hare, J.; Grachev, A.; Edson, J. Bulk parameterization of air-sea fluxes: Updates and verification for the COARE algorithm. J. Climate 2003, 16, 571-591. 
54. Madsen, O.S. Spectral Wave-Current Bottom Boundary Layer Flows. In Proceedings of the 24th International Conference on Coastal Engineering, Kobe, Japan, 23-28 October 1994; American Society of Civil Engineers: Reston, VA, USA, 1994; pp. 384-398.

55. Syvitski, J.P.; Asprey, K.; Clattenburg, D.; Hodge, G.D. The prodelta environment of a fjord: Suspended particle dynamics. Sedimentology 1985, 32, 83-107.

56. Parchure, T.M.; Mehta, A.J. Erosion of soft cohesive sediment deposits. J. Hydraul. Eng. 1985, 111, 1308-1326.

57. Paterson, D.M. Biological Mediation of Sediment Erodibility: Ecology and Physical Dynamics. In Proceedings of the 4th Nearshore and Estuarine Cohesive Sediment Transport Conference, Wallingford, UK, 11-15 July 1994; Burt, N., Parker, R., Watts, J., Eds.; Wiley: Chichester, UK, 1997; pp. 215-229.

58. Ariathurai, R.; Arulanandan, K. Erosion rates of cohesive soils. J. Hydraul. Div. 1978, 104, 279-283.

59. Harris, C.K.; Wiberg, P.L. Approaches to quantifying long-term continental shelf sediment transport with an example from the Northern California STRESS mid-shelf site. Cont. Shelf Res. 1997, 17, 1389-1418.

60. Flather, R.A. A tidal model of the northwest European continental shelf. Mém. Soc. R. Sci. Liège 1976, 10, 141-164.

61. Røed, L.P.; Smedstad, O.M. Open boundary conditions for forced waves in a rotating fluid. SIAM J. Sci. Stat. Comput. 1984, 5, 414-426.

62. Martinsen, E.A.; Engedahl, H. Implementation and testing of a lateral boundary scheme as an open boundary condition in a barotropic ocean model. Coast. Eng. 1987, 11, 603-627.

63. Palma, E.D.; Matano, R.P. On the implementation of passive open boundary conditions for a general circulation model: The barotropic mode. J. Geophys. Res. 1998, 103, 1319-1341.

64. Carter, G.S.; Merrifield, M.A. Open boundary conditions for regional tidal simulations. Ocean Model. 2007, 18, 194-209.

65. Hadfield, M.G. National Institute of Water and Atmosphere, Wellington, New Zealand. Unpublished model results, 2012.

66. Hadfield, M.G.; Rickard, G.J.; Uddstrom, M.J. A hydrodynamic model for Chatham Rise, New Zealand. N. Z. J. Mar. Freshw. Res. 2007, 41, 239-264.

67. Palma, E.D.; Matano, R.P. On the implementation of open boundary conditions for a general circulation model: The three-dimensional case. J. Geophys. Res. 2000, 105, 8605-8627.

68. Lavelle, J.; Thacker, W. A pretty good sponge: Dealing with open boundaries in limited-area ocean models. Ocean Model. 2008, 20, 270-292.

69. McNinch, J.E.; Wadman, H.M.; Perkey, D.W. Sediment segregation and dispersal across the land-sea interface: Waipaoa sedimentary system, New Zealand. In Proceedins of 2008 Ocean Sciences Meeting, Orlando, FL, USA, 2-7 March 2008; Integration and Synthesis of MARGINS Sediment Source-to-Sink Research Workshop: Gisborne, New Zealans, 2009.

70. Stephens, S. National Institute of Water and Atmosphere, Wellington, New Zealand. Personal Communication, 2006. 
71. National Institute of Water and Atmosphere, Viaduct Harbour, Auckland, New Zealand. Unpublished historical gridded bathymetry, 2006.

72. Tolman, H.L.; Balasubramaniyan, B.; Burroughs, L.D.; Chalikov, D.V.; Chao, Y.Y.; Chen, H.S.; Gerald, V.M. Development and implementation of wind-generated ocean surface wave modelsat NCEP*. Weather Forecast. 2002, 17, 311-333.

73. Davies, T.; Cullen, M.; Malcolm, A.; Mawson, M.; Staniforth, A.; White, A.; Wood, N. A new dynamical core for the Met Office's global and regional modelling of the atmosphere. Q. J. R. Meteorol. Soc. 2005, 131, 1759-1782.

74. Egbert, G.D.; Erofeeva, S.Y. Efficient inverse modeling of barotropic ocean tides. J. Atmos. Ocean. Technol. 2002, 19, 183-204.

75. Egbert, G.D.; Bennett, A.F.; Foreman, M.G. TOPEX/POSEIDON tides estimated using a global inverse model. J. Geophys. Res. 1994, 99, 24821-24852.

76. National Institute of Water and Atmosphere. National Climate Database Web System. Available online: http://cliflo.niwa.co.nz (accessed on 28 March 2011).

77. Hall, G.; Peacock, D. Gisborne District Council, Gisborne, New Zealand. Unpublished river observations, 2011.

78. Wood, M.P. Sedimentation on a High Input Continental Shelf at the Active Hikurangi Margin. Master's Thesis, Victoria University of Wellington, Wellington, New Zealand, 2006.

79. Sikiric, M.D.; Janekovic, I.; Kuzmic, M. A new approach to bathymetry smoothing in sigma-coordinate ocean models. Ocean Model. 2009, 19, 128-136.

80. Wiberg, P.L.; Sherwood, C.R. Calculating wave-generated bottom orbital velocities from surface-wave parameters. Comput. Geosci. 2008, 34, 1243-1262.

81. Harris, C.K.; Traykovski, P.A.; Geyer, W.R. Flood dispersal and deposition by near-bed gravitational sediment flows and oceanographic transport: A numerical modeling study of the Eel River shelf, northern California. J. Geophys. Res. 2005, 110, doi:10.1029/2004JC002727.

82. Walsh, J.P. East Carolina University, Greenville, NC, USA. Unpublished data from 2010 to 2011 Waipaoa shelf research cruises, 2011.

83. Fall, K.A.; Harris, C.K.; Friedrichs, C.T.; Rinehimer, J.P.; Sherwood, C.R. Model behavior and sensitivity in an application of the cohesive bed component of the Community Sediment Transport Modeling System for the York River Estuary, VA. J. Mar. Sci. Eng. 2014, submitted for publication. 


\title{
Model Behavior and Sensitivity in an Application of the Cohesive Bed Component of the Community Sediment Transport Modeling System for the York River Estuary, VA, USA
}

\author{
Kelsey A. Fall, Courtney K. Harris, Carl T. Friedrichs, J. Paul Rinehimer and \\ Christopher R. Sherwood
}

\begin{abstract}
The Community Sediment Transport Modeling System (CSTMS) cohesive bed sub-model that accounts for erosion, deposition, consolidation, and swelling was implemented in a three-dimensional domain to represent the York River estuary, Virginia. The objectives of this paper are to (1) describe the application of the three-dimensional hydrodynamic York Cohesive Bed Model, (2) compare calculations to observations, and (3) investigate sensitivities of the cohesive bed sub-model to user-defined parameters. Model results for summer 2007 showed good agreement with tidal-phase averaged estimates of sediment concentration, bed stress, and current velocity derived from Acoustic Doppler Velocimeter (ADV) field measurements. An important step in implementing the cohesive bed model was specification of both the initial and equilibrium critical shear stress profiles, in addition to choosing other parameters like the consolidation and swelling timescales. This model promises to be a useful tool for investigating the fundamental controls on bed erodibility and settling velocity in the York River, a classical muddy estuary, provided that appropriate data exists to inform the choice of model parameters.
\end{abstract}

Reprinted from J. Mar. Sci. Eng. Cite as: Fall, K.A.; Harris, C.K.; Friedrichs, C.T.; Rinehimer, J.P.; Sherwood, C.R. Model Behavior and Sensitivity in an Application of the Cohesive Bed Component of the Community Sediment Transport Modeling System for the York River Estuary, VA, USA. J. Mar. Sci. Eng. 2014, 2, 413-436.

\section{Introduction}

Fine sediment transport in coastal and estuarine environments has significant physical, biological, and chemical ramifications. Mobilized sediments reduce water clarity, transport toxic materials, pathogens and nutrients, and fill navigational channels [1,2]. Bed erodibility and settling velocity are key parameters influencing fine sediment dynamics in coastal and estuarine environments. Bed erodibility controls the amount of sediment suspended while settling velocity influences how far it is transported [3-7]. Erodibility and settling velocity vary widely over time and space in estuaries, and these variations are closely related to sediment flux convergences and divergences at Estuarine Turbidity Maxima (ETMs) [8-12].

ETMs are regions of locally high suspended-sediment concentrations that often occur immediately landward of the salt limit, where convergence in near-bottom flow traps suspended sediment in the bottom layer [13-15]. Suspended sediment trapped in the bottom layer near the head of salt cannot be entrained into the upper layer due to damping of turbulent mixing by stratification [16]. Tidal asymmetries in vertical velocity and suspended-sediment profiles can also produce ETMs $[9,17,18]$. 
Although these processes tend to be most important near the head of salt, they can create ETMs in other areas where the channel geometry alters the salinity field, often called Secondary Turbidity Maxima or STMS [19-22]. Hydrodynamic forces and sediment and bed properties influence both ETMs and STMs, and because these factors vary with time and in all three spatial dimensions, they are difficult to study using field measurements alone. A three-dimensional model is helpful for evaluating and understanding these complex processes that influence sediment dynamics in muddy estuaries.

Erosion of sediment from the bed provides an important control on estuarine turbidity. Here we define erodibility $(\varepsilon)$ as the asymptotic relationship between a steady, externally imposed bed stress $(\tau b)$, and total eroded mass from the seabed when $\tau_{b}$ exceeds the critical stress $\left(\tau_{c}\right)$ of the sediment surface. The critical shear stress, $\tau_{c}$, represents the stress at which motion or suspension of sediment first occurs [23]. Erosion rates have been estimated using many different formulas [24-27], but the simple linear Ariathurai-Partheniades erosion formulation has been assumed in many cases:

$$
E=M\left(\tau_{b}-\tau_{c}\right)
$$

Here, the erosion rate, $E\left(\mathrm{~kg} \mathrm{~m}^{-2} \mathrm{~s}^{-1}\right)$, varies linearly with the excess shear stress $\left(\tau_{b}-\tau_{c}\right)(\mathrm{Pa})$ according to the erosion rate parameter, $M\left(\mathrm{~kg} \mathrm{~m}^{-2} \mathrm{~s}^{-1} \mathrm{~Pa}^{-1} \mathrm{~m}^{-2}\right)$ [11,12,28-33]. Though developed for cohesive sediment, Equation (1) can also be applied to non-cohesive beds. For purely non-cohesive beds, $\tau_{c}$ mostly depends on the grain size and density of individual particles, and typically increases with diameter [23]. For cohesive sediment, $\tau_{c}$ represents a bulk characteristic of the seabed, and may depend on grain size, porosity, organic content, and depositional history, and often increases with depth in the seabed and with time since deposition [24].

Many three-dimensional numerical models assume a constant $\tau_{c}$, even for cohesive sediment [7,34-36], which can produce satisfactory results when applied for short time scales, but neglects feedbacks between erodibility, erosion, and deposition that develop in response to events such as flood deposition, spring freshets, storm erosion, or biogenic seasonal variations [37-40]. A model of the York River estuary in Virginia that defined a constant value of $\tau_{c}[35,41]$ was able to represent the STM but underestimated suspended-sediment concentrations, despite using $0.05 \mathrm{~mm} / \mathrm{s}$ for settling velocity, significantly smaller than the values inferred from recent observations $[8,10,42]$. More recently, a York River model was implemented to estimate suspended-sediment concentrations associated with Hurricane Isabel [7]. This used Sanford's (2008) consolidation model [43] that allows $\tau_{c}$ to vary in response to consolidation. The parameters in their bed consolidation model were based, when possible, on data from the York River, or otherwise from literature values, however the article did not discuss the sensitivity of calculations to these parameters.

In this study we applied a three-dimensional hydrodynamic and sediment-transport model to represent processes in the York River estuary, VA, USA, using the Community Sediment Transport Modeling System (CSTMS) with a cohesive bed sub-model [33]. The critical shear stress profile of the cohesive bed was estimated following the consolidation and swelling model presented in [43]. The objectives of this paper are to (1) describe the application of the three-dimensional hydrodynamic York cohesive bed model, (2) compare calculations to observations, and (3) investigate sensitivities of the cohesive bed sub-model to user-defined parameters. 


\section{Study Site: York River Estuary, VA, USA}

The York River (Figure 1), a partially mixed microtidal estuary, spans $50 \mathrm{~km}$ from West Point to Gloucester Point [44]. Tidal currents approach $1 \mathrm{~m} / \mathrm{s}$ at the water surface and dominate sediment resuspension [45]. The estuary contains a main channel ( $\sim-20 \mathrm{~m}$ deep) and a secondary channel ( $\sim 5 \mathrm{~m}$ deep), both dominated by mud, and bordered by well-developed sandy shoals ( 2 $\mathrm{m}$ deep) $[44,46]$. The primary ETM occurs upstream near West Point. A secondary turbidity maximum (STM) occurs about $40 \mathrm{~km}$ landward of the river mouth in a mid-estuary transition region near the Intermediate site between the well-mixed zone upriver and more stratified zone seaward [20]. Physical processes dominate in the upper and middle York, where the benthic diversity, productivity and biomass are suppressed by the more intense tidal currents, greater range of salinities, and the ephemeral presence of the STM [44]. In the lower York, near Gloucester Point, the estuary turns toward the northwest, widens from about $3 \mathrm{~km}$ to $6 \mathrm{~km}$, and the main channel depth increases to $20 \mathrm{~m}$. As a result, the seabed is only disturbed during storms, and suspended-sediment concentrations are lower (10 s of mg/L), creating a more favorable environment for benthic organisms [45].

Figure 1. Map of York River estuary, southeastern VA, USA. The location of the Multidisciplinary Benthic Exchange Dynamics (MUDBED) Intermediate site is in green and MUDBED Biologically Dominated site is in blue.

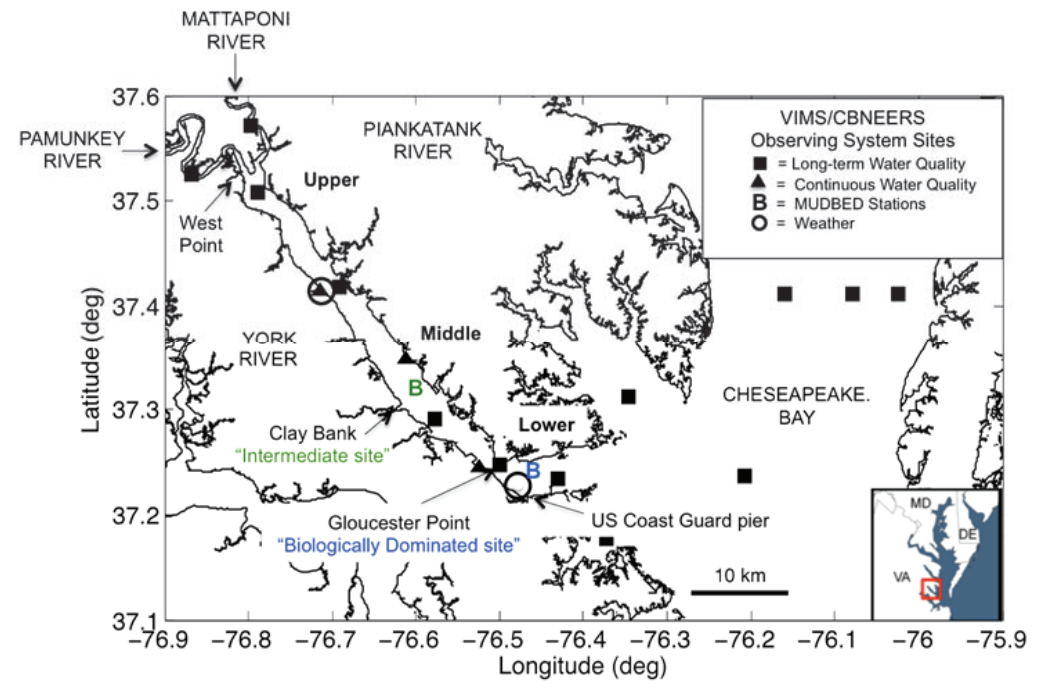

The York River estuary has been studied as a part of the Multidisciplinary Benthic Exchange Dynamics (MUDBED) project [4], particularly near Clay Bank at the MUDBED Intermediate site, and near Gloucester Point at the MUDBED Biologically Dominated site (Figure 1). The seabed at both sites is dominated by mud and resilient biologically repackaged fecal pellets, with very little sand $[47,48]$. Individual mud particles and flocculated muds form the major fraction of suspended material in the York. Repackaged fecal pellets are suspended during periods of high bed stresses [42]. 
While data from the Biologically Dominated site revealed little variability in either settling velocity or erodibility, at the Intermediate Site long-term observations from the MUDBED benthic Acoustic Doppler Velocimeter (ADV) tripod [4,10] and Gust microcosm experiments [11] showed temporal variability in sediment settling velocity and bed erodibility. During the late winter and spring (February-May), erodibility at the Intermediate site generally exceeded that during the summer and fall, with the most erodible beds occurring in April and May [11]. Settling velocities based on ADV data, and bed erodibilities estimated by the Gust microcosm and ADV data were inversely correlated at the Intermediate site, with lower settling velocities observed during periods of increased erodibility, while settling velocities increased during periods of reduced erodibility [10].

Observations indicated that the temporal variability in bed erodibility and settling velocity at the Intermediate site can be attributed to the presence or absence of the STM [4,11,49]. At times of high river flow, stratification of the water column increased, and slowly settling, easily erodible flocculated muds became trapped as the STM formed. The STM migrates along the middle reach of the estuary over pools of easily erodible, muddy sediment $[11,20]$, similar to "mud reaches" observed in other estuaries including the Hudson [37] and the Weser [50]. During periods of elevated river flow, high suspended-sediment concentrations associated with the STM, in combination with increased salinity stratification, dampened near-bed turbulence and prevented the suspension of faster-settling biologically repackaged material [49]. When river discharge dropped, stratification decreased, allowing fine sediment to disperse through the water column, reducing sediment-induced stratification. This permitted higher bed stresses that could suspend the less erodible, faster settling biologically repackaged pellets in addition to slowly settling muddy flocs, so that lower bulk erodibility and higher bulk settling velocities were observed at the site.

The York River estuary is a cohesive and highly dynamic sedimentary environment subject to the presence of a seasonal STM [20]. Erosion and deposition occur alternately, resulting in temporal and spatial variability in seabed $\tau_{c}$ profiles $[11,47]$. Therefore, a cohesive bed model that accounted for time varying $\tau_{c}$ profiles would best represent the York and could be based on observed seabed profiles.

\section{Methods}

A three-dimensional representation of the York River estuary was developed using the Regional Ocean Modeling System (ROMS) v3.1 [51,52]. ROMS solves the hydrostatic Reynolds-averaged Navier-Stokes equations on a curvilinear orthogonal grid with vertical stretched terrain-following coordinates. ROMS provides a choice of boundary conditions, advection schemes, turbulence parameterizations, and sub-models for sediment transport [53]. Our implementation modified a previously described model [54] by adding wind forcing and updating parameters. We used ROMS options for the Mellor and Yamada level 2.5 turbulence closure model [55], a third-order upstream advection method for momentum, and the MPDATA advection method for tracers such as sediment [56]. Bottom drag was parameterized with a logarithmic current velocity profile [57] with a bed roughness of $0.005 \mathrm{~cm}$ based on observed bed stresses (discussed below). The ROMS sediment model of [53] was included but modified to account for consolidation and swelling processes following [43] and [33] as described below. The model run simulated two months after 
first completing month spin-up, and the model performance was evaluated using values obtained from ADV observations. Additionally, we investigated sensitivities of the cohesive bed model to two user-defined parameters.

\subsection{Cohesive Bed Model}

The CSTMS cohesive sediment bed model is based on [43] and represents consolidation and swelling processes, and an increase of $\tau_{c}$ with depth in the sediment, which is typically observed in muddy seabeds. A brief summary of the model implementation in ROMS follows, see $[33,58]$ for more detail. The model represents the seabed at each horizontal grid point as a stack of several bed layers, and stores a value of the critical shear stress for erosion, $\tau_{c}(m)$, at the top of each bed layer, with $m\left(\mathrm{~kg} \mathrm{~m}^{-2}\right)$ being the sediment mass overlying that layer. Under erosional conditions, surficial sediment is entrained into suspension, and the $\tau_{c}$ at the bed surface increases as sediment having a higher $\tau_{c}$ becomes exposed. During times of deposition, the model assumes a low critical stress, $\tau_{c}=0.01 \mathrm{~Pa}$, for newly deposited material, creating an easily erodible layer at the bed surface.

Relaxation equations account for the temporal effects of consolidation and swelling on $\tau_{c}$ [43]. The bed sediment is assumed to have an equilibrium critical stress profile $\tau_{c e q}(m)$. At the end of every model time-step, the instantaneous critical stress profile, $\tau_{c}(m)$, is nudged toward $\tau_{c e q}(m)$ to simulate consolidation and swelling according to:

$$
\begin{gathered}
\frac{\partial}{\partial t}\left[\tau_{c}(m)\right]=\frac{1}{T_{c}}\left[\tau_{c e q}(m)-\tau_{c}(m)\right] ; \text { if } \tau_{c e q}(m) \geq \tau_{c}(m) ; \\
\frac{\partial}{\partial t}\left[\tau_{c}(m)\right]=-\frac{1}{T_{s}}\left[\tau_{c e q}(m)-\tau_{c}(m)\right] ; \text { if } \tau_{c e q}(m)<\tau_{c}(m) ;
\end{gathered}
$$

where $T_{c}$ and $T_{s}$ are timescales for consolidation and swelling processes, respectively. Reasonable ranges for $T_{s}$ are suggested to be on the order of 100 days, while the $T_{c}$ is expected to be much shorter at around one day [42]. Following [33], profiles for $\tau_{c e q}$ were based on power law fits to erodibility experiments performed by [48] on cores collected in September, 2007, and April, 2007 (Figure 2).

The model calculates erosion when bed shear stress $\left(\tau_{b}\right)$ exceeds $\tau_{c}$ at the sediment surface (Equation (1)). In its original form, the model allowed $M$ to vary with depth as a function of solids volume fraction $\varphi_{s}$ [43]. As implemented here, however, both solids fraction and the erosion rate parameter were held constant with $\varphi_{s}=0.1$ and $M=1 \times 10^{-3} \mathrm{~kg} / \mathrm{m}^{2} \mathrm{~s}$ Pa. Previous analysis concluded that erosion in the York River was primarily depth-limited and hence depended more on the critical stress profile than on the erosion rate parameter [33]. The York River model calculated bed stress assuming a logarithmic current profile in the bottom boundary layer. Stresses were computed by ROMS subroutine $u v_{-}$logdrag from the velocity in the bottom cell and a user-defined hydraulic roughness parameter $\left(Z_{0}\right)[53,54]$. Based on observations $Z_{0}$ was defined as a constant $0.005 \mathrm{cmab}$. 
Figure 2. Profiles of $\tau_{c e q}$ obtained by power law fit to observations (as in [33]). Power law fit to observed (solid lines) critical stress profiles for April and September, 2007. Triangles and asterisks show observed data from [48].

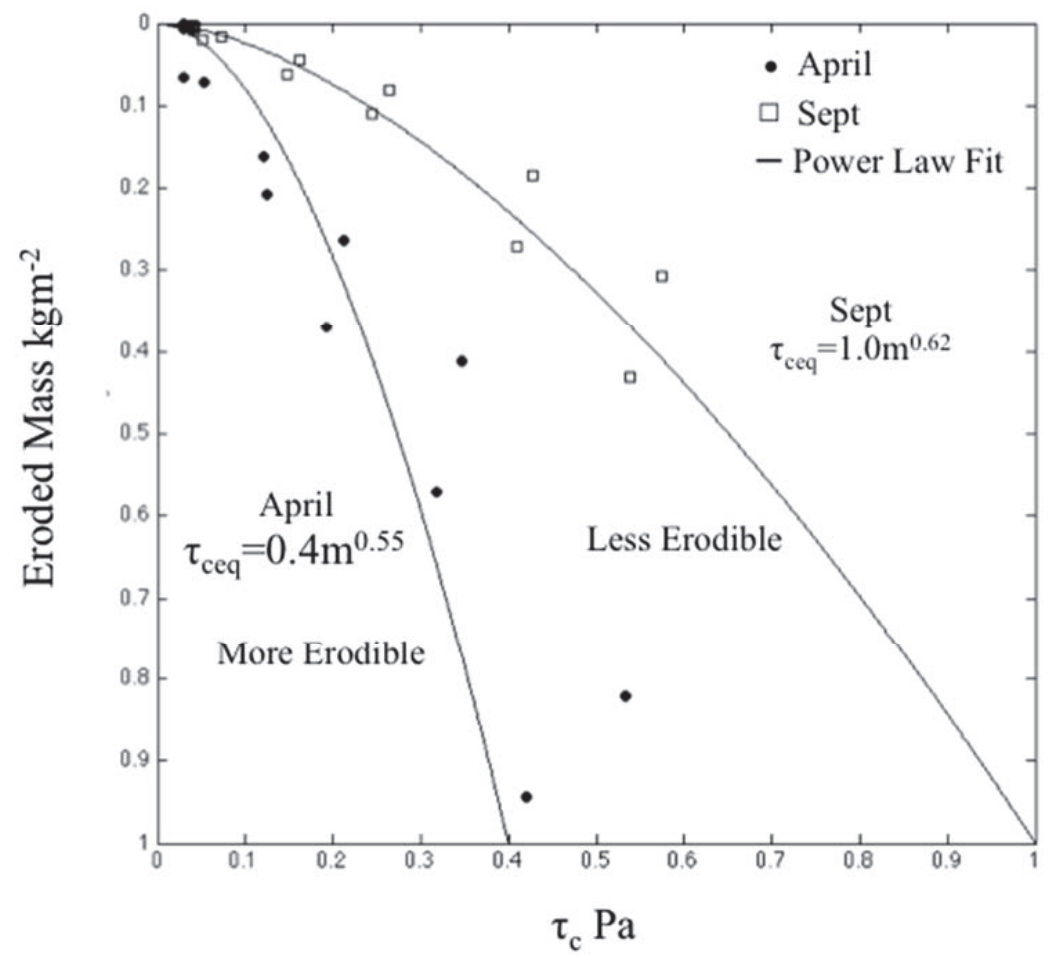

\subsection{Implementation of Three-Dimensional York River Hydrodynamic Cohesive Bed Model}

This describes the three-dimensional York River hydrodynamic cohesive bed model, originally developed by [55], and the more recent modifications used in this study. The "Standard Model" refers to the version that best matched observations from the Intermediate site on the York River. Later sections evaluate the sensitivity of calculations to changes in model parameters by comparing results from the Standard Model to those from other implementations.

The horizontal model grid of [41] adopted for this study had an average grid resolution of $170 \mathrm{~m}$ in the along-channel direction and $110 \mathrm{~m}$ in the cross-channel direction (Figure 3). The major tributaries of the York, the Mattaponi, and Pamunkey Rivers, were represented in the model with only one cell in the cross-channel direction due to their narrow width. The model extended about $60 \mathrm{~km}$ up-river from West Point, VA, USA to Hanover, VA, USA on the Mattaponi River, and Beulahville, VA, USA on the Pamunkey River. The vertical grid used stretched terrain-following coordinates, with 20 stretched grid layers, and increased resolution at the seafloor and water surface. 
Figure 3. The York River estuary cohesive bed ROMS model grid used in in this study had 92 across channel cells and 334 along channel grid cells. Each square in the figure represents twenty-five model grid cells. This paper focuses on model results from the area around the Intermediate site (Clay Bank, VA, USA), which is marked with a black circle.

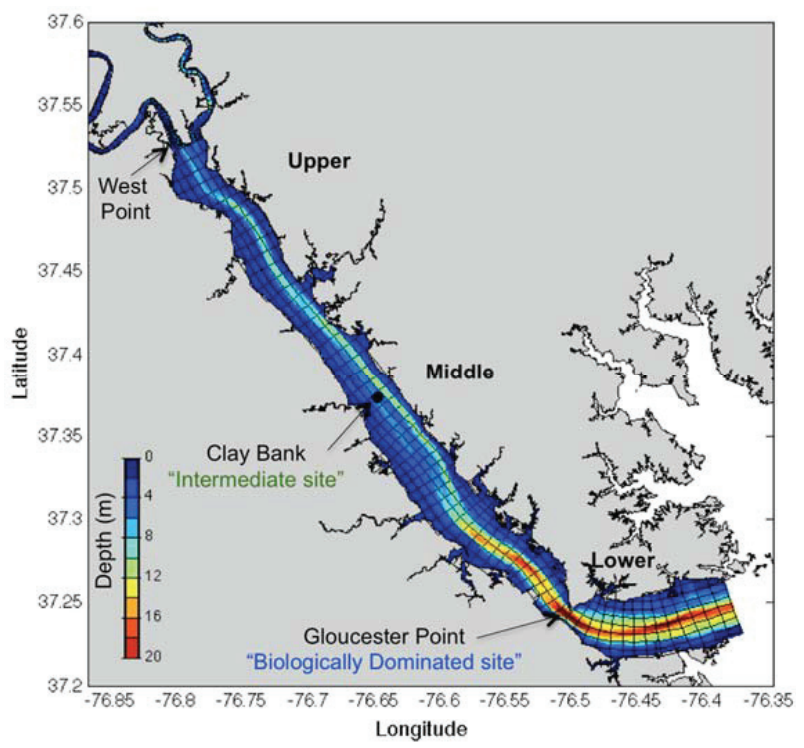

Velocity and salinity estimates from the final time step of a spin-up model were used to initialize the hydrodynamic model presented here. For this spin-up, ROMS was run for 60 days including a spring-neap tidal cycle with $0.2 \mathrm{~m}$ neap amplitude and $0.4 \mathrm{~m}$ spring amplitude. The spin-up model used a steady river input equal to the 60 -year median freshwater flows of $42 \mathrm{~m}^{3} / \mathrm{s}$ and $25 \mathrm{~m}^{3} / \mathrm{s}$ from the Pamunkey and Mattaponi Rivers, respectively [59].

Calculations included two cohesive sediment classes having settling velocities of $2.4 \mathrm{~mm} / \mathrm{s}$ and $0.8 \mathrm{~mm} / \mathrm{s}$. These values were based on observed settling velocities of the two dominate particle types in suspension, biologically repackaged pellets and flocculated muds [42,49]. The sediment bed was initialized having a total bed thickness of $1 \mathrm{~m}$, with a uniform distribution of sediment types, containing $20 \%$ of the coarser sediment class and $80 \%$ of the finer sediment class. Bed $\tau_{c}$ throughout the grid was initialized as the power law fit used by [33] to represent the September profile, $\tau_{\text {cinit }}(m)=1.0 \mathrm{~m}^{0.62}$, while the $\tau_{\text {ceq }}$ profile was defined by the power law fit to the more erodbile April (more erodible) profile, $\tau_{c e q}(m)=0.4 m^{0.55}$ (Figure 2). Model sensitivity tests, presented in Section 5.2, found that this configuration produced a better match between calculations of suspended sediment concentrations and observed values, compared to other configurations studied. A consolidation timescale of $T_{c}=1$ day and a swelling timescale of $T_{s}=25$ days were used. The model configuration, specifically the model simulation time, must be considered when defining $\tau_{c i n i t}, \tau_{c e q}, T_{c}$ and $T_{s}$, as discussed further in Section 6.2. In the runs presented here, the model simulation time of only 120 days included 90 days of spin-up time. With this short 
simulation time the model instantaneous $\tau_{c}$ profiles were sensitive to $\tau_{c i n i t}$ and $T_{s}$, because of the limited time for the bed to adjust towards $\tau_{c e q}$.

The model was then run to represent May-August, 2007. Results from May to June were treated as spin-up for the sediment field, and our analysis centered on results from July-August, which coincided with ADV deployment. Freshwater discharges were specified using data from USGS gages 1,674,500 near Beulahville, VA, USA for the Mattaponi River and 1,673,000 near Hanover, VA, USA for the Pamunkey River. Suspended-sediment concentrations at these boundaries were set at $5 \mathrm{mg} / \mathrm{L}$. The value chosen approximates typical suspended-sediment concentrations at the boundaries. Material from upriver sources generally remains trapped at the primary ETM at West Point and therefore has little influence on conditions downstream. Wind velocities were assumed to be spatially uniform, and hourly velocities measured at the York Coast Guard Meteorological station near Gloucester Point (see Figure 1, weather station) were used as model input.

The open boundaries at the mouth of the river where the York River meets Chesapeake Bay were specified as follows to account for tides, sediment fluxes, and the salinity gradient. For sea surface elevation, we used data from about $10 \mathrm{~km}$ upstream at the US Coast Guard pier (see Figure 3 for location). To improve the agreement between the modeled and observed time series of water elevation at the Coast Guard pier, the data was lagged by $1 \mathrm{~h}$ and scaled by a factor of 1.4 before being applied at the open boundary [54]. For the suspended-sediment open boundary condition, a zero-gradient condition was applied.

Salinity in the interior of the model was calculated as a state variable, but near the open boundary the salinity gradient was specified as follows using an empirical relationship that assumed the salinity along the river fit the hyperbolic tangent function [57],

$$
\bar{S}(x)=\frac{S_{0}}{2}\left[1+\tanh \left(2-\frac{X}{\beta}\right)\right]
$$

where $S_{0}$ was the maximum salinity at the river mouth, $X$ was the along-channel distance, and $\beta$ was a length scale for the salt intrusion, based on river flow. These were used to estimate the crosschannel averaged salinity, $\bar{S}(x)$. The along-channel gradient at the open boundary could then be specified from the derivative of Equation (3) with respect to $X$,

$$
\frac{\partial}{\partial x} s(1, y, z, t)=-\frac{S_{0}}{2 \beta} \operatorname{sech}^{2}\left(\tanh ^{-1}\left(\frac{2 s_{1}}{S_{0}}-1\right)\right)
$$

where $s 1$ and $\frac{\partial s}{\partial x}(1, y, z, t)$ were the salinity and the salinity gradient at the first interior grid point. The salinity at the boundary $s_{0}$ was then defined as:

$$
s_{0}=s_{1}-\frac{\partial s}{\partial x} \Delta x
$$

where $\Delta x$ was the along channel grid cell width. Data from the Chesapeake Bay Program [60] were used to fit $\beta$ in Equation (3). Best fit values of $\beta$ were then regressed against a four-day running mean, four-day lagged river flow $\left(Q_{4}\right)$ resulting in $\beta=290 / Q_{4}+50$. These data fit the hyperbolic 
tangent function (Equation (3)) with $r^{2}=0.65$. The exercise described above (Equations (3)-(5)) was used to set a flow-dependent open boundary condition for salinity, as has been done for a model of the Hudson River estuary [57].

\subsection{Acoustic Doppler Velocimeter (ADV) Observations}

Sontek ADV Ocean Probes have been maintained nearly continually at the MUDBED Intermediate site since 2006 (see Figure 1). The ADVs were attached to bottom-mounted tripods and measured three-dimensional water velocity $(u, v, w)$ and acoustic backscatter at roughly $35 \mathrm{~cm}$ above the bed, see [10] for details of the instrumentation. This project used observations collected by a $5 \mathrm{MHz}$ ADV deployed from June to August 2007 to estimate burst-averaged bottom stress ( $\tau b$, via Reynolds averaging of turbulent velocity), suspended-sediment concentration $(C$, via acoustic backscatter calibrated by pump samples), and bulk sediment settling velocity ( $W_{S B U L K}$, via an assumed Rouse balance between upward Reynolds flux and gravitational settling) [8,10,61].

\subsection{Standard Model Evaluation}

The Standard Model, run from July-August 2007, encompassed a time period for which ADV data and bed samples from the Intermediate site were available. This study especially focused on model behavior over individual tidal phases at the MUDBED Intermediate site. Model estimates from a three-by-three set of adjacent grid cells were averaged to represent the Intermediate site (Figure 3, black dot). These grid cells were chosen because they were within the area where the ADV tripod was deployed, these model cells had water depths similar to that of the observations ( 5-6 m), and previous studies collected sediment cores from this location [48].

Data averaged over tidal phases collected by the ADV during this study period has been analyzed to examine the influence of the presence and departure of the STM on sediment dynamics, using the tidal cycles having the top $20 \%$ of the observed bed stresses [49]. Typically, bed stresses in the York estuary are low, (tidal $\max \tau_{b}<1 \mathrm{~Pa}$ [62]). Our focus on the most energetic tidal cycles did bias our analysis towards spring-tide periods relative to neap-tide periods, but highlighted the study on times when significant sediment would be suspended from the bed. Tidal cycles were defined using the time series of ADV observed current speed $(U)$, such that an individual ebb or individual flood formed a full cycle, with its beginning and end corresponding to times of minimum observed $U$. Observations over the tidal cycles were then interpolated to a common interval in the tidal phase to produce tidal-phase averaged values of $U, \tau b, C$ and $W_{s B U L K}$. No distinction was made between floods and ebbs, removing any flood-ebb asymmetry.

Model results from the Standard Model were phase averaged to obtain representative values of hydrodynamic parameters $\left(U, \tau b, C\right.$, and $\left.W_{s B U L K}\right)$. Model estimates of these values were interpolated to the height of the ADV measurements $(\sim 35 \mathrm{cmab})$ prior to the tidal-phase averaging, and model performance was assessed based on the degree to which model calculations of these values represented those derived from ADV observations. The observed estimates of $W_{S B U L K}$ were obtained by assuming a Rouse balance, while $W_{S B U L K}$ from model results were estimated as the average of the settling velocities of the two size classes $(2.4 \mathrm{~mm} / \mathrm{s}$ and $0.8 \mathrm{~mm} / \mathrm{s})$, weighted by their respective suspended-sediment 
concentrations at the height of the ADV sensor. Though they used different methods, both the model-calculated $W_{S B U L K}$ and ADV-based values provided a bulk settling velocity that accounts for all particle sizes present in suspension [63].

Modeled estimates of bed erodibility were calculated by evaluating the depth of the sediment bed that could be resuspended by bed stresses that exceed some threshold, following the definition presented by [11]. For example, the instantaneous profile of critical bed stress $\left(\tau_{\text {cinit }}\right)$ estimated for a location in the model typically had a low value at the sediment-water interface and increased with depth in the bed $(m)$. The depth at which the critical stress exceeded the threshold of, e.g., 0.2 Pa, would give a model estimate of the erodibility of the bed at $\tau_{b}=0.2 \mathrm{~Pa}$. Because the $\left(\tau_{\text {cinit }}\right)$ changed in response to erosion, deposition, consolidation, and swelling, the model estimates of erodibility varied in both time and space.

\section{Standard Model Results}

System behavior is illustrated during times of high (Figure 4) and low (Figure 5) sediment bed erodibility, showing daily-averaged bed stresses, near-bed suspended-sediment concentrations, erodibility at $0.2 \mathrm{~Pa}$, and near-bed settling velocities throughout the York River. These time periods corresponded to a spring tide (Figure 4) and a neap tide (Figure 5). At both times, the upper and middle estuary had increased erodibility and suspended-sediment concentrations, compared to the lower estuary. Both times had similar bed stresses (Figures 4a and 5a), but when erodibility was higher (Figure 4), more material was suspended, having $\sim 0.9 \mathrm{~kg} \mathrm{~m}^{-2}$ more material in suspension than during the less erodible situation in Figure 5. The increased concentrations were associated with lower near bed settling velocities, particularly in the middle estuary (Figure 4b,d). Ten days later, erodibilty was lower (Figure 5), and decreased suspended-sediment concentrations ( 100 mg/L) and higher near-bed settling velocities characterized conditions in the middle estuary (Figure 5b,d). This result was consistent with field observations indicating that during periods of high erodibility, the suspended material was composed of more slowly settling flocculated muds $[10,11,48]$. The model was also able to capture observed trends in erodibility attributed to the spring/neap tidal cycle. Generally, the sediment bed is more erodible during spring tides and less erodible during neap tides [64].

The results of the tidal-phase average analysis for current speed, concentration, and bed stresses from the model were compared to the ADV estimates from [49]. The model reproduced realistic patterns of all of the parameters over individual tidal cycles. Both model and observed bed stresses and concentration increased with current speed (Figure 6). Peak bed stresses and current speeds in the model had an offset lag compared to the observations (Figure 6a,c). This suggested that the modeled tides may have been slightly out of phase with the observed ones. Overall, the model had more skill at predicting tidal-phase averaged current speeds than the other values considered (Figure 6a). Only at peak flow did model current speeds show a slight bias, underestimating measured speed by less than $5 \mathrm{~cm} / \mathrm{s}$ (about 12\%). The model overestimated suspended-sediment concentrations during the accelerating and decelerating phases of the tide, but matched the concentrations at peak flow (Figure 6b). Bed stresses were overestimated in the model over the 
entire tidal phase by as much as $0.05 \mathrm{~Pa}(\sim 18 \%)$ (Figure $6 \mathrm{c})$, but this bias was accepted because the modeled currents and sediment concentrations matched reasonably well.

Figure 4. Daily-averaged model estimates of (a) bed stress, (b) near bed suspended sediment concentration, (c) mass eroded at $0.2 \mathrm{~Pa}$, and (d) near bed settling velocity during a spring tide when high erodibility was found mid-estuary (15 July 2007).

(a) Bed Stress

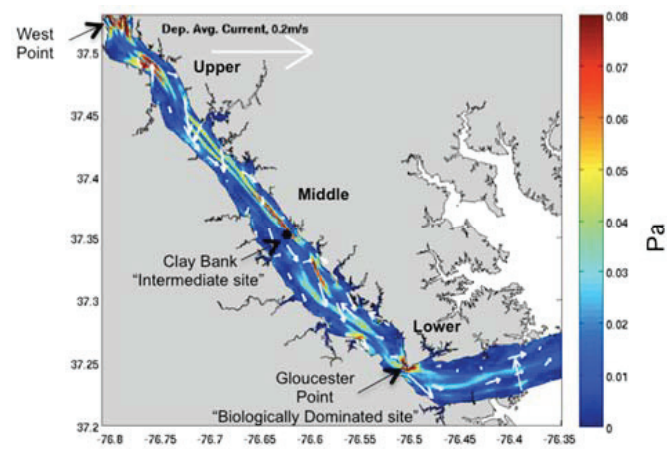

(c) Eroded Mass at $0.2 \mathrm{~Pa}$ (erodibility)

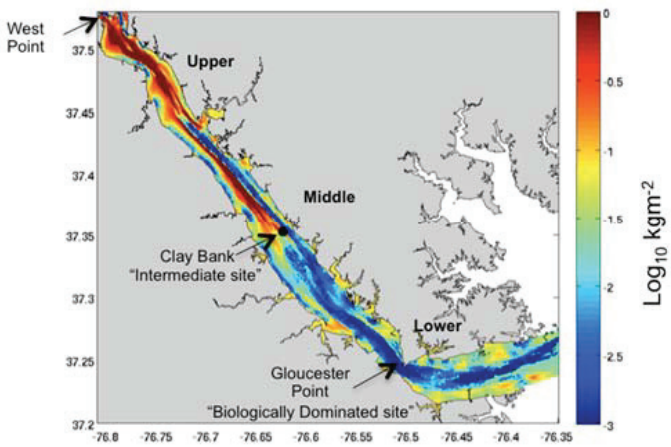

(b) Near Bed SSC

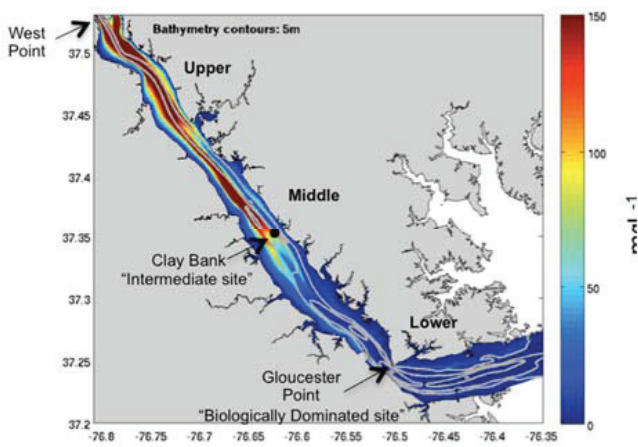

(d) Near Bed Setting Velocity

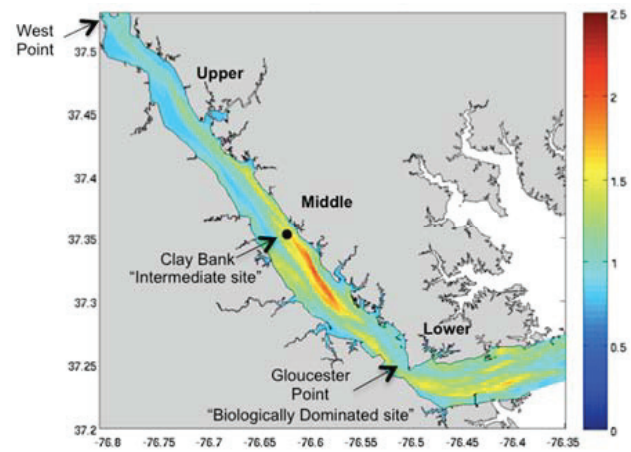

The most reliable approximation of $W_{S B U L K}$ from ADV data was obtained during the accelerating portion of the tidal phase, when the assumptions in the Rouse balance were most likely to be appropriate [49]. During the accelerating phase of the tide, the tidal-phase averaged analysis showed that observed $W_{S B U L K}$ increased from about $1 \mathrm{~mm} / \mathrm{s}$ to $1.4 \mathrm{~mm} / \mathrm{s}$ (Figure 7). More specifically, the tidal-phase averaged analysis showed that observed $W_{S B U L K}$ increased from about 1 $\mathrm{mm} / \mathrm{s}$ to $1.4 \mathrm{~mm} / \mathrm{s}$ during the accelerating tide (Figure 7). The model represented the observed changes in $W_{S B U L K}$ seen in the phase averaged analysis, with modeled $W_{S B U L K}$ increasing from about $0.9 \mathrm{~mm} / \mathrm{s}$ to $1.7 \mathrm{~mm} / \mathrm{s}$, though the model estimated slightly higher $(\sim 0.3 \mathrm{~mm} / \mathrm{s}) W_{S B U L K}$ at peak bed stresses. 
Figure 5. Daily-averaged model estimates of (a) bed stress, (b) near bed suspended sediment concentration, (c) mass eroded at $0.2 \mathrm{~Pa}$ and (d) near bed settling velocity during a neap tide when lower erodibility was found mid-estuary (25 July 2007).

(a) Bed Stress

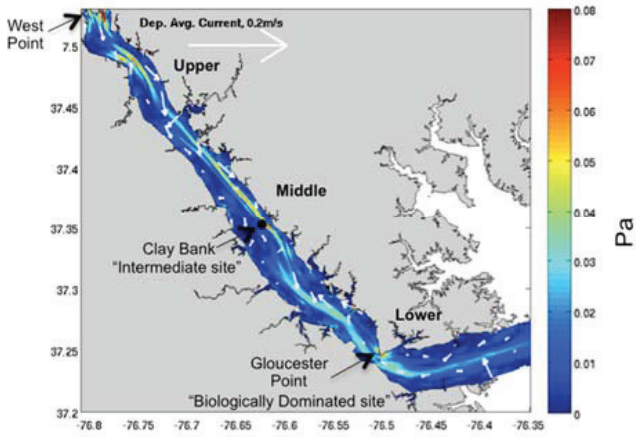

(c) Eroded Mass at 0.2 Pa (erodibility)

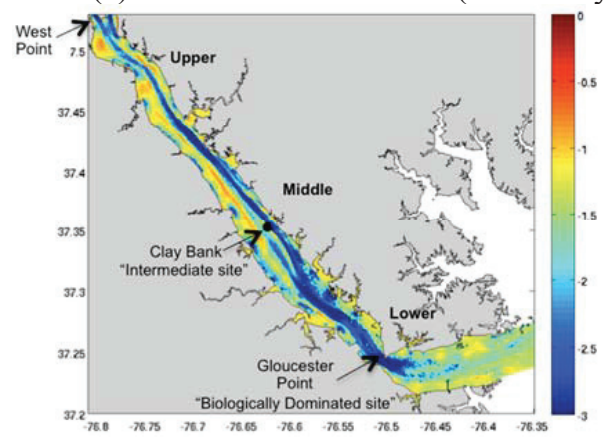

(b) Near Bed SSC

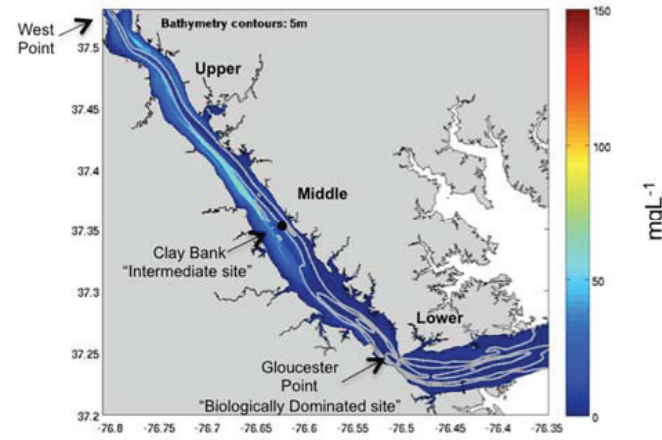

(d) Near Bed Setting Velocity

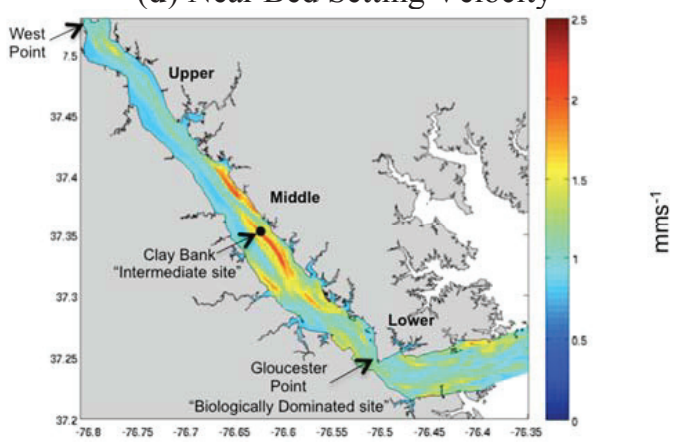

Figure 6. ADV and model estimated (see legend) (a) current speed, (b) concentrations, and (c) bed stresses for the top $20 \%$ of tidal cycles with strongest bed stresses. Error bars denote \pm 1 standard error.

(a) Current Speed $\left(\mathrm{cm} \mathrm{s}^{-1}\right)$

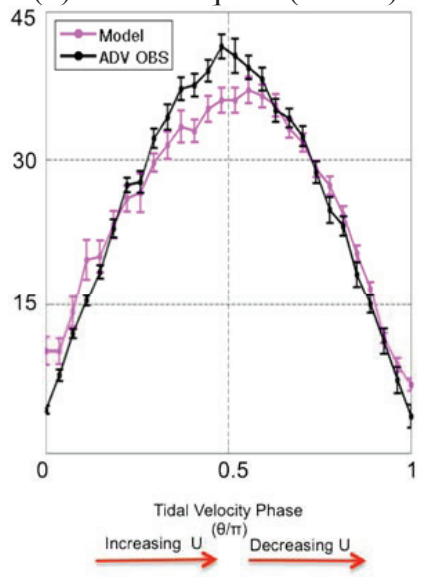

(b) Concentration $\left(\mathrm{mg} \mathrm{L}^{-1}\right)$

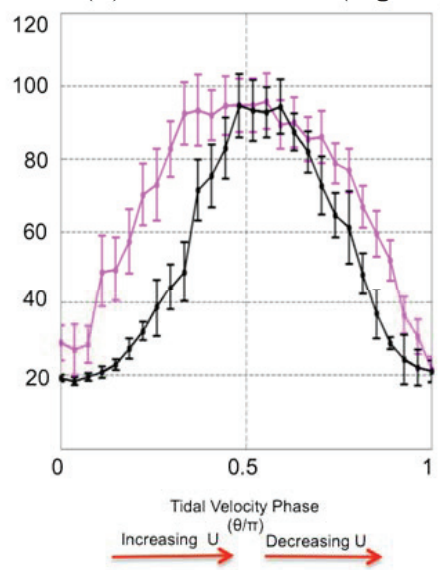

(c) Bed Stress $(\mathrm{Pa})$

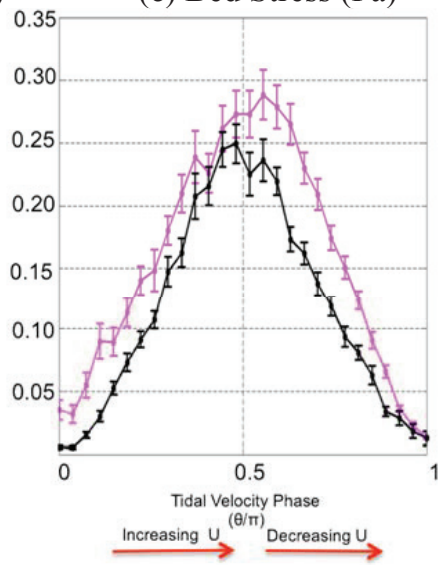


Figure 7. ADV and model estimated (see legend) bulk settling velocity during periods of increasing tidal velocity for the top $20 \%$ of tidal cycles with the highest bed stresses. Error bars denote \pm 1 standard error.

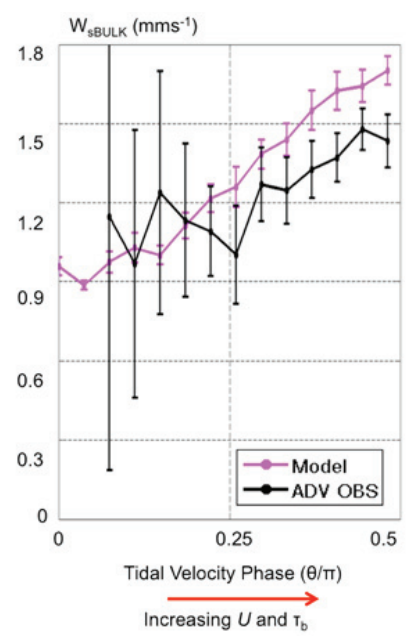

\section{Cohesive Bed Sub-Model Sensitivity}

Additional model runs were analyzed to investigate the sensitivity of the cohesive bed model to the swelling time $\left(T_{s}\right)$, critical shear stress equilibrium profile $\left(\tau_{c e q}\right)$, and initial critical shear stress profile $\left(\tau_{\text {cinit }}\right)$. The sensitivity to $T_{s}$ (section 5.1 ) was evaluated by varying it from 2 to 50 days, bracketing the value of 25 days used in the Standard Model. To test the sensitivity to $\tau_{c e q}$ and $\tau_{\text {cinit }}$ (section 5.2), models were run that defined $\tau_{c e q}=\tau_{\text {cinit }}$ using power-law fits based on the September or the April data (Figure 2). Recall that in the Standard Model, the equilibrium and initial critical shear stress profiles differed as $\tau_{c e q}$ was based on the April power law fit, while $\tau_{\text {cinit }}$ was based on the September profile.

\subsection{Sensitivity to $T_{s}$}

Results from model runs that used different values of $T_{s}$ (specifically 2, 25, and 50 days) were compared to investigate the sensitivity of the instantaneous $\tau_{c}$ profiles and resultant suspendedsediment concentrations to swelling timescale. The model configurations were identical to the Standard Model except for the swelling timescales to isolate the influence of $T_{s}$. As for the Standard Model, different critical stress profiles were used to initialize the model, and for the equilibrium state toward which the model calculations were nudged $\left(\tau_{c e q}\right)$. Bed $\tau_{c}$ throughout the grid was initialized as the power law fit used by [33] to represent the September sediment bed profile while the $\tau_{c e q}$ profile was defined by the power-law fit found to represent the April (more erodible) profile (Figure 2). $T_{s}=25$ days was used in the Standard Model described above.

Figure 8 shows the values of daily calculated instantaneous $\tau_{c}$ profiles, along with the user-defined $\tau_{\text {ceq }}$ and $\tau_{\text {cinit }}$ for these three models. Recall, the model simulations defined $\tau_{\text {ceq }} \neq \tau_{\text {crinit }}$. When a short $T_{s}$ of two days was defined (Figure $8 \mathrm{a}$ ) the instantaneous $\tau_{c}$ profiles rapidly became more erodible 
as the bed adjusted from the less erodible $\tau_{\text {cinit }}$ to the more erodible $\tau_{c e q}$. When a longer $T_{s}$ of 50 days was defined (Figure $8 \mathrm{c}$ ) the instantaneous $\tau_{c}$ profiles showed minimal adjustment from $\tau_{c i n i t}$ to $\tau_{c e q}$, so that the bed remained more consolidated. In the Standard Model, where $T_{s}$ was defined as 25 days, the instantaneous $\tau_{c}$ profiles adjusted somewhat from the less erodible $\tau_{c i n i t}$ to $\tau_{c e q}$.

Figure 8. Daily instantaneous model calculated $\tau_{\mathrm{c}}$ profiles (colored lines) shown with user defined equilibrium $\left(\tau_{c e q}\right)$ and initial bed profiles $\left(\tau_{c r i n i t}\right)$ for model runs with swelling times defined as (a) 2 days, (b) 25 days, and (c) 50 days. Note: $\tau_{c e q} \neq \tau_{\text {crinit }}$. Black arrows show the directions that Equation (2) will nudge the instantaneous $\tau_{c}$ profiles toward $\tau_{\text {ceq }}$.

(a) $T_{s}=2$ Days

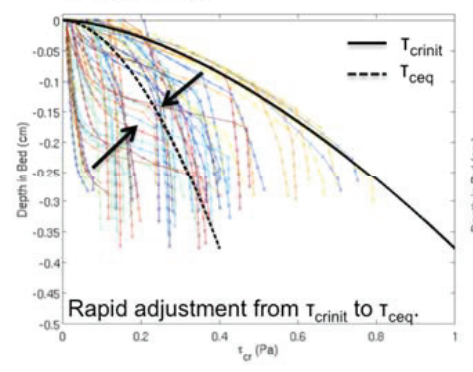

(b) $T_{s}=25$ Days

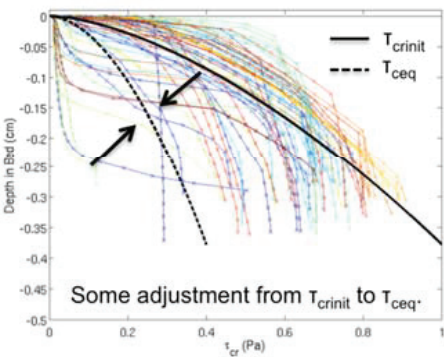

(c) $T_{\mathrm{s}}=50$ Days

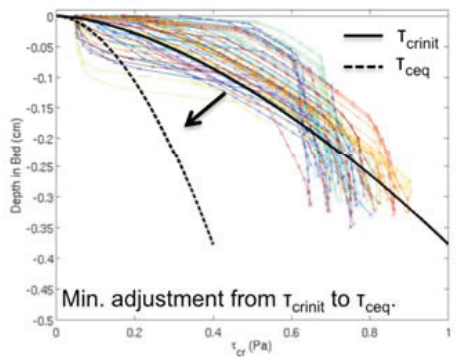

Figure 9 compares the resulting tidal-phase average concentrations from these three models and the values derived from ADV observations. The concentrations increased as $T_{s}$ decreased. Comparison of the three model simulations suggested that using a $T_{s}$ of 25 days resulted in the most realistic estimates for suspended-sediment concentration, justifying the choice of $T_{s}=25$ days in the Standard Model.

Figure 9. Phase-averaged concentration from ADV observations (black), and estimated by model using swelling times defined as 2 days (blue), 25 days (pink), and 50 days (blue).

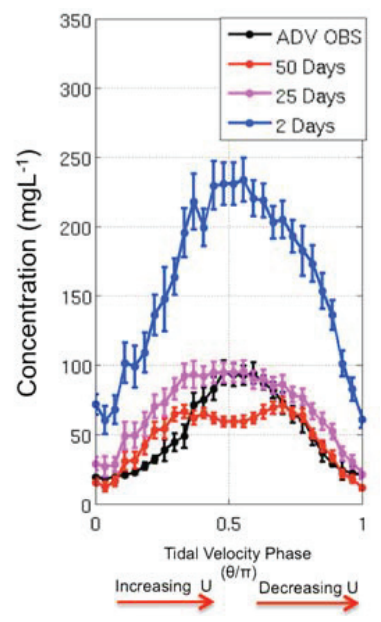




\subsection{Sensitivity to $\tau_{c e q}$ and $\tau_{\text {cinit }}$}

Power law fits to Gust microcosm data for the York River were used to define two depth-dependent critical shear stress profiles, $\tau_{c}(m)$, one based on cores collected in September 2007 and the second on cores collected in April 2007 [47] (Figure 2). Compared to the September data, the $\tau_{c}(m)$ profiles from April 2007 represented a time that had a more erodible seafloor. For the model runs described in this section, the same profiles were used for model initialization $\left(\tau_{\text {cinit }}\right)$ and to define the equilibrium toward which instantaneous profiles $\left(\tau_{c}\right)$ were nudged ( $\tau_{c e q}$ in Equation (2)). Results from two model simulations were compared to evaluate the sensitivity of model calculations to parameterization of the sediment bed's critical shear stress profile. One used the power law fit to the September profile for both $\tau_{c i n i t}$ and $\tau_{c e q}$, while the second used the April profiles for both. Like the Standard Model, both assumed timescales for consolidation and swelling as $T_{c}=1$ day and $T_{s}=25$ days, but recall that the Standard Model used the April, more erodible, profile as $\tau_{c e q}$ and the September, less erodible, profile for model initialization $\tau_{\text {cinit }}$. A second set of these sensitivity tests used identical parameterization as the first two, except $T_{s}=50$ days. The limits on computational time precluded doing additional tests such as a model using $T_{s}=2$ days.

Figure 10 shows the calculated instantaneous $\tau_{c}$ profiles for the first two sensitivity tests, compared to the user-defined profiles of $\tau_{c e q}$ and $\tau_{c i n i t}$. When $\tau_{c e q}$ and $\tau_{c i n i t}$ were defined using the September fit, the instantaneous $\tau_{c}$ profiles showed slight adjustment back to $\tau_{c e q}$ (Figure 10a). This was not the case when $\tau_{c e q}$ and $\tau_{c i n i t}$ were based on the more erodible April seabed (Figure 10b). Instead, the increased erodibility of the initial sediment bed provided a pool of easily resuspended material that when redeposited at slack tide, further increased the erodibility of the bed. With the consolidation timescale of one day, the instantaneous $\tau_{c}$ could not readjust to the equilibrium profile, $\tau_{c e q}$, but developed into an environment dominated by easily erodible, newly deposited sediment throughout the model run.

Figure 10. Daily instantaneous model calculated $\tau_{c}$ profiles (colored lines) shown with the profile used to parameterize these models (black lines). The equilibrium profile $\left(\tau_{c e q}\right)$ and initial bed profile $\left(\tau_{c r i n i t}\right)$ were defined based on (a) September and (b) April profiles. Note: $\tau_{c e q}=\tau_{c r i n i t}$ for these model runs. The black arrows show the direction that Equation (2) will nudge the instantaneous $\tau_{c}$ toward the user-defined $\tau_{c e q}$.

(a) Less Erodible $\tau_{\text {ceq }}$ and $\tau_{\text {crinit }}$

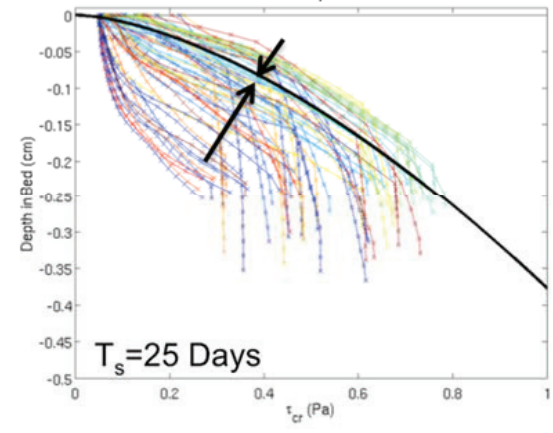

(b) More Erodible $\tau_{\text {ceq }}$ and $\tau_{\text {crinit }}$

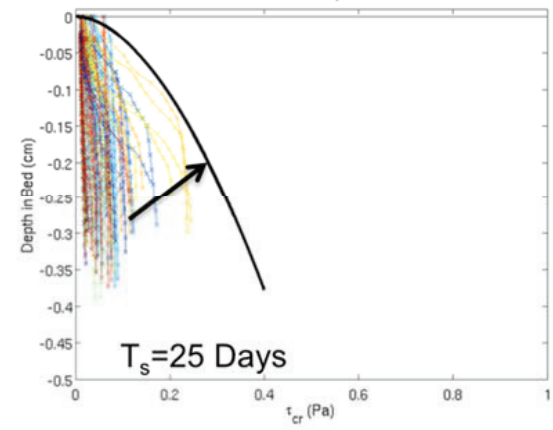


The increased erodibility of the second case led to a positive feedback between bed erodibility and sediment concentrations. This resulted in much higher estimated suspended-sediment concentrations than either the Standard Model or the case using the September profiles for both the equilibrium and initial values, as seen in the tidal phase averaged values (Figure 11). This result was insensitive to the swelling timescale used, which was not surprising because the modeled bed was always freshly deposited and thus easily erodible. Regardless of the defined $T_{s}$, concentrations estimated by the model simulation that defined $\tau_{c e q}$ and $\tau_{c i n i t}$ based on the April fit exceeded the observed values by about $80-300 \mathrm{mg} / \mathrm{L}$, while the model that used the September profiles provided much better estimates.

\section{Discussion}

This section first summarizes the model behavior for the York River case, and then discusses issues relating to model implementation and model parameters.

\subsection{Summary of York River 3-D Hydrodynamic Cohesive Bed Model Performance}

Implementation of the cohesive bed model in conjunction with the MUDBED field study provided a unique opportunity to evaluate model behavior both in terms of the system-wide feedbacks between bed erodibility and sediment concentration, and more specifically in comparison to field data from the MUDBED Intermediate site. Analyses of model results from July-August 2007 showed that the model represented trends in the spatial and temporal variability of bed erodibility and settling velocity observed in the York River estuary (Figures 4 and 5).

Figure 11. Phase averaged concentration observed using the ADV, and estimated by model runs that defined $\left(\tau_{c e q}\right)$ and $\left(\tau_{c r i n i t}\right)$ using the power law fits to the September and April profiles with swelling times of 50 and 25 days (see legend).

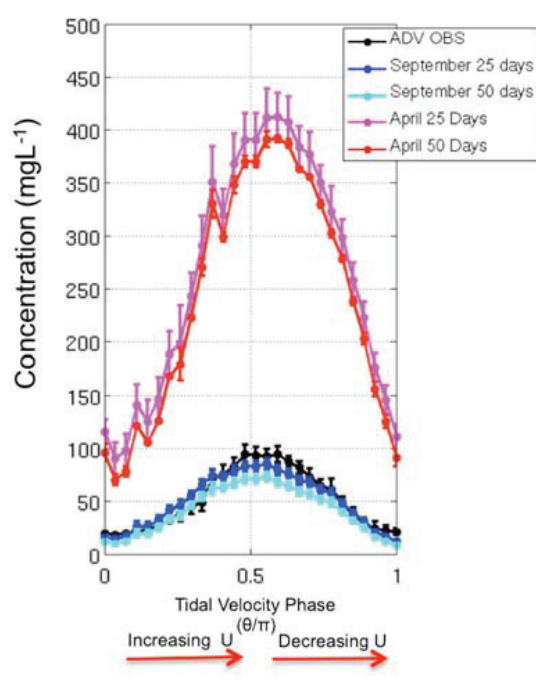


Ongoing analysis of ADV data collected at the MUDBED Intermediate site during the summer of 2007 revealed that the variability in settling velocity and bed erodibility appear to fall into two regimes having distinct hydrodynamic and sediment characteristics [49]. Regime 1 represented periods dominated by easily suspended, slow settling flocculated muds, while Regime 2 represented periods strongly influenced by less easily suspended, faster settling, biologically repackaged fecal pellets mixed with flocs [49]. The analysis presented in this paper focused on a time classified as Regime 2.

Results from the three-dimensional York River Hydrodynamic Cohesive Bed model showed good agreement to field data from the observational period defined as Regime 2 [49], with only slight differences between model estimated and ADV observed bed stresses and bulk settling velocities $(\sim 18 \%)$. Though the model was biased towards higher bed stresses (Figure $6 \mathrm{c}$ ) and higher settling velocities at peak flow, both model estimated and observed bulk settling velocities increased along with bed stress (Figure 7). This implied that differential resuspension of sediment types having the range of settling velocities considered in the model $(0.8$ to $2.4 \mathrm{~mm} / \mathrm{s})$ could account for the changes to settling velocity seen during a tidal cycle, without invoking aggregation and disaggregation processes. Looking more closely, the model overestimated bulk settling velocity as flow accelerated, with the biggest difference occurring at peak flow, which can be attributed to two things. First, the model only included two settling classes $(0.8 \mathrm{~mm} / \mathrm{s}$ and $2.4 \mathrm{~mm} / \mathrm{s})$, while suspended material in the York River estuary consists of many more particle types having a wide range of settling velocities $[42,65]$. Second, the model overestimated bed stresses throughout the tidal phase (Figure 6), which may have contributed to the overestimated concentrations (Figure 6b) as well as bulk settling velocities (Figure 7). Higher bed stresses were able to suspend a greater mass of material, including a greater amount of faster settling particles, which resulted in a higher estimate of bulk settling velocity [42]. Additionally the higher bed stresses would increase eddy diffusivity, mixing the more slowly settling material higher in the water column, and resulting in a greater fraction of faster settling material near the bed.

Though not shown in this paper, the model had less skill when applied to the period defined as Regime 1, overestimating the observed modeled bed stresses by $50 \%$, while underestimating suspended-sediment concentrations by $17 \%$. Field data imply that sediment-induced stratification more strongly influenced the system during Regime 1 than during Regime 2, and that stratification from both salinity and suspended-sediment gradients suppressed bed stresses during Regime 1 [49,61]. ROMS has the capacity to account for sediment induced stratification, but the process was neglected in this implementation. Future work will evaluate whether the turbulence closures in ROMS can represent sediment - induced stratification at the relevant vertical scales for the York River estuary, and whether including this process this improves the model skill during Regime 1.

\subsection{Cohesive Bed Model Sensitivities}

The cohesive bed model sensitivity tests done in this study explored the impact on estimated instantaneous critical stress profiles $\left(\tau_{c}\right)$ and suspended-sediment concentration to user-defined cohesive bed swelling time $\left(T_{s}\right)$ and the initial and equilibrium $\tau_{c}$ profiles $\left(\tau_{c i n i t}\right.$ and $\left.\tau_{c e q}\right)$. We did not 
examine sensitivity to the consolidation timescale, because it seemed better constrained in the literature than the swelling timescale $[33,43]$.

Use of a short $T_{s}$ allowed the instantaneous $\tau_{c}$ profiles to rapidly adjust to the equilibrium profile for a case where the system was less erodible than the equilibrium (Figure 8a). As $T_{s}$ increased to 50 days, the adjustment of the instantaneous $\tau_{c}$ profiles became negligible (Figure $8 \mathrm{c}$ ). Use of a shorter $T_{s}$ resulted in a more erodible bed, which increased suspended-sediment concentrations in the water column (Figure 9). The sensitivity to $T_{s}$ should be considered in the context of the model configuration, which for the Standard Model used a less erodible bed for initialization than for the equilibrium profile. The model simulation time, 120 days, included 90 days before the time period analyzed. When swelling timescale was long compared to the spin-up time, the model would be especially sensitive to the seabed initialization (i.e., $\left.\tau_{c i n i t}\right)$. For example, using a $T_{s}$ of 50 days meant that the instantaneous $\tau_{\mathrm{c}}$ profiles would be especially sensitive to the initialization over the timescale considered by the model.

For the case where the model's seabed was initialized to be especially erodible, however, positive feedbacks between sediment erodibility and concentrations led to the development of an even more erodible bed, and model estimates were then insensitive to $T_{s}$ (Figure 10). This sensitivity test found that the model estimated instantaneous $\tau_{c}$ profiles and suspended-sediment concentrations were less sensitive to $T_{s}$ than the profiles that were used to define $\tau_{\text {cinit }}$ and $\tau_{c e q}$ (Figures 10 and 11). We expect that the model estimates for this case would be more sensitive to $T_{c}$ than $T_{s}$, but this was not evaluated directly, in part because the literature provides guidance for the consolidation timescales in the literature than the swelling timescales.

An important step in model implementation for the cohesive bed model was specification of both the initial and equilibrium critical stress profiles, and the consolidation and swelling timescales. The cohesive bed model is still fairly new, and a consensus for how the initial and equilibrium profiles should be defined has not been established. It is clear, however, that for a case where measured critical shear stress profiles exist, the model parameters, including both the initial and equilibrium profiles, should be defined so that instantaneous shear stress profiles usually remain within the realm of measured profiles. Additionally, the choice of erosion rate parameter $(M)$ probably would influence model behavior and have implications for the suitability of different values of these parameters, but the value of $M=1 \times 10^{-3} \mathrm{~kg} /\left(\mathrm{m}^{2} \mathrm{~s}\right.$ P) was not modified for this implementation from the value originally used by [54]. Each sensitivity test required significant computer time (a few days on our cluster), and full three-dimensional model runs were needed to evaluate system behavior under various parameter sets. For that reason, an exhaustive set of parameter choices was not explored, and we were limited to the cases discussed in section 5.2.

The availability of field observations from the MUDBED Intermediate site were valuable for constraining reasonable seabed profiles of critical shear stress, and water column estimates of bulk settling velocity and sediment concentration. In cases when field observations are unavailable, model estimates may reproduce realistic processes and trends, but should be analyzed with caution. Although this study offered much insight on implementing the cohesive bed model in a realistic environment, ongoing work is needed to further understand the use of the cohesive bed model in a complex system. 


\section{Conclusions}

This study described the use of the CSTSMS cohesive bed model that accounts for erosion, deposition, consolidation and swelling in a three-dimensional hydrodynamic model to represent the York estuary, VA, USA. Results from a time period when sediment-induced stratification seemed to be unimportant showed good agreement with observations of sediment concentration, bed stress, and current velocity. The sensitivities of the cohesive model were explored by evaluating the impact on calculations of changes to the swelling timescale and the initial and equilibrium critical stress profiles, and model estimates were found to be sensitive to these parameters. The Standard Model was developed by choosing a swelling timescale and initial and equilibrium critical stress profiles for the York River three-dimensional model that showed good agreement with field observations of bed stress, current velocity, and sediment concentration using a tidal-phase averaged analysis. The model was able to capture observed spatial and temporal trends in settling velocity, and unlike previous models that did not allow for a depth varying $\tau_{c}$ this model was able to adequately represent feedbacks between erosion and deposition in a highly dynamic cohesive environment. The cohesive bed model is still fairly new, and more work is needed to determine how the initial and equilibrium profiles should be defined, especially in cases where observations are limited. However, results from this study demonstrate that this model promises to be a useful tool for investigating the fundamental controls on bed erodibility and settling velocity in the York River, a classical muddy estuary.

\section{Acknowledgments}

Funding by the National Science Foundation (OCE-1061781 and OCE-0536572) supported Fall, Harris, Friedrichs, and Rinehimer. Lindsey Kraatz (formerly VIMS) contributed to some of the model runs. The authors appreciate discussions with Linda Schaffner, Marjorie Friedrichs (both VIMS) and Larry Sanford (U. Maryland Center for Environmental Science), who aided model development. Comments from Patrick Dickhudt (U.S. Geological Survey) improved an earlier version of this paper. Use of trade, product, or firm names is for descriptive purposes only and does not imply endorsement by the U.S. Government. This is contribution number 3363 of the Virginia Institute of Marine Science, College of William \& Mary.

\section{Author Contributions}

K.A. Fall completed model runs and data analysis. She drafted the manuscript, which the co-authors then edited. C.K. Harris supervised the model runs and analysis. C.T. Friedrichs supervised the data analysis. J.P. Rinehimer initially implemented the model for the York River. C.R. Sherwood oversaw changes to the model source code to include the cohesive bed formulation.

\section{Conflicts of Interest}

The authors declare no conflicts of interest. 


\section{References}

1. Winterwerp, J.C.; Van Kesteren, W.G. Introduction to the Physics of Cohesive Sediment Dynamics in the Marine Environment; Elsevier: Amsterdam, The Netherlands, 2004.

2. Reay, W.G. Water quality within the York River estuary. J. Coast. Res. 2009, 25, 23-39.

3. Sanford, L.; Chang, M. The bottom boundary condition for suspended sediment deposition. J. Coast. Res. 1997, 13, 3-17.

4. Friedrichs, C.T.; Cartwright, G.M.; Dickhudt, P.J. Quantifying benthic exchange of fine sediment via continuous, noninvasive measurements of settling velocity and bed erodibility. Oceanography 2008, 21, 168-172.

5. Harris, C.K.; Sherwood, C.R.; Signell, R.P.; Bever, A.J.; Warner, J.C. Sediment dispersal in the northwestern Adriatic Sea. J. Geophys. Res. Oceans 2008, 113, doi:10.1029/2006JC003868.

6. Gong, W.; Shen, J. Response of sediment dynamics in the York River Estuary, USA to tropical cyclone Isabel of 2003. Estuar. Coast. Shelf Sci. 2009, 84, 61-74.

7. Gong, W.; Shen, J. A model diagnostic study of age of river-borne sediment transport in the tidal York River Estuary. Environ. Fluid Mech. 2010, 10, 177-196.

8. Fugate, D.C.; Friedrichs, C.T. Controls on suspended aggregate size in partially mixed estuaries. Estuar. Coast. Shelf Sci. 2003, 58, 389-404.

9. Scully, M.E.; Friedrichs, C.T. The influence of asymmetries in overlying stratification on near-bed turbulence and sediment suspension in a partially mixed estuary. Ocean Dyn. 2003, 53, 208-219.

10. Cartwright, G.M.; Friedrichs, C.T.; Dickhudt, P.J.; Gass, T.; Farmer, F.H. Using the acoustic doppler velocimeter (ADV) in the MUDBED real-time observing system. In Marine Technology for Our Future: Global and Local Challenges, Proceedings of OCEANS 2009, MTS/IEEE Biloxi, Gloucester, VA, USA, 1-9 November 2009.

11. Dickhudt, P.J.; Friedrichs, C.T.; Schaffner, L.C.; Sanford, L.P. Spatial and temporal variation in cohesive sediment erodibility in the York River estuary, eastern USA: A biologically influenced equilibrium modified by seasonal deposition. Mar. Geol. 2009, 267, 128-140.

12. Amos, C.L.; Umgiesser, G.; Ferrarin, C.; Thompson, C.; Whitehouse, R.; Sutherland, T.; Bergamasco, A. The erosion rates of cohesive sediments in Venice Lagoon, Italy. Cont. Shelf Res. 2010, 30, 859-870.

13. Postma, H. Sediment transport and sedimentation in the estuarine environment. Am. Assoc. Adv. Sci. 1967, 83, 158-179.

14. Schubel, J.R. Turbidity maximum of the northern Chesapeake Bay. Science 1968, 161, 1013-1015.

15. Dyer, K.R. Sediment transport processes in estuaries. Dev. Sedimentol. 1995, 53, 423-449.

16. Geyer, W.R. The importance of suppression of turbulence by stratification on the estuarine turbidity maximum. Estuaries 1993, 16, 113-125.

17. Jay, D.A.; Musiak, J.D. Particle trapping in estuarine tidal flows. J. Geophys. Res. Oceans 1994, 99, 20445-20461. 
18. Scully, M.E.; Friedrichs, C.T. Sediment pumping by tidal asymmetry in a partially mixed estuary. J. Geophys. Res. 2007, 112, doi:10.1029/2006JC003784.

19. Schoellhamer, D. Influence of salinity, bottom topography, and tides on locations of estuarine turbidity maxima in northern San Francisco Bay. In Coastal and Estuarine Fine Sediment Transport Processes; McAnally, W.H., Mehta, A.J., Eds.; Elsevier: Amsterdam, The Netherlands, 2001; pp. 343-357.

20. Lin, J.; Kuo, A.Y. Secondary turbidity maximum in a partially mixed microtidal estuary. Estuaries 2001, 24, 707-720.

21. Woodruff, J.D.; Geyer, W.R.; Sommerfield, C.K.; Driscoll, N.W. Seasonal variation of sediment deposition in the Hudson River Estuary. Mar. Geol. 2001, 179, 105-119.

22. Ralston, D.K.; Warner, J.C.; Geyer, W.R.; Wall, G.R. Sediment transport due to extreme events: The Hudson River Estuary after tropical storms Irene and Lee. Geophys. Res. Lett. 2013, 40, 5451-5455.

23. Shields, A. California Institute of Technology, Pasadena, CA, USA. Application of Similarity Principles and Turbulence Research to Bed-Load Movement. Unpublished work, 1936.

24. Parchure, T.M.; Mehta, A.J. Erosion of soft cohesive sediment deposits. J. Hydraul. Eng. 1985, 111, 1308-1326.

25. Amos, C.L.; Daborn, G.; Christian, H.; Atkinson, A.; Robertson, A. In situ erosion measurements on fine-grained sediments from the Bay of Fundy. Mar. Geol. 1992, 108, 175-196.

26. Maa, J.P.; Sanford, L.; Halka, J.P. Sediment resuspension characteristics in Baltimore Harbor, Maryland. Mar. Geol. 1998, 146, 137-145.

27. Roberts, J.; Jepsen, R.; Gotthard, D.; Lick, W. Effects of particle size and bulk density on erosion of quartz particles. J. Hydraul. Eng. 1998, 124, 1261-1267.

28. Ariathurai, C.R.; Krone, R.B. Finite element model for cohesive sediment transport. J. Hydraul. Div. 1976, 102, 323-338.

29. McLean, S.R. Theoretical modelling of deep ocean sediment transport. Mar. Geol. 1985, 66, 243-265.

30. Andersen, T. Seasonal variation in erodibility of two temperate, microtidal mudflats. Estuar. Coast. Shelf Sci. 2001, 53, 1-12.

31. Sanford, L.P.; Maa, J.P. A unified erosion formulation for fine sediments. Mar. Geol. 2001, 179, 9-23.

32. Sanford, L.P. Uncertainties in sediment erodibility estimates due to a lack of standards for experimental protocols and data interpretation. Int. Environ. Assess. Manag. 2006, 2, 29-34.

33. Rinehimer, J.P.; Harris, C.K.; Sherwood, C.R.; Sanford, L.P. Estimating cohesive sediment erosion and consolidation in a muddy, tidally-dominated environment: Model behavior and sensitivity. In Proceedings of 10th Estuarine and Coastal Modeling, Reston, VA, USA, 5-7 November 2008; American Society of Civil Engineers: Reston, VA, USA, 2008; pp. 819-838.

34. Wang, X.; Pinardi, N. Modeling the dynamics of sediment transport and resuspension in the northern Adriatic Sea. J. Geophys. Res. 2002, 107, doi:10.1029/2001JC001303.

35. Lin, J.; Kuo, A.Y. A model study of turbidity maxima in the York River Estuary, Virginia. Estuaries 2003, 26, 1269-1280. 
36. Harris, C.K.; Traykovski, P.A.; Geyer, W.R. Flood dispersal and deposition by nearbed gravitational sediment flows and oceanographic transport: A numerical modeling study of the Eel River Shelf, Northern California. J. Geophys. Res. Oceans 2005, 110, doi:10.1029/2004JC002727.

37. Geyer, W.R.; Woodruff, J.D.; Traykovski, P. Sediment transport and trapping in the Hudson River Estuary. Estuaries 2001, 24, 670-679.

38. Harris, C.K.; Wiberg, P.L. A two-dimensional, time-dependent model of suspended sediment transport and bed reworking for continental shelves. Comput. Geosci. 2001, 27, 675-690.

39. Sanford, L.P.; Suttles, S.E.; Halka, J.P. Reconsidering the physics of the Chesapeake Bay estuarine turbidity maximum. Estuaries 2001, 24, 655-669.

40. Stevens, A.; Wheatcroft, R.; Wiberg, P. Seabed properties and sediment erodibility along the western Adriatic margin, Italy. Cont. Shelf Res. 2007, 27, 400-416.

41. Kwon, J.-I. Simulation of Turbidity Maximums in the York River, Virginia. Ph.D. Thesis, School of Marine Science, College of William and Mary, Gloucester Point, VA, USA, June 2005.

42. Cartwright, G.; Friedrichs, C.; Sanford, L. In situ characterization of estuarine suspended sediment in the presence of muddy flocs and pellets. In Proceedings of Coastal Sediments, Miami, FL, USA, 2-6 May 2011; pp. 642-655.

43. Sanford, L.P. Modeling a dynamically varying mixed sediment bed with erosion, deposition, bioturbation, consolidation, and armoring. Comput. Geosci. 2008, 34, 1263-1283.

44. Friedrichs, C.T. York River physical oceanography and sediment transport. J. Coast. Res. 2009, 25, 17-22.

45. Schaffner, L.C.; Dellapenna, T.M.; Hinchey, E.K.; Friedrichs, C.T.; Thompson Neubauer, M.; Smith, M.E., Kuehl, S.A. Physical energy regimes, seabed dynamics and organism-sediment interactions along an estuarine gradient. In Organism-Sediment Interactions; Aller, J.Y., Woodin, S.A., Aller, R.C., Eds.; University of South Carolina Press: Columbia, SC, USA, 2001.

46. Dellapenna, T.M.; Kuehl, S.A.; Schaffner, L.C. Ephemeral deposition, seabed mixing and fine-scale strata formation in the York River Estuary, Chesapeake Bay. Estuar. Coast. Shelf Sci. 2003, 58, 621-643.

47. Maa, J.P.; Kim, S. A constant erosion rate model for fine sediment in the York River, Virginia. Environ. Fluid Mech. 2001, 1, 345-360.

48. Dickhudt, P.J. Controls on Erodibility in a Partially Mixed Estuary: York River, Virginia. Master's Thesis, School of Marine Science, College of William and Mary, Gloucester Point, VA, USA, July 2008.

49. Fall, K.A.; Friedrichs, C.T.; Cartwright, G.M. Controls on Particle Settling Velocity and Bed Erodibility in the Presence of Muddy Flocs and Pellets as Inferred by ADVs, York River Estuary, Virginia, USA. Ocean Dyn. 2014, to be submitted for publication.

50. Uncles, R.; Stephens, J. Distributions of suspended sediment at high water in a macrotidal estuary. J. Geophys. Res. 1989, 94, 14395-14405. 
51. Shchepetkin, A.F.; McWilliams, J.C. The regional oceanic modeling system (ROMS): A split-explicit, free-surface, topography-following-coordinate oceanic model. Ocean Model. 2005, 9, 347-404.

52. Haidvogel, D.B.; Arango, H.; Budgell, W.; Cornuelle, B.; Curchitser, E.; Di Lorenzo, E.; Lanerolle, L. Ocean forecasting in terrain-following coordinates: Formulation and skill assessment of the regional ocean modeling system. J. Comput. Phys. 2008, 227, 3595-3624.

53. Warner, J.C.; Sherwood, C.R.; Signell, R.P.; Harris, C.K.; Arango, H.G. Development of a three-dimensional, regional, coupled wave, current, and sediment-transport model. Comput. Geosci. 2008, 34, 1284-1306.

54. Rinehimer, J.P. Sediment Transport and Erodibility in the York River Estuary: A Model Study. Master's Thesis, School of Marine Science, College of William and Mary, Gloucester Point, VA, USA, October 2008.

55. Mellor, G.L.; Yamada, T. Development of a turbulence closure model for geophysical fluid problems. Rev. Geophys. 1982, 20, 851-875.

56. Smolarkiewicz, P.K.; Margolin, L.G. MPDATA: A finite-difference solver for geophysical flows. J. Comput. Phys. 1998, 140, 459-480.

57. Warner, J.C.; Geyer, W.R.; Lerczak, J.C. Numerical modeling of an estuary: A comprehensive skill assessment. J. Geophys. Res. 2005, 110, doi:10.1029/2004JC002691.

58. Sherwood, C.R.; Aretzabaleta. A.; Harris, C.K.; Rinehimer, J.P.; Ferre, B.; Veraney, R. Extension of the Community Sediment Transport Modeling System for Coheisve Sediment: Floc and Muddy Bed Dynamics. 2014, to be submitted for publication.

59. USGS Water Data Website. Available online: http://waterdata.usgs.gov/nwis (accessed on 10 May 2010).

60. Chesapeake Bay Program Data Hub Website. Available online: http://www.chesapeakebay. net/data (accessed on 26 February 2010).

61. Fugate, D.C.; Friedrichs, C.T. Determining concentration and fall velocity of estuarine particle populations using ADV, OBS and LISST. Cont. Shelf Res. 2002, 22, 1867-1886.

62. Friedrichs, C.; Wright, L.; Hepworth, D.; Kim, S. Bottom-boundary-layer processes associated with fine sediment accumulation in coastal seas and bays. Cont. Shelf Res. 2000, 20, 807-841.

63. Dyer, K. Coastal and Estuarine Sediment Dynamics; Wiley: Chichester, UK, 1986.

64. Kraatz, L.M.; Friedrichs, C.T.; Cartwright, G.M.; Fall, K.A.; Wilkerson, C.N. Relationships between erodibility and fine-grained sea bed properties on tidal to seasonal time-scales, York River Estuary, Virginia, USA. In Proceedings of Physics of Estuaries and Coastal Seas, 16th International Biennial Conference, New York, NY, USA, 12-16 August 2012.

65. Cartwright, G.M.; Friedrichs, C.T.; Smith, S.J. A test of the ADV-based Reynolds flux method for in situ estimation of sediment settling velocity in a muddy estuary. Geo-Mar. Lett. 2013, 33, 477-484. 


\title{
Predicting the Storm Surge Threat of Hurricane Sandy with the National Weather Service SLOSH Model
}

\author{
Cristina Forbes, Jamie Rhome, Craig Mattocks and Arthur Taylor
}

\begin{abstract}
Numerical simulations of the storm tide that flooded the US Atlantic coastline during Hurricane Sandy (2012) are carried out using the National Weather Service (NWS) Sea Lakes and Overland Surges from Hurricanes (SLOSH) storm surge prediction model to quantify its ability to replicate the height, timing, evolution and extent of the water that was driven ashore by this large, destructive storm. Recent upgrades to the numerical model, including the incorporation of astronomical tides, are described and simulations with and without these upgrades are contrasted to assess their contributions to the increase in forecast accuracy. It is shown, through comprehensive verifications of SLOSH simulation results against peak water surface elevations measured at the National Oceanic and Atmospheric Administration (NOAA) tide gauge stations, by storm surge sensors deployed and hundreds of high water marks collected by the U.S. Geological Survey (USGS), that the SLOSH-simulated water levels at $71 \%$ (89\%) of the data measurement locations have less than $20 \%$ (30\%) relative error. The RMS error between observed and modeled peak water levels is $0.47 \mathrm{~m}$. In addition, the model's extreme computational efficiency enables it to run large, automated ensembles of predictions in real-time to account for the high variability that can occur in tropical cyclone forecasts, thus furnishing a range of values for the predicted storm surge and inundation threat.
\end{abstract}

Reprinted from J. Mar. Sci. Eng. Cite as: Forbes, C.; Rhome, J.; Mattocks, C.; Taylor, A. Predicting the Storm Surge Threat of Hurricane Sandy with the National Weather Service SLOSH Model. J. Mar. Sci. Eng. 2014, 2, 437-476.

\section{Introduction}

The purpose of this study is to quantify the ability of the National Oceanic and Atmospheric Administration (NOAA)/National Weather Service (NWS) Sea Lakes and Overland Surges from Hurricanes (SLOSH) storm surge prediction model [1] to replicate the height, timing, evolution and extent of the storm tide that occurred along the US Atlantic coastline during Hurricane ("Superstorm") Sandy (2012). It will also provide an assessment of the storm surge forecast skill during the storm compared to the model improvements incorporated in the model since. This analysis will serve as a baseline for the evaluation of further enhancements to SLOSH and for comparisons against the results from other modeling systems as NWS moves toward a multi-model ensemble.

Hurricane Sandy [2] began as a tropical wave off the west coast of Africa on 11 October 2012. It formed in the western Caribbean, south of the island of Jamaica in a region of low wind shear, warm water and a broad area of low pressure on 22 October 2012. The storm made its first landfall near Kingston, Jamaica as a category 1 hurricane on the Saffir-Simpson hurricane wind scale. It reached its peak intensity of $185 \mathrm{kph}$ (115 mph, $100 \mathrm{kts})$ and made its second landfall in Cuba at 05:25 UTC on 25 October as a category 3 hurricane. The destruction was severe. 17,000 homes 
were damaged by extensive coastal flooding and high winds. Gusts topped $177 \mathrm{kph}(110 \mathrm{mph})$ in Santiago de Cuba before the anemometer stopped measuring wind speed and $265 \mathrm{kph}$ (165 mph) at Gran Piedra, just west of Guantanamo. Hurricane Sandy then weakened and began expanding in size, reaching a radius of maximum winds (RMW) larger than $185 \mathrm{~km}(100 \mathrm{~nm})$ over the Bahamas. It re-intensified over the warm Gulf Stream waters as it turned northwest towards the mid-Atlantic states. An anomalous blocking high over the North Atlantic prevented Sandy from moving out to sea, while a baroclinic trough associated with an early winter storm deepened over the southeast US. This accelerated the storm's forward speed to $37 \mathrm{kph}(20 \mathrm{kts})$ and steered it northwest, where it encountered cold water and transitioned to an extratropical cyclone $83 \mathrm{~km}(45 \mathrm{~nm})$ southeast of Atlantic City, NJ [2], $2.5 \mathrm{~h}$ prior to its final landfall. It approached the coast as a category 1 hurricane and made landfall at 23:30 UTC Monday 29 October 2012, near Brigantine, NJ (northeast of Atlantic City) as a post-tropical cyclone, with maximum sustained winds of $130 \mathrm{kph}$ (80 mph, $70 \mathrm{kts}$ ) and a central pressure of $945 \mathrm{mb}$. The GOES-13 natural color satellite image in Figure 1a shows the cold front interacting with Hurricane Sandy approximately one day before landfall. The lowest pressure found was $940 \mathrm{mb}$ (dropsonde estimate) a few hours before landfall in NJ [2] and a warm front developed in the storm's northeast quadrant, as seen in the NOAA surface weather chart in Figure 1b.

One of the most dangerous aspects of Hurricane Sandy was its large size, approximately 1150 miles $(1850 \mathrm{~km})$ in diameter, based on the extent of the last closed isobar, with a wind field that created a significant storm tide threat to vast areas along the Atlantic coastline and inland. Hurricane Sandy retained its large wind field, large radius of maximum winds, and hybrid characteristics through landfall [2]. After Hurricane Sandy made landfall in NJ, its sustained winds increased as an effect of the winter storm approaching from the west. The combination of both Hurricane Sandy and the winter storm, timed with the full-moon high tide on the night of 29 October, worsened the storm-tide flooding along the NJ, NY and CT coastlines and caused significant flooding far inland along the Delaware and Hudson Rivers [3]. Hurricane Sandy caused 147 direct deaths (286 total) and damage of $\$ 68$ billion dollars. It is the second-costliest Atlantic hurricane on record.

The storm surge above astronomical tide produced by Hurricane Sandy reached its highest observed levels of $3.86 \mathrm{~m}$ (12.65 ft) at Kings Point at the western end of Long Island Sound. A storm surge of $2.91 \mathrm{~m}(9.56 \mathrm{ft})$ was recorded along the northern side of Staten Island at Bergen Point West Reach. At The Battery, on the southern tip of Manhattan, values of $2.87 \mathrm{~m}(9.40 \mathrm{ft})$ were measured and at Sandy Hook, NJ the gauge failed when the surge crested to $2.61 \mathrm{~m}(8.57 \mathrm{ft})$. In Montauk, at the east tip of Long Island, Atlantic City, NJ and Cape May, NJ storm surge values peaked at $1.80 \mathrm{~m}(5.89 \mathrm{ft}), 1.77 \mathrm{~m}(5.82)$ and $1.57 \mathrm{~m}(5.16 \mathrm{ft})$, respectively.

According to a recent National Hurricane Center (NHC) technical memorandum [4], inundation is defined as the total water level that occurs on normally dry ground as a result of the storm tide. It is expressed in terms of height of water, in feet, above ground level (AGL). NHC's official forecasts provide storm surge-induced flooding information in terms of inundation (feet of water above ground level). The tidal datum MHHW (Mean Higher High Water) is considered the best 
possible approximation of the threshold at which inundation can begin to occur since at the coast, areas higher than MHHW are typically dry most of the time.

Figure 1. (a) GOES-13 natural color satellite image at 17:45 UTC on 28 October 2012 (courtesy of NASA Earth Observatory); and (b) surface weather chart at 21 UTC 29 October 2012, approximately two and a half hours before landfall (courtesy of the National Oceanic and Atmospheric Administration (NOAA)). Note the interaction of the hurricane with the approaching winter storm, the subsequent drop in mean sea level pressure to $940 \mathrm{mb}$, and the development of cold and warm fronts during the hybridization process off the coast of New Jersey.

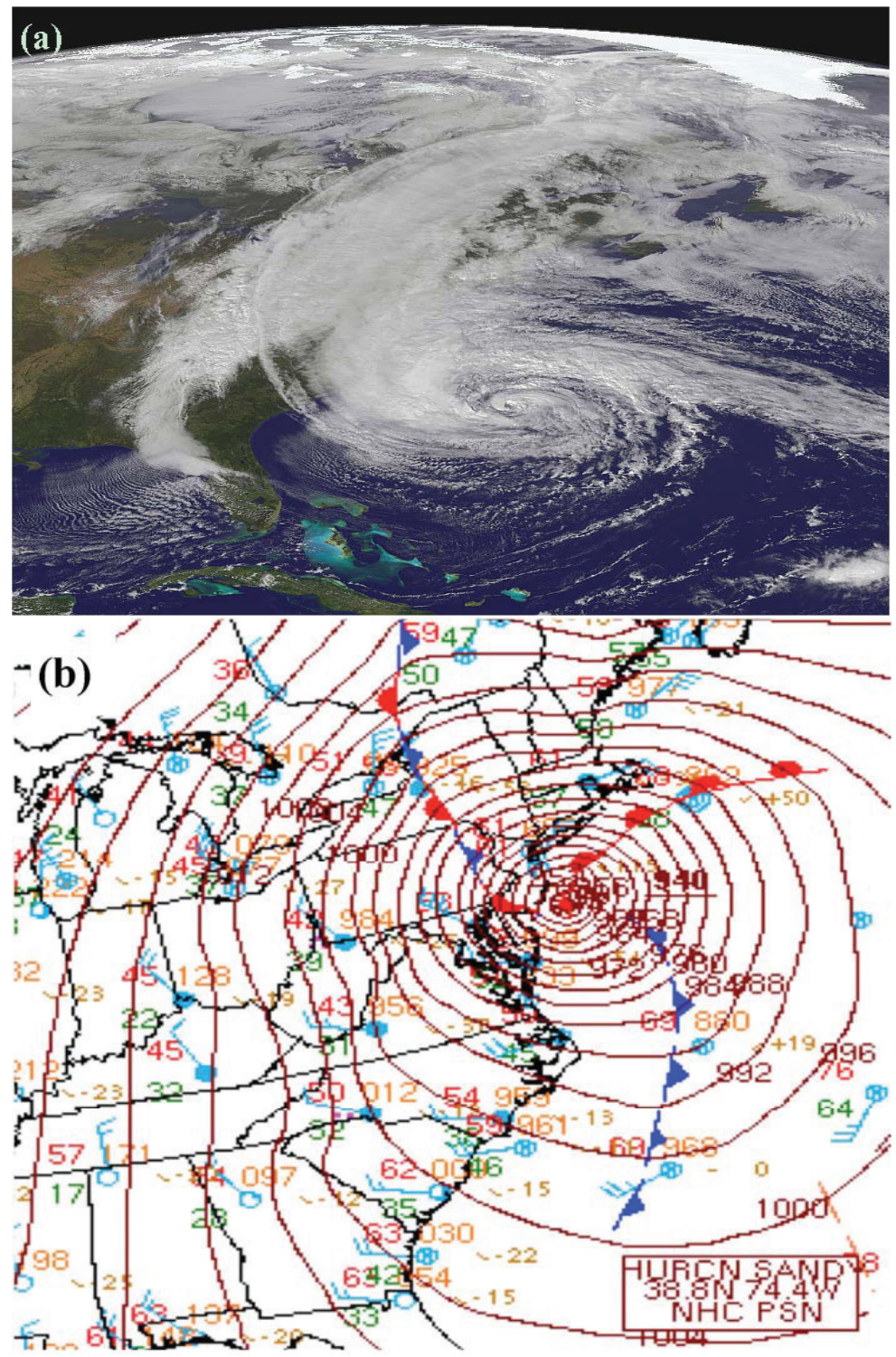


The highest recorded total water levels, which occurred within half an hour of high tide in the Staten Island and Manhattan areas, reached a record $4.28 \mathrm{~m}$ (14.06 ft) above Mean Lower Low Water (MLLW), $2.74 \mathrm{~m}(8.99 \mathrm{ft})$ above MHHW at The Battery, NY; a record $4.36 \mathrm{~m}(14.31 \mathrm{ft})$ above MLLW, $1.98 \mathrm{~m}$ (6.51 ft) above MHHW at King's Point, and $4.44 \mathrm{~m}(14.58 \mathrm{ft})$ above MLLW, $2.76 \mathrm{~m}$ (9.06 ft) above MHHW at Bergen Point West Reach. At The Battery, the storm

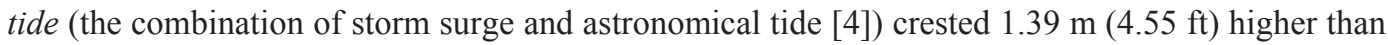
the water that occurred during Hurricane Irene (2011) [2]. Storm tide records were broken in Sandy Hook, NJ with $4.03 \mathrm{~m}$ (13.23 ft) MLLW, $2.44 \mathrm{~m}$ (8.01 ft) MHHW and at Philadelphia, PA with $3.24 \mathrm{~m}$ $(10.62 \mathrm{ft})$ MLLW, $1.2 \mathrm{~m}(3.93 \mathrm{ft})$ MHHW $8 \mathrm{~h}$ after landfall. The tide gauge at Sandy Hook failed before the peak water levels were reached.

Table 1 summarizes the maximum total, tide (referenced to various vertical datums) and surge water levels reached at three NOAA stations at the coast: The Battery, Bergen Point and Kings Point. At The Battery total water levels crested at the same time as the surge, even though the highest tides arrived half an hour earlier. At Bergen Point the maximum surge arrived half an hour after the highest total water level, while at Kings Point the maximum surge arrived two hours before the highest total water level.

A buoy at the entrance of New York Harbor (Station 44065), $15 \mathrm{~nm}$ southeast of Breezy Point, NY, measured a record significant wave height (SWH, the highest one-third of all wave heights

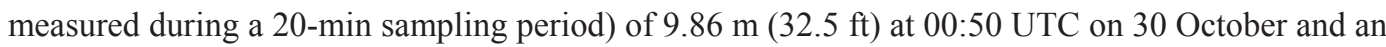
atmospheric pressure of $958 \mathrm{hPa}$, while buoys in Central (44039) and Western (44040) Long Island Sound recorded SWHs of $2.2 \mathrm{~m}$ and $2.1 \mathrm{~m}$, respectively. Buoy (44009) at Delaware Bay, $48 \mathrm{~km}$ $(26 \mathrm{~nm}) \mathrm{SE}$ of Cape May, NJ, USA, reached a SWH of $7.38 \mathrm{~m}$. At more than $300 \mathrm{~km}$ (190 miles) away from the point of landfall at Block Island, RI (44097), SWHs reached $9.48 \mathrm{~m}$. Even as far away as $450 \mathrm{~km}$ (280 miles) at Buoy 44008, located $54 \mathrm{~nm}$ SE of Nantucket Shoals, a SWH of $10.97 \mathrm{~m}$ was registered.

High Water Marks measured by USGS sensors recorded the highest water level inland, a value of $2.71 \mathrm{~m}(8.9 \mathrm{ft})$ AGL, at the US Coast Guard Station in Sandy Hook, NJ, followed by $2.44 \mathrm{~m}$ (8.0 $\mathrm{ft})$ AGL at the South Street Seaport near the Brooklyn Bridge and $2.41 \mathrm{~m}(7.9 \mathrm{ft})$ AGL in the Oakwood neighborhood of Staten Island and on the south side of Raritan Bay. Values between 1 and $2 \mathrm{~m}$ occurred at Maspeth, Fire Island, Battery Park, Oak Beach-Captree, Rockaways, Lower Manhattan, Freeport, Hempstead, Long Island, Nassau County, Brooklyn, Wading River in Town of Riverhead, Inwood, near John F. Kennedy Airport (JFK), Bronx, Throgs Neck area. Runways and tarmacs at JFK and La Guardia were inundated as well.

These various measurements depict the difficulty in assessing the storm surge threat because water level values might be referenced to different vertical datums or the quoted water surface elevations might represent only partial components of the total water level (e.g., tide or surge). It is easy to see how the public could become confused by this plethora of information and why it is crucial to communicate the storm surge threat clearly to the public to minimize the loss of life. Therefore, in addition to producing operational storm surge forecasts and issuing public advisories, the National Hurricane Center (NHC) has worked extensively with social scientists to craft graphics and text that convey the potential dangers of storm surge effectively [6]. 
Table 1. Maximum total, tide (referenced to various vertical datums) and surge water levels reached at three NOAA tide gauge stations at the coast: The Battery, Bergen Point and Kings Point, NY (see Figure 2 for station locations).

\begin{tabular}{|c|c|c|c|c|}
\hline $\begin{array}{l}\text { Station } \\
\text { (ID) }\end{array}$ & $\begin{array}{c}\text { Time/Vertical } \\
\text { Datum }\end{array}$ & $\begin{array}{c}\text { Maximum } \\
\text { Total Water } \\
\text { Level m (ft) }\end{array}$ & $\begin{array}{l}\text { Maximum Tide } \\
\text { m (ft) }\end{array}$ & $\begin{array}{l}\text { Maximum Surge Above } \\
\text { Astronomical Tide m (ft) }\end{array}$ \\
\hline \multirow{7}{*}{$\begin{array}{l}\text { The Battery, NY } \\
(8518750)\end{array}$} & \multirow{2}{*}{ Time } & 30 October 2012 & 30 October 2012 & 30 October 2012 \\
\hline & & 01:24 UTC & 00:54 UTC & 01:24 UTC \\
\hline & MHHW & 2.74 (8.999) & $-0.10(-0.315)$ & \multirow{5}{*}{$\begin{array}{c}2.87 \\
(9.40)\end{array}$} \\
\hline & NAVD88 & $3.44(11.280)$ & $0.60(1.965)$ & \\
\hline & MSL & $3.50(11.486)$ & $0.66(2.172)$ & \\
\hline & MLW & $4.22(13.848)$ & $1.38(4.534)$ & \\
\hline & MLLW & $4.28(14.055)$ & $1.44(4.741)$ & \\
\hline \multirow{7}{*}{$\begin{array}{l}\text { Bergen Point, NY } \\
\quad(8519483)\end{array}$} & \multirow{2}{*}{ Time } & 30 October 2012 & 30 October 2012 & 30 October 2012 \\
\hline & & 01:24 UTC & 00:54 UTC & 02:00 UTC \\
\hline & MHHW & $2.76(9.065)$ & $-0.80(-0.259)$ & \multirow{5}{*}{$\begin{array}{c}2.91 \\
(9.56)\end{array}$} \\
\hline & NAVD88 * & $3.54(11.623)$ & $0.70(2.299)$ & \\
\hline & MSL & $3.60(11.801)$ & $0.75(2.477)$ & \\
\hline & MLW & $4.38(14.367)$ & $1.54(5.042)$ & \\
\hline & MLLW & $4.44(14.577)$ & $1.60(5.252)$ & \\
\hline \multirow{7}{*}{$\begin{array}{l}\text { Kings Point, NY } \\
\quad(8516945)\end{array}$} & \multirow{2}{*}{ Time } & 30 October 2012 & 30 October 2012 & 30 October 2012 \\
\hline & & 02:06 UTC & 04:24 UTC & 23:06 UTC \\
\hline & MHHW & $1.98(6.509)$ & $-0.07(-0.224)$ & \multirow{5}{*}{$3.86(12.65)$} \\
\hline & NAVD88 ${ }^{\dagger}$ & $3.11(10.201)$ & $1.06(3.468)$ & \\
\hline & MSL & $3.18(10.423)$ & $1.12(3.690)$ & \\
\hline & MLW & $4.28(14.035)$ & $2.22(7.302)$ & \\
\hline & MLLW & $4.36(14.311)$ & $2.31(7.578)$ & \\
\hline
\end{tabular}

MHHW $=$ Mean Higher High Water; MSL $=$ Mean Sea Level; MLW = Mean Low Water;

MLLW = Mean Lower Low Water; NAVD88 = North American Vertical Datum of 1988;

* NAVD88-MSL $=0.0542 \mathrm{~m}(0.178 \mathrm{ft})[5] ;{ }^{\dagger} \mathrm{NAVD} 88-\mathrm{MSL}=0.0676 \mathrm{~m}(0.222 \mathrm{ft})[5]$.

Operational storm surge forecasts during the storm and post-storm hindcast simulations of Hurricane Sandy were run by forecasters in NHC's Storm Surge Unit using the NWS Sea, Lake, and Overland Surges from Hurricanes (SLOSH) model. This manuscript describes the operational forecasts of Hurricane Sandy run in the SLOSH ny3 basin (Figure 3), the improvements to the surge forecasting system implemented during 2013, and how the storm would have been predicted had the enhanced system been available in 2012.

Hindcast simulations of Hurricane Sandy were run for analysis and verification. Comparisons of observed water levels at NOAA tide gauge stations, by USGS temporary storm surge sensors (SSS) and high water marks (HWM) were compared with the numerically simulated water levels to assess model performance. 
Figure 2. Map of NOAA tide gauge station locations.

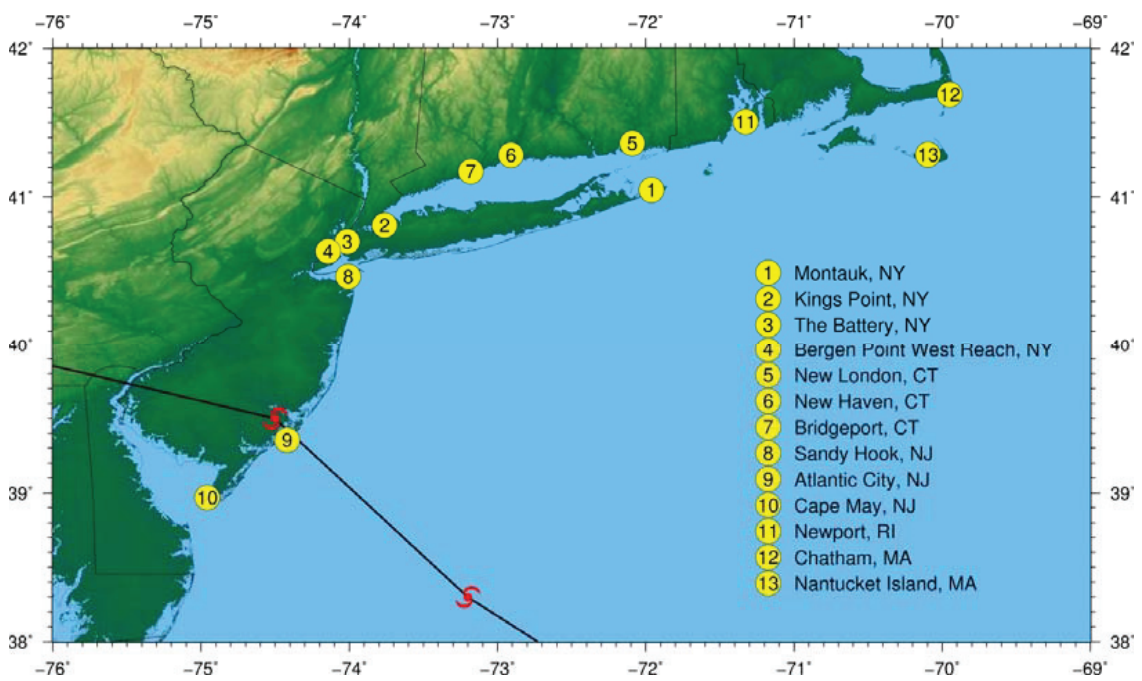

Figure 3. Hurricane Sandy track and the storm tide (m) simulated by the Sea, Lake, and Overland Surges from Hurricanes (SLOSH) numerical storm surge prediction model in the ny3 basin.

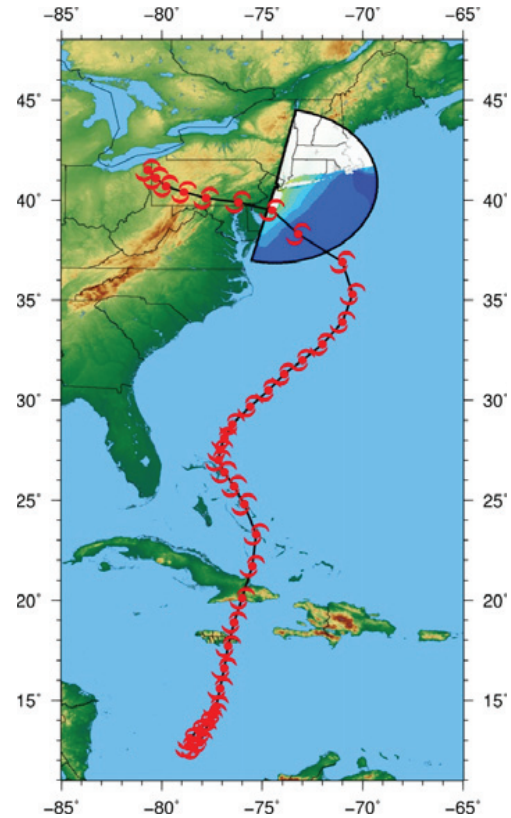

\section{Model}

SLOSH [1] is a numerical coastal ocean model used by the National Weather Service to run: (1) real-time operational; (2) hypothetical (for evacuation planning); (3) historical (for validation purposes); (4) probabilistic [7]; and (5) extratropical storm surge prediction simulations. 
It is an extremely computationally efficient, 2-D explicit, finite-difference model, formulated on a semi-staggered Arakawa B-grid [8]. The horizontal transport equations are solved through the application of the Navier-Stokes momentum equations for incompressible and turbulent flow. The SLOSH model transport equations were derived by Platzman [9], in which the dissipation is determined solely by an eddy viscosity coefficient. A bottom slip coefficient was included by Jelesnianski [10]. The governing equations are integrated over the entire depth of the water column. At every time step, the horizontal transports are solved from the pressure, Coriolis and frictional forces. These transports generate an updated level of surge at every model grid point. SLOSH includes a wetting-and-drying algorithm to predict inland inundation.

A simplified parametric wind model is embedded in the SLOSH model. The input parameters of the wind model consist of the storm track (latitude and longitude of the center's location), radius of maximum winds and the difference between the environmental and the central pressures (pressure drop) of the storm. The wind-driven forcing is incorporated into SLOSH as wind stress.

SLOSH grids have different shapes (hyperbolic, elliptical or polar) that can be customized for specific coastline geometries, with higher resolution near the coast and grid cells that telescope outward concentrically to lower resolution offshore. There are 37 operational SLOSH basins that cover the east coast of the US, the Gulf of Mexico, the Bahamas, Puerto Rico and the Virgin Islands. The bathymetry and topography in the model grid cells are derived from National Elevation Dataset (NED) digital elevation models (DEMs) from the U.S. Geological Survey (USGS), the NOAA National Geophysical Data Center (NGDC) Tsunami inundation DEMs, and Light Detection and Ranging (LIDAR) data from the US Army Corps of Engineers (USACE) or from state and local sources, if available, and the bathymetry from NGDC 3 arc-second Coastal Relief Model. All the bathymetric/topographic data must be referenced to a single vertical datum and averaged to obtain the depth/elevation of each individual SLOSH cell. The land cover classifications are derived from the USGS $30 \mathrm{~m}$ spatial resolution National Land Cover Database (NLCD). SLOSH basins include subgrid-scale features that allow simulation of the flow through barriers, gaps, passes, overtopping of barriers, roads, and levees.

An automated, event-triggered, storm surge prediction system, AutoSurge [11], was developed at NHC in 2010 to accelerate forecaster workflows by eliminating labor-intensive tasks, computing storm parameters with greater accuracy and preventing human input error. The system runs the SLOSH model; the input is determined objectively and consistently for all operational simulations. AutoSurge automatically generates a vast array of products from the SLOSH model output to provide internal guidance to the Storm Surge Specialists.

\section{Forecasts}

As soon as a tropical disturbance with the potential of developing into a tropical cyclone in the subsequent 48-h is identified in the Atlantic Ocean, Caribbean Sea, or the Gulf of Mexico, AutoSurge begins generating storm surge forecast simulations using the SLOSH model. The system alerts the Storm Surge Specialists at NHC, sending guidance products via e-mail, and the results are available on an internal web site, both in tabular and graphical format. Forecasts are run using storm track information that includes the latitude and longitude of the storm's center, 
intensity (maximum sustained 1-min wind speed), pressure drop and radius of maximum winds from NHC's Best Track operational data and parameters from all of the model information available to the Hurricane Specialists at NHC. The SLOSH parametric wind model is used to ensure that the parameters in the SLOSH wind formulation are consistent with those in the model guidance, i.e., the resulting wind speed in the SLOSH wind model is in accordance to the NHC's Best Track and the model guidance intensity, in a manner similar to other storm surge forecast systems [12,13].

Graphics of the ensemble maximum envelope of water, model track spread, individual ensemble member maximum water levels, wind intensity, the radius of maximum winds, and forecast trends are generated to depict the expected range of the storm surge forecasts to account for variability in the atmospheric forcing.

AutoSurge was run in surge-only mode during the 2012 hurricane season. More than 1000 AutoSurge numerical simulations were run during Hurricane Sandy using the Best Track and the internal NHC model guidance used to create the official track (OFCL). The ensembles are derived from the suite of statistical, dynamical and consensus track and intensity models that NHC's Hurricane Specialists use to create their forecasts (National Weather Service Global Forecast System and Global Ensemble Forecast System, Hurricane Weather Research and Forecasting Model, Statistical Hurricane Intensity Prediction Scheme, Climatology and Persistence model, Logistic Growth Equation Model, Limited Area Barotropic Model, Navy Operational Global Prediction System, Canadian Global Environmental Multiscale Model, United Kingdom Met Office model, University of Wisconsin non-hydrostatic modeling system, European Center for Medium-range Weather Forecasting global model, Florida State University Super-ensemble, Geophysical Fluid Dynamics Laboratory model). This meteorological forcing was used to drive the SLOSH storm surge prediction model over multiple SLOSH basins, from Puerto Rico to the Bahamas and along the U. S. East Coast. Results for the ny3 basin will be described and the model output graphics will be shown in this manuscript. These ensemble simulations are run in conjunction with the probabilistic P-Surge modeling system [7] developed at NOAA/Meteorological Development Laboratory (MDL), which runs an ensemble of storm surge simulations using historical error statistics of the wind parameters to generate the forecast tracks.

Enhancements made to AutoSurge in 2013 include:

(1) Simulations with a new version of the tides (V. 2);

(2) Model results relative to both the NAVD88 (North American Vertical Datum of 1988) datum and above ground level;

(3) Mini-MEOW (Maximum Envelope Of Water) simulations (a handful of ensembles created by permutations of the OFCL track);

(4) Ensemble maximum water level ranges and trends; and

(5) Calculations of inundation area.

The new version of SLOSH + Tides (V. 2) incorporates the tides dynamically at every time step and at every SLOSH model grid point [14]. The location-dependent amplitudes and phases of 37 tidal constituents (selected to be consistent with NOAA/NOS station data) at all locations in the SLOSH 
grid [15] used are: M2, S2, N2, K1, M4, O1, M6, MK3, S4, MN4, NU2, S6, MU2, 2N2, OO1, LAM2, S1, M1, J1, MM, SSA, SA, MSF, MF, RHO, Q1, T2, R2, 2Q1, P1, 2SM2, M3, L2, 2MK3, $\mathrm{K} 2$, M8, MS4 (for definitions of the harmonic constituents see Table 2 and the glossary at [16]).

Table 2. Harmonic tidal constituents used in SLOSH. Each constituent represents a periodic variation in the relative positions of the earth, moon and sun.

\begin{tabular}{|c|c|c|c|}
\hline Harmonic Constituent Number & Name & Speed (Deg Per Hour) & Description \\
\hline 1 & M2 & 28.9841042 & Principal lunar semidiurnal constituent \\
\hline 2 & S2 & 30.0 & Principal solar semidiurnal constituent \\
\hline 3 & N2 & 28.4397295 & Larger lunar elliptic semidiurnal constituent \\
\hline 4 & K1 & 15.0410686 & Lunar diurnal constituent \\
\hline 5 & M4 & 57.9682084 & Shallow water overtides of principal lunar constituent \\
\hline 6 & $\mathrm{O} 1$ & 13.9430356 & Lunar diurnal constituent \\
\hline 7 & M6 & 86.9523127 & Shallow water overtides of principal lunar constituent \\
\hline 8 & MK3 & 44.0251729 & Shallow water terdiurnal \\
\hline 9 & S4 & 60.0 & Shallow water overtides of principal solar constituent \\
\hline 10 & MN4 & 57.4238337 & Shallow water quarter diurnal constituent \\
\hline 11 & NU2 & 28.5125831 & Larger lunar evectional constituent \\
\hline 12 & S6 & 90.0 & Shallow water overtides of principal solar constituent \\
\hline 13 & MU2 & 27.9682084 & Variational constituent \\
\hline 14 & $2 \mathrm{~N} 2$ & 27.8953548 & Lunar elliptical semidiurnal second-order constituent \\
\hline 15 & OO1 & 16.1391017 & Lunar diurnal \\
\hline 16 & LAM2 & 29.4556253 & Smaller lunar evectional constituent \\
\hline 17 & S1 & 15.0 & Solar diurnal constituent \\
\hline 18 & M1 & 14.4966939 & Smaller lunar elliptic diurnal constituent \\
\hline 19 & $\mathrm{~J} 1$ & 15.5854433 & Smaller lunar elliptic diurnal constituent \\
\hline 20 & MM & 0.5443747 & Lunar monthly constituent \\
\hline 21 & SSA & 0.0821373 & Solar semiannual constituent \\
\hline 22 & SA & 0.0410686 & Solar annual constituent \\
\hline 23 & MSF & 1.0158958 & Lunisolar synodic fortnightly constituent \\
\hline 24 & MF & 1.0980331 & Lunisolar fortnightly constituent \\
\hline 25 & $\mathrm{RHO}$ & 13.4715145 & Larger lunar evectional diurnal constituent \\
\hline 26 & Q1 & 13.3986609 & Larger lunar elliptic diurnal constituent \\
\hline 27 & $\mathrm{~T} 2$ & 29.9589333 & Larger solar elliptic constituent \\
\hline 28 & $\mathrm{R} 2$ & 30.0410667 & Smaller solar elliptic constituent \\
\hline 29 & 2Q1 & 12.8542862 & Larger elliptic diurnal \\
\hline 30 & $\mathrm{P} 1$ & 14.9589314 & Solar diurnal constituent \\
\hline 31 & 2SM2 & 31.0158958 & Shallow water semidiurnal constituent \\
\hline 32 & M3 & 43.4761563 & Lunar terdiurnal constituent \\
\hline 33 & L2 & 29.5284789 & Smaller lunar elliptic semidiurnal constituent \\
\hline 34 & $2 \mathrm{MK} 3$ & 42.9271398 & Shallow water terdiurnal constituent \\
\hline 35 & $\mathrm{~K} 2$ & 30.0821373 & Lunisolar semidiurnal constituent \\
\hline 36 & M8 & 115.9364166 & Shallow water eighth diurnal constituent \\
\hline 37 & MS4 & 58.9841042 & Shallow water quarter diurnal constituent \\
\hline
\end{tabular}


The harmonic constituents used in the SLOSH + Tides code had recently been extracted from the new, updated experimental EC2013 ADCIRC tidal database. This database employs high-resolution NOAA VDatum meshes (coastal resolution down to $14 \mathrm{~m}$ ) along the Atlantic and Gulf Coasts of the United States, Puerto Rico and US Virgin Islands, an updated offshore bathymetry using the latest global sources, namely, Space Shuttle Radar Topography Mission SRTM30_PLUS V8.0 from the Scripps Institution of Oceanography and ETOPO1 global relief model from NOAA [17] and open boundary forcing with the latest global tidal models (TPXO 7.2 OSU Tidal Inversion Software, and later on from the FES 2004 Global Tidal Atlas and the newly released FES2012 model) [18].

AutoSurge incorporated V. 2 of SLOSH + Tides in the forecast system workflow for the 2013 hurricane season. AutoSurge used V. 2.1 of SLOSH + Tides for the ny3 basin, which has a tide-forcing threshold (bathymetric depth of influence) from the deep ocean up to a specified depth. Testing and analysis of various threshold depths for the ny 3 basin determined that the optimum setting was $100 \mathrm{ft}(30.48 \mathrm{~m})$.

Due to the limited amount of time available to complete the numerical forecasts, the model runtime has to be short to be able to construct the storm surge prediction ensembles. The runtime performance for a typical SLOSH model simulation run over the ny3 basin on a typical desktop PC or Linux workstation is shown in Table 3.

Table 3. AutoSurge runtime performance for the SLOSH ny3 basin.

\begin{tabular}{cccc}
\hline SLOSH Basin & SLOSH Surge-Only & SLOSH Tides + Surge & SLOSH Tides + Surge+ Graphics \\
\hline ny3 & $1 \mathrm{~min} 49 \mathrm{~s}$ & $3 \mathrm{~min} 14 \mathrm{~s}$ & $4 \mathrm{~min}$ \\
\hline
\end{tabular}

Figure 4. The National Hurricane Center's (NHC) Public Advisory 26A, valid at 8:00 PM EDT (00:00 UTC) on Sunday, 28 October 2012; one day before Hurricane Sandy made landfall. Note that the inundation depths are given in feet above ground level, with the caveat that these values would be reached only if the peak of astronomical tides coincided with the peak of the storm surge.

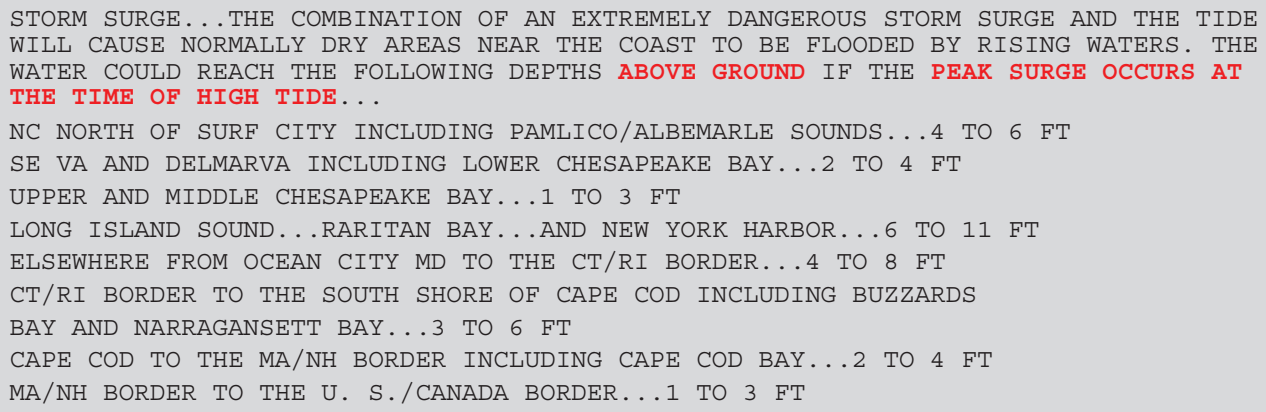

In the past two years, directed by research, testing and recommendations from social scientists [6], NHC's public advisories were modified to include values of inundation above ground level at the peak of high tide so the public would better understand the storm surge threat. An example, Public Advisory 26A, issued for 8:00 PM EDT (00:00 UTC) Sunday 28 October 2012, one day before 
Hurricane Sandy made landfall in New Jersey, is shown in Figure 4. Note that the water levels are referenced "above ground" and are considered valid only if the peak surge occurs at the time of high tide.

\subsection{Surge Forecast Simulations}

SLOSH surge-only simulations (without tides) were run operationally in 2012 for Hurricane Sandy, as described above. Figure 5 shows an example of the model tracks used by NHC's Hurricane Specialists as guidance to determine the OFCL track for Hurricane Sandy 48-hours prior to landfall. It depicts a large spread in the model tracks with various intensities, sizes and storm center locations. This guidance is used to run the ensemble SLOSH simulations. Figure 6 displays the ensemble maximum envelope of water 48 -hours prior to landfall with a maximum total water level of $4.94 \mathrm{~m}(16.2 \mathrm{ft})$ NAVD88. A summary plot of the ensemble results for the simulations, valid $48 \mathrm{~h}$ prior to landfall, is shown in Figure 7.

Figure 5. Example of the model tracks used by the Hurricane Specialists at NHC to develop the OFCL forecast track for Hurricane Sandy. It depicts the large spread in the model tracks with various wind intensities, sizes and track locations. This meteorological guidance is used as forcing to run the SLOSH ensemble storm surge simulations. The label inside the white box at the end of each track indicates the ensemble member number that corresponds to the number in the horizontal axis in Figure 7.

\section{SLOSH Basin ny3} Time of Forecast Advisory 2012102800

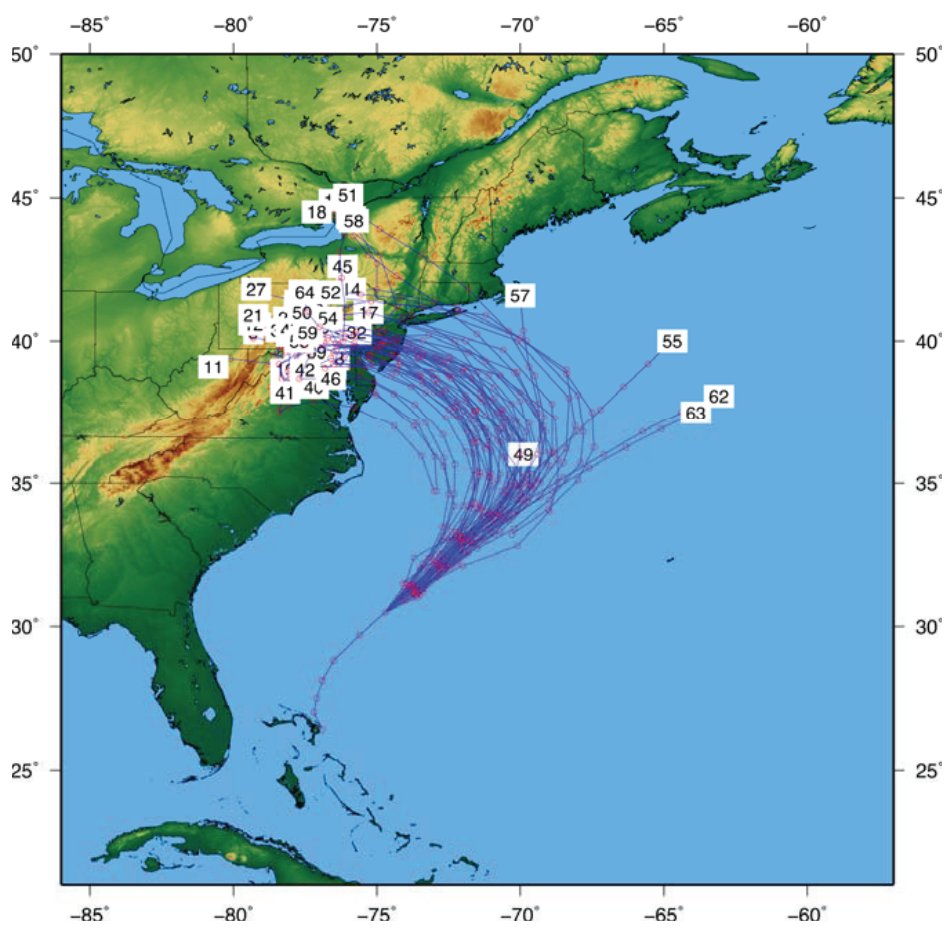


Figure 6. Ensemble maximum envelope of water (m) $48 \mathrm{~h}$ prior to landfall with a maximum total water level of $4.94 \mathrm{~m}(16.2 \mathrm{ft})$ relative to the NAVD88 vertical datum.

\section{Ensemble Maximum Envelope of Water}

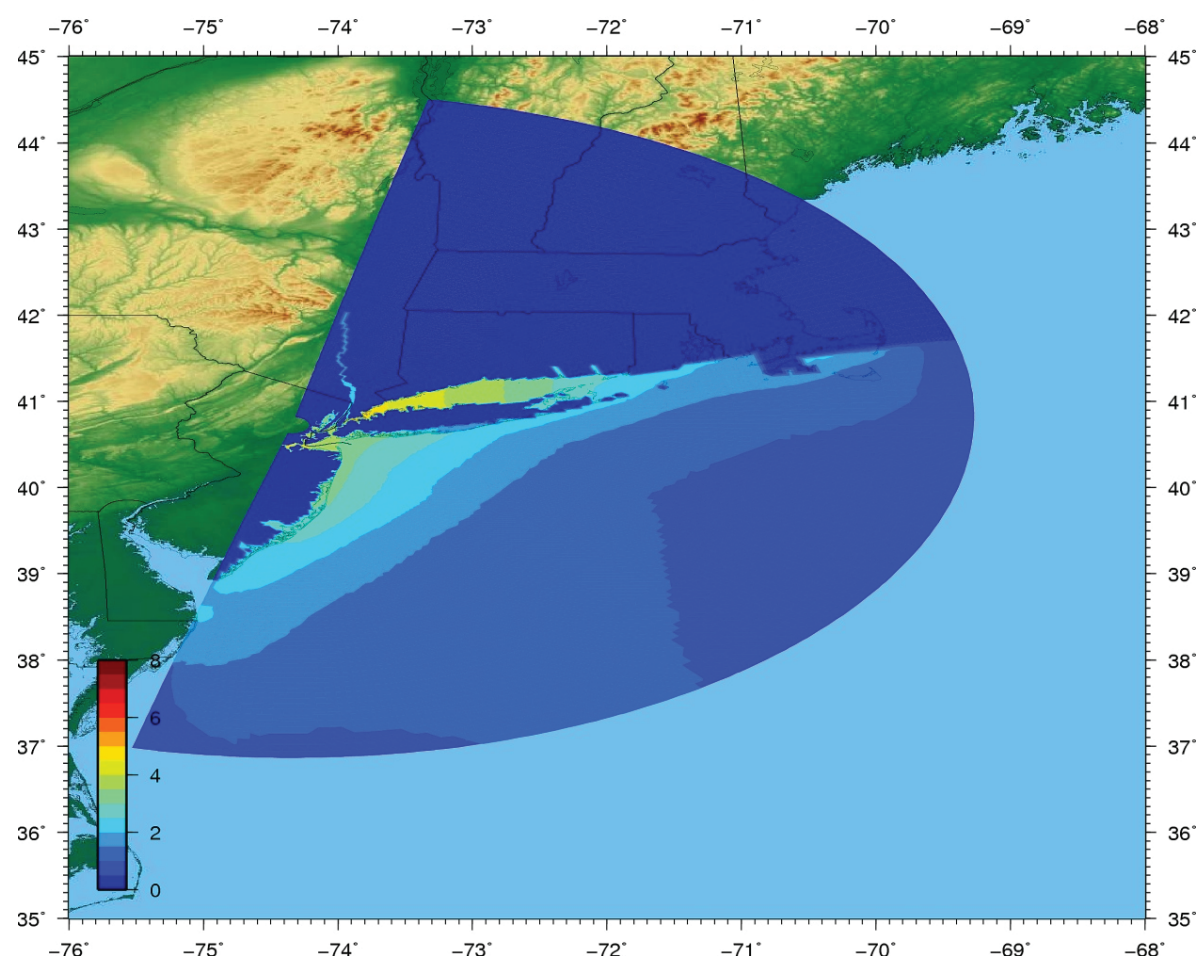

The bottom (blue) panel provides the maximum predicted water levels relative to both NAVD88 (dark blue dots) and AGL (black triangles) for each ensemble member. The solid (dashed) red lines show the maximum water levels in NAVD88 (AGL) and the solid (dashed) purple lines show the average water levels in NAVD88 (AGL) for each ensemble member. The storm surge threat $48 \mathrm{~h}$ prior to the storm was $4.94 \mathrm{~m}(16.2 \mathrm{ft})$ relative to the NAVD88 datum, a maximum inundation of $4.30 \mathrm{~m}(14.1 \mathrm{ft}, \mathrm{AGL})$. The NHC OFCL track (last ensemble member) produced a $3 \mathrm{~m}(10.0 \mathrm{ft})$ surge ( $2.3 \mathrm{~m}$ (7.6 ft) of inundation), about $1 \mathrm{~m}$ higher than the average of all the ensemble members but lower than the ensemble maximum. The middle (yellow) panel shows the maximum wind speeds (red dots) and wind speeds at the closest point of approach (CPA, blue dots) of each model guidance ensemble member.

The maximum wind speed of $51 \mathrm{~ms}^{-1}(100 \mathrm{kt})$ shows in all the models, which occurred when Sandy made landfall in Cuba on October 25. The winds at the closest point of approach (prior to or at landfall) vary from 8 to $37 \mathrm{~ms}^{-1}$ (17 to $72 \mathrm{kts}$ ), which indicates the uncertainty in the wind forcing and, therefore, the variability in the storm surge potential. The top (purple) panel indicates the radius of maximum winds at CPA for each model/aid ensemble, which varies from 8 to $218 \mathrm{~km}$ ( 5 to 136 miles, 4 to $118 \mathrm{~nm}$ ). This also contributes to the unpredictability of the storm surge hazard, even $48 \mathrm{~h}$ prior to actual landfall. 
Figure 7. Summary plot of the ensemble results for the simulations of Hurricane Sandy (2012) valid $48 \mathrm{~h}$ prior to landfall. The bottom (blue) panel shows the maximum water levels relative to both the NAVD88 vertical datum (dark blue dots) and AGL (black triangles) for each ensemble member. The solid (dashed) red lines show the maximum water levels in NAVD88 (AGL) and the solid (dashed) purple lines show the average water levels in NAVD88 (AGL) for each ensemble member. The middle (yellow) panel shows the maximum wind speed (red dots) and wind speed at the closest point of approach (CPA) (blue dots) of each model guidance ensemble member. The top (purple) panel indicates the radius of maximum winds at CPA for each model/aid ensemble member.

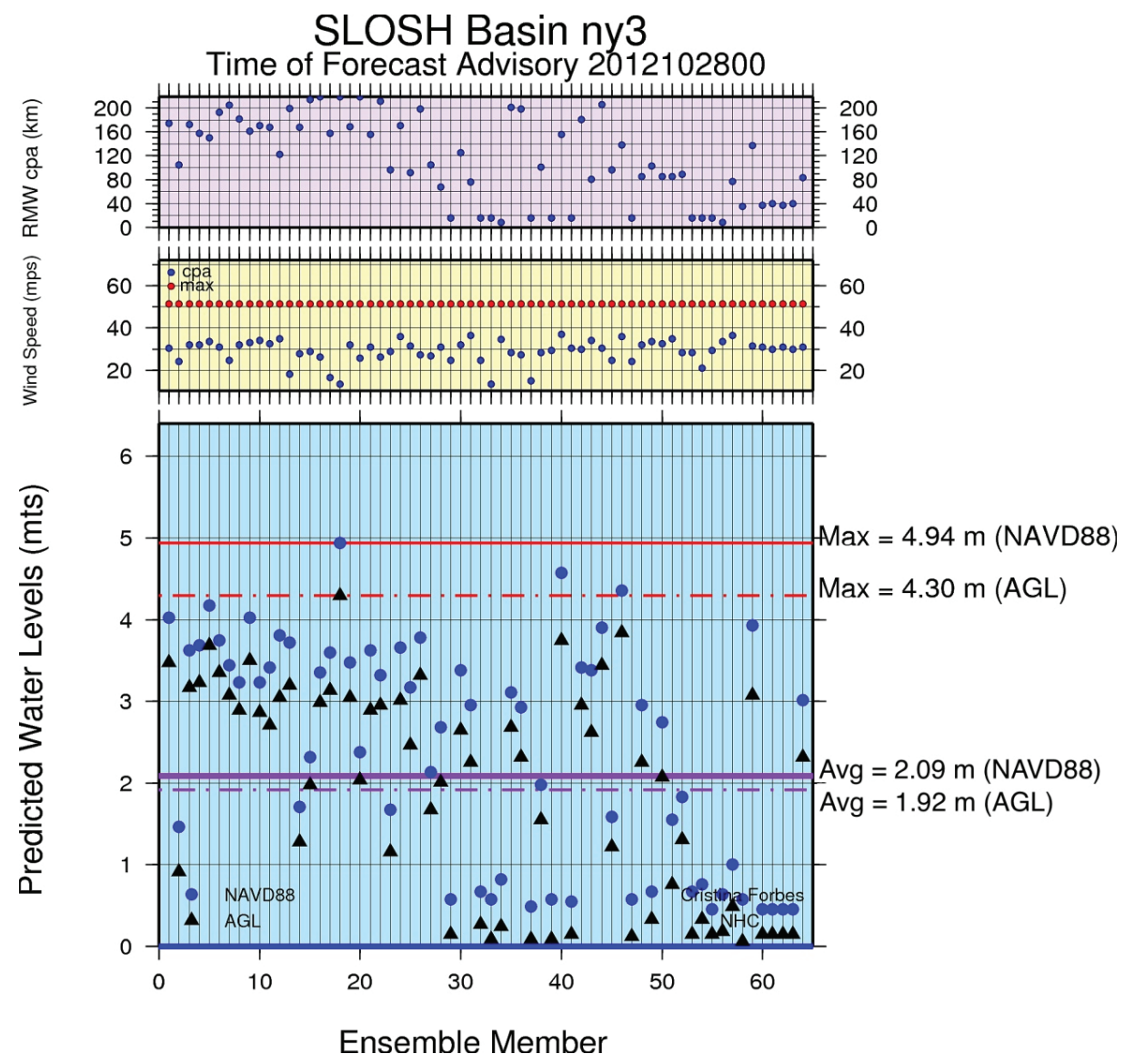

As the storm evolves in time, the AutoSurge forecast system calculates the trend of maximum water elevation above NAVD88 and the water height above ground level for all the ensemble members at each synoptic time, as shown in Figure 8a,b. The yellow box depicts the range of water levels issued by NHC in the forecast advisories. The maximum water elevation levels predicted converge to $3.8 \mathrm{~m}(12.4 \mathrm{ft})$ relative to the NAVD88 vertical datum or $2.9 \mathrm{~m}(9.5 \mathrm{ft})$ of inundation (AGL). 
Figure 8. Trend of (a) maximum water elevation in the entire SLOSH basin relative to the NAVD88 vertical datum, and (b) the water height above ground level (AGL) for all ensemble members in the SLOSH storm surge-only simulations. The time in days (horizontal axis) denotes the initial time (UTC) of the model forecasts. The yellow box depicts the range of water levels issued in real-time by NHC in the forecast advisories.

(a)

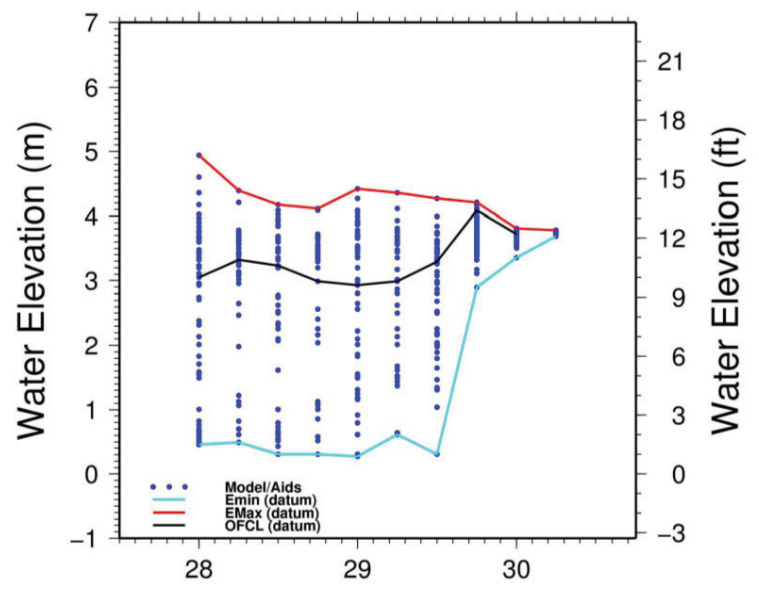

(b)

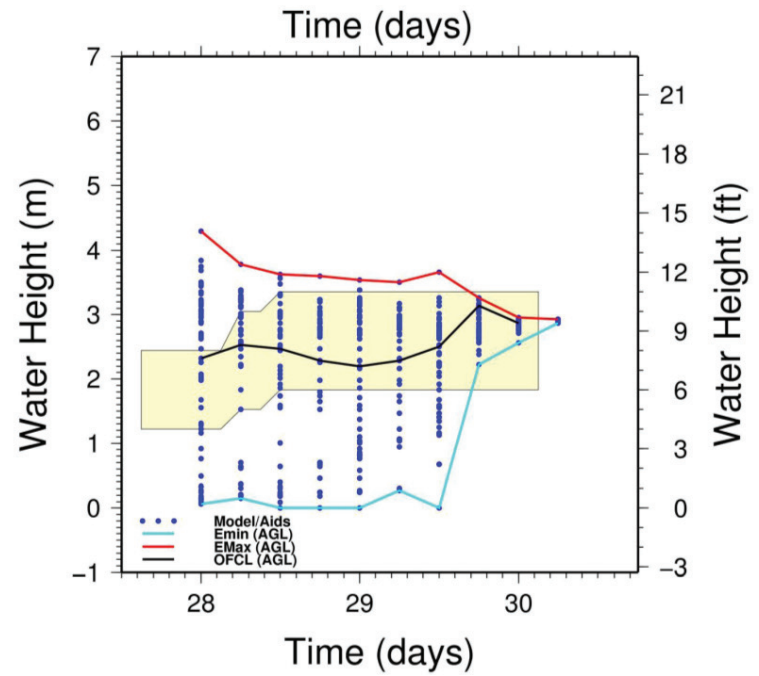

\subsection{Surge-Plus-Tides Forecast Simulations}

If Hurricane Sandy were to be forecast today with the enhancements described earlier, then the SLOSH model simulations would have tides included in the hydrodynamic equations and would depict the total water levels. A comparison of surge vs. surge-plus-tides simulation results, in the form of an ensemble summary plot, is shown in Figure 9a,b, respectively.

Depending on the timing of the tides, the water levels of each ensemble member vary accordingly, in some cases higher and other cases lower than the counterpart without tides. In the case of the surge-plus-tides simulations, the water levels AGL are lower since the cells (areas) that 
would be wetted by the tides alone at any time during the model simulation are not considered inundated in the results. The maximum water level simulated $48 \mathrm{~h}$ prior to landfall is $3.6 \mathrm{~m}(11.7 \mathrm{ft})$ AGL for surge-plus-tides, while it is $4.3 \mathrm{~m}$ (14.1 ft) for surge-only. The maximum water levels in NAVD88 are higher for the surge-plus-tides simulations, with a maximum of $5.46 \mathrm{~m}(17.9 \mathrm{ft})$ as opposed to $4.9 \mathrm{~m}(16.1 \mathrm{ft})$ for the surge-only simulations.

Figure 9. Summary plot of the ensemble results for the simulations of Hurricane Sandy (2012) valid $48 \mathrm{~h}$ prior to landfall: (a) for surge and (b) for surge + tides. Ensemble maximum envelope of water for (c) surge and (d) surge + tides $48 \mathrm{~h}$ prior to landfall with maximum total water levels of $4.94 \mathrm{~m}$ and $5.46 \mathrm{~m}$, respectively (relative to the NAVD88 vertical datum).
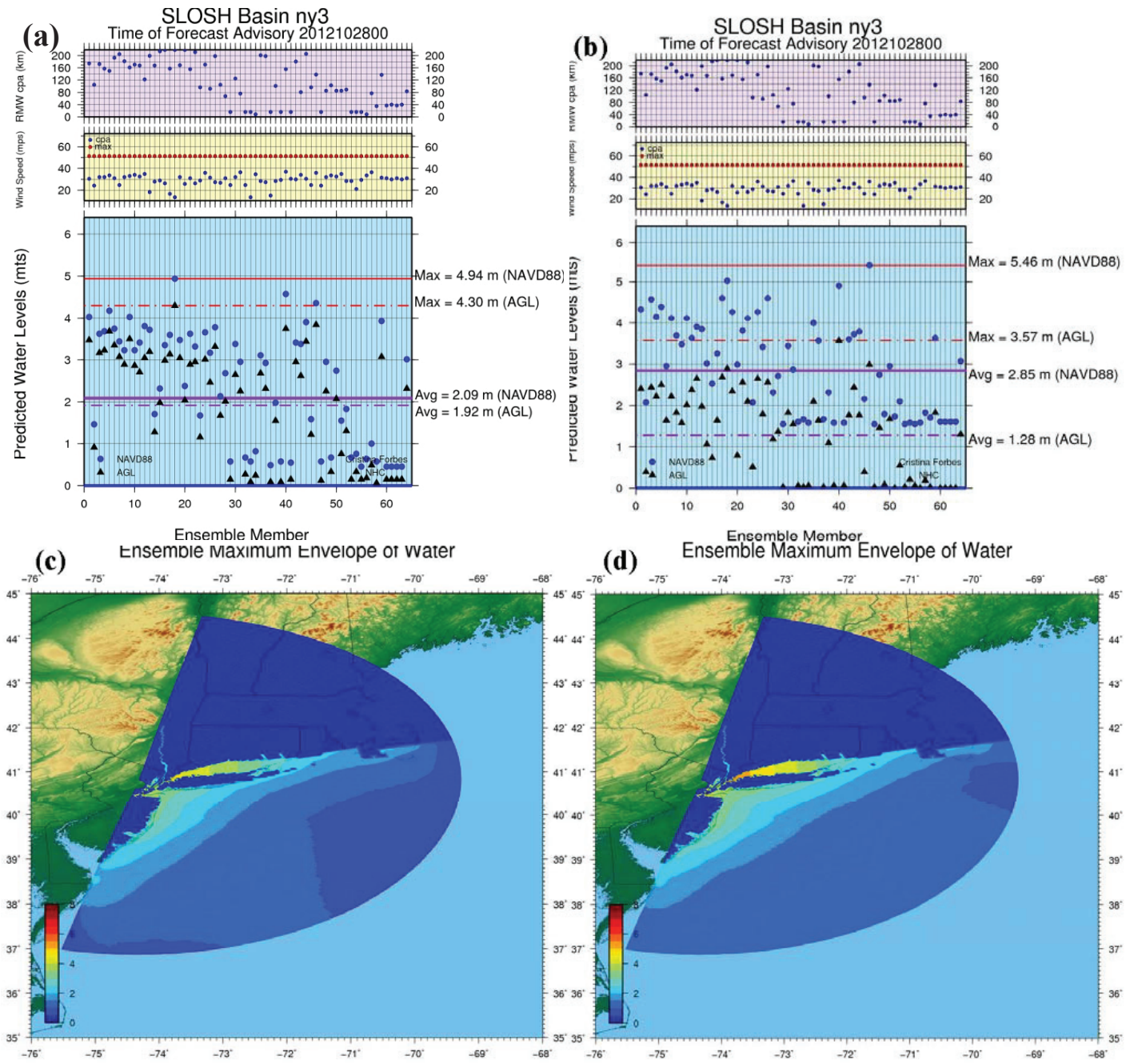

(d) Ensemble Maximum Envelope of Water

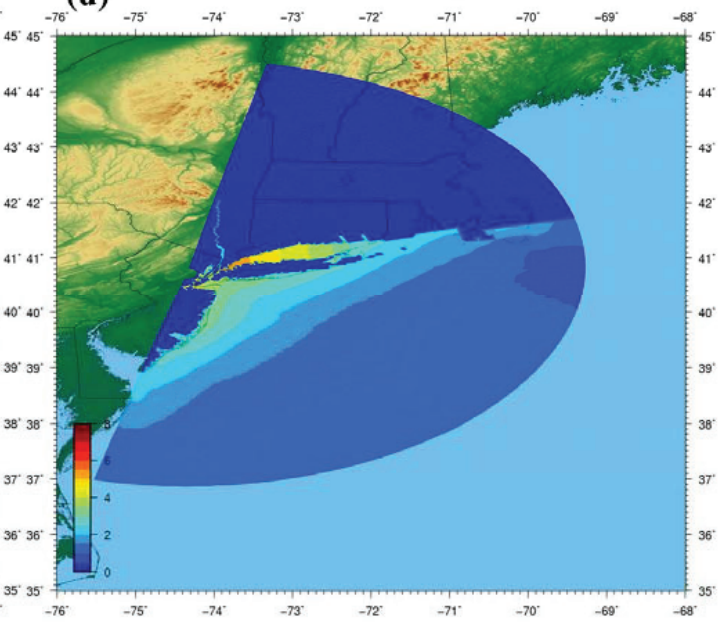

The ensemble maximum envelope relative to the NAVD88 vertical datum for both predicted surge-only and surge-plus-tides at 00 UTC on 28 October 2012 are shown in Figure 9c,d. Clearly, 
higher values are predicted by the surge-plus-tides ensemble than the surge-only ensemble, as highlighted by the east-west gradient across the Long Island Sound.

The forecast trends of the surge-plus-tides simulations are shown in Figure 10. The water level values converge to $3.9 \mathrm{~m}(12.9 \mathrm{ft})$ relative to NAVD88, or $2.6 \mathrm{~m}(8.5 \mathrm{ft})$ AGL. The light yellow polygon delineates the range of water levels issued in real-time by NHC in its forecast advisories, which encompasses the maximum inundation actually recorded during this storm event of $2.71 \mathrm{~m}$ $(8.9 \mathrm{ft})$ AGL.

Figure 10. Trend of (a) maximum water elevation relative to the NAVD88 vertical datum and (b) the water height above ground level (AGL), for all the ensemble members for the surge + tides simulations. The light yellow polygon delineates the range of water levels issued in real-time by NHC in its forecast advisories, which encompasses the maximum inundation actually recorded during this storm event.

(a)

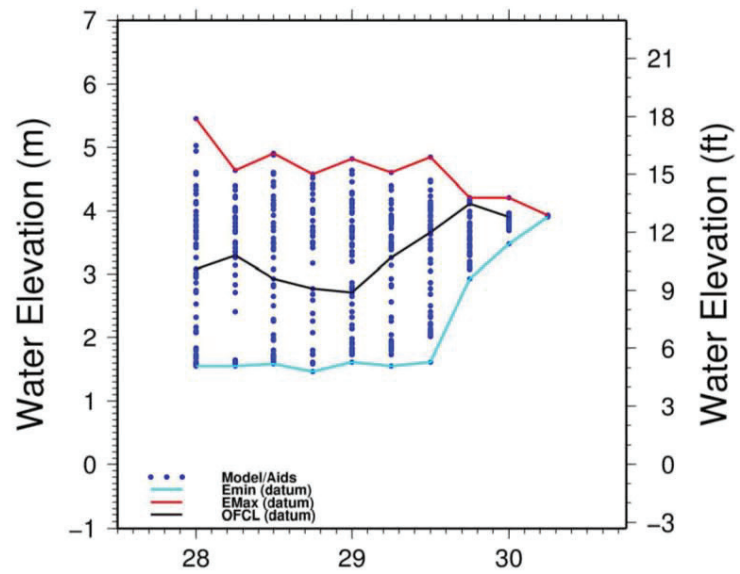

(b)

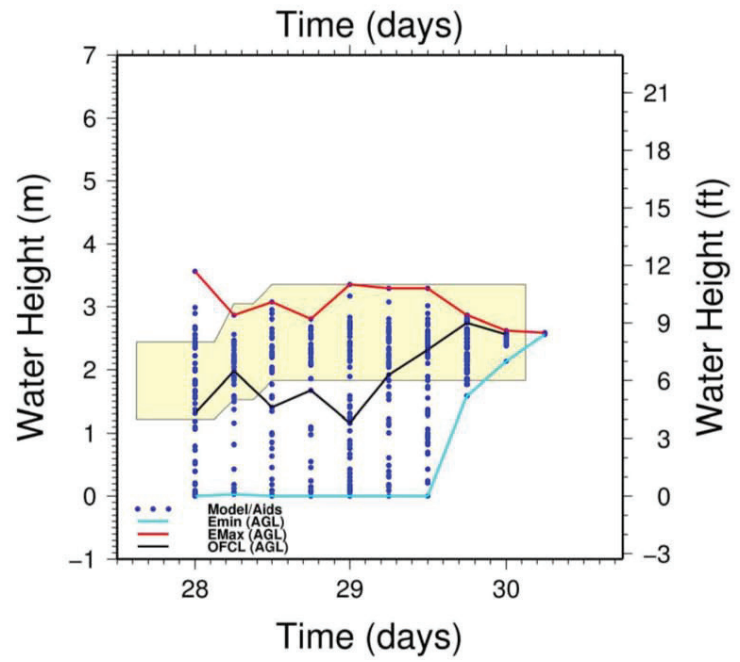




\section{Hindcasts}

Post-storm hindcast surge (S) and surge-plus-tides (ST) simulations were run for the SLOSH ny3 basin to determine the accuracy of the results. The hindcast simulation that generated surgeonly water levels was forced by wind parameters from the Hurricane Sandy Best Track to drive the SLOSH model.

A second hindcast simulation was run with surge plus tides. First, tides were spun up for $720 \mathrm{~h}$. After this 30-day spin-up period with tides alone, a 100-hour SLOSH hindcast simulation was run with both tides and Best Track wind forcing.

The results were then compared with the water surface elevations recorded at NOAA tide gauge stations, measurements from temporary USGS storm surge sensors (SSS) and high water mark (HWM) estimates made by the USGS.

\subsection{NOAA Stations vs. SLOSH Water Levels}

The tide and total water levels were extracted from 13 NOAA stations (Figure 2) located in New York (NY), New Jersey (NJ), Rhode Island (RI), Connecticut (CT), and Massachusetts (MA) within the ny3 basin area and compared to the SLOSH water levels from the surge-only and surgeplus-tide hindcast simulations.

The time evolution of the observed $v s$. modeled water levels is shown in Figure 11 for the surgeonly (left panels) and surge-plus-tides (right panels) runs.

Figure 11. Hydrographs of surge (left panels) and surge + tides (right panels) at NOAA stations (red) vs. SLOSH simulations (blue) with RMS error and correlation calculated between the two time series. Time is in month/day and hours UTC (horizontal axis) and water elevations are in meters (vertical axis). The station numbers in the time series plots correspond to the locations shown in Figure 2.
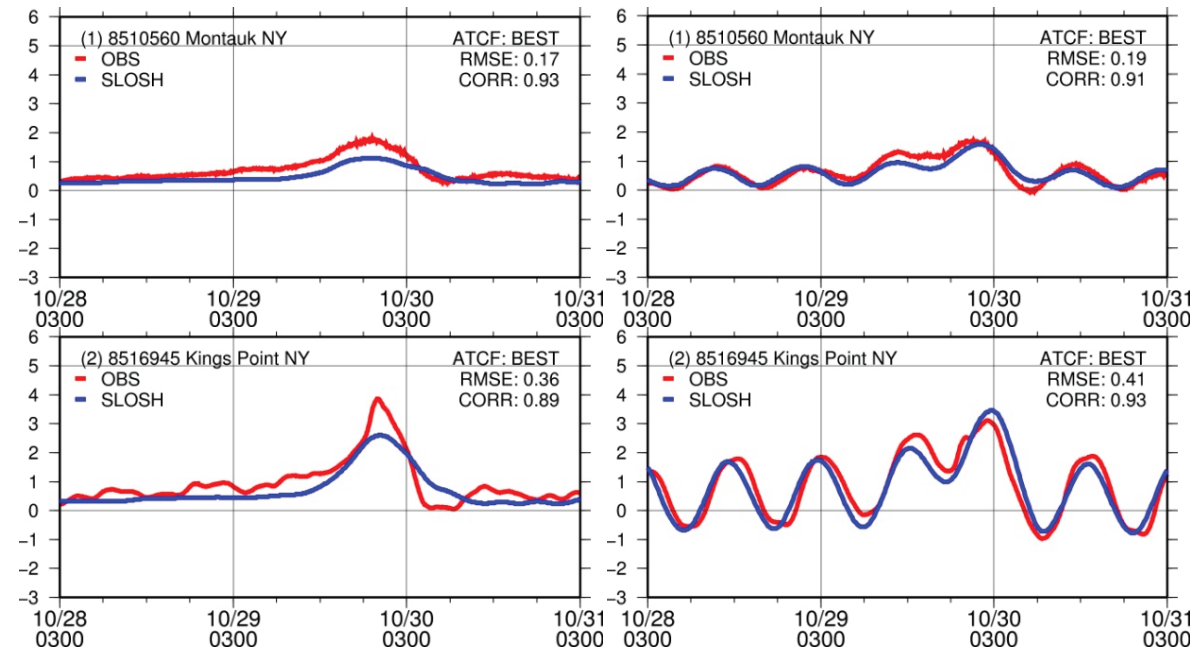
Figure 11. Cont.
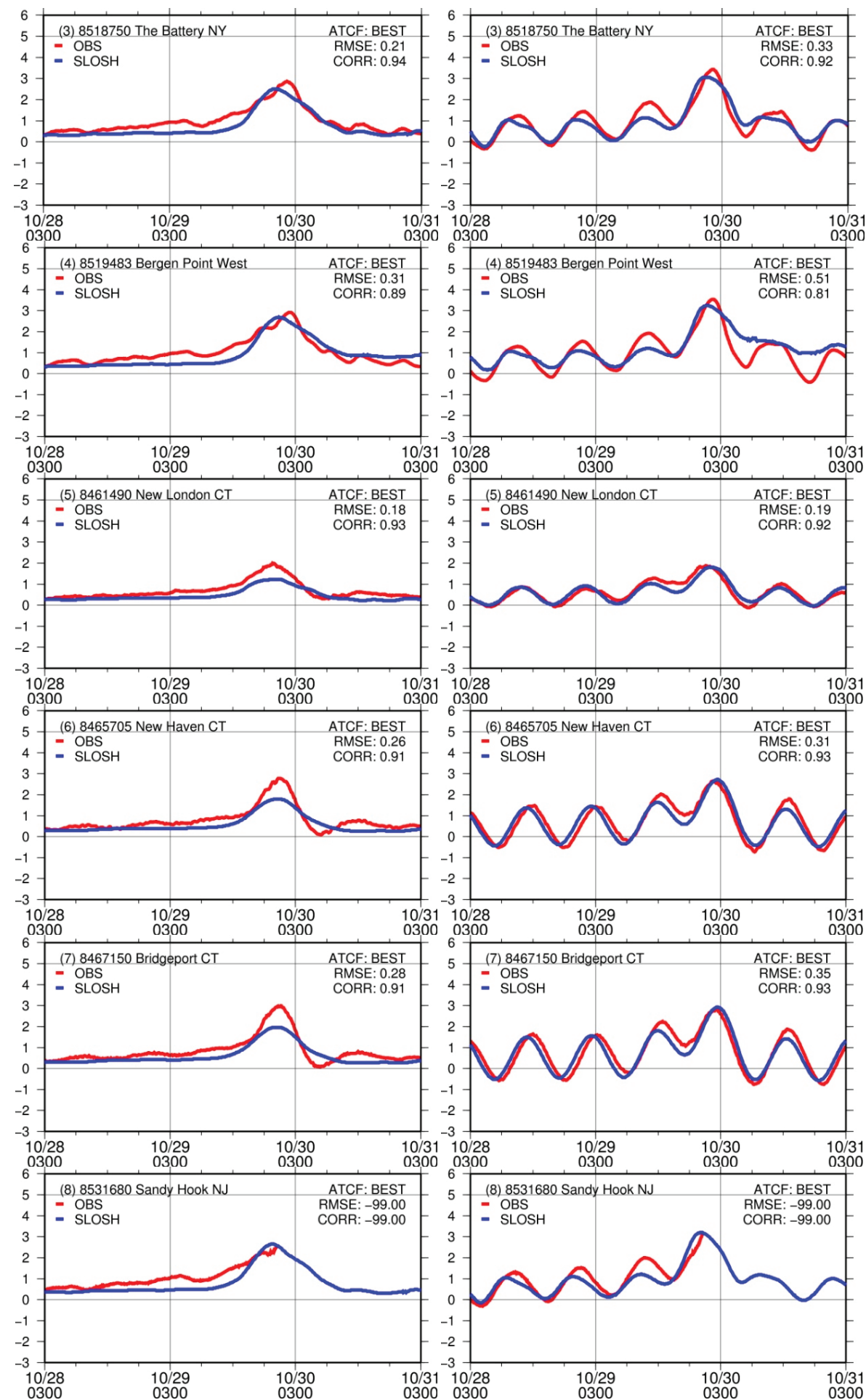
Figure 11. Cont.
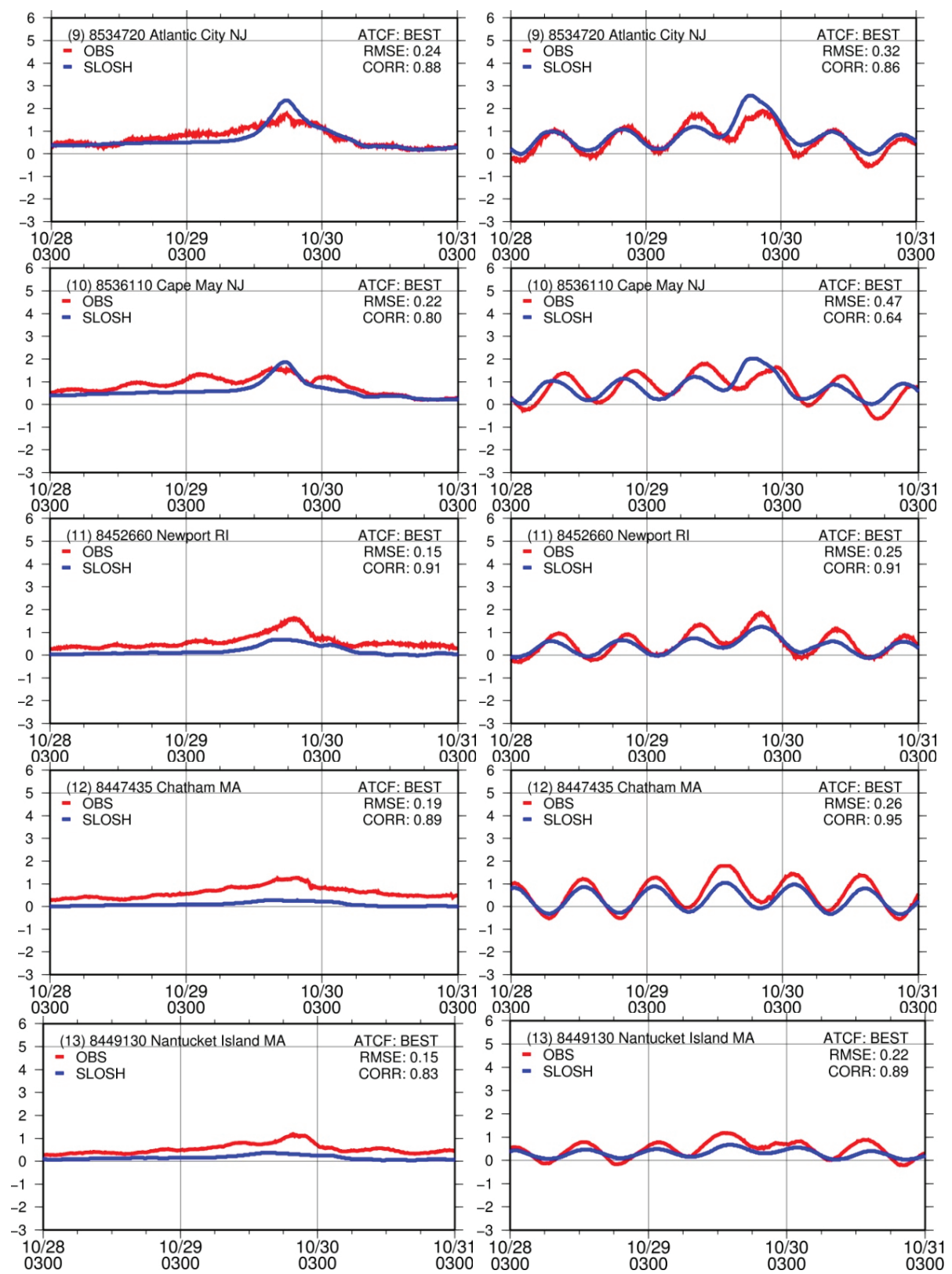

The water levels for surge and total water levels (surge-plus-tides) at the NY stations are in good agreement with the observations, as evidenced by root mean square errors (RMSE) of $0.17-0.36 \mathrm{~m}$ for surge and 0.19-0.51 for total water levels. SLOSH seems to underestimate the surge, but not the total water levels at CT stations. The RMSE ranges from 0.18 to $0.28 \mathrm{~m}(0.19$ to $0.35 \mathrm{~m})$ for surge (surge-plus-tides), respectively, in that state. The modeled surge and total water levels are slightly underestimated at RI and MA stations, with RMSEs of 0.15-0.19 $\mathrm{m}(0.22-0.26 \mathrm{~m})$. The simulated 
water surface elevations at $\mathrm{NJ}$ stations are characterized by RMSEs between 0.22 and $0.24 \mathrm{~m}(0.32$ and $0.47 \mathrm{~m}$ ) for surge (surge-plus-tides), respectively. The Cape May, NJ station is located near a SLOSH boundary, thus the phase is slightly accelerated (the simulated surge arrives too early) relative to the observations. Preliminary experiments, in which the boundary condition in the SLOSH grid was modified from deep to shallow water (since it is so close to the coast) at that model boundary, seem to improve the results for this station. It is anticipated that this adjustment will be included when a new higher-resolution SLOSH New York grid is built. The highest resolution in the current ny 3 basin is $213 \mathrm{~m}$. Considering only those stations away from the basin boundary, the correlations between the model-simulated and measured water surface elevations range from 0.83 to 0.94 for the surge-only, and 0.81 to 0.95 for the surge-plus-tides simulations.

Table 4 shows a summary of the NOAA stations and SLOSH surge (S) and surge-plus-tide (ST) simulation results. The observed peak of S arrived earlier than the observed peak of ST, except at Bergen Point, NY, Cape May, NJ, Chatham, MA and Nantucket, MA. The same timing was replicated in the SLOSH simulations, except at Bergen Point and Cape May where the peaks of S were simulated to arrive earlier than the peaks of ST. The RMS errors range from 0.15 to $0.41 \mathrm{~m}$. The correlations range from 0.80 to 0.95 .

Table 4. Summary of the NOAA stations vs. SLOSH surge (S) and surge-plus-tides (ST) simulation results. Times are in elapsed hours from the start of the model run-03:00 UTC, 27 October 2012. The numbers in column 1 correspond to the locations shown in Figure 2 and the time series plots in Figure 11.

\begin{tabular}{|c|c|c|c|c|c|c|c|c|c|c|c|c|c|c|c|c|}
\hline & \multirow[t]{2}{*}{ Stn ID } & \multirow[t]{2}{*}{ Station Name } & \multirow[t]{2}{*}{$\begin{array}{l}\text { Long } \\
\text { (deg) } \\
\end{array}$} & \multirow[t]{2}{*}{ Lat (deg) } & \multicolumn{2}{|c|}{$\begin{array}{c}\text { Obs Peak } \\
\text { Time (h) } \\
\end{array}$} & \multicolumn{2}{|c|}{$\begin{array}{c}\text { Model Peak } \\
\text { Time (h) } \\
\end{array}$} & \multicolumn{2}{|c|}{$\begin{array}{l}\text { Obs Max } \\
\text { Elev (m) } \\
\end{array}$} & \multicolumn{2}{|c|}{$\begin{array}{c}\text { Model Max } \\
\text { Elev (m) } \\
\end{array}$} & \multicolumn{2}{|c|}{$\begin{array}{c}\text { RMS Error } \\
\text { (m) }\end{array}$} & \multicolumn{2}{|c|}{ CORR } \\
\hline & & & & & $\mathrm{S}$ & ST & $\mathrm{S}$ & $\mathrm{ST}$ & $\mathrm{S}$ & $\mathrm{ST}$ & $\mathrm{S}$ & ST & $\mathrm{S}$ & $\mathrm{ST}$ & $\mathrm{S}$ & $\mathrm{ST}$ \\
\hline 1 & 8510560 & Montauk, NY & -71.9600 & 41.0483 & 67.2 & 69.2 & 65.83 & 69.50 & 1.79 & 1.69 & 1.11 & 1.57 & 0.17 & 0.19 & 0.93 & 0.91 \\
\hline 2 & 8516945 & Kings Pt., NY & -73.7633 & 40.8100 & 68.1 & 71.1 & 68.16 & 71.50 & 3.85 & 3.11 & 2.61 & 3.47 & 0.36 & 0.41 & 0.89 & 0.93 \\
\hline 3 & 8518750 & The Battery, NY & -74.0133 & 40.7000 & 70.4 & 70.4 & 67.66 & 68.33 & 2.86 & 3.44 & 2.50 & 3.05 & 0.21 & 0.33 & 0.94 & 0.92 \\
\hline 4 & 8519483 & Bergen Pt., NY & -74.1417 & 40.6367 & 71.0 & 70.4 & 68.83 & 69.16 & 2.91 & 3.54 & 2.69 & 3.24 & 0.31 & 0.51 & 0.89 & 0.81 \\
\hline 5 & 8461490 & New London CT & -72.0900 & 41.3600 & 67.9 & 69.2 & 66.99 & 69.66 & 1.98 & 1.88 & 1.23 & 1.80 & 0.18 & 0.19 & 0.93 & 0.92 \\
\hline 6 & 8465705 & New Haven, CT & -72.9083 & 41.2833 & 69.1 & 70.5 & 67.83 & 71.33 & 2.78 & 2.65 & 1.78 & 2.73 & 0.26 & 0.31 & 0.91 & 0.93 \\
\hline 7 & 8467150 & Bridgeport, CT & -73.1817 & 41.1733 & 69.3 & 71.1 & 67.49 & 71.16 & 3.00 & 2.83 & 1.95 & 2.92 & 0.28 & 0.35 & 0.91 & 0.93 \\
\hline 8 & 8531680 & Sandy Hook, NJ & -74.0083 & 40.4667 & 68.6 & 68.6 & 67.33 & 67.99 & 2.61 & 3.18 & 2.65 & 3.20 & NA & NA & NA & NA \\
\hline 9 & 8534720 & Atlantic City, NJ & -74.4183 & 39.3550 & 65.7 & 69.4 & 65.33 & 66.16 & 1.77 & 1.91 & 2.35 & 2.57 & 0.24 & 0.32 & 0.88 & 0.86 \\
\hline 10 & 8536110 & Cape May, NJ & -74.9600 & 38.9683 & 63 & 58.7 & 65.16 & 66.16 & 1.57 & 1.80 & 1.86 & 2.02 & 0.22 & 0.47 & 0.80 & 0.64 \\
\hline 11 & 8452660 & Newport, RI & -71.3267 & 41.5050 & 67.3 & 68 & 63.16 & 67.99 & 1.62 & 1.87 & 0.67 & 1.25 & 0.15 & 0.25 & 0.91 & 0.91 \\
\hline 12 & 8447435 & Chatham, MA & -69.9500 & 41.6883 & 67.7 & 61 & 61.83 & 61.33 & 1.27 & 1.79 & 0.27 & 1.04 & 0.19 & 0.26 & 0.89 & 0.95 \\
\hline 13 & 8449130 & Nantucket I. MA & -70.0967 & 41.2850 & 67.7 & 61.1 & 62.16 & 61.66 & 1.19 & 1.18 & 0.37 & 0.67 & 0.15 & 0.22 & 0.83 & 0.89 \\
\hline
\end{tabular}

Panels in Figure 12 display the maximum water levels for (a) surge and (b) surge-plus-tides and the time-of-arrival of the peaks for (c) surge and (d) surge-plus-tides, measured at NOAA stations vs. those simulated by SLOSH. Figure 12a,b shows the stations that fall within the $10 \%$ height error (dark orange) cone, 20\% error (orange) cone and 30\% error (yellow) cone. In Figure 12a the simulated surge at station locations in NJ and at two station locations in NY show errors between 
$10 \%$ (dark orange) and 20\% (orange cone), while at station locations far from the point of landfall the modeled maximum surge is underestimated, The simulated surge-plus-tides water surface elevation errors at most station locations in Figure $12 \mathrm{~b}$ are within the $10 \%-20 \%$ range. In Figure $12 \mathrm{c}, \mathrm{d}$ the stations that fall in the $\pm 3 \mathrm{~h}$ error range for the time-of-arrival of the peak are within the orange band and the $\pm 6 \mathrm{~h}$ error range are within the yellow band.

Figure 12. NOAA stations vs. SLOSH maximum water levels for (a) surge and (b) surge-plus-tides and the time-of-arrival of the peak water levels for (c) surge and (d) surge-plus-tides. In (a) and (b), the dark orange cone depicts 10\% error, the orange cone depicts $20 \%$ error and the yellow cone depicts $30 \%$ error. In panel (a) the simulated surge at $3 \mathrm{NJ}$ and at $2 \mathrm{NY}$ station locations show errors between $10 \%$ and $20 \%$, while at station locations far from the point of landfall the modeled maximum surge is underestimated. In panel (b) the simulated surge-plus-tides water surface elevation errors at most station locations are within the $10 \%-20 \%$ range. In panels (c) and (d) the stations that fall in the $\pm 3 \mathrm{~h}$ error range for the time-of-arrival of the peak are within the orange band and the $\pm 6 \mathrm{~h}$ error range are within the yellow band. The simulated peak arrival times at most sensor locations are within $3 \mathrm{~h}$ of that which was observed, except at stations in RI and MA far from the landfall location in panel (c), and at Cape May (8536110) in panel (d) which is close to the boundary of the model grid.
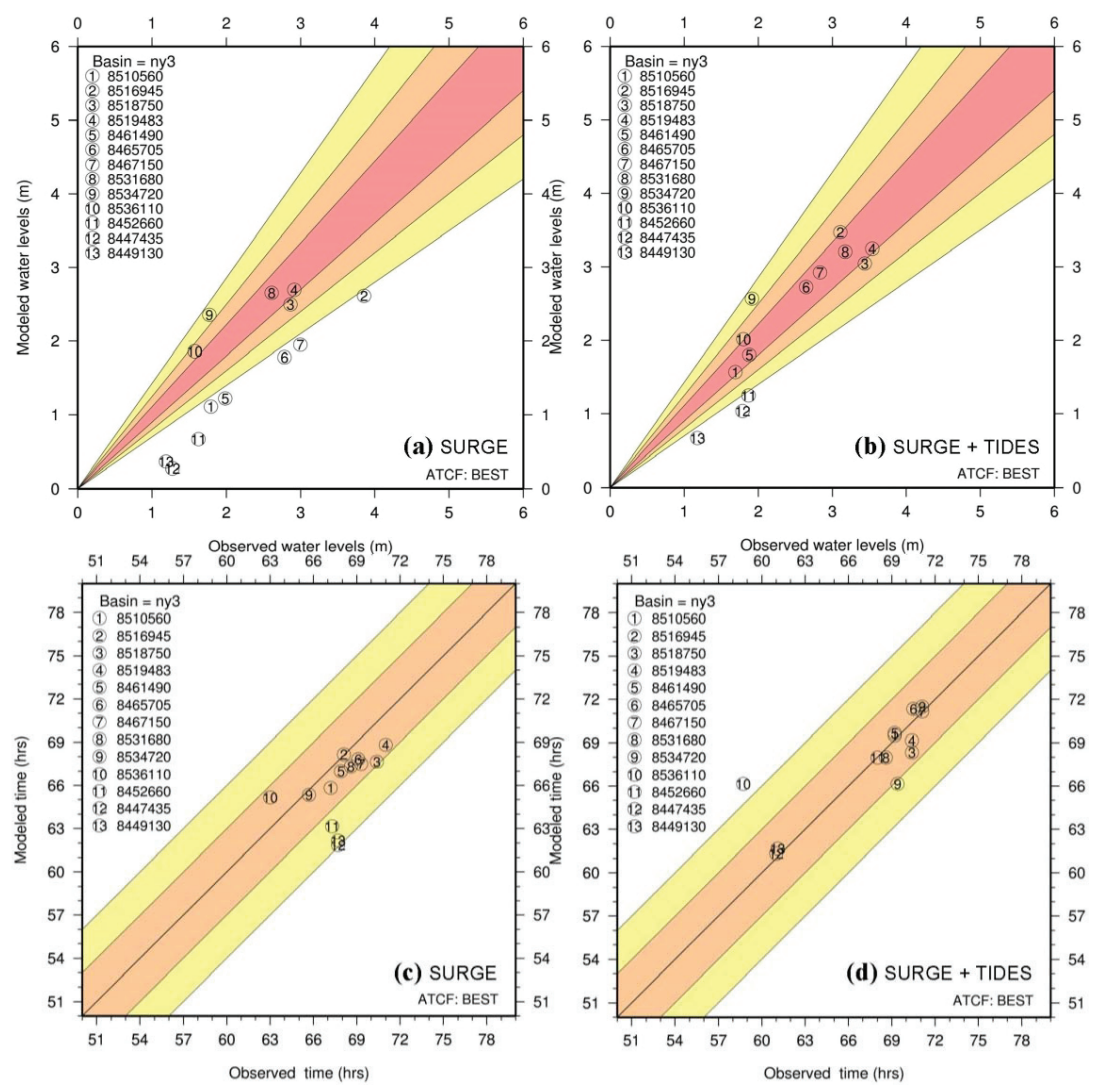
The simulated peak arrival times at most sensor locations are within $3 \mathrm{~h}$ of that which was observed, except at stations in RI and MA far from the landfall location in panel (c), and at Cape May (station 8536110) in panel (d) because, as mentioned above, the station is located too close to the model boundary.

\subsection{USGS Storm Surge Sensors vs. SLOSH Water Levels}

The USGS deployed a temporary network of water level and barometric pressure sensors at 224 locations along the Atlantic coast from Virginia (VA) to Maine (MN). This was the second-largest deployment of storm-tide sensors, exceeded only by the number distributed during Hurricane Irene (2011), which made landfall in the same area of the US [3]. 145 water level and 9 wave-height sensors were deployed at 147 locations while 8 rapid deployment gauges (RDGs), and 62 barometric pressure sensors were deployed at additional locations. The water level sensors recorded water levels at 30-second intervals, the wave sensors recorded data every 2 s, the RDG sensors recorded water levels and meteorological data every $15 \mathrm{~min}$ and the barometric pressure sensors recorded at 30-second intervals. The water levels were recorded in feet above NAVD88. Unfortunately, 7 water level sensors were lost or the structures to which they were attached were damaged, 4 water level sensors and 1 wave sensor did not record (the water did not rise high enough to be measured) and 2 RDGs were destroyed by flood. This temporary monitoring network augmented the existing tide gauge networks and helped characterize the height, extent and timing of the storm tides.

Table 5 shows the USGS storm surge sensors (SSS) deployed in each state that were used to compare water level measurements against results from the SLOSH surge-plus-tides simulation.

Table 5. The numbers of USGS storm surge sensors (SSS) deployed in each state, eliminated from the analysis, and used to verify the SLOSH model surge-plus-tides simulation results (* denotes that the sensor was both outside the SLOSH basin and measured waves, not surge or tides).

\begin{tabular}{|c|c|c|c|c|c|}
\hline U.S. State & Number Deployed & $\begin{array}{c}\text { Outside } \\
\text { SLOSH Basin }\end{array}$ & $\begin{array}{l}\text { Wave } \\
\text { Height }\end{array}$ & $\begin{array}{c}\text { Sub-Grid Features } \\
\text { Not in Model }\end{array}$ & $\begin{array}{c}\text { Number Used } \\
\text { in Analysis }\end{array}$ \\
\hline $\mathrm{CT}$ & 27 & 4 & & 1 & 22 \\
\hline $\mathrm{DE}$ & 13 & 12 & $1 *$ & & \\
\hline $\mathrm{ME}$ & 3 & 3 & & & \\
\hline MD & 4 & 4 & & & \\
\hline MA & 22 & 19 & & 3 & \\
\hline $\mathrm{NH}$ & 2 & 2 & & & \\
\hline NJ & 14 & 4 & 4 & 2 & 4 \\
\hline NY & 43 & 5 & 4 & 5 & 29 \\
\hline $\mathrm{PA}$ & 6 & 6 & & & \\
\hline RI & 10 & 4 & & 1 & 5 \\
\hline VA & 10 & 10 & & & \\
\hline Total & 154 (+8 RDG) & 73 & 9 & 12 & 60 \\
\hline
\end{tabular}


Of the 154 sensors, only 81 were located in the ny3 basin. 9 sensors that recorded highfrequency wave heights could not be used for verification purposes because the coupled surge (SLOSH) plus wave (SWAN, Simulating WAves Nearshore) modeling system is still undergoing development and testing. 12 sensors were close to the SLOSH basin boundary or were sited in locations that were contaminated by local effects (some sensors were buried under the sand attached to an underground piling, others were surrounded by high marsh grass/weeds, some sensors were mounted on structures that block flow in most directions, other sensors were located in narrow alleys between buildings where extreme, unrepresentative channeling can occur, etc.). These sub-grid scale features and geomorphologies are not modeled or resolved by the SLOSH grid, so those sensors were not employed in the verification process. Therefore, 60 SSS sensors (Figure 13a) were compared with the model results (Figure 13b).

Figure 13. (a) Map of USGS Storm Surge Sensor (SSS) locations; (b) Hydrographs of inundation recorded by USGS SSS (red) vs. SLOSH-simulated surge-plus-tides water levels above ground level (AGL) (blue) with RMS error and correlation calculated between the two types of time series. Time is in month/day and hours UTC (horizontal axis) and water elevations are in meters (vertical axis). The sensor numbers in the time series plots in (b) correspond to the locations shown in panel (a).

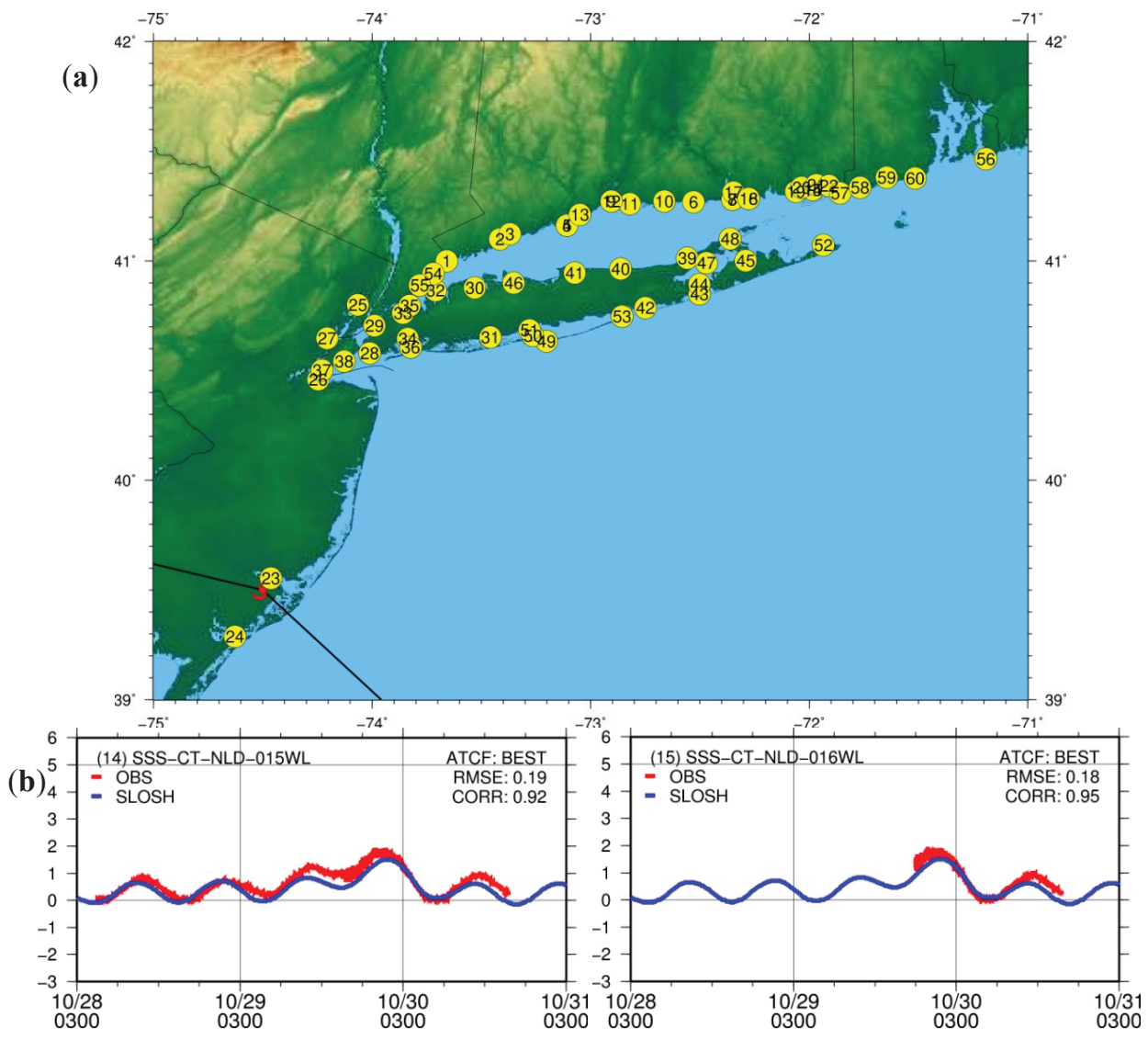


Figure 13. Cont.

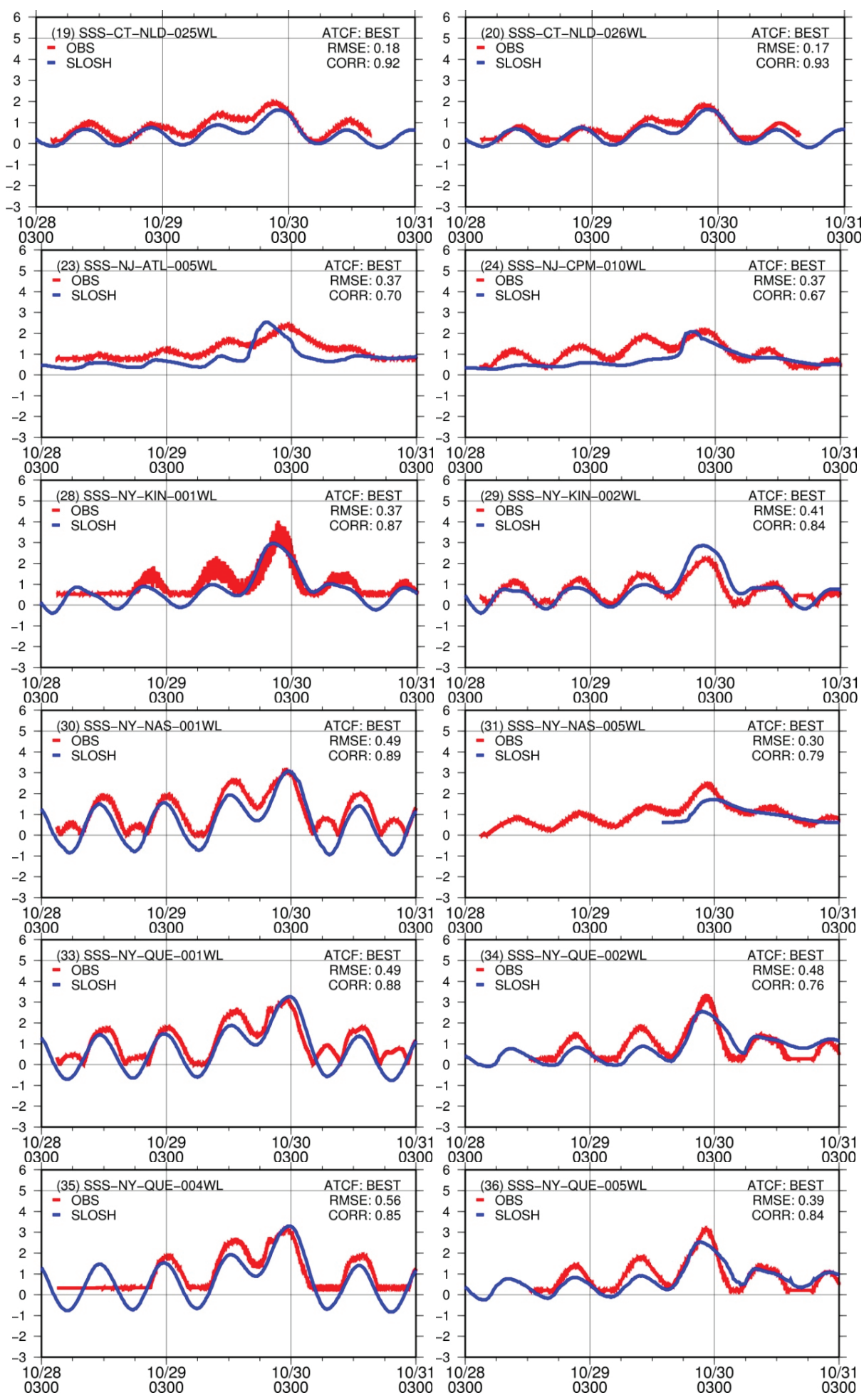


Figure 13. Cont.
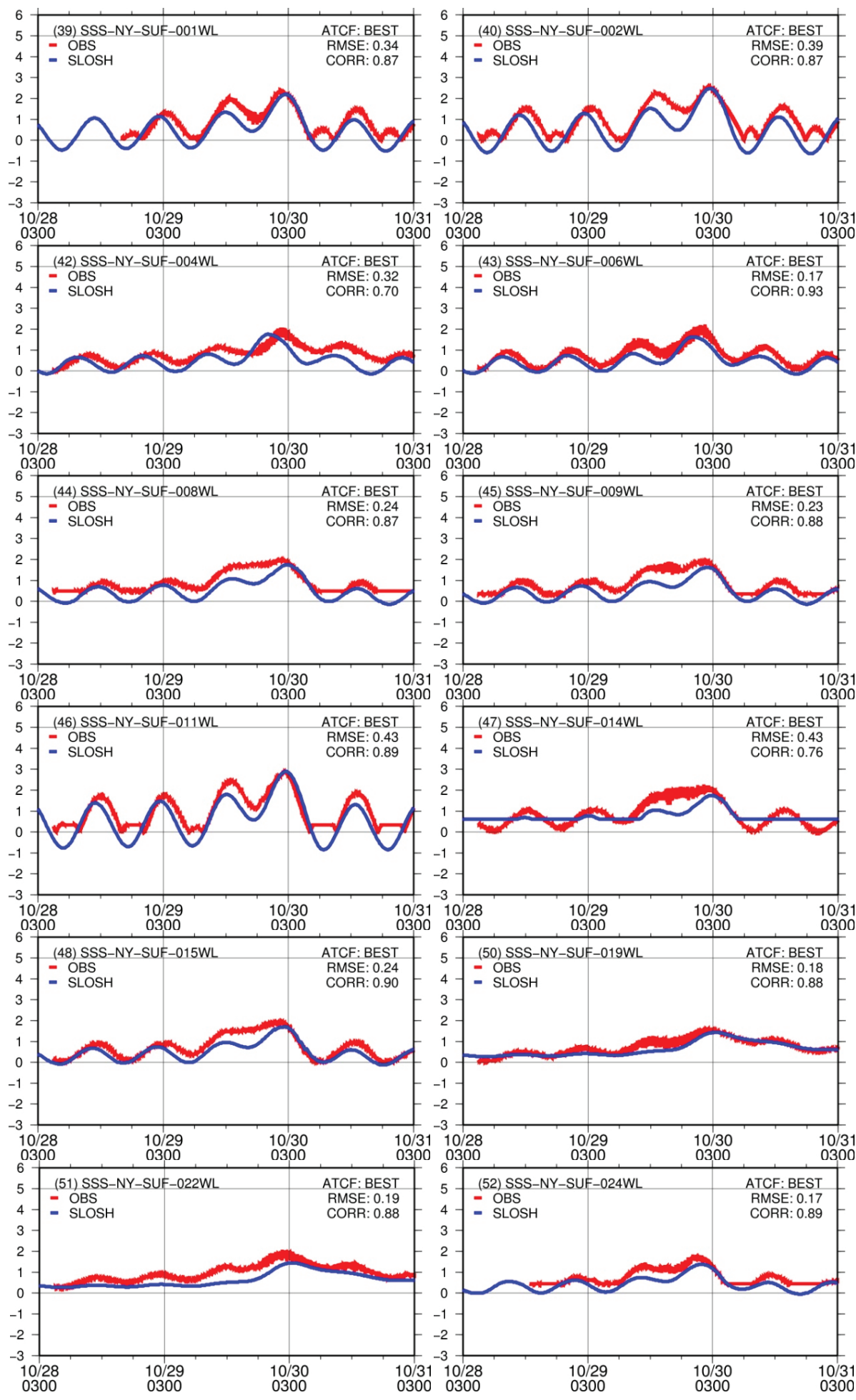
Figure 13. Cont.
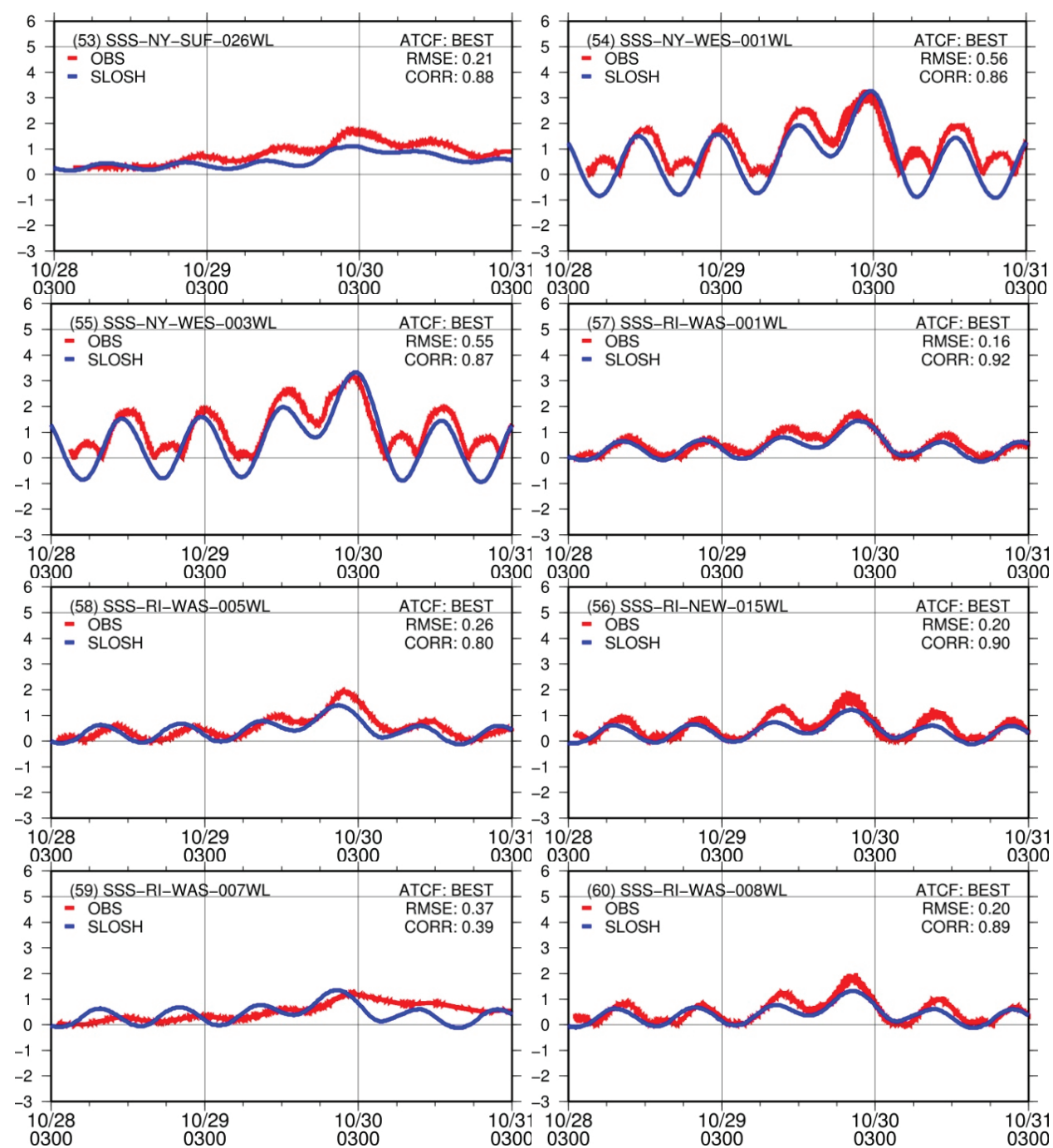

A comparison between the SSS sensor measurements and SLOSH-simulated water levels AGL, displayed in Figure 13b, show the extent and degree of inundation and how well the model values agree with the observed water levels. The hydrographs at the SSS stations show excellent agreement in both amplitude and phase with the SLOSH model-simulated surge-plus-tides results.

Figure 14a shows the SSS sensor measurements that fall within the $10 \%$ error (dark orange) cone, $20 \%$ error (orange) cone and 30\% error (yellow) cone. The SLOSH-simulated surge-plus-tides values at most station locations are within the 10\%-20\% error range. Figure $14 \mathrm{~b}$ shows the stations that fall in the $\pm 3 \mathrm{~h}$ error range in the arrival time of the peak (orange) and $\pm 6 \mathrm{~h}$ error (yellow). Most of the simulated peak arrival times are accurate within $3 \mathrm{~h}$ of the observed arrival times.

Table 6 compares the USGS storm surge sensor (SSS) vs. SLOSH maximum water surface elevations from the SLOSH surge-plus-tides simulation, the timing of the peak water levels, and 
calculations of the RMS errors and the correlations. Tables 7, 8 and 9 provide summary statistics for the data in Table 6. The RMSE of the SSS vs. SLOSH-simulated water levels show that $80 \%$ of the values simulated at station locations are less than $0.5 \mathrm{~m}(1.6 \mathrm{ft})$ in error and have correlations greater than 0.60. The SLOSH-simulated relative errors are less than 0.30 at $92 \%$ of the SSS sensor locations.

Figure 14. USGS SSS sensor vs. SLOSH-simulated surge-plus-tides (a) maximum water levels (m) and (b) time-of-arrival (hours) of the peak water levels. In (a), the dark orange cone depicts the $10 \%$ error, the orange cone depicts $20 \%$ error and the yellow cone depicts the $30 \%$ error. The water surface elevation errors at most sensors are within the 10\%-20\% range. In (b) the stations that fall in the $\pm 3 \mathrm{~h}$ error range for the timing of the peak are within the orange band and the $\pm 6 \mathrm{~h}$ error range are within the yellow band. Most sensors' observed vs. modeled peak arrival times are within $3 \mathrm{~h}$.

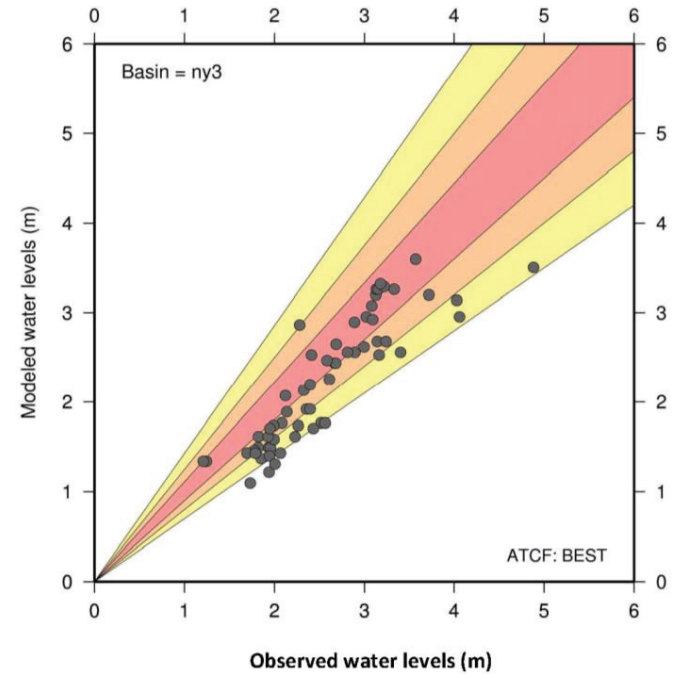

(a)

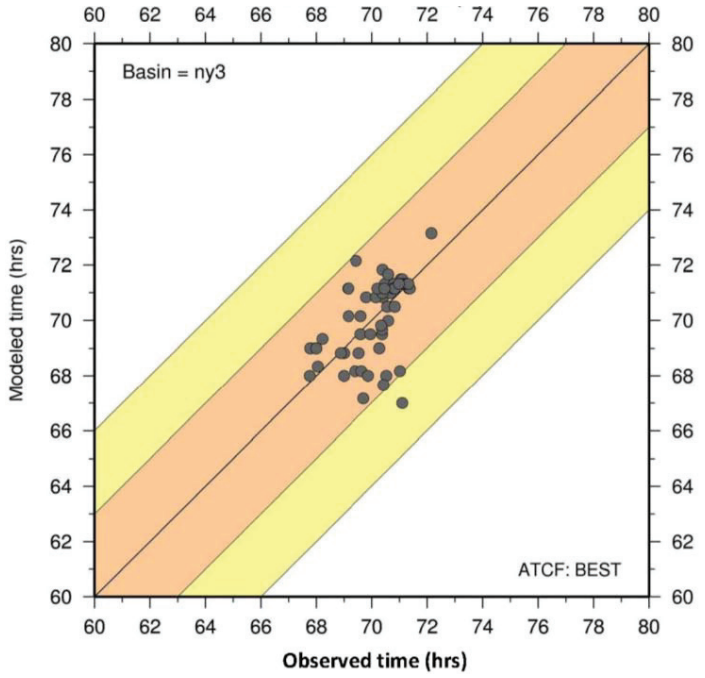

(b)

Table 6. USGS Storm Surge Sensors vs. SLOSH Peak Arrival Times and Water Levels. Times are in elapsed hours from the start of the model run-03:00 UTC, 27 October 2012.

\begin{tabular}{|c|c|c|c|c|c|c|c|c|c|c|}
\hline \multirow[b]{2}{*}{1} & Sensor ID & \multirow{2}{*}{$\begin{array}{c}\begin{array}{c}\text { Lon } \\
(\mathrm{deg})\end{array} \\
-73.6594\end{array}$} & \multirow{2}{*}{$\begin{array}{c}\begin{array}{c}\text { Lat } \\
(\mathrm{deg})\end{array} \\
40.9991\end{array}$} & \multicolumn{4}{|c|}{$\begin{array}{c}\text { Peak Time (h) Peak WL (m) } \\
\text { Obs Model Obs Model }\end{array}$} & \multirow{2}{*}{$\begin{array}{c}\text { RMSE } \\
(\mathrm{m})\end{array}$} & \multirow{2}{*}{$\begin{array}{c}\text { CORR } \\
0.57\end{array}$} & \multirow{2}{*}{$\begin{array}{c}\begin{array}{r}\text { Relative } \\
\text { Error }\end{array} \\
0.02\end{array}$} \\
\hline & SSS-CT-FFD-001WL & & & 70.92 & 71.33 & 3.13 & 3.20 & & & \\
\hline 2 & SSS-CT-FFD-003WL & -73.4157 & 41.0998 & 71.34 & 71.16 & 3.02 & 2.96 & 0.28 & 0.91 & 0.02 \\
\hline 3 & SSS-CT-FFD-006WL & -73.3700 & 41.1231 & 71.38 & 71.16 & 3.09 & 2.93 & 0.41 & 0.91 & 0.05 \\
\hline 4 & SSS-CT-FFD-010WL & -73.1090 & 41.1632 & 69.14 & 71.16 & 3.14 & 2.68 & 0.69 & 0.34 & 0.15 \\
\hline 5 & SSS-CT-FFD-012WL & -73.1090 & 41.1632 & 69.16 & 71.16 & 3.24 & 2.68 & 0.46 & 0.51 & 0.17 \\
\hline 6 & SSS-CT-MSX-018WL & -72.5294 & 41.2692 & 70.44 & 71.16 & 2.33 & 2.13 & 0.28 & 0.90 & 0.08 \\
\hline 7 & SSS-CT-MSX-019WL & -72.3522 & 41.2811 & 69.81 & 70.83 & 2.36 & 1.92 & 0.28 & 0.87 & 0.18 \\
\hline 8 & SSS-CT-MSX-020WL & -72.3522 & 41.2811 & 70.41 & 70.83 & 2.40 & 1.92 & 0.27 & 0.90 & 0.20 \\
\hline
\end{tabular}


Table 6. Cont.

\begin{tabular}{|c|c|c|c|c|c|c|c|c|c|c|}
\hline 9 & SSS-CT-NHV-013WL & -72.9048 & 41.2722 & 70.48 & 71.33 & 2.90 & 2.56 & 0.36 & 0.90 & 0.12 \\
\hline 10 & SSS-CT-NHV-015WL & -72.6636 & 41.2718 & 70.16 & 70.83 & 2.61 & 2.26 & 0.26 & 0.93 & 0.14 \\
\hline 11 & SSS-CT-NHV-018WL & -72.8206 & 41.2604 & 70.49 & 71.16 & 2.67 & 2.44 & 0.24 & 0.73 & 0.09 \\
\hline 12 & SSS-CT-NHV-019WL & -72.9048 & 41.2722 & 70.48 & 71.33 & 2.81 & 2.56 & 0.35 & 0.90 & 0.09 \\
\hline 13 & SSS-CT-NHV-020WL & -73.0495 & 41.2113 & 70.68 & 71.00 & 3.00 & 2.62 & 0.45 & 0.85 & 0.13 \\
\hline 14 & SSS-CT-NLD-015WL & -71.9846 & 41.3252 & 67.97 & 69.00 & 1.94 & 1.49 & 0.19 & 0.92 & 0.23 \\
\hline 15 & SSS-CT-NLD-016WL & -71.9846 & 41.3252 & 67.78 & 69.00 & 1.96 & 1.49 & 0.18 & 0.95 & 0.24 \\
\hline 16 & SSS-CT-NLD-019WL & -72.2776 & 41.2843 & 69.60 & 70.16 & 2.52 & 1.77 & 0.52 & 0.34 & 0.30 \\
\hline 17 & SSS-CT-NLD-022WL & -72.3461 & 41.3125 & 70.57 & 70.50 & 2.14 & 1.89 & 0.55 & 0.65 & 0.12 \\
\hline 18 & SSS-CT-NLD-023WL & -72.2776 & 41.2843 & 69.16 & 70.16 & 2.56 & 1.77 & 0.50 & 0.23 & 0.31 \\
\hline 19 & SSS-CT-NLD-025WL & -72.0609 & 41.3167 & 69.60 & 69.50 & 2.00 & 1.58 & 0.18 & 0.92 & 0.21 \\
\hline 20 & SSS-CT-NLD-026WL & -72.0355 & 41.3350 & 69.96 & 69.50 & 1.82 & 1.62 & 0.17 & 0.93 & 0.11 \\
\hline 21 & SSS-CT-NLD-029WL & -71.9677 & 41.3467 & 68.00 & 69.00 & 1.82 & 1.49 & 0.39 & 0.22 & 0.18 \\
\hline 22 & SSS-CT-NLD-030WL & -71.9095 & 41.3443 & 69.00 & 68.83 & 1.78 & 1.46 & 0.37 & 0.24 & 0.18 \\
\hline 23 & SSS-NJ-ATL-005WL & -74.4628 & 39.5533 & 71.11 & 67.00 & 2.41 & 2.53 & 0.37 & 0.70 & 0.05 \\
\hline 24 & SSS-NJ-CPM-010WL & -74.6275 & 39.2883 & 69.70 & 67.16 & 2.12 & 2.07 & 0.37 & 0.67 & 0.02 \\
\hline 25 & SSS-NJ-HUD-002WL & -74.0661 & 40.7998 & 72.15 & 73.16 & 2.68 & 2.44 & 0.55 & 0.53 & 0.09 \\
\hline 26 & SSS-NJ-MID-001WL & -74.2469 & 40.4591 & 68.04 & 68.33 & 3.57 & 3.60 & 0.87 & 0.43 & 0.01 \\
\hline 27 & SSS-NJ-UNI-001WL & -74.2051 & 40.6478 & 70.61 & 70.00 & 3.72 & 3.20 & 0.84 & 0.69 & 0.14 \\
\hline 28 & SSS-NY-KIN-001WL & -74.0116 & 40.5800 & 69.39 & 68.16 & 4.06 & 2.96 & 0.37 & 0.87 & 0.27 \\
\hline 29 & SSS-NY-KIN-002WL & -73.9883 & 40.7046 & 70.38 & 69.50 & 2.28 & 2.87 & 0.41 & 0.84 & 0.26 \\
\hline 30 & SSS-NY-NAS-001WL & -73.5306 & 40.8779 & 70.82 & 71.33 & 3.08 & 3.08 & 0.49 & 0.89 & 0.00 \\
\hline 31 & SSS-NY-NAS-005WL & -73.4585 & 40.6524 & 70.40 & 71.00 & 2.43 & 1.71 & 0.30 & 0.79 & 0.30 \\
\hline 32 & SSS-NY-NAS-008WL & -73.7102 & 40.8662 & 71.05 & 71.50 & 3.14 & 3.26 & 0.65 & 0.78 & 0.04 \\
\hline 33 & SSS-NY-QUE-001WL & -73.8583 & 40.7623 & 71.11 & 71.50 & 3.15 & 3.26 & 0.49 & 0.88 & 0.03 \\
\hline 34 & SSS-NY-QUE-002WL & -73.8364 & 40.6453 & 70.38 & 69.66 & 3.40 & 2.56 & 0.48 & 0.76 & 0.25 \\
\hline 35 & SSS-NY-QUE-004WL & -73.8288 & 40.7965 & 71.10 & 71.33 & 3.22 & 3.29 & 0.56 & 0.85 & 0.02 \\
\hline 36 & SSS-NY-QUE-005WL & -73.8227 & 40.6062 & 70.28 & 69.00 & 3.16 & 2.53 & 0.39 & 0.84 & 0.20 \\
\hline 37 & SSS-NY-RIC-003WL & -74.2303 & 40.5019 & 69.64 & 68.16 & 4.88 & 3.51 & 1.42 & 0.78 & 0.28 \\
\hline 38 & SSS-NY-RIC-004WL & -74.1277 & 40.5434 & 69.88 & 68.00 & 4.03 & 3.14 & 0.45 & 0.86 & 0.22 \\
\hline 39 & SSS-NY-SUF-001WL & -72.5583 & 41.0126 & 70.79 & 71.16 & 2.40 & 2.19 & 0.34 & 0.87 & 0.08 \\
\hline 40 & SSS-NY-SUF-002WL & -72.8632 & 40.9644 & 70.83 & 71.16 & 2.58 & 2.47 & 0.39 & 0.87 & 0.04 \\
\hline 41 & SSS-NY-SUF-003WL & -73.0723 & 40.9462 & 71.01 & 71.33 & 2.69 & 2.65 & 0.62 & 0.53 & 0.01 \\
\hline 42 & SSS-NY-SUF-004WL & -72.7503 & 40.7871 & 70.53 & 68.00 & 2.08 & 1.77 & 0.32 & 0.70 & 0.15 \\
\hline 43 & SSS-NY-SUF-006WL & -72.5029 & 40.8489 & 70.42 & 67.66 & 2.23 & 1.62 & 0.17 & 0.93 & 0.28 \\
\hline 44 & SSS-NY-SUF-008WL & -72.5030 & 40.8933 & 70.99 & 71.33 & 1.99 & 1.74 & 0.24 & 0.87 & 0.13 \\
\hline 45 & SSS-NY-SUF-009WL & -72.2903 & 41.0020 & 70.84 & $\mathbf{7 0 . 5 0}$ & 1.93 & 1.62 & 0.23 & 0.88 & 0.16 \\
\hline 46 & SSS-NY-SUF-011WL & -73.3530 & 40.9005 & 71.28 & 71.33 & 2.89 & 2.90 & 0.43 & 0.89 & 0.00 \\
\hline 47 & SSS-NY-SUF-014WL & -72.4707 & 40.9907 & 70.22 & 71.16 & 2.27 & 1.74 & 0.43 & 0.76 & 0.23 \\
\hline 48 & SSS-NY-SUF-015WL & -72.3614 & 41.1010 & 70.47 & 71.16 & 1.95 & 1.71 & 0.24 & 0.90 & 0.13 \\
\hline 49 & SSS-NY-SUF-018WL & -73.2022 & 40.6347 & 69.43 & 72.16 & 1.25 & 1.34 & 0.30 & 0.29 & 0.08 \\
\hline 50 & SSS-NY-SUF-019WL & -73.2649 & 40.6593 & 70.39 & 71.83 & 1.70 & 1.43 & 0.18 & 0.88 & 0.16 \\
\hline 51 & SSS-NY-SUF-022WL & -73.2799 & 40.6852 & 70.61 & 71.66 & 2.07 & 1.43 & 0.19 & 0.88 & 0.31 \\
\hline
\end{tabular}


Table 6. Cont.

\begin{tabular}{lllllllllll}
\hline 52 & SSS-NY-SUF-024WL & -71.9344 & $\mathbf{4 1 . 0 7 3 2}$ & $\mathbf{6 8 . 2 2}$ & $\mathbf{6 9 . 3 3}$ & $\mathbf{1 . 8 5}$ & $\mathbf{1 . 3 7}$ & $\mathbf{0 . 1 7}$ & $\mathbf{0 . 8 9}$ & $\mathbf{0 . 2 6}$ \\
53 & SSS-NY-SUF-026WL & $-\mathbf{7 2 . 8 5 5 5}$ & $\mathbf{4 0 . 7 4 6 9}$ & $\mathbf{7 0 . 3 4}$ & $\mathbf{6 9 . 8 3}$ & $\mathbf{1 . 7 3}$ & $\mathbf{1 . 1 0}$ & $\mathbf{0 . 2 1}$ & $\mathbf{0 . 8 8}$ & $\mathbf{0 . 3 7}$ \\
54 & SSS-NY-WES-001WL & $-\mathbf{7 3 . 7 1 9 8}$ & $\mathbf{4 0 . 9 4 2 8}$ & $\mathbf{7 1 . 3 3}$ & $\mathbf{7 1 . 3 3}$ & $\mathbf{3 . 3 3}$ & $\mathbf{3 . 2 6}$ & $\mathbf{0 . 5 6}$ & $\mathbf{0 . 8 6}$ & $\mathbf{0 . 0 2}$ \\
55 & SSS-NY-WES-003WL & $-\mathbf{7 3 . 7 8 1 7}$ & $\mathbf{4 0 . 8 9 0 4}$ & $\mathbf{7 0 . 9 9}$ & $\mathbf{7 1 . 3 3}$ & $\mathbf{3 . 1 8}$ & $\mathbf{3 . 3 2}$ & $\mathbf{0 . 5 5}$ & $\mathbf{0 . 8 7}$ & $\mathbf{0 . 0 4}$ \\
56 & SSS-RI-NEW-015WL & $-\mathbf{7 1 . 1 9 2 4}$ & $\mathbf{4 1 . 4 6 5 0}$ & $\mathbf{6 7 . 7 5}$ & $\mathbf{6 8 . 0 0}$ & $\mathbf{1 . 9 4}$ & $\mathbf{1 . 2 2}$ & $\mathbf{0 . 2 0}$ & $\mathbf{0 . 9 0}$ & $\mathbf{0 . 3 7}$ \\
57 & SSS-RI-WAS-001WL & $-\mathbf{7 1 . 8 5 9 1}$ & $\mathbf{4 1 . 3 1 0 3}$ & $\mathbf{6 8 . 8 8}$ & $\mathbf{6 8 . 8 3}$ & $\mathbf{1 . 7 9}$ & $\mathbf{1 . 4 3}$ & $\mathbf{0 . 1 6}$ & $\mathbf{0 . 9 2}$ & $\mathbf{0 . 2 0}$ \\
58 & SSS-RI-WAS-005WL & $-\mathbf{7 1 . 7 6 6 6}$ & $\mathbf{4 1 . 3 3 4 8}$ & $\mathbf{6 9 . 5 3}$ & $\mathbf{6 8 . 8 3}$ & $\mathbf{1 . 9 5}$ & $\mathbf{1 . 4 0}$ & $\mathbf{0 . 2 6}$ & $\mathbf{0 . 8 0}$ & $\mathbf{0 . 2 8}$ \\
59 & SSS-RI-WAS-007WL & $-\mathbf{7 1 . 6 4 4 7}$ & $\mathbf{4 1 . 3 8 1 0}$ & $\mathbf{7 1 . 0 2}$ & $\mathbf{6 8 . 1 6}$ & $\mathbf{1 . 2 1}$ & $\mathbf{1 . 3 4}$ & $\mathbf{0 . 3 7}$ & $\mathbf{0 . 3 9}$ & $\mathbf{0 . 1 1}$ \\
60 & SSS-RI-WAS-008WL & $-\mathbf{7 1 . 5 1 4 7}$ & $\mathbf{4 1 . 3 7 7 3}$ & $\mathbf{6 8 . 9 9}$ & $\mathbf{6 8 . 0 0}$ & $\mathbf{2 . 0 1}$ & $\mathbf{1 . 3 1}$ & $\mathbf{0 . 2 0}$ & $\mathbf{0 . 8 9}$ & $\mathbf{0 . 3 5}$ \\
\hline
\end{tabular}

Table 7. Partition of USGS storm surge sensors (SSS) vs. SLOSH root mean square errors (m).

\begin{tabular}{cccc}
\hline Threshold $(\mathbf{m})$ & \# SSS Sensors & \# SSS Cumulative & $\mathbf{\%}$ \\
\hline $\mathrm{RMSE} \leq 0.20$ & 11 & 11 & $\mathbf{1 8}$ \\
$0.20<\mathrm{RMSE} \leq 0.30$ & 12 & 23 & $\mathbf{3 8}$ \\
$0.30<\mathrm{RMSE} \leq 0.40$ & 15 & 37 & $\mathbf{6 2}$ \\
$0.40<\mathrm{RMSE} \leq 0.50$ & 13 & 48 & $\mathbf{8 0}$ \\
$\mathrm{RMSE}>0.50$ & 12 & 60 & $\mathbf{1 0 0}$ \\
Total & $\mathbf{6 0}$ & $\mathbf{6 0}$ & \\
\hline
\end{tabular}

Table 8. Partition of USGS storm surge sensors (SSS) vs. SLOSH correlations.

\begin{tabular}{cccc}
\hline Threshold & \# SSS Sensors & \# SSS Cumulative & $\mathbf{\%}$ \\
\hline Correlation $\geq 0.90$ & 11 & 11 & $\mathbf{1 8}$ \\
Correlation $\geq 0.80$ & 26 & 37 & $\mathbf{6 2}$ \\
Correlation $\geq 0.70$ & 7 & 44 & $\mathbf{7 3}$ \\
Correlation $\geq 0.60$ & 4 & 48 & $\mathbf{8 0}$ \\
Correlation $<0.60$ & 12 & 60 & $\mathbf{1 0 0}$ \\
Total & $\mathbf{6 0}$ & $\mathbf{6 0}$ & \\
\hline
\end{tabular}

Table 9. Partition of USGS storm surge sensor (SSS) vs. SLOSH relative errors.

\begin{tabular}{cccc}
\hline Threshold & \# SSS Sensors & \# SSS Cumulative & $\mathbf{\%}$ \\
\hline Relative Error $\leq 0.10$ & 21 & 21 & $\mathbf{3 5}$ \\
Relative Error $\leq 0.20$ & 19 & 40 & $\mathbf{6 7}$ \\
Relative Error $\leq 0.30$ & 15 & 55 & $\mathbf{9 2}$ \\
Relative Error $\leq 0.40$ & 5 & 60 & $\mathbf{1 0 0}$ \\
Total & $\mathbf{6 0}$ & $\mathbf{6 0}$ & \\
\hline
\end{tabular}

\subsection{USGS High Water Marks vs. SLOSH Maximum Water Levels}

The observational measurements for Hurricane Sandy were supplemented by an extensive dataset of post-flood high water marks (HWMs). The USGS flagged, surveyed and collected more than 950 HWMs. Of those 950 HWM, 650 were classified to be independent (greater than $1000 \mathrm{ft}$ apart from each other), and 257 flagged in CT, RI and MA were not surveyed due to lack of funding. Vertical accuracy was $0.26 \mathrm{ft}$ in all counties except $0.47 \mathrm{ft}$ in NJ-Union, Middlesex and Monmouth 
counties [3]. 559 HWMs were inside the SLOSH ny3 basin, and 312 had valid data, so excluding those close to the SLOSH boundaries, 284 HWMs were analyzed and 17 outliers (a HWM estimated from a streak on the wall of a steel shipping container, another identified by a mud line inside a small enclosed room under an air-conditioning unit, etc.) were removed. The remaining 268 HWMs distributed in different states (Table 10) were then compared to SLOSH-simulated inundation values AGL.

A comparison of the HWM estimates vs. SLOSH surge-plus-tides maximum water levels is shown in Figure 15. 34\% of the simulated height at HWM locations have relative errors less than or equal to $10 \%$ (dark orange), $72 \%$ have errors less than or equal to $20 \%$ (orange cone) and $89 \%$ have errors less than or equal to $30 \%$ (yellow cone).

Table 10. Number of USGS High Water Marks (HWM) used to verify SLOSHsimulated maximum water levels for each state.

\begin{tabular}{cc}
\hline State & HWM \\
\hline NY & 161 \\
NJ & 95 \\
RI & 4 \\
CT & 8 \\
Total & $\mathbf{2 6 8}$ \\
\hline
\end{tabular}

Figure 15. USGS High Water Marks (HWM) vs. SLOSH model-simulated surge-plustides maximum height of inundation (m) AGL. The dark orange cone depicts the $10 \%$ error, the orange cone depicts $20 \%$ error and the yellow cone depicts $30 \%$ error. The water surface elevation errors at most stations are within the $10 \%-20 \%$ range.

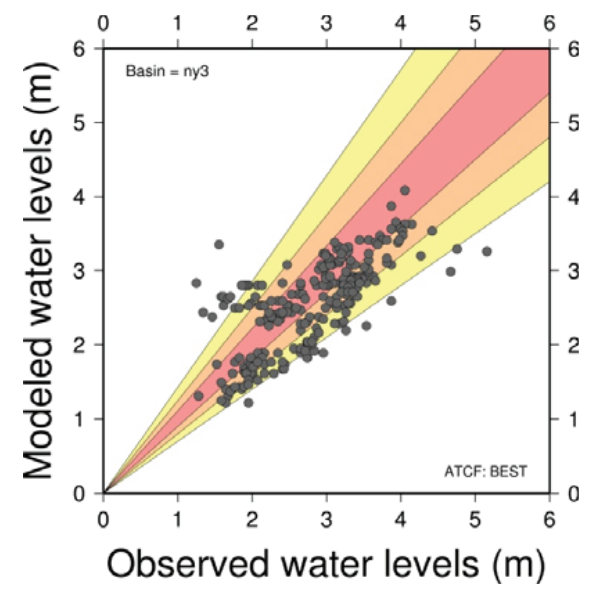

Table 11 summarizes the relative error of the HWM vs. SLOSH maximum water levels. Almost $90 \%$ have errors less than or equal to $30 \%$. Of the remaining HWM locations where the relative error exceeds $30 \%$, there were 17 locations where the SLOSH-simulated maximum water levels were greater than HWM and 13 locations where the SLOSH-simulated maximum water levels were less than HWM, so there is no clear error bias. 
Table 11. Summary of USGS High Water Marks (HWM) vs. SLOSH-simulated maximum water level relative errors.

\begin{tabular}{cccc}
\hline Relative Error & \# HWM & \# HWM Cumulative & \% HWM \\
\hline$\leq 0.10$ & 90 & 90 & $\mathbf{3 4}$ \\
$\leq 0.20$ & 102 & 192 & $\mathbf{7 2}$ \\
$\leq 0.30$ & 46 & 238 & $\mathbf{8 9}$ \\
$\leq 0.40$ & 16 & 254 & $\mathbf{9 5}$ \\
$>0.40$ & 14 & 268 & $\mathbf{1 0 0}$ \\
Total & $\mathbf{2 6 8}$ & $\mathbf{2 6 8}$ & \\
\hline
\end{tabular}

\subsection{Horizontal Distribution of Observations vs. SLOSH}

Figure 16 shows the SLOSH-simulated surge-plus-tides maximum envelope of water (relative to NAVD88) for Hurricane Sandy. Observations at NOAA stations (squares), SSS (triangles) and HWM (circles) have been added with the same color range for comparison. For the most part, the observations are in good agreement with the model results. Some HWMs have higher water level values than those simulated (red circles), particularly in west Raritan Bay, NY. It seems the water in the East River is not flowing through the grid properly. There could be many reasons for this including: unsimulated features in the wind field, the formulations of the surface and bottom stresses, lack of coupling to a wave model, and/or sophistication of the boundary conditions; however of particular significance is a lack of resolution in that area and a non-optimal orientation angle of the grid lines with respect to the river. More detailed investigation needs to be conducted and a new New York basin might need to be built to remedy this retardation of the water flow.

The distribution of the relative error between the observed and modeled maximum heights is shown in Figure 17. Errors are less than $10 \%$ in the Long Island Sound, the CT and RI coastlines and $20 \%$ along the south shore of Long Island (Breezy Point, Atlantic Beach, Long Beach, Jones Beach the Hamptons). Some isolated areas along the east NJ coastline (Surf City) exhibit higher relative errors.

The SLOSH model-simulated surge-plus-tides AGL results over land and maximum envelope of water over the ocean, as rendered by the interactive SLOSH Display Program [19], are compared to the Federal Emergency Management Agency (FEMA) Modeling Task Force (MOTF) fieldverified, "ground-truth" Hurricane Sandy Impact Analysis graphic [20], which depicts the final high-resolution storm surge extent (grey) and very high-resolution extent in NYC (blue) in Figure 18 to provide a more detailed verification of the inundation area. The geographical patterns of inundation agree quite well, especially at Breezy Point, Rockaway, the low-lying areas surrounding JFK airport and further east along the shores of East Bay and South Oyster Bay. The SLOSH wetting-and-drying algorithm performs skillfully inland to the west, in the area extending from south to north along the west bank of the Hudson River from Hoboken to Union City, NJ and further west in the larger Jersey City, Secaucus and Ridgefield area. Flooding over the river banks is also accurately simulated to the south along the Raritan River, the Washington Canal and the South River. The inundation area calculated from the SLOSH Best Track hindcast simulation was $561 \mathrm{~km}^{2}$ (216 sq mi). 
Figure 16. SLOSH model-simulated surge-plus-tides maximum envelope of water (relative to the NAVD88 vertical datum) for Hurricane Sandy. Observations at NOAA stations (squares), SSS (triangles) and HWM (circles) have been added with the same color range for comparison. Water levels are in meters.

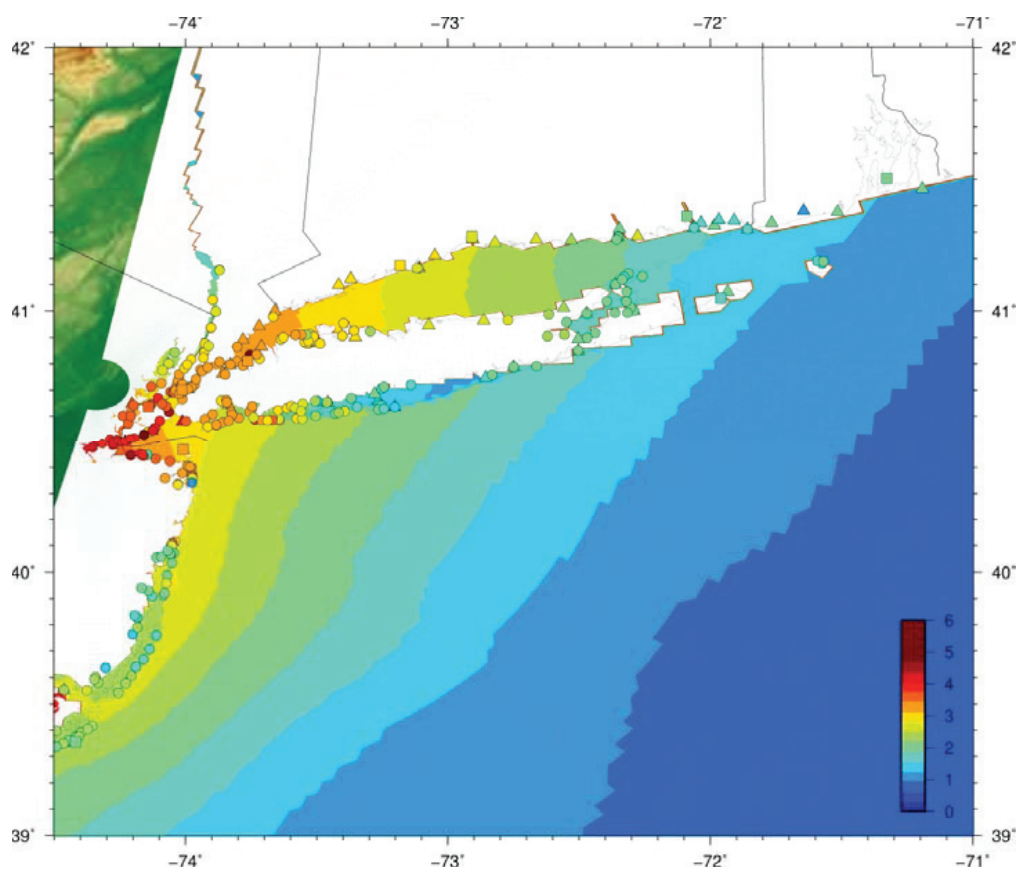

Figure 17. Geographical distribution of the relative error between the observed and SLOSH-simulated maximum water levels.

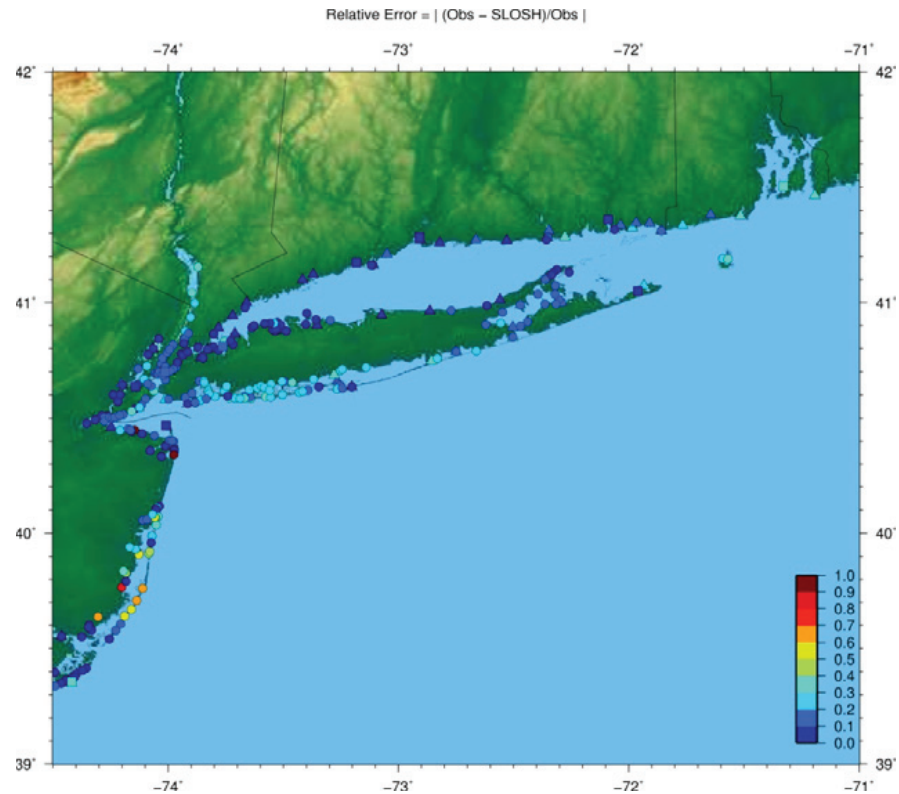


Figure 18. (a) SLOSH model-simulated inundation (ft) above ground level (AGL) over land and maximum envelope of water over the ocean, as rendered by the interactive SLOSH Display Program; and (b) Modeling Task Force (MOTF) field-verified, "ground-truth" Hurricane Sandy Impact Analysis graphic (courtesy of FEMA), which depicts the final high-resolution storm surge extent (grey) and very high-resolution extent in NYC (blue).

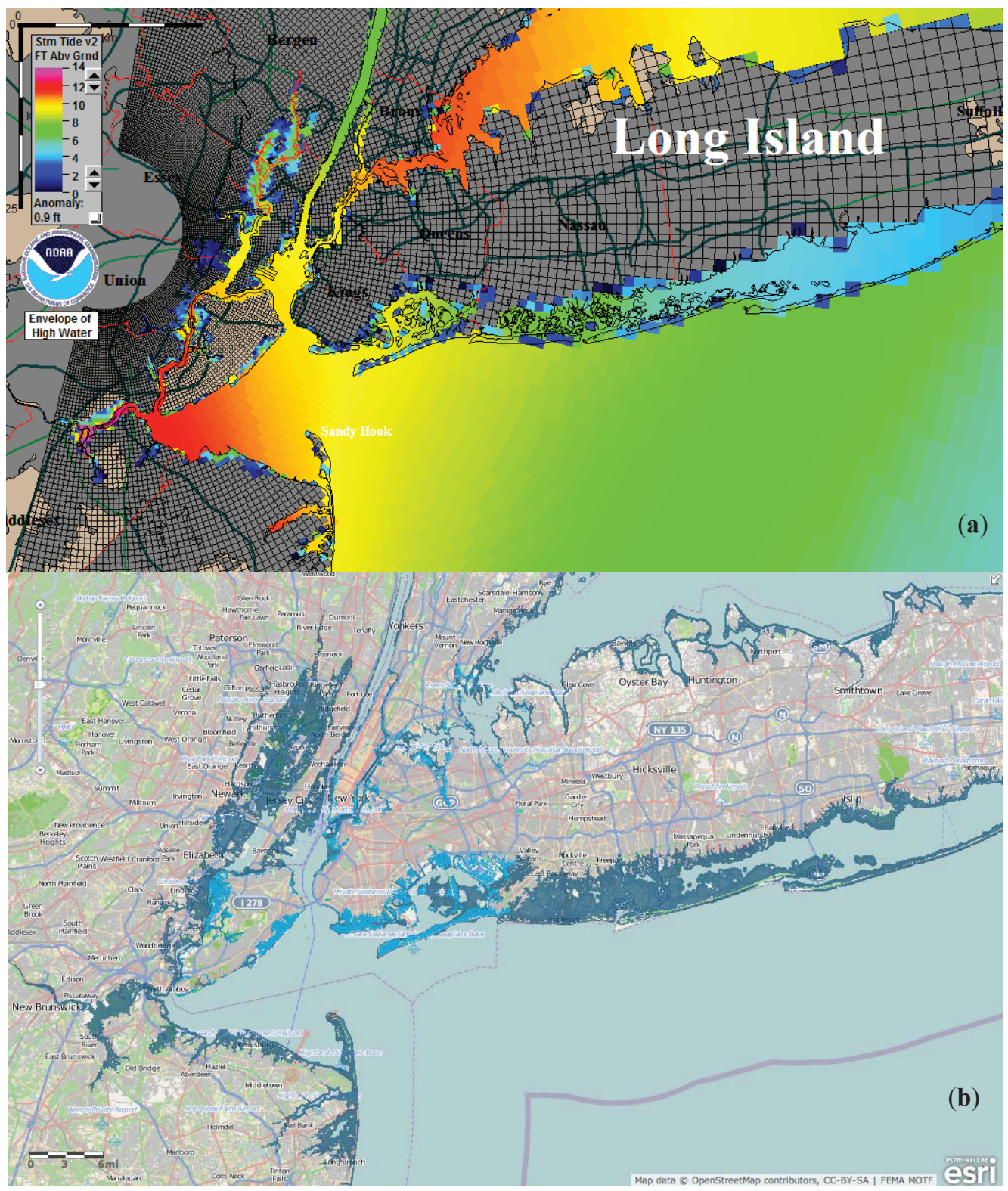




\section{Conclusions}

The verification analyses conducted in this study show that the NWS SLOSH storm surge prediction model is able to simulate the height, timing, evolution and extent of the water that was driven ashore by Hurricane Sandy (2012) with a high degree of fidelity. Upgrades to the numerical model in 2013, including the incorporation of astronomical tides with 37 harmonic constituents, have increased its hindcast accuracy and will enable forecasters to better predict the timing and extent of the total water level and inundation.

In addition, the model's extreme computational efficiency enables it to run large, automated ensembles of predictions in real-time to account for the high variability in atmospheric forcing that can occur in tropical cyclone forecasts, which makes the guidance designed to alert the public and prevent the loss of life more robust and reliable.

Quantitative comparisons (Figure 19, summary provided in Table 12) of SLOSH simulation results against water surface peak elevations measured at all 13 NOAA tide gauge stations, by 60 storm surge sensors deployed by the USGS prior to the storm, and from 268 HWMs collected by USGS - a total of 341 observations - reveal that the SLOSH model-simulated water levels at more than one-third $(34 \%)$ of the data measurement locations have less than $10 \%$ error (dark orange cone), while $71 \%$ (89\%) have less than $20 \%$ (30\%) error (orange and yellow cones, respectively). The RMS error between the observed and modeled peak water levels is $0.47 \mathrm{~m}$ (1.5 ft) (Table 13).

Figure 19. Comparison of water levels (m) at all NOAA tidal gauges, USGS storm surge sensors (SSS) and High Water Marks (HWM) vs. SLOSH model-simulated maximum water levels $(\mathrm{m})$. Water surface elevation errors at most locations are within the $10 \%-20 \%$ range (dark orange cone).

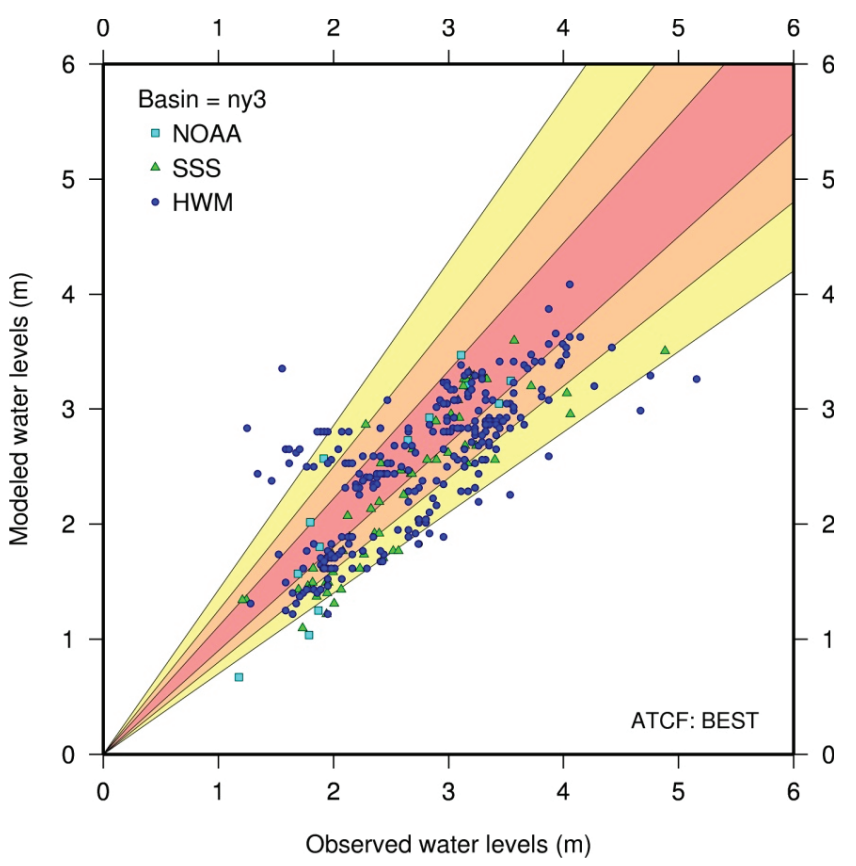


Table 12. Partition of relative error between observed and SLOSH-simulated maximum water elevation for all measurements: NOAA tide gauge stations and USGS storm surge sensors (SSS) and high water marks (HWM), cumulative (Cum) and individual (Ind).

\begin{tabular}{ccccccccc}
\hline Relative Error & $\begin{array}{c}\text { NOAA } \\
\text { Cum (Ind) }\end{array}$ & $\%$ & $\begin{array}{c}\text { SSS Cum } \\
\text { (Ind) }\end{array}$ & $\begin{array}{c}\text { HW } \\
\text { (Ind) }\end{array}$ & $\begin{array}{c}\text { \% } \\
\text { (Ind }\end{array}$ & $\begin{array}{c}\text { NOAA HWM + } \\
\text { SSS Cum (Ind) }\end{array}$ & \% \\
\hline$\leq 0.10$ & $6(6)$ & 46 & $21(21)$ & 35 & $90(90)$ & 34 & $117(117)$ & $\mathbf{3 4}$ \\
$\leq 0.20$ & $9(3)$ & 69 & $40(19)$ & 67 & $192(102)$ & 72 & $241(124)$ & $\mathbf{7 1}$ \\
$\leq 0.30$ & $9(0)$ & 69 & $55(15)$ & 92 & $238(46)$ & 89 & $302(61)$ & $\mathbf{8 9}$ \\
$\leq 0.40$ & $11(2)$ & 85 & $60(5)$ & 100 & $254(16)$ & 95 & $325(23)$ & $\mathbf{9 5}$ \\
$\leq 1.00(>0.40)$ & $13(2)$ & & $60(0)$ & & $268(14)$ & & $341(16)$ & $\mathbf{1 0 0}$ \\
Total & $\mathbf{1 3}$ & & $\mathbf{6 0}$ & & $\mathbf{2 6 8}$ & & $\mathbf{3 4 1}$ & \\
\hline
\end{tabular}

Table 13. Root mean square error between observed and SLOSH-simulated maximum water elevation for all measurements: NOAA tide gauge stations and USGS storm surge sensors (SSS) and high water marks (HWM), cumulative (Cum) and individual (Ind).

\begin{tabular}{ccccc}
\hline & NOAA & SSS & HWM & ALL \\
\hline RMSE & $0.38 \mathrm{~m}(1.27 \mathrm{ft})$ & $0.34 \mathrm{~m}(1.11 \mathrm{ft})$ & $0.49 \mathrm{~m}(1.62 \mathrm{ft})$ & $0.47 \mathrm{~m}(1.54 \mathrm{ft})$ \\
Number of Observations & 13 & 60 & 268 & 341 \\
\hline
\end{tabular}

The arrival times of the peaks in the water elevation observations at NOAA and USGS SSS stations and their SLOSH-simulated counterparts are in good agreement, as demonstrated by the hydrographs and the statistical calculations (RMSE and correlation) from the time series.

The SLOSH simulations underestimated the surge in some areas far from the point of landfall and far from the center of the SLOSH grid where the resolution is coarser (CT, MA, RI) and in the Raritan Bay where the resolution ( 2 grid cells) across the East River might not be allowing the water to flow freely into the bay. Many other factors may have contributed to the underestimation of water levels in these locations: grid resolution, basin size, boundary conditions, lack of waves in the simulations, the tidal method, wind field, surface stress, bottom stress, etc. In this case, the most likely reason for the error is the coarseness of the grid. Previous SLOSH studies [21] have shown that larger and higher resolution SLOSH grids and different parameterizations of the surface and bottom stresses can improve the accuracy of the storm surge results. Efforts are currently underway to test and validate a coupled SLOSH + SWAN modeling system [21] that includes surge, tides and waves.

The highly complex structure of Hurricane Sandy presented an operational challenge for the standard tropical version of SLOSH. Figure 20 shows a comparison between the winds produced by the SLOSH parametric wind model and the real-time multi-platform satellite surface wind analysis at 00 UTC on 30 October 2012 from the NOAA National Environmental Satellite, Data and Information Service (NESDIS), the Cooperative Institute for Research in the Atmosphere (CIRA) Regional and Mesoscale Meteorology Branch (RAMMB) at Colorado State University (CSU) [22] as Hurricane Sandy made landfall northeast of Atlantic City, NJ. The wind analysis combines information from five different data sources to create a mid-level wind analysis, which is 
then adjusted to the surface using empirical, radially varying coefficients obtained from reconnaissance aircraft and GPS dropwindsonde data. Despite the simplicity of the SLOSH parametric wind model, the simulated winds are remarkably realistic. There is strong wavenumber 1 asymmetry due to the storm's forward motion. The $50 \mathrm{kt}\left(25.72 \mathrm{~ms}^{-1}\right)$ isotachs in panels (a) and (b) are similar in orientation, shape and extent. The SLOSH surface friction simulates a reduction in wind speed of about 10 knots $\left(5.14 \mathrm{~ms}^{-1}\right)$ over Long Island Sound due to the downwind effects of the Long Island land cover. The wind directions in both panels also compare quite favorably.

Figure 20. Comparison of wind speeds from (a) the SLOSH parametric wind model and (b) the multi-platform surface wind analysis (courtesy of NOAA/NESDIS and CSU/CIRA/RAMMB). The white square in panel (a) depicts the area where the wind analysis (b) was conducted. Wind speeds are in kts for comparison $\left(1 \mathrm{kt}=0.52 \mathrm{~ms}^{-1}\right)$.

(a)

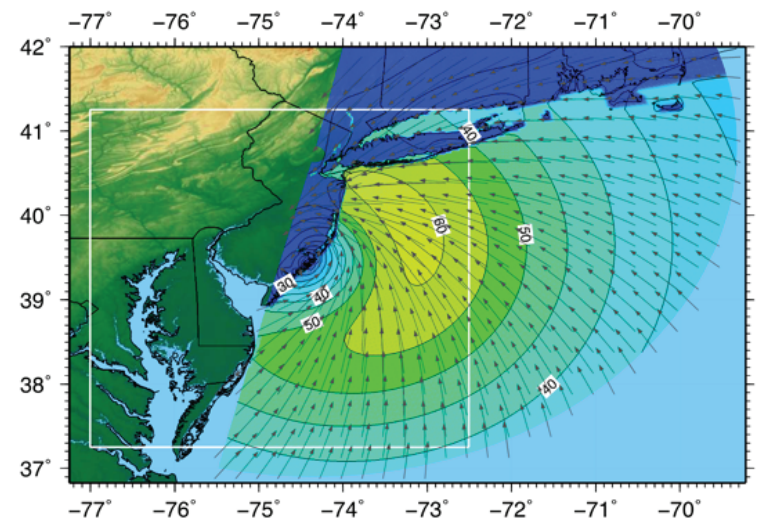

(b)

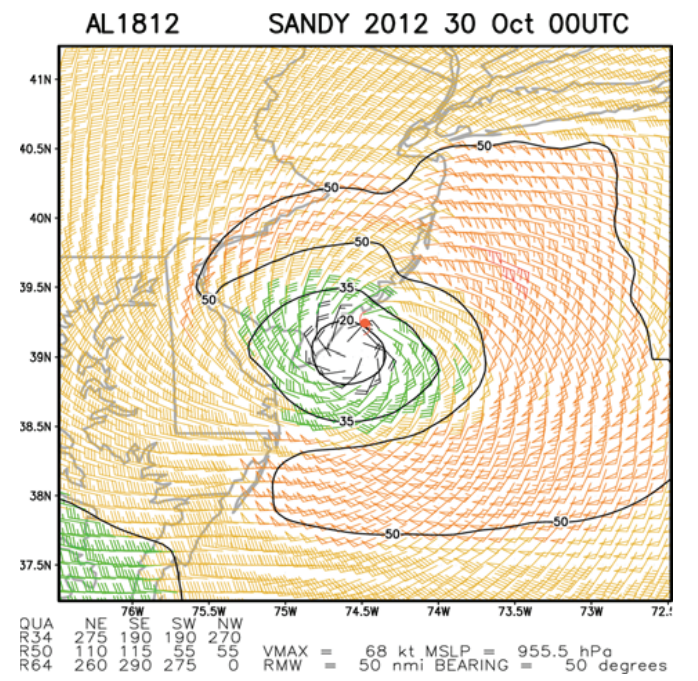

The basis of this study was to assess a baseline skill level of SLOSH and compare it to its latest improvements demonstrated by the inclusion of tidal constituents in SLOSH. Implementing gridded wind fields, an improved parametric wind model [12], and a combination thereof are planned upgrades to SLOSH. 
The ExtraTropical Storm Surge Model (ETSS), developed by the NOAA/NWS Meteorological Development Laboratory (MDL), is a variation of the NWS SLOSH that runs operationally on NCEP's central computing system four times daily. The model is forced by real-time output of winds and pressures from the NCEP Global Forecast System (GFS) and produces numerical storm surge guidance for extratropical systems in 6 grids that cover the US East Coast, Gulf of Mexico, West Coast, Gulf of Alaska, Bering Sea and Arctic. This modeling system does not currently include overland flooding or tides. Work is currently underway to combine the ETSS and the newer versions of SLOSH, which include tides and inundation, via nesting from the coarser ETSS grids down to the latest higher resolution SLOSH grids.

An improved version of the Mattocks and Forbes [12] asymmetric parametric wind model, GWAVA (Gradient Wind Asymmetric Vortex Algorithm), is currently being incorporated into SLOSH. Blending the near-field winds from this more advanced parametric wind model with gridded far-field winds from the GFS or other numerical weather prediction models will potentially improve storm surge prediction by providing more realistic multi-scale wind forcing at the ocean surface and its hydrodynamic response.

The value of future upgrades to the SLOSH model and basin refinements can later be compared to this baseline study. This analysis will also be instrumental in the evaluation of other modeling systems and to assess how they might contribute to operational forecasting as NHC moves toward a multi-model ensemble.

\section{Author Contributions}

Cristina Forbes developed AutoSurge, ran the operational forecast and hindcast simulations, generated graphics and did the analysis and validation of observations vs. SLOSH results; Jamie Rhome provided his expertise in operational storm surge forecasting and communication of the storm surge threat; Craig Mattocks contributed his knowledge on the atmospheric forcing of storm surge simulations, forecast ensembles, parametric wind models, optimization of numerical models and visualization of the results; Arthur Taylor provided his expertise on the SLOSH model and implementation of the various upgrades used in the operational and hindcast simulations.

\section{Conflicts of Interest}

The authors declare no conflict of interest.

\section{References}

1. Jelesnianski, C.P.; Chen, J.; Shaffer, W.A. SLOSH: Sea, Lake, and Overland Surges from Hurricanes; NOAA Technical Report NWS 48; National Oceanic and Atmospheric Administration, U.S. Department of Commerce: Silver Spring, MD, USA, 1992; pp. 1-71. Available online: http://slosh.nws.noaa.gov/sloshPub/pubs/SLOSH_TR48.pdf (accessed on 5 May 2013).

2. Blake, E.S.; Kimberlain, T.B.; Berg, R.J.; Cangialosi, J.P.; Beven, J.L. Tropical Cyclone Report, Hurricane Sandy (AL182012) 22-29 October 2012; National Hurricane Center: 
Miami, FL, USA, 2013; pp. 1-300. Available online: http://www.nhc.noaa.gov/data/tcr/AL182012_Sandy.pdf (accessed on 26 November 2013).

3. McCallum, B.E.; Wicklein, S.M.; Reiser, R.G.; Busciolano, R.; Morrison, J.; Verdi, R.J.; Painter, J.A.; Frantz, E.R.; Gotvald, A.J. Monitoring Storm Tide and Flooding from Hurricane Sandy along the Atlantic Coast of the United States, October 2012; U.S. Geological Survey Open-File Report 2013-1043; U.S. Department of the Interior, U.S. Geological Survey: Reston, VA, USA, 2013; pp. 1-42. Available online: http://pubs.usgs.gov/of/2013/1043/ (accessed on 26 November 2013).

4. Defining Storm Surge, Storm Tide and Inundation. Available online: http://www.nhc.noaa.gov/news/20130806_pa_defineSurge.pdf (accessed on 26 November 2013).

5. NOAA/NOS/CO-OPS, Silver Spring, MD, USA. NAVD88-MSL conversion at Bergen Point and Kings Point. Personal communication, 2013.

6. Demuth, J.L.; Morss, R.E.; Morrow, B.H.; Lazo, J.K. Creation and Communication of Hurricane Risk Information. Bull. Am. Meteorol. Soc. 2012, 93, 1133-1145; doi:10.1175/BAMS-D-1100150.1 .

7. Taylor, A.A.; Glahn, B. Probabilistic guidance for hurricane storm surge. In Proceedings of the 88th Annual Meeting of the American Meteorological Society, New Orleans, LA, USA, 20-24 January 2008. Available online: http://www.nws.noaa.gov/mdl/pubs/Documents/ Papers/psurge_ofcl_200801_AMS.pdf (accessed on 27 November 2013).

8. Arakawa, A.; Lamb, V.R. Computational design of the basic dynamical processes of the UCLA general circulation model. In Methods of Computational Physics; Chang, J., Ed.; Academic Press: New York, NY, USA, 1977; pp. 173-265.

9. Platzman, G.W. The Dynamic Prediction of Wind Tides on Lake Erie. Meteorol. Monogr. 1963, 26, 1-44.

10. Jelesnianski, C.P. Numerical computation of storm surges with bottom stress. Mon. Weather Rev. 1966, 95, 740-756. Available online: http://docs.lib.noaa.gov/rescue/mwr/094/mwr-094-060379.pdf (accessed on 27 November 2013).

11. Forbes, C.; Rhome, J. An Automated Operational Storm Surge Prediction System for the National Hurricane Center. In Proceedings of the International Conference on Estuarine and Coastal Modeling, St. Augustine, FL, USA, 7-9 November 2011; pp. 213-229, doi:10.1061/9780784412411.00013. Available online: http://ascelibrary.org/doi/abs/10.1061/ 9780784412411.00013 (accessed on 27 November 2013).

12. Mattocks, C.; Forbes, C. A real-time, event-triggered storm surge forecasting system for the State of North Carolina. Ocean Model. 2008, 25, 95-119. Available online: http://www.sciencedirect.com/science/article/pii/S1463500308000905 (accessed on 27 November 2013).

13. Forbes, C.; Luettich, R.; Mattocks, C. A Retrospective Evaluation of the Storm Surge Produced by Hurricane Gustav: Forecast and Hindcast Results. Weather Forecast. 2010, 25, 1577-1602. Available online: http://journals.ametsoc.org/doi/full/10.1175/2010WAF2222416.1 (accessed on 27 November 2013). 
14. Taylor, A.; Myckow, A.; Haase, A.; Wang, J.; Feyen, J.C. Recent Developments in Probabilistic Hurricane Storm Surge. In Proceedings of the Estuarine and Coastal Modeling Conference XIII, ECM13, San Diego, CA, USA, 4-7 November 2013.

15. Haase, A.; Wang, J.; Taylor, A.; Feyen, J. Coupling of Tides and Storm Surge for Operational Modeling on the Florida Coast. In Proceedings of the International Conference on Estuarine and Coastal Modeling, St. Augustine, FL, USA, 7-9 November 2011; pp. 230-238, doi:10.1061/9780784412411.00014. Available online: http://ascelibrary.org/doi/abs/10.1061/ 9780784412411.00014 (accessed on 27 November 2013).

16. NOAA/NOS/CO-OPS. Tide and Current Glossary; U.S. Department of Commerce: Silver Spring, MD, USA, 2000; pp. 1-18. Available online: http://tidesandcurrents.noaa.gov/ publications/glossary2.pdf (accessed on 26 November 2013).

17. NOAA/NGDC ETOPO1 Global Relief Model. Available online: http://www.ngdc.noaa.gov/ $\mathrm{mgg} / \mathrm{global} /$ (accessed on 28 November 2013).

18. Szpilka, C.; Dresback, K.; Kolar, R.; Bush, S. Towards an Updated ADCIRC 2013 Database of Tidal Constituents within the Western North Atlantic Ocean, Gulf of Mexico and Caribbean Sea. In Proceedings of the Estuarine and Coastal Modeling Conference XIII, ECM13, San Diego, CA, USA, 4-7 November 2013.

19. SLOSH Display. Available online: http://slosh.nws.noaa.gov/sloshPub/ (accessed on 27 November 2013).

20. FEMA Modeling Task Force (MOTF) Hurricane Sandy Impact Analysis Graphic. Available online: http://fema.maps.arcgis.com/home/webmap/viewer.html?webmap=307dd522499d4a44a 33d7296a5da5ea0 (accessed on 27 November 2013).

21. SURA, 2012: A Super-Regional Testbed to Improve Models of Environmental Processes on the U.S. Atlantic and Gulf of Mexico Coasts. Available online: http://www.ioos.noaa.gov/ modeling/reports/part1_testbed_to_improve_models_june2012.pdf (accessed on 7 May 2014).

22. NESDIS and CIRA/RAMMB: Multi-platform Tropical Cyclone Surface Wind Analysis for Hurricane Sandy (AL182012). Available online: http://rammb.cira.colostate.edu/products/tc realtime/archive_sub_products.asp?product=mpsatwnd\&storm_identifier=AL182012 (accessed on 7 May 2014). 


\title{
NOAA's Nested Northern Gulf of Mexico Operational Forecast Systems Development
}

\author{
Eugene Wei, Aijun Zhang, Zizang Yang, Yi Chen, John G.W. Kelley, Frank Aikman and \\ Degui Cao
}

\begin{abstract}
The NOAA National Ocean Service's (NOS) Northern Gulf of Mexico Operational Forecast System (NGOFS) became operational in March 2012. Implemented with the Finite Volume Coastal Ocean Model (FVCOM) as its core three-dimensional oceanographic circulation model, NGOFS produces a real-time nowcast ( $-6 \mathrm{~h}$ to zero) and six-hourly, two-day forecast guidance for water levels and three-dimensional currents, water temperature and salinity over the northern Gulf of Mexico continental shelf. Designed as a regional scale prediction system, NGOFS lacks sufficient spatial coverage and/or resolution to fully resolve hydrodynamic features in critical seaports and estuaries. To overcome this shortcoming and better support the needs of marine navigation, emergency response, and environmental management, two FVCOM-based, high-resolution, estuaryscale nested forecast modeling systems, namely the Northwest and Northeast Gulf of Mexico Operational Forecast Systems (NWGOFS and NEGOFS), have been developed through one-way nesting in NGOFS. Using the atmospheric forecast guidance from the NOAA (National Oceanic and Atmospheric Administration)/NWS (National Weather Services)' North American Mesoscale (NAM) Forecast System, US Geological Survey (USGS) river discharge observations, and the NGOFS water level, current, water temperature and salinity as the surface, river, and open ocean boundary forcing, respectively, a six-month model hindcast for the period October 2010-March 2011 has been conducted. Modeled water levels, currents, salinity and water temperature are compared with observations using the NOS standard skill assessment software. Skill assessment scores indicated that NWGOFS and NEGOFS demonstrate improvement over NGOFS. The NWGOFS and NEGOFS are under real-time nowcast/forecast test and evaluation by NOS's Center for Operational Oceanographic Products and Services (CO-OPS). The forecast systems are scheduled to be implemented operational on NOAA Weather \& Climate Operational Supercomputing System (WCOSS) in June 2014.
\end{abstract}

Reprinted from J. Mar. Sci. Eng. Cite as: Wei, E.; Zhang, A.; Yang, Z.; Chen, Y.; Kelley, J.G.W.; Aikman, F.; Cao, D. NOAA's Nested Northern Gulf of Mexico Operational Forecast Systems Development. J. Mar. Sci. Eng. 2014, 2, 1-17.

\section{Introduction}

The northern Gulf of Mexico (GOM) coastal circulation results from a combination of astronomical tides, GOM deep water eddies impinging against the shelf, the local atmospheric wind stress and heat flux, and riverine discharges through a vast stretch of wetlands and marshes into the coastal waters. Numerous studies including observations, analytical basic researches, reanalysis, and numerical simulations have been done for either the entire or part of the GOM at basin, regional, and local scales. A recent published book, edited by Sturges and Lugo-Fernandez [1], collected a series 
of GOM circulation studies. Papers addressing the northern GOM coastal circulation in this book are the analysis of long term mooring data on the Louisiana and Texas continental shelf (LATEX) by Nowlin et al. [2] and a numerical model study by Morey et al. [3] of the northern and western GOM. With the advancement of oceanographic knowledge through start-of-the-art observational systems of the atmosphere, surface water, and deep water, each study represents successive steps in an understanding the circulation of the GOM. These studies indicated the coastal shelf circulation in the northern GOM has a large degree of variance in both space and time.

Figure 1. Schematic NOS PORTS ${ }^{\circledR}$ locations and nested Northern Gulf of Mexico model domain.

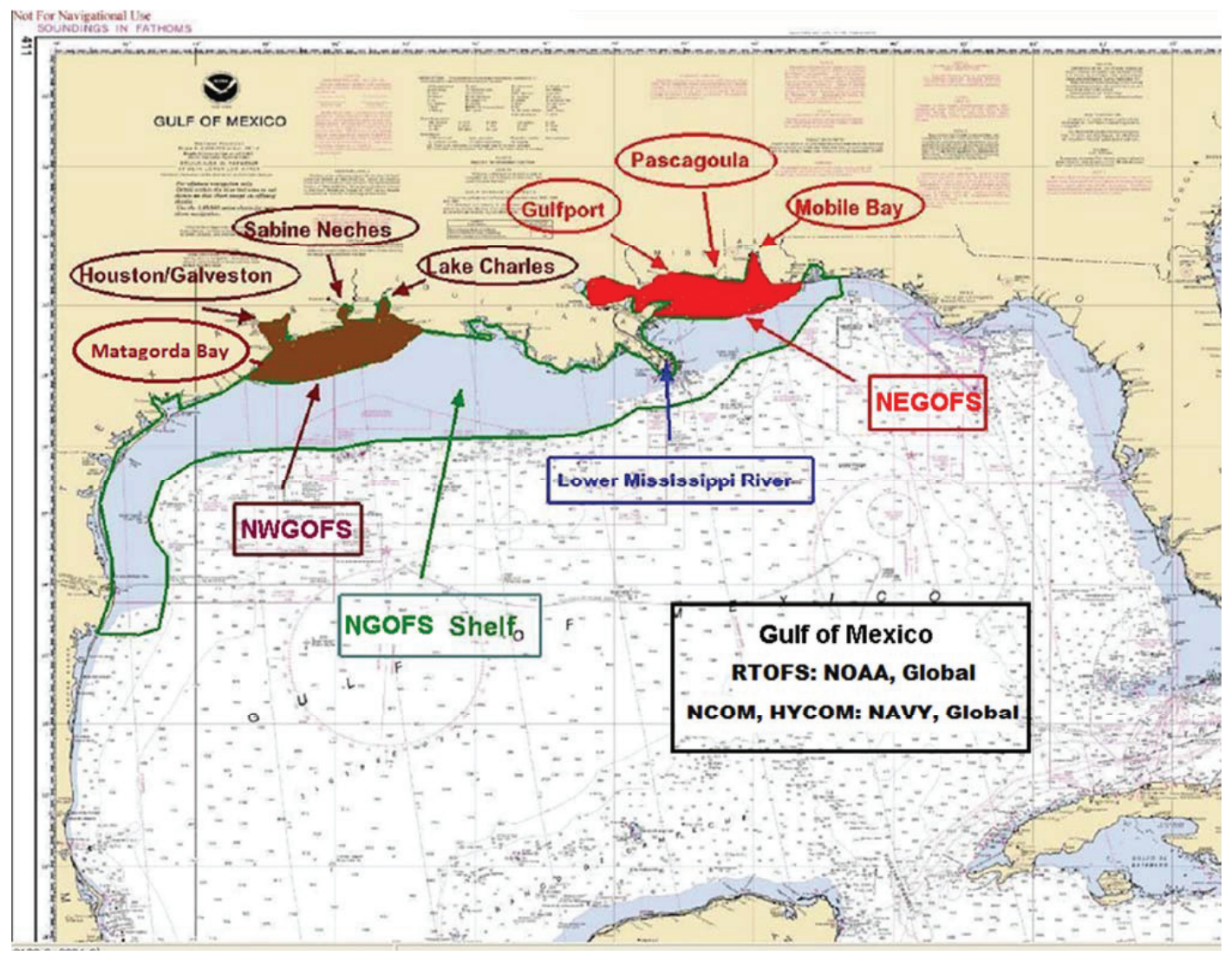

NOS Physical Oceanographic Real-Time System (PORTS ${ }^{\circledR}$ ) along the northern coast of the Gulf of Mexico provides real-time oceanographic data to promote safe and efficient navigation. These PORTS $^{\circledR}$ in this region currently include Mobile Bay, Pascagoula, Gulfport, Lake Charles, Sabine Neches, Houston/Galveston Bay, and the proposed Matagoda Bay (Figure 1). In conjunction with these real-time local observing networks, NOS has been tasked to develop numerical oceanographic prediction systems to accurately provide short-term forecast guidance of water levels, currents, salinity, and water temperature to primarily support safe and efficient maritime navigation in this region. The NGOFS, based on the three-dimensional unstructured-grid, free-surface primitive 
equation FVCOM [4-6], was then developed by NOS and implemented operationally in March 2012 to provide forecast guidance out to two days for the northern Gulf of Mexico shelf region [7] from South Padre Island, TX (west) to Panama City, FL (east). With the shelf circulation properly modeled by NGOFS, its predictions can be used for emergency responses and to support water quality, biological and ecological forecast activities.

In order to capture the spatial and temporal variability especially in inland bays and intra-coastal waterways where the commercial and recreational mariners require detailed forecasts for safe and efficient navigation, two higher resolution forecast systems were nested in the operational NGOFS. The NWGOFS covers Lake Charles, Sabine-Neches, Houston/Galveston, and proposed Matagoda Bay PORTS ${ }^{\circledR}$ (Figure 1). The NEGOFS covers Mobile Bay, Pascagoula, and Gulfport PORTS ${ }^{\circledR}$ (Figure 1).

\section{Model and Grid Configuration}

The FVCOM has been successfully applied in several coastal ocean regions to simulate the hydrodynamics using an unstructured grid. The governing equations and detail formulation has been documented in [4-6]. Publications based on FVCOM applications can be found from this web page [8]. In particular, the Northeast Coastal Ocean Forecast System (NECOFS) has been implemented by the University of Massachusetts at Dartmouth (UMASSD) in a real-time mode since 2007 with high resolution grid nesting functionality [9]. FVCOM was chosen by NOS for the northern GOM region to simulate features such as the meso-scale eddies, the wind-driven coastal circulation, and the smaller scale coastal and estuarine circulation associated with complex shorelines, topography, tidal dynamics, and fresh water inputs.

Figure 2. Northwest Gulf of Mexico Operational Forecast System (NWGOFS) model grid.

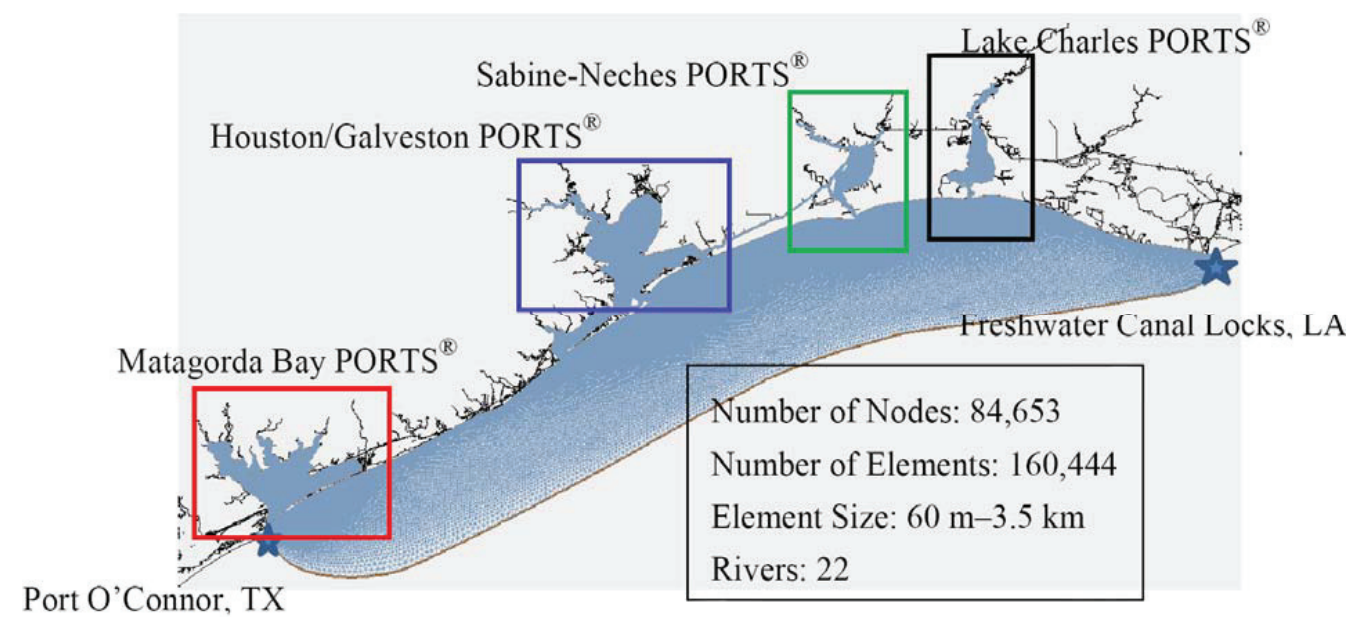

The FVCOM Version 3.1.6 was used in the NGOFS regional shelf modeling system and also the nested NWGOFS and NEGOFS. The NWGOFS and NEGOFS focus on inland and coastal water 
dynamics of seven NOS's PORTS ${ }^{\circledR}$ in the area. Two rows of node from the NGOFS model grid with the corresponding elements are defined as the nesting boundary for the nested models. For NWGOFS, the nesting boundary node near NOS's National Water Level Observation Network (NWLON) gage locations Port O'Connor, Texas (NOS ID 8773701) on the west and Freshwater Canal Locks, Louisiana (8766072) on east were selected as the nested boundary locations (Figure 2). For NEGOFS, the nested boundary locations selected were near the Shell Beach, Louisiana (8761305) gage on the west and Pensacola, Florida (8729840) gage on the east (Figure 3).

Figure 3. Northeast Gulf of Mexico Operational Forecast System (NEGOFS) model grid.

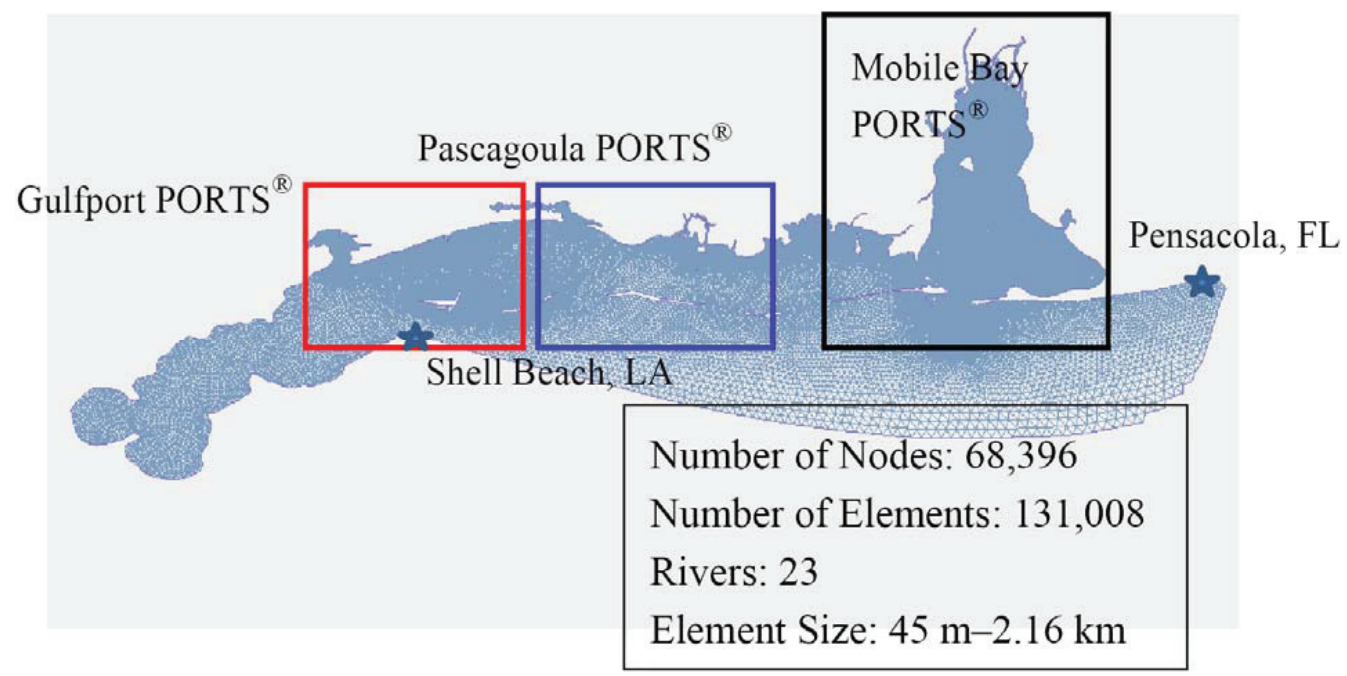

The shoreline data are taken from NOAA's National Geophysical Data Center (NGDC) high resolution shoreline/coastline resources data base. The nested model domains with corresponding NOS's PORTS ${ }^{\circledR}$ are shown as Figures 2 and 3. Note that the smallest grid size has been set to $60 \mathrm{~m}$ and $45 \mathrm{~m}$ for NWGOFS and NEGOFS, respectively. The model bathymetry is obtained by interpolating the most recent NOAA hydrographic survey data and US Army Corps of Engineers (USACE) bathymetry database onto each unstructured NGOFS model grid node. The minimum water depth (for wetting and drying) of the grid is defined as $0.13 \mathrm{~m}$ below mean sea level and the land topography is not considered. The deepest water depths are $37 \mathrm{~m}$ and $25 \mathrm{~m}$ for NWGOFS and NEGOFS, respectively, shown as bathymetry plots in Figures 4 and 5. The most recent bathymetry from NOAA's Vertical Datum (VDatum) projects and USACE's channel and beach restoration project information (e.g., Lake Calcasieu Channel) are also used to update the nest model bathymetry.

The freshwater discharges from 22 and 23 major rivers flows to NWGOFS and NEGOFS model domain, respectively, modifying the circulation including the density flow in the inland bay and near shore coastal waters. The nested models extend the grid domain upstream to the nearest United States Geological Survey (USGS) river gage location for accurate river boundary conditions. 
Figure 4. Northwest Gulf of Mexico Operational Forecast System (NWGOFS) bathymetry map.

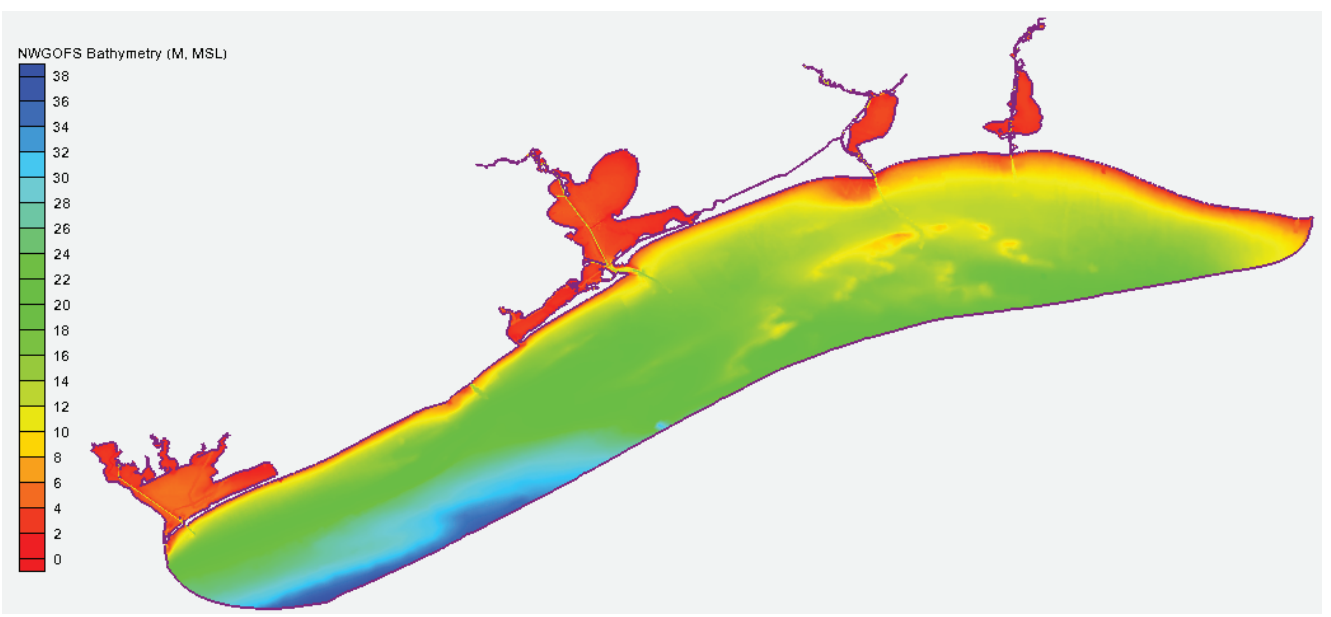

Figure 5. Northeast Gulf of Mexico Operational Forecast System (NEGOFS) bathymetry map.

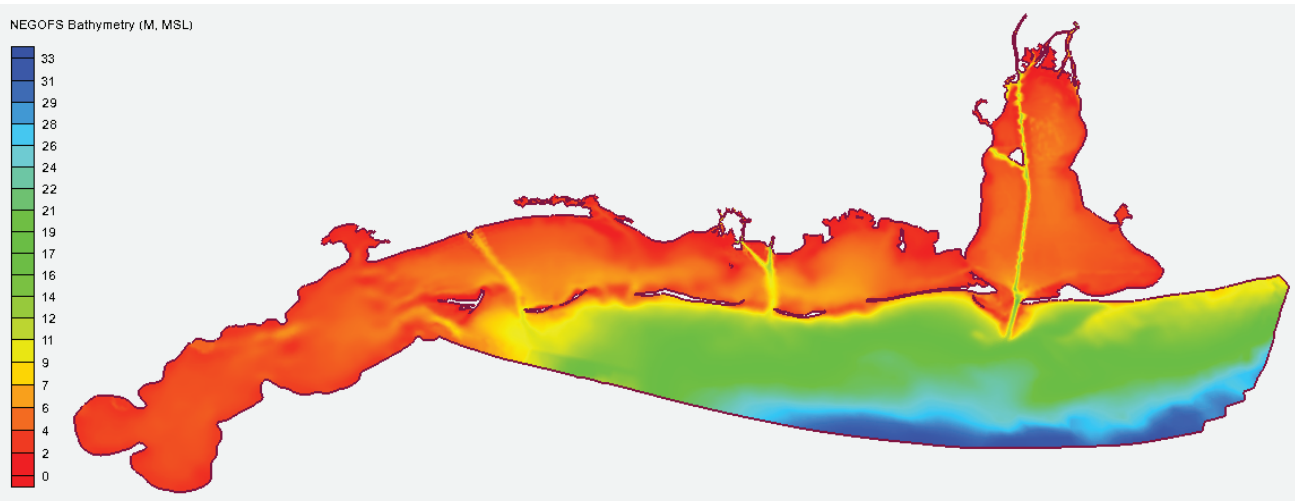

Navigation channels of four bays within NWGOFS (Matagoda Bay, Galveston Bay, Sabine Lake, and Lake Calcasieu) are protected by solid jetties at the entrance. The flow near the entrance is regulated by these jetties. Although the circulation pattern at the bay entrance may not have an effect on the far field circulation, it does plays an important role for the navigation and circulation induced sediment transportation in the local area, especially when the jetties are submerged due to a high wind or storm event. The "Thin Dam" numerical approach [10] in FVCOM to the coastal jetty is therefore applied to NWGOFS at the entrance of these four bays to accurately simulate the flow at and near the entrance channel. Duplicated nodes are added to the model along the jetty to separate the elements inside and outside the channel thus the water surface elevation may be different and no flow crosses the emerged jetty. When the jetty submerges the flow is free for crossing over the top portion of the submerged jetty. The sensitivity test shows the flow at the entrance is confined within 
the emerged jetties while the velocity vectors are along the shoreline without the jetties present (Figure 6).

Figure 6. Velocity vectors at Lake Calcasieu entrance without (left) and with (right) jetties.
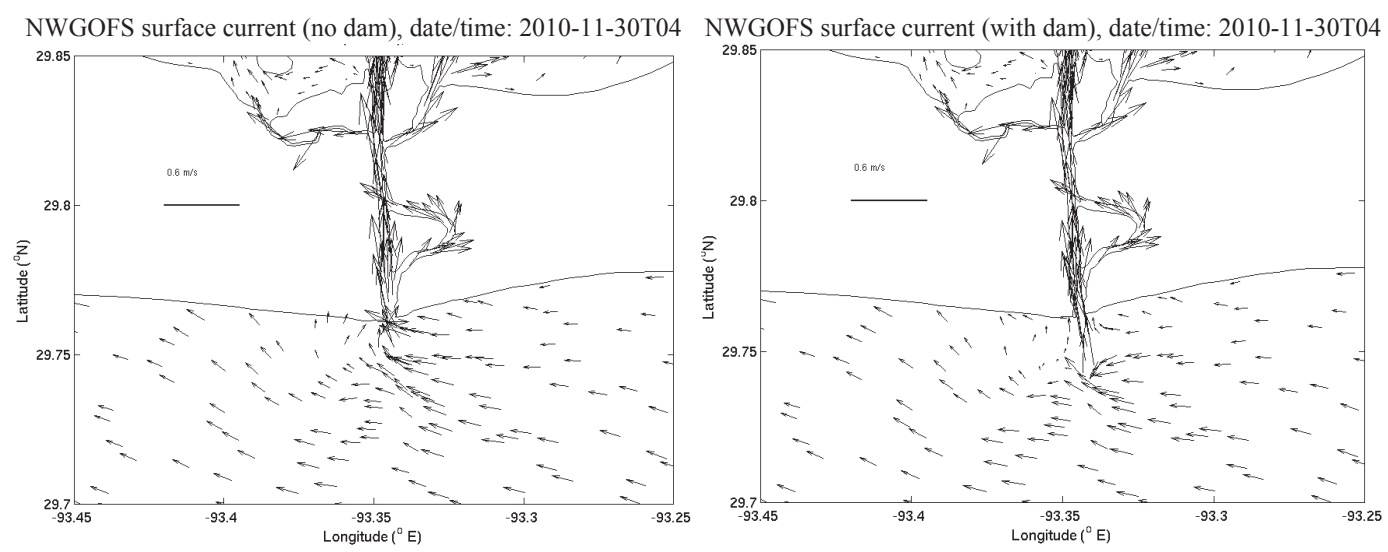

\section{Model Hindcast}

The NWGOFS and NEGOFS model verification have been conducted using similar approach of NGOFS hindcast simulation. The 2nd hindcast simulation period for NGOFS from 14 September 2010 to 1 April 2011 has been repeated to provide open ocean boundary conditions for the nested model hindcasts.

The salinity and temperature initial condition for NWGOFS and NEGOFS were obtained by interpolating the Navy's global Navy Coastal Ocean Model (NCOM) three-dimensional salinity and temperature field at hour 0, 14 September 2010. The surface elevations and velocity fields are specified as zero. The surface forcing data required for the NWGOFS and NEGOFS hindcast simulations consists of meteorological parameters from NAM model. Forecast guidance from 12-km NAM model at three-hour time intervals include surface wind velocity at $10 \mathrm{~m}$ above ground level (AGL), air pressure at mean sea level, surface air temperature at $2 \mathrm{~m}$ AGL, surface relative humidity at $2 \mathrm{~m}$ AGL, and short- and long-wave radiation are interpolated onto the NWGOFS and NEGOFS model domains at each node. The sensible heat, latent heat, and the net heat flux at each model grid node are then calculated based on the bulk flux parameterization empirical formula. River forcing including freshwater discharge and temperature are obtained at 22 (for NWGOFS) and 23 (for NEGOFS) river locations from the USGS, USACE, or CO-OPS.

Observations of water level, current, salinity and water temperature are collected from NOS, Texas Automated Buoy System (TABS), and Integrated Ocean Observed System (IOOS)/National Data Buoy Center (NDBC) for model verification and skill assessment. However, due to the lack of salinity data for the hindcast period, only water level, current and temperature are analyzed and presented in this study. 
The approach of running nesting NWGOFS and NEGOFS is through one-way coupling with NGOFS. First, the NGOFS simulation was run to output water surface elevation, three-dimensional velocities, temperature and salinity at nesting boundary nodes and elements. The nested model simulations are then conducted with the atmospheric surface forcing, river forcing, and the nesting boundary information from NGOFS as the open ocean boundary.

Several sensitivity tests have been conducted to calibrate parameters in the FVCOM applied to the NWGOFS and NEGOFS. The constant and variable bottom roughness logarithm scale length $\left(\mathrm{z}_{0 \mathrm{~b}}\right)[11,12]$ and bottom friction coefficient $\left(\mathrm{C}_{\mathrm{d}}\right)$ were tested and found insignificant effects to the surface elevations and velocity compared with observations. The NGOFS uses 41 sigma levels to resolve the vertical structure in shelf and shelf break area. For shallow water NWGOFS and NEGOFS, both 41 and 21 sigma levels are tested to evaluate the effect of the number of vertical layers to water level and velocity at stations with observations. Test results also show insignificant difference (less than $0.01 \mathrm{~m}$ in surface elevation and $0.02 \mathrm{~m} \mathrm{~s}^{-1}$ in horizontal velocity at all levels). Therefore, the nested models use 21-sigma level in the vertical and the information of velocity, salinity, and temperature from NGOFS at every other layer are extracted as the nesting boundary conditions for NWGOFS and NEGOFS.

The hindcast starts at hour 0, 14 September 2010. Forced with nesting open ocean boundary information from NGOFS, the NWGOFS and NEGOFS take about seven days for water level and tidal currents to spin-up and about 1.5 month for salinity and temperature to reach quasi-equilibrium. Simulated water level, current, salinity and temperature are saved at stations with observations during the hindcast period for model verification. Surface elevation and three-dimensional fields for the entire NWGOFS and NEGOFS domains are also outputs for model verification.

The comparisons of model simulated water level, temperature, and current velocity time series with observations at representative locations are shown in Figures 7-9. Water level time series show predominated diurnal and mixed tide with wind event effect (Figure 7). Simulated water levels follow the observation tidal and event signal very well except underestimate the low surge from a storm event by approximately $0.4 \mathrm{~m}$ at NWGOFS coast and $0.2 \mathrm{~m}$ at NEGOFS coast on 13 December 2010 . The simulated near surface water temperature matches with observations throughout the 2010-2011 winter (Figure 8). This agreement can also be seen in the NGOFS temperature hindcast from August 2008 to August 2009 [7]. Model simulated and observed current speed time series at station g0601 (Galveston Bay entrance, Galveston, TX, USA) and sn0201 (USCG Sabine, Sabine, LA, USA) are shown in Figure 9. The maximum tidal currents over $1.0 \mathrm{~m} \mathrm{~s}^{-1}$ at the bay entrance of NWGOFS are shown in Figure 9, left column. Weaker currents are observed at Gulfport PORTS ${ }^{\circledR}$ in NEGOFS domain (gp0401, Figure 9, right column). At the Mobile Bay entrance (mb0101), the model underestimated the peak tidal current speed. 
Figure 7. Simulated (red) and observed (black) water level time series at stations in NWGOFS (left column) and NEGOFS (right column) from 1 November 2010 to 31 December 2010.

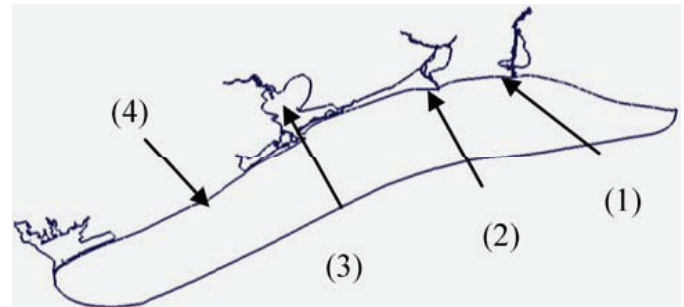

(1) 8768094 Calcasieu, LA

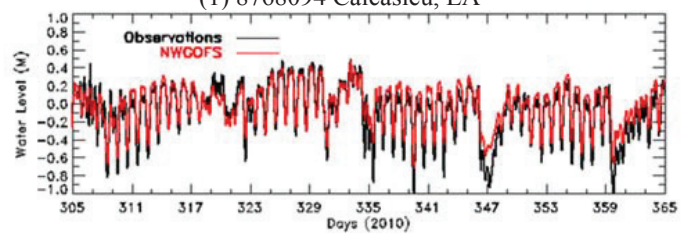

(2) 8770570 Sabine Pass N. TX

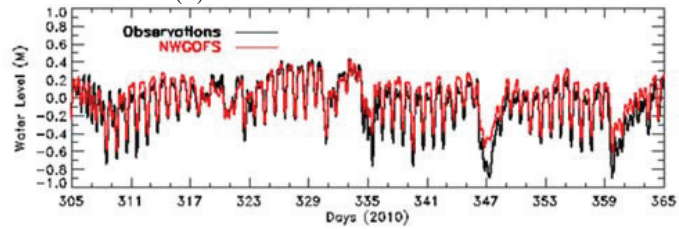

(3) 8771013 Eagle Pt, TX

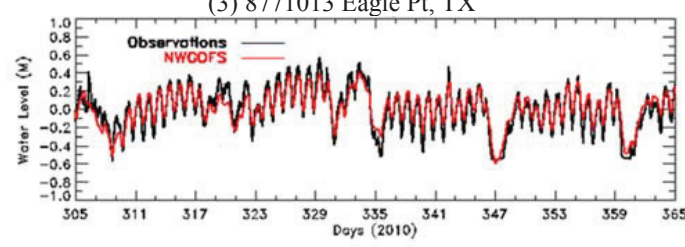

(4) 8772447 USCG Freeport, TX

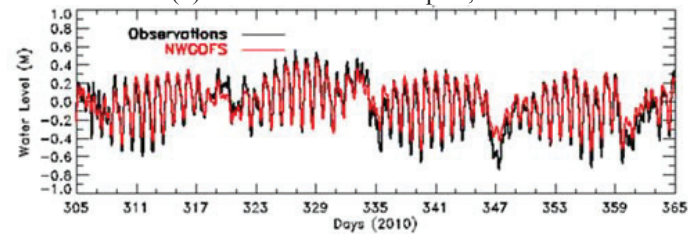

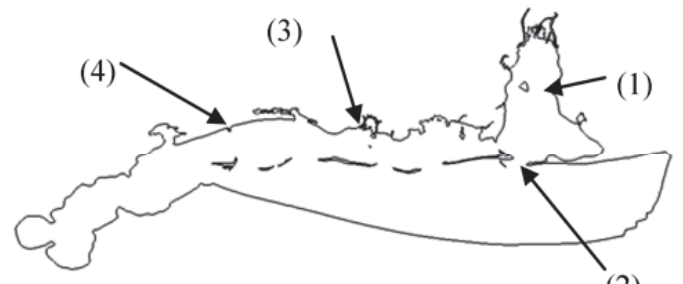

(2)

(1) 8733839 Meaher, MB, AL obs: black, NEGOFS: red

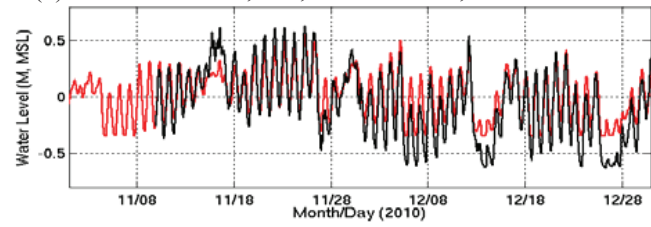

(2) 8735180 Dauphin Is Hydro, AL obs: black, NEGOFS: red

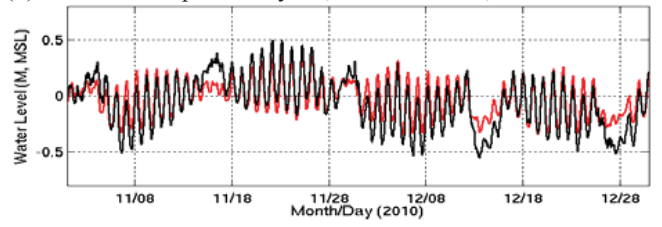

(3) 8741533 Pascagoula NOAA, MS obs: black, NEGOFS: red

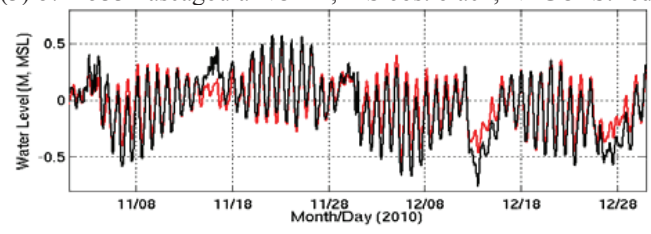

(4) 8747437 Bay Waveland, MS obs: black, NEGOFS: red

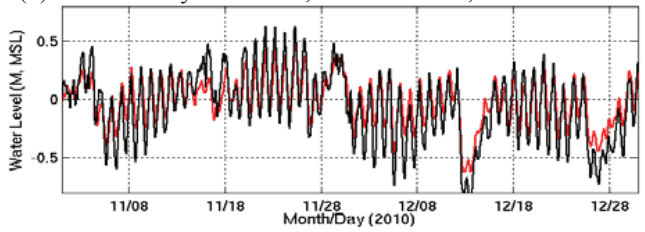


Figure 8. Simulated (red) and observed (black) temperature time series at stations in NWGOFS (left column) and NEGOFS (right column) from 1 November 2010 to 31 December 2010.

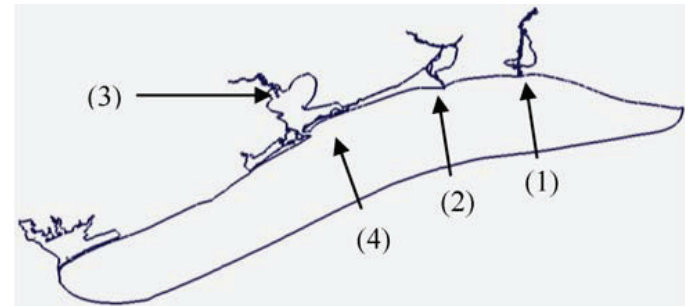

(1) 8768094 Calcasieu, LA

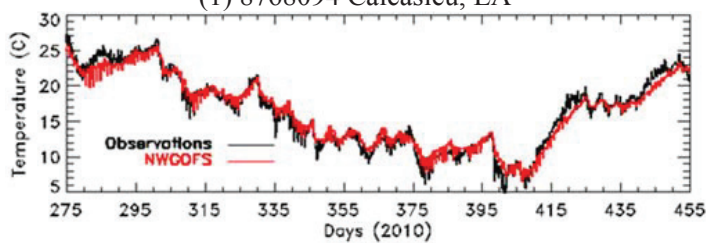

(2) 8770570 Sabine Pass N. TX

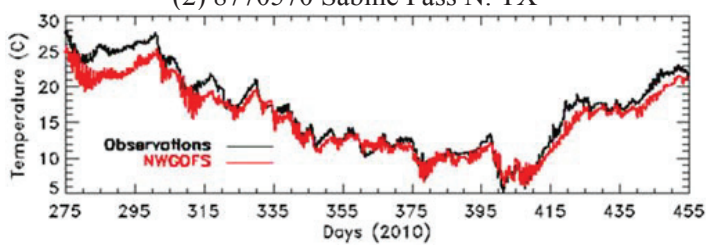

(3) 8770613 Morgans Pt, TX

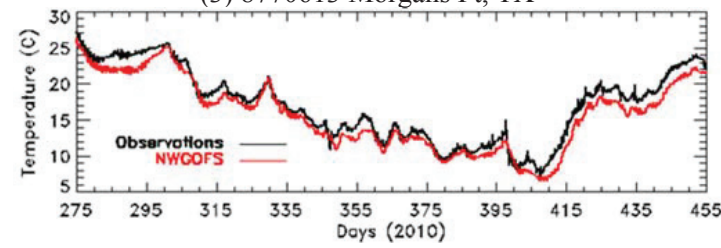

(4) TABSV_F TABS Buoy F, TX

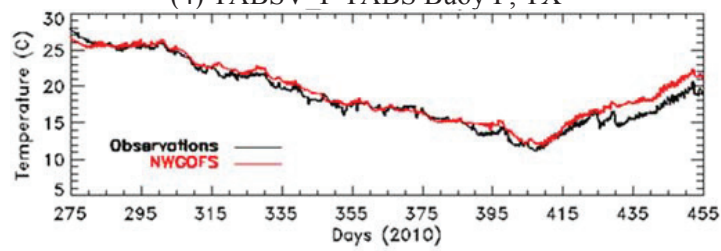

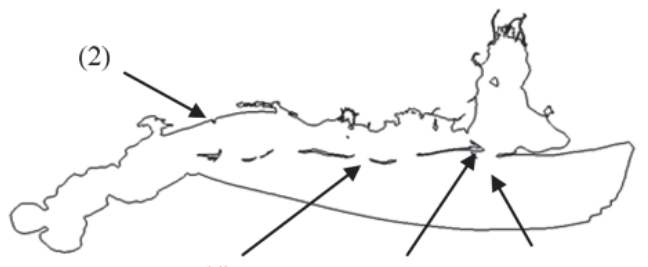

(4)
(3)

(1) $\mathrm{T}\left({ }^{\circ} \mathrm{C}\right)$ : Station 8735181

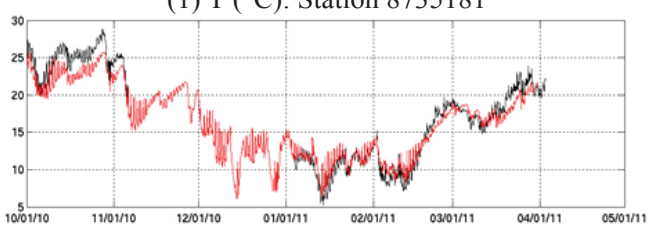

(2) $\mathrm{T}\left({ }^{\circ} \mathrm{C}\right)$ : Station gp0201t

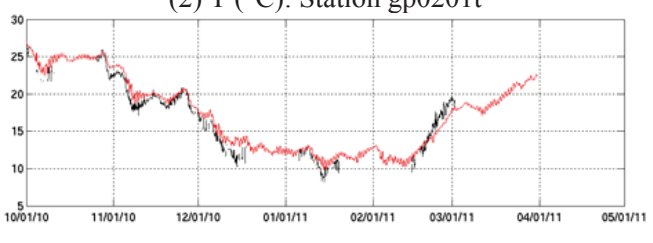

(3) $\mathrm{T}\left({ }^{\circ} \mathrm{C}\right)$ : Station mb0101t

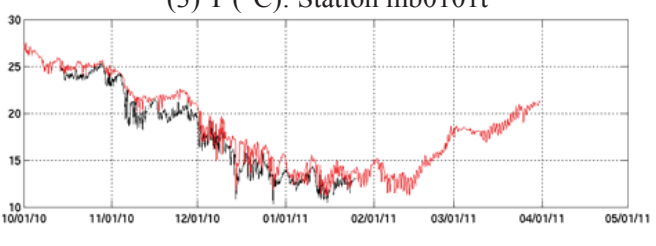

(4) $\mathrm{T}\left({ }^{\circ} \mathrm{C}\right)$ : Station ps0201t

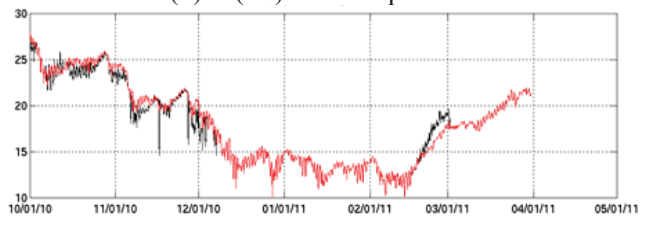


Figure 9. Simulated (red) and observed (black) near surface current speed time series at stations in NWGOFS (left column) and NEGOFS (right column) from 1 October 2010 to 1 April 2011.

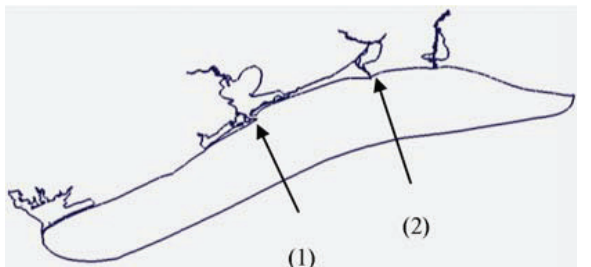

(1) g06010c Galves Ent, TX

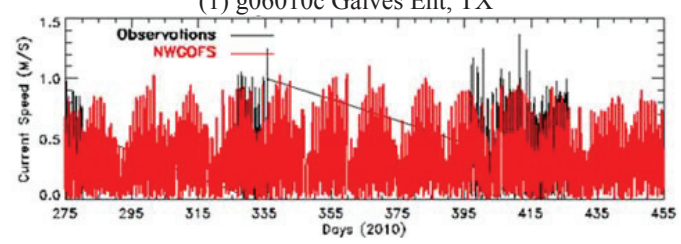

(2) sn0201c USCG Sabin, LA

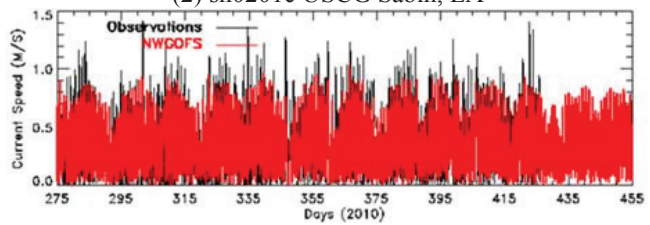

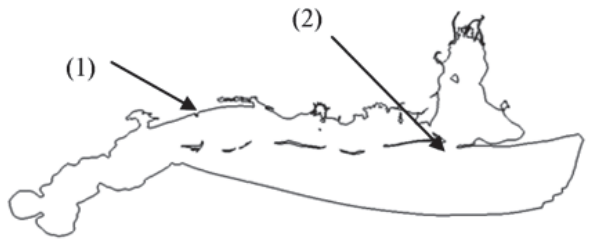

(1) Station: gp0401, Current speed, obs (blue), model (red)

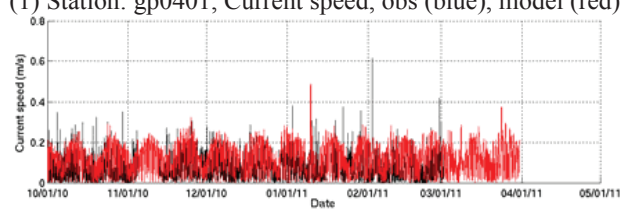

(2) Station: mb0101, Current speed, obs (blue), model (red)

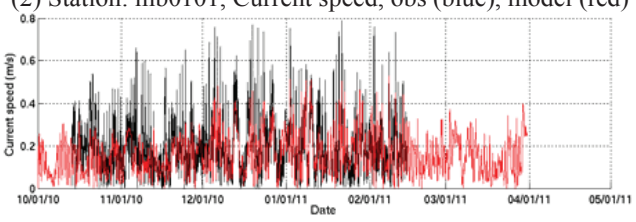

\section{Skill Assessment}

The model hindcast performance has been evaluated with the skill assessment by comparing simulated water level, current, and temperature time series with observation. The Root Mean Squared Deviation (RMSD), Standard Deviation, and Correlation Coefficient are calculated and plotted as concise Taylor Diagrams shown in Figure 10. The RMSD for water level is less than $10 \mathrm{~cm}$ for both NWGOFS and NEGOFS except at three locations. High correlation over around 0.95 for water level and temperature indicates good model hindcast skills. The current velocity correlation coefficient is under-performed compared to the water level and temperature.

The NWGOFS and NEGOFS model hindcast are also analyzed using NOS standard skill assessment software [13] to further quantify the model performance. Statistic parameters in the NOS skill assessment for operational forecast systems [14,15] include the Root Mean Squared Error (RMSE), Central Frequency (CF), and Positive Outlier Frequency (POF) and Negative Outlier Frequency (NOF). The NOS standard criteria $\left(0.15 \mathrm{~m}\right.$ for water level and $0.26 \mathrm{~m} \mathrm{~s}^{-1}$ for current speed) are greater than $90 \%$ for $\mathrm{CF}$ and less than $1 \%$ for NOF and POF. More detailed definitions of the above parameters can be found in Hess et al. [15].

The RMSE and CF for water level, current and temperature extracted from the detail skill assessment report can be presented as a skill summary map as shown in Figures 11-13 convenient for users and decision makers. The range of RMSE and CF are presented in three color categories; green (g), yellow (y), and red (r) with corresponding skill ranges shown in the figures. The water 
level CF satisfies the $90 \%$ NOS criteria except for one location west of Mississippi Sound where the sounding survey is not well covered. The temperature CF also exceeds $90 \%$.

Figure 10. Taylor Diagrams of water level, current, and temperature for NWGOFS (upper row) and NEGOFS (bottom row). Standard deviation, Correlation coefficient, and The Root Mean Squared Deviation (RMSD) are presented in one diagram.

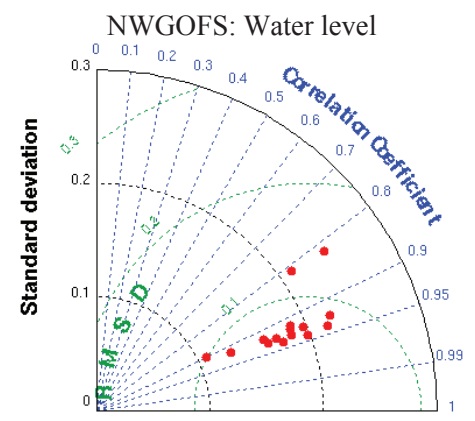

NEGOFS: Water level

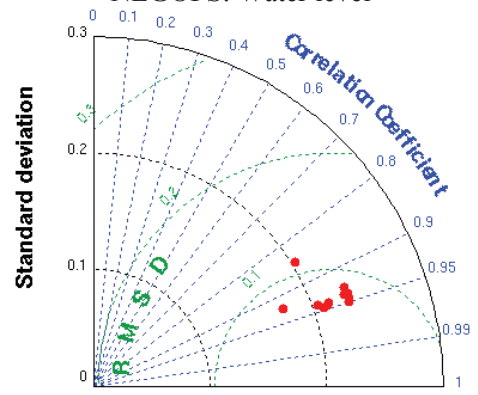

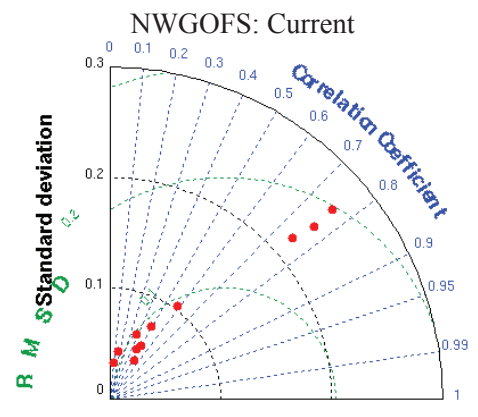

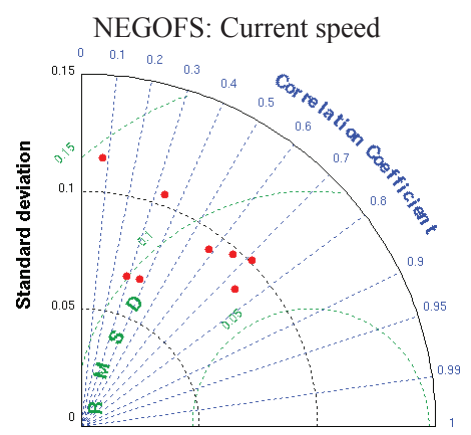

NWGOFS: Temperature

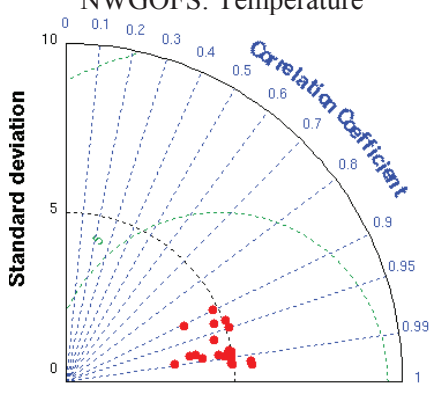

NEGOFS: Temperature

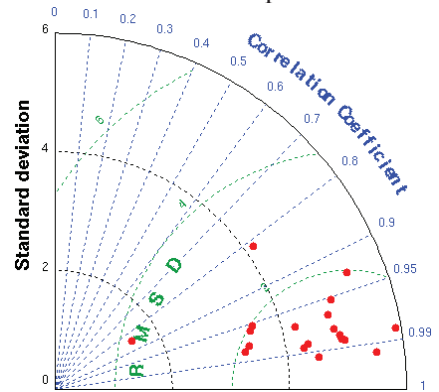

The water level and water temperature skill assessments from the nested NWGOFS and NEGOFS are compared with the parent model system NGOFS and listed in Tables 1 and 2. The station locations are shown in Figures 14 and 15. The nested NWGOFS and NEGOFS water level RMSEs (Table 1) are either comparable with or better than the parent NGOFS with NEGOFS water level skill show slight edge over NGOFS. No significant difference between the nested model temperature skill and the parent model. 
Figure 11. Hindcast water level RMSE and Central Frequency (CF) skill assessment summary map for NWGOFS (left column) and NEGOFS (right column).
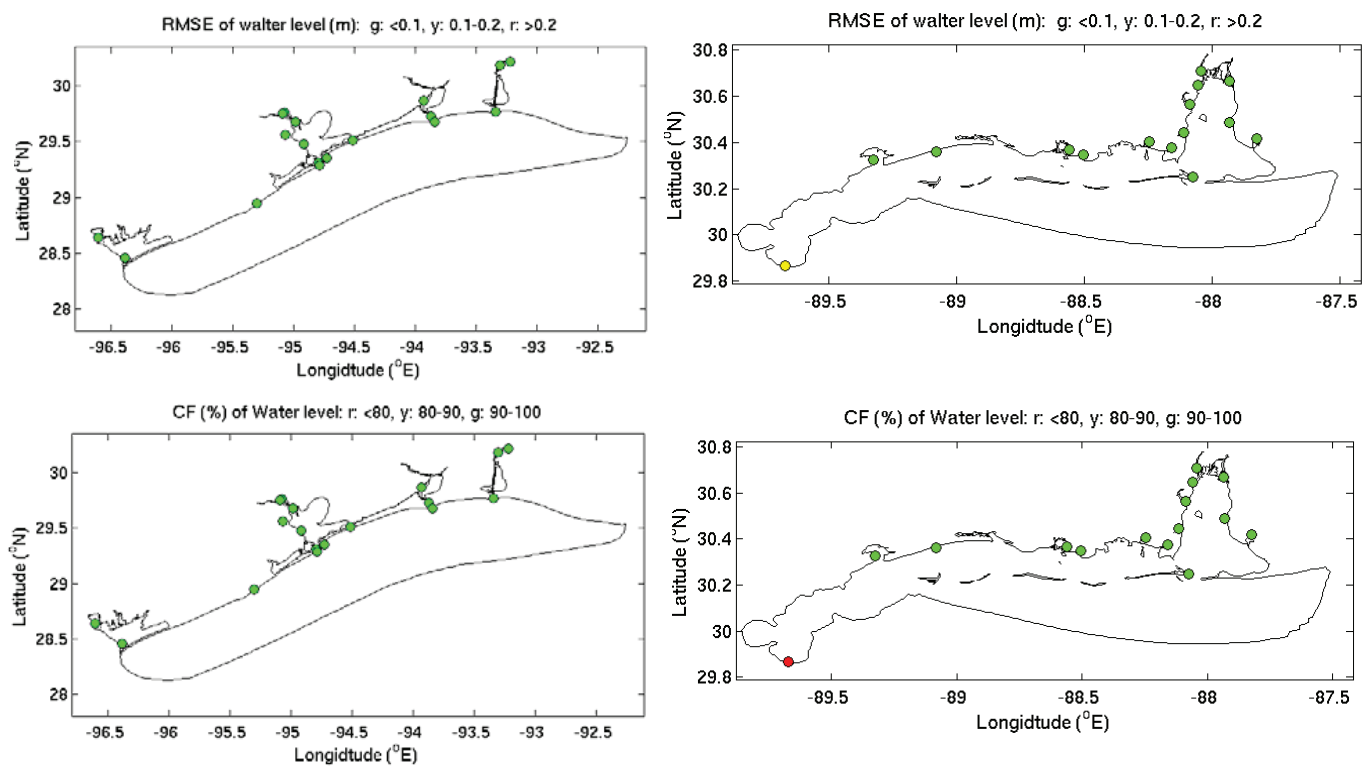

Figure 12. Hindcast current velocity RMSE and CF skill assessment summary map for NWGOFS (left column) and NEGOFS (right column).
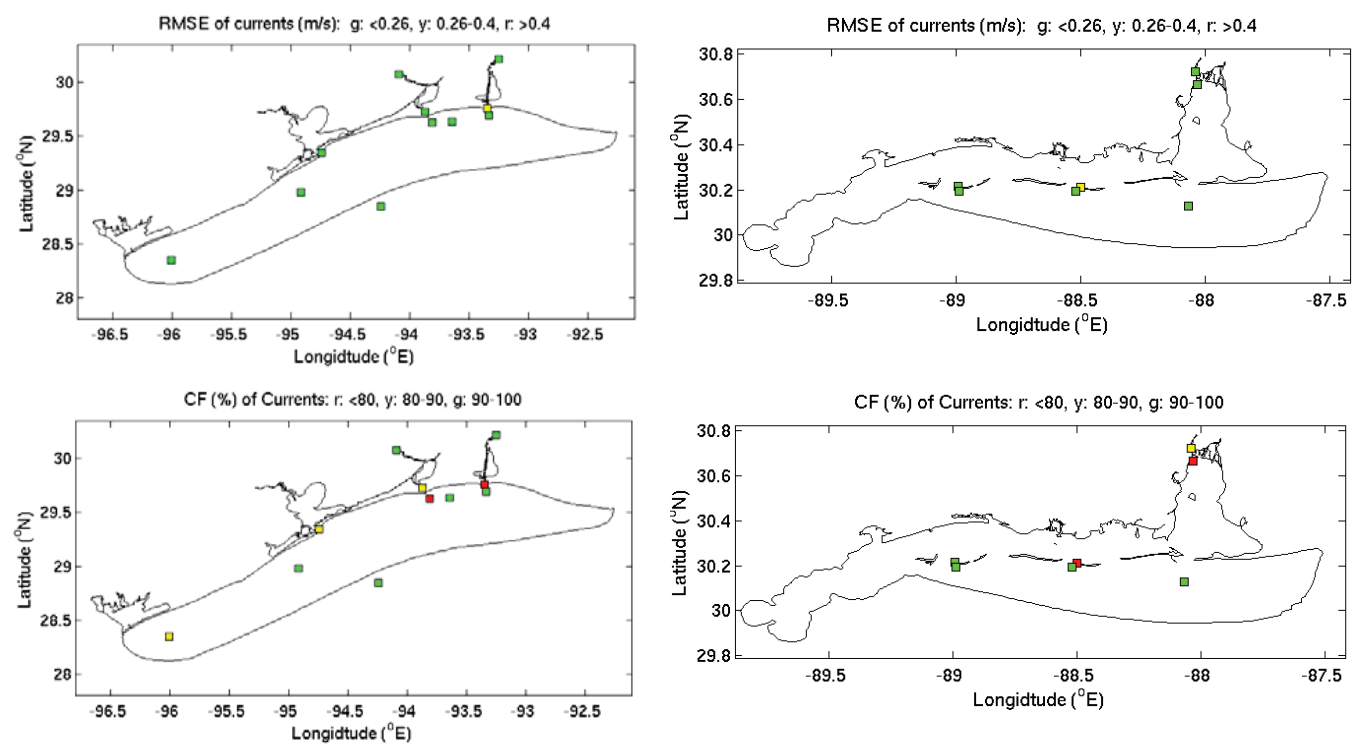
Figure 13. Hindcast temperature RMSE and CF skill assessment summary map for NWGOFS (left column) and NEGOFS (right column).
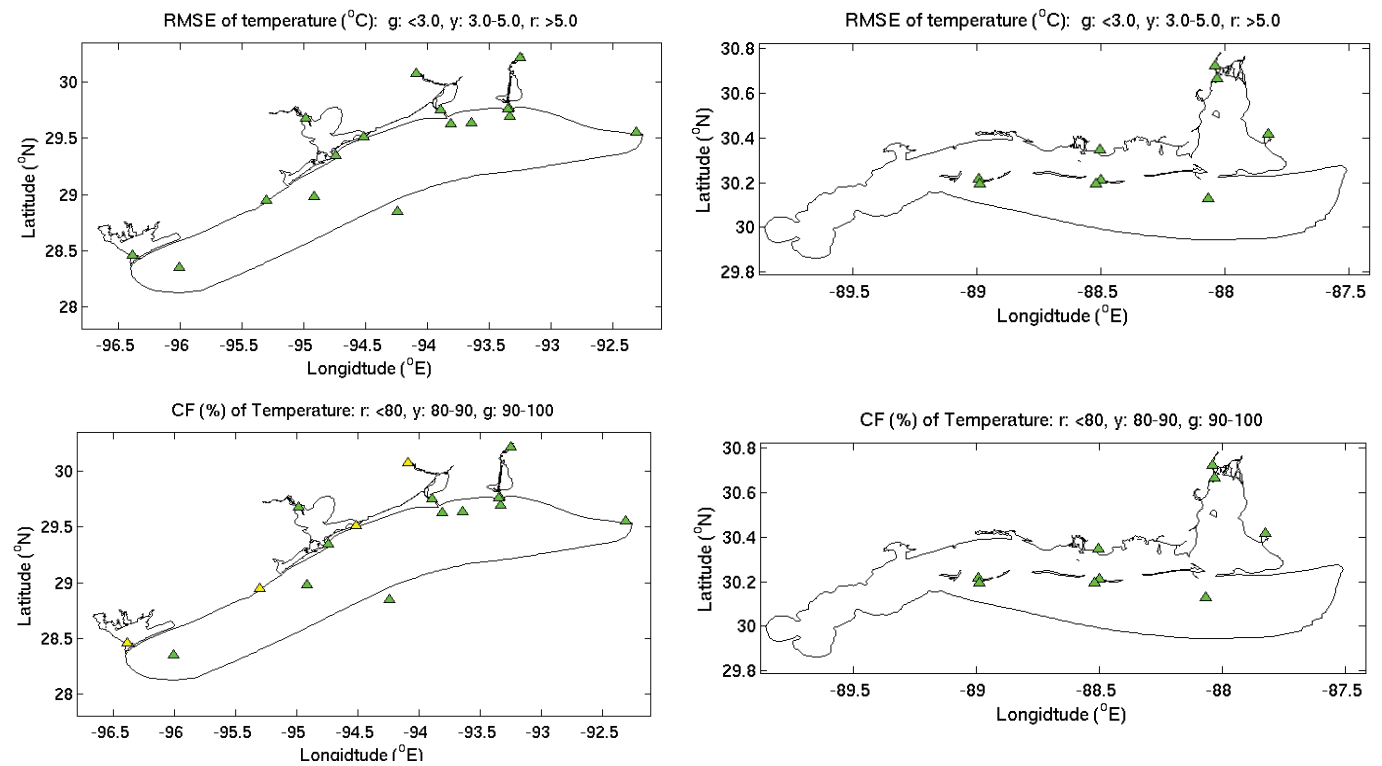

Table 1. Water level hindcast skill comparison between nested NGOFS and NGOFS.

\begin{tabular}{ccccccc}
\hline & \multicolumn{3}{c}{ RMSE (m) } & \multicolumn{2}{c}{ CF (\%) } \\
\cline { 2 - 7 } Station Name & Nested & NGOFS & Nested-NGOFS & Nested & NGOFS & Nested-NGOFS \\
\hline 1. Freshwater Canal Docks, LA & 0.12 & 0.12 & 0.00 & 80.6 & 82.0 & -1.4 \\
2. Calcasieu Pass, LA & 0.12 & 0.12 & 0.00 & 81.0 & 79.9 & 1.1 \\
3. Sabine Pass North, TX & 0.11 & 0.13 & -0.02 & 83.6 & 73.0 & 10.6 \\
4. Morgans Point, TX & 0.13 & 0.14 & -0.01 & 75.3 & 69.5 & 5.8 \\
5. Rollover Pass, TC & 0.11 & 0.10 & 0.01 & 82.5 & 84.5 & -2.0 \\
6. Eagle Point, TC & 0.10 & 0.08 & 0.02 & 85.0 & 95.6 & -9.4 \\
7. Galveston Pleasure Pier, TX & 0.11 & 0.10 & 0.01 & 80.3 & 85.5 & -5.2 \\
8. USCG Freeport, TC & 0.10 & 0.09 & 0.01 & 86.6 & 90.5 & -5.9 \\
9. Weeks Bay, AL & 0.10 & 0.12 & -0.02 & 85.7 & 76.9 & 8.8 \\
10. CG Mobile, AL & 0.12 & 0.15 & -0.03 & 79.8 & 67.7 & 12.1 \\
11. Mobile St Dock, AL & 0.13 & 0.15 & -0.02 & 73.8 & 68.3 & 5.5 \\
12. Pascagoula Dock, MS & 0.08 & 0.10 & -0.02 & 95.1 & 88.6 & 6.5 \\
13. Pascagoula NOAA, MS & 0.08 & 0.10 & -0.02 & 94.0 & 89.7 & 4.3 \\
14. Gulfport Harbor, MS & 0.09 & 0.12 & -0.03 & 92.0 & 80.7 & 11.3 \\
15. Bay Waveland, MS & 0.10 & 0.14 & -0.04 & 88.8 & 70.9 & 17.9 \\
16. Shell Beach, LA & 0.12 & 0.16 & -0.04 & 79.0 & 62.1 & 16.9 \\
\hline
\end{tabular}


Table 2. Temperature hindcast skill comparison between nested NGOFS and NGOFS.

\begin{tabular}{|c|c|c|c|c|c|c|}
\hline \multirow[b]{2}{*}{ Station Name } & \multicolumn{3}{|c|}{ RMSE (m) } & \multicolumn{3}{|c|}{ CF $(\%)$} \\
\hline & Nested & NGOFS & Nested-NGOFS & Nested & NGOFS & Nested-NGOFS \\
\hline 1. Calcasieu Pass, LA & 1.01 & 0.96 & 0.05 & 99.2 & 99.6 & -0.4 \\
\hline 2. Sabine Pass North, TX & 1.23 & 1.06 & 0.17 & 90.6 & 98.8 & -8.2 \\
\hline 3. Morgans Point, TX & 1.42 & 1.62 & 0.20 & 99.6 & 98.7 & 0.9 \\
\hline 4. Galves. Bay Channel LB 11, TX & 0.73 & 0.71 & 0.02 & 100. & 100. & 0.0 \\
\hline 5. USCG Freeport, TX & 2.26 & 2.32 & -0.06 & 89.4 & 87.9 & 1.5 \\
\hline 6. Calcasieu Channel LB 36, TX & 0.94 & 1.20 & -0.26 & 100. & 99.9 & 0.1 \\
\hline 7. Sabine Channel LBB 34, LA & 1.84 & 1.05 & 0.79 & 86.4 & 100. & -13.6 \\
\hline 8. CG Mobile, AL & 3.51 & 3.74 & -0.23 & 37.7 & 50.0 & -12.3 \\
\hline 9. Mobile St Dock, AL & 1.95 & 2.22 & -0.27 & 89.0 & 81.0 & 8.0 \\
\hline 10. Pascagoula Dock, MS & 2.85 & 2.41 & 0.44 & 61.2 & 71.4 & -10.2 \\
\hline 11. Pascagoula NOAA, MS & 1.12 & 1.21 & -0.09 & 100.0 & 98.6 & 1.4 \\
\hline 12. Bay Waveland, MS & 1.24 & 1.69 & -0.45 & 97.7 & 94.4 & 3.3 \\
\hline 13. Shell Beach, LA & 1.07 & 1.37 & -0.30 & 99.8 & 96.5 & 3.3 \\
\hline 14. Gulfport,LB22 MS & 0.93 & 0.84 & 0.09 & 99.7 & 100.0 & -0.3 \\
\hline 15. Gulfport,LB26 MS & 1.03 & 1.19 & -0.16 & 99.5 & 99.2 & 0.3 \\
\hline 16. GP Harbor WP, MS & 0.83 & 1.45 & -0.62 & 99.4 & 98.6 & 0.8 \\
\hline 17. MB Buoy M, AL & 1.49 & 1.44 & 0.05 & 96.9 & 98.0 & -1.1 \\
\hline 18. MB St Pier E, AL & 3.44 & 1.85 & 1.58 & 46.9 & 94.5 & -47.6 \\
\hline 19. MB Container Term, AL & 1.28 & 1.76 & -0.48 & 98.1 & 99.8 & -1.7 \\
\hline 20. Pascaga,LB17, MS & 0.86 & 1.06 & -0.20 & 100 & 99.4 & 0.6 \\
\hline
\end{tabular}

Figure 14. Station location maps for water level skill assessment comparison between nested NGOFS and NGOFS.
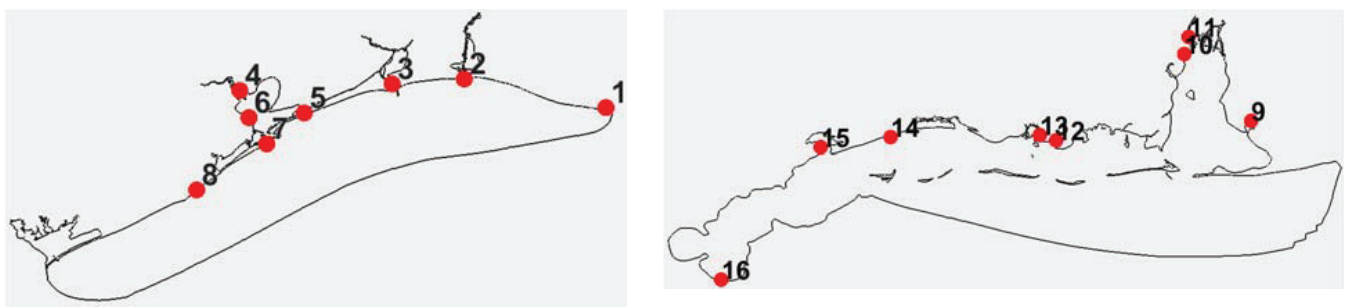

Figure 15. Station location maps for temperature skill assessment comparison between nested NGOFS and NGOFS.
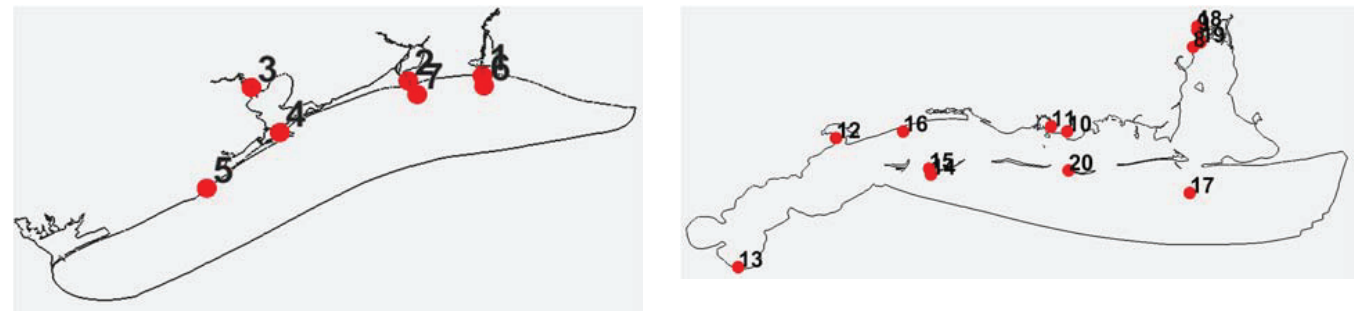


\section{Nowcast/Forecast Set-Up}

The NWGOFS and NEGOFS are in the process of setting up the real-time operational nowcast/forecast test on NCEP WCOSS [16]. The model systems will take operational NGOFS output at the open ocean nesting boundary for both nested models. Forced with 4-km NAM model's atmospheric wind, air pressure, and heat flux as the surface boundary condition, and USGS real-time river discharge and water temperature, the systems will run four cycles a day with $6 \mathrm{~h}$ nowcast and $48 \mathrm{~h}$ forecast to produce water level, current, salinity and temperature nowcast and forecast guidance. The NOS High Performance Computer Coastal Ocean Modeling Framework (HP COMF) [17] manages the pre- and post-process of NOS OFS including observed and modeled data ingestion, open and surface boundary condition generation, and reformatting nowcast and forecast guidance as products for displaying on the Internet. Examples of NGOFS operational products [18] are shown in Figure 16. The NWGOFS and NEGOFS are scheduled to be operational in June 2014 after the nowcast/forecast test and evaluation on NCEP WCOSS.

Figure 16. Surface elevation and temperature contours from NGOFS forecast guidance.

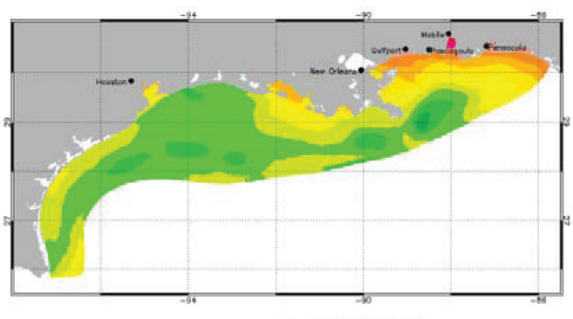

Volid ot 2200 (CDP) 10/31/13
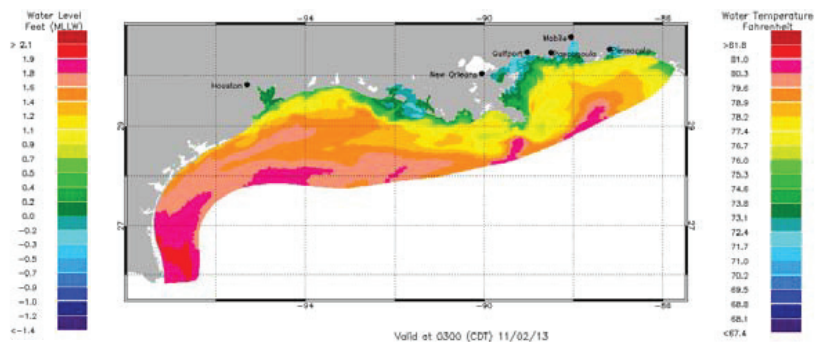

\section{Summary and Conclusions}

The nested NOGFS models NWGOFS and NEGOFS have been developed at NOS to provide days short term nowcast and forecast guidance of water level, current velocity, salinity and temperature over the model grid domain of the northwest and northeast Gulf of Mexico inland and coastal. The NWGOFS and NEGOFS cover six NOS PORTS ${ }^{\circledR}$ systems (Houston/Galveston, Sabine/Neches, Lake Charles, Gulfport, Pascagoula, and Mobile Bay) and one proposed PORTS ${ }^{\circledR}$ (Matagoda Bay) where NOS provides real-time information to the navigation community. The NWGOFS and NEGOFS are two inland forecast systems using the unstructured grid FVCOM developed by UMASS Dartmouth. A synoptic hindcast simulation covering the period of September 2010 to April 2011 has been conducted. The performance of NWGOFS and NEGOFS model hindcasts were evaluated through the NOS skill assessment software to compare the model simulated water level, current, temperature and salinity with the observations available from NOAA, TABS, and IOOS. The skill assessment has been briefly synthesized in graphics and presented in this paper. In general, the simulated water levels, current velocity, and water temperature meet the skill requirement of NOS. The average RMSE ranges from: 0.07 to $0.12 \mathrm{~m}$ for water level, 0.06 to $0.26 \mathrm{~m} \mathrm{~s}^{-1}$ for current speed, and 0.5 to $3.8^{\circ} \mathrm{C}$ for water temperature, respectively. 
The skill assessment results comparison between NWGOFS and NEGOFS hindcasts and NGOFS's hindcast for the same period indicates a slight skill edge to the nested models over the parent NGOFS model. However, nested models' higher resolution assists resolving detailed features that were unable to be resolved in NGOFS. Since the nesting approach in this application requires more computation resources to maintain three model systems, an alternative approach is replacing three models with a large model covering the entire nested and the parent model domain with same grid resolution. A future study will be carried out to evaluate the computation resource and skill differences between two approaches.

\section{Acknowledgement}

We thank our colleague Richard Schmalz for providing many suggestions and comments from his experience in San Francisco Bay OFS development (SFBOFS). Special thanks are to the FVCOM developers Changsheng Chen and Jianhau Qi of University of Massachusetts-Dartmouth for their support in providing the FVCOM code and upgrade in addition to the FVCOM model application assistance. We are grateful to Jianzhong Ge of East China Normal University, China, for providing information, suggestion, and discussion on the dike-groyne algorithm.

\section{Conflicts of Interest}

The authors declare no conflict of interest.

\section{References}

1. Sturges, W.; Lugo-Fernandez, A. Circulation in the Gulf of Mexico: Observations and Models; American Geophysical Union: Washington, DC, USA, 2005.

2. Nowlin, W.; Jochens, A.; DiMarco, S.; Reid, R.; Howard, M. Low-Frequency Circulation Over the Texas-Louisiana Continental Shelf. In Circulation in the Gulf of Mexico: Observations and Models; Sturges, W., Lugo-Fernandez, A., Eds.; American Geophysical Union: Washington, DC, USA, 2005; pp. 219-240.

3. Morey, S.; Zavala-Hidalgo, J.; O'Brien, J.J. The Seasonal Variability of Continental Shelf Circulation in the Northern and Western Gulf of Mexico from a High-Resolution Numerical Model. In Circulation in the Gulf of Mexico: Observations and Models; Sturges, M., Lugo-Fernandez, A., Eds.; American Geophysical Union: Washington, DC, USA, 2005; pp. 203-218.

4. Chen, C.; Liu, H.; Beardsley, R. An Unstructured Grid, Finite-Volume, Three-Dimensional Primitive Equations Ocean Model: Application to Coastal Ocean and Estuaries. J. Atmos. Ocean. Technol. 2003, 20, 159-186.

5. Chen, C.; Huang, H.; Beardsley, R.; Liu, H.; Xu, Q.; Cowles, G. A finite volume numerical approach for coastal ocean circulation studies: Comparisons with difference models. J. Geophys. Res. 2007, 112, C03018. 
6. Chen, C.; Beardsley, R.; Cowles, G.; Qi, J.; Lai, Z.; Gao, G.; Stuebe, D.; Xu, Q.; Xue, P.; Ge, J.; et al. An Unstructured Grid, Finite-Volume Coastal Ocean Model FVCOM User Manual; UMASS Dartmouth: New Bedford, MA, USA, 2013; p. 416.

7. Wei, E.; Yang, Z.; Chen, Y.; Kelley, J.; Zhang, A. The Northern Gulf of Mexico Operational Forecast System (NGOFS): Model Development and Skill Assessment; NOAA Technical Report NOS CS3; Silver Spring: Maryland, MD, USA, 2013; p. 202.

8. FVCOM Publication List. Available online: http://fvcom.smast.umassd.edu/ Extra/publication.html (accessed on 10 November 2013).

9. Northeast Coastal Ocean System. Available online: http://fvcom.smast.umassd.edu/ research_projects/NECOFS/index.html (accessed on 15 November 2013).

10. Ge, J.; Chen, C.; Qi, J.; Ding, P.; Beardsley, R.C. A dike-groyne algorithm in a terrain-following coordinate ocean model (FVCOM): Development, validation and application. Ocean Model. 2012, 47, 26-40.

11. Cheng, R.T.; Casulli, V.; Gartner, J.W. Tidal, Residual, Intertidal Mudflat (TRIM) Model and Its Applications to San Francisco Bay California. Estuar. Coast. Shelf Sci. 1993, 36, 235-280.

12. Schmalz, R. Three-Dimensional Hydrodynamic Model Developments for the San Francisco Bay Nowcast/Forecast System; NOAA Technical Report NOS CS33; Silver Spring: Maryland, MD, USA, 2013.

13. Zhang, A.; Hess, K.W.; Wei, E.; Myers, E. Implementation of Model Skill Assessment Software for Water Level and Current in Tidal Regions; NOAA Technical Report NOS CS24; Silver Spring: Maryland, MD, USA, 2006; p. 61.

14. Zhang, A.; Hess, K.W.; Aikman, F. User-based Skill Assessment Techniques for Operational Hydrodynamic Forecast Systems. J. Oper. Oceanogr. 2010, 3, 11-24.

15. Hess, K.H.; Gross, T.; Schmalz, R.; Kelley, J.; Aikman, F.; Wei, E.; Vincent, M. NOS Standards for Evaluating Operational Nowcast and Forecast Hydrodynamic Model Systems; NOAA Technical Report NOS CS17; Silver Spring: Maryland, MD, USA, 2003; p. 47.

16. Tide \& Gyer New NOAA Supercomputers. Available online: http://www.nwas.org/committees/ waf/new_supercomputer.php (accessed on 13 December 2013).

17. Zhang, A.; Yang, Z.; Greg, M.; Cao, D.; Aikman, F.; Kelley, J.; Wei, E.; Schmalz, R.; Lanerolle, L.; Vincent, M. High Performance Computer Coastal Ocean Modeling Framework for the NOS Costal Operational Forecast System; NOAA Technical Report CO-OPS TRXX, 2013, Unpublished work.

18. Northern Gulf of Mexico Operational Forecast System. Available online: http://tidesandcurrents.noaa.gov/ofs/ngofs/ngofs.html (accessed on 15 November 2013). 


\title{
Hydrodynamic Modeling Analysis to Support Nearshore Restoration Projects in a Changing Climate
}

\author{
Zhaoqing Yang, Taiping Wang, Dave Cline and Brian Williams
}

\begin{abstract}
To re-establish the intertidal wetlands with full tidal exchange and improve salmonid rearing habitat in the Skagit River estuary, State of Washington, USA, a diked agriculture farm land along the Skagit Bay front is proposed to be restored to a fully functional tidal wetland. The complex and dynamic Skagit River estuarine system calls for the need of a multi-facet and multi-dimensional analysis using observed data, numerical and analytical methods. To assist the feasibility study of the restoration project, a hydrodynamic modeling analysis was conducted using a high-resolution unstructured-grid coastal ocean model to evaluate the hydrodynamic response to restoration alternatives and to provide guidance to the engineering design of a new levee in the restoration site. A set of parameters were defined to quantify the hydrodynamic response of the nearshore restoration project, such as inundation area, duration of inundation, water depth and salinity of the inundated area. To assist the design of the new levee in the restoration site, the maximum water level near the project site was estimated with consideration of extreme high tide, wind-induced storm surge, significant wave height and future sea-level rise based on numerical model results and coastal engineering calculation.
\end{abstract}

Reprinted from J. Mar. Sci. Eng. Cite as: Yang, Z.; Wang, T.; Cline, D.; Williams, B. Hydrodynamic Modeling Analysis to Support Nearshore Restoration Projects in a Changing Climate. J. Mar. Sci. Eng. 2014, 2, 18-32.

\section{Introduction}

Estuarine wetland provides important fish habitats for salmon during their juvenile rearing period before they migrate from freshwater to the saltwater environment [1]. However, population shift and land use change over the past century have resulted in a significant impact on the coastal ecosystem and the associated marine wildlife. Construction of dikes in estuarine and coastal systems for protection of agriculture land use has eliminated the natural tidal exchange to the agriculture farm land, altered tidal prism, and changed the sedimentation pattern in estuarine systems. The Skagit River, located in the Whidbey Basin, is the largest river in Puget Sound and is responsible for about $34 \%-50 \%$ of the total freshwater flow into Puget Sound (Figure 1). Over the past century, urban development and construction of dikes for agriculture land use have caused significant losses of nearshore habitat and impact on salmon migration in the Skagit River, Port Susan Bay and Lower Snohomish River in Whidbey Basin of Puget Sound. To protect and improve estuarine habitats that are vital to marine wildlife, many nearshore restoration projects are currently underway to restore estuarine habitats and improve fish migration pathway through dike breaches, setbacks, and removals in the Puget Sound region.

Coastal hydrodynamic models have been used extensively to support nearshore restoration actions and provide vital hydrodynamic information to guide the restoration engineering design in 
Whidbey Basin. For example, Yang et al. [2] applied a coastal hydrodynamic model to help select and design restoration alternatives in Skagit River Delta for improvement of estuarine habitats and salmon migration. Lee et al. [3] conducted a hydrodynamic and sediment transport modeling analysis to evaluate the feasibility of restoring natural fish habitat in Cottonwood Island, approximately $16 \mathrm{~km}$ upstream from the mouth of Skagit River estuary. Yang et al. [4] investigated the cumulative effects of multiple nearshore restoration projects on estuarine hydrodynamics in the Lower Snohomish River estuary, the second largest river in Puget Sound. Yang et al. [5] conducted a hydrodynamic and ecological assessment of a nearshore restoration project in Port Susan Bay in Whidbey Basin. Yang and Wang [6] simulated the drainage process of a restored intertidal wetland in the Snohomish River estuary using a high-resolution hydrodynamic model with spatial varying bottom roughness to better represent the high bottom roughness due to the presence of dense vegetation. An integrated modeling approach was taken to link the inundation process in the upstream river floodplain and the downstream intertidal zone for fish habitat restoration and flood management in the middle Skagit River, estuary and bay system [7].

Figure 1. Puget Sound estuarine system (left) and Skagit River Estuary (right). Red circle indicates the location of the restoration project site.
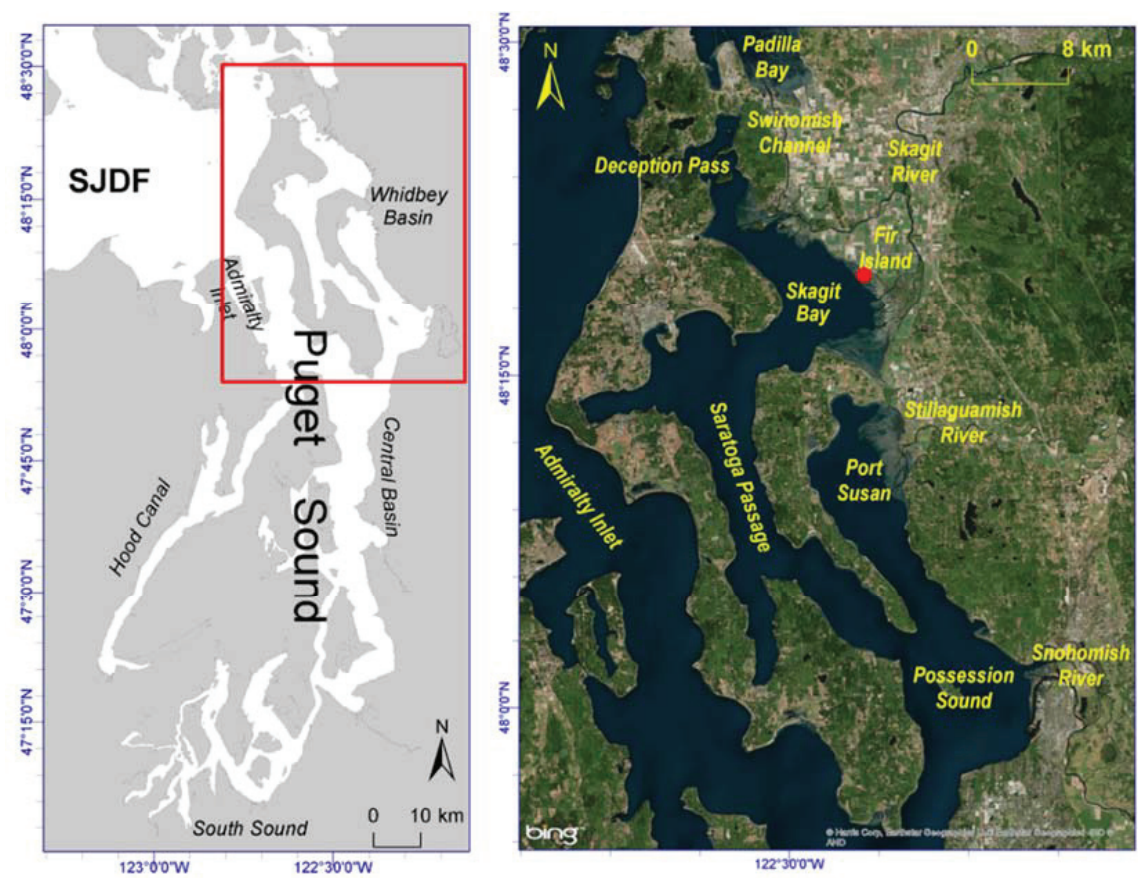

In this paper, a three-dimensional (3D) unstructured-grid finite volume coastal ocean model (FVCOM) was applied to simulate the tidal circulation in the Skagit River estuary and assist an estuarine restoration project in Fir Island, a large river delta bounded by the North Fork and South Fork of Skagit River. The numerical model was used to evaluate the hydrodynamic response of different restoration configurations and assist the selection of a preferred restoration alternative for 
engineering design. A set of hydrodynamic parameters were calculated based on model results to quantify the outcome of nearshore restoration. To assist the design of a new levee, a practical approach based on numerical model results and coastal engineering calculation was proposed to estimate the maximum water level that accounts for the combined effects of extreme high tide, significant wave height, wind-induced storm surge and future sea-level rise as a result of climate change.

\section{Methodology}

\subsection{Study Site}

Skagit Bay connects to Puget Sound and the Strait of Juan de Fuca (SJDF) through three pathways. The main pathway for water exchange with Puget Sound is the Saratoga Passage of Whidbey Basin from the south, which connects to the Central Basin of Puget Sound. Deception Pass connects Skagit Bay from the east to SJDF, and the Swinomish Channel connects Skagit Bay from the north to Padilla Bay (Figure 1). The Skagit River enters Skagit Bay through the North Fork and the South Fork branches. A significant portion of Skagit Bay is covered by shallow-water tide flats. The water depth in the Skagit Bay front is very shallow. The average bed elevation in the bay front area near the project site is approximately $2.5 \mathrm{~m}$ relative to NAVD88. The large river delta between the North Fork and South Fork is Fir Island. Fir Island has been extensively diked for flood protection for agricultural land use. The Washington Department of Fish and Wildlife is conducting the Fir Island Farm Restoration project along Skagit Bay front to restore tidal exchange and improve salmonid rearing habitat. The project involves setting back an existing dike and restoring approximately 127 acres of tidal wetland. The project site in the existing (pre-restoration) condition is bounded by Brown Slough on the west and Dry Slough on the east, Fir Island Road on the north and bay front dike on the south. There are two drainage channels inside the project site, the No Name Slough and Claude O. Davis Slough (Figure 2). Interior drainage runoff (Brown Slough, No Name Slough, and Dry Slough) in the project site is very small and assumed to be zero in the modeling analysis.

\subsection{Hydrodynamic Modeling Analysis}

The coastal hydrodynamic model used in this study is FVCOM [8]. FVCOM is a 3D, unstructuredgrid, finite volume coastal ocean model with a robust capability of simulating wetting and drying processes in the intertidal zone. FVCOM solves the 3D momentum, continuity, temperature, salinity, and density equations in an integral form for water-surface elevation and flow fields. Companion modules for sediment transport, water-quality kinetics, and biological models are also integrated into FVCOM, but were not used in this study. The model computes water depths, velocities, salinities and water-surface elevations based on the geometry and bathymetry of the system, the specified lateral and vertical boundary conditions, and model input parameters. FVCOM has been extensively applied to study tidal hydrodynamics, estuarine circulation and transport processes in Puget Sound [2-7,9]. 
Figure 2. Restoration project site-Fir Island Farm (left) and model grid for the restoration site (right).

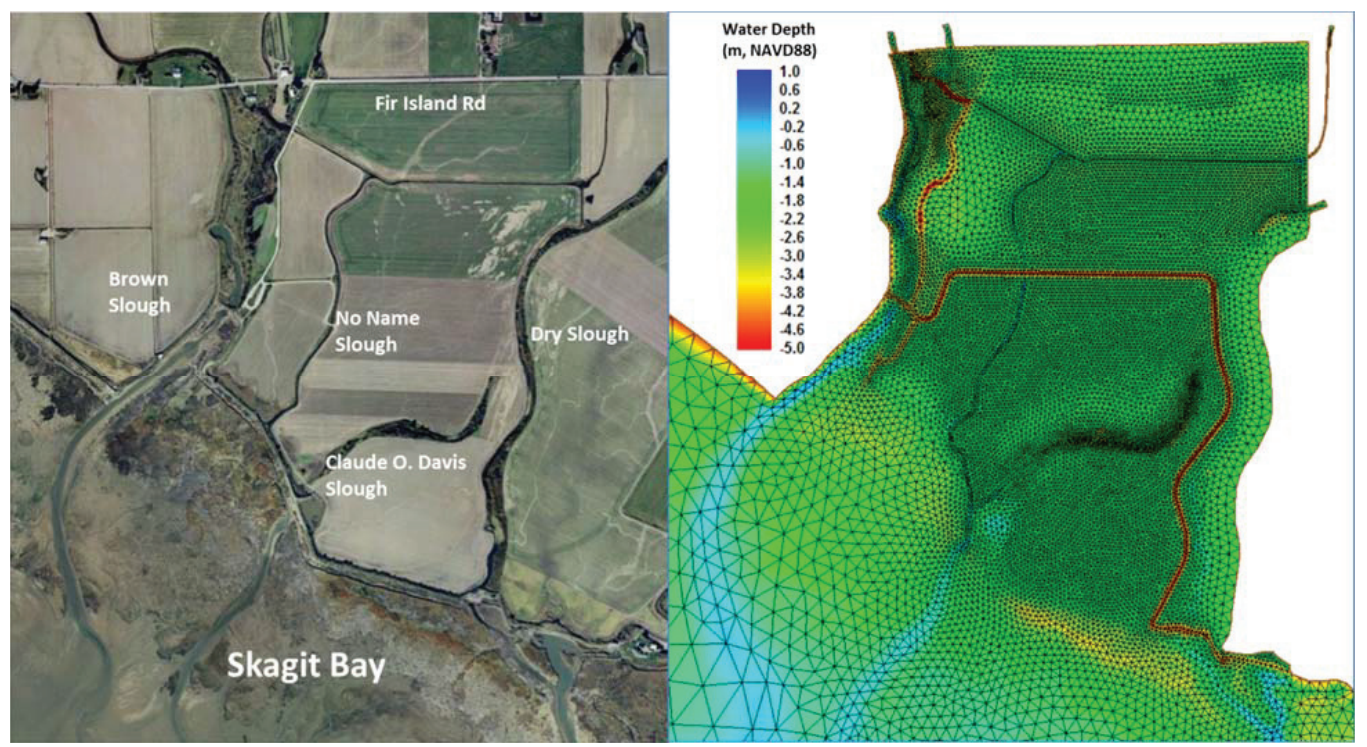

The Skagit River estuary model is a sub-domain model of the larger Puget Sound and Pacific Northwest Straits model [9] with further modification in the Fir Island Farm restoration project site (Figure 3). Model bathymetry was interpolated using high-resolution Digital Elevation Model (DEM) data from the University of Washington and LIght Detection And Ranging (LIDAR) data from the Puget Sound LIDAR Consortium. The model consists of 20,454 nodes, 38,400 elements, and 10 uniform vertical layers. The average grid size inside the Fir Island Farm project site is about $16 \mathrm{~m}$. The model has three open boundaries, which are located in Saratoga Passage, Deception Pass and Swinomish Channel, respectively.

The model was set up to simulate the hydrodynamics in the Skagit River estuary for a one-month period (15 March 2003 to 15 April 2003), which represents the spring juvenile Chinook migration season. The tidal surface elevations at the open boundaries were specified using XTIDE predictions at Greenbank, Yokeko Point and Swinomish Channel Entrance stations (Figure 3). The model upstream boundary condition was specified by the Skagit River flow obtained from the US Geological Survey stream gage at Mt. Vernon station. Surface wind data was obtained from the National Oceanic and Atmospheric Administration (NOAA) weather station in Whidbey Island (Figure 3) and applied to the entire model domain uniformly. No salinity data available near the open boundaries for the model simulation period. Salinity boundary conditions were specified as 30 ppt at all the open boundaries through the water column based on historical observations. Salinity at the upstream river boundary was specified as zero. Initial conditions for water-surface elevation, velocity, and salinity were all set to zero. 
Figure 3. (Finite volume coastal ocean model) FVCOM grids of Puget Sound (left) and Skagit River Estuary (right).

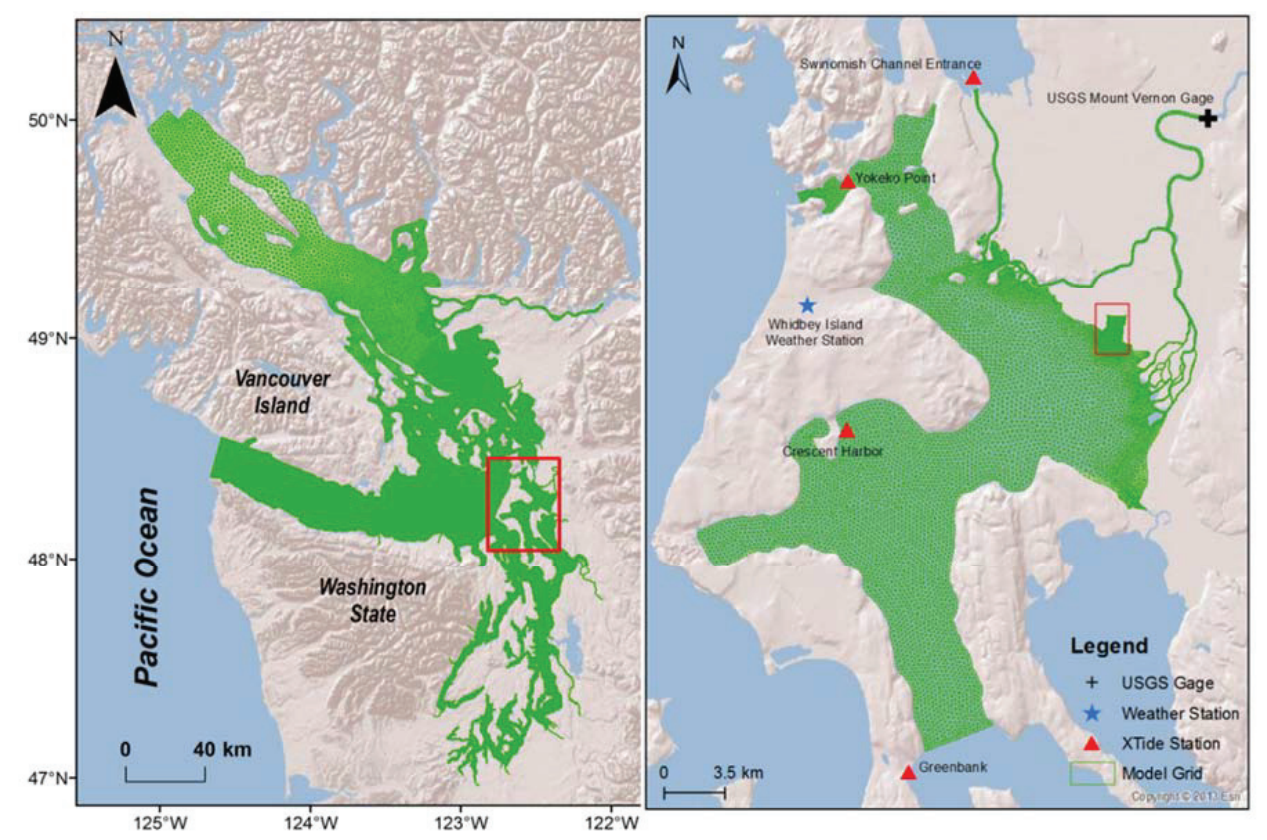

\subsection{Estimate of 100-Year Maximum Water Level}

Many of the nearshore restoration projects involve dike setback, removal and construction of new dike. To evaluate the risk of flooding or overtopping on the new dike around the restored project site under extreme high tide, storm surge, and future sea-level rise conditions, the 100-year maximum water level in the Skagit Bay front near the project site was estimated. It was assumed the restoration project would not affect the maximum water level because it was estimated at a bay front location outside the project site. An analysis that combines numerical model results, observed data, and engineering calculation was used to estimate the 100-year maximum water level $\eta_{\max }$ near the project site. Specifically, water-surface elevation was determined based on four components: (1) extreme tidal elevation; (2) wave run-up; (3) wind-induced storm surge under restored condition; and (4) long term sea-level rise. The 100-year maximum water level $\eta_{\max }$ is computed as the sum of the following four components:

$$
\eta_{\max }=\eta_{\text {tide }}+\eta_{\text {surge }}+\eta_{\text {wave }}+\eta_{\text {slr }}
$$

where $\eta_{\text {tide }}$ is the extreme tidal elevation, $\eta_{\text {surge }}$ is the water-surface elevation caused by storm surge, $\eta_{\text {wave }}$ is the wave run-up induced by wind waves, and $\eta_{s l}$ is the change in water level due to sea-level rise. It is assumed that there is no significant stream flow discharged into the project site because the interior drainage flows in the project site are very small compared to the tidal prism. To account for the nonlinear interaction between these forcing mechanisms and their effects on the 
100-year maximum water level in the project site, a dynamically-coupled modeling approach is necessary to estimate the 100-year maximum water level.

\section{Results and Discussion}

\subsection{Hydrodynamics for the Baseline Condition}

The hydrodynamic model of Skagit River estuary was first applied to simulate the tidal circulation under the baseline (pre-restoration) condition. Because field observations were unavailable for the simulation period 15 March-15 April 2003, the model results were compared to XTide prediction at Crescent Harbor station inside the model domain (Figure 3). Figure 4 shows that the simulated water level matched the XTide data very well, indicating the Skagit River estuary model is able to simulate the tidal hydrodynamics in the Skagit Bay properly.

Figure 4. Comparison of water-surface elevations between model results and XTide prediction at Crescent Harbor station.

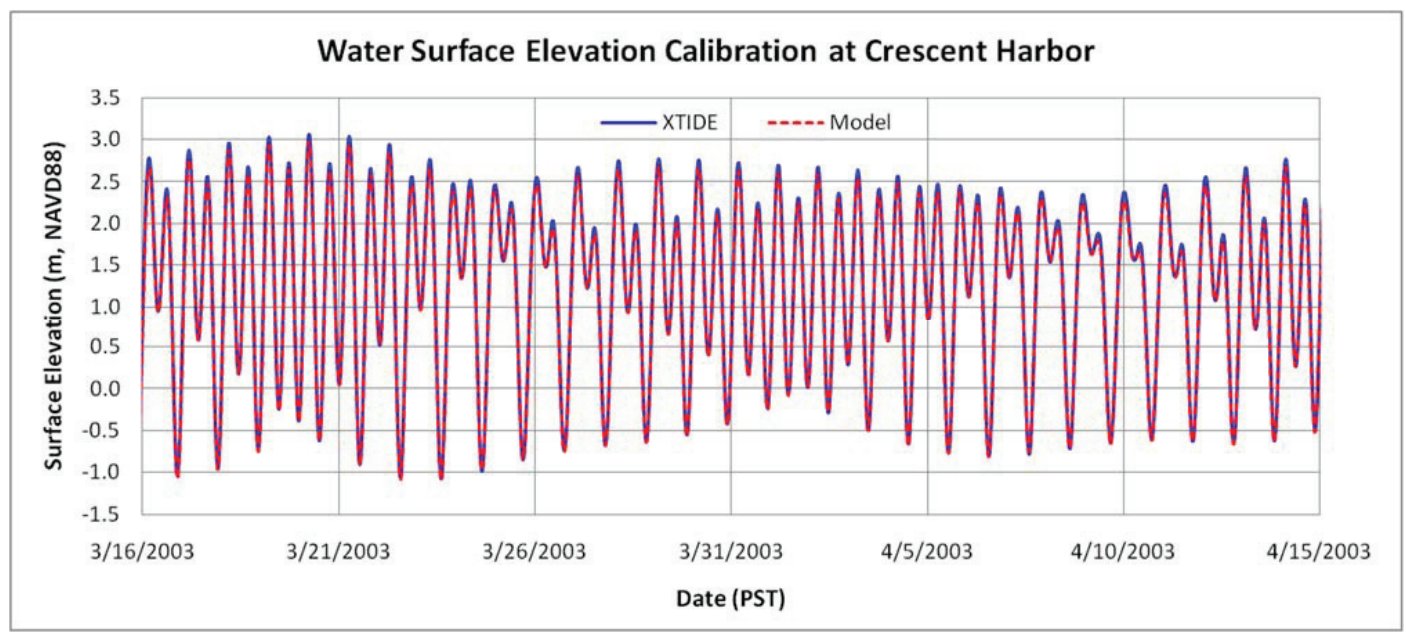

Depth-average horizontal two-dimensional (2D) velocity and salinity distributions were generated and examined in Skagit Bay at four different tidal phases. Figure 5 shows the instantaneous depth-average velocity and salinity distributions at low tide, flood tide, high tide and ebb tide under baseline condition in Skagit River estuary. Significant parts of Skagit Bay were occupied by the Skagit River plume with salinity less than 5 ppt during low tide (Figure 5a). Large areas of tide flats were exposed (blank areas) and velocities in the tide flat region were very small. At flood tide (Figure 5b), velocities in Skagit Bay increased and the freshwater plume was pushed shoreward. At high tide (Figure 5c), brackish water only remained in a very narrow region along the bay front dikes and velocities in the bay became small (slack before ebbing). Salinity and velocity distributions at ebb tide (Figure 5d) were somewhat similar to those at flood tide (Figure 5b) except velocity directions in bay were revised and the river plume was pushed seaward. 
Figure 5. Instantaneous depth-average velocity and salinity at low tide (a); flood tide (b); high tide (c); and ebb tide (d) in Skagit River estuary under baseline condition.

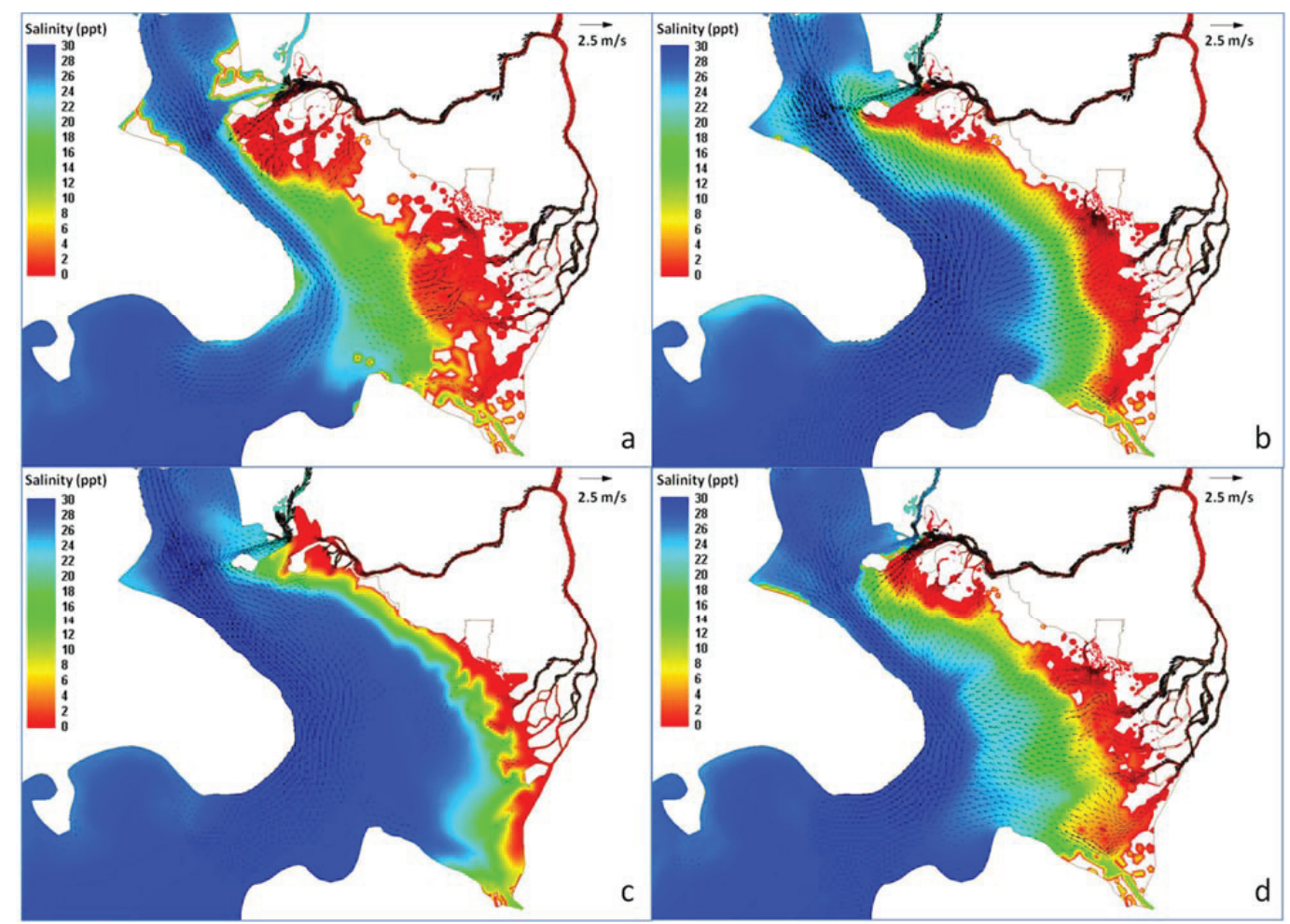

\subsection{Hydrodynamics for the Restoration Condition}

Once the hydrodynamics in the Skagit River estuary under the baseline condition was established, the model was applied to simulate the hydrodynamic responses under different restoration configurations. Model results of the final preferred restoration alternative were presented here. The preferred restoration alternative involved removal of the exterior dike to the end of the public access trail on the western section of the existing dike, extension of the spur dike across the adjacent tidal channel to limit hydrodynamic effects on Brown Slough, placement of a new dike at the northern and eastern boundaries of the project site, addition of small drainage channels within the project site, and deepening of the existing interior drainage channels of No Name and Claude O. Davis Sloughs. The new model grid for the preferred alternative consists of 23,840 nodes and 45,171 elements. To resolve the small features in the restored condition, such as the change of inchannel bathymetry in the project site, the model grid resolution was further refined to as small as 5 $\mathrm{m}$ (Figure 2). The model setup for the preferred alternative covered the same modeling period, from 15 March 2003 to 15 April 2003, as that used for the baseline condition. The boundary conditions for tidal forcing, surface wind, and Skagit River flow were also kept the same as those used for the baseline condition. 
Figure 6. Instantaneous water depth and depth-averaged velocity at low tide (a); flood tide (b); high tide (c); and ebb tide (d) under preferred restoration alternative.

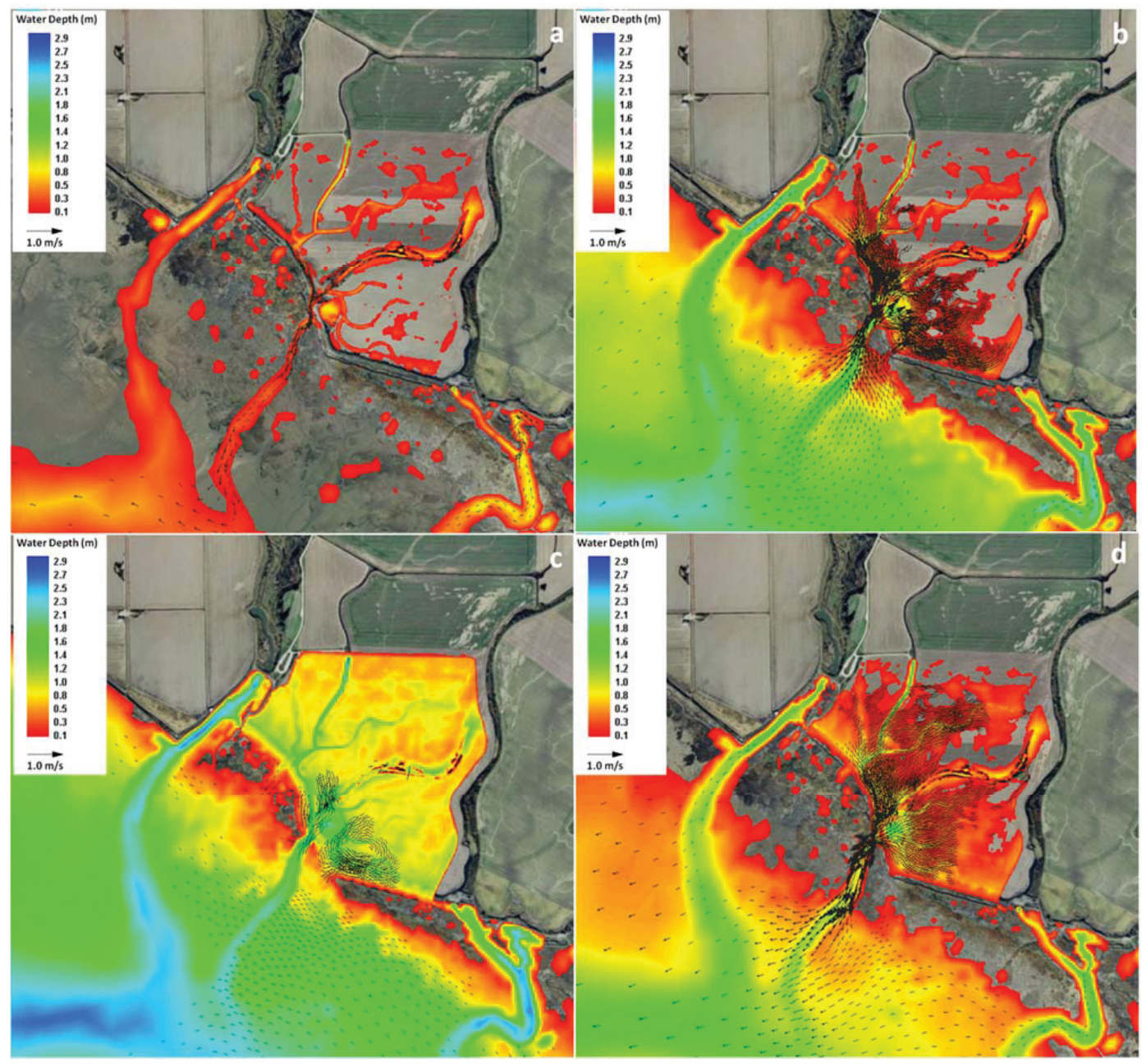

Instantaneous distributions of depth-average velocity and salinity at four tidal phases in the restoration project site under the preferred alternative are shown in Figure 6. Figure 6a shows that during low tide most of the project site becomes dry (water depth $<0.05 \mathrm{~m}$ ) and water drains out from the restoration site via Claude O. Davis Slough. When Skagit Bay begins to flood (Figure 6b), the project site is primarily flooding from Claude O. Davis Slough. Strong velocities $(>1 \mathrm{~m} / \mathrm{s})$ are seen at the channel openings to the project site. At high tide (Figure 6c), the project site is fully inundated and velocities are generally very small $(<0.03 \mathrm{~m} / \mathrm{s})$ in most parts of the restoration site. Similar to flood tide, drainage from the project site occurs primarily via Claude O. Davis Slough during ebb tide and strong velocities are seen near the mouths of the channels (Figure 6d). Based on the velocity distributions, the channel mouths may expect some initial erosion when the project site is restored but will become stabilized as the channels reach dynamic equilibrium. Based on the 
2D plots, it is expected that the spur dike constructed to the east of Brown Slough would effectively block the tidal exchange between Brown Slough and the restoration site.

The hydrodynamic response in the restoration site was quantified by a set of hydrodynamic parameters, including volume of water in the inundated area, percentage of inundated area, water depth and salinity of inundated area in the project site (Figure 7). These parameters were calculated using the hydrodynamic model results for the preferred restoration alternative. The volume of water in the project site shows strong spring-neap tidal cycle. The time series plot of the percentage of inundated area shows that almost the entire project site (100\%) is inundated during high tide and approximately $25 \%$ of the project site remains wet during low tide. The average water depth of the inundated area in the project site varies from $0.25 \mathrm{~m}$ at low tide to $1.14 \mathrm{~m}$ at high tide. The temporal average of water depth over a 14-day period is about $0.35 \mathrm{~m}$, indicating the water depth in the inundated area is very shallow most of the time, as shown in Figure 7. Spatial average salinity in the project site is very low, typically in the range of 0.5 to $2.5 \mathrm{ppt}$. Salinity time series shows strong tidal variation but weak correlation to spring-neap cycle.

Spatial distribution of percentage of inundation time over a spring-neap tidal cycle in the Fir Island Farm restoration project site was also calculated based on the model results. Figure 8 shows high variation of inundation time in the project site. Most of the upstream area in the project site is inundated under less than $20 \%$ of the time. The percentage of inundation time increases gradually seaward and becomes greater than 50\% near the bay front. As expected, in the drainage channels, such as No Name Slough and Claude O. Davis Slough, the percentage of inundation time is 100\%, indicating that there is always water in the drainage channels.

Figure 7. Hydrodynamic parameters for characterization of nearshore restoration.

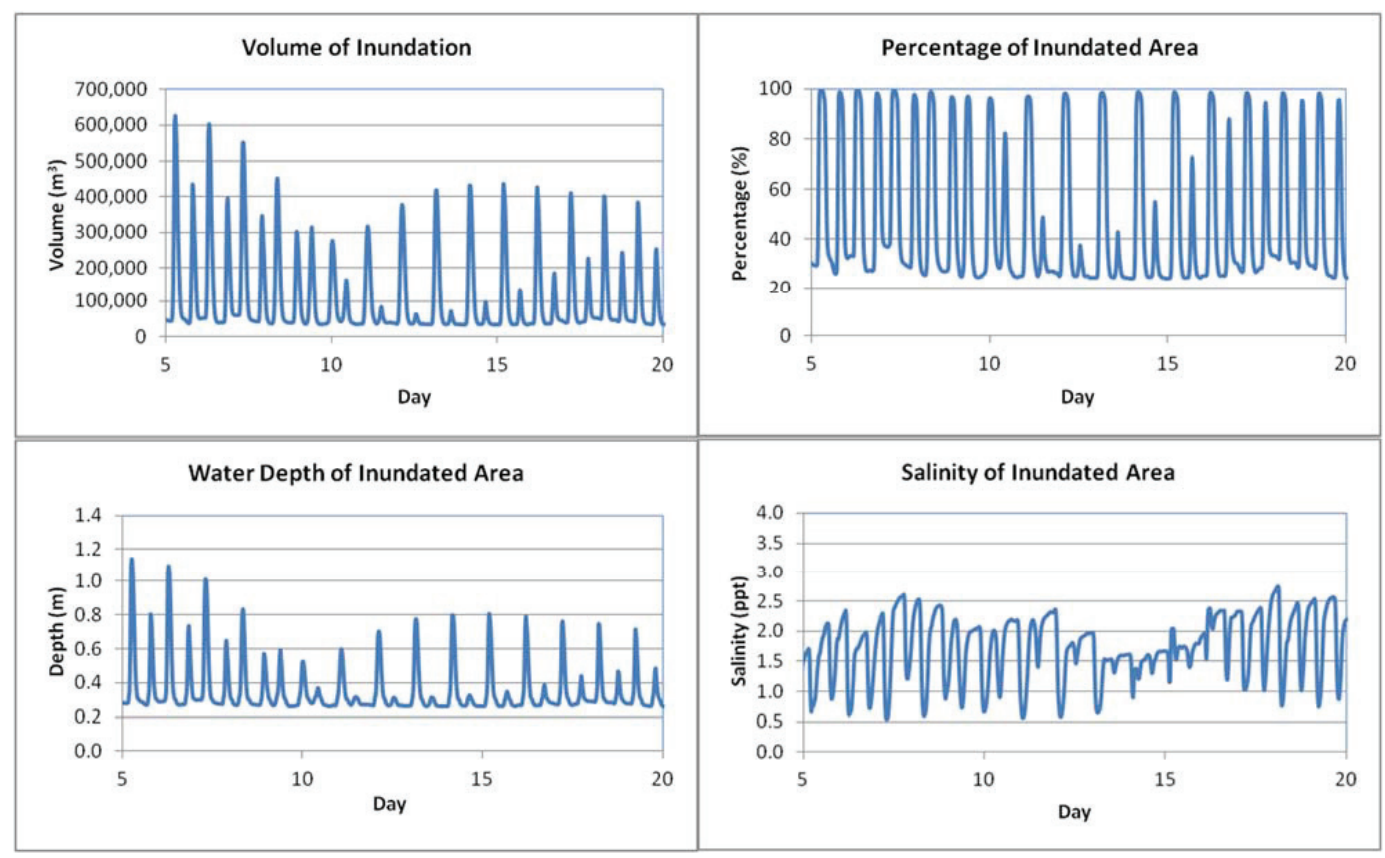


Figure 8. Percentage of inundation time over a 14-day spring-neap tidal cycle.

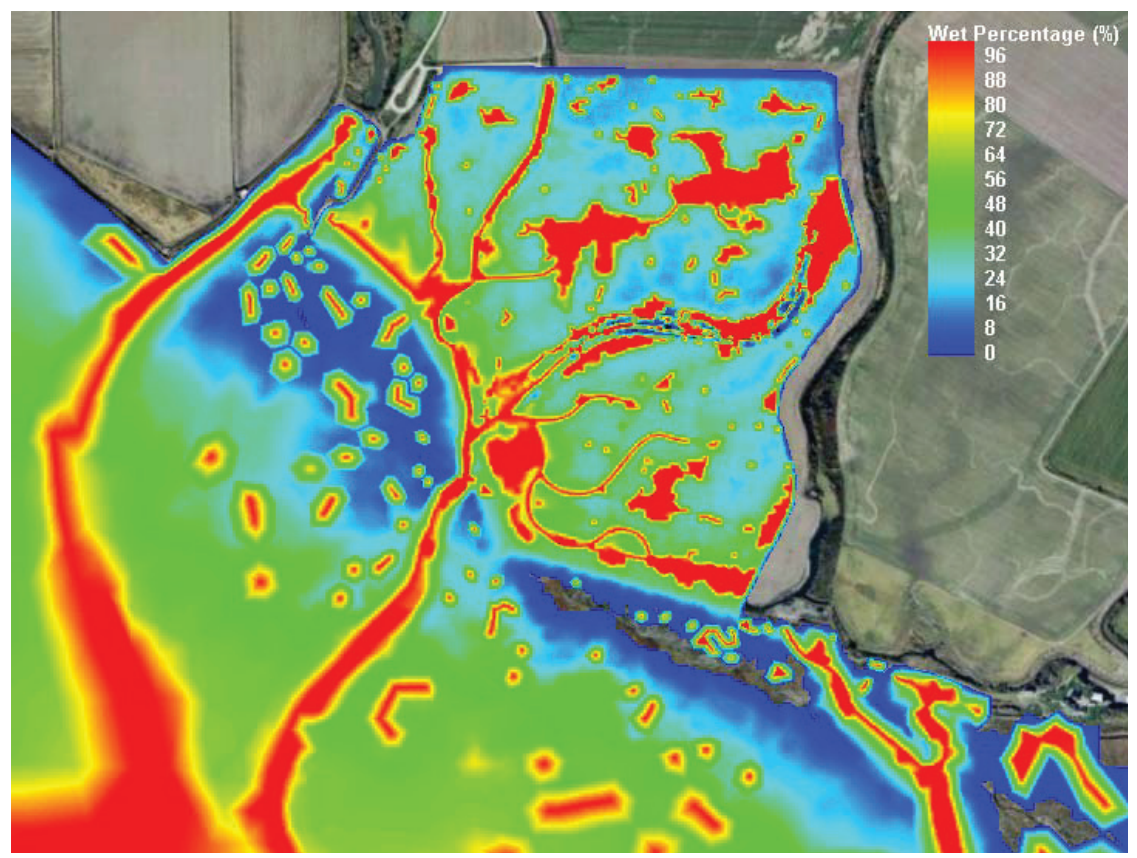

\subsection{0-Year Maximum Water Levels}

\subsubsection{Extreme Tidal Elevation}

In this study, model simulation was conducted for the period from 15 March 2003 to 15 April 2003, which did not correspond to the extreme high tide condition. Because the longest astronomic tidal cycle is about 19 years, extreme tidal elevation was estimated using long-term (19-year) predicted tide data from the XTide database at Crescent Harbor, which is located immediately outside of Skagit Bay (Figure 3). The maximum tidal elevation from the 19-year record (from 1 January 2003 to 1 January 2022) at Crescent Harbor is $3.359 \mathrm{~m}$, which is $0.296 \mathrm{~m}$ higher than the maximum tidal elevation of $3.063 \mathrm{~m}$ for the period from 15 March 2003 to 15 April 2003. The maximum tidal elevation at the bay front of the project site is 3.066. Assuming such an increase of tidal elevation in Crescent Harbor is linearly proportional to the tidal elevation in the bay front of the project site, then the extreme tidal elevation in the bay front of Fir Island Farm would be $\eta_{\text {tide }}=$ $3.362 \mathrm{~m}$ (i.e., $3.066+0.296 \mathrm{~m})$.

\subsubsection{0-Year Storm Surge Height}

Extreme storm events can result in a significant water level surge in the coastal zone. Storm surge height was estimated based on wind forcing alone in this study. The 100-year storm wind was estimated based on 66 years of long-term wind record (1948 to 2013) at NOAA's National Climate Data Center station (72797524255) on Whidbey Island. Wind data were recorded at a station height of $14.3 \mathrm{~m}$ above mean sea-level. To simulate the wind-driven storm surge, wind 
forcing at a $10-\mathrm{m}$ height should be used in the model. Therefore, wind speed data were adjusted from $14.3 \mathrm{~m}$ to the standard 10-m height based on the wind profile power law [10]. The empirical method described by Gupta [11] was used for the peak wind frequency analysis (Figure 9). The relation between peak wind speed and the probability of exceedance can be obtained by a regression-fit to the data:

$$
V_{\text {wind }}=29.58 \exp (-0.003 P)
$$

where $V_{\text {wind }}$ is the peak wind speed corresponding to the percentage of storm occurrence $P$ over a 100 -year period. Based on Equation (2), the peak wind speed for a 100 -year storm event $(P=1)$ was $29.49 \mathrm{~m} / \mathrm{s}$. Analysis of wind speed and direction distributions for the entire record period showed that wind directions were primarily from south southwest from April to September and from northwest from October to March.

Wind-driven storm surge was simulated using the Skagit River estuary hydrodynamic model with the preferred restoration alternative for a 10-day period from 16 to 26 March 2003, which corresponds to the spring tide (Figure 4). A wind speed of $29.49 \mathrm{~m} / \mathrm{s}$ blowing from the southsouthwest direction $\left(210^{\circ}\right.$ clockwise from the north) was specified. Model results showed that the water-surface elevation near the project site may rise about $\eta_{\text {surge }}=0.67 \mathrm{~m}$ at high tide during a 100 -year storm surge induced by high winds (Figure 10).

Figure 9. Wind cumulative frequency curve at NCDC station on Whidbey Island.

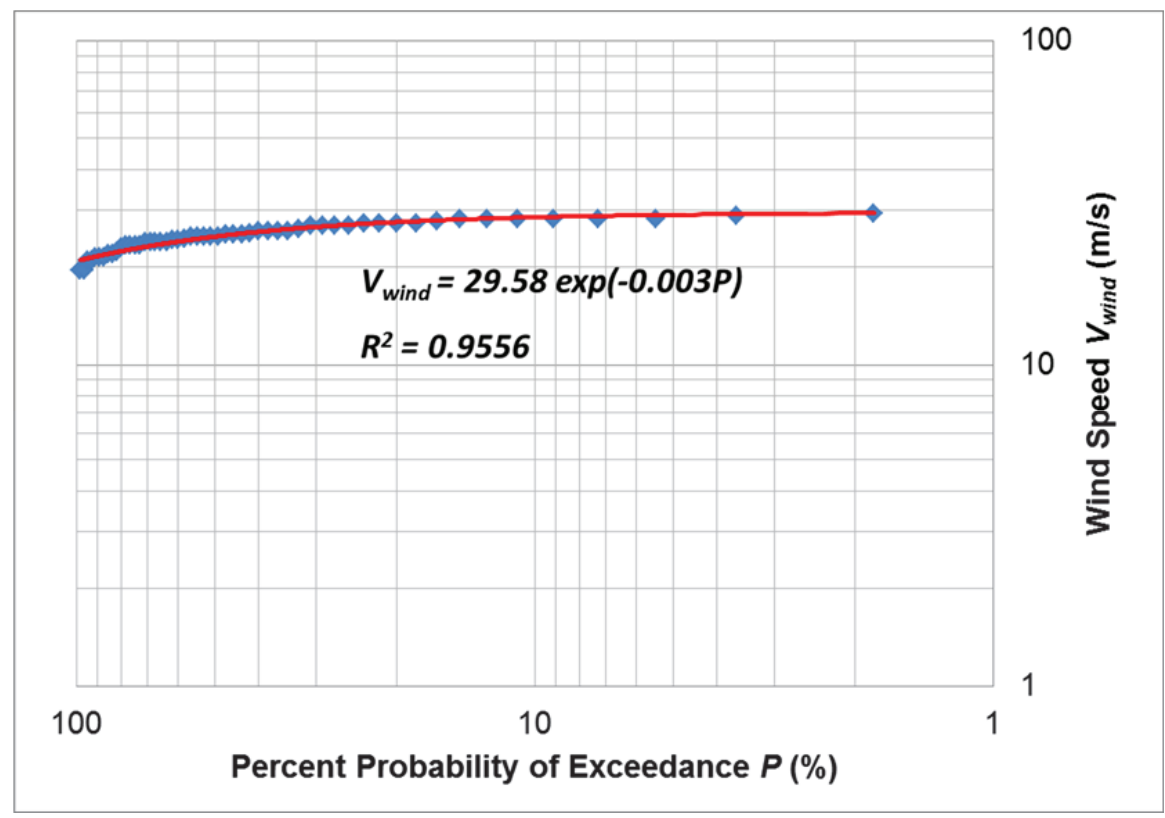


Figure 10. Comparison of water-surface elevations at the Skagit Bay front between baseline and restoration alternative with a 100-year wind storm.

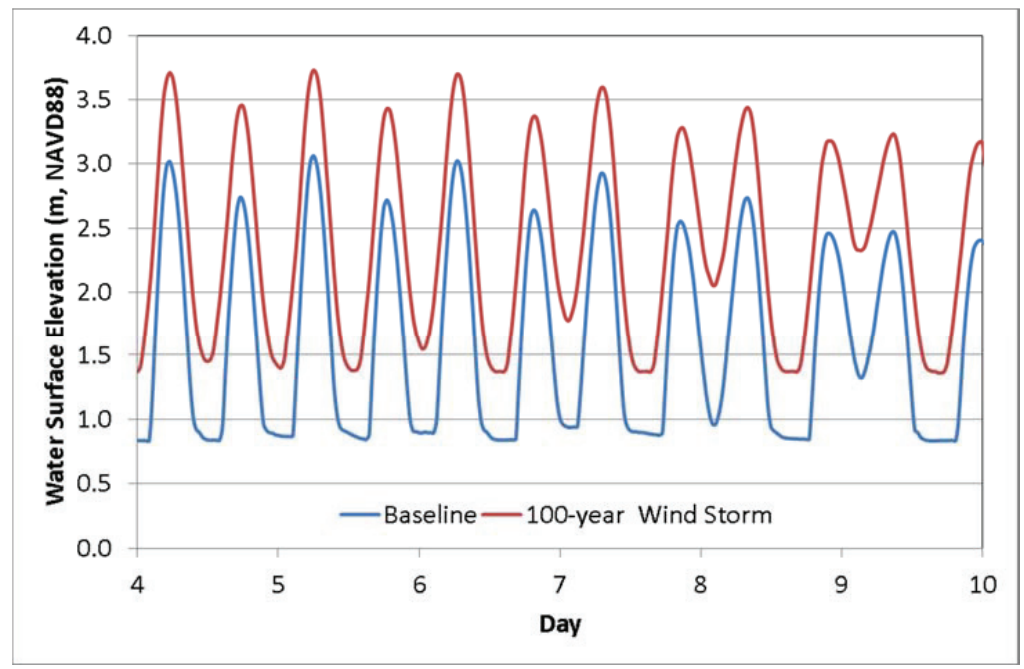

\subsubsection{Wave Run-Up-Significant Wave Height ( $\left.\eta_{\text {wave }}\right)$}

Calculation of significant wave height was based on the U.S. Army Corps of Engineer (USACE) Shore Protection Manual [12] using the 100-year peak wind speed. For a conservative estimate, it was assumed that the peak wind is blowing directly to the project site and the maximum wave height is fully developed. The estimated fetch from the eastern shore of Whidbey Island near the entrance of Penn Cove to the project site is about $20 \mathrm{~km}$. Assuming a shallow water wave condition in Skagit Bay, which has an average water depth of around $3 \mathrm{~m}$, the estimated significant wave height $H_{b}$ and period $T_{b}$ are $1.1 \mathrm{~m}$ and $4.6 \mathrm{~s}$, respectively, during extreme storm condition with a maximum wind speed of $29.49 \mathrm{~m} / \mathrm{s}(67 \mathrm{mph})$ based on the forecasting curves of shallow water waves [12].

The wave run-up elevation, which is defined as that super elevation of the mean water level caused by wave action alone, can be calculated based on the formula in the USACE Shore Protection Manual [12] using the estimated significant wave height and period as the incoming wave condition. During the 100 -year storm event under high tide condition, the average water depth in the bay front area near the project site is estimated to be $1.236 \mathrm{~m}$ (i.e., high tide + storm surge - average bed elevation $=3.066+0.67-2.5=1.236 \mathrm{~m}$ ). Based on the wave-breaking criteria of $H_{b}$ /Depth $(1.1 / 1.236=0.89) \geq 0.78$, the incoming wave will break before reaching bay front due to shallow water depth. Under breaking wave conditions, the kinetic energy of the broken wave would be converted to a quasi-steady potential energy and the wave run-up can be calculated by following formula in [12]:

$$
\eta_{\text {wave }}=0.19\left\{1-2.82\left[H_{b} /\left(g T_{b}^{2}\right)\right]^{1 / 2}\right\} H_{b}=0.19\left\{1-2.82\left[1.1 /\left(9.8 \times 4.6^{2}\right)\right]^{1 / 2}\right\} 1.1=0.166 \mathrm{~m}
$$

Therefore, the estimated wave run-up height in the bay front during a 100-year wind storm event is $\eta_{\text {surge }}=0.166 \mathrm{~m}$. 


\subsubsection{Long-Term Sea-Level Rise $\left(\eta_{s l r}\right)$}

Effect of relative sea-level rise (SLR) was superimposed on top of the water level at the project site based on values reported from literature review. Various factors, including changes in wind patterns, the gravitational and deformational effects of modern land ice melting, and the vertical land motion, contribute to the sea-level rise along the U.S. West Coast. Mote et al. [13] showed that the very low, medium, and very high estimates of relative SLR in Puget Sound are $0.08 \mathrm{~m}$, $0.15 \mathrm{~m}$, and $0.55 \mathrm{~m}$ by 2050 and $0.16 \mathrm{~m}, 0.34 \mathrm{~m}$, and $1.28 \mathrm{~m}$ by 2100 , respectively, based on the combined estimates of Intergovernmental Panel on Climate Change (IPCC) global SLR projections and location atmospheric dynamic factors. Mazzotti et al. [14] estimated that relative SLR in Seattle by 2100 will be $0.34 \mathrm{~m}$ with a $90 \%$ confidence range of $0.22-0.46 \mathrm{~m}$ from a combined tidegage and global positioning system analysis. Most recently, the U.S. National Research Council conducted a detailed analysis of SLR trends along the U.S. West Coast based on IPCC global SLR projections, relevant data, model results, and recently published research results [15]. The vertical land motion projection rate in the Cascadia Subduction Zone was $1.0 \mathrm{~mm} /$ year with a standard deviation of $1.5 \mathrm{~mm} /$ year, where positive rate denotes uplift $[15,16]$. The NRC committee projected that relative SLR in Seattle contributed by all the factors is $\eta_{s l}=0.166 \mathrm{~m}$ with an uncertainty of $\pm 0.105 \mathrm{~m}$ for the year 2050 , and $\eta_{s l r}=0.618 \mathrm{~m}$ with an uncertainty of $\pm 0.293 \mathrm{~m}$ for the year 2100 . The relative SLR value of $0.618 \mathrm{~m}$ estimated in [15] is higher than the value given in [14] but is within the range of those in [13]. Because the NRC study was a comprehensive study that was based on most recent research results, including the studies [13,14], the NRC value of $0.618 \pm$ $0.293 \mathrm{~m}$ was used for the projection of sea-level rise in this study.

Based on the estimates of water surface elevation contributed by tide, wind surge, wave and climate change related sea-level rise, the 100-year maximum water level at the Fir Island Farm restoration project site can be calculated using Equation (1):

$$
\eta_{\max }=3.362+0.67+0.166+0.618=4.816 \mathrm{~m}(\mathrm{NAVD} 88)
$$

\section{Conclusions}

A numerical modeling study was conducted to support a nearshore restoration project in the Skagit River estuary in Puget Sound using a three-dimensional unstructured-grid coastal ocean model. A set of parameters related to nearshore habitat were introduced to quantify the hydrodynamic response to the restoration action. These parameters include volume of water in the inundated area, percentage of inundated area, water depth and salinity of inundated area, and time duration of inundation in the project site. Model simulations were conducted to evaluate different restoration alternatives and to assist the selection of a preferred alternative for engineering design. Numerical model results suggest that tidal function in the Fir Island Farm project site can be restored after the removal of the bay-front dike. The area downstream from Claude O. Davis Slough will be the primary path for tidal flow. The spur dike to the east of Brown Slough can effectively block the tidal exchange between Brown Slough and the restoration site. 
The 100-year maximum water level due to the combined effects of extreme high tide, the 100year wind storm surge, and regional sea-level rise was estimated based on model simulations, coastal engineering calculation, and literature review. It should be noted that the wind-induced surge was simulated under normal spring tide condition. The empirical method (Equation (1)) also assumed there is no interaction among wave, relative sea-level rise, wind storm surge and extreme high tide.

While the results presented in this paper are site specific, the modeling approach and methodology used in this study can be applied to conduct hydrodynamic modeling analysis and support future nearshore restoration feasibility studies in other locations, especially to account for the effects of extreme events and sea-level rise as a result of climate change.

\section{Acknowledgments}

This study was funded by the Salmon Recovery Board through the Washington State Department of Fish and Wildlife, USA.

\section{Conflicts of Interest}

The authors declare no conflict of interest.

\section{References}

1. Scheuerell, M.D.; Hilborn, R.; Ruckelshaus, R.M.; Bartz, K.K.; Lagueux, K.M.; Haas, A.; Rawson, K. The Shiraz model: A tool for incorporating anthropogenic effects and fish-habitat relationship in conservation planning. Can. J. Fish. Aquat. Sci. 2006, 63, 1596-1607.

2. Yang, Z.; Liu, H.; Khangaonkar, T. Development of a hydrodynamic model for Skagit river estuary for estuarine restoration feasibility assessment. In Proceedings of the 9th International Conference on Estuarine and Coastal Modeling, Charleston, SC, USA, 31 October-2 November 2005; Spaulding, M.L., Ed.; American Society of Civil Engineers: Charleston, SC, USA, 2006; pp. 752-767; doi:10.1061/40876(209)43.

3. Lee, C.; Khangaonkar, T.; Yang, Z. Application of hydrodynamic and sediment transport model for the restoration feasibility assessment-Cottonwood Island, Washington. In Proceedings of the 10th International Conference on Estuarine and Coastal Modeling, Newport, RI, USA, 3-7 November 2007; Spaulding, M.L., Ed.; American Society of Civil Engineers: Newport, RI, USA, 2008; pp. 839-861; doi:10.1061/40990(324)45.

4. Yang, Z.; Khangaonkar, T.; Calvi, M.; Nelson, K. Simulation of cumulative effects of nearshore restoration projects on estuarine hydrodynamics. Ecol. Model. 2010, 221, 969-977; doi:10.1016/j.ecolmodel.2008.12.006.

5. Yang, Z.; Sobocinski, K.L.; Heatwole, D.; Khangaonkar, T.; Thom, R.; Fuller, R. Hydrodynamic and ecological assessment of nearshore restoration: A modeling study. Ecol. Model. 2010, 221, 1043-1053; doi:10.1016/j.ecolmodel.2009.07.011. 
6. Yang, Z.; Wang, T. Hydrodynamic modeling analysis of wetland restoration in Snohomish river, Washington. In Proceedings of the 12th International Conference on Estuarine and Coastal Modeling, St Augustine, FL, USA, 7-9 November 2011; Spaulding, M.L., Ed.; American Society of Civil Engineers: St. Augustine, FL, USA, 2012; pp. 139-155; doi:10.1061/9780784412411.00008.

7. Yang, Z.; Wang, T.; Khangaonkar, T.; Breithaupt, S. Integrated modeling of flood flows and tidal hydrodynamics over a coastal floodplain. J. Environ. Fluid Mech. 2012, 12, 63-80; doi:10.1007/s10652-011-9214-3.

8. Chen, C.; Liu, H.; Beardsley, R.C. An unstructured, finite-volume, three-dimensional, primitive equation ocean model: Application to coastal ocean and estuaries. J. Atmos. Ocean. Technol. 2003, 20, 159-186.

9. Yang, Z.; Wang, T. Tidal residual eddies and their effect on water exchange in Puget Sound. Ocean Dyn. 2013, 63, 995-1009; doi:10.1007/s10236-013-0635-z.

10. Robeson, S.M.; Shein, K.A. Spatial coherence and decay of wind speed and power in the north-central United States. Phys. Geogr. 1997, 18, 479-495.

11. Gupta, R.S. Hydrology and Hydraulic Systems; Waveland Press, Inc.: Long Grove, IL, USA, 2007.

12. U.S. Army Coastal Engineering Research Center. Shore Protection Manual. 1975. Volume 1. Available online: http://archive.org/details/shoreprotectionm01coas (accessed on 30 November 2013).

13. Mote, P.W.; Petersen, A.; Reeder, S.; Shipman, H.; Whitely Binder, L.C. Sea Level Rise in the Coastal Waters of Washington State; Climate Impacts Group, University of Washington and the Washington Department of Ecology: Seattle, WA, USA, 2008.

14. Mazzotti, S.; Jones, C.; Thomson, R.E. Relative and absolute sea level rise in western Canada and northwestern United States from a combined tide gauge-GPS analysis. J. Geophys. Res. 2008, 113, C11019; doi:10.1029/2008JC004835.

15. National Research Council (NRC), Committee on Sea Level Rise in California, Oregon, and Washington, Board on Earth Sciences and Resources and Ocean Studies Board. Sea-Level Rise for the Coasts of California, Oregon, and Washington: Past, Present and Future; The National Academies Press: Washington, DC, USA, 2012.

16. Verdonck, D. Contemporary vertical crustal deformation in Cascadia. Technophysics 2006, $417,221-230$. 


\title{
Estimate Submarine Groundwater Discharge to Crystal River/Kings Bay in Florida with the Help of a Hydrodynamic Model
}

\section{XinJian Chen}

\begin{abstract}
Crystal River/Kings Bay is a spring-fed estuarine system located on the west coast of the Florida peninsula. During 2008-2009, a field investigation was conducted to measure submarine groundwater discharges (SGDs) from numerous spring vents in Kings Bay. Based on directly measured real-time SGD data, an empirical relationship that links SGD with tides in Kings Bay and the groundwater level measured in a nearby Artesian well were obtained. A 3D unstructured Cartesian grid model was used to help verify the correctness of the empirical SGD formula, which was slightly adjusted for each individual vent when used in the model. The model was calibrated and verified against measured real-time data of water level, salinity, and temperature at two stations in the estuary. A successful simulation of circulations, salinity transport processes, and thermodynamics in the Crystal River/Kings Bay system proves that the empirical relationship is appropriate for estimating SGDs in Kings Bay.
\end{abstract}

Reprinted from J. Mar. Sci. Eng. Cite as: Chen, X.J. Estimate Submarine Groundwater Discharge to Crystal River/Kings Bay in Florida with the Help of a Hydrodynamic Model. J. Mar. Sci. Eng. 2014, 2, 66-80.

\section{Introduction}

Crystal River/Kings Bay is a small but complicated, spring-fed estuarine system located on the Gulf coast of central Florida (Figure 1). It has a very small runoff basin, as spring water accounts for $99 \%$ of the freshwater flows entering Kings Bay. The estuarine system includes the $2.43 \mathrm{~km}^{2}$ Kings Bays as its head water and the $10 \mathrm{~km}$ long Crystal River that joins Kings Bay with the Gulf of Mexico. It is a first magnitude spring system, which is defined as having a discharge rate of 100 cubic feet per second (cfs) or greater [1]. In fact, it is the fourth largest spring system in Florida with an estimated discharge of about $1000 \mathrm{cfs}$ or higher. Because SGD is an overwhelming part of the total freshwater inflow received by the estuarine system, the Crystal River/Kings Bay estuary serves as an excellent example demonstrating the importance of SGD in controlling physical, chemical, and biological processes in coastal waters.

The Crystal River/Kings Bay system is ecologically very important for some marine species such as West Indian manatees (Trichechus manatus), because a large amount of warm spring water with a relatively constant temperature of about $23{ }^{\circ} \mathrm{C}$ flows to the Kings Bay through numerous spring vents on a daily basis. This creates a large warm water pool in Kings Bay during the coldest days when the air temperature plunges to several degrees below $0{ }^{\circ} \mathrm{C}\left(32{ }^{\circ} \mathrm{F}\right)$ and the water temperature at the mouth of the Crystal River drops to $10{ }^{\circ} \mathrm{C}$ or lower. Because manatees need to be in water that is at least $20^{\circ} \mathrm{C}\left(68^{\circ} \mathrm{F}\right)$ or warmer to maintain a safe internal body temperature, this large warm water pool in Kings Bay becomes a critical refuge site for manatees to survive 
when water temperature in the area falls below $20{ }^{\circ} \mathrm{C}$ and attracts many manatees to the Crystal River/Kings Bay system in winter. With approximately 350 manatees inhabiting the spring-fed estuary during winter months, it is believed that the Crystal River/Kings Bay area is the largest natural refuge for manatees in the United States.

Figure 1. An aerial photo of the Crystal River/Kings Bay system located on the southwest coast of the Florida peninsula. Locations of USGS in-situ measurement stations are marked with triangles and locations of identified spring vents are marked with asterisks. The solid circle at the bottom right is the location of a well called ROMP TR21-3.

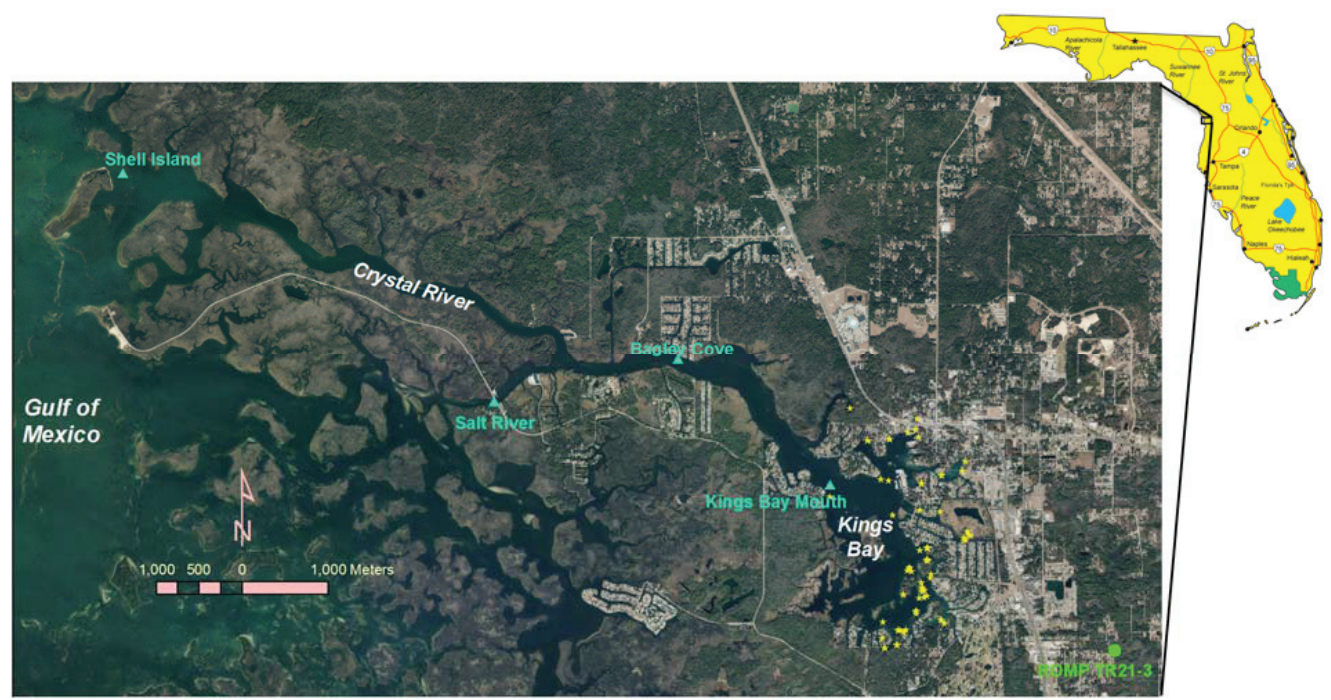

In addition to the obvious effect of the spring flow on thermo-characteristics of the Crystal River/Kings Bay system, SGD is also a key factor determining the salinity distribution in the system, which controls the ecological structure and biological productivities in the estuary. Maintaining a certain volume of fresh water or brackish pool in the Crystal River/Kings Bay system is crucial for many species. The tidal brackish ecosystem supports abundant fish and wildlife resources that are of great importance to the region both economically and ecologically.

Because of the importance of warm freshwater input to Crystal River/Kings Bay, it is necessary to have a sound management of spring flow to the estuary so that the natural warm water refuge for manatees and the health of the ecosystem are protected. Obviously, a good set of data of spring flows from all the spring vents in and around Kings Bay is critical in managing the system. A number of previous studies were conducted to study spring flow, water circulations, water quality, aquatic vegetation, water clarity, sediment characteristics, management of manatees, etc. in Crystal River/Kings Bay (e.g., [2-4]) Yobbi and Knochenmus [2] estimated the total spring discharge exiting Kings Bay to be about 975 cfs during 1965-1977. Their study reported a relatively low spring flow rate in summer and fall months, when rainfall and tides were higher, and a high spring 
flow rate in winter and spring months, when rainfall and tides were lower. They attributed this anomalous timing of SGD in the Crystal River/Kings Bay system to the seasonality of tides.

Numerous SGD-related investigations have been performed over the last couple of decades, trying to quantify SGDs and study processes affecting SGDs at various geophysical settings. Most previous SGD measurements focused on the diffusive seepage through sediments [5-7], which is a relatively slow process and is in general measured with a time scale that is much longer than that of a tidal cycle. In a Karst landscape such as the Crystal River region, SGDs from localized submarine spring vents can be quite large in magnitude and normally vary swiftly with time because of the high-frequency tidal variability. The relatively large magnitude of point flow from a coastal spring allows the discharge to be measured with a regular velocity meter such as an acoustic Doppler velocimeter.

In order to quantify the freshwater input to the Crystal River/Kings Bay system and to study effects of tides on spring flows in Kings Bay, the Southwest Florida Water Management District contracted Vanasse Hangen Brustlin, Inc. to conduct field measurements in 2008-2009. Data collected in this field investigation were analyzed and an empirical formula relating spring flow to tides and groundwater level was obtained based on real-time SGD data collected from a small portion of spring vents. A 3D hydrodynamic model that simulates circulations, salinity transport, and thermodynamics in the Crystal River/Kings Bay system was used to find out if this empirical formula is applicable for all of the identified spring vents. A successful model calibration/verification against real-time data measured in Crystal River/Kings Bay during a 2.84-year period from 24 April 2007 to 23 February 2010 confirms that this empirical formula for estimating real-time spring flows out of the numerous vents in Kings Bay is reasonable.

In the following, details of the data collection during 2008-2009 are first described, followed by an analysis of the field data, which results in an empirical formula relating spring flows with tides and the groundwater level. The use of this empirical formula to estimate discharges out of each spring vent in a 3D hydrodynamic model application to the Crystal River/Kings Bay system is then presented, before conclusions are drawn at the end of the paper.

\section{Field Data}

\subsection{Data Collection}

There exist only limited data collection activities that have tried to quantify flows out of submerged vents in Kings Bay. Rosenau et al. [8] measured instantaneous flows and water quality parameters from selected springs that flow into Kings Bay, with a total of 30 reported springs being identified and listed in their report. The same 30 springs in Kings Bay were also listed in a more recent bulletin of Florida Bureau of Geology [9]. Spring flow rates and water quality in the Crystal River were measured by Seaburn et al. [10] in April 1974 to support a water quality modeling study of the system. Yobbi and Knochenmus [2] estimated the average total spring discharge during 1965-1977 to be about 975 cfs for Kings Bay. In an effort to simulate circulation and flushing characteristics of Kings Bay [3], the United States Geological Survey (USGS) conducted a flow measurement during 7-8 June 1990 near Bagley Cove (Figure 1) in the Crystal River. The net 
flux through this cross section during the tidal cycle was found to be 735 cfs. In a 2D hydrodynamic simulation by Hammett et al. [3], 28 major springs in Kings Bay were included in their model based on information from [8]. In a spring water quality study by the Southwest Florida Water Management District (SWFWMD) during 1993-2004, additional spring vents in Kings Bay were identified.

As none of the aforementioned previous studies of spring discharges to Kings Bay is spatially or temporally comprehensive, it is necessarily to conduct a more extensive data collection study to quantify spring flows and to find out how SGD is affected by tides and the groundwater level in the estuary. For this purpose, a two-phase field investigation in Kings Bay was conducted during 2008-2009. The first phase was a thorough inventory survey, in which all the identifiable spring vents were identified with their locations (latitudes and longitudes) were recorded and configurations, including dimensions (areas) and orientations, were documented. The second phase was to measure discharges out of each spring vent with divers diving to the vents to measure the velocities of spring flows. The discharge was simply the product of the vent area and the velocity. For most of spring vents, multiple field trips were made to measure discharges under various tidal conditions.

During the inventory survey, previously documented spring vents were first visited and validated via snorkeling and SCUBA equipped diving [11]. The entire Kings Bay was then searched for additional spring vents that were not previously documented. At several spring sites, multiple vents are located in a close proximity, forming a vent cluster that jointly contributes to the overall discharge for the spring. A single set of coordinates was recorded for the vent cluster, which is considered as a single spring. The inventory survey was able to identify a total number of 70 springs, which is more than double the previously documented number of springs. Figure 1 shows locations of these 70 springs (marked with asterisks). It should be noted that some asterisks appear to be overlapped, because several springs are very close to each other.

After the inventory survey of detectable spring vents was completed, flow measurements were conducted using acoustic Doppler current profiler (ADCP) type meters. Instantaneous discharge measurements for the detectable spring vents were carried out under various tidal conditions (e.g., spring and neap tides) during 28-31 July, 17-20 August, 21-25 September, and 5-8 October 2009. In addition to the flow measurement for each spring vent, a multi-parameter water quality monitoring sonde was used to measure specific conductance and temperature at the same time. Water quality data are not the focus of this paper and thus not discussed in detail in the following discussion.

In order to study effects of tides on spring discharges, two multi-beam ADCPs were deployed to measure real-time cross-sectional fluxes in two channels, each conveying discharges out of a group of spring vents discharge to Kings Bay. In Figure 2, G1 and G2 denote the locations where Groups 1 and 2 of the springs were gauged, respectively. Group 1 consists of three springs (\#8-\#10), while Group 2 consists of eight springs (\#15,\#16,\#18-\#23). The ADCP measurements of the cross-sectional fluxes through the channel were recorded every 15 minutes and were conducted during a 25-day period between 27 July and 20 August 2009, during which both surface water level data in Kings 
Bay and groundwater level data at a nearby well were available. The groundwater well is called ROMP TR21-3 and located roughly $2.5 \mathrm{~km}$ southeast of the center of Kings Bay (Figure 1).

Figure 2. Locations where Group 1 (G1) and Group 2 (G2) spring flows were gauged. Identified springs are marked by white circles with numbers (for mapping purposes, springs in a close proximity are combined together sharing a single number).

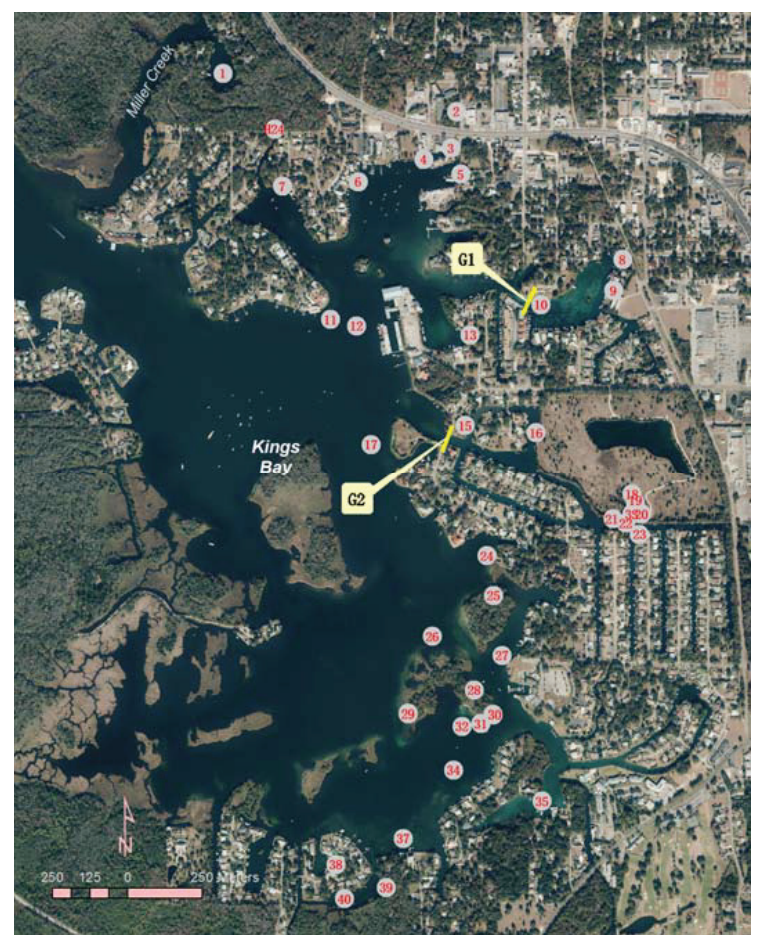

\subsection{Data Analyses}

Results of instantaneous discharge measurements during July-October 2009 are reported elsewhere [12]. Most spring sites were measured under more than one tidal condition, resulting in multiple discharge samples for these sites. At 11 sites, spring discharges were measured only one time because of their relatively low flow rates, though multiple readings were recorded for each of them to either obtain an average flow rate or get the sum for the spring site if several vents are involved. Similar to the finding reported in previous measurements, the magnitude of the spring flow in Kings Bay varies greatly from one vent to another. About 15 spring sites are second order magnitude springs with mean discharges ranging between 10 and $100 \mathrm{cfs}$, while two are fifth order magnitude (1-100 gal/min, or $0.0223-0.223 \mathrm{cfs})$ or less. For the same spring site, the discharge also varies significantly from time to time. For example, a spring vent named H24 in the north portion of Kings Bay was measured on two different days. One was on 23 September 2009 and the other was on 7 October 2009. The first measurement of the discharge was $8.35 \mathrm{cfs}$, but the second 
flow measurement was $49.5 \mathrm{cfs}$, almost six times of the previous measurement. The total of measured mean flows from all the identified vents is about $467 \mathrm{cfs}$.

Generally, salinity is higher in southern springs than in northern springs. Except for Sites No. 1 and H24 (Figure 2), most northern springs discharge fresh water, with salinity normally less than 0.5 psu. Site No. 1 is located at the headwater of Miller Creek, which is a short waterway connecting the spring with the Crystal River (Figure 2), and has an average salinity of 1.75 psu. $\mathrm{H} 24$ is connected to Kings Bay through a spring run and has an average salinity of 1.14 psu. Southern springs are brackish and salinities in these springs can be 6 psu or higher (e.g., Spring Sites 38-40). Overall, the flow-weighted salinity in spring flows out of all spring vents is about 1.58 psu.

Spring temperature is generally much more stable than spring salinity in Kings Bay, both in terms of special variation and temporal variation. Most spring flows have a temperature around 23.5. The highest spring temperature was measured at H24 Spring Site, with a value of $24.94{ }^{\circ} \mathrm{C}$. The lowest spring temperature was measured at Spring Site No. 1 located at the headwater of Miller Creek, where the average spring temperature was $22.93{ }^{\circ} \mathrm{C}$. The flow-weighted spring temperature was $23.51^{\circ} \mathrm{C}$ for all the springs in Kings Bay during the measurement period. During the coldest days in winter, spring temperature can be about $1{ }^{\circ} \mathrm{C}$ lower than in summer.

As mentioned above, real-time cross-sectional fluxes at G1 and G2 shown in Figure 2 were measured with multi-beam ADCPs during 27 July to 20 August 2009. Because cross-sectional fluxes measured at the two sites also include tidal prisms upstream of the cross sections, net spring discharges from the two groups of springs need to be adjusted as follows

$$
q_{g}=q_{m}+A(\partial \eta / \partial t)
$$

where $q_{g}$ is the net spring flow of the group, $q_{m}$ is the cross-sectional flux measured by ADCP, $A$ is the total water surface area upstream of the cross section, $t$ is time, and $\eta$ is the water surface elevation measured at the mouth of Kings Bay station. $q_{g}$ and $q_{m}$ are positive leaving the spring group. The second term on the right hand side in the above equation is the flux due to the tidal prism. Using a geographic information system, the total water surface areas upstream of Groups 1 and 2 are found to be $613,111.20$ and 1,785,544.49 square feet at the mean sea level, respectively. Because shorelines in both areas are mostly man-made vertical seawalls, both areas vary around their mean sea level values within a very small range and thus can be treated as constants. The time derivative of water surface elevation can be calculated from measured data at the USGS mouth of Kings Bay station.

Results of Equation (1) for both Groups are presented in Figure 3, along with measured water level at the USGS mouth of Kings Bay station during the same period. There were some problems with the ADCP measurement at the G1 cross section after about 9.5 days, and thus only the first 9.5 days of Group 1 spring flow data are plotted in Figure 3.

From Figure 3, one can see that spring flows for both Groups 1 and 2 exhibit strong tidal signals. Mean discharge out of Group 2 spring vents are about twice of that out of Group 1 spring vents; however, the range of discharge variation for Group 2 springs is more than five times of that for Group 1 springs. As shown in Figure 3, net spring flows from both spring groups are negatively 
proportional to the surface water elevation. As water level increases, spring flows decrease, and vice versa. When surface water level in Kings Bay increases to a certain elevation, the net spring flow from Group 2 vents becomes negative. In other words, instead of ground water being discharged out of the springs, estuarine water in Kings Bay flows into these spring vents.

Figure 3. Measured spring flows for Group 1 (red short dashed line) and Group 2 (blue long dashed line) during 27 July-20 August 2009. The green solid line is measured water level at the USGS mouth of Kings Bay station during the same period.

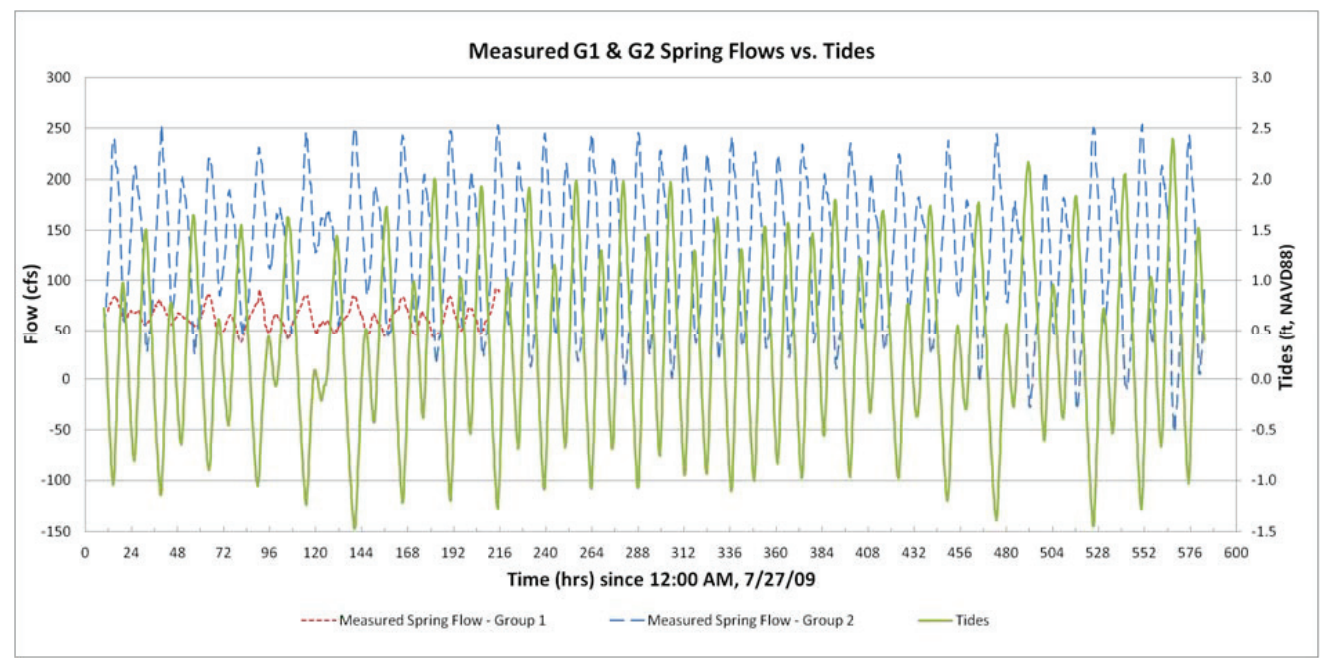

As mentioned above, the inverse relationship between tides and SGD has been reported in many previous studies all over the world, including those for Kings Bay springs [2,3]. Based on flow measurement for a single spring (Spring Site 6 in Figure 2), Hammett et al. [3] obtained the following linear regression equation

$$
q_{1}=16.97-4.25 \eta
$$

where $q_{1}$, in cfs, is the estimated spring flow for Spring Site 6 in Figure 2 and $\eta$, in feet NGVD 29, is water level measured at the mouth of Kings Bay station.

Equation (2) suggests that the spring discharge is only a function of water level. This is obviously not the whole story for spring discharges in Kings Bay, because one of the main driving forces that cause springs to discharge flows to Kings Bay, namely the groundwater level, also varies with time. Figure 4a shows measured daily and monthly groundwater level data during 1 January 2005 through 1 September 2010 in a nearby well called ROMP TR21-3 (Figure 1). A comparison of the water level measured at the USGS mouth of Kings Bay station with measured hourly groundwater level is shown in Figure 4b. Although the groundwater level is relatively stable in comparison with the tides in the system, it does have tidal signals in it. From Figure 4, it is clear that groundwater level contains not only high frequency variations but also low frequency variations with a time scale of a year. Hence, the consideration of groundwater level in predicting spring flow is necessary. 
Figure 4. (a) Measured monthly and daily groundwater levels in ROMP TR21-3 during 1 January 2005-1 September 2010. (b) Comparison of measured Kings Bay tides and hourly groundwater level in ROMP TR21-3 during the 25-day continuous recordings of cross-sectional fluxes at G1 and G2.
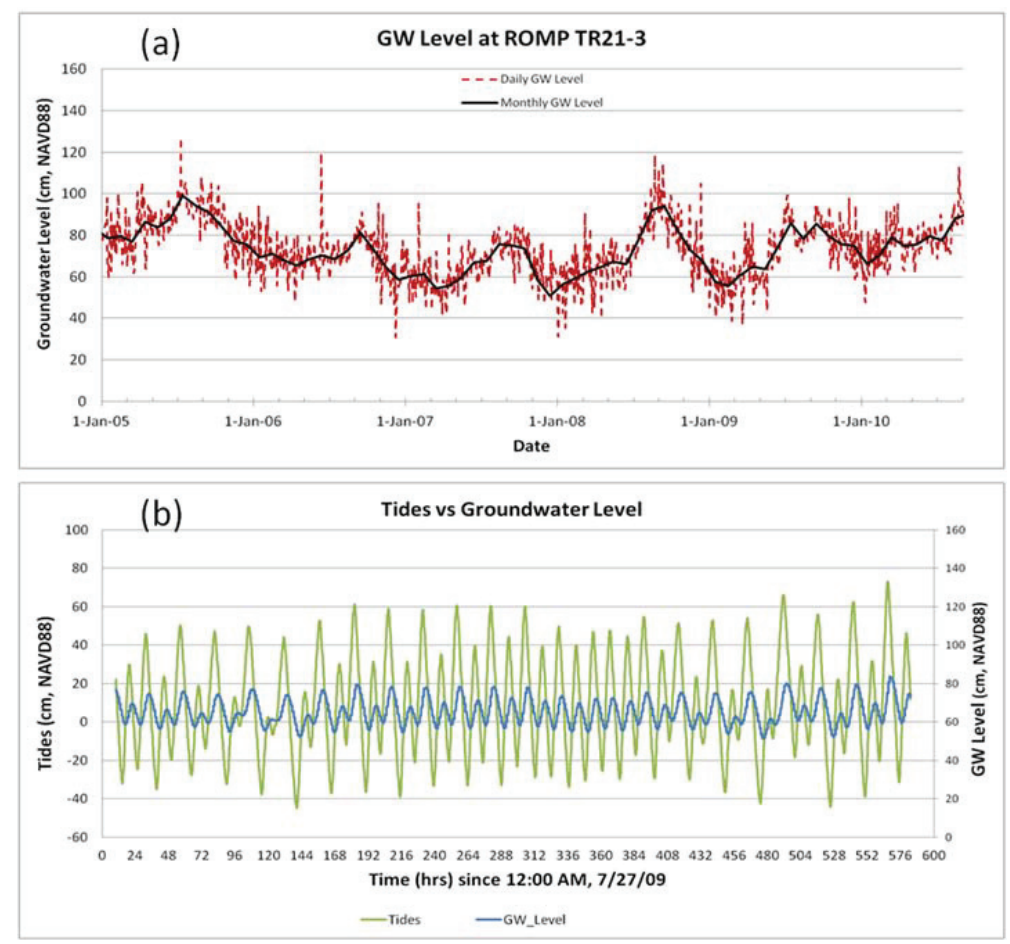

Based on available data, including continuous cross-sectional fluxes at G1 and G2, tides at the USGS mouth of Kings Bay station, and groundwater level data at ROMP TR21-3, it was found that the following linear equation can describe the effects of tides and groundwater level on the spring flow in Kings Bay very well.

$$
q=q_{0}\left[1+C_{1}(G-\Delta G-\eta)+C_{2}(\partial \eta / \partial t)\right]
$$

where $q$ denotes the estimated spring flow, $q_{0}$ is the long-term mean spring flow, $G$ represents the groundwater level in ROMP TR21-3, $\Delta G$ is the long-term mean head difference between the groundwater level in ROMP TR21-3 and the surface water level in Kings Bay, and $C_{1}$ and $C_{2}$ are two parameters which are time-independent and can be determined from measured field data. The time derivative of surface water elevation $(\partial \eta / \partial t)$ in the above equation not only allows the phase mismatch predicted by the head difference to be eliminated, but also allows higher mode oscillations shown in the measured net spring flows to be correctly matched.

Figure 5 compares time series of measured spring flows with those estimated using Equation (3). As can be seen from the figure, Equation (3) predicts spring flows very well, especially for Group 2 springs. The $\mathrm{R}^{2}$ values for the match of estimated and measured SGDs are 0.72 and 0.94 for Groups 1 and 2 springs, respectively. 
Figure 5. Time series of estimated and measured spring flows at G1 for Group 1 springs (a) and G2 for Group 2 springs (b) during 27 July-20 August 2009.

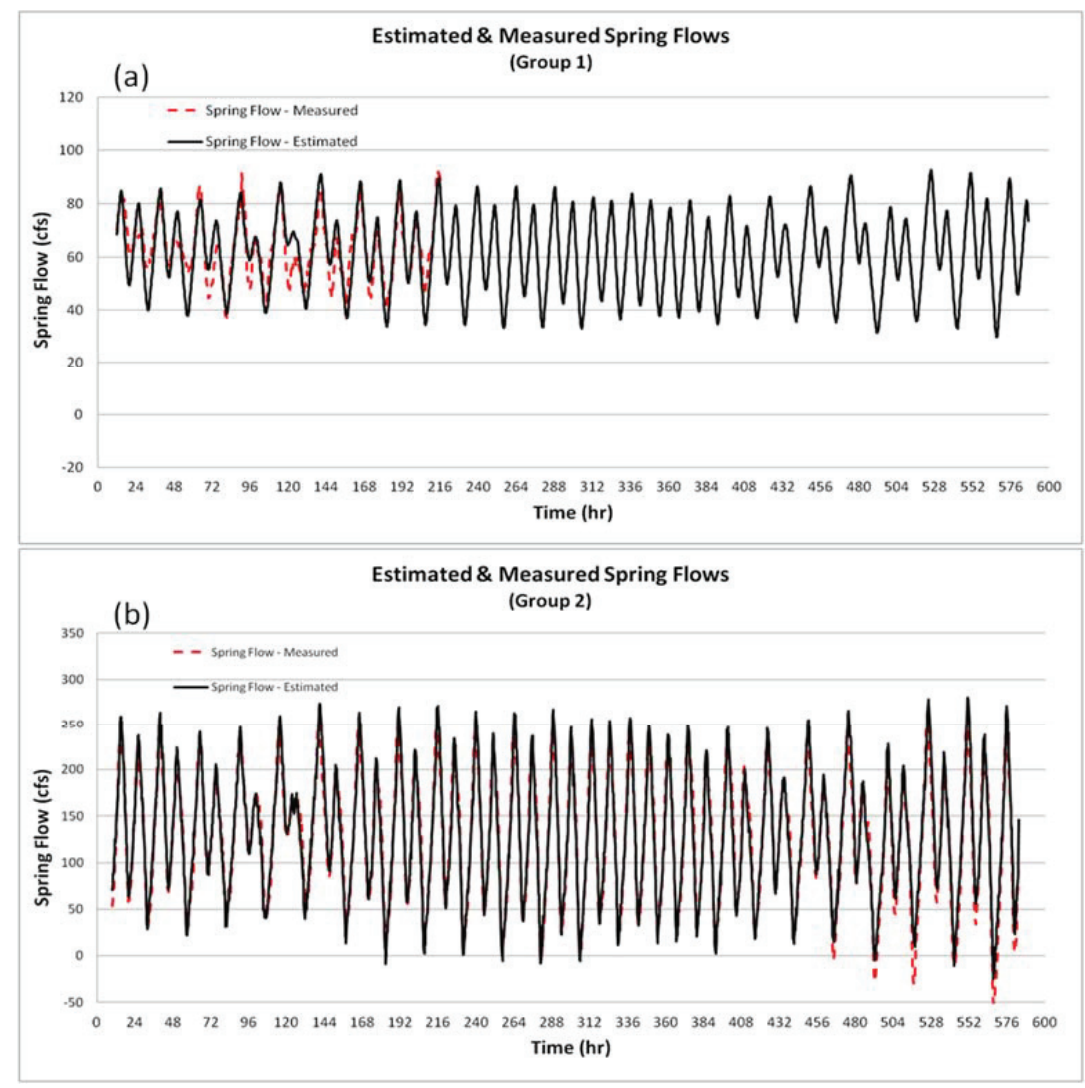

The three parameters $\left(\Delta G, C_{1}\right.$, and $\left.C_{2}\right)$ in Equation (3) were determined through a trial and error process in obtaining the best match between estimated and measured spring flows. This trial and error process yielded two sets of $\left(\Delta G, C_{1}\right.$, and $\left.C_{2}\right):\left(70.3 \mathrm{~cm},-0.0088 \mathrm{~cm}^{-1}, 3.9 \mathrm{~s} \mathrm{~cm}^{-1}\right)$ for Groups 1 and $\left(67.06 \mathrm{~cm},-0.0166 \mathrm{~cm}^{-1}, 79.78 \mathrm{~s} \mathrm{~cm}^{-1}\right)$ for Group 2. Clearly, for different spring groups, these parameters are quite different, especially $C_{1}$, and $C_{2}$.

\section{Verification of SGD Estimates via Hydrodynamic Simulations}

The empirical formula, Equation (3), for estimating SGDs from the spring vents was used in an unstructured Cartesian grid hydrodynamic model named UnLESS3D, which was developed to simulate circulations, salinity transport, and thermodynamics in the Crystal River/Kings system. Figure 6 shows the unstructured grid mesh used by the UnLESS3D model for the estuarine system, which was discretized with 3030 horizontal grids and 14 vertical layers. The model was driven by measured water elevations, salinities, and temperatures at open boundaries (USGS stations near Shell Island and in Salt River) and wind shear stresses and heat flux at the water surface, which were calculated based on measured wind, solar radiation, air temperature, and relative air humidity 
at a weather station about 10 miles north of Kings Bay. The UnLESS3D model was also driven by the spring flows at the bottom of Kings Bay. The following describes how the spring flows from all the spring vents are estimated based on data measured during 2008-2009 and how they are incorporated in the model simulation. Comparisons of model results and measured real-time data are presented to demonstrate that the spring estimates are reasonable. Details on the theory of the hydrodynamic model can be found in [13] and its application to Crystal River/Kings can be found in [14].

Figure 6. Unstructured Cartesian grid mesh used in the model application to the Crystal River/Kings Bay estuary.

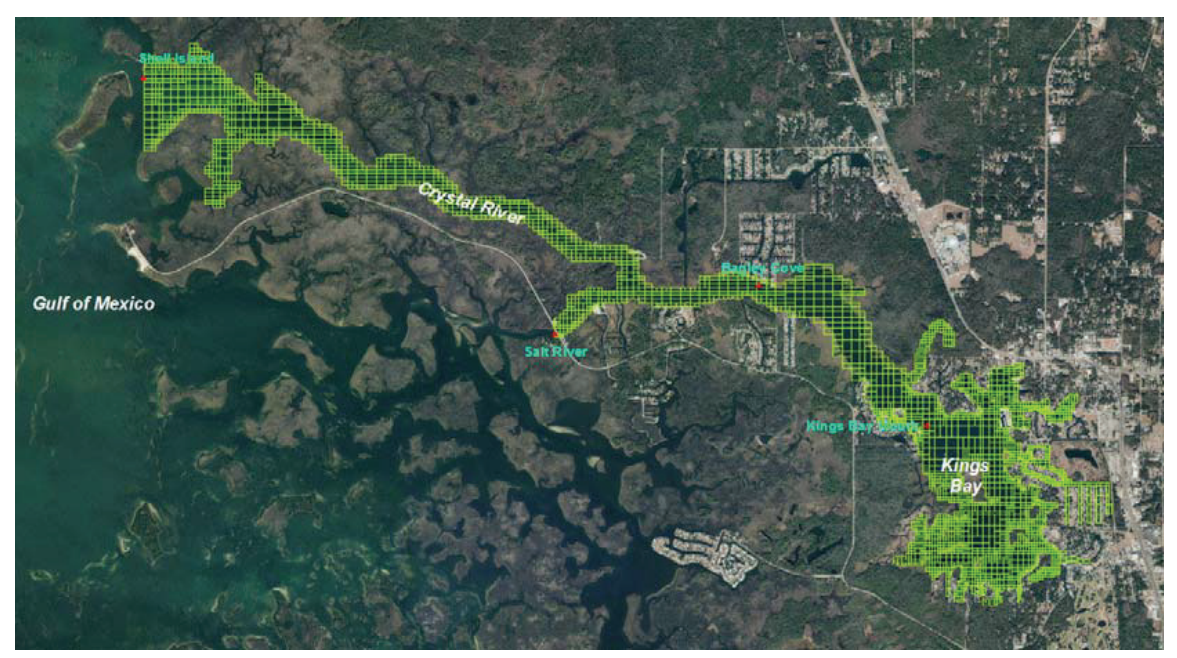

Using the mean spring discharges during the 2008-2009 field investigation as the long-term mean flow rates, Equation (3) was used to estimate the spring flow from each individual vent at each time step of the simulation during the model run. For those vents in Groups 1 and 2, the two sets of parameters $\left(\Delta G, C_{1}\right.$, and $\left.C_{2}\right)$, determined through the trial and error process mentioned in the last section, were used. For other spring sites, it is further assumed that their spring flow characteristics are similar to those of either Group 1 springs or Group 2 springs, depending on the distances from the spring site to the two spring groups. For example, if the distance from a spring site to Group 1 springs is shorter than that to Group 2 springs, the set of parameters for Group 1 is used for that spring site; otherwise, the parameters $\left(\Delta G, C_{1}\right.$, and $\left.C_{2}\right)$ for Group 2 will be used.

Another SGD to Kings Bay is hairline fractures which are spread all over the bottom of Kings Bay. In order to include this spring flow source, 40 small spring vents (one can use more) were assumed to be randomly distributed on the bottom of Kings Bay according to a uniform distribution. The long-term mean discharges of the 40 small vents were also randomly assigned with values between 0 and an assumed maximum value (e.g., $1 \mathrm{cfs}$ ). Because there is no way to measure flows out of all the hairline fractures in Kings Bay, a factor $(\alpha)$ was used in the model to adjust the magnitudes of spring discharges from these assumed spring vents which represents the hairline fractures. The determination of this adjustment factor is a part of model calibration. 
The UnLESS3D model was calibrated and verified against measured real-time water level, salinity, and temperature data at the USGS Bagley Cove and the mouth of Kings Bay stations within the simulation domain (Figure 6). The total simulation period was a 34-month period (1037 days), from 24 April 2007 to 23 February 2010. The model was calibrated against real-time data for a 150-day period during 28 December 2007-26 May 2008 after a spin-up run of 25 days. It was then verified for the remaining days before and after the 150-day calibration period.

During the model calibration process, four model parameters, including the bottom roughness, the background eddy viscosity/diffusivity, the attenuation coefficient of short wave radiation, and the flow adjustment factor $(\alpha)$ for the hairline fracture, were tuned to achieve the best agreement of model results with field data of water level, salinity, and temperature.

Figure 7. Comparison of measured and simulated water levels at the Bagley Cove station (top panel) and the mouth of King Bay station (bottom panel) during 2 August-1 October 2007.
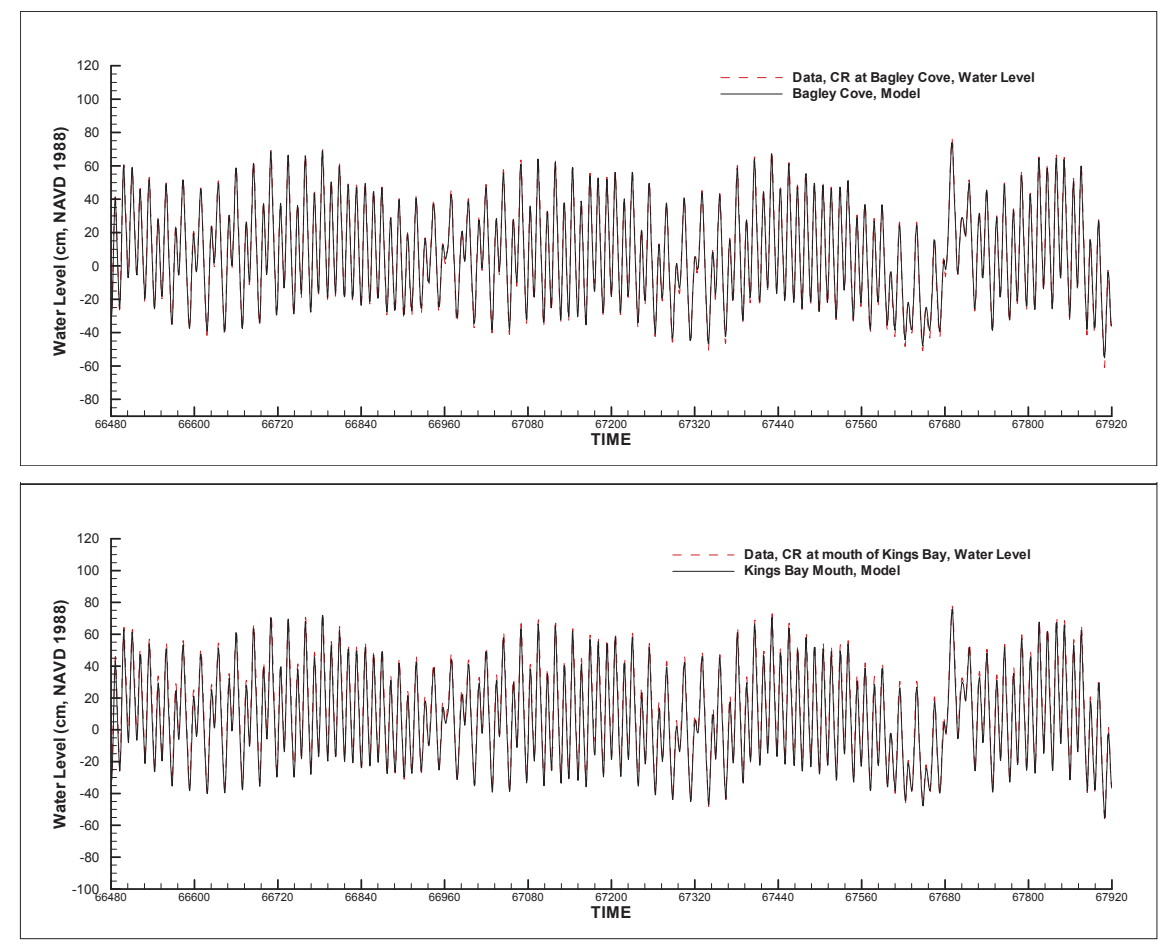

Comparisons of model results with measured field data at the two measurement stations inside the simulation domain (Bagley Cove and the mouth of Kings Bay) are presented in Figures 7-9. For simplicity and clarity, only an arbitrarily chosen, two-month period between Hour 66,480 and Hour 67,920 (2 August-1 October 2007) are shown here to demonstrate how model results are compared with measured field data. Figure 7 shows and compares simulated and measured water levels at the two measurement stations. The top panel of the figure is for the Bagley Cove station, and the bottom panel is for the mouth of Kings Bay station. Dashed lines are measured water level 
data, while solid lines are simulated water level results by the UnLESS3D model. Figure 8 shows and compares simulated and measured salinities. The top panel is for the bottom layer at the Bagley Cove station (salinity and temperature were only measured near the bottom at this station), while the middle and bottom panels are for the top and bottom layers, respectively at the mouth of Kings Bay station. Again, dashed lines are measured field data and solid lines are model results. In Figure 9, simulated and measured temperatures at Bagley Cove and the mouth of Kings Bay are shown and compared in the same manner as that in Figure 8, with dashed lines being field data and solid lines being model results.

Figure 8. Comparison of measured and simulated salinities near the bottom at the Bagley Cove station (top panel), in the top layer at the mouth of King Bay station (middle panel), and in the bottom layer at the mouth of Kings Bay station (bottom panel) during 2 August-1 October 2007.

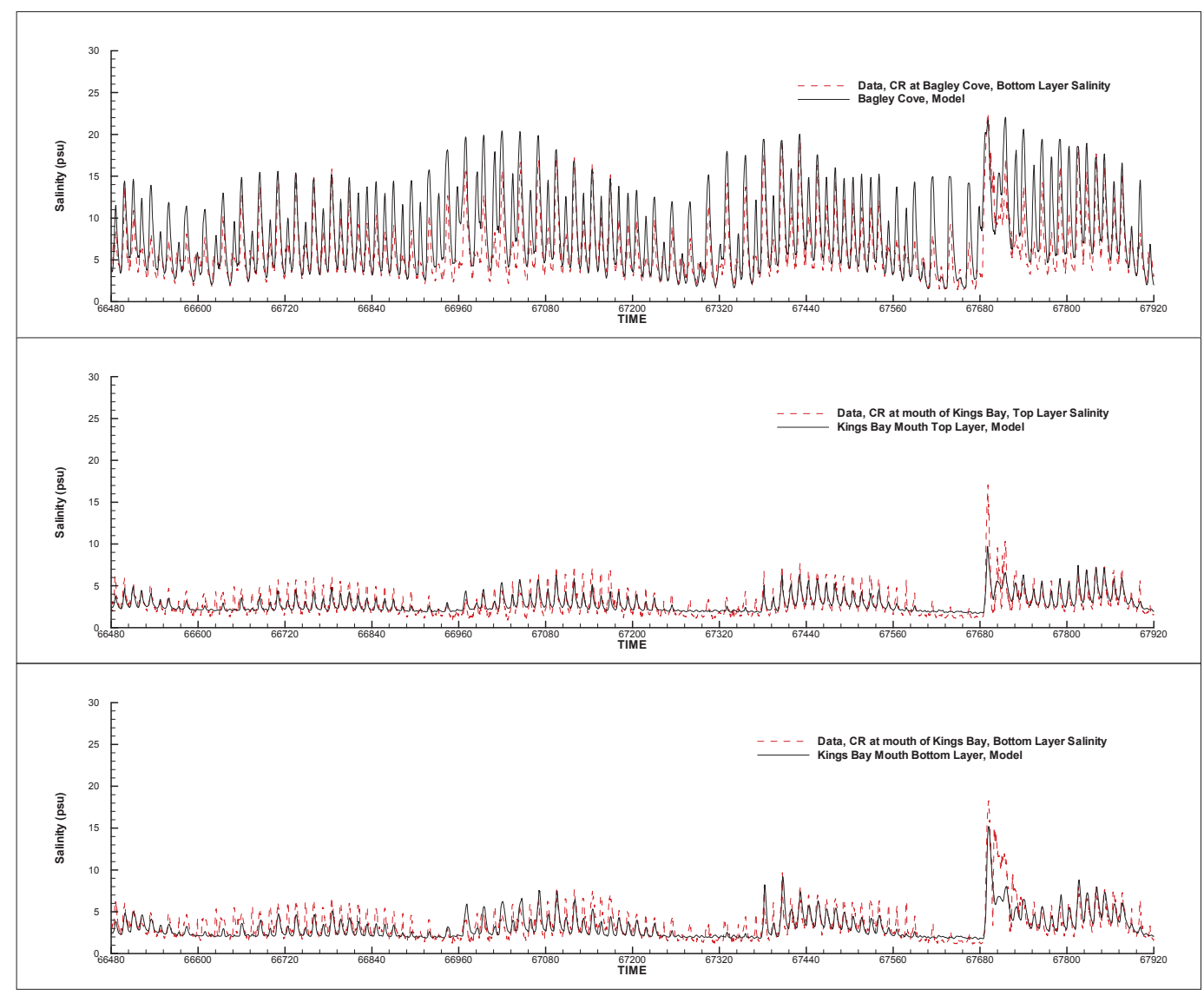


Figure 9. Comparison of measured and simulated temperatures near the bottom at the Bagley Cove station (top panel), in the top layer at the mouth of King Bay station (middle panel), and in the bottom layer at the mouth of Kings Bay station (bottom panel) during 2 August-1 October 2007.

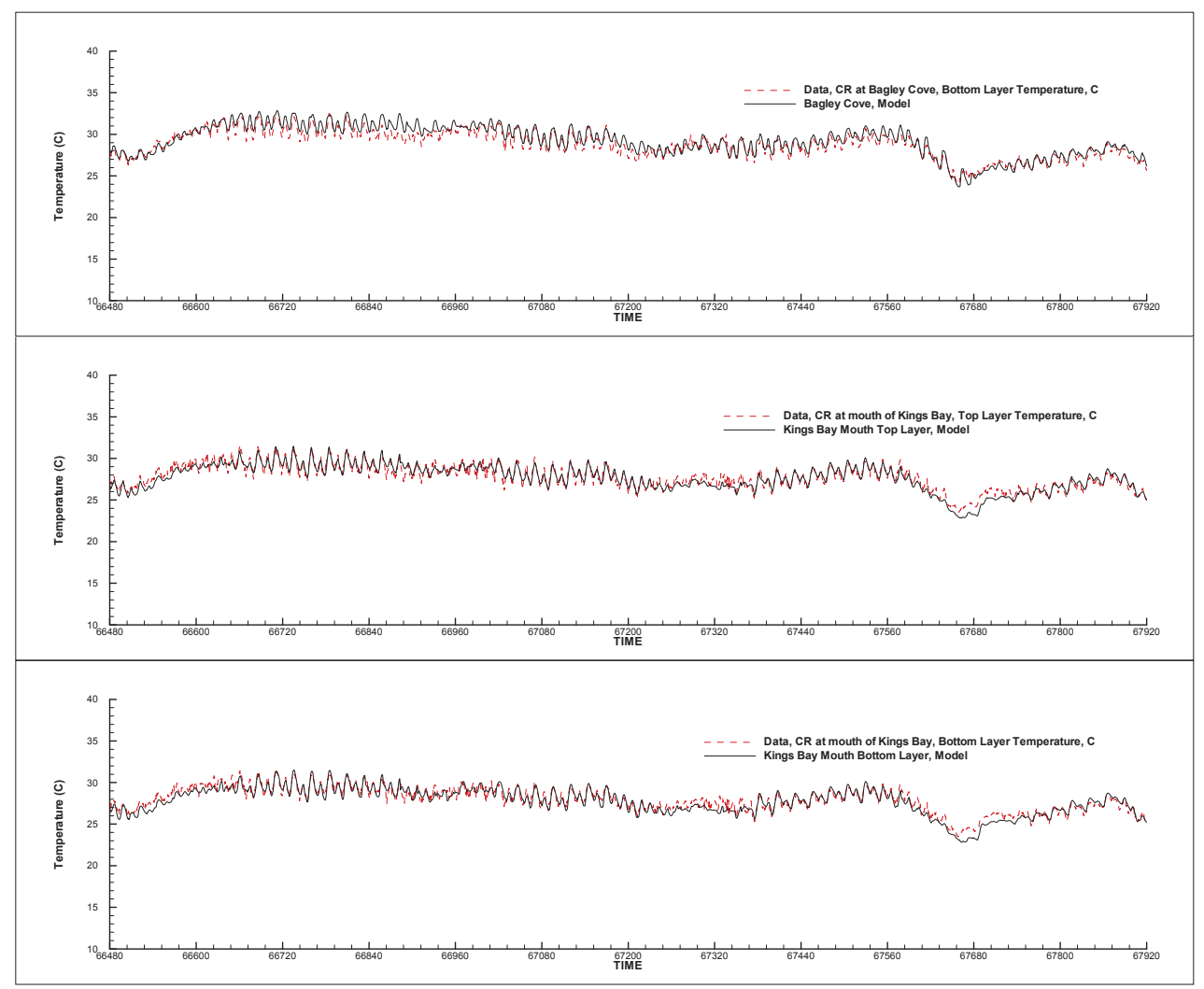

From Figures 7-9, it can be seen that the modeled water levels, salinities, and temperatures agree well with measured real-time data at the two USGS stations within the simulation domain. For the entire 34 months of the simulation period, the overall mean errors for water level, salinity, and temperature are $0.90 \mathrm{~cm},-0.06 \mathrm{psu}$, and $0.03{ }^{\circ} \mathrm{C}$, respectively, while overall mean $R^{2}$ values for water level, salinity, and temperature are $0.98,0.75$, and 0.90 , respectively. The mean skill assessment parameters of Willmott [15] are 0.99 for water level, 0.91 for salinity, and 0.98 for temperature. Detailed skill metrics of the model performance can be found in [14].

Because freshwater loading is one of the most important factors controlling circulations, salinity distributions, and thermodynamics in an estuary, a good match of model results with field data is impossible without a good quality of freshwater loading data that are used in the model. As mentioned above, $99 \%$ of fresh water loading to Kings Bay comes from the spring flows. As such, a good match between model results and measured data shown in Figures 7-9 not only suggests that the UnLESS3D model works well in simulating circulations, salinity transport processes and thermodynamics in the Crystal River/Kings Bay estuary, but also indicates that the above 
procedure in estimating SGD from the spring vents at the bottom of Kings Bay is adequate. In other words, the 3D modeling using the UnLESS3D model implies that the empirical formula expressed in the form of Equation (3), which links SGD in Kings Bay with tides and groundwater level, is applicable to all the spring vents in Kings Bay.

\section{Summary and Conclusions}

In an effort to quantify spring flows entering Kings Bay and to study how these submarine groundwater discharges are influenced by tides and groundwater level, a two-phase field investigation was conducted during 2008-2009. The first phase was to carry out an inventory study to search, identify, label, and measure the dimensions of all the detectable spring vents in Kings Bay, while the second phase included measuring instantaneous flow rates out of all the detectable spring vents and gauging cross-sectional fluxes at two spring runs continuously for about 25 days. The inventory study identified about 40 additional springs which had never been documented in any previous studies of the system.

Field data of instantaneous measurements of spring flows showed that the total mean flow from all of the detectable spring vents was about $467 \mathrm{cfs}$ during the measurement period. This number is lower than those of previous USGS studies. Effects of tides on spring flows can be clearly seen in these instantaneous measurements.

From real-time field data measured at two spring runs and the available water level and groundwater level data, it is found that the spring flow rate is a linear function of the head difference between groundwater level and water surface elevation in the bay. It is also found that the spring flow increases with the increase of the time derivative of the surface water elevation. Based on the analysis of the real-time field data, an empirical formula that relates spring flow rate with water surface elevation and groundwater level is obtained. This spring flow rate formula was used in an unstructured three-dimensional hydrodynamic model to simulate tidal circulation, salinity transport processes, and thermodynamics in the spring-fed estuary. A good match between model results with measured real-time data of water level, salinity, and temperature is achieved and suggests that the empirical formula is appropriate for estimating SGDs out of the spring vents in Kings Bay.

\section{Acknowledgments}

I would like to thank my colleagues at the SWFWMD for their support and encouragements during this study. Michael Sidney Flannery co-managed the field investigation project in Kings Bay with me, which was contracted to VHB, Inc., for whom Gary Serviss was the project manager. Many discussions and meetings with Sid and Gary led to the successful completion of the project in the field.

\section{Conflicts of Interest}

The author declares no conflict of interest. 


\section{References}

1. Meinzer, O.E. Large Springs in the United States; U.S. Geological Survey Water-Supply Paper 557; U.S. Geological Survey: Washington, DC, USA, 1927; p. 94.

2. Yobbi, D.K.; Knochenmus, L.A. Effects of River Discharge and High-Tide Stage on Salinity Intrusion in the Weeki Wachee, Crystal, and Withlacoochee River Estuaries, Southwest Florida; U.S. Geological Survey Water-Resources Investigations Report 88-4116; U.S. Geological Survey: Tallahassee, FL, USA, 1989; p. 38.

3. Hammett, K.M.; Goodwin, C.R.; Sanders, G.L. Tidal-Flow, Circulation, and Flushing Characteristics of Kings Bay, Citrus County, Florida; U.S. Geological Survey, Open-File Report 96-230; U.S. Geological Survey: Tallahassee, FL, USA, 1996; p. 63.

4. Frazer, T.K.; Notestein, S.K.; Jacoby, C.A.; Jones Littles, C.; Keller, S.R.; Swett, R.A. Effects of storm-induced salinity changes on submersed aquatic vegetation in Kings Bay, Florida. Estuar. Coasts 2006, 29, 943-953.

5. Krest, J.M.; Moore, W.S.; Gardner, L.R.; Morris, J.T. Marsh nutrient export supplied by groundwater discharge: Evidence from radium measurements. Glob. Biogeochem. Cycles 2000, 14, 167-176.

6. Moore, W.S. Large groundwater inputs to coastal waters revealed by 226Ra enrichment. Nature 1996, 380, 612-614.

7. Charette, M.A. Hydrologic forcing of submarine groundwater discharge: Insight from a seasonal study of radium isotopes in a groundwater-dominated salt marsh estuary. Limnol. Oceanogr. 2007, 52, 230-239.

8. Rosenau, J.C.; Faulkner, G.L.; Hendry, C.W., Jr.; Hull, R.W. Springs of Florida. Bulletin 31; Florida Department of Natural Resources, Division of Resource Management, Bureau of Geology: Tallahassee, FL, USA, 1977.

9. Scott, T.M.; Means, G.H.; Meegan, R.P.; Means, R.C.; Upchurch, S.B.; Copeland, R.E.; Jones, J.; Roberts, T.; Willet, A. Springs of Florida, Bulletin 66; Florida Dept. of Environmental Resources, Division of Resource Assessment and Management: Tallahassee, FL, USA, 2004.

10. Seaburn, G.E.; Jennings, M.E.; Merritt, M.L. Evaluation of a Digital Model for estuarine Water Quality Simulation in Waste Allocation Studies; U.S. Geological Survey Water Resources Investigations 78-54; U.S. Geological Survey: Tallahassee, FL, USA, 1979; p. 50.

11. VHB. An Inventory of Spring Vents in Kings Bay, Crystal River, Florida; Vanasse Hangen Brustlin, Inc. for the Southwest Florida Water Management District: Brooksville, FL, USA, 2009; p. 14.

12. VHB. Flow Measurements from Spring Vents in Kings Bay; Vanasse Hangen Brustlin, Inc. for the Southwest Florida Water Management District: Brooksville, FL, USA, 2010; p. 40.

13. Chen, $\mathrm{X}$. A three-dimensional hydrodynamic model for shallow waters using unstructured Cartesian grids. Int. J. Numer. Meth. Fluids 2011, 66, 885-905.

14. Chen, X. Simulating hydrodynamics in a spring-fed estuary using a three-dimensional unstructured Cartesian grid model. Estuar. Coastal Shelf Sci. 2012, 115, 246-259.

15. Willmott, C.J. On the validation of models. Phys. Geogr. 1981, 2, 184-194. 


\title{
Development of a Kelp-Type Structure Module in a Coastal Ocean Model to Assess the Hydrodynamic Impact of Seawater Uranium Extraction Technology
}

\author{
Taiping Wang, Tarang Khangaonkar, Wen Long and Gary Gill
}

\begin{abstract}
With the rapid growth of global energy demand, interest in extracting uranium from seawater for nuclear energy has been renewed. While extracting seawater uranium is not yet commercially viable, it serves as a "backstop" to the conventional uranium resources and provides an essentially unlimited supply of uranium resource. With recent technology advances, extracting uranium from seawater could be economically feasible only when the extraction devices are deployed at a large scale (e.g., several hundred $\mathrm{km}^{2}$ ). There is concern however that the large scale deployment of adsorbent farms could result in potential impacts to the hydrodynamic flow field in an oceanic setting. In this study, a kelp-type structure module based on the classic momentum sink approach was incorporated into a coastal ocean model to simulate the blockage effect of a farm of passive uranium extraction devices on the flow field. The module was quantitatively validated against laboratory flume experiments for both velocity and turbulence profiles.Model results suggest that the reduction in ambient currents could range from $4 \%$ to $10 \%$ using adsorbent farm dimensions and mooring densities previously described in the literature and with typical drag coefficients.
\end{abstract}

Reprinted from J. Mar. Sci. Eng. Cite as: Wang, T.; Khangaonkar, T.; Long, W.; Gill, G. Development of a Kelp-Type Structure Module in a Coastal Ocean Model to Assess the Hydrodynamic Impact of Seawater Uranium Extraction Technology. J. Mar. Sci. Eng. 2014, 2, 81-92.

\section{Introduction}

Uranium fuels more than 400 nuclear reactors worldwide and provides over $13 \%$ of the world's electricity. While uranium is among the most abundant elements found in natural crustal rock, it is seldom sufficiently concentrated to be economically recoverable. The uranium ore in the ground has remained as the single most important conventional uranium resource. Based on current consumption rates, the known uranium ore resources that can be mined at current costs are estimated to be sufficient to produce fuel for about a century. Although at low concentrations, the world oceans hold the largest reserves of uranium. In fact, extracting metals (e.g., $\mathrm{Na}, \mathrm{Mg}$, and $\mathrm{K}$ ) from seawater has been commercialized for a long time [1]. The possibility of recovery of seawater uranium by ion-exchange resins was studied shortly after World War II, but was not economically viable compared to exploitation of known uranium ores on land [2]. While extracting seawater uranium is not yet commercially viable, it serves as a "backstop" to the conventional uranium resources and provides an essentially unlimited ( $\sim 6500$ years) supply of uranium [3]. Driven by the rapid growth of global energy demand in recent decades, interest in extracting uranium from seawater for nuclear energy has been renewed. With recent advances in seawater uranium 
extraction technology, extracting uranium from seawater could become economically feasible especially when the extraction devices are deployed at large scales of several hundred $\mathrm{km}^{2}$ [4].

Sugo et al. [5] introduced the braided adsorbent farm technology that is potentially feasible for large-scale uranium extraction from seawater. The fibers are braided around a low-density core to result in positively-buoyant braids approximately 60 meters in length. The material is carried to the deployment site and moored to the ocean floor with anchor chains. The proposed design calls for deployment of over a million long braided moorings, $60 \mathrm{~m}$ in height over an area of about $680 \mathrm{~km}^{2}$. The submerged farm closely resembles a kelp forest, which is known to exert a substantial drag on coastal currents [6]. Hence, there is concern that the large scale deployment of adsorbent farms could result in potential impact to the hydrodynamic flow field in an oceanic setting.

In this study, a kelp-type structure module was incorporated into the Finite Volume Coastal Ocean Model (FVCOM) to simulate the retardation effect of a farm of uranium extraction devices on the flow field. The kelp-type structure module is based on the classic momentum sink approach that approximates the blockage effect of structures on flows as additional drag force in the momentum equations. This paper summarizes the kelp-type module development and validation processes.

\section{Methodology}

\subsection{Kelp-Type Structure Module Development}

A number of modeling studies have been carried out to investigate the hydrodynamic effects of underwater structures, including aquaculture farms, vegetation canopies, as well as wind and tidal energy farms. For instance, Grant and Bacher [7] developed a two-dimensional (2-D) finite element circulation model for Sungo Bay, China to study the effect of bivalve culture structure on flows. The drag exerted by the culture drop ropes was parameterized as additional form drag in the hydrodynamic model, which predicted a 54\% reduction in current speed in the midst of the culture area. By approximating the shellfish farm drag as additional bottom friction in a 2-D hydrodynamic model, Plew [8] studied the shellfish farm-induced changes to tidal circulation in an embayment in New Zealand, and found that the current speeds were reduced inside most farms. Struve et al. [9] studied the influence of model mangrove trees on the hydrodynamics in a flume through both flume experiments and 2-D depth-integrated numerical modeling. The model results compared very well with experiment measurements when the resistance created by mangroves was modeled as an additional drag force. Hence, in this study, a similar momentum sink approach was adopted for the kelp-type structure module to assess the hydrodynamic impact of seawater uranium extraction devices. Specifically, the additional resistance force on flow caused by a single uranium adsorbent braid or kelp frond is defined as:

$$
\tau=\frac{1}{2} \rho C_{d} A|\vec{u}| \vec{u}
$$

where $\tau$ additional resistance force by uranium adsorbent braid $(\mathrm{N}), \rho=$ seawater density $\left(\mathrm{kg} / \mathrm{m}^{3}\right)$, $C_{d}=$ drag coefficient of the equivalent (cylindrical) braid or kelp structure, $A=$ flow-facing area of 
the adsorbent braid or kelp frond $\left(\mathrm{m}^{2}\right), A=$ diameter $\times$ length for cylinders, and $\vec{u}=$ velocity vector $(\mathrm{m} / \mathrm{s})$.

The hydrodynamic model selected in this study is the finite volume coastal ocean model FVCOM developed by Chen et al. [10]. As a three-dimensional (3-D) unstructured-grid coastal ocean model, FVCOM is capable of simulating water surface elevation, velocity, temperature, salinity, sediment, and water quality constituents. The unstructured grid and finite volume approach employed in the model provides geometric flexibility and mass conservation that is well suited to simulate hydrodynamic transport at various spatial scales within a large model domain. For computational efficiency, a mode splitting scheme is used to solve the momentum equations. FVCOM has been extensively used by the estuarine and coastal modeling community to study a variety of scientific and engineering problems in estuaries and coastal oceans [11-13]. The numerical aspects and detailed formulations of FVCOM have been presented in Chen et al. [10,14] and many other FVCOM publications, thus they will not be elaborated here except for the portions in the momentum governing equations that were modified to include the momentum sink induced by underwater structures.

The modified FVCOM momentum equations in the horizontal directions have the following general form [13]:

$$
\begin{aligned}
& \frac{\partial u}{\partial t}+u \frac{\partial u}{\partial x}+v \frac{\partial u}{\partial y}+w \frac{\partial u}{\partial z}-f v=-\frac{1}{\rho_{o}} \frac{\partial p}{\partial x}+\frac{\partial}{\partial z}\left(K_{m} \frac{\partial u}{\partial z}\right)+F_{x}-F_{x}^{M} \\
& \frac{\partial v}{\partial t}+u \frac{\partial v}{\partial x}+v \frac{\partial v}{\partial y}+w \frac{\partial v}{\partial z}+f u=-\frac{1}{\rho_{o}} \frac{\partial p}{\partial y}+\frac{\partial}{\partial z}\left(K_{m} \frac{\partial v}{\partial z}\right)+F_{y}-F_{y}^{M}
\end{aligned}
$$

where $(x, y, z)$ are the east, north, and vertical axes in the Cartesian coordinates; $(u, v, w)$ are the three velocity components in the $x, y$, and $z$ directions, respectively; $\left(F_{x}, F_{v}\right)$ are the horizontal momentum diffusivity terms in the $x$ and $y$ directions, respectively; $K_{m}$ is the vertical eddy viscosity coefficient; $\rho$ is water density; $p$ is pressure; and $f$ is the Coriolis parameter. $F_{x}^{M}$ and $F_{y}^{M}$ are the momentum sink term $\left(\mathrm{m} / \mathrm{s}^{2}\right)$ induced by the uranium adsorbent device that was added to the original FVCOM governing equations [10,14], and is defined as the following general form:

$$
\overrightarrow{F^{M}}=\frac{1}{2} \frac{N C_{d} A}{V_{c}}|\vec{u}| \vec{u}
$$

where $V_{c}=$ momentum control volume in which the adsorbent device is deployed $\left(\mathrm{m}^{3}\right), N=$ the number of adsorbent braids deployed within the same momentum control volume, and the rest terms were defined previously in Equation (1).

FVCOM solves the momentum equations using the finite-volume method and sigma-stretched coordinate transformation in the vertical direction. Assuming one adsorbent braid may occupy multiple $\sigma$-layers and is located within a single momentum control element (i.e., the model grid size is much larger than the width of adsorbent braid), the integrated form of Equations (2) and (3) for the 3-D internal mode can be written as:

$$
\frac{\partial\left(A_{e} \Delta_{\sigma} D u\right)}{\partial t}+R_{u}-f A_{e} \Delta_{\sigma} D v=-\frac{1}{2} N\left[C_{d} A_{\sigma} \sqrt{u^{2}+v^{2}} u\right]
$$




$$
\frac{\partial\left(A_{e} \Delta_{\sigma} D v\right)}{\partial t}+R_{v}+f A_{e} \Delta_{\sigma} D u=-\frac{1}{2} N\left[C_{d} A_{\sigma} \sqrt{u^{2}+v^{2}} v\right]
$$

where $A_{e}=$ triangular element surface area $\left(\mathrm{m}^{2}\right), \Delta_{\sigma} D=\sigma$-layer thickness $(\mathrm{m}), R_{u}$ and $R_{v}=$ all the remaining momentum terms including advection, diffusion, and pressure gradient. The right hand side of Equations (5) and (6) represents the volumetric momentum sink rate $\left(\mathrm{m}^{4} / \mathrm{s}^{2}\right)$ contributed by the adsorbent braid or kelp frond defined in Equation (1), and $A_{\sigma}=$ flow-facing area of braid adsorbent within the $\sigma$-layer.

The integrated form for the 2-D external mode of Equations (2) and (3) are expressed as:

$$
\begin{aligned}
& \frac{\partial\left(A_{e} D \bar{u}\right)}{\partial t}+R_{\bar{u}}-f A_{e} D \bar{v}=-\frac{1}{2} N \sum_{\sigma=1}^{\sigma=k}\left[C_{d} A_{\sigma} \sqrt{u^{2}+v^{2}} u\right] \\
& \frac{\partial\left(A_{e} D \bar{v}\right)}{\partial t}+R_{\bar{v}}+f A_{e} D \bar{u}=-\frac{1}{2} N \sum_{\sigma=1}^{\sigma=k}\left[C_{d} A_{\sigma} \sqrt{u^{2}+v^{2}} v\right]
\end{aligned}
$$

where $\bar{u}$ and $\bar{v}=$ vertically averaged velocity in the $x$ and $y$ directions, respectively.

\subsection{Module Validation}

The kelp-type structure module was validated against laboratory experiments conducted by Plew [15]. The detailed experiment configuration has been described in Plew [15], and is briefly presented here. The experiments were conducted in a $6-\mathrm{m}$ long by $0.6-\mathrm{m}$ wide flume (Figure 1). The structure canopies were constructed from aluminum cylinders of 9.54-mm diameter, and extended over the full width and the entire working length $(4.8 \mathrm{~m})$ of the flume. The velocity profiles were measured using particle tracking velocimetry (PTV) at a distance of $4 \mathrm{~m}$ from the flow inlet. Velocity measurements were made in two vertical planes, mid-way between cylinders and then in line with the cylinders, and were averaged horizontally in the $x$-direction over the distance (L) between cylinder rows to give an averaged vertical profiles for each plane. This enabled a vertical profile of spatially averaged velocity and turbulence statistics to be defined.

Table 1 summarizes the configuration of the four flume experiments selected for the kelp-type module validation in this study. The cylinders were suspended in the upper half of the water column in all the experiments but with different horizontal spacing/density, allowing cylinder density to increase from runs A to D.

FVCOM was configured based on the flume experiment configurations listed in Figure 1 and Table 1 to validate the kelp-type structure module. The flume was represented with an unstructured mesh consisting of 5578 elements and 2954 nodes in the horizontal plane (Figure 2a). In the vertical direction, 40 uniform sigma layers were specified. An external time-step of 0.001 second was used in all model runs. The default Mellor-Yamada 2.5 turbulence closure was used for vertical eddy viscosity and diffusivity calculations. The drag coefficient $\left(C_{d}\right)$ of the canopy was treated as spatially uniform but its value for each validation run was calibrated based on model-data comparisons. Figure $2 \mathrm{~b}$ shows the spatial distribution of the cylinder array in Validation Run D. The corresponding model predicted surface velocity field during the baseline condition (without cylinder array) and Run D are presented in Figure 2c,d, respectively. The presence of cylinders 
significantly altered the flow field. Surface velocity was generally reduced within the cylinder canopy compared to the baseline condition.

Figure 1. Schematic of the experimental flume setup (adapted from Plew [15], with permission from (C) 2011 American Society of Civil Engineers). Cylinders were arranged in rows with a spacing of $\mathrm{L}(\mathrm{m})$ in the direction of flow, and a transverse spacing of $\mathrm{B}$ (m) between cylinders. Velocity measurements were taken at a distance of $4 \mathrm{~m}$ from the inlet. $\mathrm{H}(\mathrm{m})$ is the total water depth in the flume, $\mathrm{h}_{\mathrm{c}}(\mathrm{m})$ is the canopy height, and $\mathrm{hg}(\mathrm{m})$ is the distance between the canopy and the flume bed.

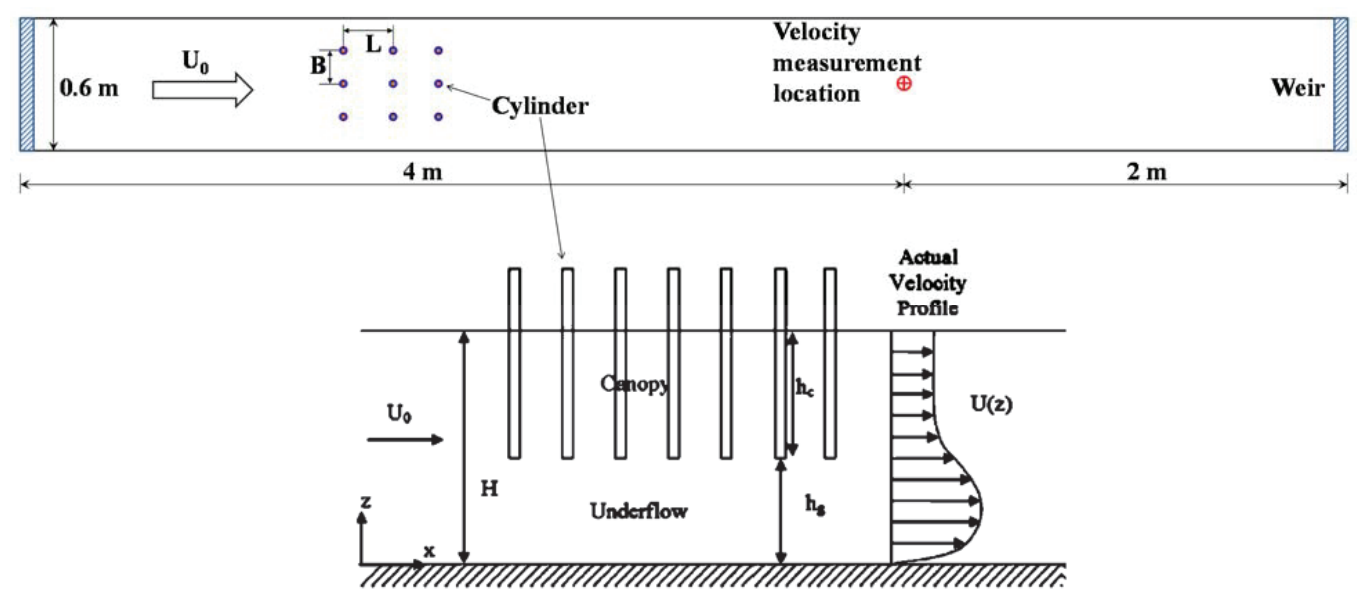

Table 1. Summary of flume experiments selected from Plew [15] for kelp-type module validation. $\mathrm{a}$ is the projected cylinder flow-facing area per unit volume inside the canopy, and Q is the flow rate (data obtained from Plew [15]).

\begin{tabular}{ccccccc}
\hline Validation Run & $\mathbf{H}(\mathbf{m m})$ & $\mathbf{h}_{\mathbf{g}}(\mathbf{m m})$ & $\mathbf{L}(\mathbf{m m})$ & $\mathbf{B}(\mathbf{m m})$ & $\mathbf{a ~ ( \mathbf { m } ^ { - \mathbf { 1 } } )}$ & $\mathbf{Q}(\mathbf{L} / \mathbf{s})$ \\
\hline A & 200 & 100 & 100 & 50 & 1.908 & 10.5 \\
B & 200 & 100 & 150 & 50 & 1.272 & 10.1 \\
C & 200 & 100 & 200 & 50 & 0.954 & 10.1 \\
D & 200 & 100 & 200 & 100 & 0.477 & 10.3 \\
\hline
\end{tabular}


Figure 2. (a) Finite Volume Coastal Ocean Model (FVCOM) model grid (in the horizontal plane) for the flume experiment. (b) Spatial distribution of cylinders in Run D. (c) Surface velocity field in the baseline condition without the cylinder array. (d) Surface velocity field in Run D.
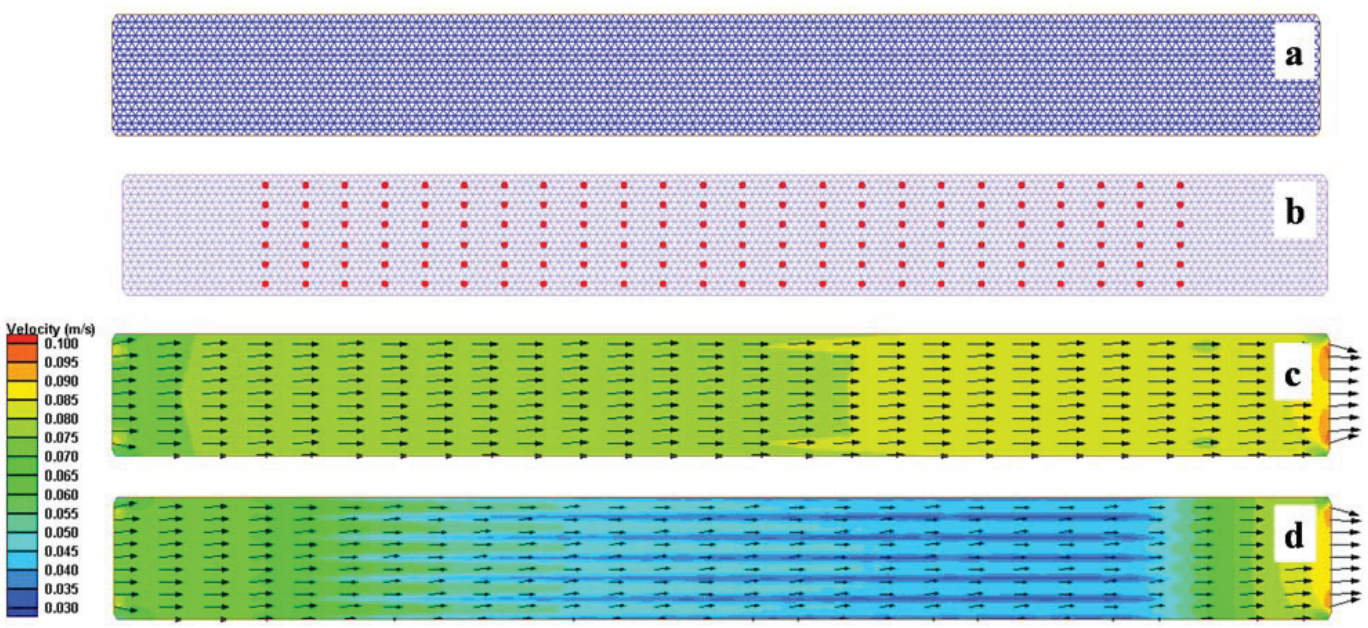

\section{Results and Discussion}

\subsection{Kelp-Type Module Validation}

The model predicted velocity and turbulent stress profiles were compared with laboratory data digitized from Plew [15]. Figure 3a shows the model predicted vertical velocity profiles for Validation Run A which has the highest cylinder density among all the runs. In general, the velocity profiles with cylinders showed a significant change from that of the baseline condition with no cylinders present. Flows were reduced within the canopy while increased beneath the canopy. As expected, the change to flow structure is more significant for flows in-line with the cylinder arrays than between arrays. Figure $3 \mathrm{~b}$ shows the corresponding model-data comparison of the normalized (by mean free-stream) velocity profiles. The model predicted mean velocity profile agrees with the laboratory measurements reasonably well. A drag coefficient $\left(C_{d}\right)$ of 1.75 was found to provide good model-data comparison in this validation run.

The model-data comparisons for all four validation runs are presented in Figure 4, and the corresponding error statistics are listed in Table 2. The model results have been normalized/non-dimensionalized so that they can be directly compared with laboratory data presented in Plew [15]. While the velocity profiles can be directly extracted from the model output, the turbulent stress was calculated using (9):

$$
u^{\prime} w^{\prime}=-K_{m} \frac{\partial u}{\partial z}
$$

where $u^{\prime} w^{\prime}=$ turbulent stress $\left(\mathrm{m}^{2} / \mathrm{s}^{2}\right)$, and $K_{m}=$ vertical eddy viscosity $\left(\mathrm{m}^{2} / \mathrm{s}\right)$. 
Figure 3. (a) FVCOM predicted vertical velocity profiles for Validation Run A. (b) Normalized velocity profiles for validation Run A compared to the experimental measurements.
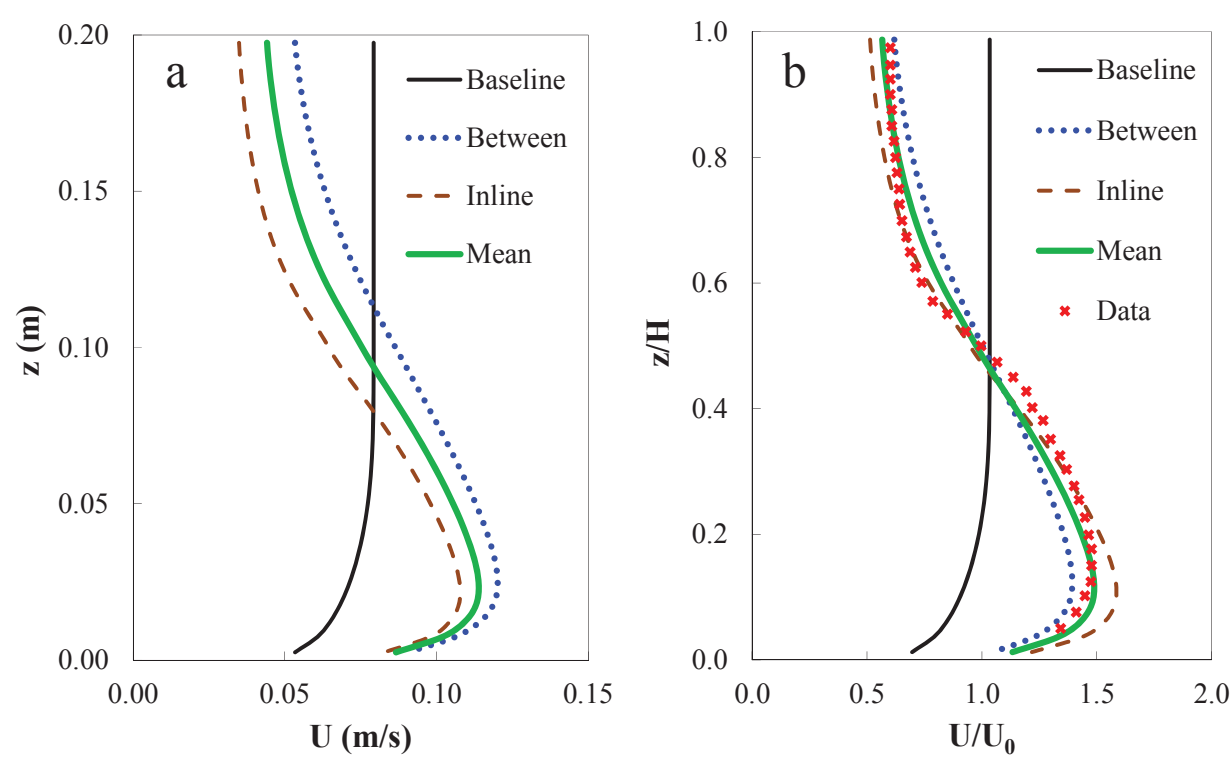

Table 2. Error statistics for kelp-type structure module validation runs ( $R^{2}$ denotes the coefficient of determination and RE stands for relative error defined by $R E=100 \% \times \frac{\sum_{i=1}^{N}\left(\eta_{i}^{m}-\eta_{i}^{o}\right)^{2}}{\sum_{i=1}^{N}\left[\left(\eta_{i}^{m}-\overline{\eta^{o}}\right)^{2}+\left(\eta_{i}^{o}-\overline{\eta^{o}}\right)^{2}\right]}$, where $\eta^{m}$ and $\eta^{\circ}$ stand for model predictions and laboratory observations, respectively, $\overline{\eta^{o}}$ is the mean of observations).

\begin{tabular}{ccccc}
\hline \multirow{2}{*}{ Validation Run } & \multicolumn{2}{c}{ Velocity } & \multicolumn{2}{c}{ Turbulent Stress } \\
\cline { 2 - 5 } & $\boldsymbol{R}^{\mathbf{2}}$ & $\mathbf{R E}(\%)$ & $\boldsymbol{R}^{\mathbf{2}}$ & $\mathbf{R E}(\%)$ \\
\hline A & 0.98 & 1.2 & 0.94 & 6.0 \\
B & 0.98 & 1.4 & 0.98 & 3.6 \\
C & 0.98 & 1.7 & 0.94 & 5.5 \\
D & 0.97 & 2.5 & 0.93 & 5.0 \\
\hline
\end{tabular}

There is an overall good agreement between model predictions and direct measurements for all the validation runs (Figure 4). The good model-data comparison is further confirmed by error statistics which show a high coefficient of determination $\left(R^{2}\right)$ and low relative error (RE) between predicted and measured velocity and turbulent stress values (Table 2). In general, the model captures the vertical structure for both velocity and turbulent stress. For instance, the velocities were significantly attenuated for flows through the cylinders and the maximum turbulence was generated near the middle depth of the water column at the interface between the bottom of the cylinder canopy and the flow immediately below. In addition, as evident from model predictions and laboratory data, higher cylinder density (Parameter a in Table 1) tends to exert a stronger impact on flows. The maximum differences between the model and data occurred in the middle 
depths of the water column. A better parameterization may be needed at canopy-water interfaces to account for this difference. For example, additional skin friction contributed by the bottom of the cylinder may be considered. This discrepancy could also be contributed by the inadequate characterization of the canopy's effects on turbulence in the current module, as suggested by other studies $[16,17]$.

Figure 4. (a-d) Model-data comparisons of normalized mean vertical velocity profiles for Validation Runs A, B, C, and D, respectively. (e-h) Model-data comparisons of normalized mean turbulent stress profiles for Validation Runs A, B, C, and D, respectively.
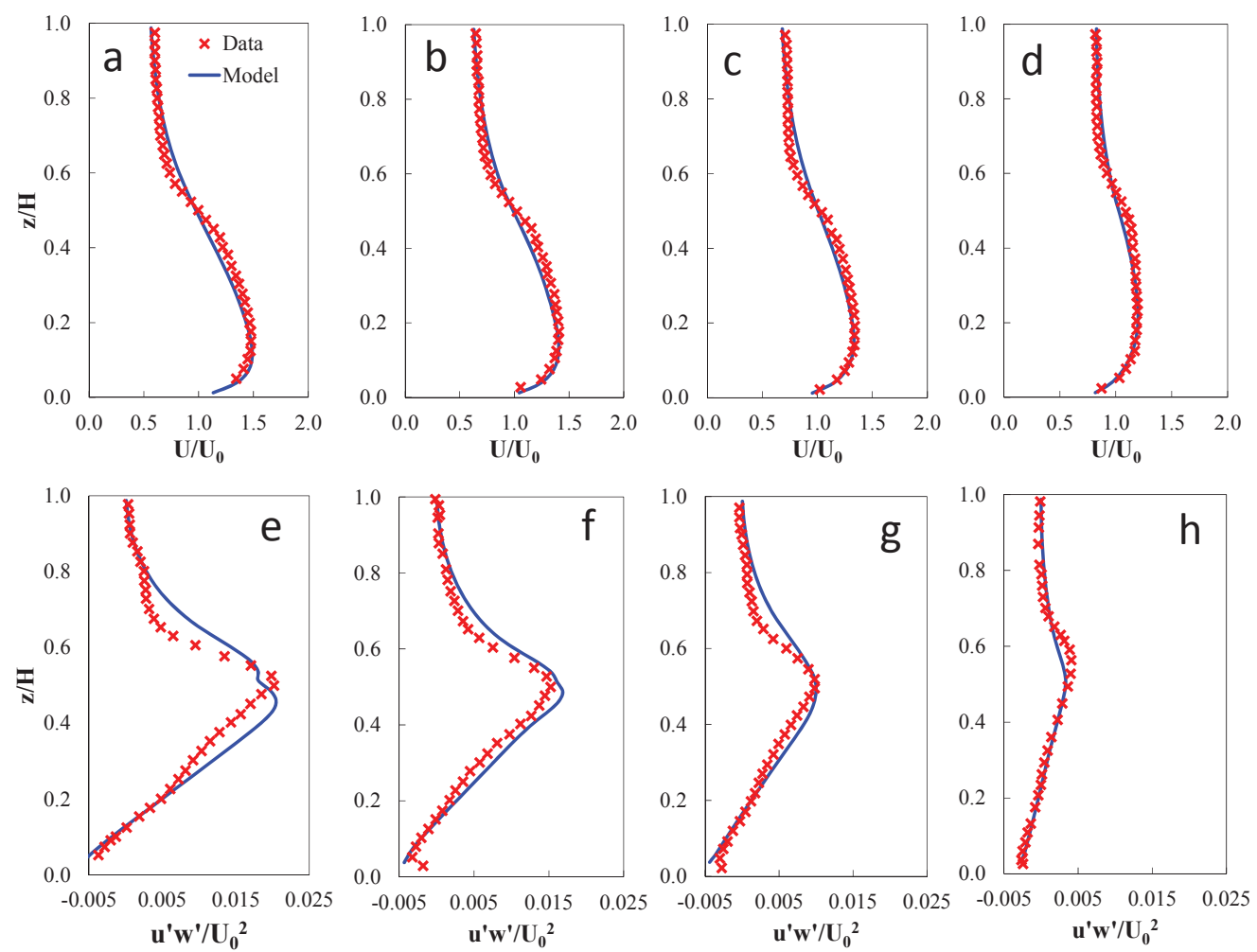

The model results also indicated that the drag coefficient $\left(C_{d}\right)$ is a function of canopy density and increases with higher density. For example, the calibrated $C_{d}$ values for Runs A, B, C and D are $1.75,1.5,1.25$, and 1.0 , respectively. This is also consistent with the findings in other similar studies $[9,15,18]$. Wu and Wang [18] and Struve et al. [9] reported that $\mathrm{C}_{\mathrm{d}}$ values greater than 3.0 were needed to reach a good agreement between model and data. As discussed by Wu and Wang [18], this is presumably due to the inherent dependency of $C_{d}$ on the Reynolds number (Re). At higher canopy densities, reduced flow velocity and Reynolds number in the model domain lead to larger drag coefficients according to the relationship between $C_{d}$ and Re for a single cylinder [19]. The validation tests also suggest this. Although the actual $C_{d}$ values varied with canopy density, a spatially uniform $C_{d}$ represented the major conditions reasonably well. 


\subsection{Module Applications-Kelp Forest and Braid Adsorbent Farm Simulation}

The validated kelp-type structure module was used to simulate the effects of a kelp forest and uranium braid adsorbent farm on coastal flows. Numerous studies have documented the effects of kelp forest on coastal currents. The current measurements conducted by Jackson [6] off the coast of California in the Point Loma kelp forest were selected as the reference for kelp forest simulation in this study. The oceanographic conditions including 7-km-long and 1-km-wide stretch of real kelp forest were setup in the FVCOM model. The kelp fronds were $0.2 \mathrm{~m}$ in diameter and occupied the full $15 \mathrm{~m}$ of water depth. The model grid used was a simplified rectangular channel which carried a mean longshore ambient current of $2 \mathrm{~cm} / \mathrm{s}$ reproducing the conditions observed during the field survey. The kelp density $\left(\mathrm{K}_{\mathrm{d}}\right)$ used for this numerical experiment was 0.08 fronds $/ \mathrm{m}^{2}$, which is the average of the observed kelp density range of 0.02 to 0.14 fronds $/ \mathrm{m}^{2}$.

The model results for the Point Loma kelp forest shown in Figure 5 suggest that the drag provided by kelp forest results in a reduction of ambient currents from $45 \%$ to $55 \%$ for typical drag coefficient values ranging from 0.2 to 0.5 . This is consistent with field observations that indicated a significant reduction in longshore currents with dense kelp forest [6,20,21]. Moreover, this prediction serves as an additional qualitative model validation study.

Figure 5. (a) Map of the Point Loma kelp forest offshore of the California coast. The dotted line represents a general outline of the kelp canopy (map adapted from Tegner et al. [22] with permission from Elsevier). (b) Predicted potential reductions in ambient currents by the kelp forest and braid adsorbent farm with typical canopy/mooring densities.
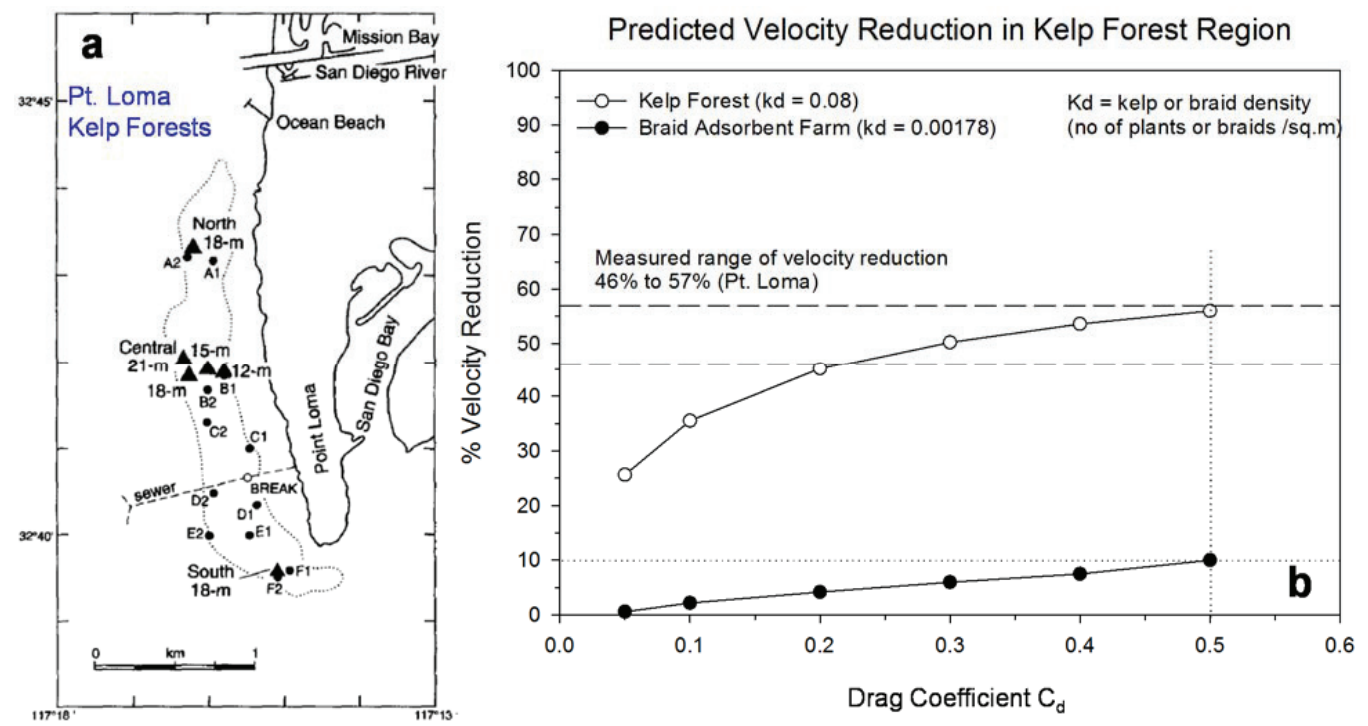

The kelp forest in the above model configuration was substituted with braid adsorbent moorings to estimate if a braid adsorbent farm for seawater uranium extraction would have a similar effect. The physical dimensions of the moorings were set identical to the kelp fronds $(0.2 \mathrm{~m}$ diameter and 
$15 \mathrm{~m}$ long occupying the full water column). The proposed braid adsorbent farm design calls for moorings on $8 \mathrm{~m} \times 70 \mathrm{~m}$ centers. This corresponds to an adsorbent mooring density $\left(K_{d}\right)$ of 0.00178 moorings $/ \mathrm{m}^{2}$, much less dense than the kelp forest $\left(0.08\right.$ fronds $\left./ \mathrm{m}^{2}\right)$. The model results suggest that with typical drag coefficient values of 0.2 to 0.5 , the reduction in ambient currents by braid adsorbent farms could range from $4 \%$ to $10 \%$.

\section{Conclusions}

A kelp-type structure module was incorporated into the coastal ocean model FVCOM based on the commonly used momentum sink approach in which the resistance force exerted by kelp-type structures is parameterized as additional form drag in the momentum equations. The module was reasonably validated using observations from both laboratory flume experiments and field surveys conducted in the kelp forest near Pt. Loma off the Californian coast. Model results suggest that the reduction in ambient currents could range from $4 \%$ to $10 \%$ for a farm of uranium adsorbent material having configurations for mooring density described previously by Japanese scientists [5] and employing a typical drag coefficient. This study demonstrates that a momentum sink approach based on structure module is capable of characterizing the general hydrodynamic impact of kelptype structures on coastal flows. Improvements in the current module could be made by including other processes such as the effect of canopy on turbulence [16,17,23] and calibrated drag coefficients by braid adsorbents.

\section{Acknowledgments}

This work was funded by the Office of Nuclear Energy, U.S. Department of Energy. The authors also thank David Plew for providing additional information on the flume experiment configurations.

\section{Conflicts of Interest}

The authors declare no conflict of interest.

\section{References}

1. Bardi, U. Extracting minerals from seawater: An energy analysis. Sustainability 2010, 2, 980-992; doi:10.3390/su2040980.

2. Davies, R.V.; Kennedy, J.; McIlroy, R.W.; Spence, R.; Hill, K.M. Extraction of uranium from sea water. Nature 1964, 203, 1110-1115.

3. Annual Report: Powerful Partnerships: The Federal Role in International Cooperation on Energy Innovation; Office of the President of the United States: Washington, DC, USA, June 1999.

4. Tamada, M.; Seko, N.; Kasai, N.; Shimizu, T. Cost estimation of uranium recovery from seawater with system of braid type adsorbent. Trans. Atomic Energy Soc. Jpn. 2006, 5, $358-363$. 
5. Sugo, T.; Tamada, M.; Seguchi, T.; Shimizu, T.; Uotani, M.; Kashima, R. Recovery system for uranium from seawater with fibrous adsorbent and its preliminary cost estimation. J. Atomic Energy Soc. Jpn. 2001, 43, 1010-1016.

6. Jackson, G.A. Currents in the high drag environment of a coastal kelp stand off California. Cont. Shelf Res. 1998, 17, 1913-1928.

7. Grant, J.; Bacher, C. A numerical model of flow modification induced by suspended aquaculture in a Chinese Bay. Can. J. Fish. Aquat. Sci. 2001, 58, 1003-1011.

8. Plew, D.R. Shellfish farm-induced changes to tidal circulation in an embayment, and implications for seston depletion. Aquac. Environ. Interact. 2011, 1, 201-214.

9. Struve, J.; Falconer, R.A.; Wu, Y. Influence of model mangrove trees on the hydrodynamics in a flume. Estuar. Coast. Shelf Sci. 2003, 58, 163-171.

10. Chen, C.; Liu, H.; Beardsley, R.C. An unstructured, finite-volume, three-dimensional, primitive equation ocean model: Application to coastal ocean and estuaries. J. Atmos. Ocean. Technol. 2003, 20, 159-186.

11. Chen, C.; Huang, H.; Beardsley, R.; Liu, H.; Xu, Q.; Cowles, G. A finite volume numerical approach for coastal ocean circulation studies: Comparisons with finite difference models. J. Geophys. Res. 2007, 112, C03018; doi:10.0129/2006JC003485.

12. Ji, R.; Davis, C.; Chen, C.; Beardsley, R. Influence of local and external processes on the annual nitrogen cycle and primary productivity on Georges Bank: A 3-D biological-physical modeling study. J. Mar. Syst. 2008, 73, 31-47.

13. Yang, Z.; Wang, T.; Copping, A.E. Modeling tidal stream energy extraction and its effects on transport processes in a tidal channel and bay system using a three-dimensional coastal ocean model. Renew. Energy 2013, 50, 605-613.

14. Chen, C.; Beardsley, R.C., Cowles, G. An Unstructured Grid, Finite-Volume Coastal Ocean Model: FVCOM User Manual; School for Marine Science and Technology, University of Massachusetts Dartmouth: North Dartmouth, MA, USA, 2006; p. 315.

15. Plew, D.R. Depth-averaged drag coefficient for modeling flow through suspended canopies. J. Hydraul. Eng. 2011, 137, 234-247.

16. Li, C.; Yan, K. Numerical investigation of wave-current-vegetation interaction. J. Hydraul. Eng. 2007, 133, 794-803.

17. Sheng, Y.P.; Lapetina, A.; Ma, G. The reduction of storm surge by vegetation canopies - three-dimensional simulations. Geophys. Res. Lett. 2012, 39, L20601; doi:10.1029/ 2012 GL053577.

18. Wu, W.; Wang, S.S.Y. A depth-averaged two-dimensional numerical model of flow and sediment transport in open channels with vegetation, In Riparian Vegetation and Fluvial Geomorphology; American Geophysical Union: Washington, DC, USA, 2004.

19. Schlichting, H. Boundary Layer Theory; McGraw Hill Book Co.: New York, NY, USA, 1968.

20. Jackson, G.A.; Winant, C.D. Effect of a kelp forest on coastal currents. Cont. Shelf Res. 1983, $20,75-80$. 
21. Rosman, J.H.; Koseff, J.R.; Monismith, S.G.; Grover, J. A field investigation into the effects of a kelp forest (Macrocystis pyrifera) on coastal hydrodynamics and transport. J. Geophys. Res. 2007, 112, C02016; doi:10.1029/2005JC003430.

22. Tegner, M.J.; Dayton, P.K.; Edwards, P.B.; Riser, K.L.; Chadwick, D.B.; Dean, T.A.; Deysher, L. Effects of a large sewage spill on a kelp forest community: Catastrophe or disturbance? Mar. Environ. Res. 1995, 40, 181-224.

23. Katul, G.G.; Mahrt, L.; Poggi, D.; Sanz, C. One- and two-equation models for canopy turbulence. Bound. Layer Meteorol. 2004, 113, 81-109. 


\title{
Conceptual Site Model for Newark Bay-Hydrodynamics and Sediment Transport
}

\author{
Parmeshwar L. Shrestha, Steave H. Su, Scott C. James, Philip J. Shaller, Macan Doroudian, \\ Clifford E. Firstenberg and Carlie T. Thompson
}

\begin{abstract}
A conceptual site model (CSM) has been developed for the Newark Bay Study Area (NBSA) as part of the Remedial Investigation/Feasibility Study (RI/FS) for this New Jersey site. The CSM is an evolving document that describes the influence of physical, chemical and biological processes on contaminant fate and transport. The CSM is initiated at the start of a project, updated during site activities, and used to inform sampling and remediation planning. This paper describes the hydrodynamic and sediment transport components of the CSM for the NBSA. Hydrodynamic processes are influenced by freshwater inflows, astronomical forcing through two tidal straits, meteorological conditions, and anthropogenic activities such as navigational dredging. Sediment dynamics are driven by hydrodynamics, waves, sediment loading from freshwater sources and the tidal straits, sediment size gradation, sediment bed properties, and particle-to-particle interactions. Cohesive sediment transport is governed by advection, dispersion, aggregation, settling, consolidation, and erosion. Noncohesive sediment transport is governed by advection, dispersion, settling, armoring, and transport in suspension and along the bed. The CSM will inform the development and application of a numerical model that accounts for all key variables to adequately describe the NBSA's historical, current, and future physical conditions.
\end{abstract}

Reprinted from J. Mar. Sci. Eng. Cite as: Shrestha, P.L.; Su, S.H.; James, S.C.; Shaller, P.J.; Doroudian, M.; Firstenberg, C.E.; Thompson, C.T. Conceptual Site Model for Newark Bay-Hydrodynamics and Sediment Transport. J. Mar. Sci. Eng. 2014, 2, 123-139.

\section{Introduction}

Since the late 1800s, Newark Bay and adjoining waterways located in New Jersey, USA, have been highly industrialized, receiving direct and indirect discharges from numerous industrial facilities. A Remedial Investigation/Feasibility Study (RI/FS) under the Comprehensive Environmental Response, Compensation, and Liability Act (CERCLA "Superfund") began in 2004 for the Newark Bay Study Area (NBSA) — which has been defined as Newark Bay (the Bay) and portions of the Hackensack River, Arthur Kill, and Kill van Kull (Figure 1).

To initiate the field investigations for the NBSA, Tierra first developed a Preliminary Conceptual Site Model (CSM) [1], based on historical data, and used the model to plan the first two phases of the remedial investigation (RI) [1,2]. The new data generated from these investigations were used to create the revised CSM described herein, to inform additional data needs for the RI. The specific objectives of the CSM include:

- Update the current understanding of the conditions and processes in the NBSA based on the data generated from recent RI investigations $[1,2]$ and secondary data $[3,4]$. 
- Guide the planning and development of future sampling and investigation activities as part of the RI/FS program, including both the human health and ecological risk assessments.

- Provide further insight into the sources of hazardous substances or contaminants of potential concern (COPCs) to the NBSA and its adjoining tributaries.

Figure 1. Regional map of Newark Bay and the Newark Bay Study Area (NBSA) outlined in green.

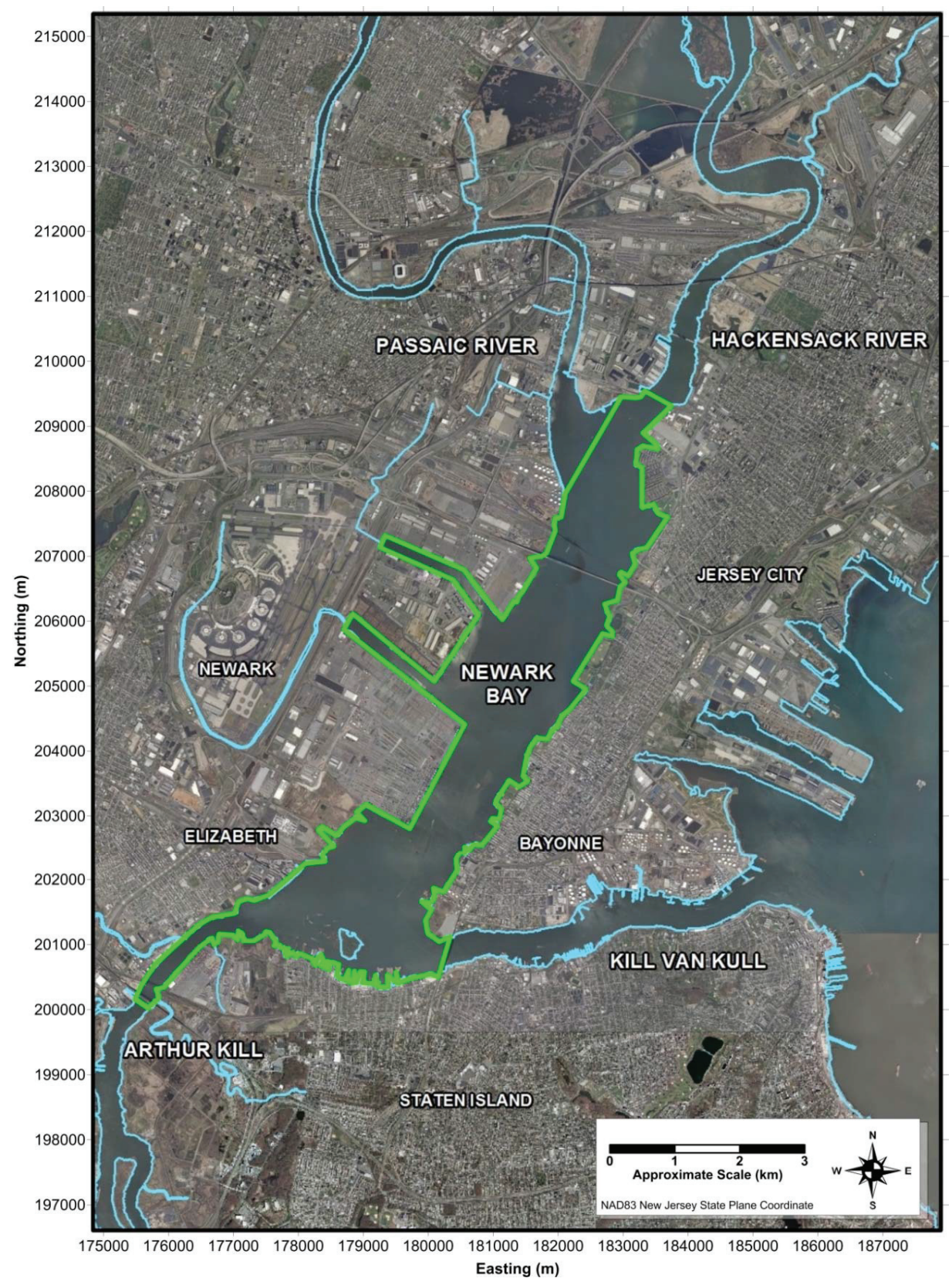


The comprehensive NBSA CSM addresses: (1) the general physico-chemical characteristics of the NBSA (including geology and geomorphology, surface water quality, biological communities), as well as (2) contaminant sources, (3) hydrodynamics and sediment transport, (4) contaminant fate and transport, (5) nature and extent of sediment contamination, (6) human and ecological exposure pathways, and (7) identification of data gaps. The focus of this paper is the hydrodynamics and sediment transport components of the NBSA CSM.

\section{Environmental History of the Newark Bay Study Area}

Newark Bay is situated within a highly industrialized and heavily populated region, adjacent to the cities of Newark and Elizabeth. It is bordered by Newark Liberty International Airport to the west; Jersey City and Bayonne to the east; and Staten Island, New York, to the south. As part of the New York/New Jersey Harbor Estuary, Newark Bay has evolved over more than two centuries into a key shipping port and a convenient site for industrial operations [5-9].

Environmental degradation has occurred in the NBSA over the past two centuries due to a variety of factors - including shoreline and land development [10], wetlands destruction, habitat degradation, garbage and sewage disposal, and releases of contaminants [11]. As a result of urban and industrial practices, the NBSA is contaminated with a number of COPCs-including polychlorinated biphenyls (PCBs), polycyclic aromatic hydrocarbons (PAHs), pesticides, herbicides, volatile and semivolatile organic compounds (VOCs and SVOCs, respectively), polychlorinated dibenzo- $p$-dioxins and polychlorinated dibenzofurans (PCDDs and PCDFs), and metals $[12,13]$.

\section{Conceptual Site Model-Hydrodynamics and Sediment Transport}

The NBSA is a partially mixed estuary that receives large freshwater contributions from the Passaic and Hackensack Rivers at the northern end of the Bay and additional freshwater contributions from a number of other tributaries, combined sewer overflows (CSOs), storm water outfalls (SWOs), and publically owned treatment works (POTWs) distributed throughout the Bay. It also receives salt water contributions through the Kill van Kull and the Arthur Kill tidal straits at the southern end of the Bay. The NBSA and the surrounding area have a long history of human activity that has modified the shorelines and bathymetry of Newark Bay and its tributaries. As a result, the Bay's bathymetry consists of shallow tidal flats adjacent to deeper, dredged navigation channels, which results in a complex bathymetry with sharp elevation gradients. Large bathymetric gradients, highly variable freshwater loading, astronomical tides, and prevailing and event-based meteorological forcing all contribute to the system's complex hydrodynamic and sediment transport patterns and processes.

\subsection{Hydrodynamics}

The hydrodynamics of Newark Bay are influenced primarily by three physical processes: (1) freshwater tributary flows; (2) astronomical forcing (including classical estuarine gravitational circulation) through the Kill van Kull and Arthur Kill tidal straits; and (3) local and regional 
meteorological events [14,15]. These primary influences combine to yield complex, event-driven circulation and make it challenging to identify a long-term average pattern [16].

A substantial amount of dredging has been done over the past 150 years [10], and flows are much different now in Newark Bay from what they were before human activities began. In general, it is understood that, because of the freshwater inputs in the northern end of the Bay, the system is partially mixed and displays the characteristics of classic two-layer estuarine circulation with a landward flow of salt water in the bottom layer and a seaward flow of less saline water in the surface layer [15-18]. High freshwater discharge from the Passaic River increases both vertical stratification and flow rate in the landward-flowing, saline bottom layer in Newark Bay [16].

This estuarine gravitational circulation pattern can be interrupted (i.e., daily-averaged currents become uniform with depth) during periods of very low freshwater discharge from the Passaic River or during strong meteorological events $[16,19]$. Moreover, the consensus view in published literature is that there is, on average, a counterclockwise circulation around Staten Island [20-22]. In addition, because the Kill van Kull is shorter, straighter, and better aligned with tidal and gravitational forcing, it typically experiences flows about an order of magnitude greater than the Arthur Kill [23]. Because of the complexity and variability of the circulation patterns, it is most efficient to examine individually the responses of the NBSA to each of the primary influences.

\subsubsection{Tributary Inflows}

Freshwater is delivered to Newark Bay through a number of major and minor waterways (Figure 2). The principal sources of freshwater are the Passaic [24] and Hackensack Rivers [25] with mean daily discharges of $47 \mathrm{~m}^{3} / \mathrm{s}\left(1500 \mathrm{ft}^{3} / \mathrm{s}\right)$ and $6 \mathrm{~m}^{3} / \mathrm{s}\left(218 \mathrm{ft}^{3} / \mathrm{s}\right)$, respectively. Minor contributors include the Peripheral Ditch and Piersons Creek (no flow data available), which empty directly into the Bay. The Rahway and Elizabeth Rivers, Piles Creek, Morses Creek, Old Place Creek and Fresh Kills Creek enter the Bay by way of the Arthur Kill tidal strait. The mean daily discharges from Rahway River [26], Elizabeth River [27], Morses Creek [28] and Fresh Kills Creek [29] are $1.2 \mathrm{~m}^{3} / \mathrm{s}$ $\left(41 \mathrm{ft}^{3} / \mathrm{s}\right), 0.7 \mathrm{~m}^{3} / \mathrm{s}\left(24 \mathrm{ft}^{3} / \mathrm{s}\right), 0.06 \mathrm{~m}^{3} / \mathrm{s}\left(2 \mathrm{ft}^{3} / \mathrm{s}\right)$, and $0.4 \mathrm{~m}^{3} / \mathrm{s}\left(14 \mathrm{ft}^{3} / \mathrm{s}\right)$; the remaining waterways (Piles Creek and Old Place Creek) do not have flow data available. Two other waterways, Oyster Creek and Maple Island Creek, formerly drained to the Bay (circa 1917), but have since been filled. Figure 2 shows the magnitude of the peak freshwater inflows into the NBSA, wherein the size of the open arrows qualitatively indicates the magnitude of the peak flows. The solid arrows indicate the typical flow direction of estuarine circulation during flood tide (red arrows are bottom salt water flows, and blue arrows are freshwater surface flows).

\subsubsection{Point Sources (CSOs, SWOs, and POTWs)}

In addition to these freshwater tributaries, there are also significant anthropogenic freshwater inputs to Newark Bay, including urban runoff, CSOs, SWOs, and POTWs. Suszkowski [18] reported undifferentiated industrial and municipal wastewater discharges totaling $6.6 \mathrm{~m}^{3} / \mathrm{s}\left(232 \mathrm{ft}^{3} / \mathrm{s}\right)$ to Newark Bay. HydroQual Inc. [30] subsequently reported wastewater discharges during 1989, yielding a combined total of $13.4 \mathrm{~m}^{3} / \mathrm{s}\left(474 \mathrm{ft}^{3} / \mathrm{s}\right)$ of industrial and municipal runoff into tributaries 
of Newark Bay during that year. Another estimate places freshwater flows into the Arthur Kill from sewage treatment plants at $4.8 \mathrm{~m}^{3} / \mathrm{s}$ or $\left(170 \mathrm{ft}^{3} / \mathrm{s}\right)$, and from permitted industrial discharges at 0.5 $\mathrm{m}^{3} / \mathrm{s}\left(18 \mathrm{ft}^{3} / \mathrm{s}\right)$ into the Arthur Kill [29]. A more recent approximation indicates that the Bergen County POTW and Secaucus POTW discharge an average of $3 \mathrm{~m}^{3} / \mathrm{s}\left(108 \mathrm{ft}^{3} / \mathrm{s}\right)$ and $0.15 \mathrm{~m}^{3} / \mathrm{s}(5.3$ $\mathrm{ft}^{3} / \mathrm{s}$ ), respectively, to the Hackensack River [31].

Figure 2. Freshwater flows into the NBSA where the size of the open arrows reflects the relative magnitude of the flows.

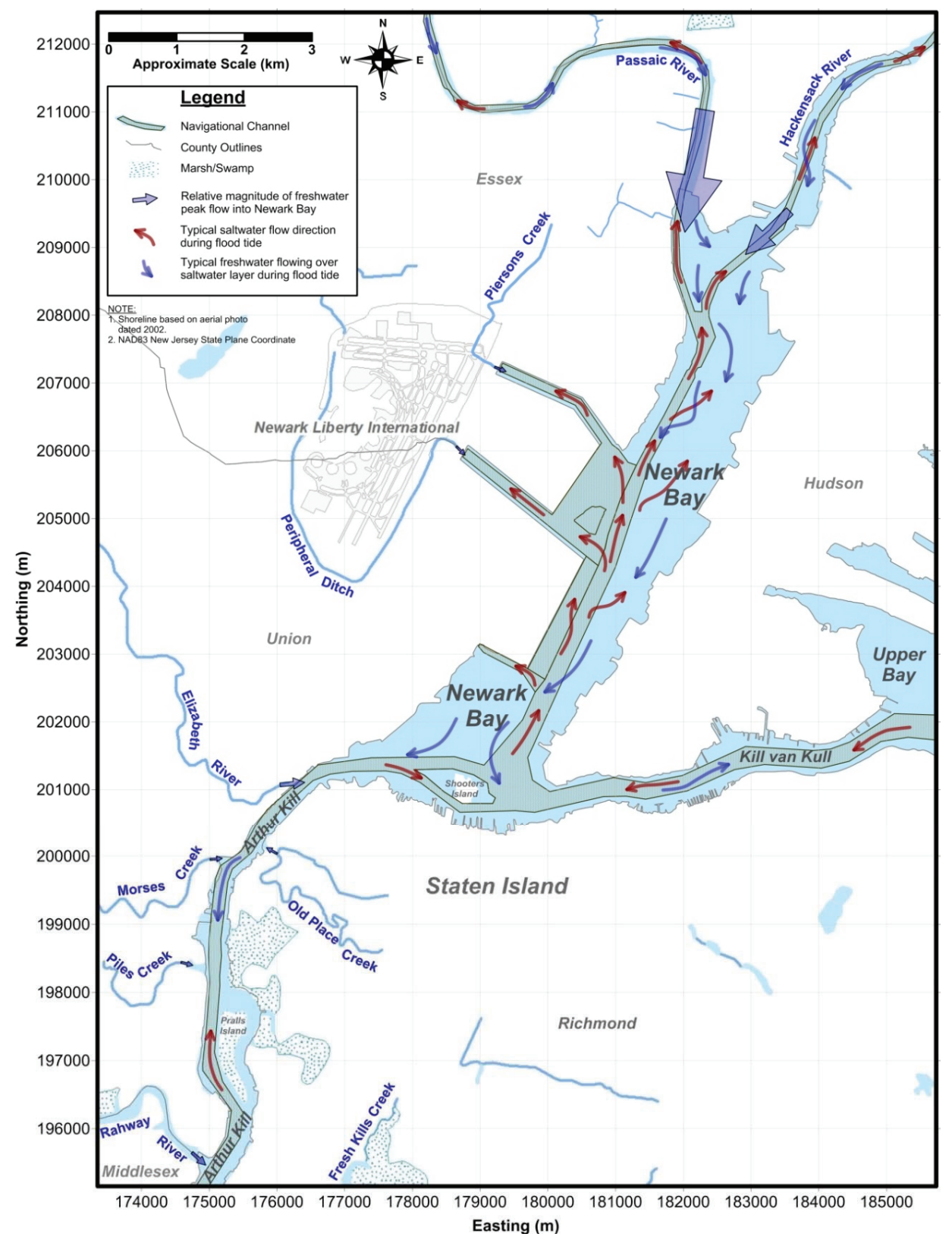




\subsubsection{Non-Point Sources (Direct Runoff and Groundwater)}

The State of New Jersey's annual rainfall typically ranges between $813 \mathrm{~mm}$ (32 in.) and $1219 \mathrm{~mm}$ (48 in.) with an average of $1151 \mathrm{~mm}$ (45.3 in.) from 1895 to 2012 [32]. Newark averages slightly more rain at $1174.8 \mathrm{~mm} /$ year (46.25 in./year) [33]. Most of the rain falling on the Newark Bay watershed eventually enters the Bay in the form of runoff or groundwater influx, the amount of which is highly variable and dependent on the annual climatic conditions.

\subsubsection{Flows through the Tidal Straits}

Newark Bay is connected to the Atlantic Ocean by two straits: the Kill van Kull on the southeast and the Arthur Kill on the southwest. The Kill van Kull connects Newark Bay to the Upper Bay of New York Harbor (to the east), while the Arthur Kill connects Newark Bay to Raritan Bay (to the south). The combination of tidal forcing, significant freshwater flows from the Passaic and Hackensack Rivers, and dredged navigational channels results in measurable salinity stratification within both tidal straits, yielding daily-averaged, two-layer subtidal flow patterns with seaward flows of less saline water near the surface that are offset by landward flows of saltier water near the bottom [16,22,34].

The Kill van Kull is a tidally dominated strait where the tidal excursion (distance that water travels over half a tidal cycle) is much greater than its length. Because of its relatively short length, the Kill van Kull exhibits strong currents and relatively weak stratification (up to $1.5 \mathrm{psu}$ ), promoting a greater degree of tidal exchange and mixing between Newark Bay and New York Harbor than occurs between Newark Bay and Raritan Bay by way of the Arthur Kill [16,35]. The movement of water through the Arthur Kill is impeded relative to the Kill van Kull, because the tidal excursion is shorter than its length. Its freshwater sources support a mild vertical salinity gradient of up to 1 psu. LMS [36] estimated tidal flows through the Kill van Kull and the Arthur Kill to occasionally exceed $1417 \mathrm{~m}^{3} / \mathrm{s}\left(50,000 \mathrm{ft}^{3} / \mathrm{s}\right)$ and $283 \mathrm{~m}^{3} / \mathrm{s}\left(10,000 \mathrm{ft}^{3} / \mathrm{s}\right)$, respectively, with average flows passing through Kill van Kull ranging up to an order of magnitude larger than those passing through Arthur Kill [23].

\subsubsection{Gravitational Circulation and Tidal Currents}

Flows through the tidal straits are a result of both salinity gradients (gravitational circulation) and water-elevation differences (tidal current) between the ends of each strait (meteorological forcing also plays an important role). Freshwater inflow, primarily from the Passaic and Hackensack Rivers, supports both the gravitational circulation and tidal current mechanisms. Figure 3 is a schematic of the two-layer circulation in the NBSA. Red arrows indicate salt water flow, and blue arrows freshwater flow. For the relatively larger inputs, the numbers near each arrow indicate the volumetric inflow over a tidal cycle as a fraction of the estimated volume of the Bay (with water at sea level). The Kill van Kull and Arthur Kill straits tend to form a through-flow pattern of circulation around Staten Island, in contrast to a tidal pumping mode of circulation in which Newark Bay is filled (or emptied) by simultaneous inflow (or outflow) through both Kills [16,19,20]. 
Figure 3. Schematic of the two-layer circulation pattern in the NBSA.

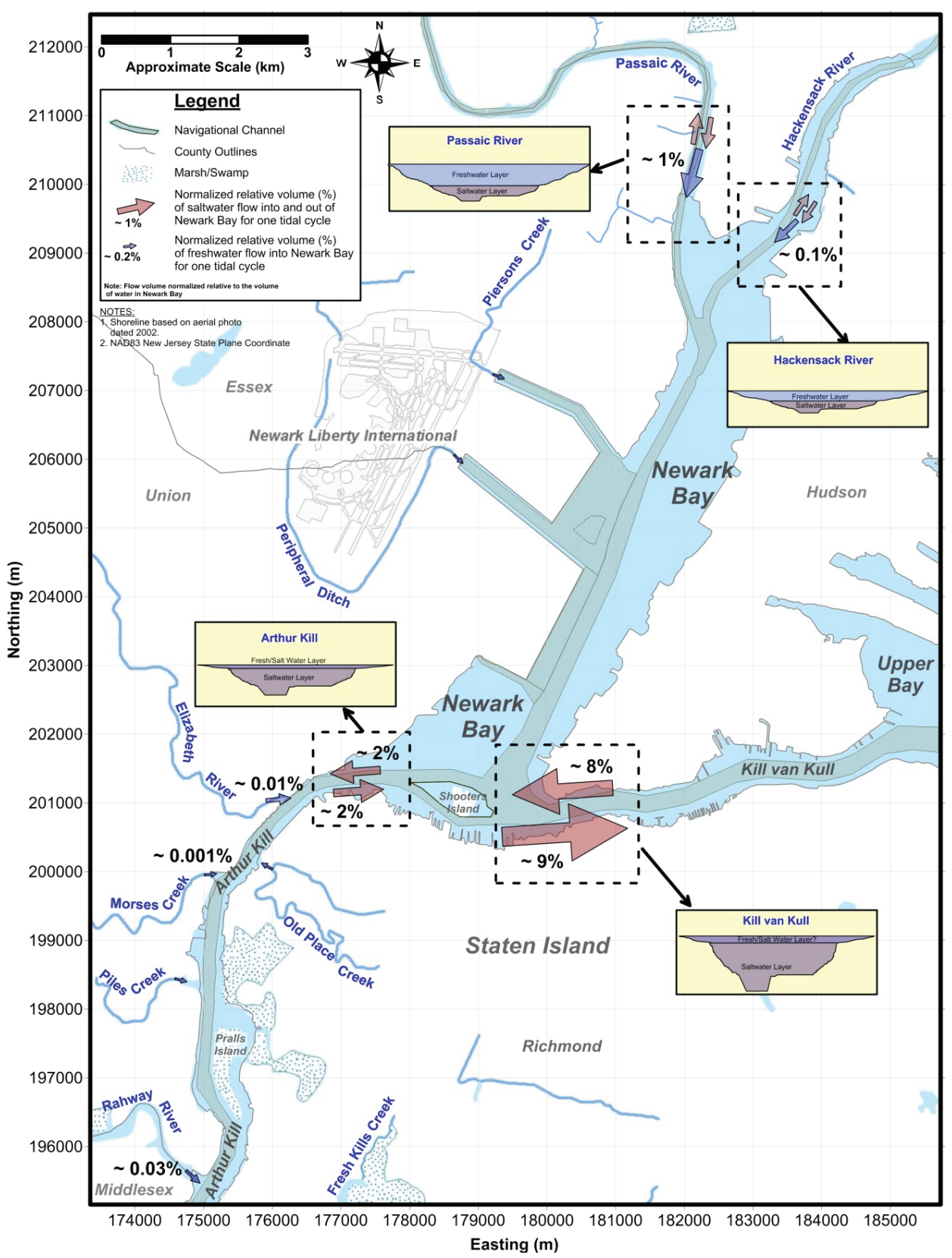

\subsubsection{Meteorological Forcing}

Although tidal circulation patterns through the Kill van Kull and the Arthur Kill are generally counterclockwise around Staten Island [20], strong and persistent meteorological events can, at times, dominate the circulation pattern in Newark Bay, as well as the magnitude and direction of 
flows in the Kill van Kull and the Arthur Kill [16,17,29,37,38]. The primary types of storms that affect Newark Bay include tropical storms that typically occur in late summer and fall, and extra-tropical ("Nor'easter") storms that occur primarily in the winter. The extra-tropical storms can cause high water levels and enhanced wave conditions. Potential wave heights can be over $1.8 \mathrm{~m}$

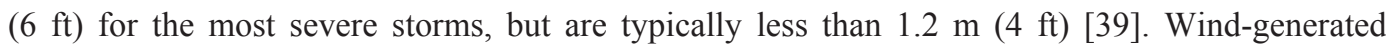
currents affect water mixing and possibly sediment transport within Newark Bay [39]. Strong wind events were also shown to generate large episodic flushing.

\subsection{Sediment Dynamics}

Sediment dynamics in estuarine environments such as the NBSA are driven by several factors, including hydrodynamics, episodic meteorological events, sediment loading from freshwater inflows, sediment loading at open boundaries, sediment size gradation, bed sediment properties, bioturbation, and particle-to-particle interactions. Significant human activities including long term maintenance and navigational dredging and ship traffic also affect sediment dynamics. A significant volume of research has been conducted to better understand the role that tidal circulation patterns and wind-driven episodic events play in the fate and transport of sediments within the NBSA $[15,16,18,19,22,34,37,38,40]$. Fluid mud transport is not considered in this CSM because site characterization data collected to date have not indicated the presence of fluid mud. In addition, no previous publication related to the NBSA has considered the effects of fluid mud as a potential transport pathway for sediments and associated contaminants. Until such processes are observed, there is no basis to include them in the CSM.

\subsubsection{Sediment Transport Processes}

A schematic of the processes that influence sediment transport in the water column and the sediment bed of the NBSA is shown on Figure 4. Local advection and dispersion in the water column control the distribution of sediment particles throughout the system. Advection moves the sediments according to the local water velocity while dispersion spreads sediments based on concentration gradients. Sediments are typically classified as either cohesive (small grain sizes) or noncohesive (larger grain sizes). Cohesive sediments are composed primarily of clay-sized $(<2 \mu \mathrm{m})$ and silt-sized $(<63 \mu \mathrm{m})$ particles, mixed with organic matter and sometimes small quantities of very fine sand. Noncohesive sediments are primarily sand and gravel-sized materials $(>63 \mu \mathrm{m})$. Each sediment class is subject to different physical processes [41-43].

\subsubsection{Bed Shear Stresses}

Hydrodynamic flows will result in variable shear stresses at the sediment bed that, depending upon erodibility, may lead to erosion. When wind-waves are present, it is necessary to account for the shear stress on the sediment bed caused by wave-current interaction, which is a function of the bottom orbital amplitude and bottom orbital currents, both of which depend on the wave climate $[44,45]$. Including the effect of waves is necessary because the bed shear stresses can be an order of magnitude greater than stresses caused by currents alone. Vessel-generated wakes, 
associated with tugs, barges, and deep-draft vessel traffic in the Navigation Channels, represent another source of wave action in the Bay $[10,15]$. Although minor compared to wind-waves, these waves can also contribute to the resuspension of bottom sediments in shallow Subtidal Flat areas. Ship traffic can also resuspend sediments in the deeper dredged portions of the channel due to prop wash.

Figure 4. Schematic of sediment transport processes where $C$ is the suspended sediment concentration profile, $U$ is the velocity profile, $\tau_{b}$ is the bed shear stress, and $u *$ is the shear velocity. Concentration and velocity profiles are conceptual only. The concentration profile reflects increased sediment concentration with depth, and the velocity profile decreases to zero at the sediment bed.

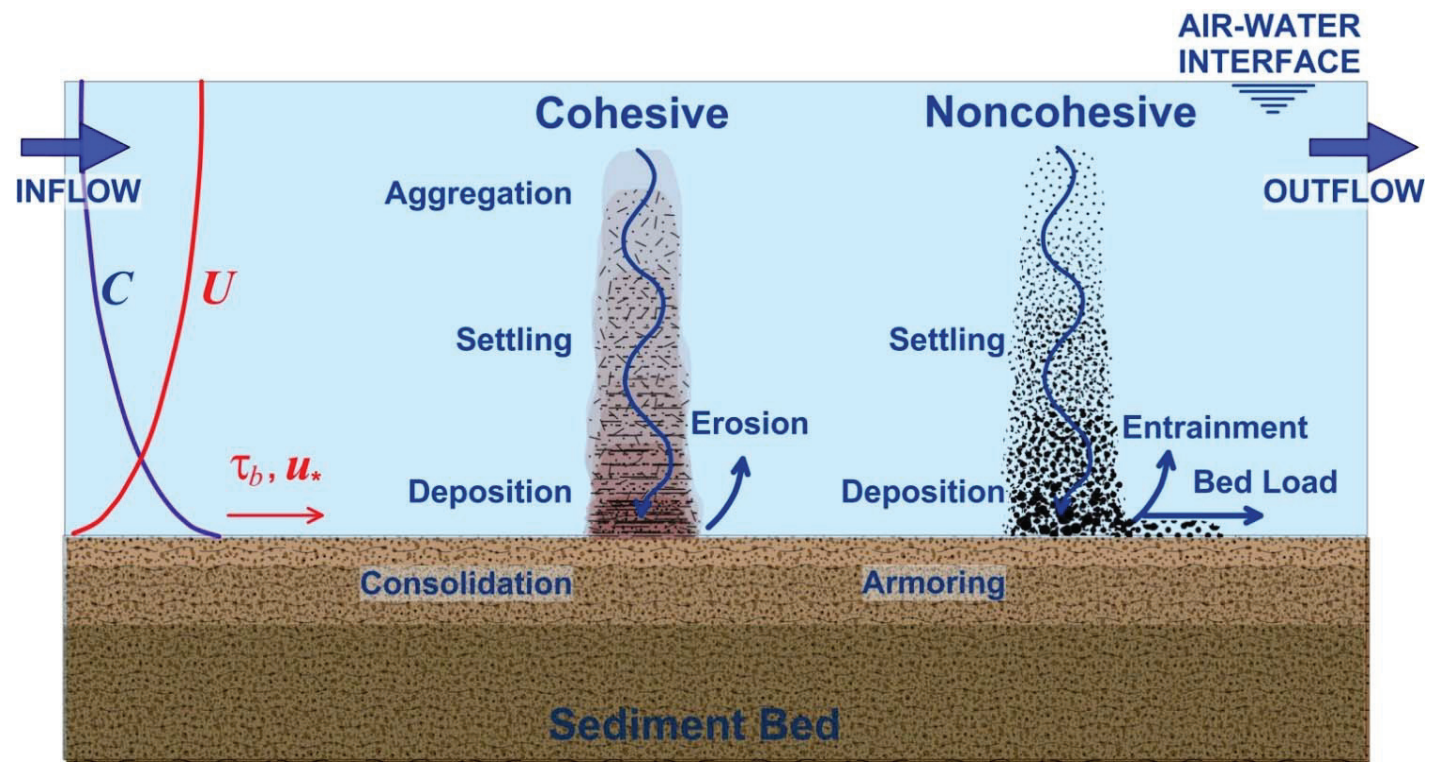

\subsubsection{Sediment Loading}

In terms of general sediment inputs to the NBSA, LMS [36] estimated that the Kill van Kull and the Arthur Kill provide approximately $60 \%$ and $12 \%$ of the total sediment load to the Bay, respectively. The Passaic and Hackensack Rivers deliver 23\% and 2\% of the total sediment load, respectively. Other sources of sediment to Newark Bay include POTWs (Bergen County and Secaucus), CSOs, SWOs, and atmospheric deposition, which are estimated to deliver a combined total of approximately $3 \%$ of the total sediment load [36]. Figure 5 shows the relative magnitude of the sediment loading to the NBSA (scaled by the percentages listed above). These estimates are similar to those of Suszkowski [18], Lowe et al. [31], and Sommerfield and Chant [22]. The two notable differences are that Sommerfield and Chant [22] and Pence [17] suggest that the Arthur Kill is a net exporter of sediment, and that Suszkowski [18] found the Hackensack to be a net sink for Bay sediments. There is significant variability across the estimates, the consequence of which is 
that there is appreciable uncertainty in the annual sediment input to Newark Bay. Table 1 lists published sediment loading estimates for the Passaic River into Newark Bay.

Figure 5. Sediment loads to the NBSA where the size of the arrows reflects the relative magnitude of sediment loading.

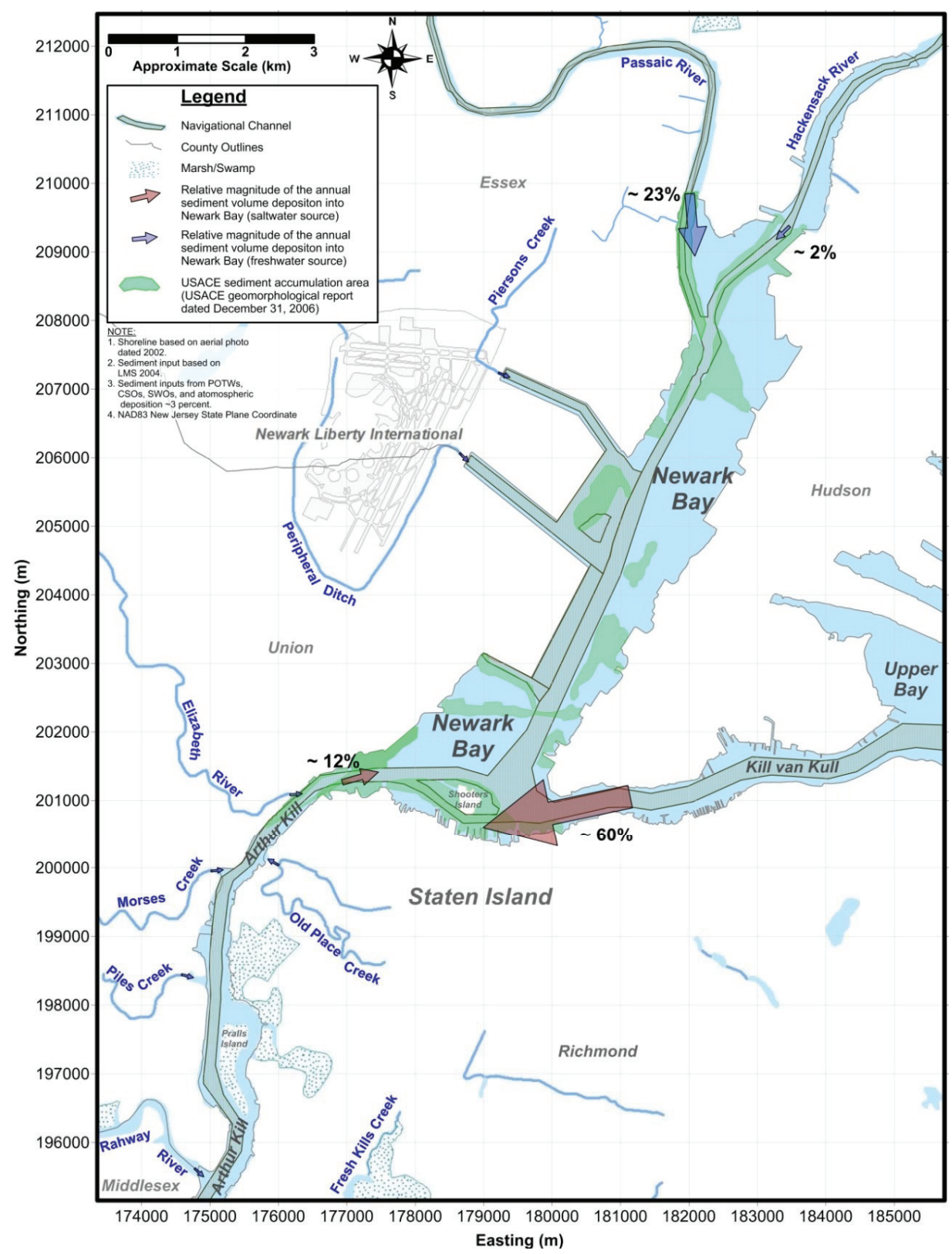


Sediment transport modeling conducted by Wakeman III [15] and sediment transport observations by Sommerfield and Chant [22] suggest that suspended sediments in the upper portion of the Bay do not leave the Bay during ebb tide or during periods of normal freshwater discharge to the Bay, and only up to about $15 \%$ of sediments in the lower portion of the Bay might exit the system. Sommerfield and Chant [22] evaluated suspended sediment deposition patterns during a Passaic River high-flow event and found that sediment deposition from such an event was greatest in the northern portions of the Bay, primarily within the Navigation Channel, with little evidence of flood-tide-related deposition on the Subtidal Flats. In the southern portion of the Bay, Sommerfield and Chant [22] indicate that most of the Kill van Kull sediment influx is not carried into the northern portion of the Bay. This suggests that Newark Bay experiences a localized convergence of sediment flux (deposition), which is consistent with the hypothesis [22] that the historical dredging of the Bay is required because otherwise the system tends to return to its natural, shallow state.

Table 1. Passaic River sediment loading rates.

\begin{tabular}{ccc}
\hline Source & Load (MT/year) & Analysis \\
\hline Table 4-7 in [46] & 7440 & Solids balance $^{1}\left(0.6 \mathrm{MT}_{\text {yard }}{ }^{3}\right)$ \\
page 1 in [22] & 17,000 & Sediment flux data $^{2}$ \\
Table 10 in [18] & 18,100 & Sediment flux data $^{2}$ \\
Table 4-7 in [46] & 21,360 & Chemical balance $^{3}\left(0.6 \mathrm{MT}\right.$ yard $\left.^{3}\right)$ \\
page 1 in [47] & 22,700 & Sediment flux data $^{2}$ \\
page 35 in [16] & 30,000 & Sediment flux data $^{2}$ \\
Table 5-3 in [30] & 30,790 & Sediment flux data $^{2}$ \\
Table 3-5 in [15] & 36,109 & Sediment runoff data $^{4}$ \\
Table 3 in [31] & 47,456 & Sediment flux data $^{5}$ \\
\hline
\end{tabular}

${ }^{1}$ Based on measured sediment flux data; ${ }^{2}$ Based on a solids balance of sediment loads through the Dundee Dam from Lowe et al. [31] with deposition of $2.54 \mathrm{~cm} /$ year (1 in./year) along the Passaic River; ${ }^{3}$ Based on the chemical mass balances of 2,3,7,8-tetrachlorinated-p-dibenzodioxin (TCDD) and total TCDD of the solids mass balance in note $1 ;{ }^{4}$ Based on a sediment yield of $39 \mathrm{MT} / \mathrm{km}^{2} /$ year for the Passaic River watershed; ${ }^{5}$ Based on measured sediment flux data; however, it is not clear if these are tons/year or MT/year.

\subsubsection{Historical and Ongoing Dredging Activities}

As documented in USACE [16], the volume of the Navigation Channels excavated in Newark Bay has continually grown since the early 1900s. Moreover, substantial dredging is required simply for maintenance of the existing channels.

Olsen et al. [48] reported that the average annual dredge volume (Newark Bay, the Kills, and the Passaic and Hackensack Rivers) measured by the USACE in 1942-1973 was 439,864 $\mathrm{m}^{3} /$ year (575,320 yard 3 year; $220,000 \mathrm{MT} /$ year assuming $0.5 \mathrm{~g} / \mathrm{cm}^{3}$ dry density). This volumetric rate is higher than that reported by Lowe et al. [31], who evaluated USACE data from 1924 to 1985 and reported that the average annual dredge volume for 1953-1985 (when the channels were fairly stable) was $161,680 \mathrm{~m}^{3} /$ year $\left(211,469 \mathrm{yard}^{3} /\right.$ year or 80,840 MT/year). Moreover, Lowe et al. [31] also reported estimates from the Port Authority of New York and New Jersey, because they 
dredged a significant additional amount of 100,388 $\mathrm{m}^{3} /$ year $\left(131,303 \mathrm{yard}^{3} /\right.$ year or 50,194 MT/year). After studying several sources of information, Wakeman III [15] concluded that the majority of the annual sediment load of $276,000 \mathrm{~m}^{3} /$ year $\left(361,000\right.$ yard $^{3} /$ year or $138,000 \mathrm{MT} /$ year $)$ is being removed by maintenance dredging operations in the USACE channels and private berths totaling $262,000 \mathrm{~m}^{3} /$ year $\left(342,683 \mathrm{yard}^{3} /\right.$ year or 131,000 MT/year). It is the general consensus that the Navigation Channels in Newark Bay are the ultimate sinks for most fine-grained sediments entering the Bay, while the tidal flats are only temporary repositories for sediments that are subsequently resuspended for deposition into the Navigation Channels or for export.

More recently, the Port Authority of New York and New Jersey's Harbor Deepening Project (HDP) included dredging the channels from the Ambrose Channel entrance to the Upper Bay and Newark Bay, providing access to the Global Marine Terminal, New York Container Terminal, Port Newark, and Elizabeth Marine Terminal. Over 2,752,397 $\mathrm{m}^{3}$ (3,600,000 yard $\left.{ }^{3}\right)$ will be dredged by 2014. In 2011, 405,979 $\mathrm{m}^{3}$ (531,000 yard ${ }^{3}$ ) was dredged from Newark Bay. By 2013, 298,940 m $\left(391,000 \mathrm{yard}^{3}\right)$ of silt and 1,070,377 $\mathrm{m}^{3}\left(1,400,000 \mathrm{yard}^{3}\right)$ of clay, sand, and blasted rock were dredged from the Arthur Kill. The HDP channels constitute $21 \%$ of the total area in Newark Bay. In channels that are deep and flat, the sedimentation rate is moderate at $3 \mathrm{~cm} /$ year $(0.1 \mathrm{ft} /$ year $)$. USACE [10] modeling suggests that the HDP will only have small effects on sedimentation on the flats because the planned dredging will not change the configuration of the channels - it will only deepen the existing channels. Sommerfield and Chant [22] and a modeling study by Pecchioli et al. [19] suggest increased sediment deposition in the Bay due to channel deepening at the Kill van Kull and Arthur Kill.

\subsubsection{Overall Sediment Dynamics in Newark Bay}

Particle size, salinity, and velocity gradients are key factors in sediment transport within the NBSA. Burke et al. [40] indicate that the Navigation Channels act as the primary pathway for sediment transport and, once suspended, the fate of the sediments in the Navigation Channel depends on many factors, including the size of the particles and their settling velocity. Heavier particles tend to settle more quickly into the Navigation Channel bed, while finer particles that remain suspended during flood tide are caught in the gravitational estuarine circulation and transported to the northern portion of the Bay. During ebb tide, these same particles tend to settle and, depending upon conditions, deposit onto the sediment bed [15].

Water-column stratification also has important implications for sediment transport. During ebb tides, stratification is intensified, significantly reducing resuspension and encouraging suspended sediment deposition, particularly in the Navigation Channel [22]. For example, during a 2001 high-flow event on the Passaic River, Chant [16] reported increased suspended sediment concentrations within Newark Bay, and that coarser particles settled out of the seaward-flowing surface water into the landward bottom flow, effectively becoming trapped. Sommerfield and Chant [22] found that sediment deposition from a high-flow event in the Passaic River was greatest in the northern portions of the Bay, with little evidence of flood-tide-related deposition on the Subtidal Flats, and that most of the sediment influx from the Kill van Kull was not carried into the northern portion of the Bay, which led them to conclude that greater Newark Bay acts as a 
sediment convergence zone. This process corresponds to the dredged Bay bathymetry moving toward equilibrium of a natural, shallow state. Moreover, sediment may be deposited preferentially near and along the base of the steeply sloped edges of the Navigation Channel. Concurrently, the steep banks of the Navigation Channels may be eroded preferentially at the uphill edge with sediment transported downslope and into the toe of the Navigation Channel [10].

Sommerfield and Chant [22] also observed a short-term convergent deposition pattern based on their analysis of Be-7 in the surface sediments. There was a large range in Be-7 inventory, 0.2 to $6.7 \mathrm{pCi} / \mathrm{cm}^{2}$, with higher Be-7 inventories detected in the Navigation Channels than in Subtidal Flats. The Be-7 stations in the Navigation Channel also appeared to be responsive to a Passaic River high-flow event, with a sharp increase in inventory. In the Navigation Channels of the northwestern portion of the Bay (near the mouth of the Passaic River) and around Shooters Island in the south, Be-7 was detected to a depth of 2.4 in. In the Subtidal Flats, however, a much thinner sediment layer, less than 0.8 inches, was found to have Be-7 activity. The differences in Be-7 depth are thought to represent differences in the physical mixing present in the various areas. Seasonal deposition and bed reworking appear to be relatively intense in the Navigation Channels of the northwestern portion of the Bay, as well as the southern portion of the Bay around Shooters Island (where tidal currents and vessel-induced stresses are strong) compared to the shallower Subtidal Flats where biological mixing dominates [22].

\section{Conclusions}

The CSM for the NBSA has met its objectives of supporting a comprehensive understanding of the physical, chemical and biological processes influencing the fate and transport of contaminants of potential concern from sources to exposure media (water, sediment, and biota). The CSM provides an updated description of the conditions and processes in the NBSA based on the data generated from recent RI investigations and secondary data.

The NBSA's complex hydrodynamics and sediment dynamics can pose challenges to accurately quantify freshwater and sediment loadings, circulation patterns, and transport of sediments and contaminants. To quantify current, historical, and future fate and transport of contaminants in this system in support of the RI/FS, it is necessary to develop a numerical model. The processes and variables described in the CSM can guide the development and application of the numerical model.

The major aspects of the hydrodynamic and sediment transport processes within the NBSA system are summarized below:

- In the absence of strong wind forcing or large tidal gradients, the Navigation Channel displays classic estuarine, gravitational, two-layer circulation with a seaward surface flow of freshwater and a landward bottom flow of salt water. Without freshwater or atmospheric forcing, landward flow in the channels is balanced by seaward flow in the shallow tidal flats.

- A counterclockwise residual circulation is most often observed around Staten Island, although this can reverse depending on the tidal and atmospheric forcing.

- Low freshwater inputs or episodic wind and storm events can break down the classic estuarine circulation pattern generally observed in the Bay. 
- The primary source of imported sediment to Newark Bay is the Kill van Kull, which may supply up to $140,000 \mathrm{MT} /$ year.

- By comparison, the Passaic and Hackensack Rivers supply about an order of magnitude less sediment than the Kill van Kull, despite being the largest freshwater sources.

- Under the existing dredged configuration, most of the sediment originating from the Kill van Kull is deposited within the southern half of the Bay; most of the sediment originating from the Passaic River is deposited within the northern half of the Bay.

- Long-term average sedimentation in Newark Bay, particularly within the dredged channels, is offset by rates of maintenance dredging.

- The Subtidal Flats have low deposition rates and appear to be in long-term equilibrium.

- The extensive history of dredging and shoreline development that have taken place in the NBSA have resulted in changing historical circulation and sediment transport patterns. Historical transport patterns are likely quite different from current transport patterns.

\section{Acknowledgements}

Exponent thanks Tierra Solutions for supporting the development of this manuscript.

\section{Conflicts of Interest}

The authors declare no conflict of interest.

\section{References}

1. Tierra Newark Bay Study Area Remedial Investigation Work Plan. Sediment Sampling and Source Identification Program; Tierra Solutions, Inc.: East Brunswick, NJ, USA, September 2005.

2. Tierra Newark Bay Study Area Phase II Remedial Investigation Work Plan; Tierra Solutions, Inc.: East Brunswick, NJ, USA, November 2007.

3. Tierra Draft Phase I and Phase II Data Evaluation and Analysis Report. Newark Bay Study Area Remedial Investigation; Tierra Solutions, Inc.: East Brunswick, NJ, USA, March 2013.

4. Tierra Draft Data Gaps Report. Newark Bay Study Area Remedial Investigation; Tierra Solutions, Inc.: East Brunswick, NJ, USA, March 2013.

5. Meyers, W.S. The Story of New Jersey; Lewis Historical Publishing: New York, NY, USA, 1945.

6. Cunningham, J.T. Made in New Jersey: The Industrial Story of a State; Rutgers University Press: New Brunswick, NJ, USA, 1954.

7. Cunningham, J.T. Newark: Revised and Expanded; New Jersey Historical Society: Newark, NJ, USA, 1966.

8. Cunningham, J.T. New Jersey: America's Main Road; Doubleday \& Company: New York, NY, USA, 1966.

9. Brydon, N.F. The Passaic River: Past, Present, Future; Rutgers University Press: New Brunswick, NJ, USA, 1974. 
10. USACE. Geomorphological/Geophysical Characterization of the Nature and Dynamics of Sedimentation and Sediment Transport in Newark Bay Focusing on the Effects Related to Continued and Future Federal Navigation Channel Deepening and Maintenance; US Army Corps of Engineers: New York, NY, USA, 2006.

11. Iannuzzi, T.J.; Ludwig, D.F.; Kinnell, J.C.; Wallin, J.M.; Desvouges, W.H.; Dunford, R.W. A Common Tragedy: History of an Urban River, 1st ed.; Amherst Scientific Publishers: Amherst, MA, USA, 2002.

12. NOAA. Magnitude and Extent of Sediment Toxicity in the Hudson Raritan Estuary; National Oceanic and Atmospheric Administration: Silver Spring, MD, USA, 1995.

13. USEPA. Sediment Quality of the NY/NJ Harbor System; U.S. Environmental Protection Agency: Edison, NJ, USA, 1998.

14. Herrington, T.O.; Rankin, K.L.; Bruno, M.S. Frequency of Sediment Suspension Events in Newark Bay. In Proceedings of the International Conference Protection and Restoration of the Environment VI, Skiathos, Greece, 1-5 July 2002; pp. 371-378.

15. Wakeman, T.H., III. Effects of Changes in Sediment and Contaminant Loads in Newark Bay on Future Disposal of Dredged Sediments; Columbia University: New York, NY, USA, 2006.

16. Chant, R.J. Hydrodynamics of the Newark Bay/Kills System; Rutgers University, Institute of Marine and Coastal Sciences: New Brunswick, NJ, USA, 2006; p. 90.

17. Pence, A.M. Dominant Forces in an Estuarine Complex with Multiple Tributaries and Free Connections to the Open Ocean with Applications to Sediment Transport; Stevens Institute of Technology: Hoboken, NJ, USA, 2004.

18. Suszkowski, D.J. Sedimentology of Newark Bay, New Jersey: An urban Estuarine Bay; University of Delaware: Newark, DE, USA, 1978.

19. Pecchioli, J.A.; Bruno, M.S.; Chant, R.J.; Pence, A.M.; Blumberg, A.F.; Fugate, D.; Fullerton, B.J.; Glenn, S.; Haldeman, C.; Hunter, E.; et al. The New Jersey Toxics Reduction Workplan for New York-New Jersey Harbor: Study I-E-Hydrodynamic Studies in the Newark Bay Complex; New Jersey Environmental Department: Trenton, NJ, USA, 2006; p. 10.

20. Blumberg, A.F.; Khan, L.A.; St. John, J.P. Three-dimensional hydrodynamic model of New York Harbor Region. J. Hydraul. Eng. 1999, 125, 799-816.

21. Chant, R.J. Secondary circulation in a region of flow curvature: Relationship with tidal forcing and river discharge. J. Geophys. Res. Oceans 2002, 107, 14-1-14-11.

22. Sommerfield, C.K.; Chant, R.J. Mechanism of Sediment Trapping and Accumulation in Newark Bay, New Jersey: An Engineered Estuarine Basin; Hudson River Foundation: New York, NY, USA, 2010; p. 40.

23. Caplow, T.; Schlosser, P.; Ho, D.T.; Santella, N. Transport dynamics in a sheltered estuary and connecting tidal straits: SF6 tracer study in New York Harbor. Environ. Sci. Technol. 2003, 37, 5116-5126.

24. USGS. Real-time data for USGS 01389500 Passaic River at Little Falls, NJ, USA. Available online: http://waterdata.usgs.gov/nwis/uv?01389500 (accessed on 9 April 2013).

25. USGS. Real-time data for USGS 01378500 Hackensack River at New Milford, NJ, USA. Available online: http://waterdata.usgs.gov/usa/nwis/uv?01378500 (accessed on 9 April 9 2013). 
26. USGS. Real-time data for USGS 01395000 Rahway River at Rahway, NJ, USA. Available online: http://waterdata.usgs.gov/nwis/nwisman/?site_no=01395000\&agency_cd=USGS (accessed on 12 April 2013).

27. Bonin, J.L. Organic Compounds and Cadmium in the Tributaries to the Elizabeth River in New Jersey, October 2008 to November 2008: Phase II of the New Jersey Toxic Reduction Workplan for New York-New Jersey Harbor; US Geological Survey: Reston, VA, USA, 2010; p 27.

28. USGS. Real-time data for USGS 01393690 Morses Creek at West Stimpson Avenue at Linden NJ, USA. Available online: http://waterdata.usgs.gov/nj/nwis/measurements/?site_ no $=01393690$ (accessed on 2 May 2013).

29. Thomas, S. Wind, Tide and Buoyancy Induced Residual Circulation in a Tidal Strait; Stevens Institute of Technology: Hoboken, NJ, USA, 1993.

30. HydroQual Inc. Assessment of Pollutant Loadings to New York-New Jersey Harbor; HydroQual: Mahwah, NJ, USA, 1991; p. 268.

31. Lowe, S.; Abood, K.; Ko, J. A sediment budget analysis of Newark Bay. J. Mar. Sci. Environ. 2005, 3, 37-44.

32. Rutgers University Monthly precipitation in New Jersey from 1895 to 2013. Available online: http://climate.rutgers.edu/stateclim_v1/data/njhistprecip.html (accessed on 8 May 2013).

33. FindTheData Average rainfall for US cities. Available online: http://average-rainfall-cities. findthedata.org/ (accessed on 8 May 2013).

34. Pence, A.M.; Chant, R.J.; Pecchioli, J.A.; Douglas, W.S. Hydrodynamics of the Newark Bay/Kills System: New Jersey Toxics Reduction Workplan for New York-New Jersey Harbor; Rutgers University, Institute of Marine and Coastal Sciences: New Brunswick, NJ, USA, 2006.

35. Geyer, R.; Chant, R.J. The Physical Oceanographic Processes in the Hudson River Estuary. In The Hudson River Estuary; Levinton, J., Waldman, J., Eds.; Cambridge University Press: New York, NY, USA, 2006; pp. 24-38.

36. LMS. A Macro Assessment of Newark Bay Sediment Budget; Lawler, Matusky \& Skelly Engineers LLP: Pearl River, NY, USA, 2004; p. 65.

37. Chant, R.J. Circulation and Sediment Dynamics in the Newark Bay and Kills System from Moored Observations. In Sediment Transport Workshop; Suszkowski, D.J., Geyer, W.R., Eds.; Hudson River Foundation: New York, NY, USA, 2003.

38. Rankin, K.L.; Chant, R.J.; Bruno, M.S.; Glenn, S. Meteorological Forcing of the Kills in New York/New Jersey Harbor. In American Geophysical Union Fall Meeting; American Geophysical Union Press: San Francisco, CA, USA, 2002.

39. USACE. Final Environmental Impact Statement on the Newark Bay Confined Disposal Facility; U.S. Army Corps of Engineers, New York District: New York, NY, USA, 1997; p. 351 . 
40. Burke, P.B.; Rankin, K.L.; Herrington, T.O.; Bruno, M.S. Sediment Transport between Deep Navigation Channels and Shallow Side Banks under Variable Tidal and Meteorological Forcings. In American Geophysical Union Fall Conference; American Geophysical Union Press: San Francisco, CA, USA, 2002.

41. HydroQual. Final Modeling Work Plan. Lower Passaic River Restoration Project; HydroQual, Inc.: Mahwah, NJ, USA, 2006.

42. HydroQual. Final Modeling Work Plan Addendum; HydroQual, Inc.: Mahwah, NJ, USA, 2006.

43. van Rijn, L.C. Principles of Sediment Transport in Rivers, Estuaries and Coastal Seas; Aqua Publications: Amsterdam, The Netherlands, 1993.

44. Grant, W.D.; Madsen, O.S. Combined wave and current interaction with a rough bottom. J. Geophys. Res. 1979, 84, 1797-1808.

45. Glenn, S.M.; Grant, D.W. A suspended sediment stratification correction for combined waves and current flows. J. Geophys. Res. 1987, 92, 8244-8264.

46. Malcom Pirnie Inc. Lower Passaic River Restoration Project: Draft Geochemical Evaluation (Step 2); Malcom Pirnie Inc.: White Plains, NY, USA, 2006; p. 421.

47. Wilson, T.P.; Bonin, J.L. Concentrations and Loads of Organic Compounds and Trace Elements in Tributaries to Newark and Raritan Bays, New Jersey; USGS: Reston, VA, USA, 2007; p. 176.

48. Olsen, C.R.; Larsen, I.L.; Brewster, R.H.; Cutshall, N.H.; Bopp, R.F.; Simpson, H.J. $A$ Geochemical Assessment of Sedimentation and Contaminant Distributions in the Hudson-Raritan Estuary; Oak Ridge National Laboratory: Oak Ridge, TN, USA, 1984; p. 101. 


\title{
A Numerical Implementation of a Nonlinear Mild Slope Model for Shoaling Directional Waves
}

\section{Justin R. Davis, Alex Sheremet, Miao Tian and Saurabh Saxena}

\begin{abstract}
We describe the numerical implementation of a phase-resolving, nonlinear spectral model for shoaling directional waves over a mild sloping beach with straight parallel isobaths. The model accounts for non-linear, quadratic (triad) wave interactions as well as shoaling and refraction. The model integrates the coupled, nonlinear hyperbolic evolution equations that describe the transformation of the complex Fourier amplitudes of the deep-water directional wave field. Because typical directional wave spectra (observed or produced by deep-water forecasting models such as WAVEWATCH III ${ }^{\mathrm{TM}}$ ) do not contain phase information, individual realizations are generated by associating a random phase to each Fourier mode. The approach provides a natural extension to the deep-water spectral wave models, and has the advantage of fully describing the shoaling wave stochastic process, i.e., the evolution of both the variance and higher order statistics (phase correlations), the latter related to the evolution of the wave shape. The numerical implementation (a Fortran 95/2003 code) includes unidirectional (shore-perpendicular) propagation as a special case. Interoperability, both with post-processing programs (e.g., MATLAB/Tecplot 360) and future model coupling (e.g., offshore wave conditions from WAVEWATCH IIITM), is promoted by using NetCDF-4/HD5 formatted output files. The capabilities of the model are demonstrated using a JONSWAP spectrum with a $\cos ^{2 s}$ directional distribution, for shore-perpendicular and oblique propagation. The simulated wave transformation under combined shoaling, refraction and nonlinear interactions shows the expected generation of directional harmonics of the spectral peak and of infragravity (frequency $<0.05 \mathrm{~Hz}$ ) waves. Current development efforts focus on analytic testing, development of additional physics modules essential for applications and validation with laboratory and field observations.
\end{abstract}

Reprinted from J. Mar. Sci. Eng. Cite as: Davis, J.R.; Sheremet, A.; Tian, M.; Saxena, S. A Numerical Implementation of a Nonlinear Mild Slope Model for Shoaling Directional Waves. J. Mar. Sci. Eng. 2014, 2, 140-158.

\section{Introduction}

As waves propagate into shallow water, they change from almost sinusoidal in deep water to a sawtooth like shape in the surf zone. Troughs become wide and shallow; crests peak and lean forward, eventually overturning and breaking. In the spectral domain, this evolution is expressed in energy transfers from the spectral peak to peak harmonics and low frequency (between $0.001 \mathrm{~Hz}$ and $0.02 \mathrm{~Hz}$ ) waves, as well as the development of phase correlations across the spectrum. Wave-shape evolution and the generation of zero-frequency motions (mean flow, wave setup) have significant effects on nearshore sediment transport and inundation.

Modeling nonlinear shoaling is challenging. Off-the-shelf finite-depth spectral models (e.g., SWAN [1]) are typically based on variance balance equations originally developed for 
deep-water waves [2], and therefore cannot account for phase correlation effects. Describing directional nonlinear wave interactions is problematic in intermediate depth. Shallow water spectra are typically wide (containing harmonics and low frequency waves) precluding the use of simpler weak dispersion approximations (cubic Schrodinger equation e.g., [3-6] or Boussinesq approximations, e.g., [7-10]).

The fundamental challenge of modeling nonlinear shoaling in the spectral domain resides in the character of wave interactions. The basis of the spectral representation is the decomposition of the wave field into statistically independent (in the leading order) Fourier modes. For a flat bottom (water depth $h=$ constant), this representation is formally

$$
\begin{gathered}
\eta(\boldsymbol{x}, t)=\sum_{n, m} a_{n} e^{i\left(\boldsymbol{K}_{n, m} \cdot \boldsymbol{x}-\omega_{n} t\right)}+c . c . \\
\omega_{n}^{2}=g K_{n} \tanh \left(K_{n} h\right)
\end{gathered}
$$

where $\eta$ is the free surface displacement, $a$ is the complex modal amplitude, $\omega$ is the radian frequency, and "c.c." stands for "complex conjugate". The sum (used here to denote symbolically any type of superposition, either discrete or continuous) is carried out over frequencies (indexed by $n$ ). Different directions of propagation are represented here by the wave number vector $\boldsymbol{K}_{n, m}$ which depends on both the frequency index and an additional index $m$, specifying, say, the propagation angle. For a given $\omega_{n}$ and a given depth $h$, Equation (1) constrains the modulus of the wave number vector of modulus $K_{n}$. The efficiency of wave nonlinearities [3,11] depends on the system of equations describing the resonance state of $N$ interacting modes.

$$
\begin{aligned}
& \sum_{j=1}^{N} \omega_{j}=0 \\
& \sum_{s=1}^{N} \boldsymbol{K}_{s}=0
\end{aligned}
$$

Note that Equation (3) is a system of two equations for the components of the horizontal wave number vector. With the additional constraint (Equation (2)), only two of the three scalar equations (Equations (2) and (3)) can be independent. A set of $N$ modes that satisfy Equations (2) and (3) is said to interact resonantly; those that do not are called non-resonant. In the wave evolution equation, the efficiency of resonant $N$-wave interactions scales like $O\left(\varepsilon^{N-1}\right)$, where $\varepsilon$ is the characteristic wave slope. Non-resonant effects are weaker and dynamically less relevant (produce higher order bound waves). Due to the form of the dispersion relation (Equation (1)), the smallest number of modes that can be resonant is $N=4$ (quadruplet, or four-wave interaction); triad interactions $(N=3)$ are non-resonant in any water depth [12]; however, they approach resonance in shallow water.

The statistics of wave evolution can be described in terms of competing effects of dispersion and nonlinearity $[13,14]$ : nonlinearity builds phase correlations and skews the statistical distribution of the wave-field; dispersion breaks them and restores the symmetry of the distribution.

In deep water, the dispersive terms of the evolution equation are of order $\varepsilon$, while the competing leading-order nonlinearity (resonant four-wave interactions) is of order $\varepsilon^{3}$. Consequently, the wave field is Gaussian in the leading order, with its statistics completely determined by second order 
moments (variance, power spectrum; [2,15]), hence the suitability of models based on energy-balance equations.

As water becomes shallow, dispersion weakens to order $\varepsilon^{2}$ while nonlinearity strengthens. Near-resonant triad interaction (order $\varepsilon^{2}$ ) becomes the leading order nonlinear mechanism (e.g., [16-20] and many others). The evolution is characterized by the broadening of the spectrum, and the generation of significant phase correlations across the spectrum (wave crests peak, wave fronts steepen). The waves are no longer Gaussian: wave statistics are no longer completely determined by second order moments (power spectrum) alone, and higher order moments and spectra (e.g., bispectra) become important. Evolution depends on both local sea state and wave history (history of phase correlations).

The dynamics of triad interaction in shallow water are poorly (or not at all) implemented in existing numerical models. For example, SWAN [1] arguably the most advanced coastal spectral model, is essentially built on a WAM [15] energy balance structure [2]. It implements a crude and unrealistic triad interaction parameterization [21], limited to approximating collinear second harmonic generation exclusively, with depth dependent interaction coefficients alone (i.e., accounting only for local effects, and not for wave history). Important processes such as infragravity (IG) wave generation, recurrence effects, and spectrum widening are also ignored.

A deterministic, unidirectional but complete triad interaction formulation was first introduced by [16] based on the Boussinesq approximation. Agnon et al. [20] proposed a generalization for arbitrary depth based on the Nonlinear Mild Slope Equation (NMSE, [22,23]). Limited directionality can be introduced using the parabolic approximation (e.g., [24-26]). Hyperbolic forms for nearly planar beaches were developed by $[20,27,28]$.

This paper describes the modeling techniques used to implement the hyperbolic form of the NMSE developed by [20,29] for directional three-wave interaction. Development of the model is presented first followed by a demonstration of the model's capabilities for shore-perpendicular and oblique wave propagation. Finally, a summary of the work is presented along with a discussion of future enhancements to the model.

\section{Model Development}

\subsection{Nearshore Directional Waves}

In Equation (1), the directionality of mode $n$ is expressed by the direction of the wave number $\boldsymbol{K}$. The wave number vector is an invariant of propagation in deep water, and can be used to label directional modes. The wave number is considered an independent variable, with $\omega$ given by Equation (1), and modes are identified by the wave number components or, in polar coordinates, by the pair $(K, \theta)$, where $\theta$ is the angle of propagation. Thus, directional modes are represented by a two-dimensional parameter space (e.g., indices $n$ and $m$ in Equation (1)).

In the nearshore, $\boldsymbol{K}$ is no longer invariant, but the wave frequency typically is. If the beach has straight and parallel isobaths, the alongshore wave number provides a second invariant that can be used to complete the two degrees of freedom necessary for describing directional waves. Therefore, in the nearshore, the Fourier representation of Equation (1) can be replaced by 


$$
\begin{gathered}
\eta(x, t)=\sum_{n, m} a_{n, m} e^{i\left(\int^{x} k_{n, m} d x+\kappa_{m} y-\omega_{n} t\right)}+c . c . \\
K_{n}^{2}=k_{n, m}^{2}+\kappa_{m}^{2}
\end{gathered}
$$

where $x$ and $y$ are the cross- and alongshore coordinates. The independent parameters are, in the approach, the frequency $f_{n}$ ( or $\omega_{n}=2 \pi f_{n}$ ), and the alongshore wave number $\kappa_{m}$. The wave number modulus $K$ depends on the frequency through Equation (1), and the cross-shore wave number $k$ is a function of both $f$ and $\kappa$ through Equation (5). A mode is therefore defined as the pair $\left(f_{n}, \kappa_{m}\right)$ - indexing modes rather than the independent parameters - and mode $J$ is defined as the pair

$$
J=\left(f_{j}, \kappa_{j}\right)
$$

From Equation (6), for a given frequency $f$, and at a given cross-shore location $x$, progressive modes satisfy the condition

$$
\kappa^{2} \leq K^{2}(f, x)
$$

where $K(f, \kappa)$ is the local wavenumber modulus, given by the linear dispersion relation, Equation (1). Modes that do not satisfy this relation in some nearshore domain are called trapped modes. The location $x_{0}$ at which $k=K\left(f, x_{0}\right)$ is called the "turning point". For simple (e.g., monotonic) beach profiles, shoreward of the turning point, trapped modes can acquire oscillatory behavior since $K \rightarrow \infty$ as $h \rightarrow 0$.

\subsection{A Hyperbolic Nonlinear Mild Slope Equation (NMSE)}

The numerical model described here implements the formulation proposed by [27] (see also [20]) for the nonlinear evolution of directional waves over a mildly sloping beach. The stationary nonlinear mild-slope equation can be written as

$$
\begin{gathered}
\frac{\partial B_{J}}{\partial x}=i\left(k_{J}+i d_{J}\right) B_{J}+\sum_{P, Q}\left(-\delta_{J, Q+P}+2 \delta_{J, Q-P}\right) i W_{J, \pm P, Q} B_{ \pm P} B_{Q} \\
B_{J}=\left[c^{1 / 2} a e^{i \int k d x}\right]_{J}, c_{J}=\left(\frac{k}{K} C\right)_{J}
\end{gathered}
$$

where $J, P$, and $Q$ are directional Fourier modes in the sense of Equation (6), and $c_{j}$ is the cross-shore component of the model group velocity $C$. The parameter $d_{j}$ represents dissipation and/or growth processes, such as breaking, wind input, bottom friction, and others. In Equation (8), $\delta$ is the Kronecker symbol, for example,

$$
\delta_{J, Q \pm P}=\left\{\begin{array}{ll}
1 & J=Q \pm P \\
0 & J \neq Q \pm P
\end{array} \text { with } \pm P=\left( \pm f_{p}, \kappa_{P}\right)\right.
$$

where the equality $J=P$ has the regular meaning for ordered pairs, i.e., $f_{J}=f_{P}$ and $\kappa_{J}=\kappa_{P}$. Only modes that satisfy the selection criteria given by Equation (10) are allowed to contribute to the nonlinear terms. Triads satisfying $J=P+Q$ ("sum" interaction) are responsible for transferring energy toward high frequencies; difference interactions $J=-P+Q$ transfer energy toward low 
frequencies. An example of a sum-interaction triad is shown in Figure 1. With the notation $\sigma=$ $\omega / \sqrt{g}$, the interaction coefficient is

$$
W_{J, \pm P, Q}=\frac{1}{8} \frac{\sqrt{g} \sigma_{J}}{\sigma_{P} \sigma_{Q}}\left(c_{J} c_{P} c_{Q}\right)^{-1 / 2}\left( \pm 2 \boldsymbol{K}_{P} \cdot \boldsymbol{K}_{Q}+K_{p}^{2} \frac{\sigma_{Q}}{\sigma_{J}} \pm K_{Q}^{2} \frac{\sigma_{P}}{\sigma_{J}}+\sigma_{P}^{2} \sigma_{Q}^{2} \mp \sigma_{J}^{2} \sigma_{P} \sigma_{Q}\right)
$$

Figure 1. An example of a sum-interaction triad $J(j, s)=Q(q, v)+P(p, u), j=q+p$ and $s=v+u$ with $j=3, q=1, p=2$ and $s=4, v=3, u=1$.

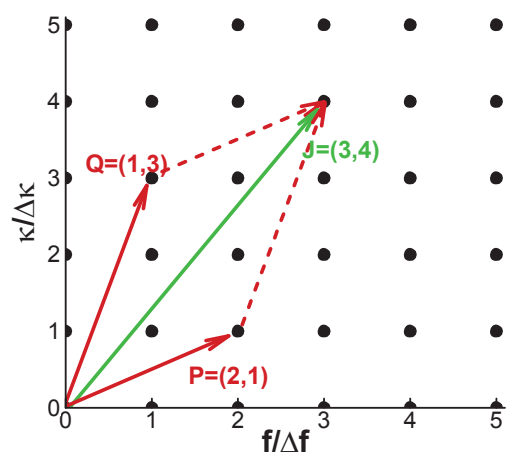

Equation (8) represents the Nonlinear Mild Slope Equation (NMSE) model. The NMSE is hyperbolic and describes wave shoaling, refraction, and three-wave nonlinear interactions. The unknown function $B_{J}$ is related to the energy flux in the cross-shore direction, $\left|B_{J}\right|^{2}=\left|a_{J}\right|^{2} c_{J}$. The linear part of the equation describes the conservation of the cross-shore component of the modal energy flux (the alongshore component is conserved trivially). The quadratic term represents the contribution of three-wave interaction to mode evolution and redistributes energy flux between modes.

The numerical implementation of Equation (8) is restricted only to triads that are close enough to resonance, as measured by the "detuning" parameter

$$
\mu=\frac{\left|k_{J} \pm k_{P}-k_{Q}\right|}{\left|k_{J}\right|}=\frac{\left|\Delta_{J, Q \pm P} k\right|}{\left|k_{J}\right|}
$$

The parameter $\mu$ compares the wavelength of the nonlinear term with the wavelength of mode $J$ (on the left-hand side of the equation). If $\mu>>1$, the oscillations of the nonlinear term are fast and result in a small (second-order) "bound wave" correction to mode $J$ that can be calculated approximately as

$$
B_{J}^{\text {bound }}=\sum_{\substack{P, Q \\ \Delta k=O\left(k_{J}\right)}}\left(\delta_{J, Q+P}-2 \delta_{J, Q-P}\right) \frac{W_{J, \pm P, Q}}{\Delta_{J, \pm P, Q} k} B_{ \pm P} B_{Q}
$$

This approximation becomes singular as $\mu \rightarrow 0$. This occurs as $h \rightarrow 0$, i.e., triads approach resonance as the water becomes shallow. In this case, the oscillation of the nonlinear term is slow and the equation has to be integrated numerically. In principle, the numerical solver should be able to handle triads with arbitrary values of $\mu$. In practice, however, numerical calculations for $\mu=O(1)$ are slow because the model has to resolve fast oscillations that yield small contributions to the derivative. Controlling the errors becomes increasingly difficult for larger values of $\mu$ and the benefit 
of the effort becomes negligible. Because of that, an efficient numerical implementation of Equation (8) would limit the integration to triads characterized by $\mu<\mu_{c}$, for some critical value of $\mu_{c}$, with bound waves computed using Equation (13). The numerical simulations shown here use $\mu_{c}=0.5$, while the bound waves are ignored (will be included in future modifications of the code).

Equation (8) is valid strictly for progressive waves. Trapped modes are not allowed to interact in the spatial domain where their cross-shore structure is exponential, but are allowed in the domain where they have oscillatory behavior. The NMSE model is phase resolving, in that it requires initial values for both modal amplitudes and modal phases.

Equation (8) reduces to the unidirectional equation for a mild sloping beach $[16,20,25]$ if all the modes propagate perpendicular to the shoreline, i.e., for all $\kappa_{J}=0$. Numerical simulations using the unidirectional hyperbolic NMSE [27,29] have been extensively verified against both single-triad analytic solutions as well as laboratory and field observations.

In the current implementation of the model, the only dissipation mechanism used is depth-limited wave breaking, based on the frequency dependent parameterization developed by [29,30], with dissipation uniformly distributed over all directions.

\subsection{Model Discretization and Computational Grid}

In Fourier series representation, the frequency-alongshore wave number is discretized as

$$
\begin{aligned}
& f_{j}=j \Delta f, \quad 0 \leq j \leq N \\
& \kappa_{s}=s \Delta \kappa, \quad-M \leq s \leq M
\end{aligned}
$$

and a directional mode index $J$ is a pair of indices $J=(j, s)$. For a triad of interacting modes $J, P$, and $Q$, the selection criterion given in Equation (10) can be written as indicial equations

$$
\begin{aligned}
& j= \pm p+q(f) \\
& s=u+v(\kappa)
\end{aligned}
$$

where

$$
\begin{aligned}
\pm J & =( \pm j, s) \\
\pm P & =( \pm p, u) \\
Q & =(q, v)
\end{aligned}
$$

for a given $f$, the effective $\kappa$-range of the allowable modes is limited by Equation (7), and can vary with depth. As the maximum extents of $f$ and $\kappa$ are known, a list of all possible triads can be created before shoreward marching of the solver begins. The matrix of triads involving a given mode $J$ (in the left-hand side of Equation (8)) and all the allowable modes $P$ and $Q$ (right-hand side of Equation (8)) is

$$
J=\left\{\begin{array}{lllll}
(P, Q)_{11}^{J} & (P, Q)_{12}^{J} & \cdots & (P, Q)_{1 n}^{J} & (J=Q+P) \\
(P, Q)_{21}^{J} & (P, Q)_{22}^{J} & \cdots & (P, Q)_{2 m}^{J} & (J=Q-P)
\end{array}\right.
$$

Because the selection criteria (Equation (10)) are invariants of propagation, the interacting triads can be pre-computed for a given $(f, \kappa)$ matrix. 


\subsection{Solution Algorithm}

The NMSE represents a coupled system of $N \times(2 M+1)$ complex ODEs, a hyperbolic initial value problem. These equations are solved using the Vode ODE Solver [31] using a non-stiff Adams method. Although the NMSE is written in complex form, for purposes of solving, the equation is split into real and imaginary components (doubling the number of equations to solve simultaneously) thus enabling the double precision ( 8 byte) real version of Vode to be used. An overview of the solution algorithm is shown in Figure 2.

Figure 2. Solution algorithm.

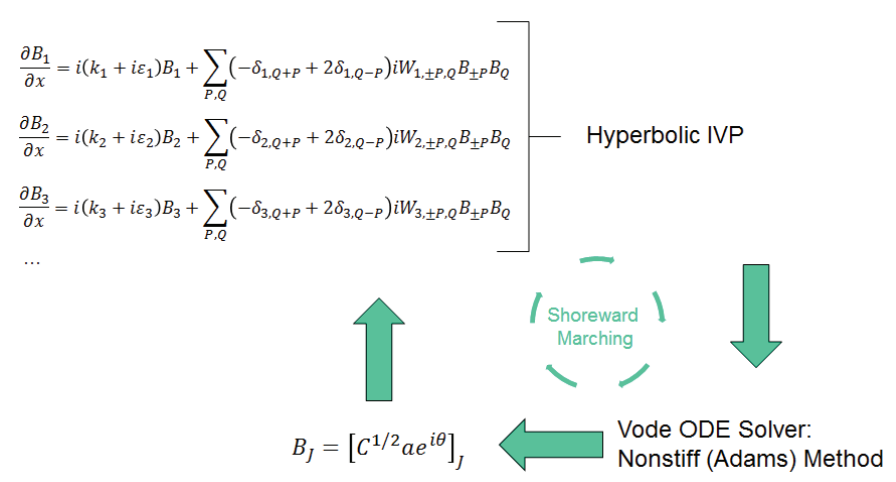

As waves propagate into shallower water, trapped modes (modes for which $k=K$ at some depth) become active and participate in the interaction. A trapped mode is considered inactive (i.e., not allowed to interact with other modes) in the domain where $k>K$, but becomes active if $k<K$ (i.e., shoreward of the turning point for monotonic beach profiles). Triads containing inactive modes are disabled; therefore, the maximum effective alongshore wave number $\left(\kappa_{\max }=M \Delta \kappa\right)$ depends on the local (cross-shore position) depth and frequency. The conditions that determine $M$ are

$$
M_{\text {local }}=M\left(f_{j}, h\right)=M_{j}(h)=\left\lfloor\frac{\left|K_{j}\right|}{\Delta \kappa}\right\rfloor
$$

where $K$ is determined by the dispersion relation (Equation (1)) and $L \perp$ refers to the integer value.

The maximum effective wave number increases with frequency and decreasing depth. The variation of $M$ with depth and frequency can be handled using two different strategies: (1) Using the minimum depth and highest frequency, the maximum $M$ for the entire domain can be determined; (2) Increase $M$ as the solution marches toward the shore. The current implementation of the model uses Approach 1. This approach will result in sparse matrices (wasting some computer memory) but the triad interaction patterns can be defined once for all runs and there is no need to dynamically modify $M$ as the solution marches toward the shore. For each evaluation of the derivatives, it is only necessary to determine whether all modes of the triad are active. Approach 2 is expected to result in dense matrices but also to significantly complicate coding as array sizes would vary as a function of cross-shore position. As with Approach 1, it is still necessary to determine whether all modes of the 
triad are active. A pseudocode representation of how the model calculates the right hand side of the NMSE (Equation (8)) is shown in the Appendix.

\subsection{Model Input/Output}

An overview of how data is imported into and exported out of the model is shown in Figure 3. The code solves the NMSE as a Monte-Carlo simulation. Typically, available offshore wave information consists of directional spectral density of free-surface variance. Offshore modal amplitudes are provided in a simple text file which either contains the complex amplitudes (includes a phase for each mode) for each "realization" to be simulated, or a spectrum can be provided and the model will use a Random Phase Approximation (RPA) to generate phases for a user-defined number of realizations. Model output is provided in a NetCDF-4/HDF5 output format using NetCDF [32]. Metadata provided in the output file is compliant to CF-1.6 [33]. The variable defining the number of realizations being simulated has the NetCDF length "UNLIMITED". Thus, for a given set of simulation parameters and offshore wave conditions, realizations can be performed independently and their output files easily combined, e.g., with "ncrcat" [34]. It is also noted that while the input file is currently a simple text file, the model could easily be setup to read a NetCDF file using the same metadata convention as the output file.

The NMSE describes the shoaling transformation of a stationary directional wave field from deep into shallow water. The details of the discretization of the frequency and alongshore wave number spaces are user defined. In the current implementation, the model resolves the shortest wave with 10 points (spectral cutoff frequency is $1 / 5$ the Nyquist frequency) and the alongshore wave field at a resolution of $5 \mathrm{~m}$. The solver (Vode) used to integrate Equation (8) uses an adaptive algorithm that implicitly discretizes internally the cross-shore domain according to the accuracy requested for the solution. The user only controls the locations for the solution output. In the simulations presented, for the purpose of describing the details of each realizations (see Section 3), values of the solution are generated every $5 \mathrm{~m}$ in the cross-shore.

Figure 3. Model input and output.

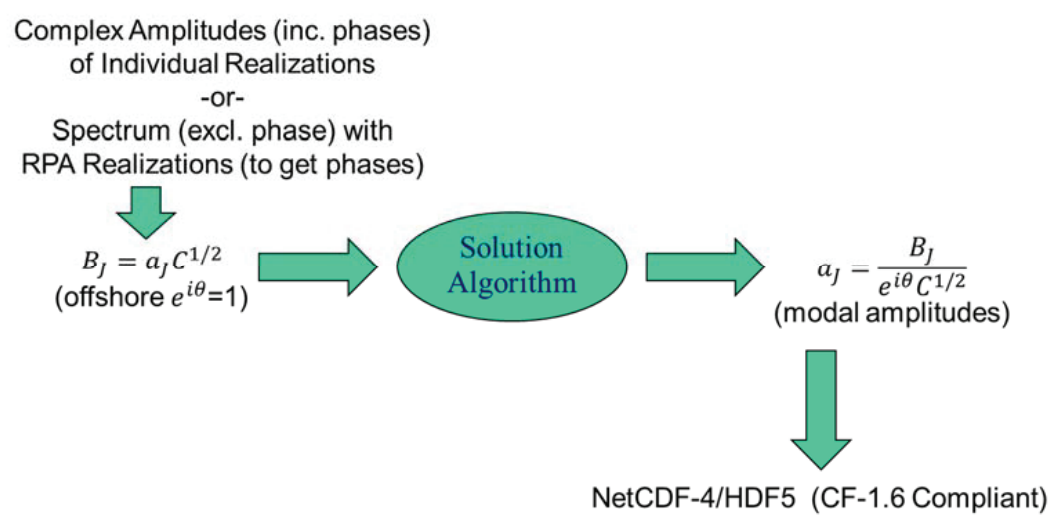


Table 1. Synthetic scenario parameters.

\begin{tabular}{|c|c|c|c|}
\hline & & Shore Perpendicular & Oblique \\
\hline \multirow[t]{3}{*}{ Domain } & Offshore Depth (m)/Position (m) & $15 / 0$ & \\
\hline & Onshore Depth (m)/Position (m) & $3 / 400$ & \\
\hline & Slope & 0.03 & \\
\hline JONSWAP & $H_{s}(\mathrm{~m})$ (sig. wave height) & 2 & \\
\hline \multirow[t]{4}{*}{ Spectrum } & $T_{p}(\mathrm{~s})$ (peak period) & 15 & \\
\hline & $2 s$ (spreading parameter) & 50 & \\
\hline & $\theta_{p}(\mathrm{deg})($ peak angle $)$ & 90 & 60 \\
\hline & Number of realizations simulated & 100 & \\
\hline Discretization & $\Delta f(\mathrm{hz})$ & 0.002 & \\
\hline \multirow[t]{3}{*}{ Frequency $(f)$} & $f_{\max }(\mathrm{hz})$ & 0.2 & \\
\hline & $N$ & 100 & \\
\hline & $T_{\min } / T_{\max }(\mathrm{s})($ period $)$ & $5 / 500$ & \\
\hline \multirow[t]{4}{*}{ Alongshore $(\kappa)$} & $\Delta \kappa(1 / \mathrm{m})$ & 0.001 & \\
\hline & $\kappa_{\max }(1 / \mathrm{m})$ & 0.03 & \\
\hline & $M / \operatorname{Total}(2 M+1)$ & $30 / 61$ & \\
\hline & $L_{\min } / L_{\max }(\mathrm{m})$ (wave length) & $33 / 1000$ & \\
\hline \multirow[t]{3}{*}{ Cross-shore $(x)$} & $\Delta x(\mathrm{~m})$ & 3.33 & \\
\hline & $\Delta h(\mathrm{~m})$ & 0.1 & \\
\hline & Number of marching steps & 121 & \\
\hline \multirow[t]{2}{*}{ Temporal $(t)$} & $\Delta t(\mathrm{~s})$ & 0.1 & \\
\hline & Number of points per $T_{\min }$ & 50 & \\
\hline
\end{tabular}

\section{Nonlinear Shoaling of Two JONSWAP Spectra: Shore-Perpendicular and Oblique Propagation}

We demonstrate the capabilities of the model with two shoaling tests over a plane beach of 0.03 slope. The offshore spectra are standard directional JONSWAP spectra propagating shore-perpendicular in the first test, and obliquely in the second. The parameters used here (Table 1) are typical for long Eastern Pacific swells; however, the directional spread is probably exaggerated in the simulations. The JONSWAP spectral shape (maybe not entirely realistic for representing the incoming waves at the deep end of the simulation domain) is used here solely to illustrate the capabilities of the current model and the use of the RPA for simulating the shoaling transformation of a deep-water variance density distribution. Because the JONSWAP spectrum does not contain any variance in the infragravity band, the second-order bound spectrum associated with the deep water swell was computed using Equation (13). A summary of the simulation parameters for both scenarios is shown in Table 1.

For input-output purposes, the numerical model requires mapping the directional wave information between the model $(f, \kappa)$ grid and the standard frequency-angle representation $(f, \theta)$ (e.g., as used in WAVEWATCH IIITM [35]). The existence of turning points makes the implementation of the mapping procedure sensitive to the bathymetric profile. For a given frequency, turning points (Section 2.1) are cross-shore locations where additional modes are introduced into the system 
(become active). Their effect on the geometry of the computational grid is illustrated in Figure 4 . The active computational grid is limited to the band defined by $|\kappa|<K(f, h)$, where $K(f, h)$ is given by Equation (1). In deep water, this is a narrow band (widening toward higher frequencies, Figure 4a). As the water depth decreases, the band widens (additional modes become active), and becomes triangular in shape (Figure 4c) and extends into higher alongshore wave numbers as the shallow water boundary approaches $|\kappa|<K_{\text {shallow }}=\omega(g h)^{-1 / 2}$. As the limiting alongshore wave number increases, the frequency-angle representation degrades slightly (in Figure $4 \mathrm{~d}$, the mapped grid does not cover the entire available $(f, \theta)$ domain).

Figure 4. Directional characteristics of the frequency-alongshore wave number $(f, \kappa)$ representation in comparison with the standard (deep-water) frequency-angle $(f, \theta)$ representation, in $15 \mathrm{~m}$ water depth (upper panels) and in $3 \mathrm{~m}$ water depth (lower panels). $(\mathbf{a}, \mathbf{c})$ The $(f, \kappa)$ representation; contours show the corresponding angles of propagation with respect to shore-parallel. The shaded area in (a) marks trapped-wave modes (i.e., modes that have the turning point between $15 \mathrm{~m}$ and $3 \mathrm{~m}$ water depth). The nodes of the $(f, \kappa)$ grid are marked by blue points.
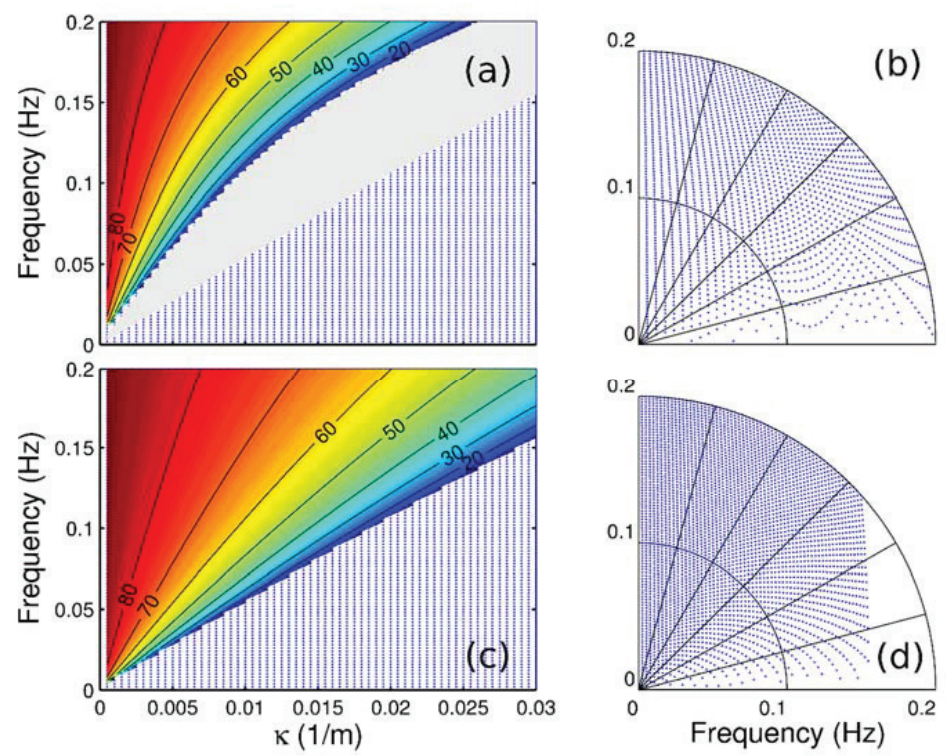

Designing the computational grid for applications poses thus the additional challenge of balancing the conflicting needs for resolving wide propagation angles (large limiting $\kappa$ ) at high resolution (small $\kappa$ increments), and for keeping the number of triads described reasonably small for numerical integrations. The need for wide angles is non-trivial: for example, it is straightforward to check that directional difference triads containing two nearly collinear, shore-normal swell modes can excite a low-frequency wave that propagates nearly parallel to the shoreline. Note also that a significant fraction of the computational grid is never used.

Mapping the directional spectral distribution between $(f, \kappa)$ and $(f, \theta)$ spaces, shown in Figure 5, consists of two steps in each direction: a direct mapping of the modal amplitudes from the uniform 
grid (or angle, Figure 5a or alongshore wave number, Figure 5c) onto a non-uniform one in the complementary space (Figure $5 \mathrm{~b}$ or $5 \mathrm{~d}$ ), and a re-sampling (interpolation) of the non-uniformly spaced values into the uniform grid. All transformations are designed to preserve the frequency spectrum (i.e., the directional spectrum integrated over either angles or wave number).

Figure 5. Illustration of the mapping of the directional JONSWAP spectrum from the $(f, \theta)$ space onto the $(f, \kappa)$ space, and back for the shore-perpendicular spectrum. Upper panels: directional spectra in different representations; lower panels: corresponding frequency spectrum. The transformation preserves the frequency spectrum. (a) Standard $(f, \theta)$ representation of the JONSWAP directional spectrum at $15 \mathrm{~m}$ isobaths; (b) Direct map from $(f, \theta)$ to $(f, \kappa)$. The resulting grid in $\kappa$ is not uniform; (c) Spectrum re-sampled in the uniform $\kappa$ grid used for computation; (d) Spectrum directly mapped back to $(f, \theta)$ space. The angle grid is not uniform. Units of the variance density contour plots are arbitrary.

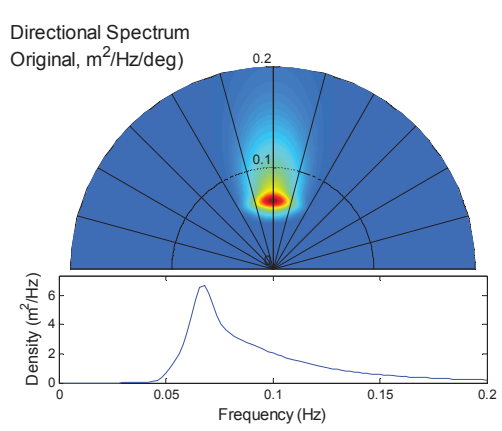

(a)

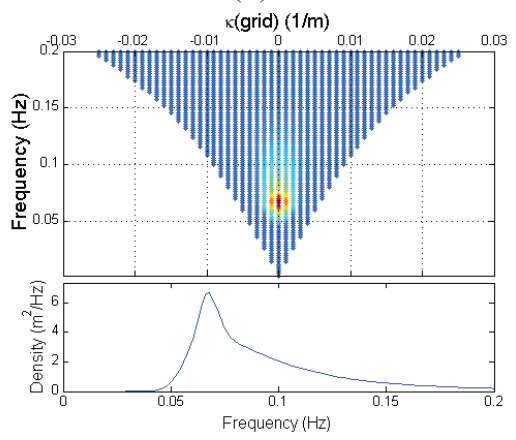

(c)

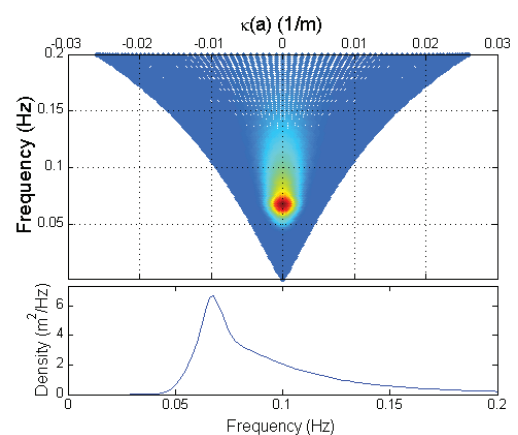

(b)

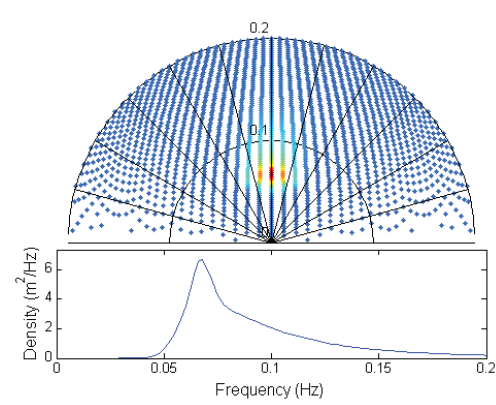

(d)

The evolution of a total of $N \times(2 M+1)=100 \times 61=6100$ possible (however, some high-frequency trapped modes never become active) directional modes are simulated (Figure 4). For each scenario, simulations are performed with both the full, and the linearized version of Equation (8). Note that the present implementation of the model only includes the linear and triad nonlinear evolution "engine" and wave breaking, with no additional physics (e.g., wave setup), that would be essential for realistic modeling of wave propagation in the nearshore. 
The simulations shown here test the representation capability of the $(f, \kappa)$ grid as well as illustrate the directional effects of nonlinear shoaling. The initial spectra at the deep-water end of the domain (15 m water depth) are shown in Figures $6 \mathrm{a}$ and $7 \mathrm{a}$. Linear runs (Figures $6 \mathrm{~b}$ and $7 \mathrm{~b}$ ) show the expected refraction effect of decreasing directional spread, with modes slowly turning around toward shore-perpendicular propagation. The main nonlinear effects (clearly visible in Figures 6c and 7c) are energy transfers from the peak to (a) peak harmonics, and (b) low-frequency infragravity modes. For oblique propagation, artifacts of the resolution of the $k$-grid are visible in the deep-water spectrum (Figure 7a), but become less severe as the waves refract and the grid coverage in the frequency-angle space increases with decreasing water depth. Note that infragravity waves (frequency $<0.05 \mathrm{~Hz}$ ) are significantly more directionally spread (approximately 60 degrees) than the rest of the spectrum (approximately 30 degrees for swell and 15 degrees for the shortest waves represented).

Figure 6. Evolution of the directional shore-perpendicular JONSWAP spectrum (see Table 1). (a) Initial spectrum in $15 \mathrm{~m}$ water depth; (b) Linear evolution (3 m water depth); (c) Nonlinear evolution (3 $\mathrm{m}$ water depth). Simulations are averages over $N=100$ random phase realizations.
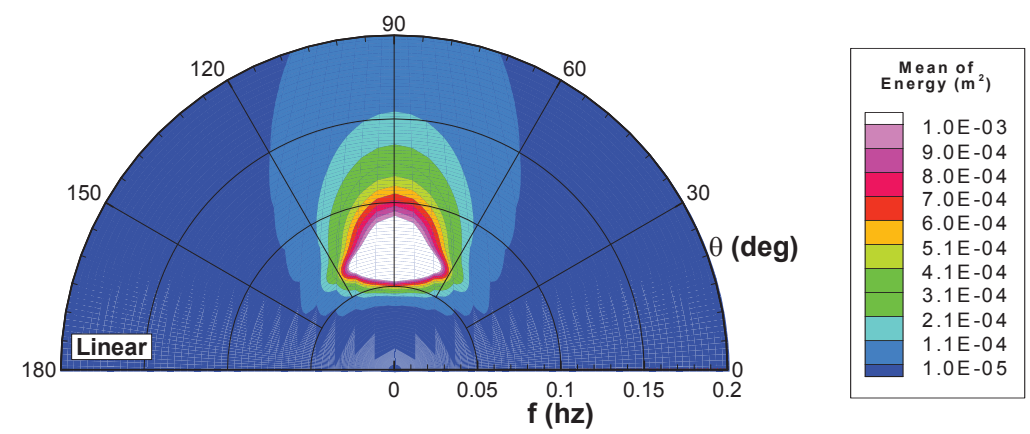

(a)

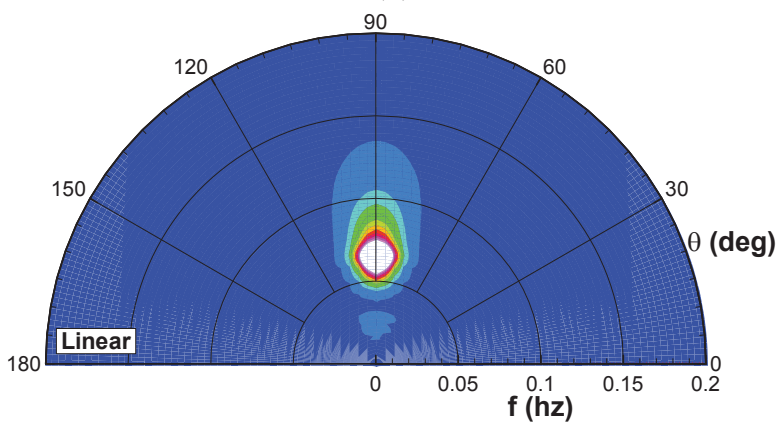

(b)

Figure 6. Cont. 


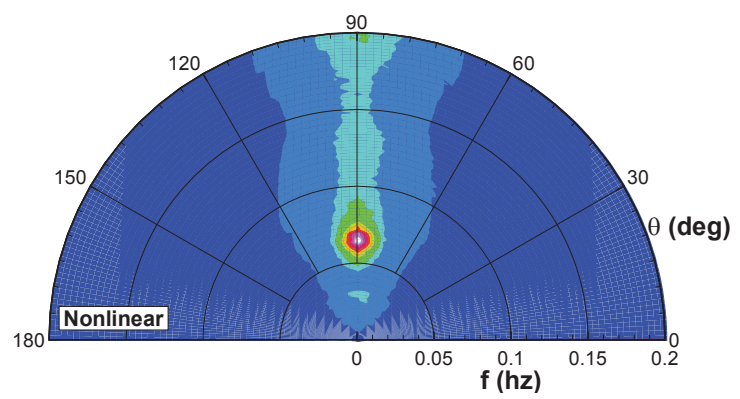

(c)

Figure 7. Evolution of the directional oblique JONSWAP spectrum (see Table 1). (a) Initial spectrum in $15 \mathrm{~m}$ water depth; (b) Linear evolution (3 m water depth); (c) Nonlinear evolution ( $3 \mathrm{~m}$ water depth). Simulations are averages over $N=100$ random phase realizations.
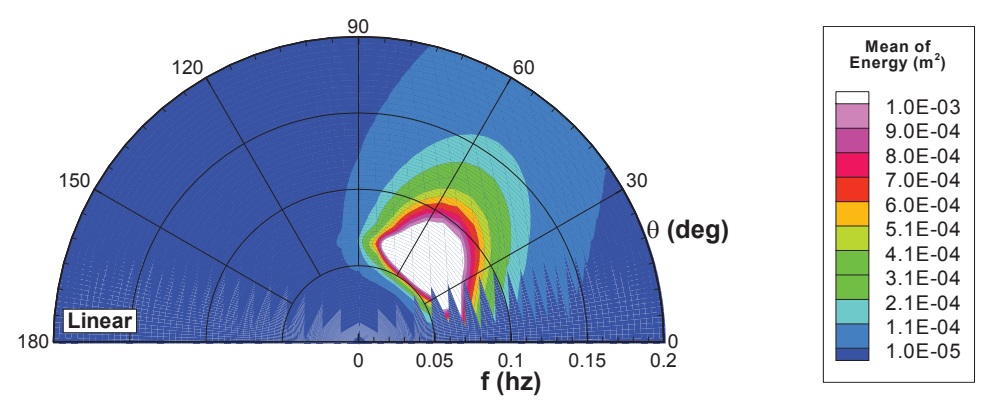

(a)

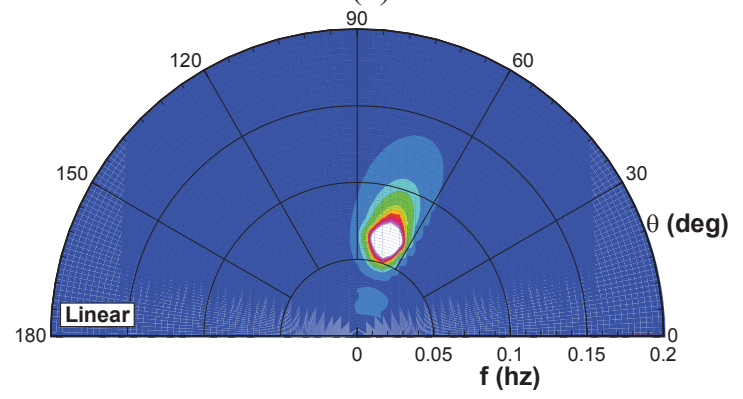

(b)

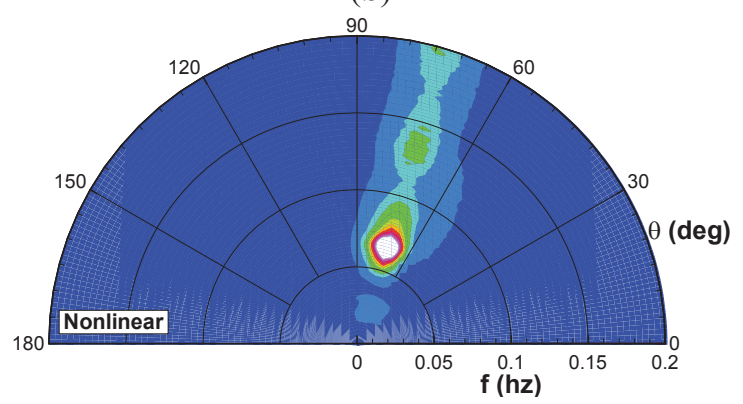

(c) 
Figures 8 and 9 show the free surface elevation corresponding to one of the realizations used to estimate the spectra in Figures 6 and 7. The figures illustrate the change in the wave shape caused by the excitation of the phase-correlated harmonics of the spectral peak. A comparison of the linear (Figure 8a) and nonlinear (Figure 8b) oblique wave field clearly shows the steepening of the wave front. Both the shore-perpendicular and the oblique propagation realizations generate a significant infragravity field, with heights between 0.2 and $0.4 \mathrm{~m}$. This effect is mainly a nonlinear shoaling effect (the linear shoaling of the initial bound infragravity band accounts for about $5 \mathrm{~cm}$ of the heights).

Figure 8. Contours of the simulated free surface elevation field for shore-perpendicular propagation, corresponding to the spectrum shown in Figure 6 at a fixed (arbitrary) time. The parameters of the offshore spectrum are given in Table 1. (a) Linear model; (b) Nonlinear model; (c) Infragravity waves $(f<0.05 \mathrm{~Hz})$ generated during nonlinear shoaling.
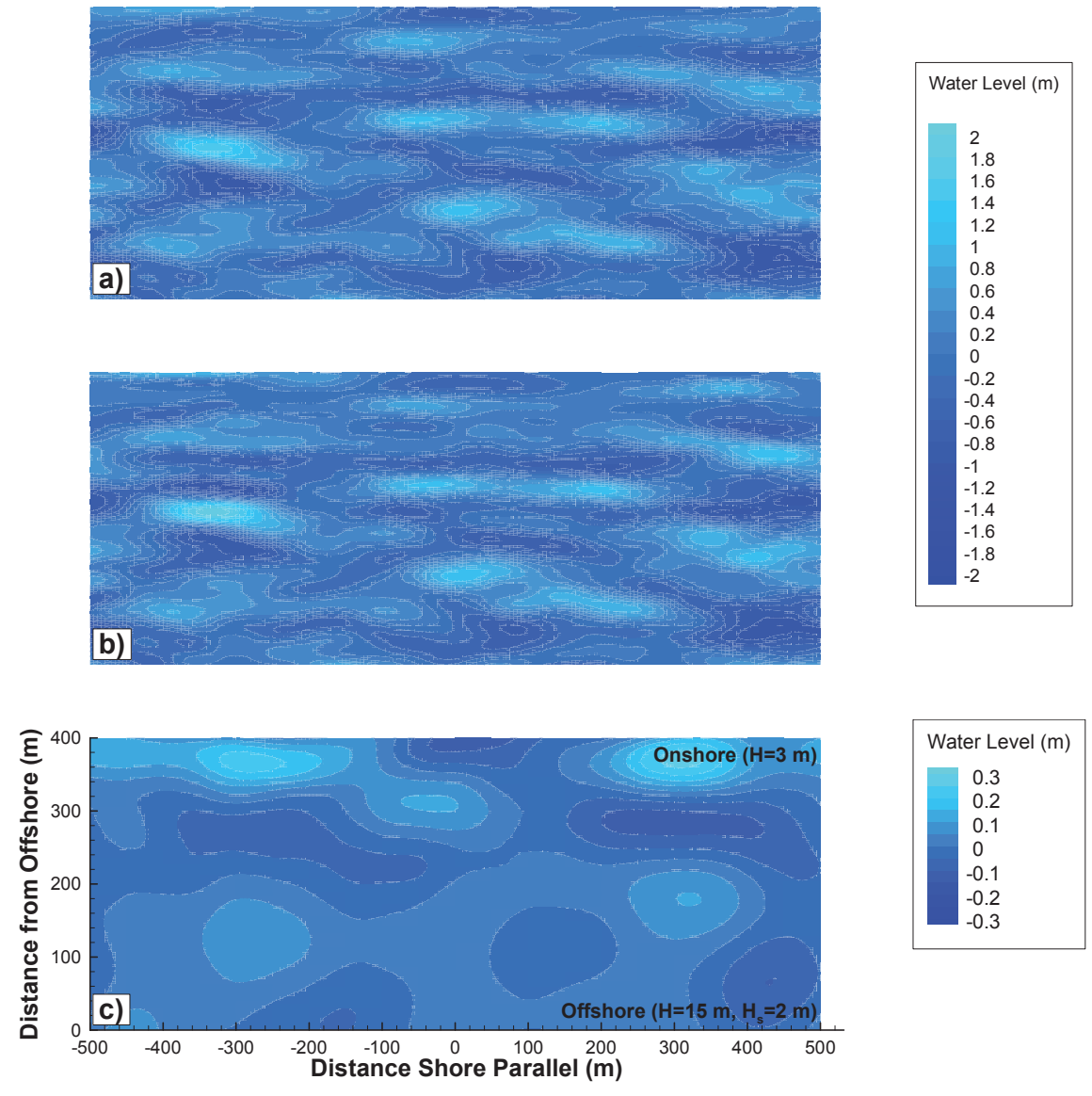
Figure 9. Contours of the simulated free surface elevation field for oblique propagation, corresponding to the spectrum shown in Figure 7 at a fixed (arbitrary) time. The parameters of the offshore spectrum are given in Table 1. (a) Linear model; (b) Nonlinear model; (c) Infragravity waves $(f<0.05 \mathrm{~Hz})$ generated during nonlinear shoaling.
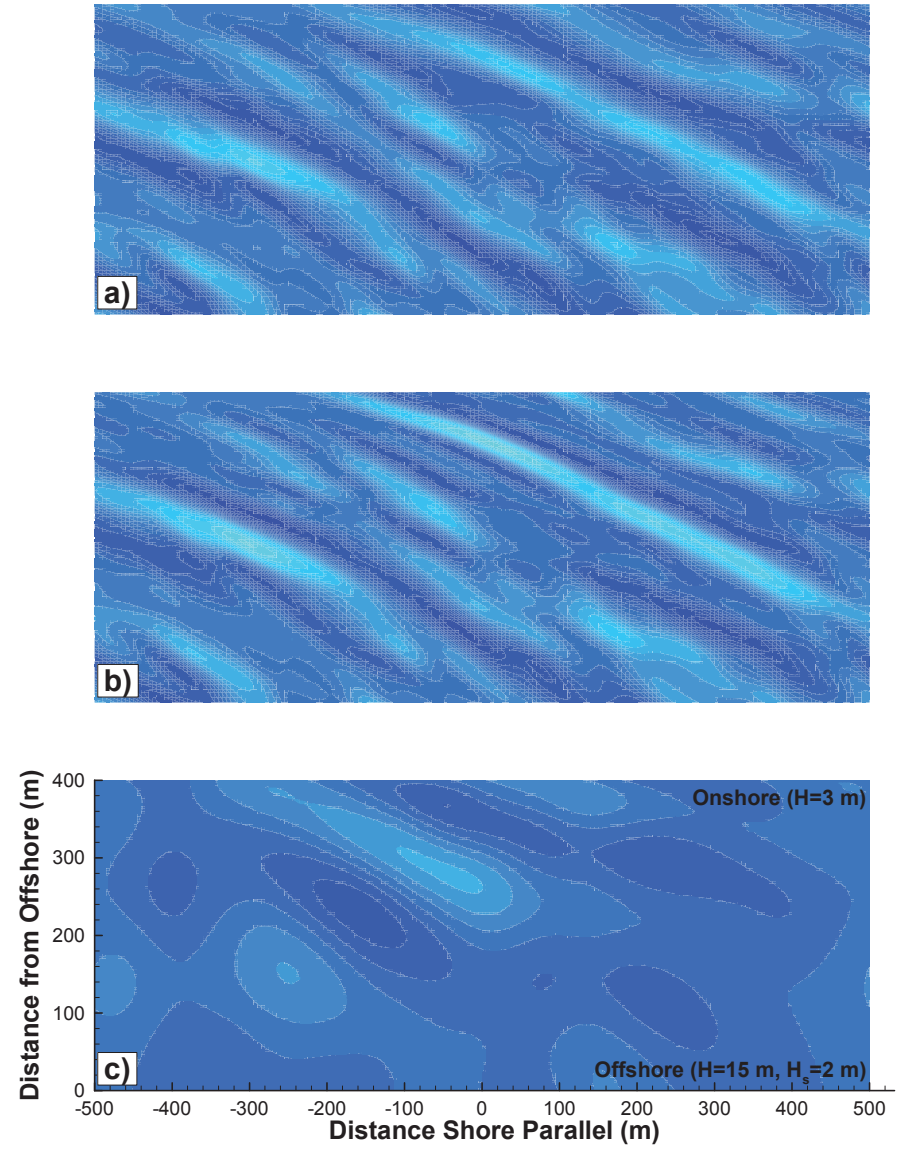
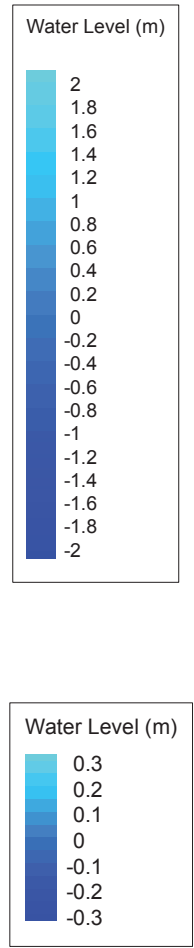

\section{Summary and Conclusions}

Based on the equations derived in [27], a Fortran 95/2003 code was written to solve the NMSE. The model (as of Version 1-38) contains approximately 32,000 lines of code, $60 \%$ of which is the Vode ODE solver and $8 \%$ are testing routines. The model has been compiled using several different Fortran compilers (GNU 4.8 and Intel 2013) and executed under several different LINUX platforms (Ubuntu and RHEL). This implementation of the NMSE is a phase-resolving, spectral $(f, k)$ model that describes wave evolution over a beach with straight and parallel isobaths. The model solves set of hyperbolic equations for a two-dimensional surface gravity wave field approaching a beach accounting for non-linear, quadratic triad interactions, shoaling and refraction. The capabilities of the model are illustrated for shore-perpendicular and oblique propagation of a directional JONSWAP spectrum. The results show wide-angle infragravity (IG) generation as well as significant energy 
transfers toward high-frequencies modes. The runs demonstrate the essential role directionality plays in nonlinear shoaling, especially in the generation of directionally spread infragravity waves.

With the "engine" of a wave model developed, future research goals include: (1) Reformulating the governing equation from its current mathematically relevant form to one which is more numerically adept. By solving an equation better suited to floating point arithmetic (e.g., a form which minimizes rounding error), we should be able to improve the model's stability, accuracy and energy flux conservation; (2) Adding modules for relevant physics such as setup (feedback to the total depth) and wind effects; (3) Performing additional numerical tests. Comparing the model to known analytic solutions (e.g., individual triad interactions) as well as observational directional wave data will provide for better model verification and validation. Additional IG scenarios will let us better understand how they are generated. Finally, future applications of the model will include making it publicly available to the community as well as incorporating it into phase-averaged deep-water models such as WAVEWATCH IIITM using the RPA mechanism described here.

\section{Acknowledgments}

This research is supported by U. S. Office of Naval Research Grants N00014-10-1-0805, N00014-10-1-0389, N00014-12-1-0220, and N00014-13-1-0620, the U. S. Strategic Environmental Research and Development Program (SERDP) Grant N00173-13-1-G012, and the University of Florida. The authors also wish to acknowledge the University of Florida Research Computing for providing computational resources and support that have contributed to the research results reported in this publication. URL: http://researchcomputing.ufl.edu.

\section{Conflicts of Interest}

The authors declare no conflict of interest.

\section{References}

1. Booij, N.; Ris, R.C.; Holthuijsen, L.H. A third-generation wave model for coastal regions: 1. Model description and validation. J. Geophys. Res. 1999, 104, 7649-7666.

2. Hasselmann, K.; Munk, W.; MacDonald, G. Bispectra of Ocean Waves. In Time Series Analysis; Rosenblatt, M., Ed.; John Wiley \& Sons, Inc.: New York, NY, USA, 1963; pp. 125-139.

3. Zakharov, V.E. Stability of periodic waves of finite amplitude on the surface of a deep fluid. J. Appl. Mech. Tech. Phys. 1972, 9, 190-194.

4. Hasimoto, H.; Ono, H. Nonlinear modulation of gravity waves. J. Phys. Soc. Jpn. 1972, 33, 805-811.

5. Yuen, H.C.; Lake, B.M. Nonlinear deep water waves: Theory and experiment. Phys. Fluids 1975, 18, 956-960.

6. Dysthe, K.B. Note on a modification to the nonlinear schrodinger equation for application to deep water waves. Proc. R. Soc. Math. Phys. Eng. Sci. 1979, 369, 105-114. 
7. Boussinesq, J. Theory of waves and swell propagated in a long horizontal rectangular canal, and imparting to the liquid contained in this canal approximately equal velocities from the surface to the bottom. J. Math. Pures Appl. 1872, 17, 55-108.

8. Madsen, P.A.; Murray, R.; Sørensen, O.R. A new form of the Boussinesq equations with improved linear dispersion characteristics. Coast. Eng. 1991, 15, 371-388.

9. Schäffer, H.A.; Madsen, P.A. Further enhancements of Boussinesq-type equations. Coast. Eng. 1995, 26, 1-14.

10. Wei, G.; Kirby, J.T.; Grilli, S.T.; Subramanya, R. A fully nonlinear Boussinesq model for surface waves. Part 1. Highly nonlinear unsteady waves. J. Fluid Mech. 1995, 294, 71-92.

11. Zakharov, V.E.; L'vov, V.S.; Falkovich, G. Kolmogorov Spectra of Turbulence; Springer-Verlag: Berlin, Germany; New York, NY, USA, 1992.

12. Phillips, O.M. On the dynamics of unsteady gravity waves of finite amplitude Part 1 . The elementary interactions. J. Fluid Mech. 1960, 9, 193-217.

13. Benney, D.J.; Saffman, P.G. Nonlinear interactions of random waves in a dispersive medium. Proc. R. Soc. Math. Phys. Eng. Sci. 1966, 289, 301-320.

14. Newell, A.C.; Aucoin, P.J. Semidispersive wave systems. J. Fluid Mech. 1971, 49, 593-609.

15. Komen, G.J.; Cavaleri, L.; Donelan, M.; Hasselmann, K.; Hasselmann, S.; Janssen, P.A.E.M.; Dynamics and Modelling of Ocean Waves; Cambridge University Press: Cambridge, UK, 1994.

16. Freilich, M.H.; Guza, R.T. Nonlinear Effects on Shoaling Surface Gravity Waves. Philos. Trans. R. Soc. Math. Phys. Eng. Sci. 1984, 311, 1-41.

17. Elgar, S.; Guza, R.T. Observations of bispectra of shoaling surface gravity waves. J. Fluid Mech. 1985, 161, 425-448.

18. Elgar, S.; Sebert, G. Statistics of bicoherence and biphase. J. Geophys. Res. 1989, 94, 10993-10998.

19. Elgar, S.; Freilich, M.H.; Guza, R.T. Model-data comparisons of moments of nonbreaking shoaling surface gravity waves. J. Geophys. Res. 1990, 95, 16055-16063.

20. Agnon, Y.; Sheremet, A.; Gonsalves, J.; Stiassnie, M. Nonlinear evolution of a unidirectional shoaling wave field. Coast. Eng. 1993, 20, 29-58.

21. Eldeberky, Y.; Battjes, J.A. Parameterisation of Triad Interactions in Wave Energy Models. In Proceedings of the Coastal Dynamics '95, Gdańsk, Poland, 4-8 September 1995; American Society of Civil Engineers: New York, NY, USA, 1995; pp. 140-148.

22. Berkhoff, J.C.W. Computation of Combined Refraction-Diffraction. In Proceedings of the Thirteenth Conference on Coastal Engineering, Vancouver, British Columbia, Canada, 10-14 July 1972; American Society of Civil Engineers: New York, NY, USA, 1972; pp. 471-490.

23. Chamberlain, P.G.; Porter, D. The modified mild-slope equation. J. Fluid Mech. 1995, 291, 393-407.

24. Kadomtsev, B.B.; Petviashvili, V.I. On the stability of solitary waves in weakly dispersing media. Sov. Phys. Dokl. 1970, 15, 539-541.

25. Kaihatu, J.M.; Kirby, J.T. Nonlinear transformation of waves in finite water depth. Phys. Fluids 1995, 7, 1903-1914. 
26. Toledo, Y. The oblique parabolic equation model for linear and nonlinear wave shoaling. J. Fluid Mech. 2013, 715, 103-133.

27. Agnon, Y.; Sheremet, A. Stochastic nonlinear shoaling of directional spectra. J. Fluid Mech. 1997, 345, 79-99.

28. Janssen, T.T.; Herbers, T.H.C.; Battjes, J.A. Evolution of ocean wave statistics in shallow water: Refraction and diffraction over seafloor topography. J. Geophys. Res. 2008, 113, doi:10.1029/2007JC004410.

29. Sheremet, A.; Kaihatu, J.M.; Su, S.-F.; Smith, E.R.; Smith, J.M. Modeling of nonlinear wave propagation over fringing reefs. Coast. Eng. 2011, 58, 1125-1137.

30. Janssen, T.T.; Battjes, J.A. A note on wave energy dissipation over steep beaches. Coast. Eng. 2007, 54, 711-716.

31. Brown, P.N.; Byrne, G.D.; Hindmarsh, A.C. VODE: A variable-coefficient ODE solver. SIAM J. Sci. Stat. Comput. 1989, 10, 1038-1051.

32. Network Common Data Form (NetCDF). Available online: http://www.unidata.ucar.edu/ software/netcdf/ (accessed on 20 November 2013).

33. Eaton, B.; Gregory, J.; Drach, B.; Taylor, K.; Hankin, S.; Caron, J.; Signell, R.; Bentley, P.; Rappa, G.; Höck, H.; et al. NetCDF Climate and Forecast (CF) Metadata Conventions; Lawrence Livermore National Laboratory: Livermore, CA, USA, 2011; p. 124.

34. NetCDF Operators (NCO), Open Source, 2013. Available online: http://nco.sourceforge.net/ (accessed on 13 November 2013).

35. Tolman, H. User Manual and System Documentation of WAVEWATCH III; NOAA/NWS/ NCEP/MMAB Technical Note 276; National Oceanic and Atmospheric Administration, U.S. Department of Commerce: Camp Springs, MD, USA, 2009.

\section{Appendix: Pseudocode for Nonlinear Derivatives}

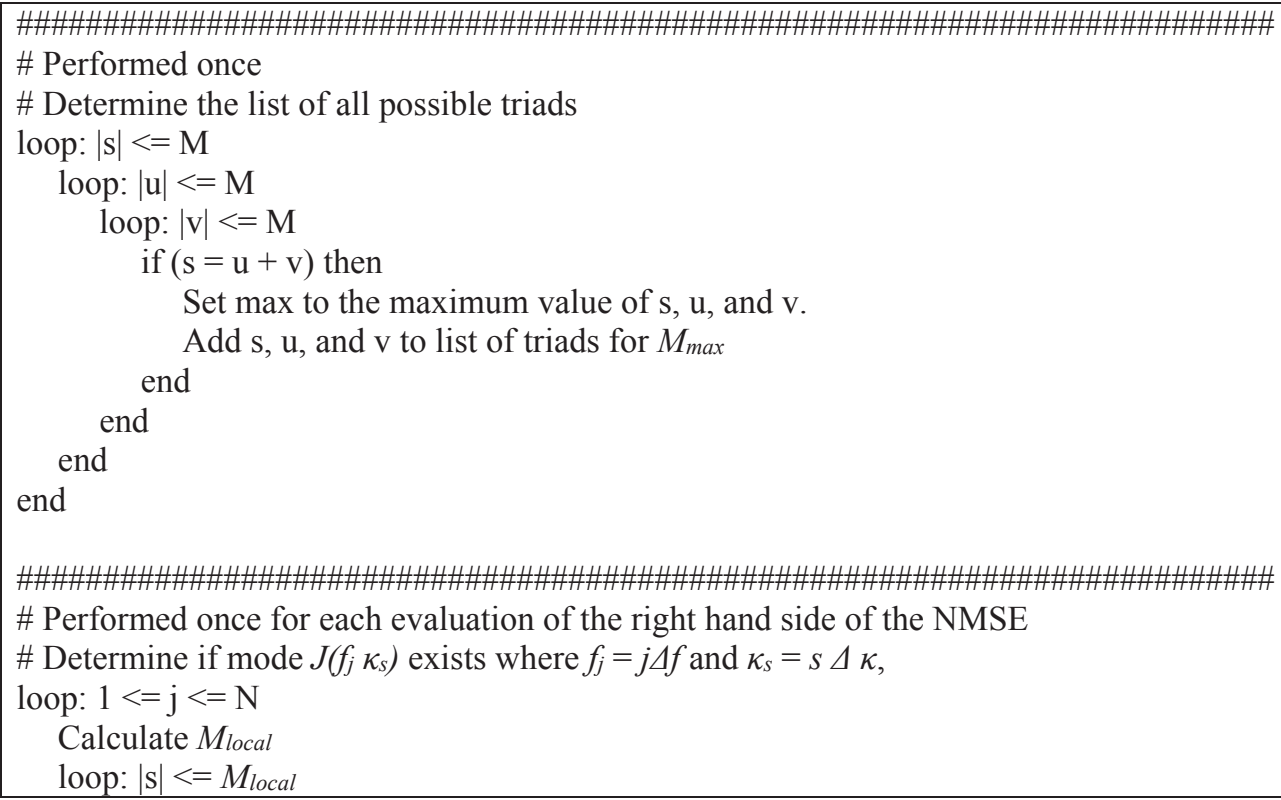




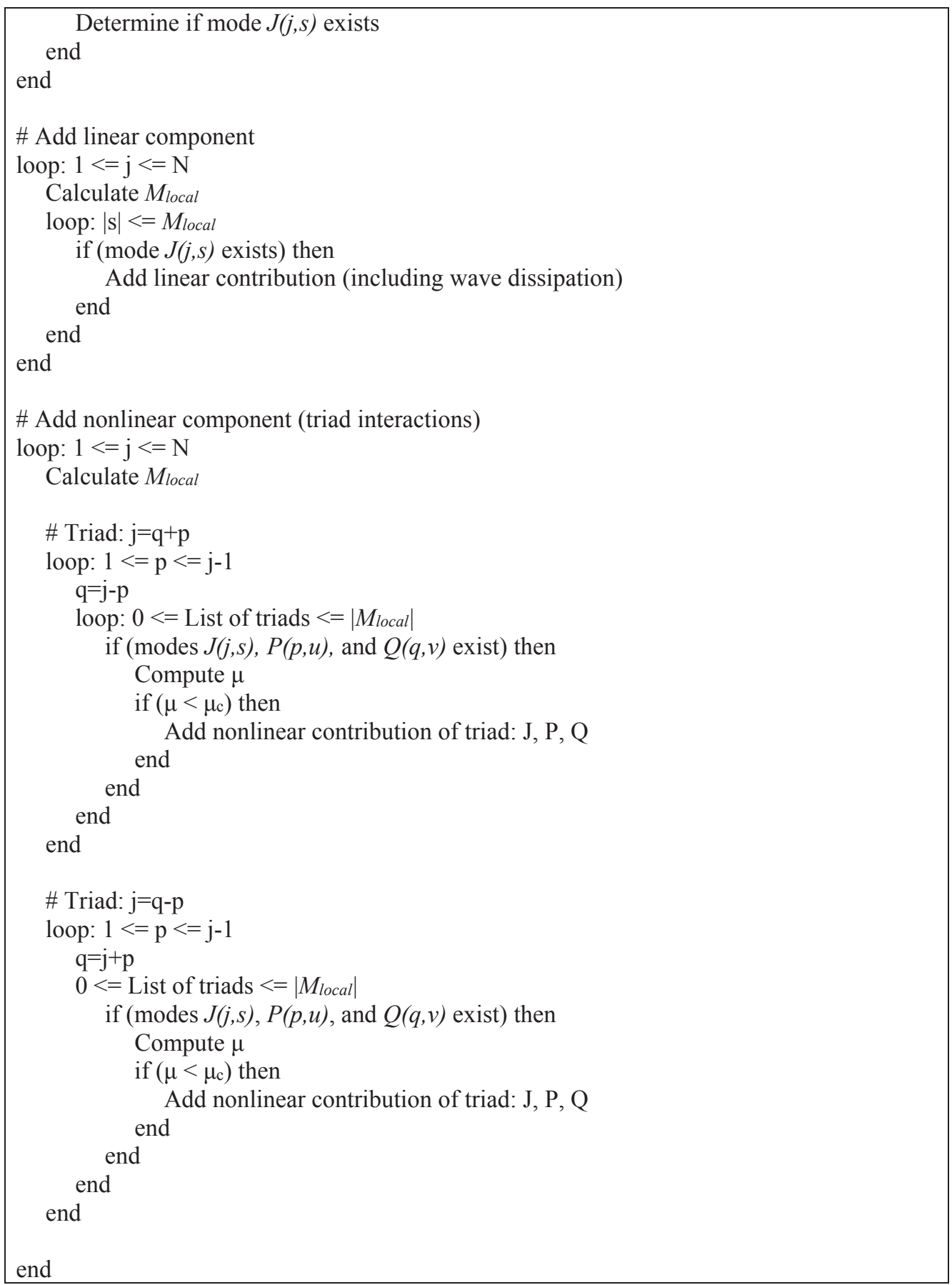




\title{
Field and Model Study to Define Baseline Conditions of Beached Oil Tar Balls along Florida's First Coast
}

\section{Peter Bacopoulos, James David Lambert, Mary Hertz, Luis Montoya and Terry Smith}

\begin{abstract}
Anecdotal data are currently the best data available to describe baseline conditions of beached oil tar balls on Florida's First Coast beaches. This study combines field methods and numerical modeling to define a data-driven knowledge base of oil tar ball baseline conditions. Outcomes from the field study include an established methodology for field data collection and laboratory testing of beached oil tar balls, spatial maps of collected samples and analysis of the data as to transport/wash-up trends. Archives of the electronic data, including GPS locations and other informational tags, and collected samples are presented, as are the physical and chemical analyses of the collected samples. The thrust of the physical and chemical analyses is to differentiate the collected samples into highly suspect oil tar balls versus false/non-oil tar ball samples. The numerical modeling involves two-dimensional hydrodynamic simulations of astronomic tides. Results from the numerical modeling include velocity residuals that show ebb-dominated residual currents exiting the inlet via an offshore, counter-rotating dual-eddy system. The tidally derived residual currents are used as one explanation for the observed transport trends. The study concludes that the port activity in the St. Johns River is not majorly contributing to the baseline conditions of oil tar ball wash-up on Florida's First Coast beaches.
\end{abstract}

Reprinted from J. Mar. Sci. Eng. Cite as: Bacopoulos, P.; Lambert, J.D.; Hertz, M.; Montoya, L.; Smith, T. Field and Model Study to Define Baseline Conditions of Beached Oil Tar Balls along Florida's First Coast. J. Mar. Sci. Eng. 2014, 2, 160-170.

\section{Introduction}

Florida's First Coast beaches have experienced occurrences of oil tar ball wash-up as anecdotally evidenced by the local beach communities of Jacksonville. There has also been the question and concern of the local port (Mayport-St. Johns River) contributing to oil tar ball washup on the beaches of Florida's First Coast, and, historically, it was practice of ships to dump their bilge (containing fresh and used oil) just offshore before entering the inlet to port into Jacksonville. In addition to this local societal context, there is also a scientific purpose to generate a sample of baseline conditions of beached oil tar balls for Florida's First Coast. This scientific purpose is motivated by the speculation of Cuba drilling for oil [1] and the possibility of an oil spill disaster that would directly affect Florida's First Coast [2,3].

Much previous work on oil tar ball transport and wash-up came about from the post-evaluation of the Deepwater Horizon oil spill (2010) in the Gulf of Mexico, as related to various aspects including tar ball characterization [4] and spill tracking via beach observation [5]. Tar ball characterizations have been done for other regions of the world (e.g., California, USA [6] and Malaysia's east coast [7]). However, there is no previous work related to oil tar ball transport and wash-up along Florida's First Coast. The objective of this study was to define baseline conditions 
of beached oil tar balls along Florida's First Coast. Defining these baseline conditions will provide a dataset to use for comparison for future oil spill/tar ball events.

\section{Field Methods}

Two stretches of Florida's First Coast beaches were selected for field observation (Figure 1):

(1) north of the St. Johns River inlet-Little Talbot Island-hereafter referred to as the north site; and

(2) south of the St. Johns River inlet-Atlantic Beach to Mayport-hereafter referred to as the south site.

Teams of two walked the stretches of beach, each $6 \mathrm{~km}$ in length (Figure 1). The team would arrive at the site, in the middle of the 6-km-long beach stretch, split up so that one walked north $3 \mathrm{~km}$ and the other walked south $3 \mathrm{~km}$, and then turn around and back-track the 3-km-long walk to arrive back at the site. If the tide was going out, the team would walk the first track along the debris line and walk the second track (the back-track) along the waterline, and vice versa for an incoming tide.

Figure 1. (a) The two stretches of Florida's First Coast beaches, the north site being north of the inlet and the south site being south of the inlet, selected for field observation. (b) View of the beach for the north site. (c) View of the beach for the south site.
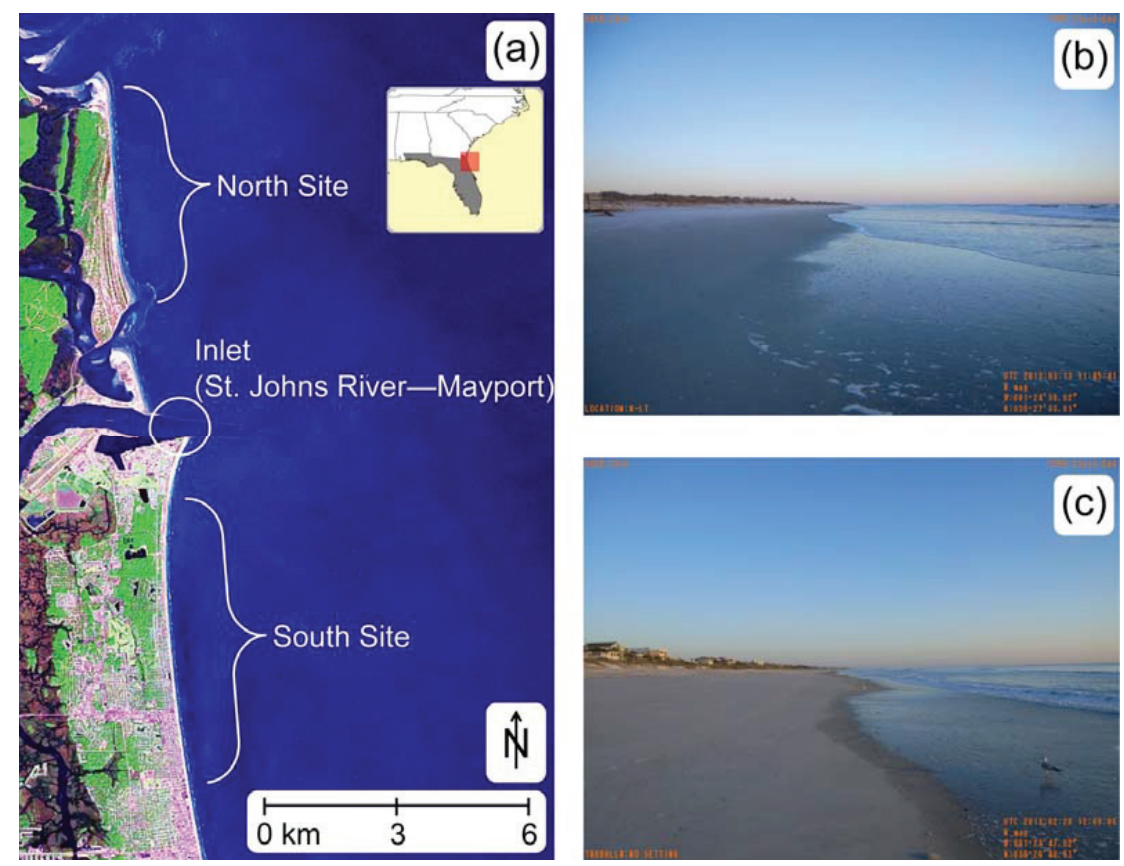

Both sites were visited roughly once a week over two months (Table 1). Each site visit required, on average, $3 \mathrm{~h}$ of walking the beach stretch. For the beach walks, the following flotsam was photographed with timestamp and GPS location: Trash; seashells; seaweed; and oil tar balls. In addition, the start and end of each beach walk was photographed with timestamp and GPS location. 
In the field, suspected oil tar balls were recognized by their deep black color, shiny and sooty appearance with varying range of sizes and consistencies (from smaller dime-sized pellets to larger racquetball-sized blobs). Additionally, the tidal condition (high/flood or low/ebb), weather (wind/storm) and wave climate (flat, knee-high, head-high or overhead-high) were noted for each beach walk; however, those data will not be used in this present study and are being reserved for future work related to understanding the temporal patterns of oil tar ball wash-up.

All samples were handled with non-powdered gloves, individually stored in separate air-tight baggies, brought to the laboratory and collectively stored in an air-conditioned environment for subsequent physical and chemical analyses. The GPS data, including the photographs of the samples in situ, were organized into a GIS database for subsequent analysis.

Table 1. Schedule of the beach walks.

\begin{tabular}{cccc}
\hline $\begin{array}{c}\text { Visit Number } \\
\text { (Site Location) }\end{array}$ & $\begin{array}{c}\text { Date } \\
\text { (mm/dd/yyyy) }\end{array}$ & $\begin{array}{c}\text { Start and End Times } \\
\text { (EST) } \text { (hh:mm:ss) }\end{array}$ & $\begin{array}{c}\text { Number of Suspected } \\
\text { Oil Tar Balls Collected }\end{array}$ \\
\hline 1 (south site) & $02 / 28 / 2013$ & $07: 09: 06$ and $11: 12: 10$ & 61 \\
2 (north site) & $03 / 05 / 2013$ & $07: 54: 33$ and $11: 14: 07$ & 20 \\
3 (south site) & $03 / 10 / 2013$ & $06: 28: 12$ and 09:40:58 & 30 \\
4 (north site) & $03 / 13 / 2013$ & $06: 45: 41$ and 08:04:59 & 3 \\
5 (south site) & $03 / 14 / 2013$ & $06: 55: 29$ and $10: 24: 09$ & 47 \\
6 (north site) & $03 / 15 / 2013$ & $06: 59: 25$ and 09:11:56 & 10 \\
7 (north site) & $03 / 29 / 2013$ & $06: 55: 42$ and $08: 30: 03$ & 12 \\
8 (south site) & $04 / 08 / 2013$ & $06: 25: 38$ and 09:35:37 & 5 \\
9 (north site) & $04 / 11 / 2013$ & $06: 40: 30$ and $08: 29: 57$ & 7 \\
10 (south site) & $04 / 15 / 2013$ & $06: 12: 34$ and 08:42:03 & 0 \\
11 (north site) & $04 / 17 / 2013$ & $07: 02: 38$ and 08:59:40 & 0 \\
12 (south site) & $04 / 21 / 2013$ & $08: 24: 00$ and $10: 35: 05$ & 0 \\
13 (north site) & $04 / 23 / 2013$ & $07: 11: 06$ and 08:27:33 & 0 \\
\hline
\end{tabular}

\section{Laboratory Testing}

Physical analysis involved categorizing all of the samples according to their suspected composition. Table 2 lists the seven different categories of physical composition that cover the range of the collected samples: coal; bone; lava; wood; rock; tar ball; and other. Figure 2 shows samples typifying the physical character of coal, bone, lava, wood, rock and tar ball.

The literature is widely varying per how to characterize oil tar balls using chemical tests [8-12], but nonetheless guided us to conduct three chemical tests on the collected samples. The objectives of the chemical tests were to provide a first-order (low-level) identification of the collected samples, which was due to the minimal budget of the project, in that for future work and when the associated higher costs can be afforded, higher order (more detailed) chemical tests will be conducted. Thus, three chemical tests (each detailed below) were attempted to characterize the chemical makeups of the collected samples and identify them as containing oil (tar ball) or as not containing oil (anything other than a tar ball; examples, in addition to coal, bone, lava, wood and rock, would include shells, jellyfish, man-o-war, fish kill, and netting/string entanglements). Additional samples 
obviously containing oil were obtained from Navarre Beach (Florida Panhandle) and Ponte Vedra Beach (Florida's First Coast), where these samples were collected on an ad hoc basis for the purpose of serving as control measures in the chemical tests.

Table 2. Categorization of the collected samples based on physical composition.

\begin{tabular}{ccc}
\hline Category & Sample Features & $\begin{array}{c}\text { Number of Suspected } \\
\text { Oil Tar Balls Falling into Category }\end{array}$ \\
\hline Coal & Sooty, brittle, shiny facets & 58 \\
Bone & Smooth exterior with highly porous center & 13 \\
Lava & Very lightweight porous rock & 34 \\
Wood & Visible wood grain & 20 \\
Rock & Sturdy, variable porosity & 44 \\
Tar ball & Tar-like smell, pliable, embedded debris & 15 \\
Other & Does not fit into any of the other categories & 11 \\
\hline
\end{tabular}

The first test attempted was gas chromatography-mass spectrometry (GC-MS) and gas chromatography/flame ionization detector (GC/FID). The GC-MS and GC/FID tests failed because, with the low-budget instrument used, temperatures were not capable of gasifying the sample compositions and producing a chemical signature. Only solvent peaks for samples obviously containing oil were obtained, which was most likely due to insufficient temperatures of the GC columns used. Columns suggested by manufacturers to characterize crude oil sludge were beyond the available budget of the study. It is hypothesized that the majority of oil obtained from tar balls are the high molecular weight portions of crude oil, commonly referred to as tar. Compounds of high molecular weight have higher melting points than lighter compounds. In order for GC techniques to be applied, the instrument must reach sufficient temperatures for the compound of interest to reach a gaseous state, pass through the column and produce a reading.

The second test attempted was solubilization of samples in DCM (dichloromethane) which is a commonly used solvent for isolating oils from particulate solid masses. A small piece from a sample in each of the categories of physical composition (Table 2) was placed into a $20-\mathrm{mL}$ scintillation vial containing roughly $10 \mathrm{~mL}$ of DCM. This test was applied by observing if any oil residue became isolated from the sample and floated to the top of the vial. No oil residue was observed to come off any sample except for all the samples that belonged to the tar ball category where there were obvious collections of oil residue floating in the vial. Results of this test allow us to conclusively state that the members of the five categories not suspected to be tar balls indeed do not contain crude oil. However, extraction of a substance using DCM does not lead to a certain conclusion that the samples in the tar ball category do indeed contain crude oil, since DCM is a commonly used organic solvent and will dissolve many nonpolar compounds. As a result, this test can only be used to eliminate possible tar ball samples, not confirm them.

The third test attempted was evaluation of melting point. In hopes to confirm the presence or absence of crude oil in the samples, we had desired to measure a melting point of bits of "oil" from the samples in the tar ball category. For all the samples in the tar ball category, a portion of each sample was powderized and the "oil" particles were separated from the larger pieces of rock and 
debris via mechanical processing. Separation of the "oil" from the surrounding sand particles was impractical (although it was attempted, again via mechanical processing). It was eventually determined that the "oil" particles would melt at a much lower temperature than the sand, therefore the presence of the sand should not make a difference. The "oil"/sand mixture was heated in a test tube using a Bunsen burner which quickly revealed that the "oil" simply softened slightly and turned the sample into a gooey mess, accompanied with the smell of hot asphalt. While these results strongly suggest the sample was indeed a tar ball, the lack of quantitative evidence leaves it undetermined.

Figure 2. Example samples typifying the physical character of (a) coal, (b) bone, (c) lava, (d) wood, (e) rock and (f) tar ball. Disregard the "tar ball" script on the forensic ruler.
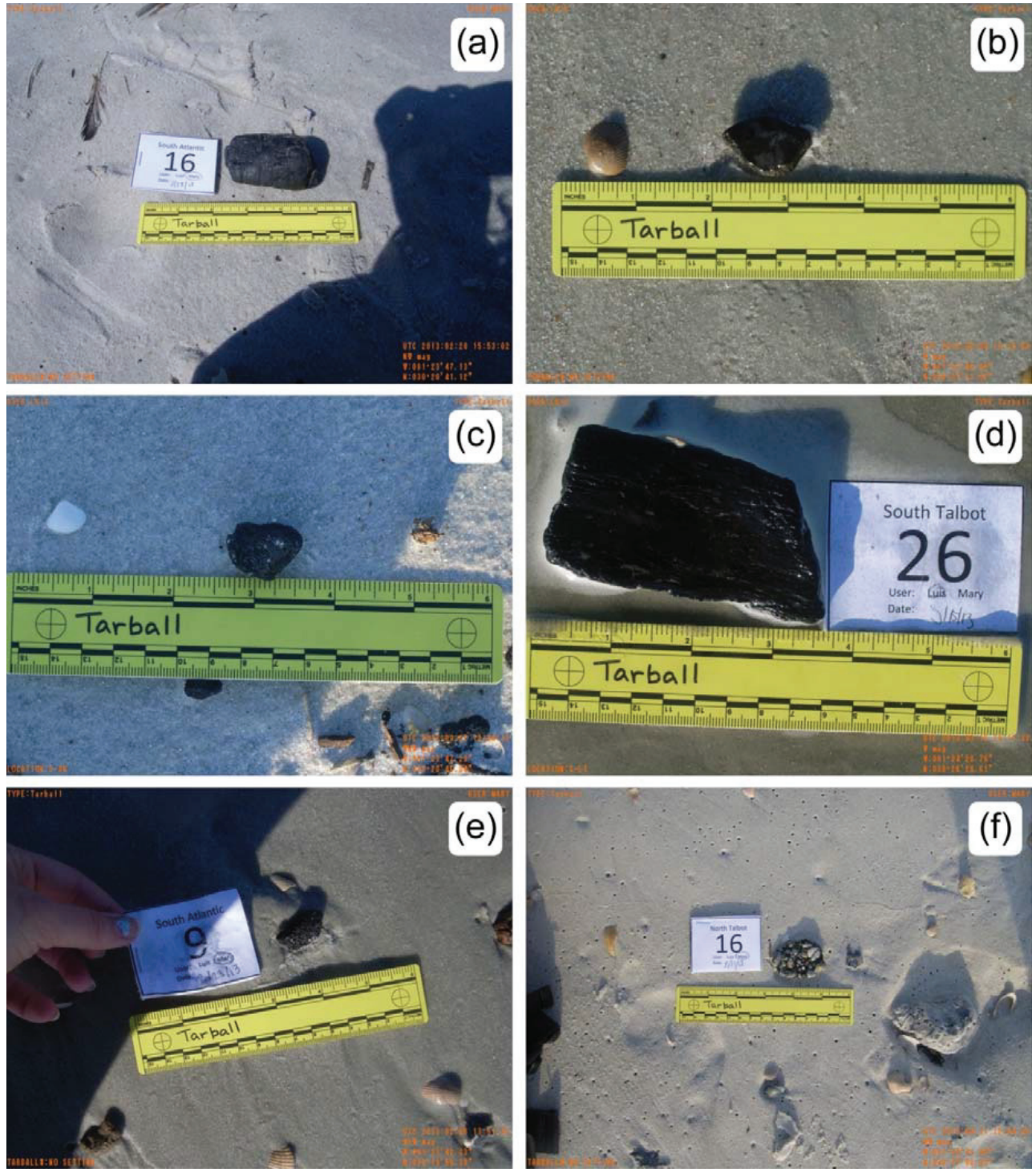


\section{Spatial Analysis}

The maps shown in Figure 3 are direct outputs of the developed GIS database showing the GPS-based locations of the furthest extents of the survey, all the collected samples and just the samples that were categorized as tar balls. Figure 3 a shows the spatial distribution of all the collected samples, as an indication of all the flotsam that washes up on Florida's First Coast beaches, with additional points indicating the furthest extent of ground covered by the team over the full duration of the fieldwork. Figure $3 \mathrm{~b}$ shows the spatial distributions of all the samples that were categorized as tar balls, as an indication of baseline conditions of oil tar ball wash-up on Florida's First Coast beaches, again with same extent of survey points for reference.

Figure 3. GPS-based locations of (a) all the collected samples and (b) just the samples that were categorized as tar balls.
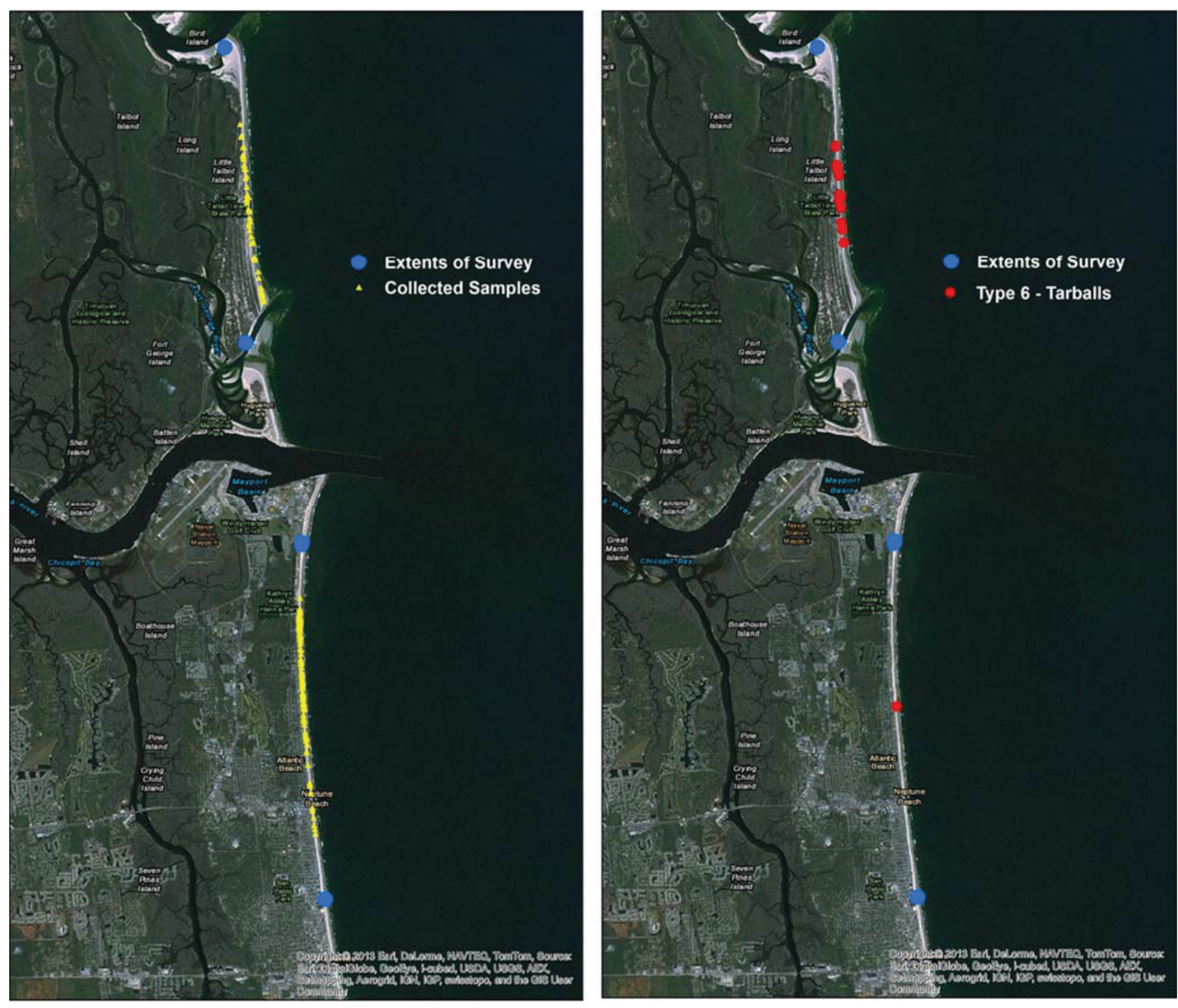


\section{Numerical Modeling}

The ADvanced CIRCulation (ADCIRC) code was used for the numerical modeling in this study. The model is depth-integrated, and it is assumed that the simulated two-dimensional hydrodynamics are a major contributor to the transport of suspended materials, including oil tar balls contained within the water column. The model does not account for resuspension of settled materials or for the chemical evolution of oil tar balls. A previously developed model for the South Atlantic Bight [13], including Florida's First Coast and the St. Johns River, was utilized. Boundary conditions included tides on the open-ocean boundary located in the deep ocean along the $60^{\circ} \mathrm{W}$ meridian. In this implementation of the model, only tides and tidal circulation were considered as the hydrodynamic driving force. In future implementations, the model will be additionally forced with winds, which are important to circulation, transport and waves whereby the wave-driven hydrodynamics will be fed back into the circulation and transport. The purpose of excluding winds in the current model implementation was to be able to obtain a picture of the tidally driven transport, before we explore the transport driven by tides plus winds and waves.

Tidally driven transport is closely related to the velocity residuals at tidal and subtidal frequencies; i.e., tidally time-averaged velocities [14,15]. Tidal currents are the dominant driver of seawater movement in coastal seas; however, to study tidally driven transport, it becomes necessary to extract the velocity residuals from the oscillating tidal currents. Eulerian velocity residuals are the rectification of transiently oscillating tidal velocities at a fixed position using a time-averaging scheme [16]. Calculation of the Eulerian velocity residuals in this work is performed using the concept of the tidal cycle mean operator [17].

Figure 4 shows vectors of velocity residuals, and the associated contours of magnitudes, computed from a harmonic analysis of 45 days of simulated (fully dynamic) tidal currents. The velocity residuals shown correspond to the STEADY constituent (frequency of zero/period of infinity) vector in the harmonically analyzed velocity (fort.54) file of ADCIRC [18]. The velocity residuals exhibit an ebb pattern through the inlet, with counter-rotating eddies spinning off the inlet. The ebb tidal velocities through the throat of the inlet reach as high as $15 \mathrm{~cm} / \mathrm{s}$ in magnitude. The north eddy is approximately $3 \mathrm{~km}$ in diameter and produces velocity residuals of $0.5-2.5 \mathrm{~cm} / \mathrm{s}$. The north eddy directs velocity residuals toward Little Talbot Island (the north site). The south eddy is approximately $6 \mathrm{~km}$ in diameter and produces velocity residuals of $0.5-2.5 \mathrm{~cm} / \mathrm{s}$. The south eddy directs velocity residuals toward Atlantic Beach to Mayport (the south site).

There were 14 oil tar balls found on the north site and there was 1 oil tar ball found on the south site (Figure 3b). The north and south sites are located in the face of the shoreward components of the counter-rotating eddies of tidally driven velocity residuals ebbing from the inlet (Mayport) of the St. Johns River (Figure 4a). It is interesting that only 1 oil tar ball was found on the south site, compared to 14 oil tar balls that were found on the north site, which cannot be explained by the numerical modeling as implemented in this study. Future work will impose wind forcing on the model as well as can explore the wave climate and resulting field of wave radiation stresses that could drive oil tar ball transport toward the shore. Local sources of oil (likely relic oil from historical bilge dumping that would take place offshore before ships would port into Jacksonville) 
could also be more prevalent north of the inlet and sparser south of the inlet. In this implementation of the model, it can only be concluded that there is a tendency in the tidal circulation for transport to be directed onto the north and south sites via tidally driven eddies.

Figure 4. Tidally driven velocity residuals: (a) vectors and (b) the associated contours of magnitudes for the offshore waters of Florida's First Coast.
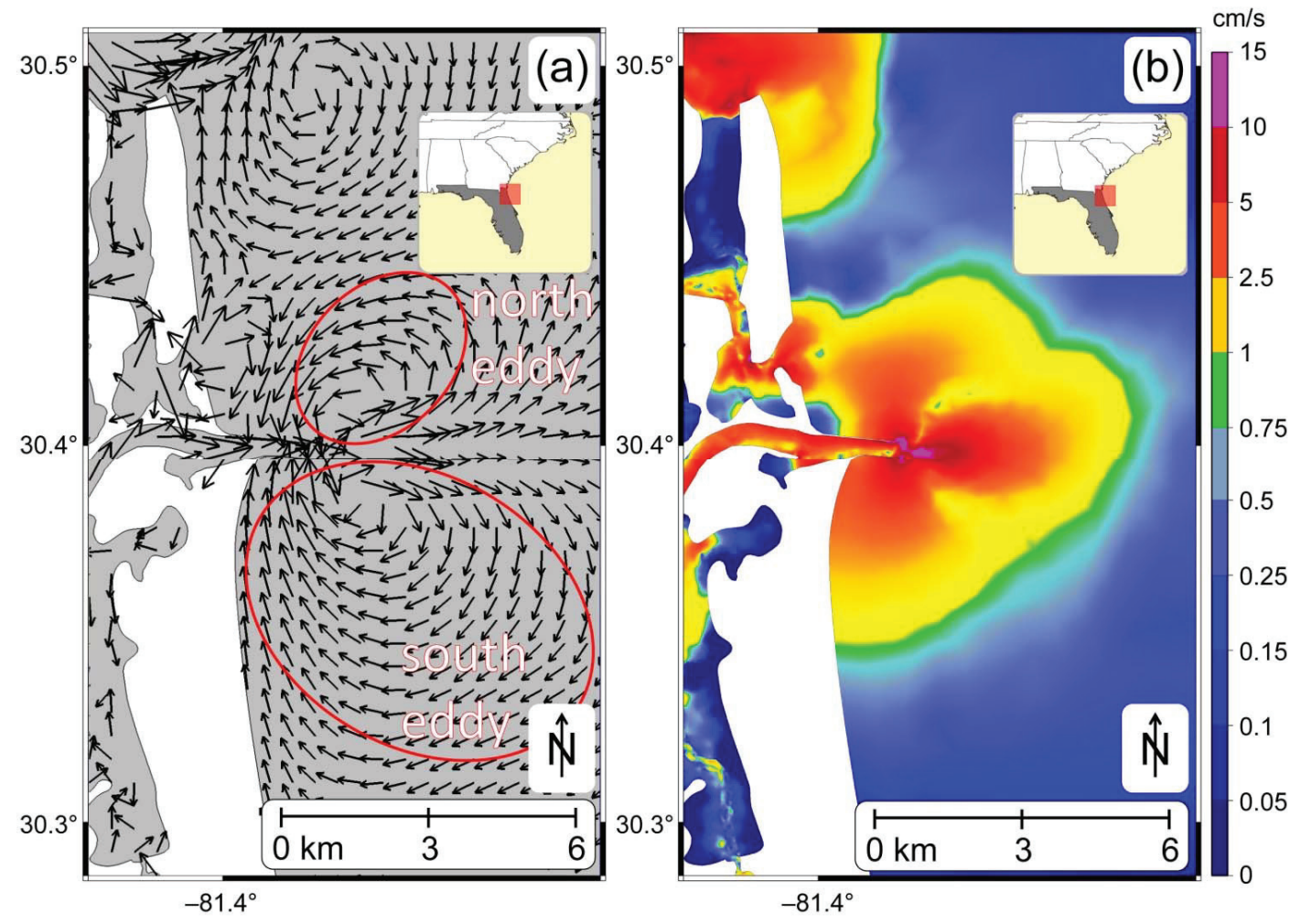

\section{Conclusions}

This study was spawned as a pilot project to define a methodology for establishing baseline conditions of beached oil tar balls along Florida's First Coast. As a result of the pilot project, a research team (local to Jacksonville) of mappers, modelers and field experts has been formed. In addition, the pilot project has established fieldwork protocols for collecting oil tar balls on Florida's First Coast beaches, modeling methods for simulating hydrodynamics in the St. Johns River and offshore waters and laboratory tests for confirming or negating collected samples as being oil tar balls.

The methodology presented in this paper for defining baseline conditions of beached oil tar balls along Florida's First Coast was designed with up-scaling in mind. The project could be scaled spatially by including a longer stretch of beach. In temporal scope, the project could involve more frequent site visits or the collection period could be extended. In the laboratory, there could be more extensive testing with the goal of more conclusively identifying oil tar balls. 
The study concludes that a limited amount of oil tar balls wash up during normal conditions, suggesting that the port activity in the St. Johns River is not a major contributor of oil tar ball washup on Florida's First Coast beaches. Future work will be to conduct a temporal analysis of the data to discover any trends or causative factors (e.g., storms) to oil tar ball wash-up. Finally, the numerical modeling will be extended to incorporate transport into the hydrodynamic simulation as well as to explore the effect of waves and wave-induced current as transport mechanisms.

\section{Acknowledgments}

Student support was funded in part by a Seed Grant from the University of North Florida Environmental Center and by the School of Engineering and College of Computing, Engineering and Construction of the University of North Florida. The fieldwork on Little Talbot Island State Park was carried out under Research and Collecting Permit \#02131312. The authors thank Matthew Davies of the University of North Florida - Chemistry Department for providing time and advice on the project.

\section{Conflicts of Interest}

The authors declare no conflict of interest.

\section{References}

1. Allen, G. US Watches Closely as Oil Drilling Begins off Cuba; National Public Radio: Washington, DC, USA, 13 February 2012.

2. Goodhue, D. New Drilling off Cuba May Pose More Risk to Florida; The Miami Herald: Doral, FL, USA, 6 July 2012.

3. Proni, J.R. Preparing the United States for Potential Impacts from Drilling Activities in Cuba and the Bahamas; Congressional Subcommittee Hearing: Washington, DC, USA, 30 January 2012.

4. Burger, B.; Cochran, J.; Whitford, J.; de Zeewu, J. Characterization of Gulf Region Tar Balls Following the Deepwater Horizon Oil Spill; Restek Corporation: Bellefonte, PA, USA, 2012.

5. Windsor, M. On the beach: Forensic Researcher Tracks Gulf Oil through Tar Balls. UAB Magazine, 30 September 2011, pp. 1-2.

6. Del Sontro, T.S.; Leifer, I.; Luyendyk, B.P.; Broitman, B.R. Beach tar accumulation, transport mechanisms and sources of variability at Coal Oil Point, California. Mar. Pollut. Bull. 2007, 54, 1461-1471.

7. Chandru, K.; Zakaria, M.P.; Anita, S.; Shahbazi, A.; Sakari, M.; Bahry, P.S.; Mohamed, C.A.R. Characterization of alkanes, hopanes, and polycyclic aromatic hydrocarbons (PAHs) in tar-balls collected from the east coast of peninsular Malaysia. Mar. Pollut. Bull. 2008, 56, 950-962. 
8. Fish Technical Working Group of the Mississippi Canyon 252 Trustees. Submerged Oil Characterization across Multiple Habitats for Assessment of Persistent Exposures in Nearshore Sediments Deepwater Horizon Oil Spill (DWHOS); Natural Resource Damage Assessment, NOAA: Washington, DC, USA, 2011.

9. Henry, C.B.; Roberts, P.O.; Overton, E.B. Characterization of chronic sources and impacts of tar along the Louisiana coast. In OCS Study MMS 93-0046; U.S. Department of Interior, Minerals Management Service, Gulf of Mexico OCS Regional Office: New Orleans, LA, USA, 1993.

10. Misselwitz, M.; Cochran, J.; English, C.; Burger, B. Characterization of Crude Oils and Tar Balls Using Biomarkers and Comprehensive Two-Dimensional Gas Chromatography; Restek Corporation: Bellefonte, PA, USA, 2013.

11. Van Vleet, E.S.; Pauly, G.G. Characterization of oil residues scraped from stranded sea turtles from the Gulf of Mexico. Caribb. J. Sci. 1987, 23, 77-83.

12. Wang, Z. Identification and Differentiation of Spilled Oils by Fingerprint Tracing Technology; Emergencies Science and Technology Division, ETC, Environment Canada: Ottawa, Canada, 2013.

13. Bacopoulos, P.; Parrish, D.M.; Hagen, S.C. Unstructured mesh assessment for tidal model of the South Atlantic Bight and its estuaries. J. Hydraul. Res. 2011, 49, 487-502.

14. Tee, K. Tide-induced residual current, a 2-D nonlinear numerical tidal model. J. Mar. Res. 1976, 34, 603-628.

15. Zimmerman, J.T.F. On the Euler-Lagrange transformation and the Stokes' drift in the presence of oscillatory and residual currents. Deep Sea Res. Part A Oceanogr. Res. Pap. 1979, 26, 505-520.

16. Nihoul, J.C.J.; Ronday, F.C. The influence of the "tidal stress" on the residual circulation: Application to the Southern Bight of the North Sea. Tellus 1975, 27, 484-490; doi:10.1111/j.2153-3490.1975.tb01701.x.

17. Delhez, E.J.M. On the residual advection of passive constituents. J. Mar. Syst. 1996, 8, 147-169.

18. ADCIRC. Available online: http://adcirc.org/ (accessed on 28 October 2013). 


\title{
Development and Use of Tide Models in Alaska Supporting VDatum and Hydrographic Surveying
}

\section{Lei Shi, Jindong Wang, Edward Myers and Lijuan Huang}

\begin{abstract}
National Oceanic and Atmospheric Administration's National Ocean Service uses observations, hydrodynamic models and interpolation techniques to develop many of its products and services. We examine how two projects, computation of tidal datums for vertical datum transformation and the estimation of tidal characteristics for hydrographic surveys, are being developed in Alaska and how they may be more seamlessly integrated. Preliminary VDatum development for Alaska is in progress for the Alaska Panhandle through the setup of a high resolution tide model that will be used to compute spatially varying tidal datums. Tide models such as these can be used for other projects that traditionally rely on estimation of tides in between data locations, such as the planning for hydrographic surveys that need correctors to adjust bathymetry to the chart datum. We therefore also examine how an existing model in western Alaska can be used for better supporting hydrographic survey planning. The results show that integration of tide models with nearshore observations can provide improved information for these correctors and future work will further evaluate this methodology with existing VDatum tide models.
\end{abstract}

Reprinted from J. Mar. Sci. Eng. Cite as: Shi, L.; Wang, J.; Myers, E.; Huang, L. Development and Use of Tide Models in Alaska Supporting VDatum and Hydrographic Surveying. J. Mar. Sci. Eng. 2014, 2, 171-193.

\section{Introduction}

National Oceanic and Atmospheric Administration (NOAA)'s National Ocean Service (NOS) develops and uses tide models and interpolation techniques in support of vertical datum transformation and hydrographic surveying. In this paper, we describe initial efforts to expand these capabilities in Alaska. VDatum [1] is a vertical datum transformation software tool, and the tidal datum transformations in VDatum are normally computed by using tide model results and corrected by interpolation [2]. These tidal datums are then related to orthometric and ellipsoid-based vertical reference systems through geoid models developed by NOS' National Geodetic Survey (NGS). Developing VDatum for Alaska presents many challenges, mainly due to the smaller amount of tidal, orthometric and GPS data available to support the development and validation of models used to generate the vertical datums and their relationships to each other. While more of the data is being collected, the VDatum team decided that the development of a tide model could begin in one selected subregion of Alaska, using existing tide data to help validate the model. As more data becomes available in the future, any necessary adjustments to the model to improve model-observation agreement could be made accordingly. Additionally, tide models developed for VDatum are increasingly being used to help address other needs within NOAA. An example of this is hydrographic survey planning, where tidal parameters normally estimated through interpolation of tide gauge data could benefit from modeled tidal characteristics between gauge locations. While development of the 
identified subregional tide model is in progress, we also evaluated how an existing tide model could be used to better define the spatial variability of tidal parameters to support hydrographic planning in western Alaska.

VDatum tidal datums are normally developed by first simulating tidal characteristics with the advanced circulation model (ADCIRC) [3,4]. The VDatum team evaluated: (1) how to break the Alaska region into subregions; and (2) which subregion would have the highest priority for tide model development. We decided that at least five subregions would be needed and, based partially on the feedback from VDatum users, that southeast (SE) Alaska is the best suited for initial development (Figure 1a,b). Several tidal model applications have been previously developed covering SE Alaska [5-9]. Most of these applications emphasize regional tidal propagation, with a minimum resolution near the coast sufficient to resolve major passages and waterways around the Alexander Archipelago [5-7]. Hill et al. [8] simulated the tides and fresh water runoff in Glacier Bay, Alaska, using ADCIRC with a high resolution unstructured grid. Inazu et al. [9] modeled tides in SE Alaska using a finite difference model with 1-km resolution and gave an estimation of large tidal dissipation around Glacier Bay. There are also Pacific basin scale and global scale tidal models available, notably the Oregon State University Tidal Inversion Software (OTIS) by Egbert and Erofeeva [10,11] and the last version of the FES (Finite Element Solution) global tide model developed in 2012, FES2012 [12]. OTIS project has a Pacific basin scale model at $1 / 12^{\circ}$ resolution, PO2009, as well as a global model, TPX07.2, that assimilates satellite altimetry data. The diurnal and semidiurnal tides in the Gulf of Alaska from these models all have similar spatial patterns [5-7,10-12]. While the overall offshore pattern is simple, the complexity of the passages and waterways inside the SE Alaska Panhandle leads to significant tidal wave deflection and dissipation and thus requires a high resolution tidal model to properly simulate the local tidal propagation and spatial variations in tidal datums [13]. Therefore, initial work towards a new tide model for SE Alaska is presented here with higher resolution to resolve both regional and local tidal dynamics.

Figure 1. (a) Alaska shoreline and coast waters, and the southeast (SE) Alaska hydrodynamic model domain (blue polygon, approximately); (b) SE Alaska, bathymetry and tidal stations (green dots); (c) SE Alaska unstructured model grid.

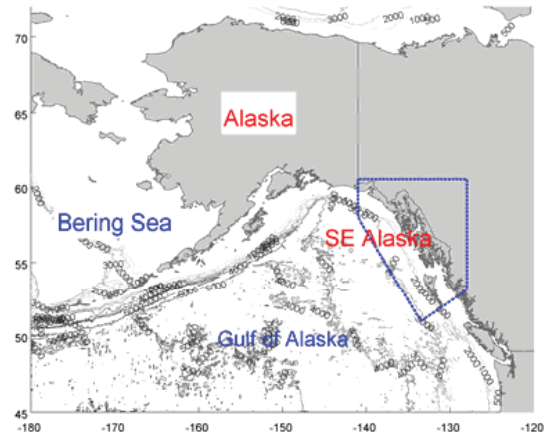

(a)

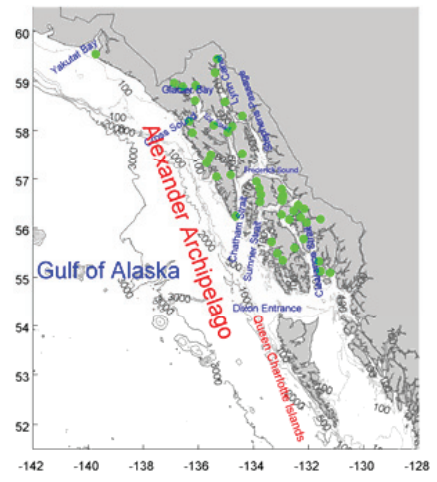

(b)

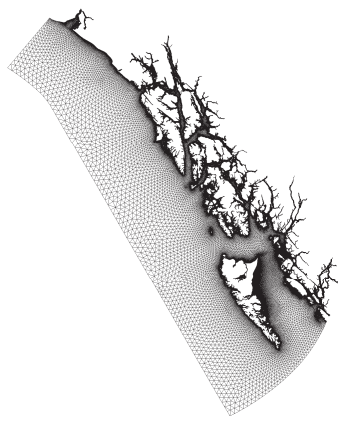

(c) 
With the start of work on the SE Alaska tide model for eventual VDatum development, the VDatum team is also looking at extending the use of tide models developed over the years for VDatum along the U.S. coasts. One such identified use is to provide offshore tidal constituents to NOAA's Hydrographic Planning Team (HPT) in the Center for Operational Oceanographic Products and Services (CO-OPS). In the assessment of users' needs in Alaska for VDatum and tide models, HPT was identified for collaboration on evaluating the use of tide model outputs as an additional source of information to support hydrographic surveys in the Bering Sea. HPT provides survey operation teams with estimated tidal curves within a survey area by interpolating/extrapolating tidal constituents and tidal parameters, such as the mean tidal range (MN) and the high water interval (HWI, the interval between the Moon's transit over the Greenwich meridian and the following high water). Current interpolation/extrapolation relies on the constituents and parameters derived from CO-OPS' measurements at tide gauges located along the shoreline. The tidal constituents and tidal parameters derived from model results should therefore provide better estimates for offshore tides. The Bering Sea of western Alaska has complex tidal characteristics with several diurnal and semidiurnal amphidromes. Some previous tide models $[14,15]$ are able to capture large-scale tidal features, but tend to perform worse in the nearshore regions, due to their relatively coarse resolution. Foreman et al. [16] used a variable triangular grid with a resolution from $1.5 \mathrm{~km}$ to $50 \mathrm{~km}$ and a barotropic finite element model to simulate tides in the Bering Sea with the assimilation of tidal harmonics derived from satellite altimetry data. Foreman's model has relatively high accuracy in the offshore and nearshore regions (the average $\mathrm{M}_{2}$ root mean square error, RMSE, is $3.0 \mathrm{~cm}$; see Section 3.3 for details), even though it is less accurate at the onshore CO-OPS tide stations (the average $\mathrm{M}_{2}$ RMSE is $10.7 \mathrm{~cm}$; see Section 3.2 for details). We therefore used Foreman's model for evaluation in this study and present the results of incorporating the model results into estimated tidal patterns to help support hydrographic survey planning. We will refer to Foreman's model as "FM" in all future discussion.

This paper is organized as follows: Section 2 presents the work on the development of a new, high-resolution tidal model for SE Alaska. Section 3 evaluates how tide models can improve current methods of estimating offshore tidal patterns to provide tide correctors for hydrographic surveys. The development of new tide models for the remainder of Alaska and further analysis of the use of tide models in hydrographic planning will continue in future years, and Section 4 identifies some key objectives of future work in this regard.

\section{Tidal Modeling in SE Alaska}

As the first step towards VDatum availability in southeast Alaska, the development of a high resolution ADCIRC tidal model is presented here for the coastal waters around the Alexander Archipelago and Alaska Panhandle. Using high-resolution shoreline and bathymetric data from NOAA, this model is able to resolve the fine detail of the shoreline with resolution down to about $50 \mathrm{~m}$. Boundary conditions were obtained from Oregon State University's regional tidal solution PO2009 tide database [17] for the $\mathrm{M}_{2}, \mathrm{~S}_{2}, \mathrm{~N}_{2}, \mathrm{~K}_{2}, \mathrm{~K}_{1}, \mathrm{O}_{1}, \mathrm{P}_{1}, \mathrm{Q}_{1}, \mathrm{M}_{4}, \mathrm{MS}_{4}$ and $\mathrm{MN}_{4}$ constituents. The skill of the model is assessed through comparison of amplitudes and phases of tidal constituents 
derived from the model and from observations. After model validation, the model will be used to compute tidal datums for future use in NOAA's VDatum software.

\subsection{Model Development}

The model domain covers all coastal waters of the SE Alaska Panhandle (Figure 1). To reduce the impact of errors propagated from the open ocean boundary, we extend the southern open boundary beyond the southern tip of the Queen Charlotte Islands and the northern open boundary to include Yakutat Bay. The length of the domain from south to north is about $1150 \mathrm{~km}$. In the offshore direction, the open boundary is extended to about $200 \mathrm{~km}$ from the nearest islands. The entire water domain covers a total of $300,000 \mathrm{~km}^{2}$. For regions inside the U.S. marine boundary, two types of bathymetric data were used: (1) sounding data of individual depth measurements; and (2) a digital elevation model (DEM) composed of multiple data sources [18]. For regions further offshore, a one arc-minute global relief model, ETOPO1 [19] was used. The reference vertical datums of the sounding data and DEM were converted to mean sea level (MSL) using gridded vertical datum conversions provided by NOAA's National Geophysical Data Center (NGDC). These conversions were calculated using kriging to interpolate the vertical datums from 93 tide gauges around SE Alaska [20]. The vertical datum of ETOPO1 is mean sea level and therefore did not require a datum conversion. The bathymetry was smoothed to reduce the maximum slope and prevent instabilities, due to steep bottom slopes. A mean high water shoreline dataset was provided by NOAA's NGS.

An unstructured triangular mesh grid (Figure 1c) was generated to represent the model domain, using the shoreline from NGS as the land boundary. The water depths, distance to the shoreline and desired minimum resolution along the shoreline were among the factors used for determining local mesh resolution. The current mesh grid has about two million node points. The smallest grid size is $50 \mathrm{~m}$ and the largest is about $20 \mathrm{~km}$. Bathymetry was interpolated to the model grid using linear interpolation.

A state-of-the-art numerical hydrodynamic model, ADCIRC [3,4], was used for tidal simulations with the SE Alaska grid. ADCIRC solves the 2D vertically-integrated generalized wave continuity equation using the finite element method on an unstructured triangular grid. This model has been widely applied to tide and storm surge simulations in estuarine, coastal and continental shelf regions [21].

To properly set up the model, three boundary conditions have to be prescribed: open boundary, surface boundary and bottom boundary conditions. Since we are only simulating the tides, there is no air-sea exchange of momentum, mass and energy applied to the surface boundary. A slip quadratic bottom friction boundary condition is used for the bottom boundary. We use a depth-dependent bottom friction coefficient, $C_{f}$,

$$
C_{f}=C_{f}\left(C_{f}^{s}, C_{f}^{d}\right)= \begin{cases}C_{f}^{s} & z \leq H^{s} \\ \frac{H^{d}-z}{H^{d}-H^{s}} C_{f}^{s}+\frac{z-H^{s}}{H^{d}-H^{s}} C_{f}^{d} & H^{s}<z<H^{d} \\ C_{f}^{d} & H^{d} \leq z\end{cases}
$$


where $\mathrm{z}$ is water depth, $H^{s}$ and $H^{d}$ are two constant water depths, equal to $100 \mathrm{~m}$ and $300 \mathrm{~m}$, respectively, in this study, and $C_{f}^{s}$ and $C_{f}^{d}$ are constant bottom friction coefficients for water shallower than $H^{s}$ and water deeper than $H^{d}$, respectively. Equation 1 provides a depth-dependent linear interpolated bottom friction for water depths between $H^{s}$ and $H^{d}$. In this study, we use $C_{f}=C_{f}(0.00375,0.00375)$, a constant over all depths, for the baseline study, and variable ${ }_{f}$ scenarios

are examined in sensitivity tests. The open boundary is forced by prescribed tidal information interpolated from Oregon State University's Pacific Ocean basin scale tidal solution PO2009 [17]. The tidal forcing along the open boundary consisted of four semidiurnal constituents $\left(\mathrm{M}_{2}, \mathrm{~S}_{2}, \mathrm{~N}_{2}\right.$ and $\left.\mathrm{K}_{2}\right)$, four diurnal constituents $\left(\mathrm{K}_{1}, \mathrm{O}_{1}, \mathrm{P}_{1}\right.$ and $\left.\mathrm{Q}_{1}\right)$ and three shallow water components $\left(\mathrm{M}_{4}, \mathrm{MS}_{4}\right.$ and $\mathrm{MN}_{4}$ ). The model has wetting and drying enabled, so as to cope with tidal flat scenarios.

\subsection{Model Validation}

Tidal harmonic constants for these 11 constituents $\left(\mathrm{M}_{2}, \mathrm{~S}_{2}, \mathrm{~N}_{2}, \mathrm{~K}_{2}, \mathrm{~K}_{1}, \mathrm{O}_{1}, \mathrm{P}_{1}, \mathrm{Q}_{1}, \mathrm{M}_{4}, \mathrm{MS}_{4}\right.$ and $\mathrm{MN}_{4}$ ) are used for model validation at $43 \mathrm{CO}-\mathrm{OPS}$ tidal stations (Figure 1b). Some of these stations are long-term, active stations, while others are historical stations with various time lengths of deployment [22].

The semidiurnal $\mathrm{M}_{2}$ tide in the Gulf of Alaska has an amphidrome in the northern Pacific Ocean, east of Hawaii. The $\mathrm{M}_{2}$ tide propagates anticlockwise along the coast of SE Alaska, with the co-phase lines perpendicular to the coast and co-amplitude lines parallel to the coast (Figure 2). There are many inter-island waterways and passages along the SE Alaska coast through which the tides branch out and propagate shoreward. Some of these major passages include the Dixon Entrance-Clearance Strait, Sumner Strait, Chatham Strait and Cross Sound in the north (Figure 1b). Once inside the passages, the tide propagates through waterways with increasing phase lag and generally increasing amplitude. The amplitude near the open boundary is about $1 \mathrm{~m}$. There are locations at the ends of inlets and passages, notably in Glacier Bay, Lynn Canal and Stephens Passage, where the amplitude is larger than $2 \mathrm{~m}$ (Figure 2). Glacier Bay has some of the largest amplitudes and phase lags in the model domain.

The diurnal tide, $\mathrm{K}_{1}$, in the Gulf of Alaska has an amphidrome in the northern Pacific Ocean, west of Hawaii. The $\mathrm{K}_{1}$ tide propagates anticlockwise in the northwest direction along the SE Alaska coast. The amplitude of $\mathrm{K}_{1}$ near the open boundary is about $0.45 \mathrm{~m}$ and increases landwards (Figure 3). The maximum $\mathrm{K}_{1}$ amplitude in Glacier Bay is around $0.6 \mathrm{~m}$. Similar to the $\mathrm{M}_{2}$ tide, the $\mathrm{K}_{1}$ phase lag increases in the northwest direction, but with less of a phase lag gradient. The largest phase lag is in Glacier Bay, around 270 degrees. In comparison, at the southern tip of the Alexander Archipelago, just north of the Dixon entrance, the $\mathrm{K}_{1}$ phase is about 258 degrees. All other semidiurnal and diurnal tides had similar patterns as the dominant $\mathrm{M}_{2}$ and $\mathrm{K}_{1}$ tides, only with smaller amplitudes.

A direct comparison between model and observed $\mathrm{M}_{2}$ amplitudes (Figure 4) shows that the model generally overestimates the $\mathrm{M}_{2}$ amplitude. The amplitude (observed, model) pairs are clustered along the $5 \%$ error line. The model underestimates $\mathrm{M}_{2}$ amplitudes only at two stations and overestimates more than $10 \%$ at one station. The $\mathrm{M}_{2}$ phase is generally underestimated. At the lower phase values (i.e., at locations closer to the southern open boundary), this underestimation is smaller. This can be 
due to the accumulation of error with the phase along the direction of wave propagation. For the $\mathrm{S}_{2}$ tide, the results are similar. For the $\mathrm{K}_{1}$ and $\mathrm{O}_{1}$ tides, the model overestimates the amplitude and underestimates the phase. The difference in both amplitude and phase is more of a constant shift. This may suggest that applying a constant shift to the $\mathrm{K}_{1}$ and $\mathrm{O}_{1}$ boundary conditions could help improve the results.

Figure 2. $\mathrm{M}_{2}$ tide (a) co-amplitude lines (meters); and (b) co-phase lines (degrees) in SE Alaska.

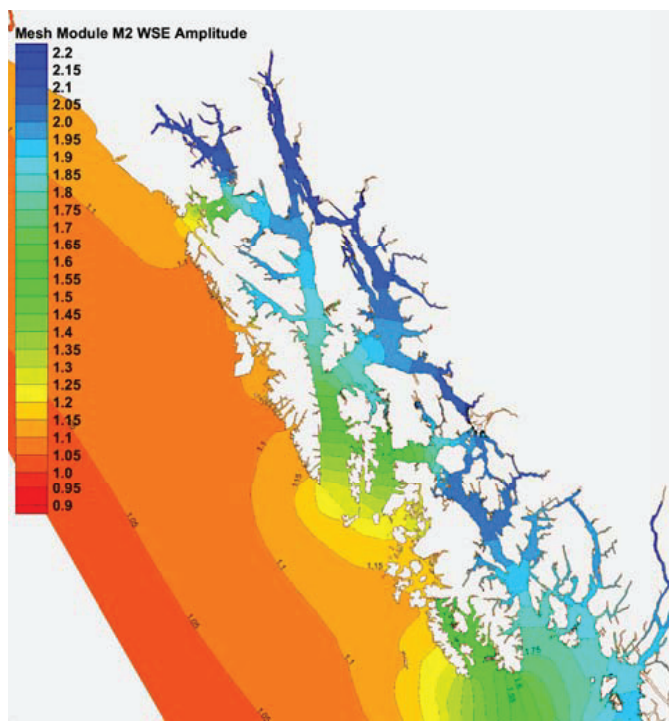

(a)

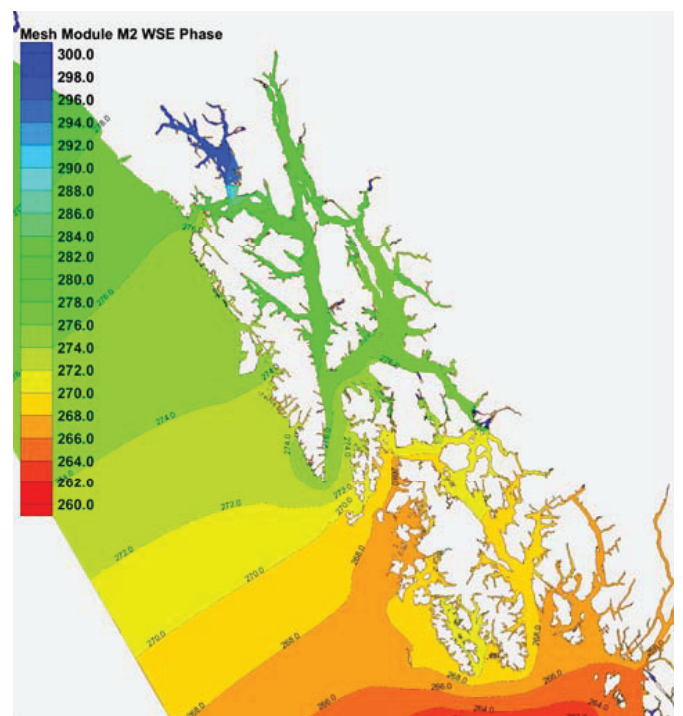

(b)

Figure 3. $K_{1}$ tide (a) co-amplitude lines (meters); and (b) co-phase lines (degrees) in SE Alaska.

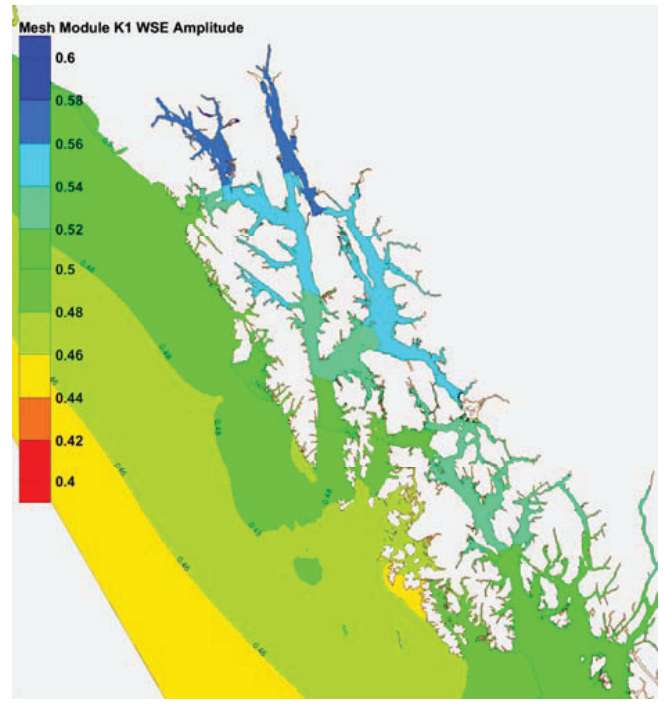

(a)

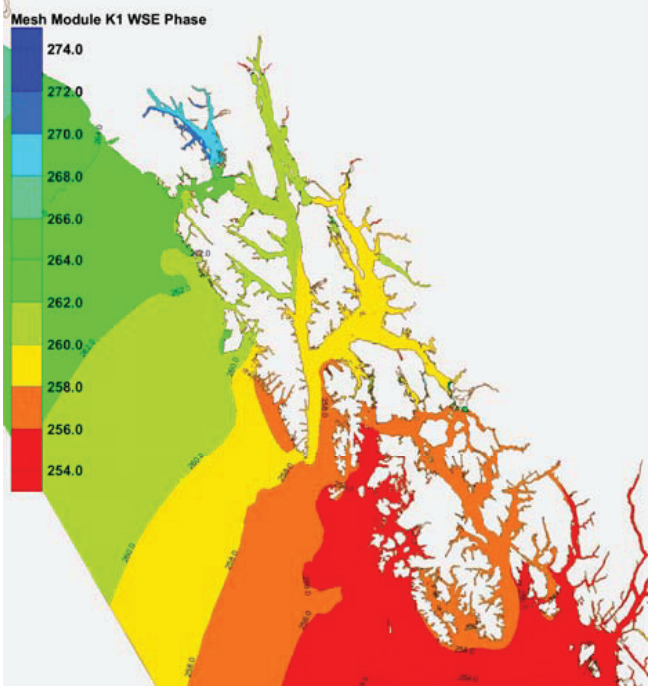

(b) 
Figure 4. $\mathrm{M}_{2}, \mathrm{~S}_{2}, \mathrm{~K}_{1}$ and $\mathrm{O}_{1}$ model-observation comparison of amplitude (meters) and phase (degrees) at 43 tidal stations in SE Alaska.
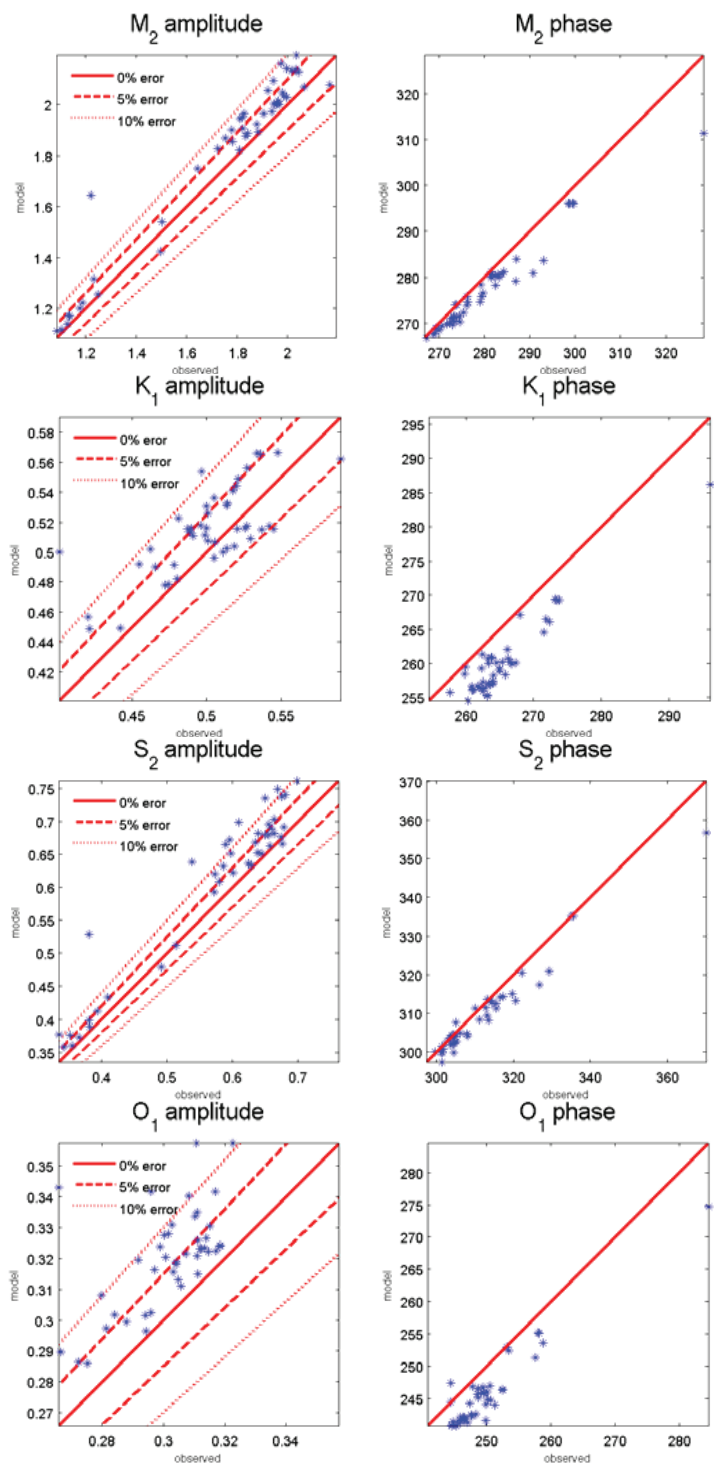

To quantify the model performance and skill, we calculated the mean absolute error (MAE) of the amplitudes and phases. We also calculated the root mean square error (RMSE), $A e$, which combines the amplitude error and phase error using the equation:

$$
A_{e}=\left(\frac{1}{2 \pi} \int_{0}^{2 \pi}\left(A_{m} \cos \left(t-h_{m}\right)-A_{o} \cos \left(t-h_{o}\right)\right)^{2} d t\right)^{\frac{1}{2}}=\left(\frac{A_{m}{ }^{2}}{2}+\frac{A_{o}{ }^{2}}{2}-A_{m} A_{o} \cos \left(h_{m}-h_{o}\right)\right)^{\frac{1}{2}}
$$

where $A_{o}$ and $A_{m}$ are observed and modeled amplitudes, respectively, and $h_{o}$ and $h_{m}$ are observed and modeled phases, respectively. The relative RMSE (\%), $\frac{A_{e}}{A_{o}}$, will measure the relative model 
performance across the different tidal constituents. Mean RMSE and mean relative RMSE are the average RMSE and relative RMSE values over 43 tidal stations for one tidal constituent. The total mean RMSE $(\mathrm{cm}), \sum_{\text {consitituent }} A_{\text {consititent }}^{\text {, }}$, measures the RMSE of all tidal constituents.

The $\mathrm{M}_{2}$ tide has the smallest mean relative RMSE over all 43 data points (Table 1). $\mathrm{K}_{2}$ has the worst mean relative RMSE of all semidiurnal and diurnal tides, at 16.8\%. All semidiurnal and diurnal tides have a mean relative RMSE between $5 \%$ and $10 \%$, with the exception of the $\mathrm{K}_{2}$ tide. The $\mathrm{M}_{4}$ tide is inaccurate, with a mean relative RMSE of $54.4 \%$. Most stations do not have $\mathrm{MS}_{4}$ and $\mathrm{MN}_{4}$ harmonic constant data, and thus, we do not present their performance statistics here. From the limited observed data points available for these constituents, $\mathrm{MS}_{4}$ and $\mathrm{MN}_{4}$ have similar relative RMSE as $\mathrm{M}_{4}$.

Table 1. Model-observation comparison: error measurements of nine tidal constituents, averaged over 43 tidal stations. MAE, mean absolute error; RMSE, root mean square error.

\begin{tabular}{ccccc}
\hline & $\begin{array}{c}\text { Amplitude error, } \\
\text { MAE }(\mathbf{c m})\end{array}$ & $\begin{array}{c}\text { Phase error, MAE } \\
\text { (degree) }\end{array}$ & $\begin{array}{c}\text { Mean RMSE } \\
(\mathbf{c m})\end{array}$ & $\begin{array}{c}\text { Mean relative RMSE } \\
(\%)\end{array}$ \\
\hline $\mathrm{M}_{2}$ & 8.29 & 2.93 & 9.47 & 5.5 \\
$\mathrm{~S}_{2}$ & 3.81 & 2.61 & 3.68 & 6.6 \\
$\mathrm{~N}_{2}$ & 1.63 & 3.53 & 2.14 & 6.3 \\
$\mathrm{~K}_{2}$ & 1.14 & 11.80 & 2.56 & 16.4 \\
$\mathrm{~K}_{1}$ & 2.96 & 4.71 & 3.90 & 7.9 \\
$\mathrm{O}_{1}$ & 2.41 & 5.56 & 2.91 & 9.7 \\
$\mathrm{P}_{1}$ & 0.62 & 6.03 & 1.35 & 8.3 \\
$\mathrm{Q}_{1}$ & 0.31 & 3.82 & 0.38 & 6.6 \\
$\mathrm{M}_{4}$ & 1.82 & 26.11 & 1.60 & 54.4 \\
$\mathrm{Total}$ & & & 28.7 & \\
\hline
\end{tabular}

Figure 5. Spatial distribution of relative RMSE (\%). (a) $\mathrm{M}_{2}$; (b) $\mathrm{K}_{1}$.

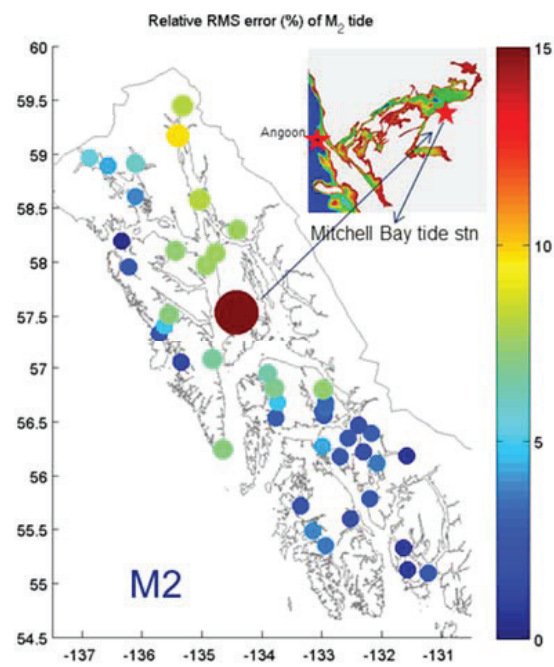

(a)

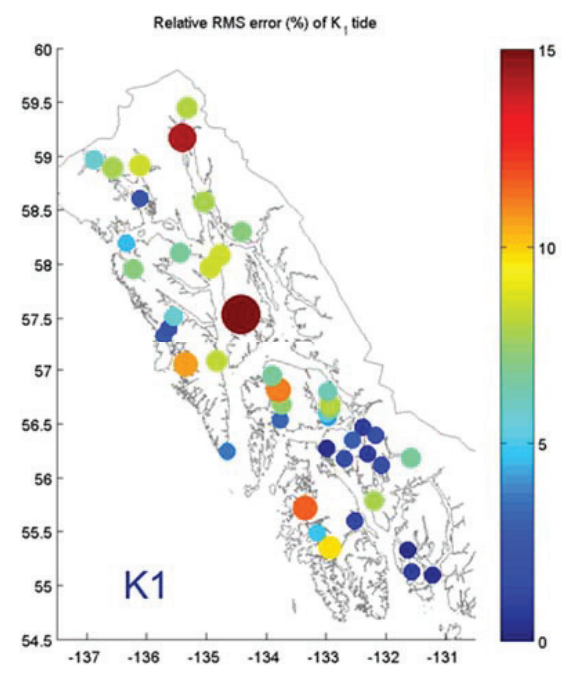

(b) 
The model skill and performance have significant spatial variations across the 43 station points (Figure 5). Mitchell Bay, a $10 \mathrm{~km}^{2}$ in size inlet connected with Chatham Strait through a long, 100 m-wide narrow channel, is the location that the model performs the worst against the observations. The relative RMSE is well above $15 \%$ for all semidiurnal and diurnal tides here. At all other stations, the relative RMSE is usually below $10 \%$.

\subsection{Discussion}

For all the semidiurnal and diurnal tidal constituents, the SE Alaska model seems to overestimate the amplitude and underestimate the phase. For the $\mathrm{M}_{2}$ tide, the model results agree better with observations with low amplitudes and small phase lags (i.e., locations closer to the south open boundary) than the results with high amplitudes and large phase lags (i.e., locations inside passages and further away from the open boundary). Bottom friction can have a significant impact on the modeled tidal phase lags and amplitudes. There are many studies [4,23] evaluating the impact of bottom friction on phase lag and amplitude. Historically, the bottom friction used in VDatum tidal simulations has ranged from 0.001 to 0.00375 [13]. In our study, the bottom friction is set to a constant value, $C_{f}=C_{f}(0.00375,0.00375)$. Besides the background run using this value, three more sensitivity tests were conducted with different values of bottom friction. Including the baseline run, the bottom friction coefficients for four test cases from low to high are $C_{f}(0.00375,0.0020)$, $C_{f}(0.00375,0.0025), C_{f}(0.00375,0.00375)$ and $C_{f}(0.0045,0.0045)$. The total mean RMSE of nine tidal constituents $\left(\mathrm{M}_{2}, \mathrm{~S}_{2}, \mathrm{~N}_{2}, \mathrm{~K}_{2}, \mathrm{~K}_{1}, \mathrm{O}_{1}, \mathrm{P}_{1}, \mathrm{Q}_{1}\right.$ and $\left.\mathrm{M}_{4}\right)$ in the four test cases were 29.7, 29.4, 28.7 and $28.7 \mathrm{~cm}$, respectively. In general, the initial increase of bottom friction reduces the model amplitude and increases the phase lag of all tidal constituents, thereby slightly reducing the total mean RMSE. However, further increasing of the bottom friction to 0.0045 did not further reduce the error. The bottom friction coefficient, $C_{f}(0.0045,0.0045)$, is larger than the values in previous VDatum tidal simulations and in other ADCIRC studies [21]. Furthermore, the model stability is too sensitive to further reduce the bottom friction coefficient. Therefore, no further sensitivity tests with lower or higher bottom friction coefficients were conducted. For semidiurnal tides, reducing the amplitudes and increasing the phase lags inside the passages is necessary to improve the model results. That implies a higher dissipation rate of tidal energy in the model inside the passages. Many studies [24,25] indicate the baroclinic tidal energy dissipation may play a more significant role than the bottom friction. A barotropic model may not be able to address the tidal dissipation associated with baroclinic processes.

For the diurnal tides, the model-data comparison (Figure 4) may suggest a shift in amplitude and phase. We compared the PO2009 database with the 1/16 degree resolution global tidal model, FES2012 [12], along the open boundary. The two databases are very consistent along the open boundary. The preliminary results using the same 11 tidal constituents from FES2012 as an open boundary condition indicate that FES2012 reduces the total mean RMSE by $1.5 \mathrm{~cm}$, from $28.7 \mathrm{~cm}$ to $27.2 \mathrm{~cm}$. There is marginal improvement, but the error distribution and pattern shown in Figure 4 is still the same.

Another source of error may come from inadequate bathymetric data processing. Two changes were made to the bathymetry to increase model stability. One was to reduce the maximum horizontal 
slope and the other was to smooth the bathymetry to reduce the formation of landlocked wet elements in the ADCIRC model. In the early stages of the model development, a vertical depth unit correction from feet to fathoms in about 5\% of the sounding data reduced the total mean RMSE by half. Any changes made to the bathymetry to help model stability may compromise the accuracy of the model. In Mitchell Bay, the grid resolution is relatively low compared to the scale of the narrow channel connecting the bay to Chatham Strait. There are only two rows of elements representing this narrow channel. In combination with the low resolution of DEM data here, the model overestimates tidal energy propagated into the bay from Chatham Strait.

The biggest challenge of tidal modeling in SE Alaska has been with the model's numerical stability. The model can be unstable in wetting/drying scenarios involving landlocked wet elements. Figure 6 shows a time sequence of tidal elevations and velocities about one hour before the simulation ends due to the instability. The wet cells can connect with the open water episodically with a period of a few minutes, even as the tides are receding. The connection of these wet cells with the open water can be very abrupt. As the wetting/drying connection/disconnection process repeats, the outflow velocity increases until, eventually, the simulation fails. If the process has neutral or negative feedback, it may remain stable. In order to achieve model stability, the current model bathymetry had been smoothed aggressively. The bottom friction coefficient for shallow water less than $100 \mathrm{~m}$ is set to 0.00375 , which is relatively large compared with other VDatum tidal modeling cases [13]. To achieve numerical stability without over-tuning the model's physical parameters and bathymetry is the direction in our continued efforts to improve the model results.

Overall, with a minimum of 50-m spatial resolution, the SE Alaska tide model mesh grid is able to resolve complex waterways and passages in SE Alaska to reach all 43 current and historical tidal stations in the CO-OPS tidal database. The tidal model produces reasonable tidal results. Of all 11 tide constituents modeled ( $\mathrm{M}_{2}, \mathrm{~S}_{2}, \mathrm{~N}_{2}, \mathrm{~K}_{2}, \mathrm{~K}_{1}, \mathrm{O}_{1}, \mathrm{P}_{1}, \mathrm{Q}_{1}, \mathrm{M}_{4}, \mathrm{MS}_{4}$ and $\mathrm{MN}_{4}$ ), three semidiurnal tides $\left(\mathrm{M}_{2}, \mathrm{~S}_{2}\right.$ and $\left.\mathrm{N}_{2}\right)$ and four diurnal tides $\left(\mathrm{K}_{1}, \mathrm{O}_{1}, \mathrm{P}_{1}\right.$ and $\left.\mathrm{Q}_{1}\right)$ have a relative error below $10 \%$. The $\mathrm{K}_{2}$ tide has a higher relative RMSE of $16.4 \%$, and the $\mathrm{M}_{4}$ tide has a relative RMSE of $54.4 \%$. The $\mathrm{MN}_{4}$ and $\mathrm{MS}_{4}$ tides do not have enough observational data to calculate the mean RMSE, but we expect the relative error to be large. The model generally overestimates the amplitude and underestimates the phase. There are a few directions to improve the model results, for example, to give a more realistic bathymetry in the tidal zone and also to prescribe a better spatially varying bottom friction. The model has a few locations, especially in Mitchell Bay (Figure 5), where significant modelobservation discrepancies exist. Usually, these are places where there is not enough grid resolution to resolve the coastal features and/or there is a lack of bathymetric data. In all of these cases, though, the model can produce a reasonable phase, but an inaccurate amplitude (it is not be able to calculate an accurate energy influx). In future work, the tidal energy flux and dissipation in SE Alaska will be more thoroughly investigated with the model. 
Figure 6. Time sequence of the modeled elevation and velocity field around landlocked wet elements. The simulation started using a restart file $65 \mathrm{~min}$ before failure.

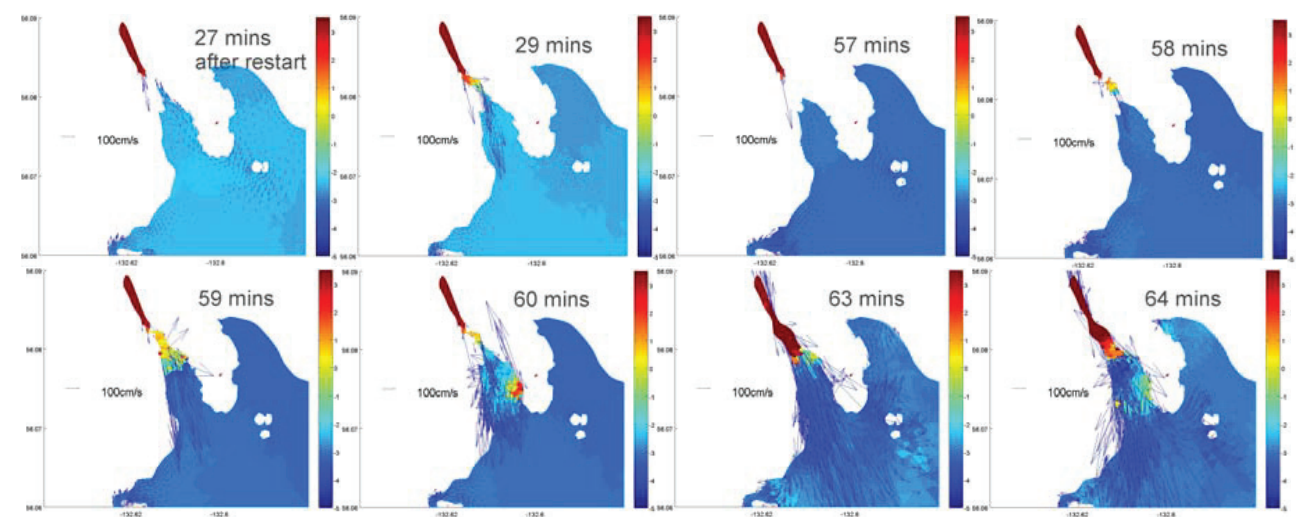

3. Use of Existing Tide Model Outputs in Western Alaska to Support Hydrographic Surveys

\subsection{Introduction}

During the development of the SE Alaska tide model, an existing model (FM) developed by Foreman et al. [16] in western Alaska was selected to evaluate how model results could improve tidal interpolation for hydrographic survey planning. The model domain covers a region of the Bering Sea where NOAA has planned upcoming survey operations. For the application to nautical charts, real-time sounding depths need to be corrected to a fixed vertical datum, such as mean lower low water (MLLW), as real-time sounding depths are impacted by non-tidal and tidal water level fluctuations. The tide correctors for both non-tidal and tidal components are derived from interpolated/extrapolated tidal fields of coastal station observations. CO-OPS' HPT team generates tide correctors from coastal stations using the Tidal Constituent And Residual Interpolation (TCARI) software. TCARI works by solving Laplace's equation constrained by boundary conditions to spatially interpolate tidal constituents, datums and water level residuals (i.e., the non-tidal component or the difference between the astronomically predicted tide and the observed water level) over an unstructured triangular grid [26,27]. Once the TCARI solution is completed for a grid, the water level data series can be derived at any given point within the grid.

The current method of interpolating/extrapolating onshore tidal observations for hydrographic surveys works well for the nearshore areas with substantial coastal stations and relatively simple tidal changes, as tidal features there can be readily captured by available coastal observations. However, in the Bering Sea of western Alaska, tides are very complex, due to the presence of amphidromic points and significant tidal amplification or reduction in coastal bays, estuaries and rivers. It is a challenge to accurately capture tidal propagation features in this region by relying only on the interpolation and extrapolation of the sparse onshore observed data [28]. 


\subsection{Methods and Results}

In this study, we examined the method of combining coastal observations with the tide model results. We first evaluate the FM performance at CO-OPS tide stations by comparing the modeled harmonic constants with observations. We then selected a number of offshore model points to be combined with onshore stations for the interpolation of harmonic constants using TCARI.

Figure 7. The spatial distribution of the relative RMSE (\%) of Foreman's model (FM) for (a) $\mathrm{M}_{2}$; and (b) $\mathrm{K}_{1}$.

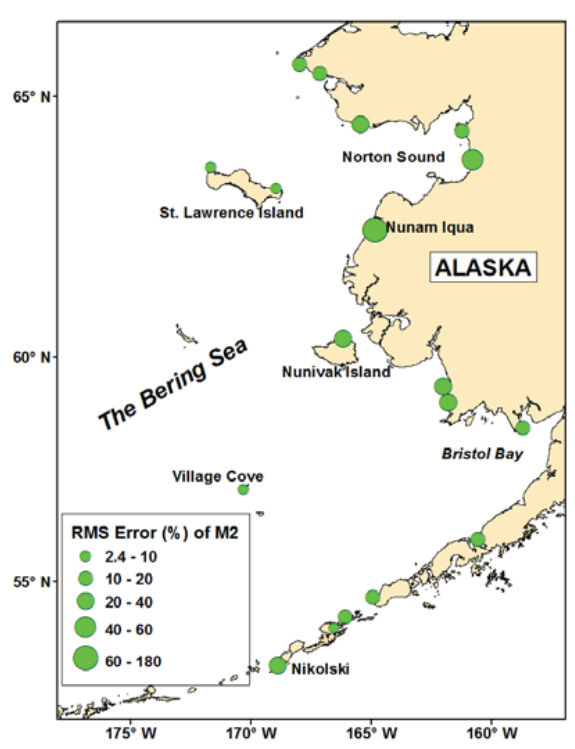

(a)

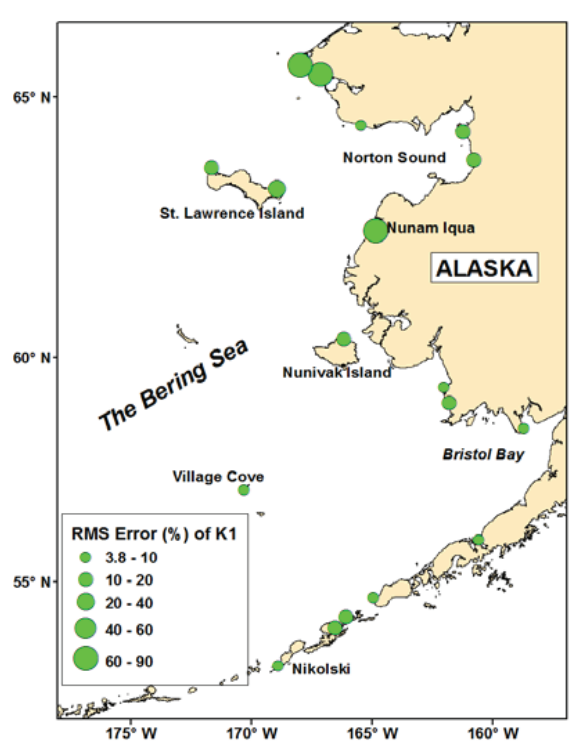

(b)

To quantify the FM performance and skill, we calculated the RMSE of tidal constituents at 18 CO-OPS coastal stations using Equation (2) from Section 2.2. The $\mathrm{M}_{2}$ RMSE ranges from $0.7 \mathrm{~cm}$ to $35.4 \mathrm{~cm}$ with an average of $10.7 \mathrm{~cm}$. The $\mathrm{K}_{1} \mathrm{RMSE}$ ranges from $0.7 \mathrm{~cm}$ to $16.7 \mathrm{~cm}$, with an average of $4.5 \mathrm{~cm}$. The relative RMSE (Figure 7) ranges from $2.5 \%$ to $177.7 \%$ for the $\mathrm{M}_{2}$ constituent and ranges from $3.8 \%$ to $85.4 \%$ for $\mathrm{K}_{1}$. Generally, the modeled tidal harmonics are comparable to the onshore observations, but have significant differences for particular stations. The discrepancies may be due to the relatively coarse resolution in particular regions and/or the absence of the local mass conservation of the model [16]. Given these discrepancies, accurate hydrographic surveys cannot rely only on the model outputs, especially in some nearshore regions. In this study, we propose to select a limited number of offshore model points to be combined with the onshore stations for interpolation, so that the interpolated harmonic constants in the nearshore regions are mainly controlled by the onshore observations.

A triangular mesh with 69,369 nodes and 112,575 elements with the resolution varying from a few meters to $30 \mathrm{~km}$ was developed for TCARI interpolation. This mesh has much higher resolution around the coast than the offshore regions, which helps to better capture tidal variations in the 
nearshore regions. The harmonic constants at a total of $18 \mathrm{CO}-\mathrm{OPS}$ stations and 21 model points in the domain (Figure 8) were used for interpolation.

Figure 8. (a) Study domain; (b) Center for Operational Oceanographic Products and Services (CO-OPS) tidal stations (blue squares), selected FM points (purple dots) and the literature stations from Pearson et al. [29] and Mofjeld [30] (brown triangles) in the domain. The thick black lines indicate the outer boundary of the triangular mesh used for Tidal Constituent and Residual Interpolation (TCARI) interpolation.

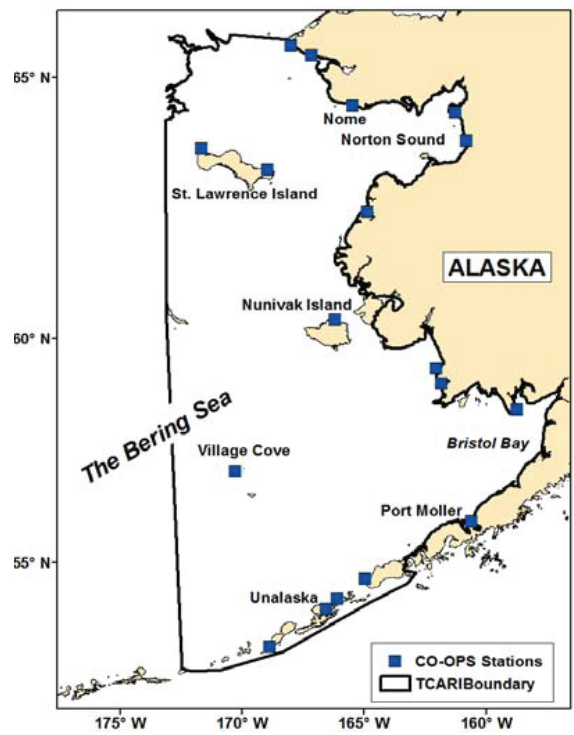

(a)

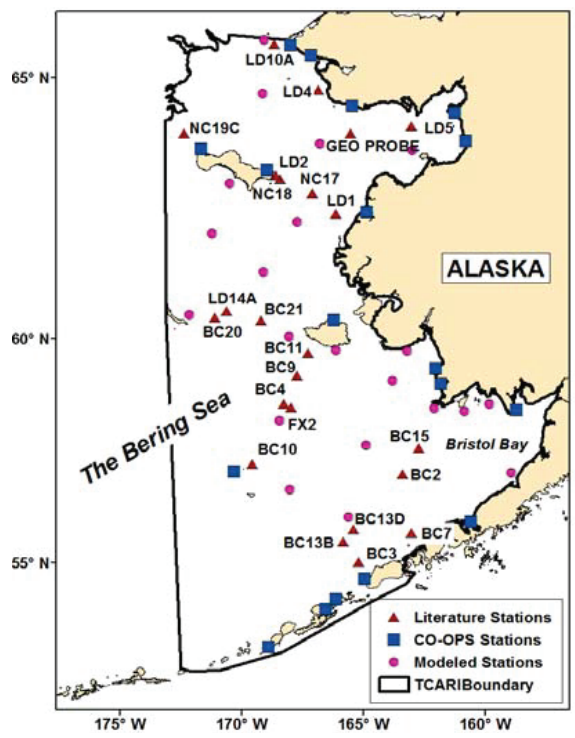

(b)

The co-amplitude and co-phase tidal fields of six constituents $\left(\mathrm{M}_{2}, \mathrm{~S}_{2}, \mathrm{~N}_{2}, \mathrm{~K}_{1}, \mathrm{O}_{1}\right.$ and $\left.\mathrm{P}_{1}\right)$ are populated from a combination of the observed and modeled data using TCARI. The amplitudes $(A)$ and phases $(h)$ at the CO-OPS stations and the model points were first transformed into two variables: Acosh and Asinh, since it is difficult to directly interpolate phases with a range of zero to 360 degrees around amphidromic points. The values of Acosh and Asinh were then populated onto the triangular mesh using TCARI. Finally, the interpolated Acosh and Asinh fields were transformed back to amplitudes and phases.

As examples, the $\mathrm{M}_{2}$ and $\mathrm{K}_{1}$ co-amplitude and co-phase contours from TCARI interpolation of combined onshore CO-OPS observations and offshore FM outputs (the combination is referred to as TOF) are shown in Figures 9a,b and 10a,b, respectively. As comparisons, the co-tidal contours from TCARI interpolation of only onshore CO-OPS observations (referred as TO) are shown in Figures $9 \mathrm{c}, \mathrm{d}$ and 10c,d. With the FM author's permission, the co-tidal contours from FM are shown in Figures 9e,f and 10e,f. The co-tidal contours from TOF are generally consistent with those from FM, but are different in the nearshore regions. The co-tidal contours from TOF are quite different from the TO contours, especially in terms of the presence and the location of the amphidromes. 
Figure 9. $\mathrm{M}_{2}$ co-amplitude (left side panels) and co-phase (right side panels) contours from TOF (a,b); TO (c,d); and FM (e,f).
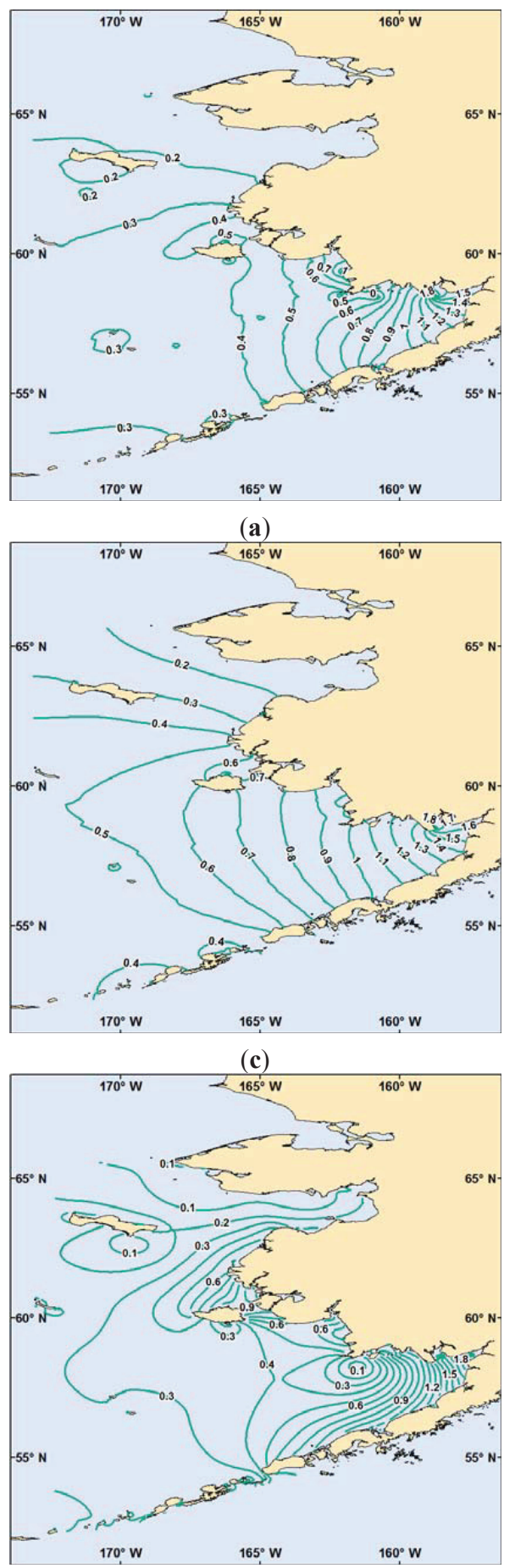

(e)

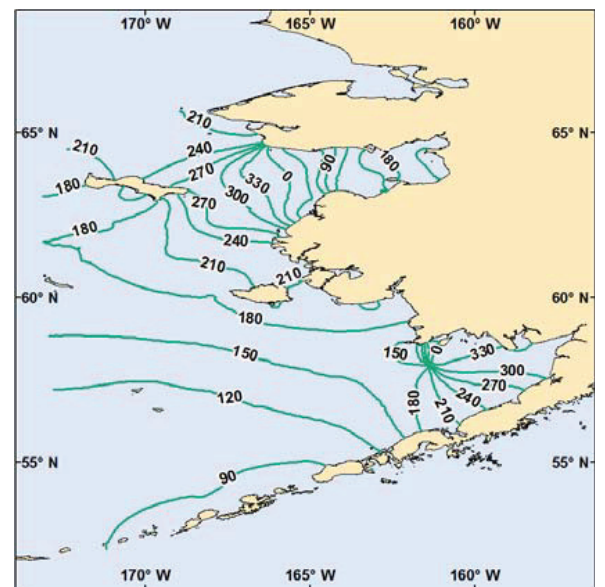

(b)

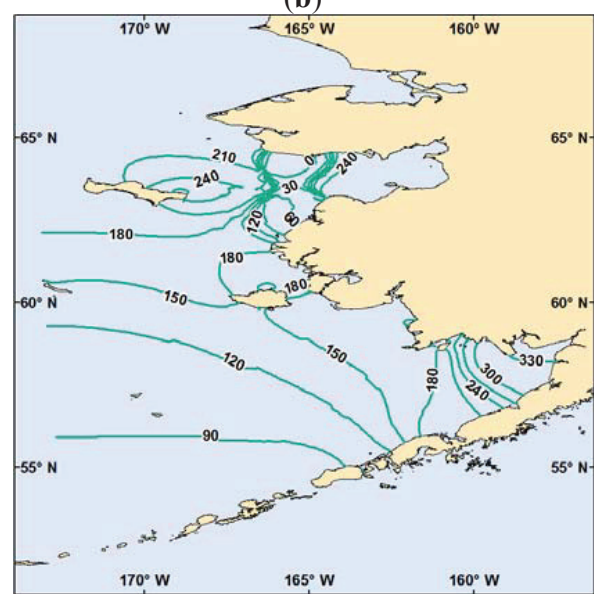

(d)

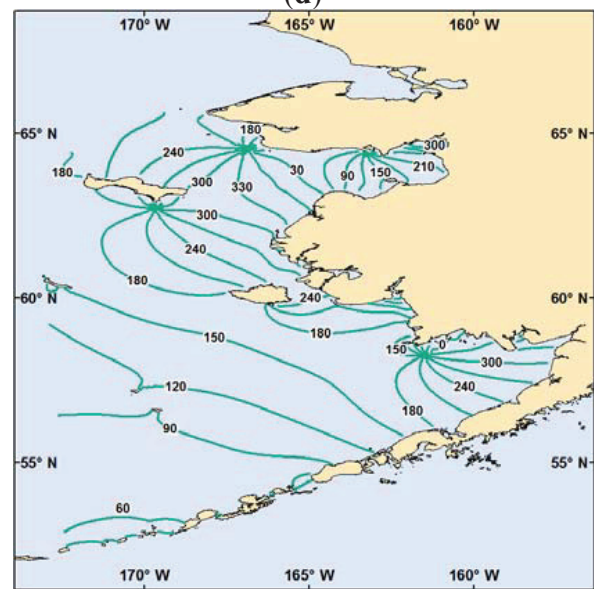

(f) 
Figure 10. $K_{1}$ co-amplitude (left side panels) and co-phase (right side panels) contours from TOF (a,b); TO (c,d); and FM (e,f).
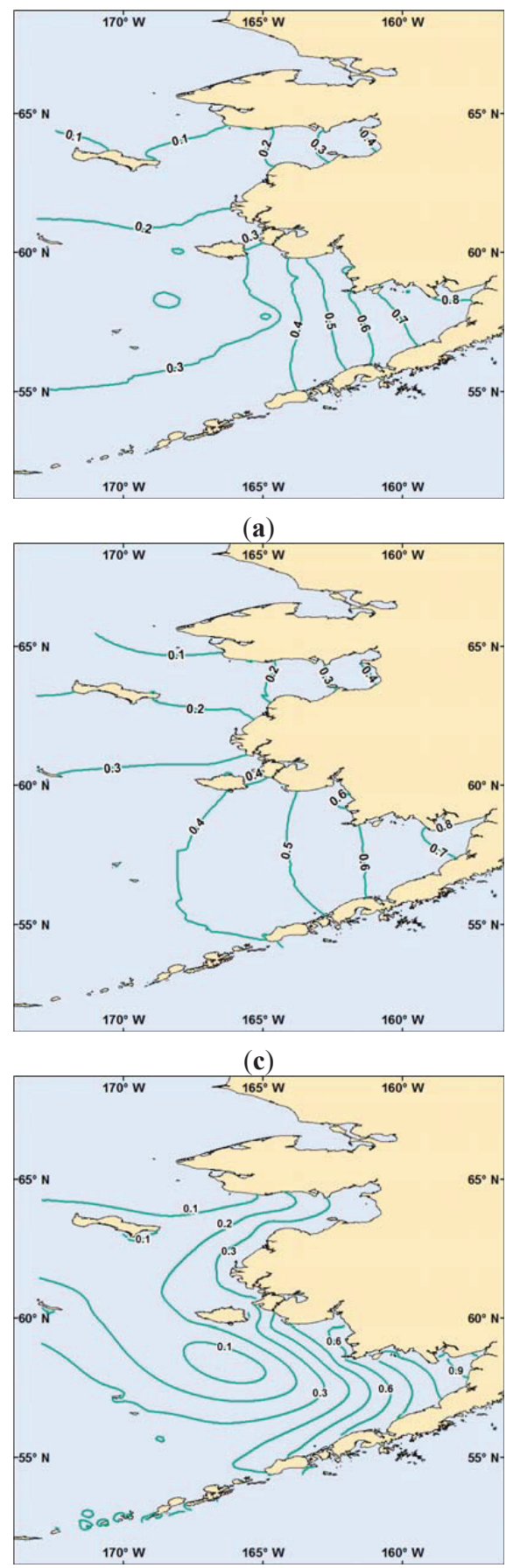

(e)

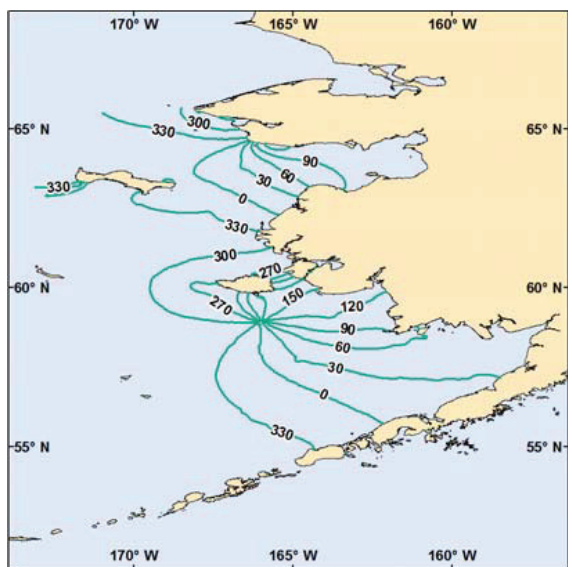

(b)

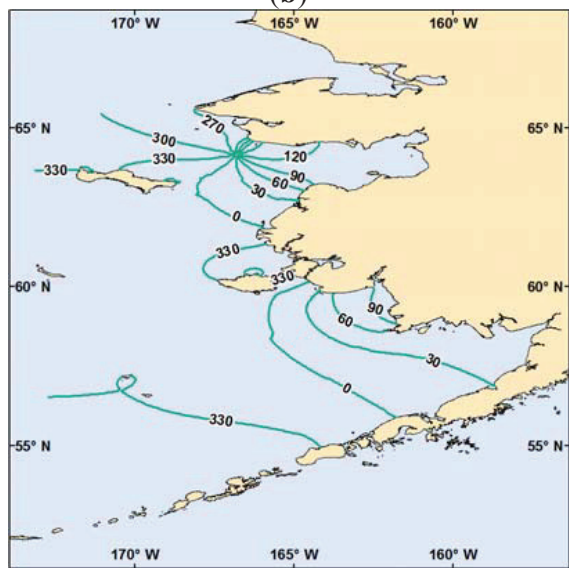

(d)

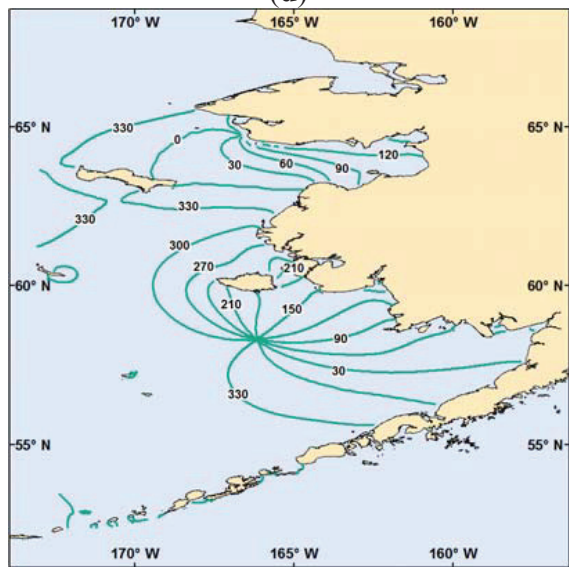

(f) 
From the TO $\mathrm{M}_{2}$ contours (Figure 9c,d), there is no amphidromic point at the northern part of the Bristol Bay entrance. The co-amplitude and co-phase lines in Bristol Bay tend to be perpendicular to the longitudinal axis of the bay, suggesting rectilinear tidal propagation. From the TOF $\mathrm{M}_{2}$ contours (Figure 9a,b), an amphidromic point appears at the north part of the Bristol Bay entrance, which is consistent with the FM M2 contours (Figure 9e,f) and indicates the more realistic presence of rotational tidal propagation. The magnitude of the TOF $\mathrm{M}_{2}$ amplitudes in the bay is also more realistic than the TO $\mathrm{M}_{2}$ amplitudes. In addition, compared to the TO contours, the $\mathrm{M}_{2}$ tide features in Norton Sound become clearer and more realistic in the TOF contours. The offshore $\mathrm{M}_{2}$ patterns have been changed even more significantly in terms of both amplitude and phase, since more model points are involved in the interpolation relative to the nearshore regions.

For the $\mathrm{K}_{1}$ constituent, an amphidromic point to the south of Nunivak Island is only present in the TOF contours (Figure 10a,b). The $\mathrm{K}_{1}$ co-amplitude lines from TOF in Bristol Bay are thus more narrowly spaced than those from TO. In addition, a second $\mathrm{K}_{1}$ amphidromic point at the Norton Sound entrance shown in the TO contours (Figure 10c,d) is moved northward onto the land in the TOF contours. However, the $\mathrm{K}_{1}$ co-amplitude lines are not considerably altered from TO to TOF.

\subsection{Discussion}

Due to the scarce nearshore observations, it is difficult to directly evaluate the FM results and the interpolation results in the nearshore regions of interest to hydrographic surveys. However, there are some historic observed data available at offshore sites from Pearson et al. [29] and Mofjeld [30]. These two studies provide third-source data to be compared with the FM results and the interpolation results. The observed data and the offshore sites in these two studies will be referred to as the literature observations and the literature stations in the next discussion. The location and name of the literature stations are shown in Figure 8b. For each of the literature stations, we extract harmonic constants from the FM results and the interpolation results to be compared with the literature observations. The results for $\mathrm{M}_{2}$ and $\mathrm{K}_{1}$ are listed in Tables 2 and 3, respectively. In these two tables, the station names are the same as listed in the original literature. OBS refers to observed data (stations LD14A, NC17C, NC19C, and LD10A, Table 2) from Mofjeld [30] and observed data (all other stations) from Pearson et al. [29]. The RMSEs relative to OBS have been calculated using Equation (2) in Section 2.2 for FM, TO and TOF individually at each literature station.

Overall, FM has the best performance, since this model has assimilated offshore altimetry data and most of the literature stations are located offshore. TO has the worst performance, suggesting that it is unreliable for capturing complex offshore tidal features by the interpolation of onshore observations only. On the other hand, TOF significantly improves the results relative to TO for almost all literature stations, confirming that TOF is a better option than TO for supporting hydrographic surveys. The only exceptions are the $\mathrm{K}_{1}$ comparisons (Table 3 ) at BC3, BC7, LD4 and LD5, where TOF is slightly worse than TO, indicating that the interpolated $\mathrm{K}_{1}$ values at these stations should be mainly controlled by the onshore observations.

The $\mathrm{M}_{2}$ comparisons at seven stations (BC3, BC13B, BC13D, BC4, FX2, BC9 and BC21) show that TOF has the best performance, indicating that interpolation from combined onshore observations and offshore model outputs is a promising method. However, the $\mathrm{M}_{2}$ comparisons at other stations 
(especially BC11, BC7, BC2, BC15, LD1, NC18, LD2, LD4 and LD5) show that TOF performs worse than FM. This may be due to the inadequate number or the inappropriate distribution of selected model points in the vicinity of these literature stations.

Table 2. Comparisons of $\mathrm{M}_{2}$ amplitude and phase at the literature stations between observed data (OBS), FM, TO and TOF. The acronyms have been described in the text.

\begin{tabular}{|c|c|c|c|c|c|c|c|c|c|c|c|c|c|}
\hline \multirow{2}{*}{ Station } & \multirow{2}{*}{$\begin{array}{c}\text { Latitude } \\
\left({ }^{\circ} \mathbf{N}\right)\end{array}$} & \multirow{2}{*}{$\begin{array}{c}\text { Longitude } \\
\left({ }^{\circ} \mathrm{W}\right)\end{array}$} & \multicolumn{4}{|c|}{ Amplitude (cm) } & \multicolumn{4}{|c|}{ Phase $\left({ }^{\circ}\right)$} & \multicolumn{3}{|c|}{ RMSE (cm) } \\
\hline & & & OBS & FM & TO & TOF & OBS & FM & TO & TOF & FM & TO & TOF \\
\hline $\mathrm{BC} 20$ & 60.43 & 171.08 & 20.5 & 26.4 & 48.7 & 31.0 & 171.0 & 169.9 & 144.8 & 177.0 & 4.1 & 44.3 & 7.7 \\
\hline $\mathrm{BC} 3$ & 55.02 & & 41.9 & 42.7 & 52.0 & 39.8 & 89.0 & 84.5 & 79.3 & 89.5 & 2.4 & 22.3 & 1.5 \\
\hline BC13B & 55.50 & 165.82 & 35.5 & 37.3 & 54.9 & 38.7 & 106.0 & 99.1 & 86.2 & 102.2 & 3.4 & 30.0 & 2.9 \\
\hline BC13D & 55.78 & 165.38 & 39.0 & 41.0 & 59.8 & 40.6 & 109.0 & 109.3 & 91.6 & 108.8 & 1.4 & 33.7 & 1.1 \\
\hline $\mathrm{BC} 10$ & 57.28 & 169.55 & 24.9 & 28.9 & 47.1 & 30.7 & 131.0 & 119.4 & 98.3 & 117.1 & 4.7 & 32.9 & 6.2 \\
\hline $\mathrm{BC} 4$ & 58.62 & 168.23 & 33.4 & 35.7 & 57.7 & 35.1 & 151.0 & 145.0 & 121.3 & 151.8 & 3.0 & 46.4 & 1.2 \\
\hline FX2 & 58.53 & & 33.8 & 35.7 & 58.8 & 35.0 & 158.0 & 145.0 & 121.9 & 151.0 & 5.7 & 47.3 & 3.1 \\
\hline BC9 & 59.22 & 167.70 & 36.7 & 38.1 & 59.8 & 36.1 & 164.0 & 157.3 & 135.8 & 169.9 & 3.3 & 53.0 & 2.7 \\
\hline $\mathrm{BC} 11$ & 59.70 & 167 & 35.9 & 38.3 & 60.8 & 37.0 & 155.0 & 161.1 & 146.2 & 182.5 & 3.2 & 57.0 & 12.3 \\
\hline $\mathrm{BC} 21$ & 60.38 & 169.18 & 30.9 & 36.8 & 51.8 & 35.6 & 189.0 & 186.2 & 152.8 & 185.2 & 4.3 & 51.6 & 3.7 \\
\hline BC7 & 55.70 & 163.02 & 71.4 & 73.2 & 75.1 & 56.5 & 134.0 & 133.0 & 118.6 & 125.9 & 1.5 & 41.5 & 12.3 \\
\hline $\mathrm{BC} 2$ & 57.07 & & 45.2 & 43.6 & 82.5 & 56.1 & 157.0 & 157.9 & 141.0 & 147.3 & 1.2 & 69.3 & 9.7 \\
\hline $\mathrm{BC} 15$ & 57.65 & 162.70 & 36.2 & 33.7 & 90.9 & 58.2 & 168.0 & 170.9 & 156.5 & 157 & 2.2 & 80.3 & 16.8 \\
\hline LD1 & 62.50 & 166.12 & 46.1 & 44.2 & 30.3 & 22.9 & 328.0 & 325.0 & 76.3 & 327.0 & 2.2 & 17.7 & 16.4 \\
\hline $\mathrm{NC} 17$ & 62.88 & 167.08 & 25.6 & 25.8 & 29.7 & 21.7 & 330.0 & 322.7 & 200.2 & 298.8 & 2.3 & 39.1 & 9.4 \\
\hline $\mathrm{NC} 18$ & 63.15 & 168.38 & 22.4 & 20.2 & 30.4 & 21.1 & 324.0 & 314.9 & 246.7 & 272.3 & 2.8 & 34.7 & 13.5 \\
\hline LD2 & 63.22 & 168.58 & 26.6 & 22.0 & 30.2 & 21.5 & 319.0 & 313.4 & 253.9 & 271.0 & 3.6 & 36.8 & 14.2 \\
\hline LD4 & 64.78 & 166.83 & 4.9 & 3.8 & 16.9 & 12.9 & 138.0 & 162.7 & 191.8 & 219.4 & 1.5 & 15.4 & 9.2 \\
\hline $\begin{array}{c}\text { GEO } \\
\text { PROBE }\end{array}$ & 64.00 & 165.50 & 13.0 & 11.4 & 18.4 & 14.4 & 44.0 & 32.5 & 35.4 & 15.6 & 2.1 & 5.7 & 4.8 \\
\hline LD5 & 64.13 & 163.00 & 2.0 & 5.6 & 17.9 & 15.9 & 233.0 & 162.0 & 230.3 & 168.4 & 3.7 & 13.7 & 10.7 \\
\hline LD14A & 60.57 & 170.60 & 21.9 & 27.8 & 48.8 & 31.3 & 180.0 & 177.0 & 149.0 & 181.1 & 4.3 & 45.5 & 6.6 \\
\hline $\mathrm{NC} 17 \mathrm{C}$ & 62.88 & 167.07 & 25.5 & 25.9 & 29.6 & 21.7 & 336.0 & 323.0 & 198.4 & 299.1 & 4.1 & 38.9 & 10.9 \\
\hline $\mathrm{NC} 19 \mathrm{C}$ & 64.00 & 172.33 & 23.5 & 25.2 & 28.5 & 20.3 & 172.0 & 181.9 & 201.7 & 200.4 & 3.2 & 36.8 & 7.9 \\
\hline LD10A & 65.58 & 168.63 & 7.6 & 9.8 & 16.0 & 11.3 & 202.0 & 211.7 & 199.8 & 208.3 & 1.8 & 16.6 & 2.7 \\
\hline Average & & & & & & & & & & & 3.0 & 37.9 & 7.8 \\
\hline
\end{tabular}

The experiments presented here are the initial step for integrating tide models and observations to better support hydrographic surveys. We are working on more sensitivity tests to determine the optimal number and locations of the model points that should be included in TCARI interpolation for further improvement. Further tests of the method may also help to determine where the new tide gauges should be installed to improve the regional interpolated tidal fields. The corresponding analysis and results will be reported in future work.

To further facilitate hydrographic survey planning, a series of tidal parameters, such as MN and HWI, are derived from the TOF amplitudes and phases of six tidal constituents using Form 180 [31]. Form 180 is an NOS CO-OPS's standard procedure for estimating tidal parameters, including tidal datums, tidal ranges and tidal time intervals from tidal harmonic constants. In general, as shown in 
Figure 11, the patterns of MN and HWI are similar to the $\mathrm{M}_{2}$ amplitude and phase (Figure 9a,b), respectively, in semidiurnal tide dominated areas. $\mathrm{MN}$ has near zero values in the vicinity of the $\mathrm{M}$ amphidromic points and to the south of some islands. HWI, mainly representing the $\mathrm{M}_{2}$ phase, shows rotational tidal propagation at the Bristol Bay entrance and rectilinear tidal propagation within Norton Sound.

Table 3. Comparisons of $\mathrm{K} 1$ amplitude and phase at the literature stations between OBS,

FM, TO and TOF. The acronyms have been described in the text.

\begin{tabular}{|c|c|c|c|c|c|c|c|c|c|c|c|c|c|}
\hline \multirow{2}{*}{ Station } & \multirow{2}{*}{$\begin{array}{c}\text { Latitude } \\
\left({ }^{\circ} \mathbf{N}\right)\end{array}$} & \multirow{2}{*}{$\begin{array}{c}\text { Longitude } \\
\left({ }^{\circ} \mathbf{W}\right)\end{array}$} & \multicolumn{4}{|c|}{ Amplitude (cm) } & \multicolumn{4}{|c|}{ Phase $\left(^{\circ}\right)$} & \multicolumn{3}{|c|}{ RMSE (cm) } \\
\hline & & & OBS & FM & TO & TOF & OBS & FM & TO & TOF & FM & TO & TOF \\
\hline $\mathrm{BC} 20$ & 60.43 & 171.08 & 18.1 & 19.7 & 30.5 & 21.5 & 326.0 & 322.8 & 337.6 & 315.6 & 1.4 & 9.4 & 3.5 \\
\hline $\mathrm{BC} 3$ & 55.02 & 165.17 & 40.9 & 42.2 & 42.8 & 36.5 & 319.0 & 315.6 & 322.3 & 323.7 & 2.0 & 2.2 & 3.8 \\
\hline $\mathrm{BC} 13 \mathrm{~B}$ & 55.50 & 165.82 & 34.4 & 36.9 & 43.0 & 34.2 & 325.0 & 323.7 & 329.3 & 328.6 & 1.9 & 6.4 & 1.5 \\
\hline $\mathrm{BC} 13 \mathrm{D}$ & 55.78 & 165.38 & 33.4 & 35.9 & 44.6 & 34.6 & 327.0 & 327.9 & 334.0 & 333.0 & 1.8 & 8.6 & 2.7 \\
\hline $\mathrm{BC} 10$ & 57.28 & 169.55 & 24.9 & 26.9 & 36.7 & 25.8 & 333.0 & 327.8 & 332.8 & 322.3 & 2.2 & 8.4 & 3.4 \\
\hline $\mathrm{BC} 4$ & 58.62 & 168.23 & 12.4 & 12.4 & 38.1 & 20.8 & 303.0 & 301.1 & 339.7 & 310.4 & 0.3 & 20.6 & 6.1 \\
\hline $\mathrm{FX} 2$ & 58.53 & 167.93 & 8.9 & 11.0 & 38.8 & 21.3 & 288.0 & 299.7 & 340.9 & 313.1 & 2.1 & 24.2 & 9.7 \\
\hline $\mathrm{BC} 9$ & & & 9.7 & 10.8 & 37.9 & 22.7 & & 255.1 & 342.9 & & 0.9 & 27.1 & 10.9 \\
\hline BC11 & 59.70 & 167. & 18.3 & 18.0 & 37.3 & 22.5 & 207.0 & 219.2 & 343.1 & 263.9 & 2.7 & 36.8 & 14.0 \\
\hline $\mathrm{BC} 21$ & 6 & & 16.6 & 18.2 & 31.4 & 20.5 & & 296.6 & 336.7 & 298.5 & 1.1 & 15.2 & 2.8 \\
\hline $\mathrm{BC} 7$ & 55.70 & 163.02 & 49.0 & 51.8 & 50.8 & 44.0 & 335.0 & 331.7 & 348.4 & 352.2 & 2.9 & 8.3 & 10.4 \\
\hline $\mathrm{BC} 2$ & 57.07 & & 28.3 & 27.9 & 52.4 & 43.1 & 13.0 & 13.7 & 3.9 & 19.0 & 0.3 & 17.6 & 10.8 \\
\hline $\mathrm{BC} 15$ & 57.65 & 162.70 & 29.9 & 31.5 & 55.5 & 49.5 & 48.0 & 49.0 & 20.6 & 43.7 & 1.2 & 22.7 & 14.0 \\
\hline LD1 & 62.50 & 166.12 & 31.7 & 30.9 & 20.6 & 17.9 & 324.0 & 333.6 & 16.6 & 356.5 & 3.8 & 17.8 & 13.6 \\
\hline $\mathrm{NC} 17$ & 62.88 & 167.08 & 19.0 & 19.2 & 19.4 & 16.2 & 341.0 & 347.9 & 10.6 & 353.1 & 1.6 & 6.9 & 3.3 \\
\hline $\mathrm{NC} 18$ & 63.15 & 168.38 & 8.9 & 11.7 & 17.3 & 13.6 & 356.0 & 358.6 & 358.8 & 349.5 & 2.0 & 6.0 & 3.4 \\
\hline LD2 & 63.22 & & 8.1 & 10.9 & 16.6 & 13.0 & 359.0 & 4.5 & 358.7 & 350.5 & 2.1 & 6.0 & 3.6 \\
\hline LD4 & 64.78 & 166.83 & 4.2 & 0.9 & 9.9 & 7.9 & 222.0 & 7.4 & 264.4 & 320.1 & 3.5 & 5.2 & 6.7 \\
\hline $\begin{array}{c}\text { GEO } \\
\text { PROBE }\end{array}$ & 64.00 & 165.50 & 14.0 & 13.3 & 16.7 & 16.0 & 71.0 & 63.4 & 118.4 & 74.6 & 1.4 & 8.9 & 1.6 \\
\hline LD5 & 64.13 & & 32.1 & 26.6 & 28.8 & 30.2 & 110.0 & 119.2 & 112.1 & 98.5 & 5.1 & 2.4 & 4.6 \\
\hline LD14A & 60.57 & 170.60 & 17.2 & 18.9 & 30.2 & 20.8 & 322.0 & 318.2 & 337.8 & 312.7 & 1.5 & 10.2 & 3.4 \\
\hline $\mathrm{NC} 17 \mathrm{C}$ & 62.88 & 167.07 & 18.5 & 19.3 & 19.4 & 16.2 & 346.0 & 348.0 & 10.8 & 353.3 & 0.7 & 5.8 & 2.2 \\
\hline $\mathrm{NC} 19 \mathrm{C}$ & 64.00 & 172.33 & 9.9 & 11.4 & 14.3 & 10.9 & 328.0 & 329.7 & 326.9 & 334.5 & 1.1 & 3.1 & 1.1 \\
\hline LD10A & 65.58 & 168.63 & 2.7 & 3.3 & 6.6 & 4.5 & 359.0 & 322.6 & 276.1 & 304.3 & 1.4 & 4.8 & 2.6 \\
\hline Average & & & & & & & & & & & 1.9 & 11.9 & 5.8 \\
\hline
\end{tabular}

The traditional co-tidal lines for hydrographic survey planning and the real-time water level time series for hydrographic surveys in an area of interest are developed mainly based on the interpolated fields of tidal harmonics and tidal parameters from coastal observations. This work could be potentially improved if the tidal constituents and tidal parameters are estimated in a more realistic way by adding offshore tide model results, especially in tidally complex areas. The methodology proposed in this study will be further tested for regions with more onshore observations and better understood co-tidal line patterns, such as in Chesapeake Bay and San Francisco Bay. 
Figure 11. (a) The mean tidal range (MN) and (b) the high water interval (HWI) derived from TOF harmonic constants.

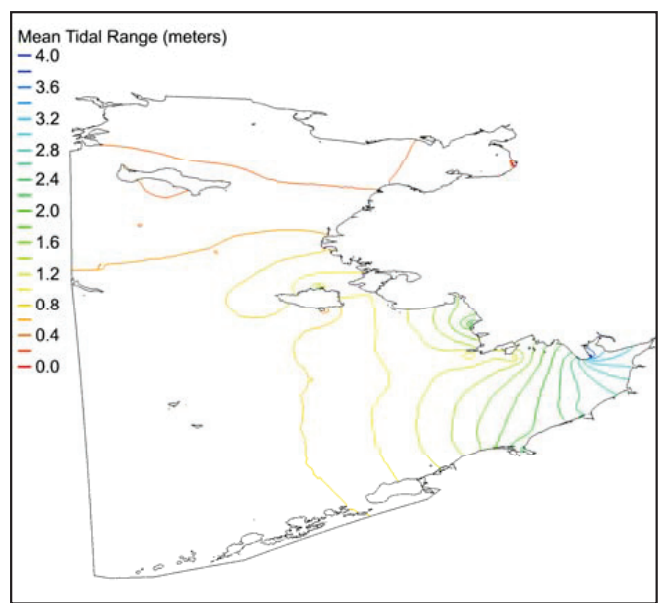

(a)

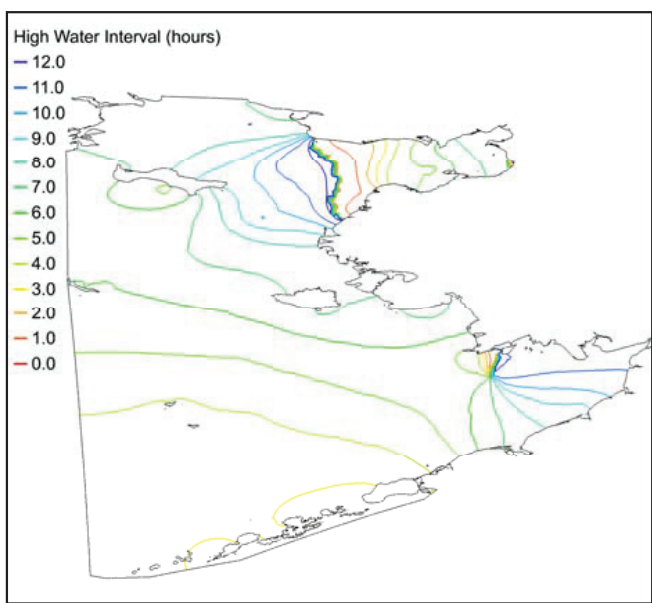

(b)

\section{Summary and Future Work}

NOAA's VDatum program has a national tidal model development effort to systematically calculate spatially varying tidal datums. These high resolution tidal models [13] were developed using a finite element hydrodynamic model, ADCIRC, to simulate the tidal propagation in estuaries and coastal environments. The latest tidal modelling development effort in SE Alaska has approximately 2 million nodes with a minimum resolution of $50 \mathrm{~m}$ near the coast. The model is able to reach all 43 CO-OPS current and historical tidal stations in the modelling domain (Figure 1) for model validation. The SE Alaska tide model presented here has shown that tidal propagation characteristics are well represented with the ADCIRC model applied to the grid developed for this region. Of all 9 tide constituents $\left(\mathrm{M}_{2}, \mathrm{~S}_{2}, \mathrm{~N}_{2}, \mathrm{~K}_{2}, \mathrm{~K}_{1}, \mathrm{O}_{1}, \mathrm{P}_{1}, \mathrm{Q}_{1}\right.$, and $\left.\mathrm{M}_{4}\right)$ used for model validation, three semidiurnal tides $\left(\mathrm{M}_{2}, \mathrm{~S}_{2}\right.$ and $\left.\mathrm{N}_{2}\right)$ and four diurnal tides $\left(\mathrm{K}_{1}, \mathrm{O}_{1}, \mathrm{P}_{1}\right.$ and $\left.\mathrm{Q}_{1}\right)$ have a relative error below $10 \%$. The $\mathrm{K}_{2}$ tide has a higher relative RMSE of $16.4 \%$, and the $\mathrm{M}_{4}$ tide has a relative RMSE of $54.4 \%$. The total mean RMSE (Table 1) for all 43 stations is $28.7 \mathrm{~cm}$. A few model sensitivity tests have been conducted to test the model sensitivity to different bottom friction coefficients and to different prescribed boundary conditions. Further adjustments to this SE Alaska model will be focused on addressing the primary issues for model improvement, namely: (1) the general overestimation of amplitudes and the underestimation of phases; (2) local issues with accuracy due to local grid resolution and/or the lack of bathymetry; and (3) model stability in areas experiencing wetting/drying and associated development of landlocked wet cells in the grid. Overall, this model grid is quite advanced in that it has a significant amount of resolution to represent the numerous complex waterways throughout the Alexander Archipelago and associated coastal features. This grid and the model results will be invaluable in future VDatum representation of both regional and localized spatial variations in tidal datums. 
While the primary output from the tidal models for VDatum has traditionally been used for computing tidal datums, new uses of modeled information should be more thoroughly evaluated. One such identified new use is to provide hydrographic survey planning with offshore tidal harmonic constants that can be integrated with tidal harmonic constants derived from observations in the TCARI interpolation. The western Alaska work presented here demonstrated a clear improvement of integrated offshore tidal harmonic constants over interpolated values based solely on tidal gauge data. The co-amplitude and co-phase contours of the $\mathrm{M}_{2}$ and $\mathrm{K}_{1}$ harmonic constituents are much more consistent with the contour output from FM by integrating modeled harmonic constants (Figures 9 and 10). The RMSE between the interpolated values and offshore observed values were improved from $37.9 \mathrm{~cm}$ to $7.8 \mathrm{~cm}$ for the $\mathrm{M}_{2}$ constituent and from $11.9 \mathrm{~cm}$ to $5.7 \mathrm{~cm}$ for $\mathrm{K} 1$ constituent by integrating modeled harmonic constants (Tables 2 and 3). Further work will continue on sensitivity tests to determine the best approaches for selecting model points to use in this process, including the total number of points and their proximal location to amphidromes. The methodology will also be further examined using different tidal models, as well as new interpolation techniques, such as that developed by Shi et al. [32]. These tests will continue for the western Alaska domain, as well as for the VDatum tide models previously developed for other regions. The SE Alaska tide model will be used similarly as input to the process of updating contours of tidal information for hydrographic survey planning purposes.

\section{Acknowledgments}

We would like to extend our gratitude to Mike Foreman for making his tide model results available to help in the effort of assessing the impact of model results on improving the hydrographic planning process in the Bering Sea. Many thanks are given as well to the CO-OPS Hydrographic Planning Team for their collaboration on this effort in western Alaska. The Cartographic and Geospatial Technology Programs branch (in particular, Cuong Hoang and Kurt Nelson) of NOAA's Coast Survey Development Laboratory (CSDL) and NOAA's National Geophysical Data Center provided the bathymetry and DEMs needed for the ADCIRC grid in southeast Alaska. Doug Graham of NOAA's National Geodetic Survey assembled the shoreline used in the development of this grid. We also thank Barry Gallagher of CSDL for providing assistance with the use of the TCARI program for the interpolation of tidal variables in western Alaska. We also would like to thank the anonymous reviewers, whose comments helped improve this manuscript.

\section{Conflicts of Interest}

The authors declare no conflict of interest.

\section{References}

1. Parker, B.B.; Hess, K.W.; Milbert, D.G.; Gill, S. A national vertical datum transformation tool. Sea Technol. 2003, 44, 10-15.

2. Vertical datum transformation. Available online: http://vdatum.noaa.gov/docs/standard procedures.html (accessed on 18 Febuary 2014). 
3. Luettich, R.A., Jr.; Westerink, J.J.; Scheffner, N.W. ADCIRC: An Advanced Three-Dimensional Circulation Model for Shelves Coasts and Estuaries, Report 1: Theory and Methodology of ADCIRC-2DDI and ADCIRC-3DL; Dredging Research Program Technical Report DRP-92-6; U.S. Army Engineers Waterways Experiment Station: Vicksburg, MS, USA, 1992; p. 137.

4. Westerink, J.J.; Blain, C.A.; Luettich, R.A., Jr.; Scheffner, N.W. ADCIRC: An Advanced Three-Dimensional Circulation Model for Shelves Coasts and Estuaries, Report 2: Users Manual for ADCIRC-2DDI; Dredging Research Program Technical Report DRP-92-6; U.S. Army Engineers Waterways Experiment Station: Vicksburg, MS, USA, 1994; p. 156.

5. Foreman, M.G.G.; Crawford, W.R.; Cherniawsky, J.Y.; Henry, R.F.; Tarbotton, M.R. A high-resolution assimilating tidal model for the northeast Pacific Ocean. J. Geophys. Res. 2000, 105, 28629-28651.

6. Myers, E.P.; Baptista, A.M. Inversion for tides in the Eastern North Pacific Ocean. Adv. Water Resour. 2001, 24, 505-519.

7. Spargo, E.A.; Westerink, J.J.; Luettich, R.A.; Mark, D.J. ENPAC 2003: A Tidal Constituent Database for the Eastern North Pacific Ocean; Department of the Army Technical Note TR-0412; U.S. Army Corps of Engineers: Washington, DC, USA, 2004.

8. Hill, D.F.; Ciavola, S.J.; Etherington, L.; Klaar, M.J. Estimation of freshwater runoff into Glacier Bay, Alaska and incorporation into a tidal circulation model. Estuar. Coast. Shelf Sci. 2009, 82, 95-107.

9. Inazu, D.; Sato, T.; Miura, S.; Ohta, Y.; Nakamura, K. Accurate ocean tide modeling in southeast Alaska and large tidal dissipation around Glacier Bay. J. Oceanogr. 2009, 65, 335-347.

10. Egbert, G.D.; Bennett, A.F.; Foreman, M.G.G. TOPEX/POSEIDON tides estimated using a global inverse model. J. Geophys. Res. 1994, 99, 24821-24852.

11. Egbert, G.D.; Erofeeva, S.Y. Efficient inverse modeling of barotropic ocean tides. J. Atmos. Oceanic Technol. 2002, 19, 183-204.

12. Carrère, L.; Lyard, F.; Cancet, M.; Guillot, A.; Roblou, L. FES2012: A New Global Tidal Model Taking Advantage of Nearly 20 Years of Altimetry. In Proceedings of the Meeting 20 Years of Altimetry, Venice, Italy, 24-29 September 2012.

13. Myers, E.P.; Yang, Z.; Xu, J.; Hess, K.W.; Dhingra, E. Tide Modeling in Support of NOAA's National VDatum Program. In Estuarine and Coastal Modeling, Proceedings of 11th International Conference on Estuarine and Coastal Modeling, Seattle, WA, USA, 4-6 November 2009; Spaulding, M.L., Ed.; American Society of Civil Engineers: Reston, VA, USA, 2010; pp. 514-526.

14. Liu, S.K.; Leendertse, J.J. Three-dimensional model of bering and chukchi sea. Coast. Eng. 1982, 18, 598-616.

15. Kowalik, Z. Bering Sea Tides. In Dynamics of the Bering Sea; Loughlin, T.R., Ohtani, K., Eds.; University of Alaska Sea Grant: Fairbanks, AK, USA, 1999; pp. 93-127.

16. Foreman, M.G.G.; Cummins, P.F.; Cherniawsky, J.Y.; Stabeno, P. Tidal energy in the Bering Sea. J. Mar. Res. 2006, 64, 797-818.

17. OSU tidal data inversion. Available online: http://volkov.oce.orst.edu/tides (accessed on 18 Febuary 2014). 
18. NOAA NGDC. Integrated Models of Coastal Relief. Available online: http://www.ngdc.noaa. gov/mgg/coastal/coastal.html (accessed on 18 Febuary 2014).

19. Amante, C.; Eakins, B.W. ETOPO1 1 Arc-Minute Global Relief Model: Procedures, Data Sources and Analysis; National Geophysical Data Center Marine Geology and Geophysics Division: Boulder, CO, USA, 2009; p. 19.

20. Caldwell, R.J.; Eakins, B.W.; Taylor, L.A.; Carigna, K.S.; Collins, S. Digital Elevation Models of Southeast Alaska: Procedures, Data Sources and Analysis; National Geophysical Data Center Marine Geology and Geophysics Division: Boulder, CO, USA, 2010; p. 67.

21. ADCIRC Related Publications. Available online: http://adcirc.org/home/documentation/ adcirc-related-publications (accessed on 18 Febuary 2014).

22. NOAA/NOS/CO-OPS-ODIN MAP. Available online: http://tidesandcurrents.noaa. gov/gmap3/index.shtml?type=TidePredictions\&region= (accessed on 18 Febuary 2014).

23. Lefèvre, F.; le Provost, C.; Lyard, F.H. How can we improve a global ocean tide model at a regional scale? A test on the Yellow Sea and the East China Sea. J. Geophys. Res. 2000, 105, 8707-8726.

24. Foreman, M.G.G.; Henry, R.F.; Walters, R.A.; Ballantyne, V.A. A finite element model for tides and resonance along the north coast of British Columbia. J. Geophys. Res. 1993, 98, 2509-2531.

25. Egbert, G.D.; Ray, R.D. Semi-diurnal and diurnal tidal dissipation from Topex/Poseidon altimetry. Geophys. Res. Lett. 2003, 30, 1907.

26. Hess, K.W. Spatial interpolation of tidal data in irregularly-shaped coastal regions by numerical solution of Laplace's equation. Estuar. Coast. Shelf Sci. 2002, 54, 175-192.

27. Hess, K.W. Water level simulation in bays by spatial interpolation of tidal constituents, residual water levels, and datums. Cont. Shelf Res. 2003, 23, 395-414.

28. Lindley, C.; Urizar, C.; Wolcott, D.; Yang, H.; Huang, L. Vertical Control and Tide Reducers in Tidal to Non-Tidal Transitional Areas. In Proceedings of the U.S. Hydro2013 Conference, The Hydrographic Society of America, New Orleans, LA, USA, 25-28 March 2013.

29. Pearson, C.A.; Mofjeld, H.O.; Tripp, R.B. Tides of the Eastern Bering Sea Shelf. In The Eastern Bering Sea Shelf: Oceanography and Resources; Hood, D.W., Calder, J.A., Eds.; University of Washington Press: Seattle, WA, USA, 1981; pp. 111-130.

30. Mofjeld, H.O. Observed Tides on the Northeastern Bering Sea Shelf. J. Geophys. Res. 1986, 91, 2593-2606.

31. C\&GS. Manual of Harmonic Constant Reductions; U.S. Government Printing Office: Washington, DC, USA, 1952; p. 74.

32. Shi, L.; Hess, K.W.; Myers, E.P. Spatial interpolation of tidal data using a multiple-order harmonic equation for unstructured grids. Int. J. Geosci. 2013, 10, 1425-1437. 


\section{Advances in a Distributed Approach for Ocean Model Data Interoperability}

\section{Richard P. Signell and Derrick P. Snowden}

Abstract: An infrastructure for earth science data is emerging across the globe based on common data models and web services. As we evolve from custom file formats and web sites to standardsbased web services and tools, data is becoming easier to distribute, find and retrieve, leaving more time for science. We describe recent advances that make it easier for ocean model providers to share their data, and for users to search, access, analyze and visualize ocean data using MATLAB ${ }^{\circledR}$ and Python ${ }^{\circledR}$. These include a technique for modelers to create aggregated, Climate and Forecast (CF) metadata convention datasets from collections of non-standard Network Common Data Form (NetCDF) output files, the capability to remotely access data from CF-1.6-compliant NetCDF files using the Open Geospatial Consortium (OGC) Sensor Observation Service (SOS), a metadata standard for unstructured grid model output (UGRID), and tools that utilize both CF and UGRID standards to allow interoperable data search, browse and access. We use examples from the U.S. Integrated Ocean Observing System $\left(\operatorname{IOOS}^{\circledR}\right)$ Coastal and Ocean Modeling Testbed, a project in which modelers using both structured and unstructured grid model output needed to share their results, to compare their results with other models, and to compare models with observed data. The same techniques used here for ocean modeling output can be applied to atmospheric and climate model output, remote sensing data, digital terrain and bathymetric data.

Reprinted from J. Mar. Sci. Eng. Cite as: Signell, R.P.; Snowden, D.P. Advances in a Distributed Approach for Ocean Model Data Interoperability. J. Mar. Sci. Eng. 2014, 2, 194-208.

\section{Introduction}

Ocean modelers typically require many different types of input data for forcing, assimilation and boundary conditions, and routinely produce GB or larger amounts of output data. Depending on which model is used, the horizontal coordinate of the output data may be on a regular, curvilinear, or unstructured (e.g., triangular) grid, while the vertical coordinate may be on a uniform or stretched grid with a number of different possibilities (e.g., sigma, sigma-over-z, s-coordinate, isopycnal). Ocean modelers therefore often spend large amounts of time on mundane data manipulation tasks such as searching and reformatting data from external sources, writing custom readers for specific models so that results between models can be compared and assessed, as well as responding to custom data requests from consumers of their model products. Better tools reduce time spent on these mundane data manipulation tasks, thereby increasing time spent on modeling and analysis work.

The U.S. Integrated Ocean Observing System (U.S. IOOS ${ }^{\circledR}$ ) has been working on better tools to support not only its member organizations, but the entire ocean science community. U.S. IOOS (hereafter referred to simply as IOOS), is a collaboration between Federal, State, Local, Academic and Commercial partners to manage ocean observing and modeling systems to meet the unique 
needs of each region around the US [1-3]. Federal partners provide the "National Backbone", and 11 IOOS Regional Associations (RAs) build upon the backbone with local assets to create observational and modeling systems designed to be more than the sum of the parts, capable of responding to the societal needs of each individual region (e.g., harmful algal blooms, eutrophication, search and rescue, oil spills, navigation, mariculture) (Figure 1).

Figure 1. The 11 United States Integrated Ocean Observing System (U.S. IOOS) Regional Associations, reproduced with permission from (C) 2011 Dynamic Network Services - DynDNS.com Internet Guide.

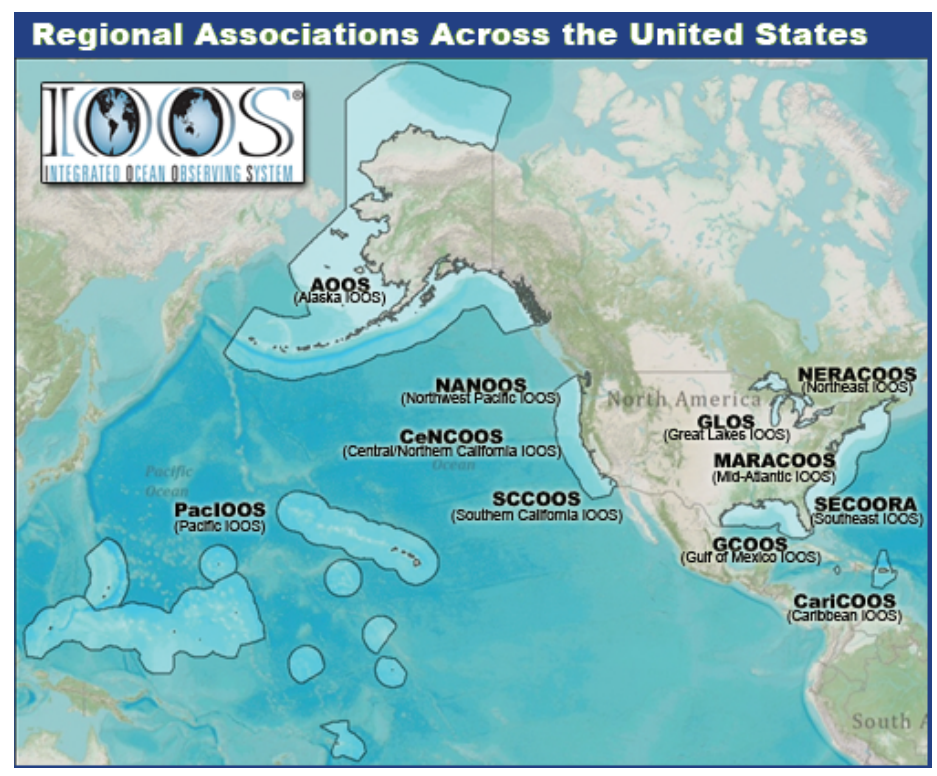

In 2008, IOOS held a community modeling workshop attended by 57 members spanning federal, research and private sectors, including modelers and stakeholders, and the workshop produced a report with nine specific recommendations to advance the state of ocean modeling in the US [4]. One of recommendations was to "develop an implementation plan for a distributed, one-stop shopping national data portal and archive system for ocean prediction input and output data". The US Geological Survey (USGS) had been working on model data interoperability for their collaborative projects on sediment transport modeling [5-7] and in 2009 agreed to send one of their modelers to the U.S. IOOS Program Office, within the National Ocean and Atmospheric Administration (NOAA), for a one year detail to lead the effort.

The one year project to develop model data interoperability for IOOS was remarkably successful. Leveraging technologies developed for the atmospheric community, a model data delivery and access system was implemented in all 11 IOOS RAs and at many of the National Backbone modeling centers [8]. The approach used mostly technologies that had grown from the community and emerged as community practices $[9,10]$. The system design allowed modelers to serve their data in a standardized manner via IOOS-approved web services without modifying their original data files or their models. Users were then able to access these standardized data streams 
using a variety of tools, from simple map-based browsing, to more sophisticated 3D visualization, to full scientific exploration on their desktop computers. With this success, future work to build on this infrastructure was recommended, including improved techniques for searching datasets, better support for unstructured grids and observational data, server-side subsetting for unstructured grids, more tools for common analysis tasks, and tools for scientific analysis and visualization environments in addition to Matlab.

Figure 2. (left) The structured (curvilinear orthogonal) grid SLOSH model. (right) The unstructured (triangular) grid ADCIRC model.
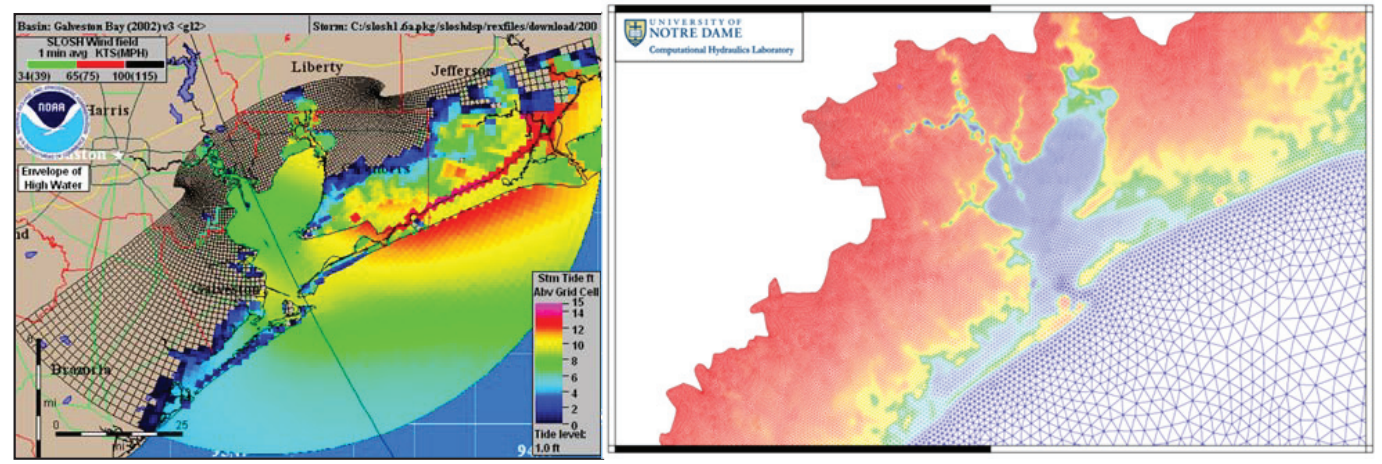

In 2010, IOOS funded a Coastal and Ocean Modeling Testbed (COMT), with the goal of accelerating improvement in ocean forecasting through targeted model assessment and comparison projects. The initial COMT focused on Estuarine Hypoxia, Shelf Hypoxia and Inundation [11,12], and prioritized assessment of model data output from both curvilinear orthogonal grid models (SLOSH, ROMS, NCOM and HyCOM) and unstructured triangular grid models (ADCIRC, FVCOM and SELFE) (Figure 2). The COMT Cyberinfrastructure team was charged with developing and implementing technologies to meet these needs.

Here we report on significant improvements of the IOOS infrastructure relevant to ocean modelers or users of ocean model products since the system described in [8]. Many of these were developed in the COMT and other IOOS activities, while other components were developed external to IOOS in the international geoscience community. These include new standards for unstructured grid model output and for observational data (e.g., time series, profiles, trajectories), new services and access tools for consuming these standardized data, more analysis tools for Matlab users, and new tools for Python users. These tools and techniques are not specific to IOOS, and should be of interest to anyone interested in more efficient distribution or access to ocean modeling and observational data. 
Figure 3. Schematic of the IOOS Coastal and Ocean Modeling Testbed (COMT) model data interoperability design. Non-standard model output and data files are converted into standardized and aggregated virtual datasets using the NetCDF Markup Language (NcML), a lightweight XML layer. A custom NcML template is developed for each type of model output (e.g., collections of SELFE files). Once the data has been standardized to Common Data Model feature types (by the use of CF-1.6 and UGRID-0.9 conventions), it can be distributed uniformly by appropriate services and consumed by standards-based clients, providing data interoperability for the user.

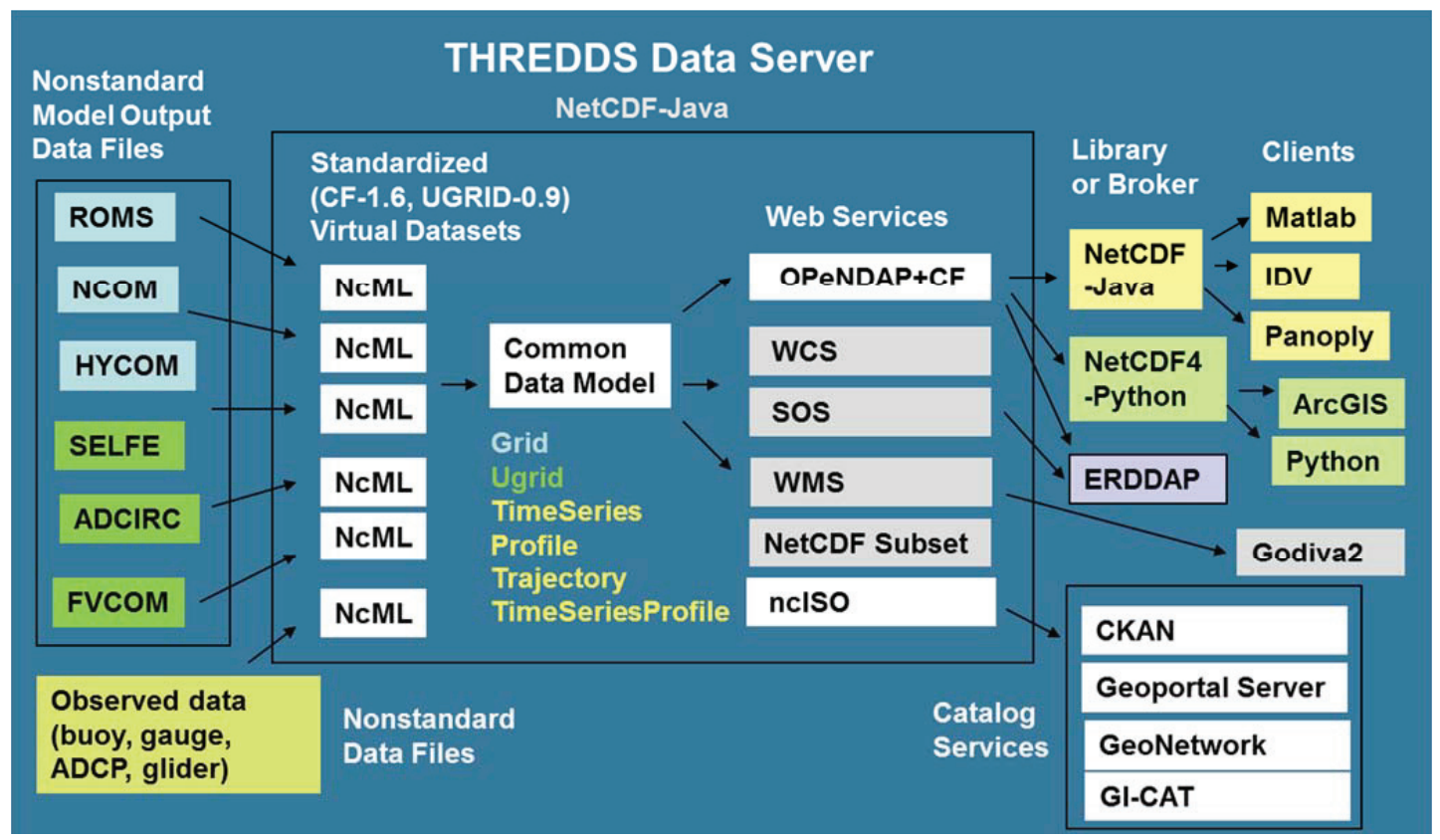

\section{Methods}

\subsection{IOOS COMT Model Data Interoperability Design}

The IOOS COMT model data interoperability design used the same basic core strategy described in [8]: Convert collections of non-standard data files to a common data model using a light-weight Extended Markup Language (XML) layer, which then allows distribution of datasets uniformly via standard services, which can be consumed by standards-based clients (applications) (Figure 3). At the heart of the system is the Unidata Thematic Realtime Environmental Distributed Data Services (THREDDS) Data Server, which is built on the Unidata NetCDF-Java library. The NetCDF-Java library is capable of reading NetCDF, HDF5, GRIB and GRIB2 data files into a common data model, which allows a uniform representation of the data regardless of input format. In addition, it can read NetCDF Markup Language (NcML) files, simple XML files that allow the provider to define aggregations of binary files as well as provide or modify metadata. Thus collections of non-standard convention binary files can be turned into aggregated, standardized 
datasets without modification of the original files. This is a powerful feature that places minimal impact on the providers. They can continue to use their existing data files with their existing software while exploring the benefits of standardized tools. The new features of this system since [8] are described individually below.

\subsection{Advances in Model Data Standards, Tools and Techniques}

\subsubsection{The ncSOS Service for Observational Data}

The CF Conventions and the Unidata Common Data Model were originally developed only for 2D, 3D, and 4D gridded data (featureType:Grid) with two spatial dimensions (e.g., longitude, latitude), and time and/or depth dimensions. The success of this approach motivated the extension of this approach to observational data. In version 1.6 of the CF Conventions, metadata were defined to support observational data such as tide gauges, CTDs, ADCPs and ocean gliders (featureTypes: TimeSeries, Profile, TimeSeriesProfile, Trajectory). The NetCDF-Java library was updated to support these featureTypes, allowing for customized methods appropriate for these data types.

The OGC Sensor Observation Service (SOS) is an IOOS-approved web service for delivering observational data, supporting GetCapabilities, DescribeSensor, and other service requests that allow for a rich exchange between the server and client. Typically SOS services connect to databases that store the observational data (e.g., NOAA-COOPS, NDBC, 52 North), but with the new CF-1.6 specifications allowing standardized collections of observed data in NetCDF files to be ingested into the Common Data Model, it was realized that an SOS service could also be developed relatively easily for the THREDDS Data Server. Under funding from IOOS COMT, RPS ASA developed ncSOS, released it as open source, where it continued to be developed with funding from USGS and IOOS [13]. Written in Java, it is a simple plug-in for the THREDDS Data Server, installing in minutes with no configuration necessary. This allows access to observational data by any broker or client that can formulate SOS requests such as XML or simple Representational State Transfer (REST) text and process the responses (currently XML, JSON or CSV).

\subsubsection{Unstructured Grid (UGRID) Standards and Tools}

To represent the data output from unstructured grid models a common way, metadata conventions need to be adopted. The CF Conventions have proven very popular and effective for structured (e.g., rectilinear, curvilinear) grid model output, but had no way of specifying the grid topology (connectivity) necessary for unstructured grids, or concepts such as location of data on the grid elements (e.g., located on faces, edges or nodes). Shortly after CF version 1.0 was released in 2008 a UGRID Interoperability Google Group was formed with representatives from organizations such as Deltares, NOAA, USGS, DOE, and the FVCOM, ADCIRC, SELFE modeling communities [14]. After several years of discussion, development and testing, unstructured grid metadata conventions were finally released in 2013 as UGRID 0.9 [15]. The conventions were developed to allow specification of data variables on fixed horizontal unstructured grids. Higher-order element representation of data variables and handling data from moving or changing meshes were 
left as future enhancements, with the realization that these enhancements might necessitate a different underlying data model, but leave the functionality for users intact.

With the new UGRID 0.9 conventions for unstructured grid data, it was possible to create a new class for NetCDF-Java to support the UGRID featureType. This Java code was also developed by RPS ASA and released as an open source plugin for NetCDF-Java and/or THREDDS Data Server [16]. This allows for unambiguous retrieval of properties such as connectivity arrays or data location on the elements (e.g., face, node), which allows interoperable clients to be developed to support any UGRID-compliant data.

The NCTOOLBOX was developed to leverage the NetCDF-Java library Common Data Model for Matlab users [17]. An evolution of the njTBX Toolbox for Matlab described in [8], it supports a wide range of operations on CF-compliant gridded data (rectilinear or curvilinear). With the new UGRID 0.9 conventions for unstructured grid data, and support in NetCDF-Java, it was possible for RPS ASA to create new tools for NCTOOLBOX to support UGRID-Compliant datasets as well. As an example, water levels from three different models used in COMT (ADCIRC, SELFE and FVCOM) can be accessed and displayed without using model specific code (Figure 4). The Matlab code to recreate this figure is the script demos/contrib/test_ugrid3.m from the UGRID version of NCTOOLBOX, available at [18].

Blanton et al. [19] leveraged the capabilities of UGRID standards and NCTOOLBOX to build a powerful GUI-based tool (ADCIRCVIZ) for accessing and visualizing storm forecasts run on unstructured grid models from multiple remote locations. While geared toward forecasts computed with ADCIRC, any model that conforms to UGRID standard can be visualized in this application.

The THREDDS Data Server [20] currently includes the built in Web Map Services (WMS) provided by ncWMS, developed by the University of Reading [21]. Although this service works exceptionally well for rectilinear data, the performance is poor for curvilinear grids and there is no support for unstructured grids.

To rectify this situation, ASA-RPS built a new Python-based WMS service called SciWMS [22] that uses standard Python plotting via the Matplotlib Basemap library to generate maps. This turns out to be several times faster than the approach ncWMS uses, at least for the current generation of models, and works for unstructured grids. Because it is written in Python, it can't be bundled with THREDDS like NcWMS. It must be installed and configured separately, but the procedure is well documented, along with instructions how to customize a THREDDS server configuration to point to the SciWMS mapping services instead of the usual THREDDS-supplied WMS services. With this configuration in place, the SciWMS services become associated with the ISO metadata, which makes the SciWMS services discoverable via the catalog services instead of the default ncWMS services. Thus tools can be developed that allow searching for relevant datasets via the ISO metadata, and then quick display of model results via the SciWMS services. 
Figure 4. Water levels from three different unstructured grid models (ADCIRC, SELFE and FVCOM) displayed by the NCTOOLBOX script demos/contrib/test ugrid3.m. The script takes advantage of the UGRID conventions to access and display data from different unstructured grid models without any model-specific code. Any UGRID-compliant model could be displayed.
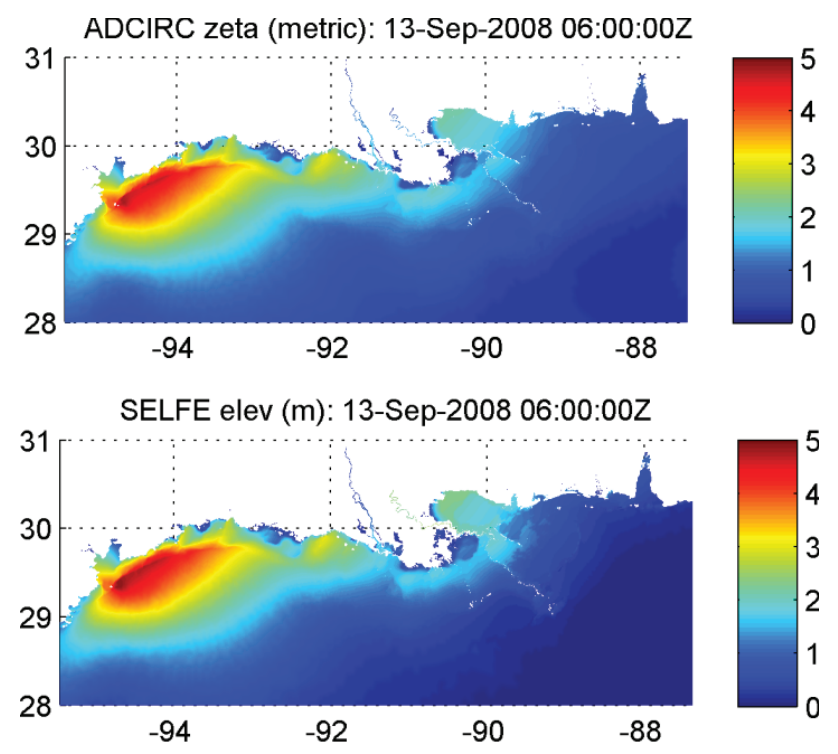

FVCOM zeta (meters): 13-Sep-2008 06:00:00Z

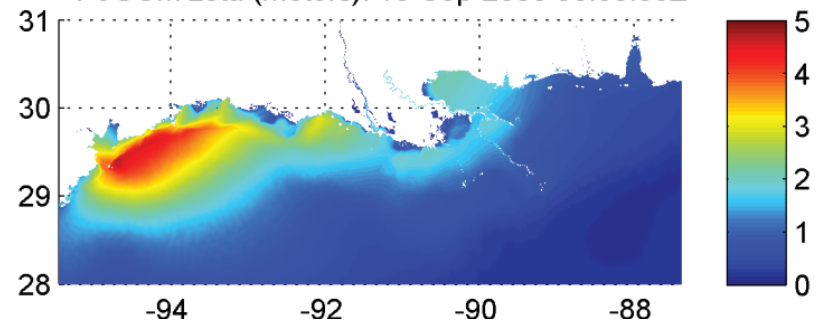


Figure 5. Comparison of ocean glider data (top panel) with forecast data from three different forecast models: the SECOORA SABGOM ROMS model from NCSTATE, the NAVY USEAST NCOM model, and the NOAA Global RTOFS HYCOM model. Tools from NCTOOLBOX were used that can extract vertical sections along time and space paths from any Climate and Forecast (CF)-compliant structured grid ocean model. The scripts that produce these plots may be found in the toolbox demos/contrib directory.

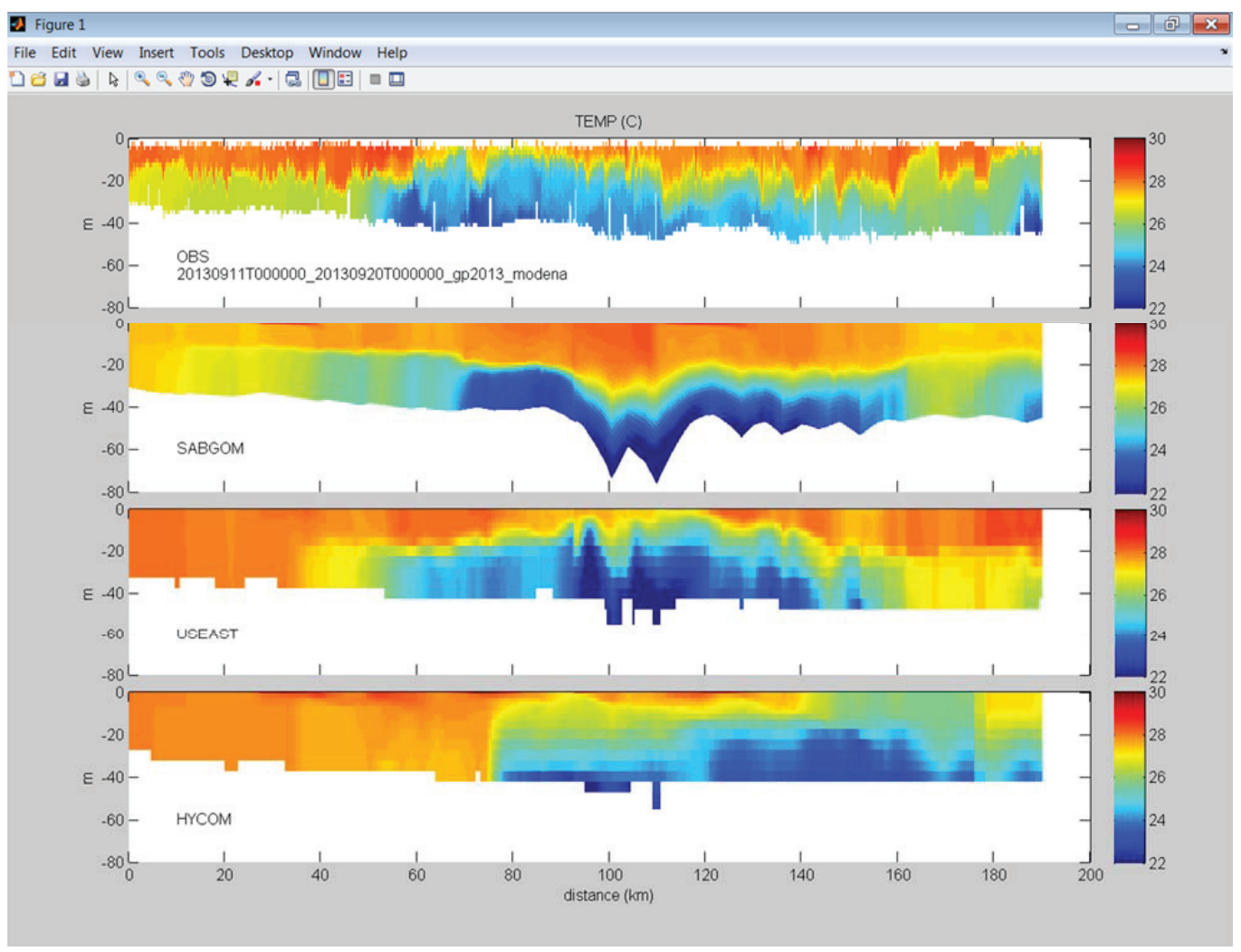

\subsubsection{Expanded Analysis Functions and Demos in NCTOOLBOX for Matlab Users}

In addition to providing support for unstructured grids, more tools and demos have been added to the NCTOOLBOX for Matlab, significantly increasing the functionality over the preceding njTBX toolbox described in [8]. As an example, the $n c$ _genslice.m function takes a CF-compliant model dataset URL and an $[\mathrm{x}, \mathrm{y}, \mathrm{z}, \mathrm{t}]$ trajectory on input, and returns an interpolated track from the selected model along that path. Instead of downloading data from the entire bounding box and temporal extent of the glider path from the model, the data is extracted in small chunks following the glider path, and the end result is typically only a few hundred $\mathrm{KB}$ of data. This provides an easy way to compare different models to ocean gliders, and was recently used with several IOOS forecast models and data collected during GliderPalooza, a collaborative glider campaign run on the US East Coast during Sep-Nov 2013 (Figure 5). Because users of NCTOOLBOX have the data, not just graphics, quantitative model assessment can be performed in addition to visual 
comparison. Wilkin and Hunter [23] leveraged the power of these new routines to objectively assess seven different forecast models in the Mid-Atlantic Bight, using IOOS community glider data collected over an 18 month period.

\subsubsection{An Improved Procedure for Modelers to Create Standardized Datasets}

In the COMT, many of the groups wanted to upload their data to a central server, requiring a procedure to catalog the datasets being uploaded. As typical in the larger ocean community, the modeling groups generated output files with differing metadata and conventions. All were NetCDF, but while some were nearly CF or UGRID-compliant, others contained only minimal metadata. For a single simulation, some modeling groups produced a single NetCDF file for all variables and time steps, while others produced collections of NetCDF files, with individual files for each variable and fixed number of time steps. To handle this situation, an approach was developed that used template NcML files and a Google Drive spreadsheet to automatically generate the THREDDS catalog.

Despite the non-uniformity of output files, NcML made it possible to virtually aggregate and standardize the datasets. For each modeling group, a template NcML file was provided that would turn their output files into a single, CF-compliant or UGRID-compliant dataset. For example, the template provided to the SELFE group aggregated each variable along the time dimension, and then aggregated all the variables together, while also aggregating a grid file that contained the lon/lat locations of the mesh, allowing the 49 different files constituting a single simulation to be accessed through a single UGRID-compliant URL. The modeling groups could use these templates without needing to understand the details of the CF or UGRID conventions, and the templates needed little or no modification to be used for each simulation performed by a particular modeling group.

A spreadsheet on Google Drive was used by modelers to specify the location of their NcML template as well as additional custom descriptors for the model run. After completing a new simulation, they would create a directory on the testbed server and upload their output files and template NcML (preferably using GridFTP via Globus [24]). They then added a row to a shared Google Drive spreadsheet that specified a title for the run, the location of the NcML template, and a short summary statement describing the model run. Every hour a Python script running on the testbed server read the spreadsheet using the Google API and combined the metadata from the numerous NcML files and additional metadata from the Google Spreadsheet into a single THREDDS Catalog of CF- and UGRID-compliant datasets.

\subsubsection{Enabling Discovery via Standardized Metadata and Catalog Services}

Enabling standardized datasets is a great step forward for interoperability, but it still can be difficult for users to find these standardized datasets. In [8] and in other projects (e.g., the NOAA Unified Access Framework project [25]) the approach was to build a single catalog that points to other catalogs, basically creating a large tree of datasets organized in a particular way (e.g., by IOOS region or NOAA Line Office). Thus a user had to navigate this tree to search for datasets that might be of interest. Instead, most users would rather search on space, time, and variable to 
dynamically find datasets that are of interest. Thanks to advances in metadata standardization and cataloging services, this is now relatively easy to enable.

With IOOS funding, NOAA NGDC developed a Java plug-in for THREDDS called NcISO that provides an ISO metadata service, converting the attributes and other metadata into ISO 19119-2 XML. Written in Java, it also can be used as a stand-alone application which scans a remote THREDDS catalog and generates ISO metadata for each dataset. This metadata, in turn, can be harvested by catalog services such as Geonetwork, GI-CAT, Geoportal Server, CKAN and PYCSW. The COMT datasets were harvested from the testbed server THREDDS catalog by the NGDC Geoportal Server that drives the IOOS Catalog. The COMT datasets are therefore discoverable by users internal and external to the COMT project using a standardized approach (Figure 6).

Figure 6. Results from a query for 3D FVCOM or ADCIRC datasets found within a specified bounding box (the extent of the map window). The user has selected one of the datasets returns, which displays the boundary of the dataset on the map (yellow rectangle), a summary (yellow-highlighted text), and dataset links, including "Open" to access the dataset using OPeNDAP, and "Metadata" to provide the full metadata document.

\section{SEARCH BROWSE}

\section{Search}

Search metadata content, including title, abstract, and keywords (FVCOM OR ADCIRC) AND 3D Search

Ð Records: NOAA National Geophysical Data Center Select site or configure search.

Advanced Search Options

Clear

WHERE

Anywhere Intersecting $\bigcirc$ Fully within

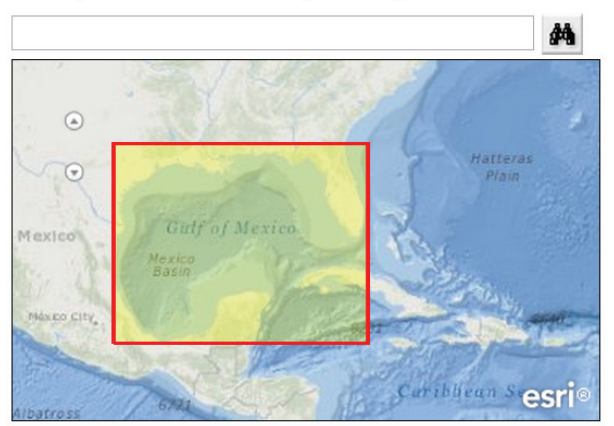

Results $1-8$ of 8 record(s)

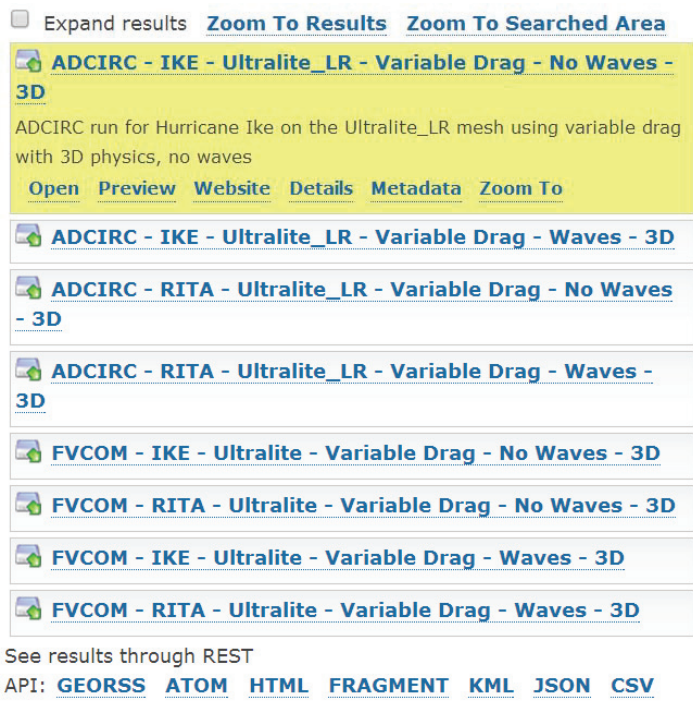




\subsubsection{CF Compliant Tools for Python}

Matlab is one of the popular analysis and visualization environments in the oceanographic community, so it made sense to focus initial effort on standards-based Matlab tools. To improve the efficiency for as many users as possible, however, standards-based tools need to be developed for all commonly used environments so that users can continue to use their favorite environment yet benefit from standards-enabled data.

One leading environment with similar capabilities to Matlab is Python. Python has the advantage of being open-source and free, so that tools and scripts developed for Python may be freely shared with scientists and other users without the requirement that they first buy a license. With hundreds of toolboxes giving capabilities like advanced time series, image processing, mapping and publication quality graphics, Python is becoming increasingly popular in the meteorological and oceanic research community.

Figure 7. Access and display of CF-compliant WaveWatch III data using the Python Iris package from the British Met Office. This demonstration was done using the IPython Notebook, which allows code, output and rich text to be combined in a web document that can be easily shared with others.

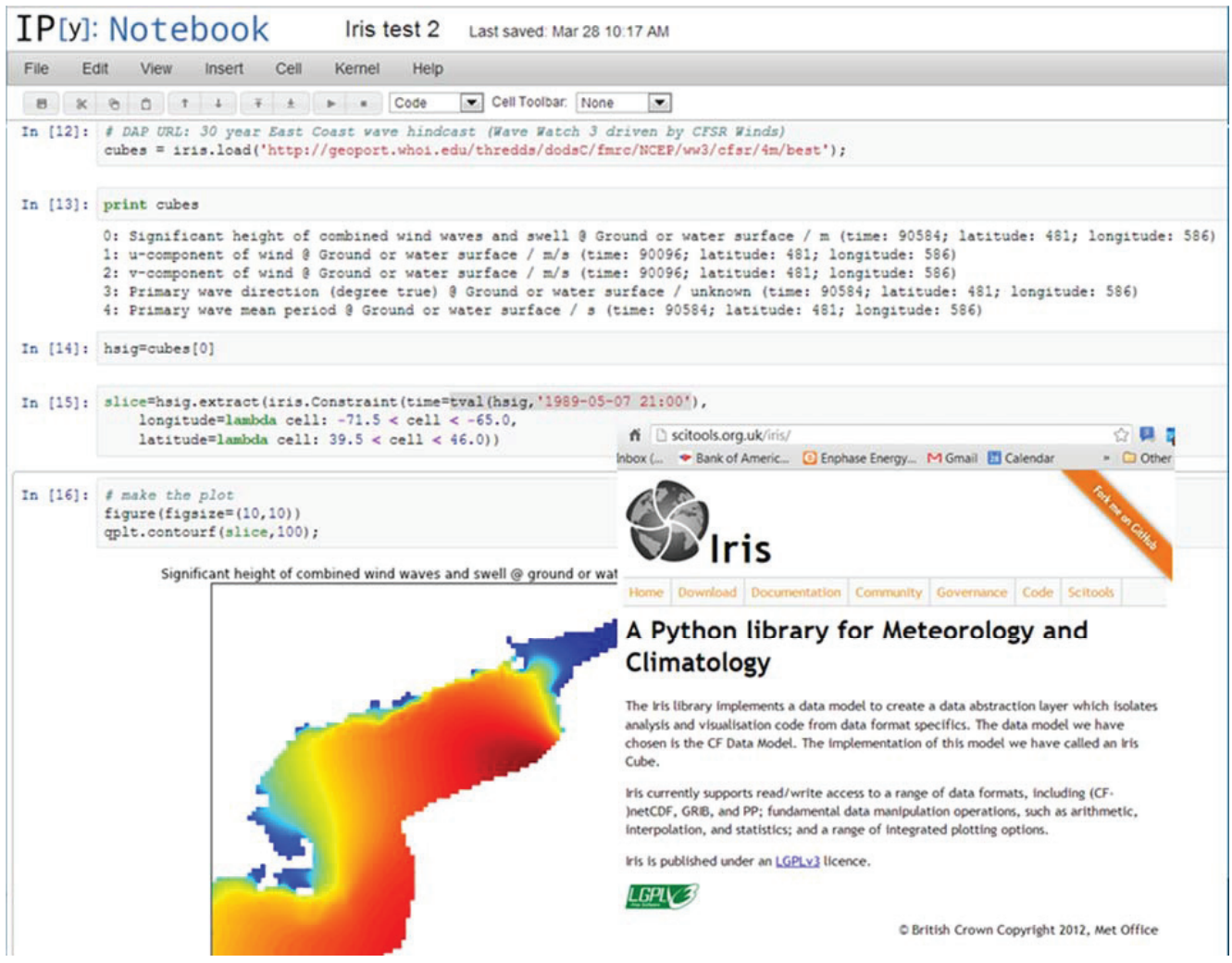


Unlike Matlab, however, Python cannot directly utilize the Unidata NetCDF-Java library to take advantage of standards-based functionality. Although Python can easily take advantage of C and Fortran modules, and Unidata began working several years ago on a $\mathrm{C}$ library to support CF conventions ("LibCF”), progress has been slow, and LibCF does not yet have the capability to perform fundamental tasks such as returning the geospatial coordinates from CF-compliant ocean models.

To fill this void, the British Met Office has created Iris, a CF-compliant package for Python [26]. The primary goal is to serve their own users, but because it is open and standards-based, Iris can support a much wider community. With Iris, as in NCTOOLBOX, users can access and work with output from different models without any specific code: any CF-compliant structured grid model can be easily opened, accessed and displayed in Iris (Figure 7).

With several full time developers, government backing, a clear roadmap, and agile and open development approach, Iris is a strong contender to be the dominant met and ocean package for standards-based data access. Although Iris currently only supports structured grids, support for UGRID-compliant unstructured grid data and CF-1.6-compliant observational data is on the development roadmap.

\section{Conclusions}

Significant progress has been made in the international geoscience community to develop standards, services and tools that make data search, access, analysis and visualization easier and more efficient. In the ocean modeling community, techniques originally developed for atmospheric forecast and climate models have been adapted and extended to serve the ocean community. Leveraging Unidata technologies such as NetCDF, NcML and the THREDDS Data Server, coupled with international standards development work on the CF Conventions, UGRID Conventions and the OGC Services, a system has been developed that places relatively little burden on data providers or data users.

There is still work to be done hardening and expanding the system. More providers need to be aware of existing tools that will allow them to easily serve standardized, aggregated data. WMS services for unstructured grids are functional, but need to be optimized for performance. Standards-based tools for Python need to be brought up to the same functionality as the tools for Matlab. Packages for other commonly used scientific analysis and visualization environments such as $\mathrm{R}$ still need to be developed.

While additional work needs to be done, the advances described here bring us closer to a future where users discover data by keyword and geospatial queries on distributed holdings, access data via standard data services, and analyze and visualize data with common, standards-based software. The basic infrastructure depends on a common data model for each data type, a system that was first demonstrated on structured gridded data, and has been expanded to work with both unstructured grid data and specific observational data types. Although this approach has been developed for atmospheric, climate and oceanographic use, it could be used for hydrology, geology or other geoscience communities that use these data types. While applied here to IOOS, it is also being applied to support other applications [19,27]. With demonstrated success for IOOS, and with 
support from the international geoscience community, the future looks promising for this distributed, standards-based approach.

\section{Acknowledgments}

The authors would like to thank the U.S. IOOS Program Office, the IOOS Data Management and Communications (DMAC) Community, the Unidata Program Center, the IOOS Regional Associations, the British Met Office, participants in the Open Geospatial Consortium, and others participating in the development of standards and standards-based tools in the international geoscience community. Without their contributions this work would not have been possible. Any use of trade, product, or firm names is for descriptive purposes only and does not imply endorsement by the U.S. Government.

\section{Author Contributions}

Signell, R.P. and Snowden, D.P. carried out this work together and Signell, R.P. wrote the paper.

\section{Conflicts of Interest}

The authors declare no conflict of interest.

\section{References}

1. Willis, Z.; Manley, J. Ocean Observing: Delivering the Benefits. Mar. Technol. Soc. J. 2010, 44, 4-5; doi:10.4031/MTSJ.44.6.2.

2. Bassett, R.; Beard, R.; Burnett, W.; Crout, R.; Griffith, B.; Jensen, R.; Signell, R. Implementing the National Integrated Ocean Observing System (IOOS) From the Federal Agency Perspective. Mar. Technol. Soc. J. 2010, 44, 32-41; doi:10.4031/MTSJ.44.6.8.

3. de La Beaujardiere, J.; Mendelssohn, R.; Ortiz, C.; Signell, R. Building the IOOS Data Management Subsystem. Mar. Technol. Soc. J. 2010, 44, 73-83; doi:10.4031/MTSJ.44.6.10.

4. Ocean.US. The Integrated Ocean Observing System (IOOS) Modeling and Analysis Workshop Report; Ocean.US Publication No. 18; Ocean.US: Arlington, VA, USA, 22-24 July 2008; p. 21.

5. Sherwood, C.R.; Book, J.W.; Carniel, S.; Cavaleri, L.; Chiggiato, J.; Das, H.; Doyle, J.D.; Harris, C.K.; Niedoroda, A.W.; Perkins, H.; et al. Sediment dynamics in the Adriatic Sea investigated with coupled models. Oceanography 2004, 17, 58-69; doi:10.5670/oceanog. 2004.04 .

6. Warner, J.C.; Sherwood, C.R.; Signell, R.P.; Harris, C.K.; Arango, H.G. Development of a three-dimensional, regional, coupled wave, current, and sediment-transport model. Comput. Geosci. 2008, 34, 1284-1306; doi:10.1080/19475721.2012.669637.

7. Signell, R.P.; Carniel, S.; Chiggiato, J.; Janekovic, I.; Pullen, J.; Sherwood, C.R. Collaboration tools and techniques for large model datasets. J. Mar. Syst. 2008, 69, 154-161; doi:10.1016/ j.jmarsys.2007.02.013. 
8. Signell, R.P. Model Data Interoperability for the United States Integrated Ocean Observing System (IOOS). In Estuarine and Coastal Modeling (2009); Spaulding, M.L., Ed.; American Society of Civil Engineers: Reston, VA, USA, 2010; pp. 221-238.

9. de La Beaujardière, J.; Beegle-Krause, C.; Bermudez, L.; Hankin, S.; Hazard, L.; Howlett, E.; Le, S.; Proctor, R.; Signell, R.P.; Snowden, D.; et al. Ocean and coastal data management. In Proceedings of OceanObs'09: Sustained Ocean Observations and Information for Society (Vol. 2), Venice, Italy, 21-25 September 2009; Hall, J., Harrison, D.E., Stammer, D., Eds.; European Space Agency Publication: Noordwijk, The Netherlands, 2010.

10. Hankin, S.; Bermudez, L.; Blower, J.D.; Blumenthal, B.; Casey, K.S.; Fornwall, M.; Graybeal, J.; Guralnick, R.P.; Habermann, T.; Howlett, E.; et al. Data management for the ocean sciences - perspectives for the next decade. In Proceedings of OceanObs'09: Sustained Ocean Observations and Information for Society, Venice, Italy, 21-25 September 2009; Hall, J., Harrison, D.E., Stammer, D., Eds.; European Space Agency Publication: Noordwijk, The Netherlands, 2010.

11. Luettich, R.A.; Wright, L.D.; Signell, R.; Friedrichs, C.; Friedrichs, M.; Harding, J.; Fennel, K.; Howlett, E.; Graves, S.; Smith, E. The US IOOS coastal and ocean modeling testbed. J. Geophys. Res. 2013, 118, 6319-6328; doi: 10.1002/2013JC008939.

12. Howlett, E.; Wilcox, K.; Crosby, A.; Bird, A.; Graves, S.; Maskey, M.; Keiser, K.; Luettich, R.; Signell, R.; Smith, L. The US IOOS Coastal and Ocean Modeling Testbed for Advancing Research to Applications. In Proceedings of Oceans, 2012, Hampton Road, VA, USA, 14-19 October 2012; IEEE: New York City, NY, USA, 2012; pp. 1-7.

13. NcSOS Home Page. Available online: https://github.com/asascience-open/ncSOS (accessed on 25 February 2014).

14. Unstructured Grid Interoperability Google Group Home Page. Available online: https://groups.google.com/d/forum/UGRID-interoperability (accessed on 25 February 2014).

15. Unstructured Grid Metadata Conventions Home Page. Available online: https://github.com/ UGRID-conventions/UGRID-conventions (accessed on 25 February 2014).

16. Unstructured Grid Package for NetCDF-Java. Available online: https:/github.com/asascienceopen/NetCDF-Java-UGRID (accessed on 25 February 2014).

17. NCTOOLBOX Toolbox for Matlab. Available online: https://github.com/nctoolbox/nctoolbox (accessed on 25 February 2014).

18. Unstructured Grid Branch of NCTOOLBOX CF-Compliant Toolbox for Matlab. Available online: https://github.com/nctoolbox/nctoolbox/tree/UGRID (accessed on 25 February 2014).

19. Blanton, B.; Signell, R.; Crosby, A.; Fleming, J.; Luettich, R. Federation of Coastal Storm Surge Forecasts using THREDDS, OPeNDAP and UGRID, a CF Extension for Unstructured Model Grids. In Proceedings of ESIP 2013 Summer Meeting, Chapel Hill, NC, USA, 9-12 July 2013.

20. THREDDS Data Server Home Page. Available online: https://www.unidata.ucar.edu/software/ thredds/current/tds/ (accessed on 25 February 2014). 
21. Blower, J.D.; Gemmell, A.L.; Griffiths, G.H.; Haines, K.; Santokhee, A.; Yang, X. A Web Map Service implementation for the visualization of multidimensional gridded environmental data. Environ. Model. Softw. 2013, 47, 218-224; doi:10.1016/j.envsoft.2013.04.002.

22. SciWMS Home Page. Available online: https://github.com/asascience-open/sci-wms (accessed on 25 February 2014).

23. Wilkin, J.L.; Hunter, E.J. An assessment of the skill of real-time models of Mid-Atlantic Bight continental shelf circulation. J. Geophys. Res. 2013, 118, 2919-2933; doi:10.1002/jgrc.20223.

24. Globus Home Page. Available online: https://www.globus.org (accessed on 25 February 2014).

25. Unified Access Framework Home Page. Available online: https://geo-ide.noaa.gov (accessed on 25 February 2014).

26. Iris Home Page. Available online: http://scitools.org.uk/iris/docs/latest/index.html (accessed on 25 February 2014).

27. Bergamasco, A.; Benetazzo, A.; Carniel, S.; Falcieri, F.; Minuzzo, T.; Signell, R.; Sclavo, M. Knowledge discovery in large model datasets in the marine environment: The THREDDS Data Server example. Adv. Oceanogr. Limnol. 2012, 3, 41-50; doi:10.1080/19475721. 2012.669637. 


\title{
High Resolution 3-D Finite-Volume Coastal Ocean Modeling in Lower Campbell River and Discovery Passage, British Columbia, Canada
}

\section{Yuehua Lin and David B. Fissel}

\begin{abstract}
The 3-D unstructured-grid, Finite-Volume Coastal Ocean Model (FVCOM) was used to simulate the flows in Discovery Passage including the adjoining Lower Campbell River, British Columbia, Canada. Challenges in the studies include the strong tidal currents (e.g., up to $7.8 \mathrm{~m} / \mathrm{s}$ in Seymour Narrows) and tailrace discharges, small-scale topographic features and steep bottom slopes, and stratification affected by the Campbell River freshwater discharges. Two applications of high resolution 3-D FVCOM modeling were conducted. One is for the Lower Campbell River extending upstream as far as the John Hart Hydroelectric dam. The horizontal resolution varies from $0.27 \mathrm{~m}$ to $32 \mathrm{~m}$ in the unstructured triangular mesh to resolve the tailrace flow. The bottom elevation decreases $\sim 14 \mathrm{~m}$ within the distance of $\sim 1.4 \mathrm{~km}$ along the river. This pioneering FVCOM river modeling demonstrated a very good performance in simulating the river flow structures. The second application is to compute ocean currents immediately above the seabed along the present underwater electrical cable crossing routes across Discovery Passage. Higher resolution was used near the bottom with inter-layer spacing ranging from 0.125 to 0.0005 of total water depth. The model behaves very well in simulating the strong tidal currents in the area at high resolution in both the horizontal and vertical. One year maximum near bottom tidal current along the routes was then analyzed using the model results.
\end{abstract}

Reprinted from J. Mar. Sci. Eng. Cite as: Lin, Y.; Fissel, D.B. High Resolution 3-D Finite-Volume Coastal Ocean Modeling in Lower Campbell River and Discovery Passage, British Columbia, Canada. J. Mar. Sci. Eng. 2014, 2, 209-225.

\section{Introduction}

Discovery Passage (Figure 1) is located between the mainland of British Columbia and Vancouver Island along with many smaller islands. Campbell River is located in the southern part of the channel on the eastern shore of Vancouver Island.

The ocean currents in Discovery Passage are very strongly dominated by tidal currents driven by a sea level difference of up to $\sim 3 \mathrm{~m}$ at the two ends of Discovery Passage (i.e., Johnstone Strait and the Strait of Georgia). Flood and ebb tides in Discovery Passage are associated with southward and northward flows, respectively. Seymour Narrows is known for strong tidal currents (up to $7.8 \mathrm{~m} / \mathrm{s}$ or 15 knots based on Canadian Hydrographic Service, CHS [1], Canadian Tide and Current Tables). However, currents in most places on the CHS Chart for Discovery Passage are not well observed (though limited data with short time periods are available from near surface measurements). 
Figure 1. Map showing model grids, and Canadian Hydrographic Service (CHS) measurements sites. Positional data are presented in Universal Transverse Mercator (UTM) coordinates as UTM easting values, UTM northing values.

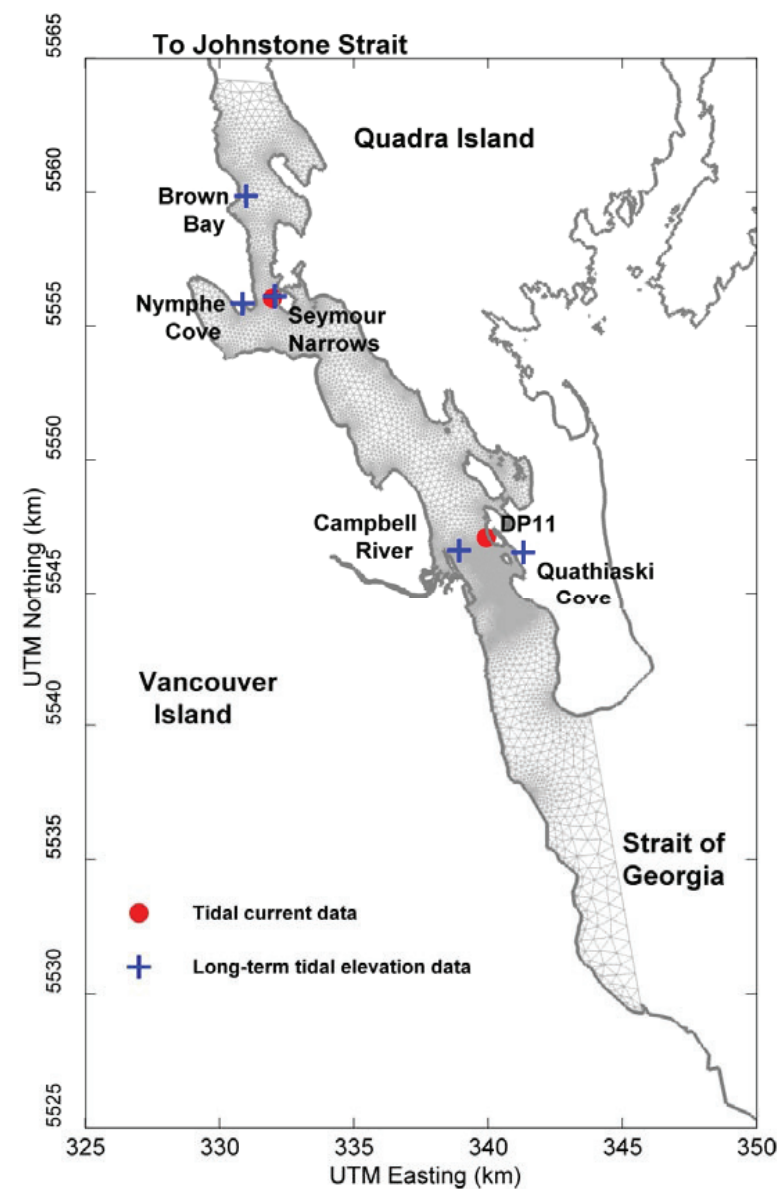

During the last decades, large river discharge events can bring over 850 cubic meters per second of freshwater into the channel (Environment Canada's Hydrometric Database, HYDAT), normally occurring in winter due to seasonal rains.

Two applications of high resolution 3D modeling in this area were conducted and presented in this paper. One is for the Lower Campbell River extending upstream up to the John Hart Hydroelectric dam. In this numerical study, the objectives are to understand the potential impact on fish habitat within the Campbell River by investigating the detailed flow regime. The second application is to compute ocean currents immediately above the seabed along the present and future underwater electrical cable crossing routes between Campbell River and Quadra Island across Discovery Passage. Using the more reliable and long term tidal measurements from CHS instrumented measurements to force a three dimensional ocean circulation model provides the detailed resolution and better understandings of the near-bottom current regime in this area. Surface wind and wave effects were not considered in the circulation model. 
FVCOM is a software framework developed by Chen et al. [2-4] and supported by Marine Ecosystem Dynamics Modeling Laboratory (MEDML) at UMASSD's School of Marine Science and Technology. The model is supported for research and operational use at School of Marine Science and Technology (SMAST) and is widely used at many other institutions around the world. At its core FVCOM is differentiated from other models by the numerical method used to solve the hydrodynamic equations. The finite volume method efficiently computes the flow on an unstructured triangular grid that can be adapted from the existing MIKE21 [5] model mesh. Recently the application of the unstructured FVCOM was conducted within ASL Environmental Sciences Inc. in studying strong tidal currents in Discovery Passage [6].

This paper includes the model approaches and results in detail. Section 2 presents the model approach for the Lower Campbell River Hydraulic Modeling. Section 3 presents the numerical study of Discovery Passage Near-Bottom Flow, followed by summary and conclusion.

\section{Lower Campbell River Hydraulic Modeling}

\subsection{Model Approach}

In this numerical study, the objectives are to understand the potential impact on fish habitat within the Campbell River by investigating the modified flow structure. The left and right channels of First Island, located some $150 \mathrm{~m}$ downstream of the existing tailrace (Figure 2), have been identified as areas of concern. Model domain and bathymetry are shown in Figure 2. Model grids and bathymetry were adopted from a previous study by Northwest Hydraulic Consultants (NHC) in 2011. The bottom elevation decreases $\sim 14 \mathrm{~m}$ within the distance of $\sim 1.4 \mathrm{~km}$ along the river, with even steeper local bottom slope fractions. Challenges also include the strong volume discharges specified at the upstream tailrace and variable bottom roughness. This numerical study has great value for FVCOM river and estuary modeling.

The 3-D hydraulic FVCOM model was applied with high horizontal resolution to incorporate the features of the powerhouse and tailrace design into the river bed. The horizontal resolution varies from $0.27 \mathrm{~m}$ to $32 \mathrm{~m}$ in the unstructured triangular mesh. The triangular grid for this FVCOM application has 16,625 nodes with 32,845 elements. A sigma-coordinate system was applied in the vertical with 3 levels, with a uniform inter-layer spacing in the vertical. The grid was generated with Gmsh (version 2.5) [7]. The wetting-and-drying option was activated in the model.

The bottom roughness type was set to be "static" (spatial varying) and the bottom roughness length scale values were derived at each time step using the method suggested by Bretschneider et al. [8]. The calculation was carried at each time step based on the Manning's M coefficients (averaged 24.9) and the total water depths in the model. A minimal value of 0.01 was set to prevent unrealistically small roughness lengths.

The FVCOM model employed numerical integration involving a second-order accuracy finite volume flux discrete scheme, where internal and external modes are "splitted" and integrated over distinct time steps. The external time step was set as $0.01 \mathrm{~s}$ to preserve stability over the simulation. The ratio of time steps between the internal and external modes was set to 2 in this application. The Smagorinsky eddy parameterization [9] was used for horizontal diffusivity with coefficient 
$C=0.15$. The background vertical diffusion and viscosity were set to $10^{-4} \mathrm{~m}^{2} / \mathrm{s}$ with a MY2.5 [10] turbulence closure.

Figure 2. A map showing the model mesh and bottom elevation of the Lower Campbell River.

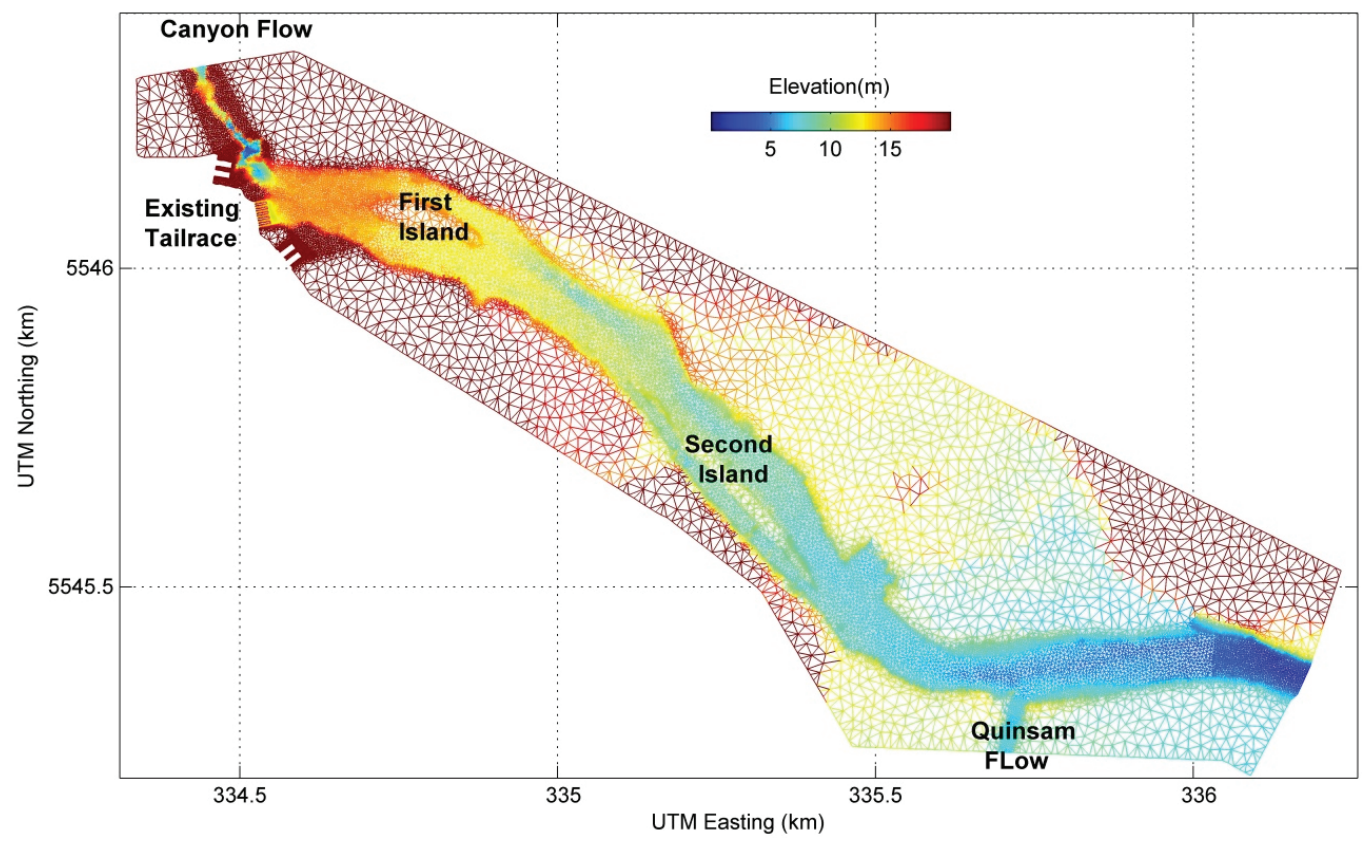

The model was driven by the tailrace discharges, Canyon inflow, and Quinsam inflow (Figure 2), with water levels specified at the southeast boundary. The model was run in a barotropic mode for $20 \mathrm{~h}$ to achieve a steady state. The model started from no water upstream, with only the specified south boundary water level. Water was then "injected" from upstream boundaries with associated discharges, and gradually filled up the whole river channel. After the spin-up period, the last 8-h results were used for analysis. Water levels and currents were outputted every 5 min during the model integration.

There are two model runs conducted in this numerical study. One is for assessing the model behavior using observed water level profile along the channel. The second run is for comparing the model reproduced flow structures and ADCP measurements at the two channels around First Island. Model boundary conditions for the two model runs are listed in Table 1.

\subsection{Model Results}

First, the model performance was assessed by comparing model results with water levels along the river in March 2011 (Figure 3). Model results appear to be in very good agreement with observed profiles. Discrepancies near the southeast open boundary are caused by the specified downstream water levels. In the interior region, the major discrepancies are seen near the tailrace and the Quinsam confluence, as well as in the downstream area of First Island (UTM Easting 
$\sim 33.48 \mathrm{~km}$ ), where the bathymetry fluctuates dramatically. The difference between the modeled surface water levels and the observations are small (within $\pm 0.2 \mathrm{~m}$ ), except the above three locations where the model seems to underestimate the water levels by a small amount $(\sim 0.4 \mathrm{~m})$.

Table 1. Model Inputs for Profile Run and Flow-Split Run.

\begin{tabular}{ccc}
\hline Boundary Location & \multicolumn{2}{c}{ Boundary Value } \\
& Water Profile Run & Flow-Split Run \\
\hline Total Flow Downstream of Powerhouse $\left(\mathrm{m}^{3} / \mathrm{s}\right)$ & 118.6 & 118.4 \\
Canyon Flow $\left(\mathrm{m}^{3} / \mathrm{s}\right)$ & 5.0 & 5.0 \\
Quinsam Flow $\left(\mathrm{m}^{3} / \mathrm{s}\right)$ & 5.0 & 10.0 \\
Existing Tailrace 1 (north most) Flow $\left(\mathrm{m}^{3} / \mathrm{s}\right)$ & 19.5 & 19.5 \\
Existing Tailrace 2 Flow $\left(\mathrm{m}^{3} / \mathrm{s}\right)$ & 18.4 & 18.4 \\
Existing Tailrace 3 Flow $\left(\mathrm{m}^{3} / \mathrm{s}\right)$ & 18.4 & 18.3 \\
Existing Tailrace 4 Flow $\left(\mathrm{m}^{3} / \mathrm{s}\right)$ & 19.5 & 19.5 \\
Existing Tailrace 5 Flow $\left(\mathrm{m}^{3} / \mathrm{s}\right)$ & 20.5 & 20.5 \\
Existing Tailrace 6 (south most) Flow (m $3 / \mathrm{s})$ & 17.4 & 17.2 \\
Downstream Water Level $(\mathrm{m})$ & 5.0 & 5.0 \\
\hline
\end{tabular}

Figure 3. Lower Campbell River profile comparison (middle and bottom panels) between the observations and the model results at the 20th hour, along the black curve in the top panel.
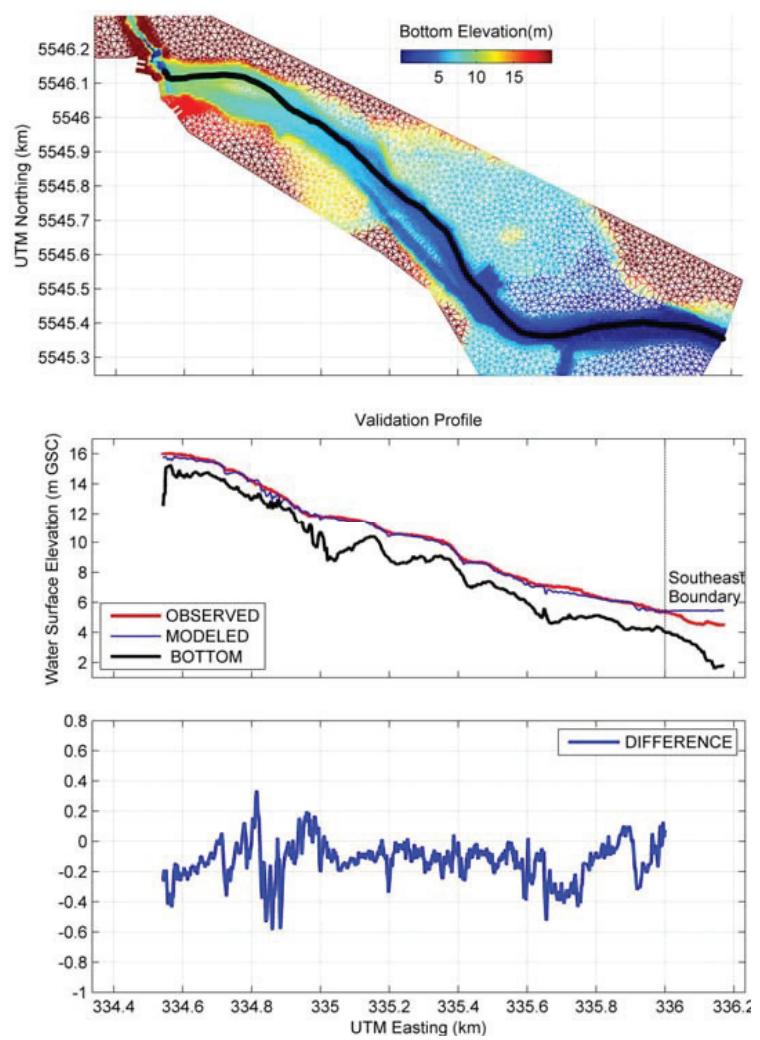
The model was further validated by comparison with observed flow splits around First Island based on the ADCP transects completed on 4 April 2011 (Figure 4). Figure 5 compares the vertical integrated flux distribution along the ADCP transects between the observations and the model results. It indicates that the model can reproduce not only the total volume transports through the channels, but also the horizontal volume transport structures. The discrepancy between model results and observations mainly come from the mesh resolution (and the associated error during integrating the volume transports) and quality of the bathymetry in the model.

Figure 4. The existing tailrace and bathymetry features near the outlets and First Island. Solid black lines mark the sections used for ADCP and model flow split assessment.

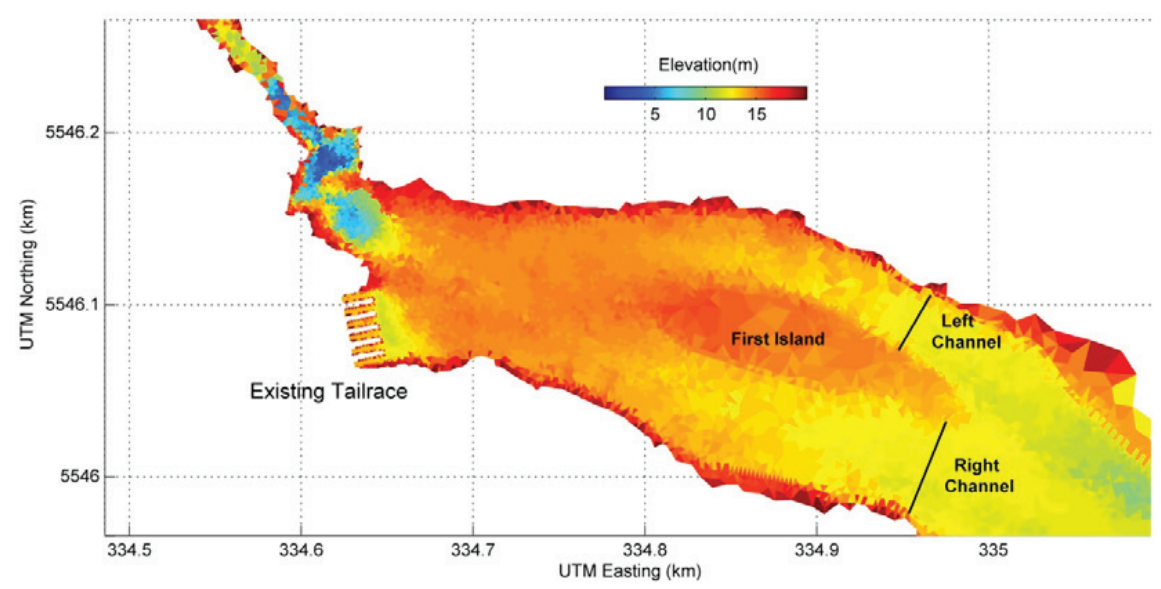

Figure 5. Comparison of horizontal transport distributions at the left channel (top panel) and right channel (bottom panel) of First Island between ADCP measurements and the 8 -h averages in the model. Distance defined from south to north.

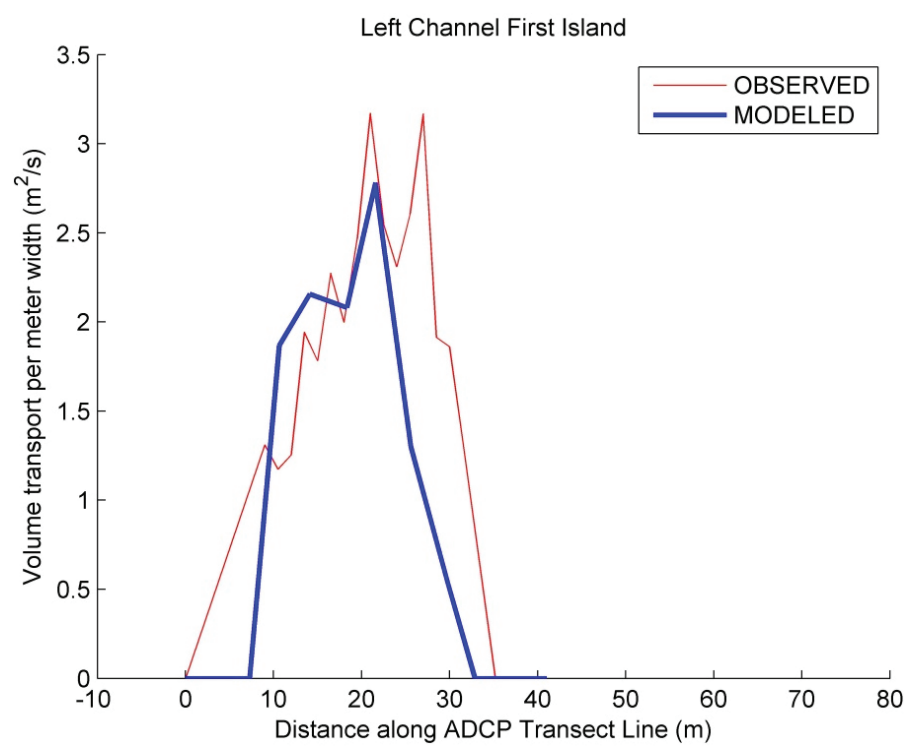


Figure 5. Cont.

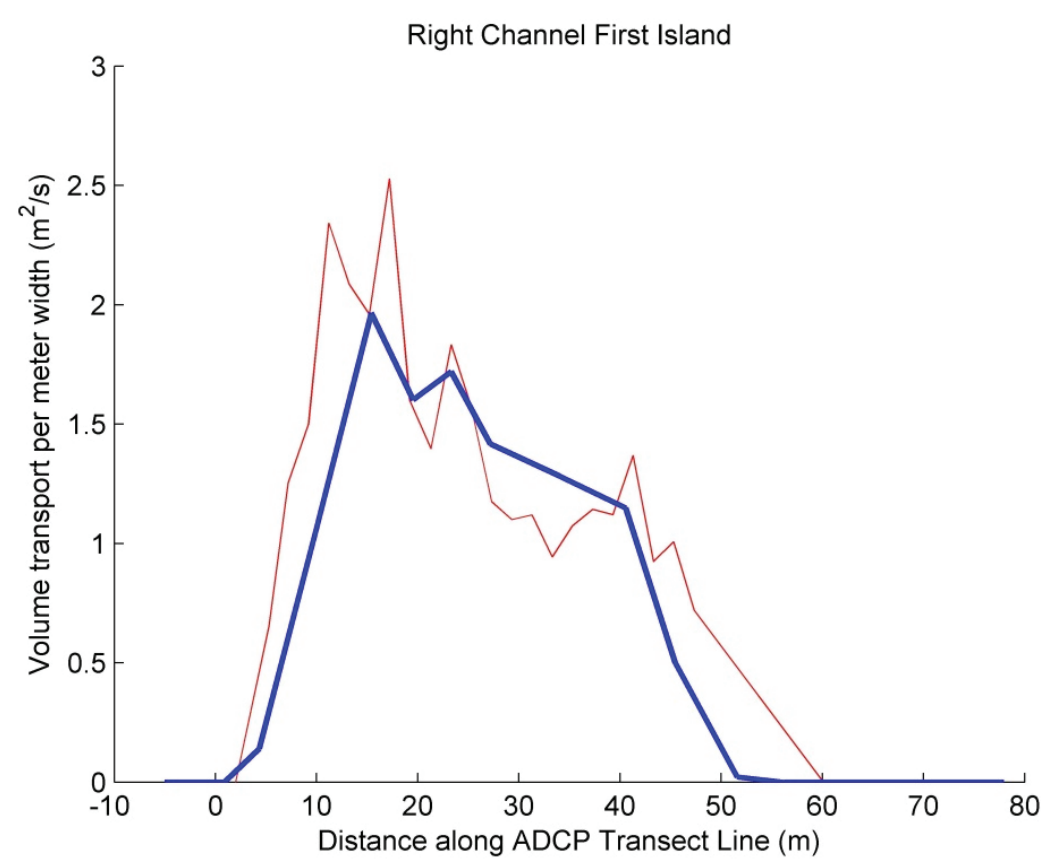

A previous 2-D MIKE21 modeling study was carried out by NHC in 2011 using the same bathymetry, triangle mesh, and bottom roughness coefficients (Manning's M numbers). MIKE21 model results were used to calculate flow splits of the left and right channels around the island at the ADCP transects marked in Figure 4. Flow split calculations based on FVCOM model results (the 8-h average after the 12-h spin-up) were compared with the MIKE21 model results [11] and the ADCP observations in Table 2. The 3-D FVCOM model reproduced a the river flow split with only $1 \%$ difference than the observed, which is similar to the 2-D MIKE21 results $(3 \%)$. The mainly improvement we found was for the left fork flow (Table 2). Overall, the high resolution 3-D FVCOM model demonstrated the capability for simulating the Lower Campbell River hydraulic regime to a reasonable accuracy.

Table 2. Model Results for Flow Split Validation.

\begin{tabular}{|c|c|c|c|c|c|c|}
\hline \multirow{2}{*}{\multicolumn{2}{|c|}{ Flow Split Validation }} & \multirow{2}{*}{ Total Flow $\left(\mathrm{m}^{3} / \mathrm{s}\right)$} & \multicolumn{2}{|c|}{ Left Fork Flow } & \multicolumn{2}{|c|}{ Right Fork Flow } \\
\hline & & & $\left(\mathrm{m}^{3} / \mathbf{s}\right)$ & Percentage & $\left(\mathrm{m}^{3} / \mathbf{s}\right)$ & Percentage \\
\hline Discharges $\mathrm{S}$ & Specified at Upstream Boundaries & 118.4 & & & & \\
\hline & Observed Transport & 120.5 & 55.5 & $46 \%$ & 65 & $54 \%$ \\
\hline \multirow{2}{*}{ MIKE21 } & Transport & 117.3 & 50.6 & $43 \%$ & 66.7 & $57 \%$ \\
\hline & Difference & $-1.1^{(1) /-3.2^{(2)}}$ & -4.9 & $-3 \%$ & +1.7 & $+3 \%$ \\
\hline \multirow{2}{*}{ FVCOM } & Transport & 122.3 & 54.9 & $45 \%$ & 67.4 & $55 \%$ \\
\hline & Difference & $+3.9^{(1) /+1.8^{(2)}}$ & -0.6 & $-1 \%$ & +2.4 & $+1 \%$ \\
\hline
\end{tabular}

(1) Based on the total discharge specified at upstream open boundaries; ${ }^{(2)}$ Based on ADCP observations. 


\section{Near-Bottom Currents Crossing the Discovery Passage}

\subsection{Model Approach}

In this section, FVCOM numerical modeling was conducted for ocean currents above the seabed near the underwater electrical cable crossing routes between Campbell River and Quadra Island across Discovery Passage. The triangular mesh for this FVCOM application has 8899 nodes with 15,896 elements (see Figure 1). The horizontal grid resolution varies from approximately $10 \mathrm{~m}$ for study area and small islands to $\sim 600 \mathrm{~m}$ in the middle channel at the open boundaries. In the vertical, a sigma-coordinate system was applied with 15 levels. Higher resolution was used near the bottom with inter-layer spacing ranging from 0.125 to 0.0005 of total water depth. The high vertical resolution near bottom can simulate currents at $0.02,0.07,0.17,0.38,0.76$, and $1.51 \mathrm{~m}$ above the seabed given the maximum water depths of $100 \mathrm{~m}$.

The model bathymetry was generated from digitized nautical charts obtained from CHS (Chart No. 3539 and 3540) [1]. Depth values are bottom elevation below chart datum (reduced to Lowest Normal Tide). In the study area near the underwater electrical cable crossing routes between Campbell River and Quadra Island, bathymetry was incorporated with the multibeam high resolution $(5 \mathrm{~m}$ ) bathymetric data set collected by Terra Remote Sensing Inc. in 2013. Based on the same survey results, the bottom roughness parameter was also determined (e.g., length scales are $30 \mathrm{~cm}$ for boulders and $2 \mathrm{~cm}$ for sand). A minimal value of 0.005 for the bottom drag coefficient was used in the model to maintain the model stability. The wetting-and-drying option was activated and the minimum water depth for a cell to be active was set to $1.0 \mathrm{~m}$ in FVCOM although it plays a minor role in overall circulation dynamics [12]. Surface winds have been shown to have little effect on the near bottom circulation over most of Discovery Bay [12].

The model was driven by tidal forcing at open boundaries and freshwater input from Campbell River. Freshwater discharge at Campbell River has minor effluence on the near bottom flow, which was retrieved from daily discharge reported in the Canadian Hydrological Data (HYDAT) and applied in the model. There are two open boundaries in the model where tidal elevations and constant inflow salinity and temperature were specified. The model was driven with tidal elevations reconstructed from 69 tidal constituents at each open boundary using Foreman's tidal prediction program [13]. Model results were saved at half hour time intervals. Readers are referred to Lin et al. (2012) [6] for more details about the model setup. The improvement in the FVCOM modeling mainly includes (1) refined model grids with higher resolution in both the horizontal and vertical, and (2) spatially variable bottom roughness derived based on the field survey.

\subsection{Model Verification}

First, the model was integrated for August 28 to September 3 in 1968 for verification. As shown in Figure 6, the model simulated water levels were compared with predicted tidal elevations (PTE) derived from CHS tidal data sets at the 5 sites inside the Discovery Passage as marked in Figure 1. The model demonstrated its capability of simulating the tidal levels throughout the whole Discovery Passage area. The associated root-mean-square deviation (RMSD) between model 
derived water levels and the PTE is listed in Table 3. Among these comparisons, the modeled water levels for Seymour Narrows have the largest error but are still in reasonable agreement with the large observed ranges of $3 \mathrm{~m}$ at Campbell River and $4 \mathrm{~m}$ in Seymour Narrows. The difference is caused by the challenge of simulating the very strong flow and the associated water head loss.

Figure 6. Model generated water levels (mod, dashed lines) at the 5 long-term tidal elevation sites as marked in Figure 1, with comparisons to the predicted tidal elevations (PTE, solid lines) derived from CHS tidal data sets.
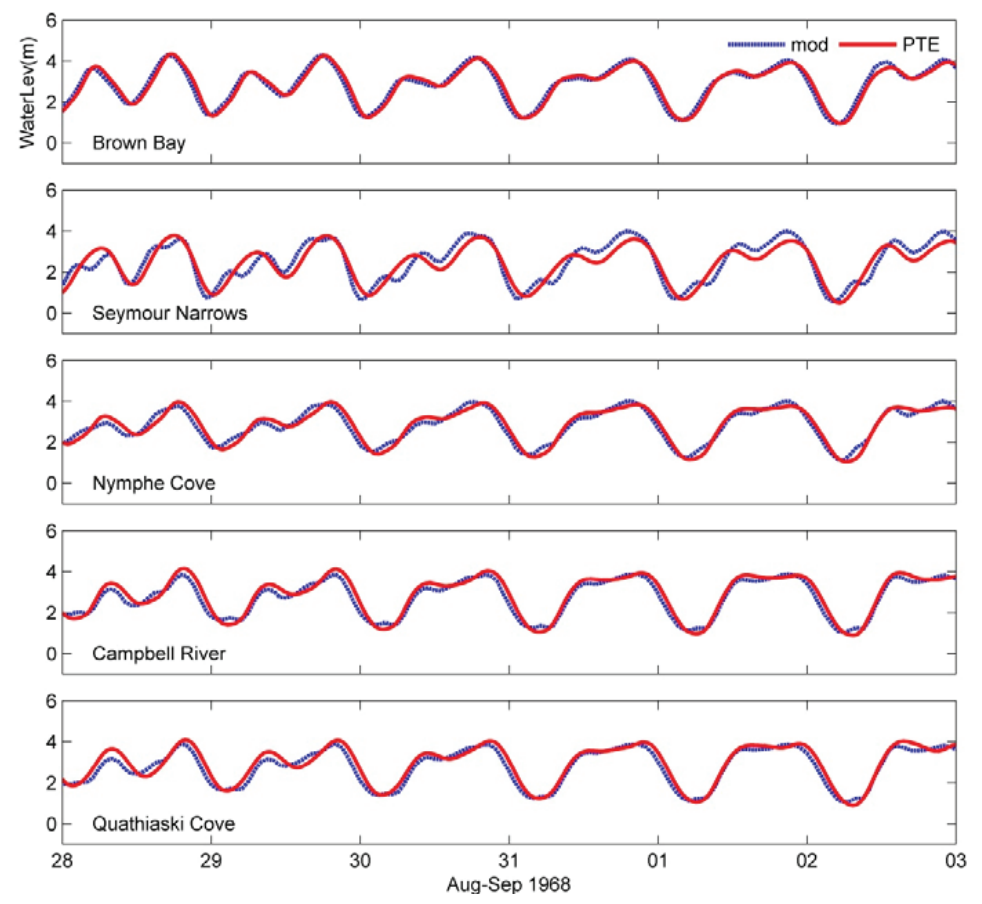

Table 3. Root-mean-square deviation (RMSD) between model derived water levels and the predicted tidal elevations (PTE).

\begin{tabular}{cccccc}
\hline PTE SITE & Brown Bay & Seymour Narrows & Nymphe Cove & Campbell River & Quathiaski Cove \\
\hline RMSD $(\mathrm{m})$ & 0.26 & 0.45 & 0.28 & 0.30 & 0.30 \\
\hline
\end{tabular}

In Figure 7, for the same verification period, model simulated tidal flow was compared with historical Institute of Ocean Sciences (IOS, Sidney, Canada) ocean current data at Seymour Narrows and ocean current data from the Department of Fisheries and Oceans (DFO, Ottawa, Canada) at DP11. Current meter data locations are also marked in Figure 1. Site DP11 is close to the study routes, with total water depth of $28 \mathrm{~m}$. The overall agreement of the model and measurements is very reasonable, including the near bottom flow at $22 \mathrm{~m}$ of DP11 (6 m above the bottom). The RMSD for eastward and northward components (U and V) between model derived and the PTC, as shown in Table 4, shows reasonably good agreement given the very large tidal currents with a typical speed of $6 \mathrm{~m} / \mathrm{s}$. 
Figure 7. Model (mod, gray lines) generated current speeds and directions (clockwise from North) at Seymour Narrows (at $1 \mathrm{~m}$ depth) and DP11 (at $10 \mathrm{~m}$ and $22 \mathrm{~m}$ depths separately) as marked in Figure 1, with comparisons to Predicted Tidal Currents based on IOS current meter measurements (PTC, red lines).
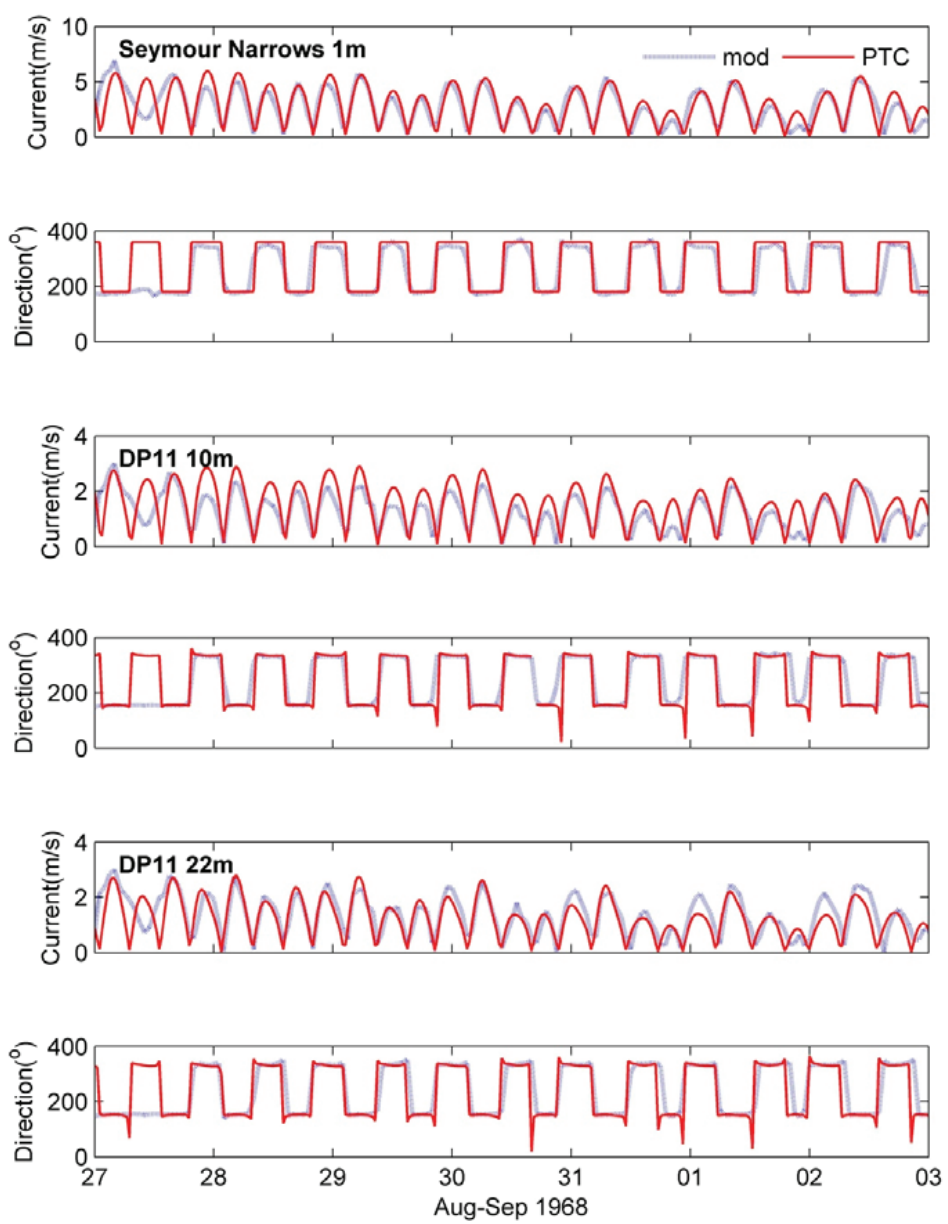

Table 4. Root-mean-square deviation (RMSD) between model derived and the predicted tidal currents (PTC).

\begin{tabular}{cccc}
\hline PTC SITE & Seymour Narrows (1 m) & DP11 (10 m) & DP11 (22 m) \\
\hline RMSD of U (m/s) & 0.66 & 0.21 & 0.17 \\
RMSD of V (m/s) & 1.00 & 0.47 & 0.37 \\
\hline
\end{tabular}

\subsection{One Year Maximum near Bottom Tidal Currents}

In the next model runs, the model was used to study the one year maximum tidal currents immediately above the seabed along the crossing routes between Campbell River and Quadra Island across Discovery Passage (Figure 8). Tidal predictions at the south and north open 
boundaries of recent years were examined. The model integration for this model run was then selected for the winter solstice in 2008 (15-day period of December 5-20). Model results for the transect along the crossing routes are summarized in Figures 8-10.

Figure 8. Near bottom vertical distribution of model derived maximum current speeds along the routes during flood (red lines) and ebb (blue lines) tides at the 5 sites marked in the bottom map.
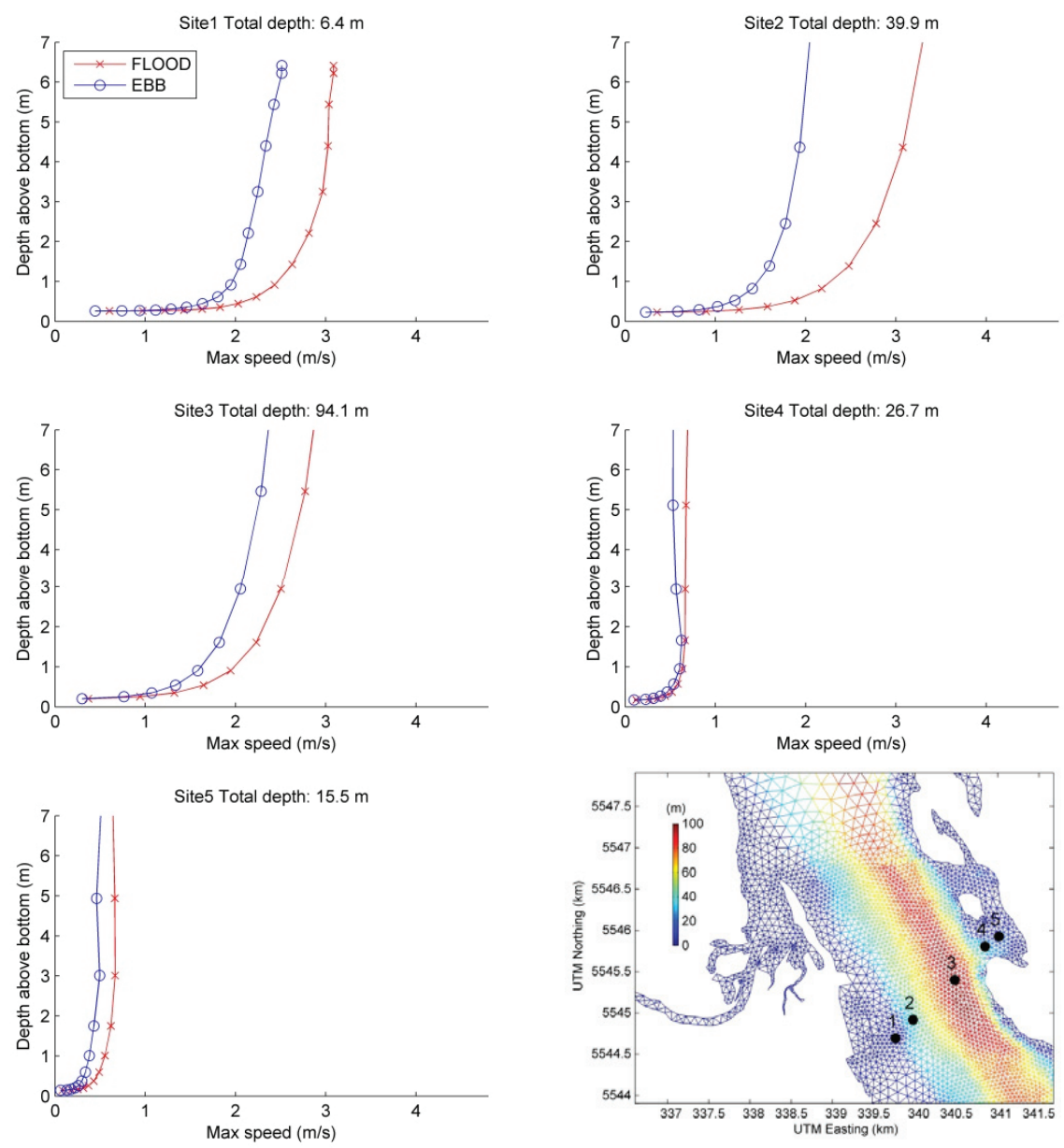

Maximum current speeds were extracted from model results within the model integration period. The vertical distribution of model derived maximum near bottom current speeds along the routes is shown in Figure 8. The near bottom flood flow is generally stronger than the near bottom ebb flow.

The vertical distribution of the one year maximum tidal currents along the crossing routes is shown in Figure 9. For the flood flow, the maximum velocities are found in the west and the middle channel (top panel of Figure 9), with the maximum value about $4.0 \mathrm{~m} / \mathrm{s}$. For the ebb flow, the maximum velocities are relatively larger slightly in the east side to the deep channel, with the maximum speed about $3.5 \mathrm{~m} / \mathrm{s}$ (bottom panel of Figure 9). 
Figure 9. Vertical distribution of model derived maximum current speeds along the routes during flood (upper panel) and ebb (bottom panel) tides.
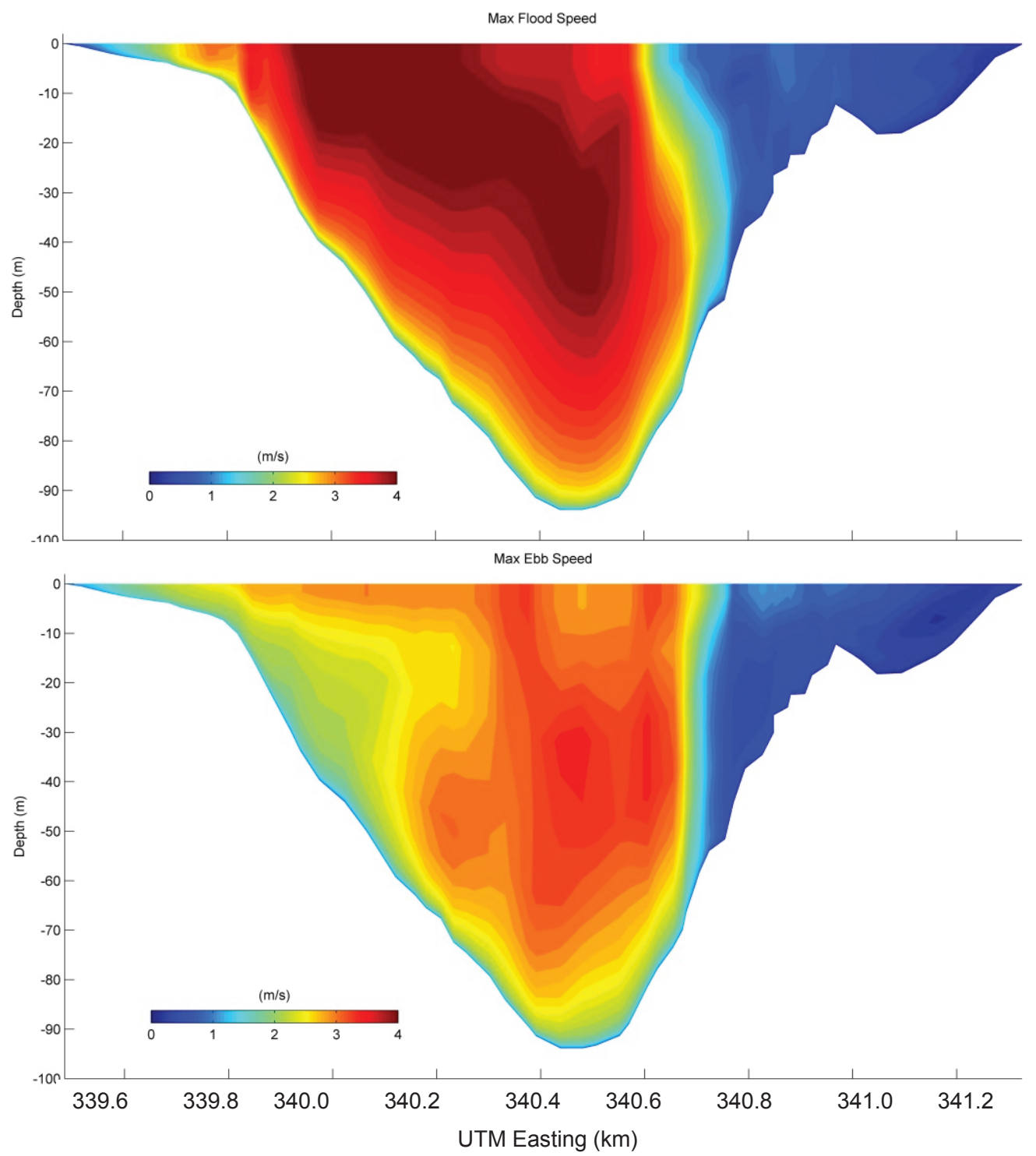

However, this maximum near surface velocity distribution feature does not exist in the near bottom velocity distribution. The one year maximum near bottom model current speeds along the crossing routes are presented in Figure 10 (up to $3 \mathrm{~m}$ above bottom). Unlike the surface maximum flow, the maximum near bottom flow was found on the west side of the channel, for both flood and ebb flow. The maximum ebb flow speeds are relatively smaller than the maximum flood flow speeds. The shallower region around UTM Easting $33.98 \mathrm{~km}$ on the west channel and the deep 
middle channel have the first and second largest speed values as to the one year maximum near bottom velocity fields along the crossing routes.

Figure 10. Near bottom vertical distribution of model produced maximum current speeds along the routes during flood (upper panel) and ebb (bottom panel) tides.
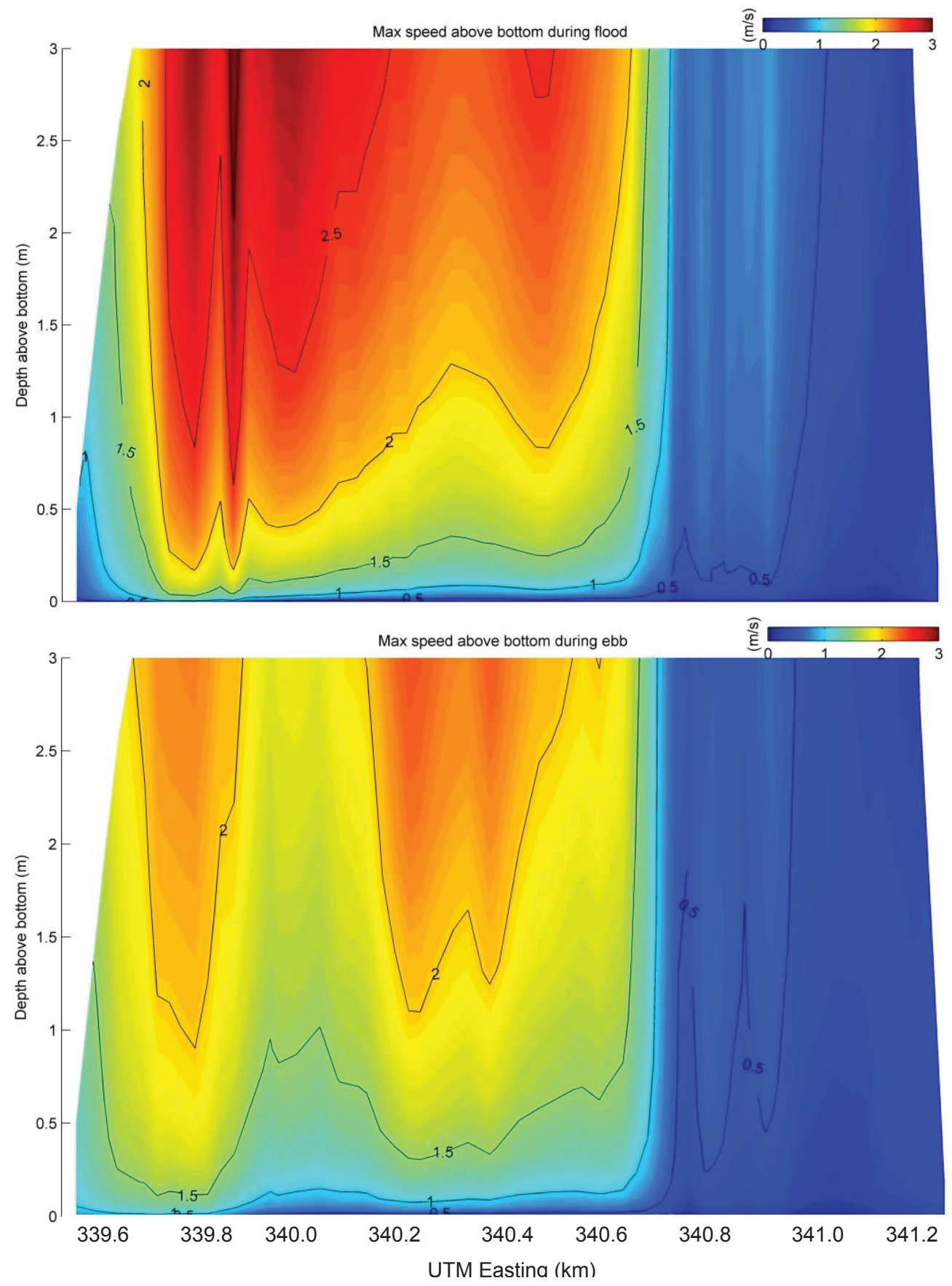


\section{Conclusions}

The unstructured-grid, Finite-Volume Coastal Ocean Model (FVCOM) was used to simulate the flows in Discovery Passage including the adjoining Lower Campbell River, British Columbia, Canada. Discovery Passage located between the mainland of British Columbia and Vancouver Island along with many smaller islands. Two applications of high resolution 3D modeling in this area were conducted and presented in this paper. One is for the Lower Campbell River from the upstream as far as the John Hart Hydroelectric dam. The horizontal resolution varies from $0.27 \mathrm{~m}$ to $32 \mathrm{~m}$ in the unstructured triangular mesh. The triangular grid for this FVCOM application has 16,625 nodes with 32,845 elements for existing dam tailrace runs. Model output was verified with observations and compared with the previous 2D MIKE21 model results with the same model grid and bottom roughness distribution. The model demonstrated a good performance in simulating the flow structures and capturing the volume transport split ratio at the left and right channels of First Island, located some $150 \mathrm{~m}$ downstream of the powerhouse as areas of concern.

The second application is to compute ocean currents immediately above the seabed along the present and potential underwater electrical cable crossing routes between Campbell River and Quadra Island across Discovery Passage. The horizontal grid resolution varies from approximately $10 \mathrm{~m}$ for the study area, incorporating a multibeam high resolution bathymetric data set. In the vertical, a sigma-coordinate system was applied with 15 levels. Higher resolution was used near the bottom with inter-layer spacing ranging from 0.125 to 0.0005 of total water depth. The high vertical resolution at near bottom levels allows simulation of currents at $0.02,0.07,0.17,0.38$, 0.76 , and $1.51 \mathrm{~m}$ above the seabed given the maximum water depths of $100 \mathrm{~m}$. Model results were verified using available tidal gauge and current meter data throughout the Discovery Passage. The model behaves very well so as to simulate the strong tidal currents at very high resolution in the horizontal and vertical. The one year maximum velocity distribution crossing the channel along the routes was examined, which is useful for extreme value analysis as related to engineering design. Differences were found in the distribution of the maximum near surface velocities and the near bottom velocities along the crossing routes.

\section{Acknowledgments}

We wish to express our appreciation to SNC-Lavalin Inc. and Terra Remote Sensing Inc. for the opportunity to undertake this study. We would also like to thank Northwest Hydraulic Consultants for observational data and early 2D MIKE21 model inputs and results.

\section{Author Contributions}

Y. Lin wrote the manuscript and led the modeling study. D. B. Fissel reviewed/edited the manuscript and supervised the design and planning of the model study.

\section{Conflicts of Interest}

The authors declare no conflict of interest. 


\section{References}

1. Canadian Hydrographic Service (CHS). Department of Fisheries and Oceans, Canada. Chart No. 3539 and 3540. Canadian Tide and Current Tables, Vol. 6, Discovery Passage and West Coast of Vancouver Island. Available online: http://www.charts.gc.ca (accessed on 1 April 2013).

2. Chen, C.; Liu, H.; Beardsley, R.C. An unstructured, finite-volume, three dimensional, primitive equation ocean model: application to coastal ocean and estuaries. J. Atmos. Oceanic. Technol. 2003, 20, 159-186.

3. Chen, C.; Beardsley, R.C.; Cowles, G. An unstructured grid, finite-volume coastal ocean model (FVCOM) system. Oceanography 2006, 19, 78-89.

4. An unstructured grid, finite-volume coastal ocean model: FVCOM user manual. Available online: http://fvcom.smast.umassd.edu (accessed on 23 April 2012).

5. MIKE21 User Guide and Reference Manual; Danish Hydraulic Institute (DHI): Hørsholm, Denmark, 1996.

6. Lin, Y.; Jiang, J.; Fissel, D.B.; Foreman, M.G.; Willis, P.G. Application of Unstructured Finite-Volume Coastal Ocean Model in Studying Strong Tidal Currents in Discovery Passage, British Columbia, Canada. In Proceedings of the Twelfth International on Estuarine and Coastal Modelling, St. Augustine, FL, USA, 7-9 November 2011; American Society of Civil Engineers: Reston, VA, USA, 2012.

7. Geuzaine and Remacle. Available online: http://geuz.org/gmsh (accessed on 5 August 2011).

8. Bretschneider, C.L.; Krock, H.J.; Nakazaki, E.; Casciano, F.M. Roughness of Typical Hawaiian Terrain for Tsunami run-Up Calculations; University of Hawaii: Honolulu, HI, USA, 1986.

9. Smagorinsky, J. General circulation experiments with the primitive equations, I. The basic experiment. Mon. Weather Rev. 1963, 91, 99-164.

10. Mellor, G.L.; Yamada, T. Development of a turbulence closure model for geophysical fluid problem. Rev. Geophys. Space Phys. 1982, 20, 851-875.

11. Northwest Hydraulic Consultants. John Hart Redevelopment Project Lower Campbell River Hydraulic Model; Ecofish Research Ltd.: Courtenay, Canada, 17 June 2011.

12. Foreman, M.G.G.; Stucchi, D.J.; Garver, K.A.; Tuele, D.; Isaac, J.; Grime, T.; Guo, M. A Circulation Model for the Discovery Islands, British Columbia. Atmos. Ocean 2012, 50, 301-316.

13. Foreman, M.G.G. Manual for Tidal Heights Analysis and Prediction; Pacific Marine Science Report 77-10; Institute of Ocean Sciences: Patricia Bay, British Columbia, Canada, 1977. 


\title{
The Storm Surge and Sub-Grid Inundation Modeling in New York City during Hurricane Sandy
}

\author{
Harry V. Wang, Jon Derek Loftis, Zhuo Liu, David Forrest and Joseph Zhang
}

\begin{abstract}
Hurricane Sandy inflicted heavy damage in New York City and the New Jersey coast as the second costliest storm in history. A large-scale, unstructured grid storm tide model, Semiimplicit Eulerian Lagrangian Finite Element (SELFE), was used to hindcast water level variation during Hurricane Sandy in the mid-Atlantic portion of the U.S. East Coast. The model was forced by eight tidal constituents at the model's open boundary, $1500 \mathrm{~km}$ away from the coast, and the wind and pressure fields from atmospheric model Regional Atmospheric Modeling System (RAMS) provided by Weatherflow Inc. The comparisons of the modeled storm tide with the NOAA gauge stations from Montauk, NY, Long Island Sound, encompassing New York Harbor, Atlantic City, NJ, to Duck, NC, were in good agreement, with an overall root mean square error and relative error in the order of $15-20 \mathrm{~cm}$ and $5 \%-7 \%$, respectively. Furthermore, using largescale model outputs as the boundary conditions, a separate sub-grid model that incorporates LIDAR data for the major portion of the New York City was also set up to investigate the detailed inundation process. The model results compared favorably with USGS' Hurricane Sandy Mapper database in terms of its timing, local inundation area, and the depth of the flooding water. The street-level inundation with water bypassing the city building was created and the maximum extent of horizontal inundation was calculated, which was within $30 \mathrm{~m}$ of the data-derived estimate by USGS.
\end{abstract}

Reprinted from J. Mar. Sci. Eng. Cite as: Wang, H.V.; Loftis, J.D.; Liu, Z.; Forrest, D.; Zhang, J. The Storm Surge and Sub-Grid Inundation Modeling in New York City during Hurricane Sandy. J. Mar. Sci. Eng. 2014, 2, 226-246.

\section{Abbreviations}

NOAA, National Oceanic and Atmospheric Administration, US Department of Commerce; USGS, U. S. Geological Survey, US Department of the Interior; SLOSH, Sea, Lake and Overland Surges from Hurricanes; ADCIRC, The ADvanced CIRCulation Model; FVCOM, Finite-Volume Coastal Ocean Model; CH3D-IMS, Integrated Modeling System based on CH3D (Curvilinear Hydrodynamic 3D); CEST, Coastal and Estuarine Storm Tide; ECOM-3D, Estuarine Coastal Ocean Model 3D.

\section{Introduction}

On 29 October 2012, around 7:30 pm EDT (UTC-4), Hurricane Sandy made landfall near Brigantine, NJ, and resulted in an enormous impact on life and property damage, with the estimated cost exceeding $\$ 50$ billion along the eastern seaboard. The storm surge created some of the most devastating impacts, including flooding in New York City's subway tunnels, LaGuardia and Kennedy airports, damage to the New Jersey transit system, and the coastal seashore [1]. 
Hurricane Sandy was formed in the Caribbean Sea on 22 October 2012. It strengthened as it moved northwards and was a Category 2 hurricane at its peak. On October 28, as it passed through the mid-Atlantic Bight, the hurricane began to make a hard turn to the northwest because of the large-scale wind flow pattern favoring an upper-level blocking over Greenland and a mid-level trough coming from the U.S. southeast. As a result, Hurricane Sandy made a landfall as a Category 1 hurricane on the New Jersey coast, impacting highly populated urban areas including nearby New York City. When it made landfall, an abnormal storm tide with catastrophic, record-setting water levels occurred in New Jersey, New York City and in a portion of Long Island Sound. The NOS tide gages records show water level at The Battery, NY, Bergen Point, NY, Sandy Hook, NJ, Bridgeport, CT, New Haven, CT, at 2.74, 2.90, 2.44, 1.77, and 1.69 meters above mean higher high water, respectively [1]. The worst flooding occurred over Staten Island and to the south along the New Jersey shore. The storm surge also caused significant flooding in parts of the Hudson River Valley, the East River, and the western part of Long Island Sound.

Many storm surge models have been developed and applied in the U.S. coastal regions; they vary either by structured/unstructured grids or by different numerical schemes used. Examples are: Sea, Lake, and Overland Surges form Hurricanes (SLOSH) [2], ADCIRC [3], FVCOM [4], CH3D-IMS [5], and CEST [6]. SELFE is a semi-implicit finite element model developed by [7] using the Eulerian-Lagrangian scheme, which is not restricted by the CFL (Courant-Friedrichs-Lewy) condition, and thus allows large time steps and robust computations. The 2-D mode of Semiimplicit Eulerian Lagrangian Finite Element (SELFE) was applied for the Hurricane Sandy simulation in a large-scale domain covering the entire U.S. East Coast. The purpose of the large domain model is to ensure that the storm tide driven by Hurricane Sandy from the ocean is accurately simulated in the major estuaries and waterways at the coast, where the model results can be evaluated by NOAA tidal gauge data. At the same time, it also provides boundary conditions for a separate, high-resolution, sub-grid inundation model designed specifically for the New York City metropolitan area. This is needed because the risk of inundated area per capita population is very high in the urbanized city. As a result, a highly resolved, accurate sub-grid inundation model UnTRIM $^{2}$ [8], which incorporates LIDAR (Laser Imaging Detection and Ranging) data directly into the sub-grid, was set up to simulate the inundation of the city during Hurricane Sandy. With the resolution and accuracy, the street-level inundation was revealed and overall accuracy for the horizontal extent of the inundation was within $30 \mathrm{~m}$ mean absolute deviation (MAD) compared with the USGS Hurricane Sandy database. The remainder of the paper is organized as follows: in Section 2, the SELFE model setup is illustrated; the results of storm tide prediction are presented in Section 2.3. Section 3 describes the sub-grid inundation modeling paradigm and its setup in the New York City. The sub-grid model results are presented in Section 3.3. Finally, Section 4 discusses the results and concludes the paper.

\section{Storm Tide Modeling along the U.S. East Coast}

The SELFE (Semi-implicit Eulerian Lagrangian Finite Element) model developed by Zhang and Baptista in 2008 is a fully 3-D, baroclinic unstructured grid, coastal ocean model [7]. The 2-D barotropic mode, which assumes vertically-averaged horizontal velocities, was applied for the 
entire U.S. East Coast for the storm tide prediction during Hurricane Sandy. The model makes computations using global coordinates and has been parallelized using MPI (Message Passing Interface), thus making it suitable for large-scale calculations. Recent upgrades to the model include the improvements in the wetting and drying scheme, and coupling with the Wind Wave Model-WWM [9].

The model domain features a curvilinear open boundary stretching from Key West, Florida, to Nova Scotia in Canada at around $62^{\circ} \mathrm{W}$ (Figure 1). The finite element grid is comprised of 207,996 nodes and 392,013 elements, and extends from the U.S. East Coast out about $1500 \mathrm{~km}$ into the Atlantic Ocean. The spatial resolutions are from about $50 \mathrm{~km}$ at the grid's open boundary near Bermuda to about $50 \mathrm{~m}$ in the Hudson River near NY Harbor. The model grid includes 134 open-boundary nodes, where the tidal constituent forcing can be applied from the open ocean far from the influence of a hurricane. Additionally, there are seven boundary nodes for applying river discharges from major rivers in the region with prescribed flux boundary conditions.

\subsection{Wind Forcing Using RAMS Model}

The high-resolution winds for Hurricane Sandy were produced from RAMS (Regional Atmospheric Modeling System) by WeatherFlow (http://www.weatherflow.com/). The wind field covers from Latitude 33.000 to 42.972 and Longitude from 78.000 to 68.026 with square elements of 2.16 arc-seconds (which is $4 \mathrm{~km}$ north-south by $3.4 \mathrm{~km}$ to $2.9 \mathrm{~km}$ east-west) with a 1-h temporal resolution. The duration of the wind and pressure field data provided is from October 24 00:00:00 GMT through October 31 00:00:00 GMT, 2012. This wind product is a continuous hindcast run in contrast to the normal $30 \mathrm{~h}$ forecast runs produced every $6 \mathrm{~h}$. The product assimilates observations from many sources, including Weatherflow's extensive network of meteorological stations. The SELFE model's atmospheric forcing field requires a fully-expanded longitude-latitude grid, specific variable names, time units measured in days, and a time origin in a specific format. The atmospheric data provided by Weatherflow is in an interoperable NetCDF format, which can be adapted to the SELFE model with minimal preprocessing. A short script using NetCDF operators can augment and adjust the metadata of this Weatherflow product in less than $10 \mathrm{~s}$ to support the SELFE model setup. The wind drag coefficient used is the Garratt formulation [10]:

$$
C_{d w}=(0.75+0.067 \mathrm{~W}) \times 10^{-3}
$$

where $W$ is the wind speed in $\mathrm{m} / \mathrm{sec}$. The $C_{d w}$ is capped at the maximum value of 0.003 in Equation (1). 


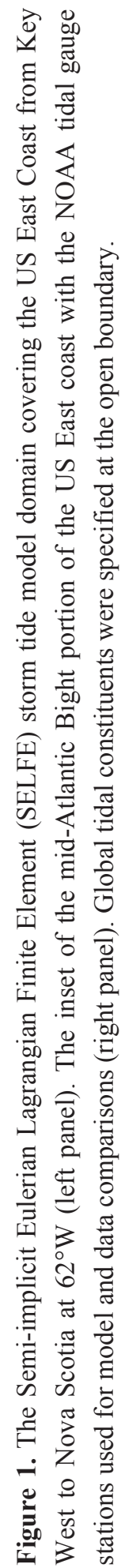
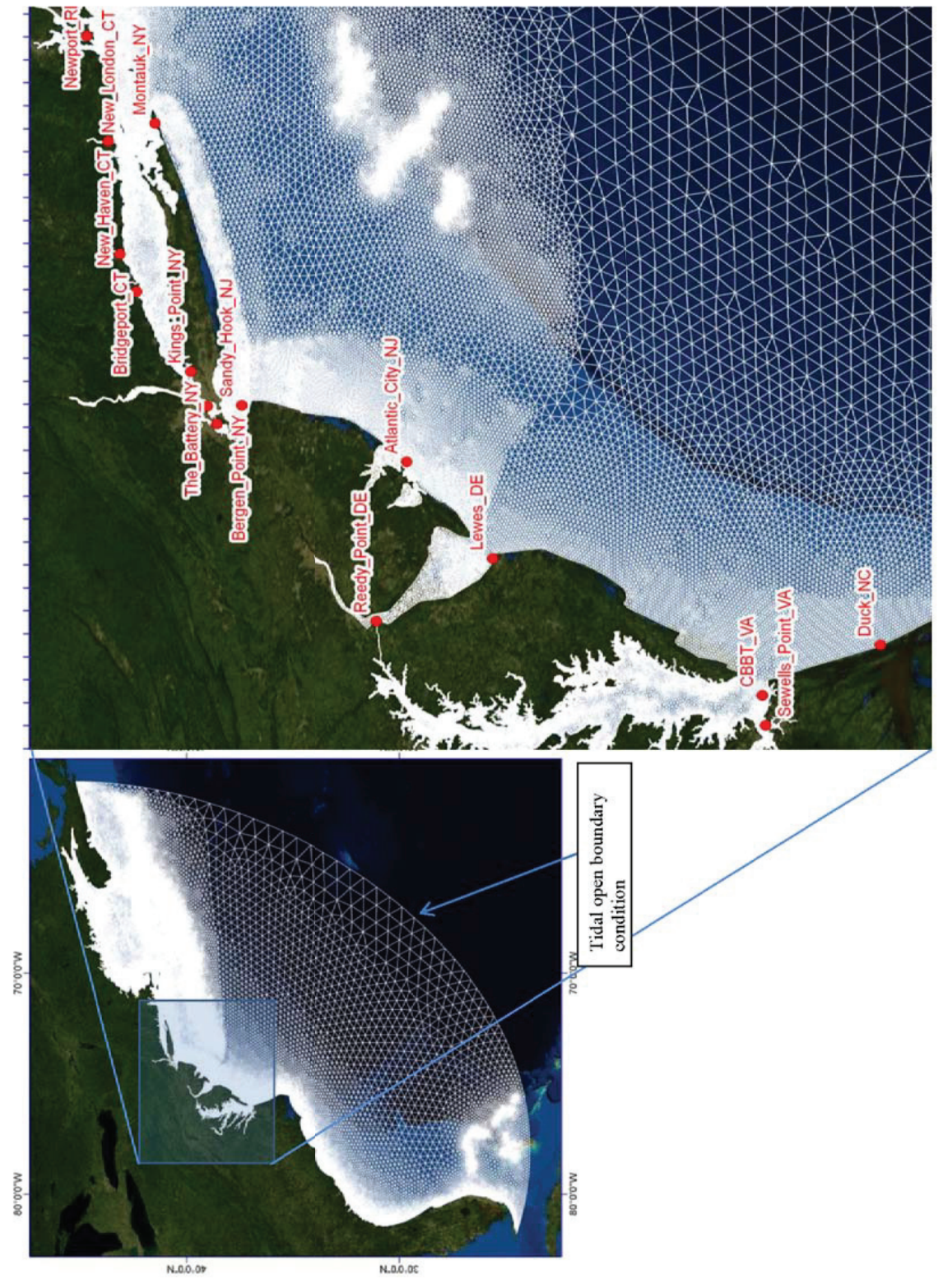


\subsection{Open Boundary Conditions and Tidal Calibration}

Eight global ocean tidal constituents, four semidiurnal constituents (M2, N2, S2, and K2) and four diurnal constituents (O1, P1, K1, and Q1), obtained via SMS (Surface-water Modeling System) version 8.0 by the FES95.2 global model formulation for harmonic tides [11] were used along the 134 nodes open boundary to force the tides along the eastern boundary. Factors that can reduce the tidal potential forcing due to the Earth's tide were also accounted for in SELFE by the nodal factor and equilibrium arguments. The friction parameters were obtained based on the calibration with tidal elevations at 14 NOS stations: Montauk, NY; Newport, RI; New London, CT; New Haven, CT; Bridgeport, CT; Kings Point, NY; The Battery, NY; Bergen Point, NY; Sandy Hook, NJ; Atlantic City, NJ; Lewes, DE CBBT, VA; Sewell Point, VA; and Duck, NC. The results showed that the Manning's $n=0.020$ could be used for the majority of the areas in the domain except: (1) $n=0.01$ for the Hudson River, New York Harbor, and Raritan Bay; and (2) $n=0.045$ for the East River and its junction with the Hudson River. These latter values were consistent with a study in the New York Bight using the ECOM-3D model [12]. During the storm tide simulation, because tangential stress on the sea surface is large, the Reid (1957)'s modified bottom friction formula [13] was used to account for the effect of wind:

$$
\tau_{b}=\rho_{w} C_{d b} U\|U\| \pm 5 \times \sqrt{C_{d b}} \tau_{w}
$$

where $\mathrm{C}_{d b}$ is the bottom drag coefficient, $U$ is the vertically average velocity, $\tau_{w}$ the wind stress. The + is used when the $U$ is opposing the wind and - is used when $U$ is following the wind.

\subsection{Storm Tide Hindcast for the U.S. East Coast}

Hurricane Sandy made landfall near Atlantic City, NJ, USA, on 29 October 2012, around 23:30 GMT. The approaching hurricane generated wind fields, which had both local and remote effects. Given that the hurricane took the path along the offshore of the U.S. East Coast from the south to the north, the Eastern Seaboard experienced the remote wind effect before the hurricane made the landfall. In order to capture the buildup, the SELFE run started the spin up run with the tide only on October 12: 00:00:00 GMT for 3 days. The storm tide simulation then started (with the hot-start file) on October 15, 00:00:00 GMT for 16 days and ended on October 31, 00 00:00 GMT, 2012. For the early part of the storm tide period from October 15 to October 23, the model used NARR (North American Regional Reanalysis) wind and pressure fields every $3 \mathrm{~h}$ from the NOAA Earth System Research Laboratory. It was followed by the RAMS wind and pressure fields starting October 24, 00:00:00 GMT until it ended on October 31, 00:00:00 GMT. Figure 2a-c show the storm tide results at nine stations from Long Island Sound, NY, encompassing New York Harbor, to Duck, NC, during the period from October 28, 00:00:00 GMT to October 31, 00:00:00 GMT. Figure 2a is grouped with the stations in the Long Island Sound. Comparing the timing of the highest water level suggested that the surge started at Montauk, NY and propagated westward toward Kings Point, NY at which the storm tide reached the peak at around $3.2 \mathrm{~m}$ above mean sea level. The model performance was satisfactory with the correlation coefficient square $\left(R^{2}\right)$ above 0.94 and root mean square error (RMS) equal to $18 \mathrm{~cm}$ on average. It was noticed that there were phase discrepancies observed in the model at King's Point, suggesting that some local effects contributed to the phase shift during the peak. Figure $2 \mathrm{~b}$ was 
grouped with the station in the New York Harbor, at the entrance of the Harbor and in Atlantic City, NJ. Comparing the timing of the highest water levels suggested that there was a primary surge originating near Atlantic City and propagating north toward the Battery. The maximum storm tide height at the Battery reached $3.5 \mathrm{~m}$ above mean sea level, which is higher than that near where the storm made landfall, suggesting occurrence of amplification in New York Harbor. The model performance was again quite satisfactory with the correlation coefficient square $\left(R^{2}\right)$ above 0.95 and the root mean square error (RMS) around $17 \mathrm{~cm}$ on average. It is obvious that during Hurricane Sandy there were two storm surges converging upon New York City; one from Long Island Sound westward and the other from the New Jersey coast. Figure 2c groups the stations in Delaware, Virginia, and North Carolina, which are in the third and fourth quadrants of the hurricane track. While the northern stations were experiencing the maximum surge setup, these stations were actually experiencing set-down, as evidenced by the data, because of the offshore wind field. The model faithfully captured the dynamics correctly. The model performance in the region has a coefficient of determination $\left(R^{2}\right)$ above 0.90 and a root mean square error (RMS) around $18 \mathrm{~cm}$ on average. For Figure $2 \mathrm{a}-\mathrm{c}$, the mean absolute errors (MAE) are all below $15 \mathrm{~cm}$ except those at the stations: Lewes, DE, and Kings Point, NY. For Lewes DE, there were observation errors found in the measurement at Lewes, DE around October 30, 00:00:00 GMT, 2012 (in the time scale near day 3), and for Kings Point, an unexplained phase shift occurred near the maximum surge. 


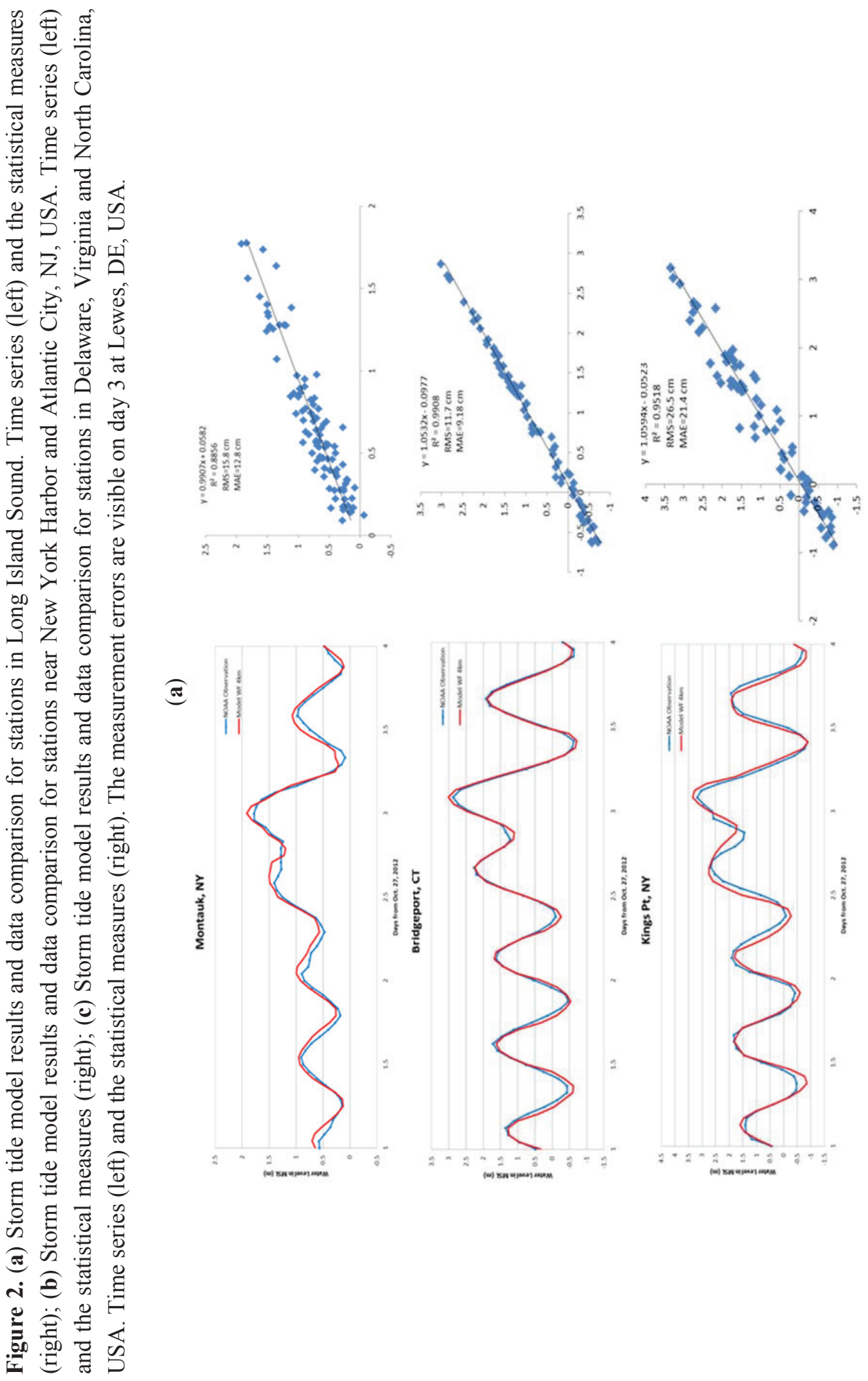




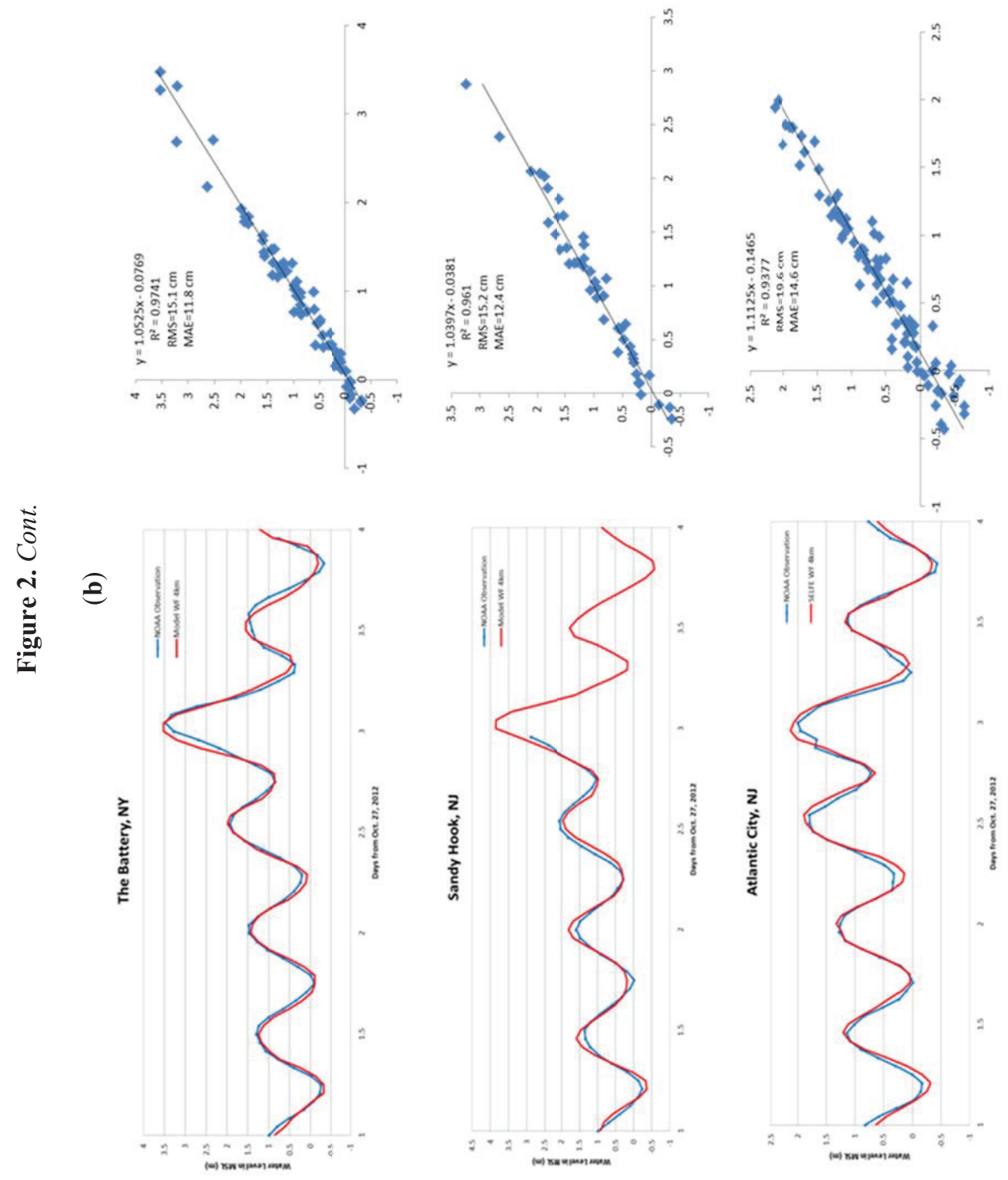




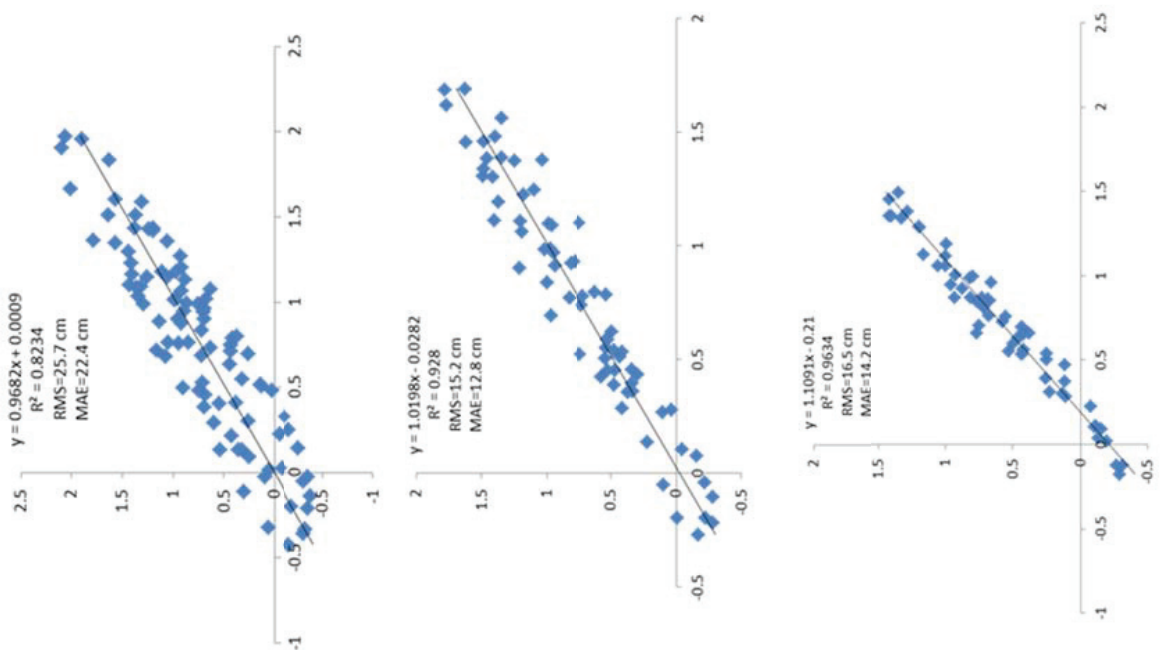

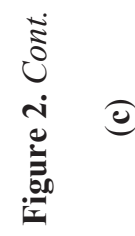
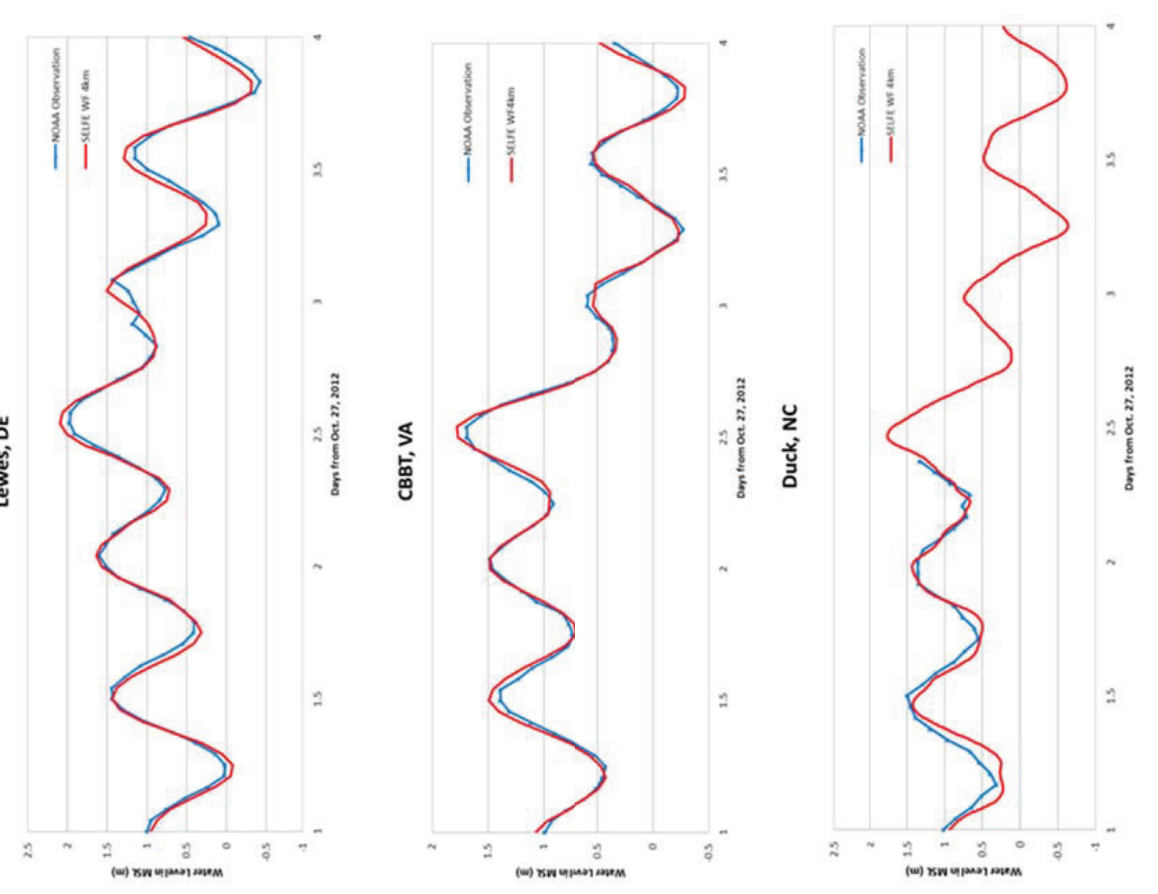


\section{Sub-Grid Inundation Modeling in New York City}

\subsection{A New Paradigm for Inundation Modeling}

When a hurricane surge floods into a city, it encounters land surfaces characterized by a wide range of features, from waterfront berms, streets, railroads, parks, highways to bridges, and building of different kinds. High-resolution hydrodynamic models are needed to simulate these local features. Even with the superior computing power available today, it is still insufficient to model these complex topographic features at the street and building scales. Given that LIDAR land data and water depths can now be collected with a very high resolution, it was recognized that the availability of detailed sub-element bathymetric data within a coarse computation grid should and can be used for further improving the model accuracy without having to use a fine computational mesh [14]. In this paper, a semi-implicit, semi-Lagrangian model: UnTRIM ${ }^{2}$ was setup with the incorporation of LIDAR data in the sub-grid to simulate the inundation for New York City during Hurricane Sandy. It contains semi-implicit formulation and nonlinear solver for accurate simulating wetting and drying condition. The sub-grid friction and conveyance formulation were also included for the friction-dominated flow. The interested reader should refer to [8] and [14] for more detailed descriptions of the model feature. The basic concept of the sub-grid approach is to incorporate topographical details in a computational grid without having to make computations on the fine, sub-grid grid and hence achieve a fast computational runtime. For example, the sub-grid topography makes the co-existence of partially wet and dry regions, and the boundary, which separates the two, within a coarse computation grid possible. The end result is that the area calculation of a partially wetting and drying region can be determined more accurately instead of being designated as either completely wet or completely dry for the entire grid. In the same way, the cross-sectional areas perpendicular to the flow can also be obtained with higher accuracy by integrating slices of the sub-grid scale bathymetry across the flow face rather than based on one averaged depth for the entire flow face of a finite volume grid. In this way, more accurate flux calculation for the conveyance of the flow is achieved. In a friction-dominated flow, sub-grid bathymetry resolution can be further incorporated into the flow resistance formula to account for detailed bottom location and local bottom shear stress $[8,15]$. The formulation is briefly explained as follows. Let us assume that a 2-D flow is frictional dominated and thus the pressure gradient term is balanced by the friction term in the momentum equation at each time step:

$$
-g \frac{\partial \zeta}{\partial x}+c f \frac{U\|U\|}{h}=0
$$

where $g$ is gravity, $\zeta$ is water surface elevation, $c f$ is the friction parameter for which formulation can be given such as Chezy, where $U$ is the velocity vector, and $\|U\|$ is the magnitude of the velocity in Equation (3). This leads to:

$$
U=\Omega \sqrt{\zeta_{x}} \quad \text { or } \quad \frac{U^{2}}{\Omega^{2}}=\zeta_{x} \quad \text { with } \quad \Omega=\sqrt{\frac{g h}{c f}}
$$

where $\Omega$ is defined as conveyance velocity in Equation (4). If we assume that the pressure gradient is constant in the coarse grid cell during one time step, then given the fixed $h$ and $c f$, it will lead to a single constant averaged velocity. On the sub-grid cell level, however, the velocity fields can vary 
because of the differences in the sub-grid bathymetry and the conveyances. If we assume that every sub-grid has the same surface size, then each sub-grid velocity will obey:

$$
\frac{c f_{j}}{g h_{j}}=\left\|u_{j}\right\|^{2}=\zeta_{x}=\text { constant }
$$

where $j$ is the index for each sub-grid cell; $h_{j}$ and $u_{j}$ are the sub-grid depth and velocity, respectively. The sub-grid velocities $u_{j}$ can be determined by $\|U\|, \Omega$ of the coarse grid, and $c f_{j}$, and $h_{j}$, as follows:

$$
\text { Given } \quad \frac{\left\|u_{j}\right\|}{\Omega_{j}}=\frac{\|U\|}{\Omega} \forall j \quad \therefore\left\|u_{j}\right\|=\Omega_{j} \frac{\|U\|}{\Omega}
$$

where:

$$
\|U\|=\frac{\sum_{j=1}^{J} h_{j}\left\|u_{j}\right\|}{\sum_{j=1}^{J} h_{j}} \quad \text { and } \quad \Omega=\frac{\sum_{j=1}^{J} h_{j} \Omega_{j}}{\sum_{j=1}^{J} h_{j}}
$$

Therefore, the sub-grid level velocities and bottom stress can be obtained from the associated quantities at the coarse grid level through a simple algebraic relationship. These sub-grid information are integrated subsequently into the semi-implicit algorithm for the computation grid, permitting a substantial improvement of model accuracy without an overly expensive computational cost.

\subsection{Sub-Grid Model Setup for New York City}

In this study, the sub-grid hydrodynamic modeling effort was applied to research high-resolution street-level spatial inundation modeling in the New York Harbor region during Hurricane Sandy (2012). The sub-grid model domain encompasses the Hudson River up to Yonkers, the Harlem River, parts of Long Island Sound up to King's Point, the East River and each of its tributaries (Figure 3a). Given that the New York City (NYC) building infrastructure is generally arranged in a block system, the grid developed using LIDAR-derived data has been scaled to square grids relatively congruent to the native resolution of the topographic data contained in the DEM (Digital Elevation Model, which is retrieved from the USGS National elevation dataset). The model grid designed for the New York City simulation makes use of a $200 \mathrm{~m} \times 200 \mathrm{~m}$ square base grid and in each of the base grid, there are 40 by 40 numbers of $5 \mathrm{~m} \times 5 \mathrm{~m}$ sub-grids embedded within each base grid cell (Figure $3 b$ ). To retain the accuracy, the uniform square grid LIDAR-derived data were imported directly into the sub-grid. When coupled with a nonlinear wetting and drying solver [14], the shoreline is intrinsically resolved in the sub-grid which allows partial wetting and drying within a coarse grid when the water level changes at with time step. The Open NYC Building Inventory is extremely important in the city landscape and was added separately to the DEM, and is resolved by the sub-grids (see right panel, Figure 3). The bathymetric and topographic data sources used in New York City are shown in Table 1. 


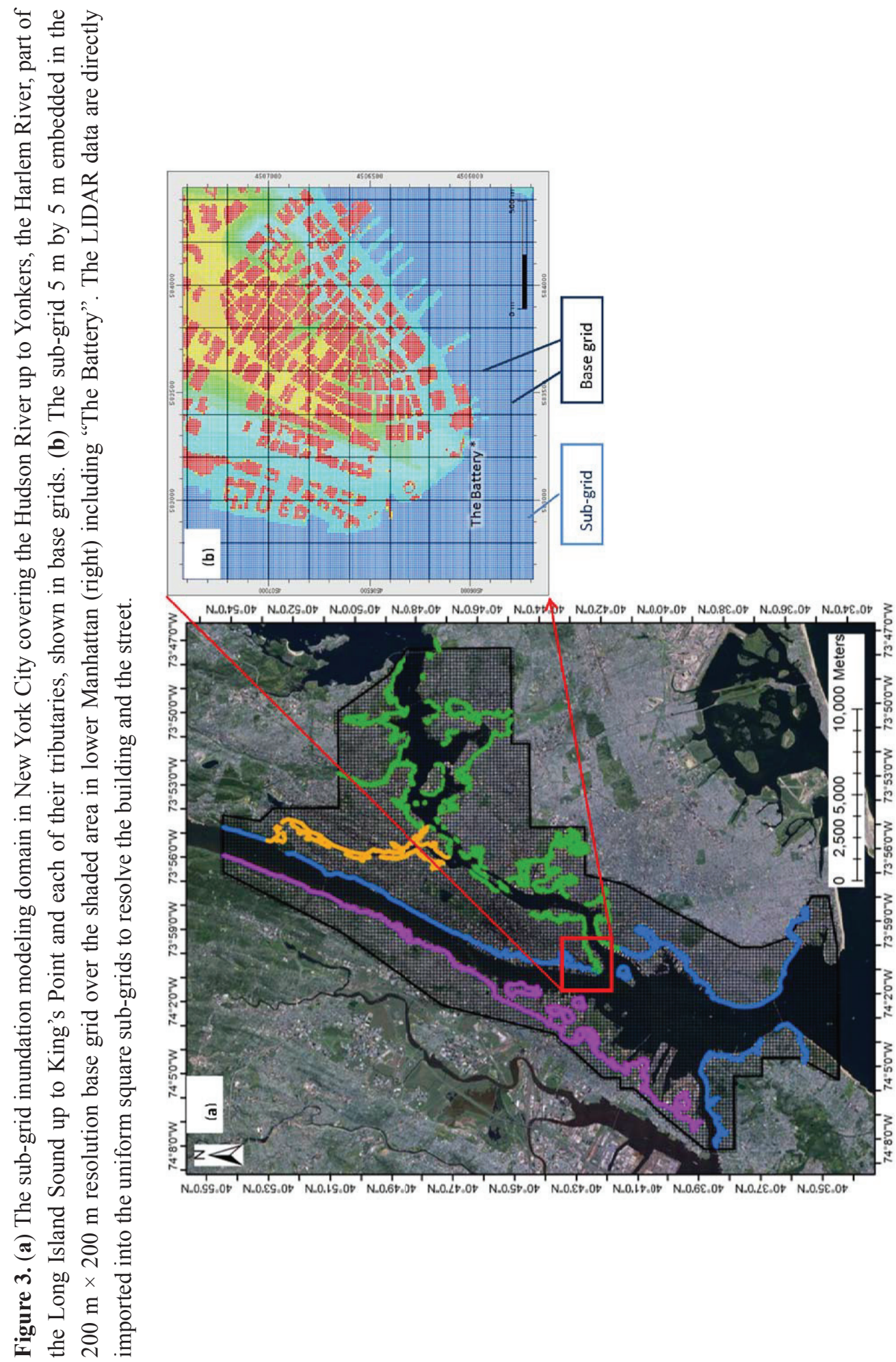


Table 1. Data sources of the bathymetry and LIDAR topography used as inputs in the sub-grid.

\begin{tabular}{|c|c|c|c|}
\hline & Bathymetry Data & Resolution & Area \\
\hline \multirow[t]{3}{*}{ Bathymetry } & NOAA Coastal Relief Model & $3 \operatorname{arcs}(\approx 90 \mathrm{~m})$ & Coastal Regions \\
\hline & NOAA Bathymetric Survey Data & $1 / 3 \operatorname{arcs}(\approx 10 \mathrm{~m})$ & Hudson River, East River, Kill van \\
\hline & & & Kull, Raritan Bay, and New York Bay \\
\hline \multirow[t]{4}{*}{ Topography } & USGS National Elevation Dataset & $1 / 3 \operatorname{arcs}(\approx 10 \mathrm{~m})$ & Low-elevation areas around the New \\
\hline & & & York Harbor and Raritan Bay \\
\hline & USGS National Elevation Dataset & $1 / 9 \operatorname{arcs}(\approx 3 \mathrm{~m})$ & Select areas of New York City \\
\hline & Open NYC Building Inventory & $0.1 \mathrm{~m}$ & New York City Buildings \\
\hline
\end{tabular}

Tides are forced via three open boundaries, one to the south, one to the west, and one to the east. The southern open boundary in the sub-grid domain is located at the mouth of the New York Bay into the Raritan Bay leading to the Atlantic Ocean. The open boundary to the west is Bergen Point (NOAA Station \#8519483) where the Kill van Kull connects Newark Bay to New York Bay. The third open boundary is near Kings Point (NOAA Station \#8516945) which lies to the east and connects the East River to Long Island Sound. Hourly fresh water flows for the Hudson River were obtained from USGS and specified as a flux distributed along nine elements at the northern boundary of the model domain near Wappingers Falls (Station \#01372500). Atmospheric data were collected from NOAA atmospheric observation data at Bergen Point (Station \#8519483). Atmospheric pressure was prescribed uniformly throughout the domain similar to that prescribed for wind. A Manning's $n$ value of 0.025 was determined to be used throughout the Hudson River and New York Bay except in the East and Harlem Rivers after the sub-grid model was calibrated with the astronomical tide data. A slightly higher Manning's $n$ value of 0.035 for the East and Harlem River was needed because the river was narrow, winding and contained many man-made features. After the forcing and the friction parameters were determined, the sub-grid model simulation was executed on a Dell Precision T-3500 with Intel Xeon W3670, Windows 7, 64-bit OS and 24 GB RAM. The CPU (Central Processing Unit) to real time ratio was roughly 240:1. Excellent storm tide results were obtained with a correlation coefficient of 0.98 compared with observed data from The Battery, NY NOAA tidal gauge station. Additional comparisons with the USGS rapid deployment gauges will be presented in the next section.

\subsection{Sub-Grid Inundation Model Results Compared with USGS Hurricane Sandy Mapper}

Aside from the modeling effort described so far, the USGS has made large efforts in deploying a monitoring network of water-level and pressure sensors along the U.S. Atlantic Coast during Hurricane Sandy [16]. These data combined with the field-verified high water marks collected post-storm were utilized to construct a water surface elevation, which was subsequently subtracted from the best available DEM to create a contour of the maximum extent of inundation, comprised of the inundation grid and surge boundary. The database and GIS (Geographic Information System) products produced by the USGS are tremendously valuable for benchmarking of the sub-grid model results. 


\subsubsection{Time Series Comparison-Timing of the Inundation}

One of the means for verifying model performance is the use of time series comparisons at fixed spatial points. Figures $4 \mathrm{a}$ and $5 \mathrm{a}, \mathrm{b}$ show the comparison of sub-grid modeled storm tide results at three separate locations: Gowanus Canal, Brooklyn, Whitestone, Queens, and Lower Harlem, at the East River, where rapid deployment gauges were installed. In all three comparisons, it can be seen that the model-simulated results (shown in red) are consistent with the measured data (shown in blue) both in terms of the timing and the amplitude. The root mean square statistics for the above stations are $7.7 \mathrm{~cm}, 9.2 \mathrm{~cm}$ and $16.8 \mathrm{~cm}$, respectively (note, only partial records are available at the station in lower Harlem at East River). In Figures $4 \mathrm{a}$ and $5 \mathrm{a}$, the gauge was set at a fixed height above the ground, which can become dry when the water falls below the gauge. What makes this comparison unique is that these stations are not permanently wet. That means the numerical wetting and drying scheme was quite robust and faithful in tracking the timing of the wetting and drying status revealed by the gauge. From the record, it is obvious that the inundation co-oscillated with the tidal cycle and that the model captured the timing and the depth of the water quite satisfactorily.

\subsubsection{Thickness of the Inundation}

When simulating inundation for the urban area such as the metropolitan area of New York City, one of the key parameters that needs to be determined is the flow resistance that includes the effects of high rise buildings and the streets. Since the flow resistance formula used is the Manning's equation, values of Manning's $n$ are needed in addition to the water level calculated by the model. Our guidance in selecting the parameter mainly came from [17], in which the laboratory experiment was conducted to determine the friction parameters during the hurricane surge. The results from the laboratory experiment are then scaled up to the prototype using the dynamic similitude relationship. To do so, aerial photos were processed in order to estimate different scales and the distribution of the building. In the end, we resorted to determine different Manning's $n$ for large sections of the different neighborhoods of the city based on the non-dimensional number scaled between the building size and the street width. The detailed procedure for selecting Manning's n for New York City can be found in [18]. The rapid deployment gauges provide unique and continuous information for checking the timing and the thickness of the inundation. Examining Figures 4 and 5 closely, it can be seen that the model under-predicted the amplitude of the measurements, particularly for Figure 5b. Our assessment is that the current model indeed used a higher than normal friction parameter (with $n=0.045$ ), in the Harlem at East River station, which may have contributed to the under-prediction of amplitude. For the stations at Gowanus Canal, and Whitestone, Queens, the RMS for the time series amount to 2.5\% and $3.1 \%$ relative error of the total water level, demonstrating that the inundation calculations are accurate enough to estimate the thickness of the inundation, which is the total water level minus the local land height imbedded in the sub-grid. 


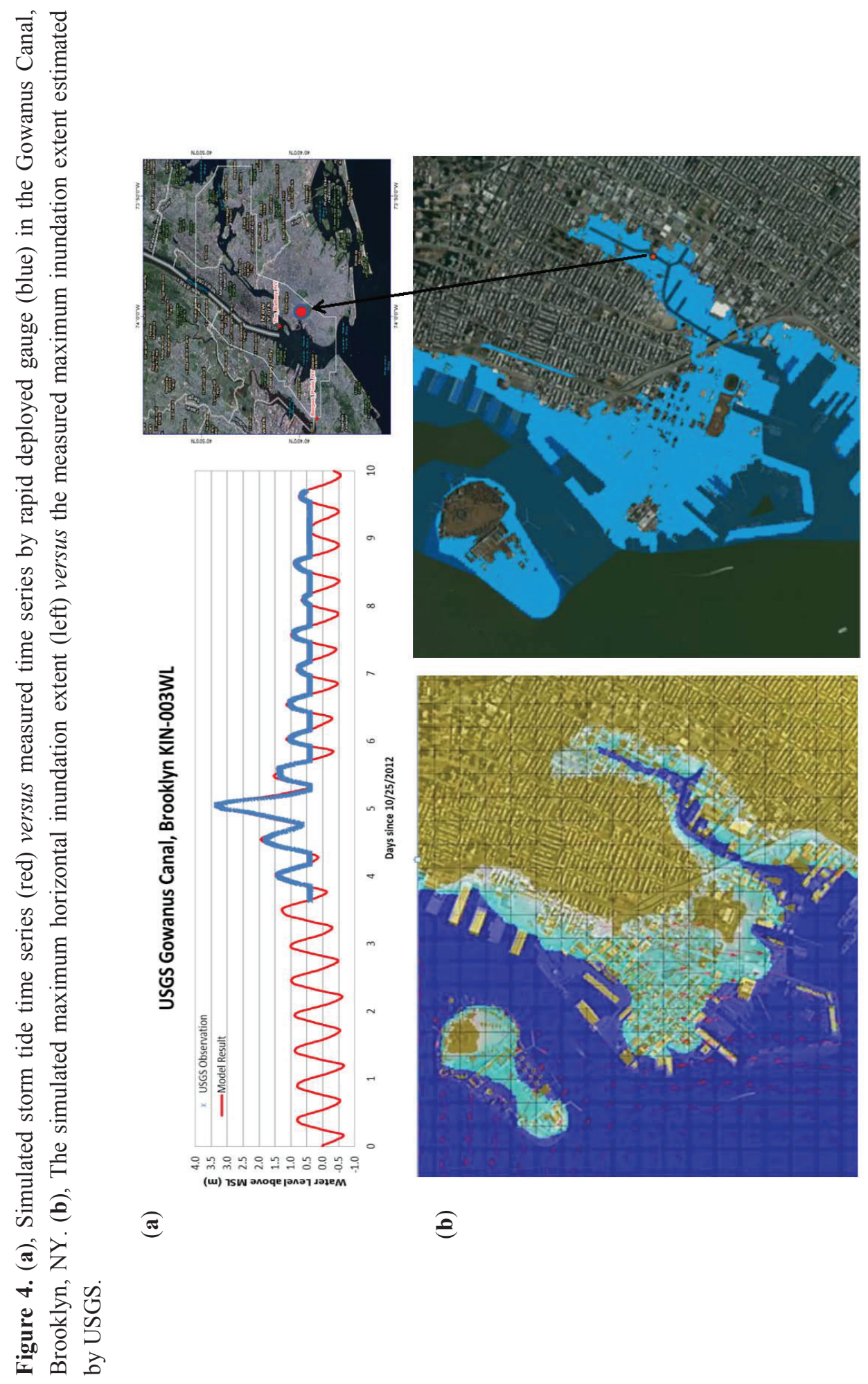




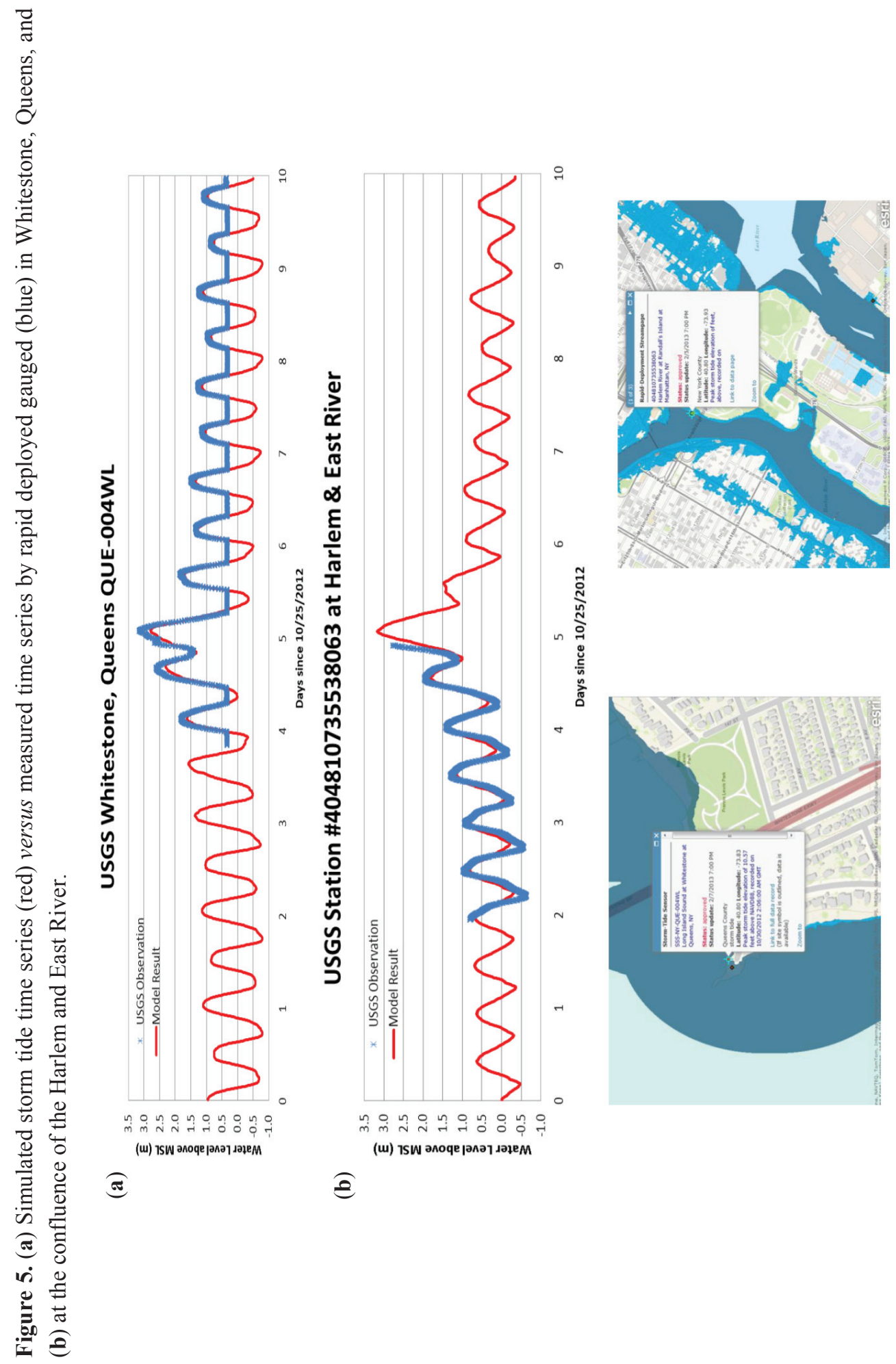




\subsubsection{Maximum Extent of the Inundation}

Maximum horizontal extent of the inundation is an important attribute for flood risk assessment. The accuracy of the horizontal extent of the inundation depends on total volume flux and the propagation speed of the long wave associated with water level variation. Using a nonlinear wetting and drying solver, UnTRIM ${ }^{2}$ sub-grid modeling allows the partially wet and dry status to be accurately resolved and switched naturally, and thus predict the maximum extent of the inundation accurately. We have made an animation of the floodwater movement in New York City during the entire event of Hurricane Sandy. With street buildings better resolved, one can clearly see the water rushing through the streets and flowing around the buildings with identifiable velocity and magnitude. The maximum extent of the inundation in the Brooklyn neighborhood is shown in the lower panel of Figure 4b: On the left is the prediction by the sub-grid model and on the right is the USGS observation. It can be seen that the patterns are extremely similar qualitatively; the model, however, provided additional quantitative information on the depth of the inundation and the velocity vector which which the water moved. The sensitivity test for running the inundation model with and without sub-grid was also conducted using $200 \mathrm{~m}, 150 \mathrm{~m}$ and $50 \mathrm{~m}$ resolutions, as shown in Figure 6. The top panel shows the result with the sub-grid and the lower panel that without sub-grid. It can be seen that the result without the sub-grid is sensitive to the grid resolution, the coarser the grid, the more dissipation on the surge wave height. In contrast, the result with the sub-grid is less sensitive to the grid resolution and closer to the observation. Lastly, the maximum extent of the horizontal inundation for the Hudson River (including the New York City and New Jersey sides), East and Harlem Rivers in New York City, was calculated and the distance between the model simulated extent and data-derived extent (estimated by USGS) was processed (see Table 2). It is pointed out that the second column in the table shows the number of points used and the third column shows the mean absolute difference in each of the regions. Overall, the mean difference of the horizontal extent is slightly less than $30 \mathrm{~m}$, with a standard deviation of $25 \mathrm{~m}$ [18]. In comparison that is equivalent to about half a city block in Manhattan or a third of a football field.

Table 2. The comparison of maximum horizontal extent of inundation in New York City between model-simulated and data-derived distance estimates by USGS.

\begin{tabular}{cccc}
\hline Survey Region & \# of Points & Abs. Mean Difference & Std. Deviation \\
\hline New York & & & \\
East River NY & 47,283 & 33.34 & 35.65 \\
Harlem River NY & 9,673 & 31.42 & 34.63 \\
Hudson River NY & 21,492 & 22.68 & 18.43 \\
All New York & 78,448 & 29.15 & 29.57 \\
\hline New Jersey & & & \\
Hudson River NJ & 16,396 & 30.49 & 21.71 \\
All New Jersey & 16,396 & 30.49 & 21.71 \\
\hline All Hudson River & 37,888 & 26.58 & 20.07 \\
\hline Total Across Domain & 94,844 & 29.82 & \\
\hline
\end{tabular}



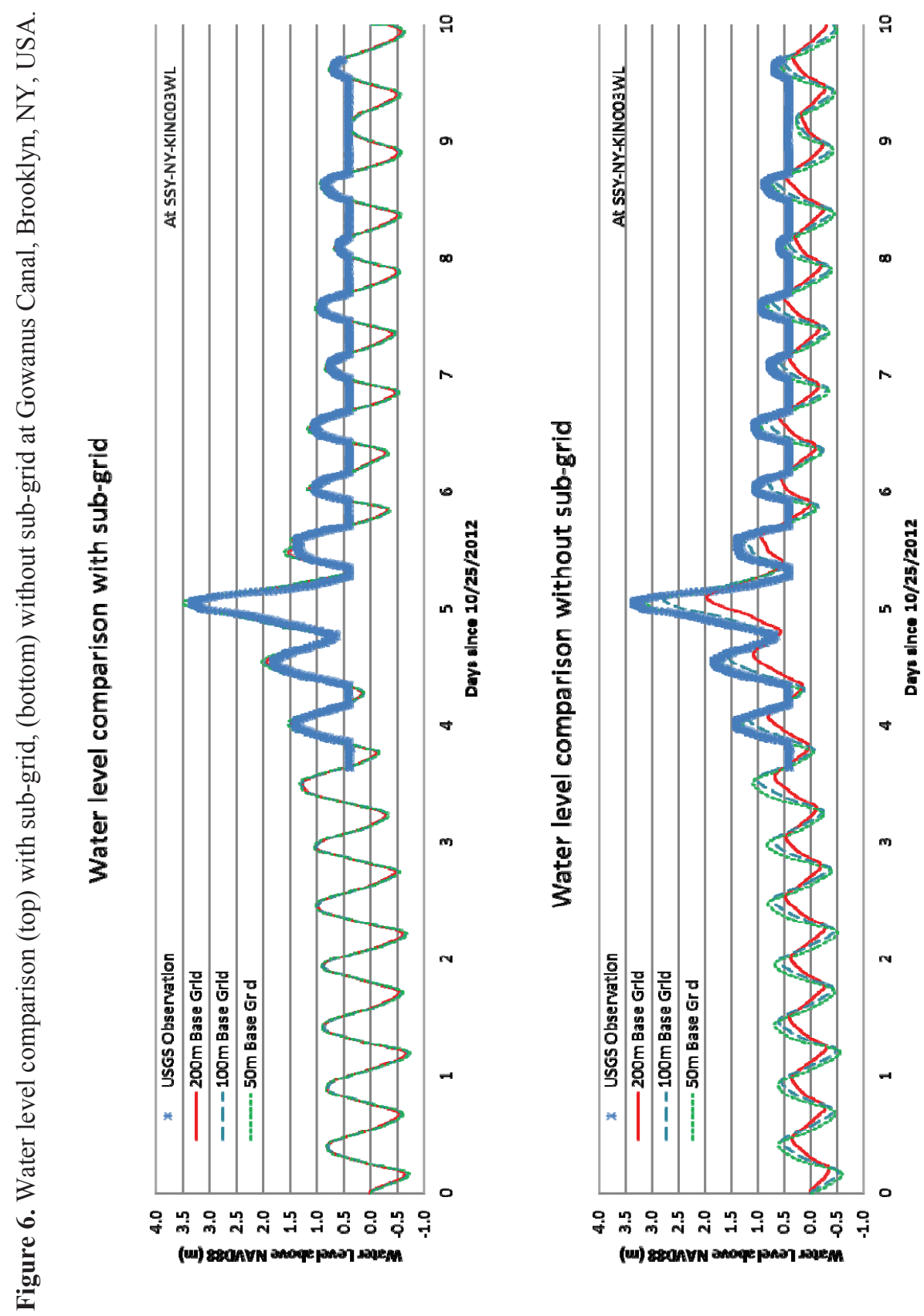


\section{Discussion and Conclusion}

In the process of modeling the storm tide during Hurricane Sandy, other atmospheric models NAM (North American Mesoscale Model) and NARR (North American Regional Reanalysis) products were initially tested. The storm tide results produced by these two products were less satisfactory than those by RAMS, possibly due to temporal and spatial resolutions. The NAM and NARR only produce outputs every $3 \mathrm{~h}$ on a $12-32 \mathrm{~km}$ grid whereas RAMS provides hourly outputs on a $3-4 \mathrm{~km}$ grid. This could be significant considering coastal waterways are sensitive to the swift change of hurricane winds. In addition, the extension of simulation periods from 3 to 14 days before Hurricane landing also improved the results and allowed better capturing of the sub-tidal variations that occurred before the event. in the inundation model, the determination of Manning's $\mathrm{n}$ for different sections of the neighborhood for New York City involved procedures to derive the building and street distribution from aerial photographs. Two GIS tools, distance and area methods, were used to compare the maximum inundation extent between modeled and USGS observed results. These procedures and many details can be found in [18].

As a conclusion, the paper describes the application of a modeling system consisting of a large-scale storm tide and a high-resolution inundation model for New York City during Hurricane Sandy. For large-scale storm tide modeling, satisfactory storm tide results were obtained over the mid-Atlantic portion of the U.S. East Coast by SELFE with an overall RMS of 15-20 cm and a relative error of $5 \%-7 \%$. The computational efficiency achieved is about 144 times that of the real time situation on a 128-processor cluster with MPI parallel programming and the usage of semi-implicit and Eulerian-Lagrangian numerical schemes. For the inundation modeling, a novel approach, the sub-grid modeling technique in UnTRIM², was used, which incorporates high resolution LIDAR data of land heights and water depths in the sub-element of the computational grid. It provides more accurate calculations of conveyance fluxes, wetting and drying areas, and the bottom stress without having to make computations on the fine computation mesh, and so achieves savings of computational cost. The reasonably accurate high-resolution inundation was generated in New York City, which is consistent with the time series measurement of rapid deployment gauges. Overall, the mean absolute difference (MAD) of the maximum extent of inundation was less than $30 \mathrm{~m}$ between modeled and the data-derived estimates conducted by USGS. Finally, there are many processes at play during a hurricane surge event that are still not included in the current model; examples are precipitation, filtration, storm water drainage, and the effect of wind waves, which will be the focus of future improvement.

\section{Acknowledgments}

The Virginia Institute of Marine Science team is grateful to Steve Woll, Jay Titlow, and Martin Bell of WeatherFlow Inc. for providing the RAMS atmospheric model results for the Hurricane Sandy storm surge and inundation simulation. 


\section{Author Contributions}

The work is a product of the intellectual environment of the whole team; and that all members have contributed in various degrees to the research concept and to the execution of the numerical experiment. Conceived and designed the numerical modeling experiments: Harry Wang, David Forrest and Joseph Zhang. Setup and performed the experiments: Jon Loftis and Zhuo Liu. Analyzed model result: Jon Loftis, Zhuo Liu, Harry Wang. Harry Wang wrote the paper.

\section{Conflicts of Interest}

The authors declare no conflict of interest.

\section{References}

1. NOAA Service Assessment. Hurricane/Post-Tropical Cyclone Sandy, October 22-29, 2012; National Weather Service, NOAA: Silver Spring, MD, USA, 2012.

2. Jelesnianski, C.P.; Shen, J.; Shaffer, W.A. SLOSH: Sea, Lake, and Overland Surges form Hurricanes; NOAA Technical Report NWS 48; National Weather Service: Silver Spring, MD, USA, April 1992.

3. Luettich, R.A., Jr.; Westerink, J.J. Implementation of the Wave Radiation Stress Gradient As a Forcing for the ADCIRC Hydrodynamic Model: Upgrades and Documentation for ADCIRC, Version 34.12; Department of the Army, U.S. Army Corps of Engineers, Waterways Experiment Station: Vicksburg, MS, USA, May 1999.

4. Weisberg, R.; Zheng, L. Hurricane storm surge simulations comparing three-dimensional with two-dimensional formulations based on an Ivan-like storm over the Tampa Bay, Florida region. J. Geophys. Res. 2008, 113, doi:10.1029/2008JC005115.

5. Sheng, P.Y.; Alymov, V.; Paramygin, V. Simulation of storm surge, wave, currents and inundation in the outer banks and Chesapeake Bay during Hurricane Isabel in 2003: The importance of waves. J. Geophys. Res. 2010, 115, doi:10.1029/2009JC005402.

6. Zhang, K.; Li, Y.; Lui, H.; Rhome, J.; Forbes, C. Transition of the Coastal and Estuarine Storm Tide Model to an operational forecast model: A case study of Florida, Weather, and Forecasting. Weather Forecast. 2013, 28, 1019-1037.

7. Zhang, Y.; Baptista, A.M. SELFE: A semi-implicit Eulerian-Lagrangian finite-element model for cross-scale ocean circulation. Ocean Model. 2008, 21, 71-96.

8. Casulli, V. Semi-implicit, subgrid modelling of three-dimensional free-surface flows. Int. J. Numer. Methods Fluid 2010, 67, 441-449.

9. Roland, A.; Zhang, Y.; Wang, H.V.; Meng, Y.; Teng, Y.; Maderich, V.; Brovchenko, I.; Dutour-Sikiric, M.; Zanke, U. A fully coupled wave-current model on unstructured grids. J. Geophys. Res. 2012, 117, doi:10.1029/2012JC007952.

10. Garratt, J.R. Review of drag coefficients over oceans and continent. Mon. Weather Rev. 1977, $105,915-929$. 
11. LeProvost, C.; Lyard, F.; Molines, J.M.; Gebco, M.L.; Rabilloud, F. A hydrodynamic ocean tide model improved by assimilating a satellite altimeter-derived dataset. J. Geophys. Res. 1998, 103, 5513-5529.

12. Blumberg, A.; Khan, L.A.; St. John, J.P. Three-dimensional hydrodynamic model of New York Harbor region. J. Hydraul. Eng. 1999, 125, 799-816.

13. Reid, R.O. Modification of the Quadric Bottom-Stress Law for the Turbulent Channel Flow in the Presence of Surface Wind-Stress; U.S. Beach Erosion Board: Washington, DC, USA, 1957; p. 33.

14. Casulli, V. A high resolution wetting and drying algorithm for free-surface hydrodynamics. Int. J. Numer. Methods Fluid 2009, 60, 391-408.

15. Stelling, G.S. Quadtree flood simulations with sub-grid digital elevation models. Proc. Inst. Civil Eng. Water Manag. 2012, 165, 567-580.

16. McCallum, B.E.; Wicklein, S.M.; Reiser, R.G.; Busciolano, R.; Morrison, J.; Verdi, R.J.; Painter, J.A.; Frantz, E.R.; Gotvald, A.J. Monitoring Storm Tide and Flooding from Hurricane Sandy Along the Atlantic Coast of the United States, October 2012; U.S. Geological Survey Open-File Report 2013-1043; Office of Surface Water, U.S. Geological Survey, MS 415 National Center: Reston, VA, USA, 2013; p. 42.

17. Wang, S.-Y.; Christensen, B.A. Friction in hurricane-induced surges. In Proceedings of 20th Conference on Coastal Engineering, Taipei, Taiwan, 9-14 November 1986; pp. 822-836.

18. Loftis, J.D. Development of a high-resolution large-scale storm surge and sub-grid inundation model coupled with LIDAR topography for coastal flooding. Ph.D. Thesis, College of William and Mary, Williamsburg, VA, USA, 2014, in preparation. 


\title{
Towards the Development of the National Ocean Service San Francisco Bay Operational Forecast System
}

\author{
Machuan Peng, Richard A. Schmalz Jr., Aijun Zhang and Frank Aikman III
}

\begin{abstract}
The National Ocean Service (NOS), Center for Operational Products and Services installed a Physical Oceanographic Real Time System (PORTS) in San Francisco Bay during 1998 to provide water surface elevation, currents at PORTS prediction depth as well as near-surface temperature and salinity. To complement the PORTS, a new nowcast/forecast system (consistent with NOS procedures) has been constructed. This new nowcast/forecast system is based on the Finite Volume Coastal Ocean Model (FVCOM) using a computational domain, which extends from Rio Vista on the Sacramento River and Antioch on the San Joaquin River through Suisun and San Pablo Bays and Upper and Lower San Francisco Bay out onto the continental shelf. This paper presents the FVCOM setup, testing, and validation for tidal and hindcast scenarios. In addition, the San Francisco Bay Operational Forecast System (SFBOFS) setup within the NOS Coastal Ocean Model Framework (COMF) is discussed. The SFBOFS performance during a semi-operational nowcast/forecast test period is presented and the production webpage is also briefly introduced. FVCOM, the core of SFBOFS, has been found to run robustly during the test period. Amplitudes and epochs of the $\mathrm{M}_{2} \mathrm{~S}_{2}$, $\mathrm{N}_{2}, \mathrm{~K}_{2}, \mathrm{~K}_{1}, \mathrm{O}_{1}, \mathrm{P}_{1}$, and $\mathrm{Q}_{1}$ constituents from the model tide-only simulation scenario are very close to the observed values at all stations. NOS skill assessment and RMS errors of all variables indicate that most statistical parameters pass the assessment criteria, and the model predictions are in agreement with measurements for both hindcast and semi-operational nowcast/forecast scenarios.
\end{abstract}

Reprinted from J. Mar. Sci. Eng. Cite as: Peng, M.; Schmalz Jr., R.A.; Zhang, A.; Aikman III, F. Towards the Development of the National Ocean Service San Francisco Bay Operational Forecast System. J. Mar. Sci. Eng. 2014, 2, 247-286.

\section{Introduction}

In 1998, the National Oceanic and Atmospheric Administration (NOAA)/National Ocean Service (NOS) installed a Physical Oceanographic Real Time System (PORTS) in San Francisco Bay to provide water surface elevation, current, near-surface and near-bottom temperature and salinity, and meteorological information to promote safe and efficient navigation in this area [1]. As PORTS only supplies measured data at selected stations, NOS' National Operational Coastal Modeling Program (NOCMP) is developing an Operational Forecast System (OFS) to complement the service.

Many researchers have employed different versions of TRIM (Tidal, Residual, Intertidal, Mudflat Model) [2-4] for their purposes in the bay. For example, Cheng and Smith [5] employed the TRIM2D (two-dimensional TRIM) for the San Francisco Bay Marine Nowcast. The TRIM3D was recently applied by Gross et al. [6] to the entire San Francisco Bay. The UnTRIM, an unstructured version of TRIM3D, has also been applied to San Francisco Bay by MacWilliams and Cheng [7].

Two- and three-dimensional models have been extensively applied to investigate the hydrodynamic and morphologic processes in San Francisco Bay. Barnard et al. [8-10] report the 
existence of sand waves with heights in the order of 2 meters at the entrance of the Bay and consider coastal process evolution and the numerical prediction of severe storms on the coastline initially using the two-dimensional vertically integrated mode of the Delft3D-FLOW model [11]. Uslu et al. [12] developed a very high resolution two-dimensional vertically integrated model for tsunami forecasts in this region.

Fringer et al. [13] developed the non-hydrostatic option SUNTANS (Stanford Unstructured Nonhydrostatic Terrain-following Adaptive Navier-Stokes) model, which has also been applied in San Francisco Bay by Chua and Fringer [14].

Some of these structured and unstructured models $[15,16]$ have been employed to understand the role of stratification and baroclinic circulation on salt intrusion in the northeastern part of Figure 1. They focus on the dynamic interactions between fresh water from the Sacramento and San Joaquin Rivers and salt water from the open ocean. Their studies, as will be seen later in this paper, have great value in evaluating the advantage and disadvantage of using a flow or stage river boundary condition for these two rivers.

Figure 1. The bathymetry of San Francisco Bay Operational Forecast System and the major gauge stations. The definition of "delta" in this paper is the region with complicated water channels to the east of Antioch and Rio Vista. The locations of the three major bays are indicated. Note: the domain in this figure is a little larger than the model grid domain as shown in Figure 2.

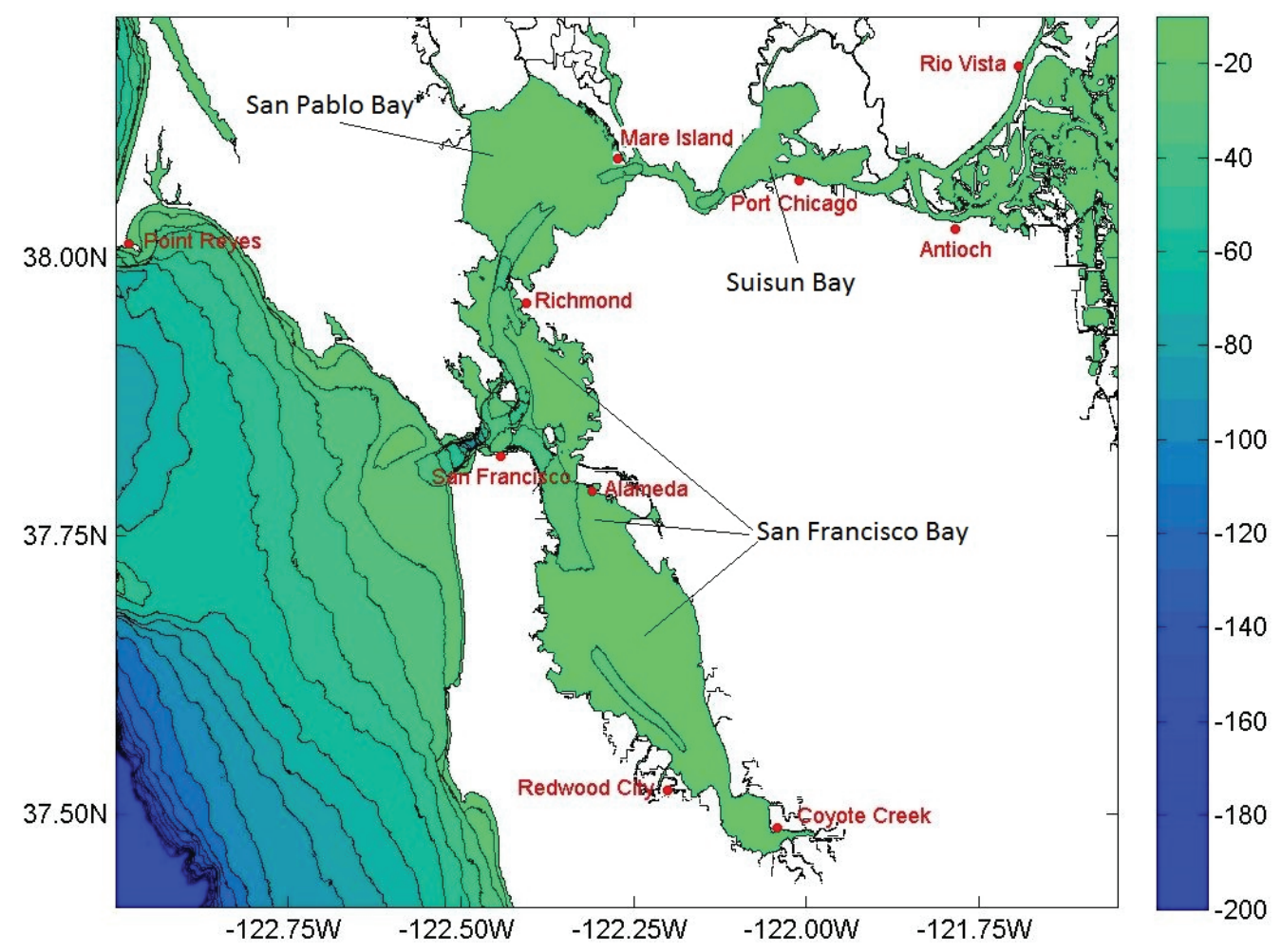


Figure 2. The SFBOFS grid structure and the open boundaries. Measured river flow data from USGS are used as river forcings for the five small rivers in blue. Measured river flow or river stage data at Rio Vista and Antioch may be used as river forcings, respectively, for Sacramento River and San Joaquin River. Technically, if river stage data are employed, the grid points across these two major rivers are treated the same way as those on the Pacific Open Boundary.

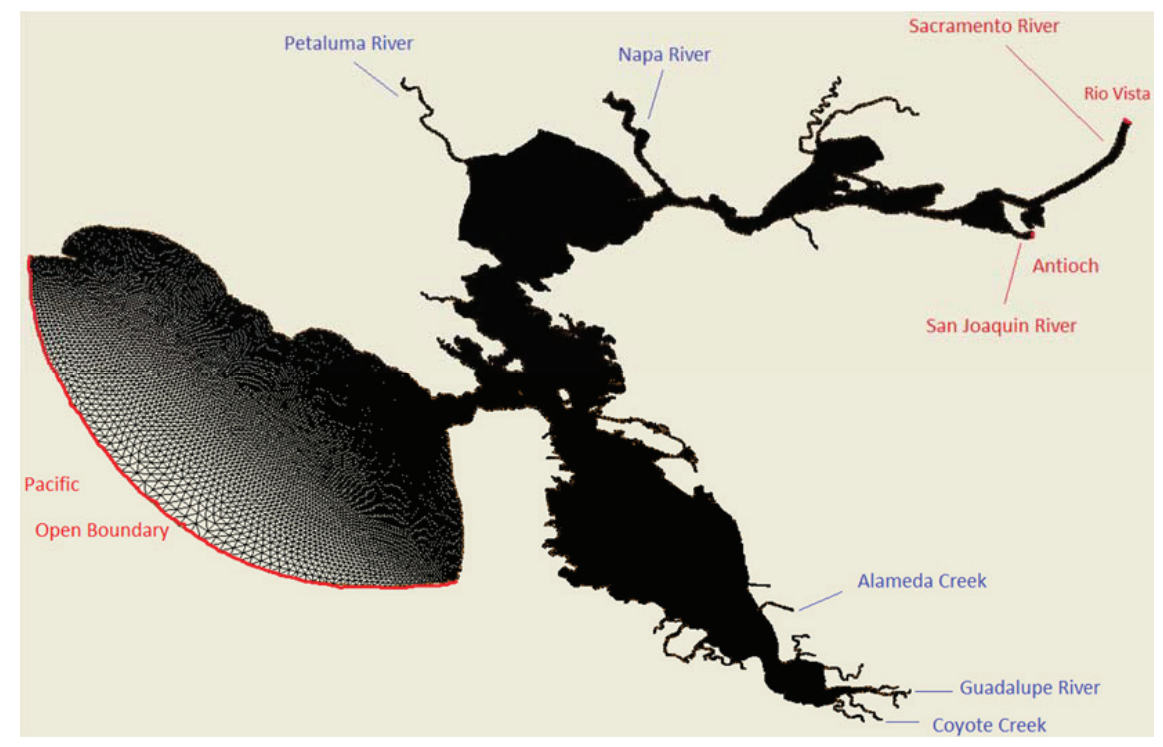

The primary objective of the NOCMP, however, is to develop and operate a national network of OFSs to support NOAA's mission goals and priorities. This ongoing San Francisco Bay Operational Forecast System (SFBOFS) will become a new member of the existing OFS family. Up to now, NOCMP has successfully developed CBOFS (Chesapeake Bay), DBOFS (Delaware Bay), TBOFS (Tampa Bay), NGOFS (Northern Gulf of Mexico), CREOFS (Columbia River Estuary) and other OFSs which along the Atlantic, Gulf of Mexico, Great Lake and Pacific Coasts.

With the use of the COMF (Coastal Ocean Model Framework) on NOAA's High Performance Computer (HPC), each OFS automatically integrates NOAA's observing system's data streams and the forecast output from meteorological and basin scale ocean models to generate necessary model input forcings, and then perform hydrodynamic model predictions with such forcings. Also with COMF, these OFSs perform nowcast and short-term forecast predictions (48 hours in most case) of pertinent parameters which include water levels, currents, salinity, and temperature and disseminate them to users. A state-of-the-art numerical hydrodynamic model driven by real-time data and meteorological, oceanographic, and river flow (or stage) forecasts forms the core of the end-to-end system. For detailed information on the COMF refer to Zhang et al. [17]. NOS CO-OPS is evolving to support two hydrodynamic models: ROMS for structured grid applications and FVCOM for unstructured grid applications.

As San Francisco Bay (Figure 1) has complex topography and shallow water features (the average water depth is less than 5 meters in the Bay), the well tested unstructured Finite Volume Coastal 
Ocean Model (FVCOM) [18-20] is employed as the core of the SFBOFS. Another reason to employ FVCOM lies in the fact that this model has already been ingested into the COMF-HPC as one of the major core models.

This paper shows the major steps in how SFBOFS has been developed, assessed and put into quasi-operational status. First, FVCOM is briefly reviewed in Section 2, followed by an overview of the model's setup in Section 3 for the tide and hindcast cases. Section 4 presents the model's astronomical tide-only scenario simulation evaluation, while the hindcast skill assessments are described in Section 5. The COMF setup and assessment of the quasi-operational nowcast/forecast test are discussed in Section 6. Conclusions and discussion are given in Section 7.

\section{The Model Overview, its Grid, and Subsequent Revisions}

The physics of the FVCOM model and many aspects of the computational scheme are equivalent to the widely used Princeton Ocean Model. The FVCOM model solves the three-dimensional, vertically hydrostatic, free surface, turbulent averaged equations of motions for a variable density fluid. The model uses a triangular unstructured horizontal grid with a generalized sigma vertical coordinate. Dynamically coupled transport equations for turbulent kinetic energy, turbulent length scale, salinity and temperature are also solved. The two turbulence parameter transport equations implement the Mellor-Yamada level 2.5 turbulence closure scheme. The numerical scheme employed in FVCOM to solve the equations of motion is summarized in [18-20].

The FVCOM application to San Francisco Bay uses external forcing of water level, ocean density, wind, sea level atmospheric pressure, air temperature, relative humidity, downward long wave radiation, short wave radiation, and fresh water discharges entering the model domain. The model calculates water levels, three dimensional velocity, salinity, and temperature.

The horizontal grid structure and open boundaries are shown in Figure 2. This grid was developed using the Surface Water Modeling System (SMS) Version 10.1 as described by Brigham Young University Surface Modeling Laboratory and was based on the VDATUM grid developed for the coastal waters of North/Central California, Oregon and Western Washington [21]. The open boundary of the San Francisco Bay grid was developed from this grid in the near shelf region external to the Bay. It was necessary to modify the VDATUM grid such that the outer boundary of the San Francisco Bay grid follows an approximate circular arc with one of the element sides near orthogonal to the boundary arc. The grid contains 102264 elements and 54120 nodes with a minimum depth of $0.2 \mathrm{~m}$ and maximum depth of $106.8 \mathrm{~m}$ [22]. A uniform 20-layer sigma level vertical discretization was considered.

The following element quality checks were used: (1) minimum and maximum interior angles of 10 and 130 degrees, respectively, (2) maximum slope of 0.1, (3) maximum adjacent element area change ratio of 0.5 , and (4) maximum number of elements connected to a node of 8 . Note the slope corresponds to the maximum allowed gradient of the edge length inside the domain. The slope determines how fast the mesh size will increase toward the middle of the region. A small slope order of 0.1 means small meshes. The paving method was used, which uses an advancing front technique to fill the polygon with elements. Based on the vertex distribution on the boundaries, equilateral triangles were created on the interior to define a smaller interior polygon. Overlapping regions were 
removed and the process is repeated until the region is filled. Interior nodal locations are relaxed to create better quality elements. Several triangles were adjusted such that the minimum interior angle was at least 30 degrees to improve FVCOM stability. In addition, along the open boundaries, the element topology was adjusted such that each boundary element contained only one boundary side. The triangle lengths are sufficiently small, that a reasonable $\mathrm{M}_{2}$ wavelength to grid size is obtained as shown in Figure 3, where element lengths decrease from 400 to $1700 \mathrm{~m}$ along the open ocean boundary to a near uniform resolution of order $150 \mathrm{~m}$ throughout the interior bays and into the lower delta.

Several modifications were made in the development of SFBOFS to Version FVCOM 3.1.6. It should be noted that if the HEATING_CALCULATED_ON options is selected then the AIR_PRESSURE_ON option must be selected. While the sea level atmospheric pressure field is needed for the heating calculations, its gradient does not need to be applied in the momentum equations. In fact, for tidal simulations this is not correct. For tidal simulations with the heat flux calculations selected, it is necessary to provide a constant sea level atmospheric pressure field $(1013 \mathrm{mb})$. Also, if one selects AIRPRESSURE ON $=\mathrm{F}$ in namelist, the flag FLAG $28=$ -DAIR_PRESSURE in file make.inc should be noted.

The bottom roughness fix reported by Warner [23] for wetting/drying was added in file brough.F. In model testing, with the min_depth as $0.05 \mathrm{~m}$, the model ran successfully and works for the wetting/drying case in San Francisco Bay. A Newtonian damping sponge layer was implemented by Lettmann [24], which provides a more robust implementation of the clamped water level open ocean boundary condition.

In the shallow mud flat regions of the Bay, there was also an issue with overheating. As a result, subroutine vdif_ts.F was modified to limit the short wave radiation and total heat flux as a function of depth. For depths less than $10 \mathrm{~m}$, the fluxes were set to zero. In this manner, the heat transfer is due to only advection and diffusion. There, the zeta1_eff and zeta2_eff parameters which control the attenuation of the short wave radiation are set never to be less than $30 \%$ of the water depth and therefore always allow attenuation. In total, the following routines are involved in the above modifications:

1. fvcom.F, mod_ncdio.F, mod_timeseries.F_-air_pressure option or heating_calculated_on option.

2. brough.F_ bottom roughness with the Warner [23] wet/dry treatment.

3. advave_edge_gcn.F, advave_edge_gcy.F, extuv_edge.F, mod_semi_implicit.F and vdif_uv.F_-Lettmann [24] sponge boundary.

4. vdif_ts.F and vdif_ts_gom.F_revised heat flux in shallow water.

The interaction between the hydrodynamic and the sediment-water interface, particularly in the shallow water mudflat areas, which occupy some $16 \%$ of the Bay surface area, is an area where further research is needed. Fang and Stefan [25] considered the dynamics of heat exchange between the sediment and the bottom boundary layer for several hypothetical lakes. They found that the direction of the heat transfer reverses frequently on daily timescales as well as following an overall seasonal cycle based on weather conditions at Minneapolis-St. Paul, MN. Smith [26] performed a series of heat budget studies in Indian River Lagoon, FL, to estimate the water-sediment heat 
exchanges using assumed values for conductivity and density. The study sought to characterize subseasonal heat fluxes and temperature changes in the sediment and overlying estuarine waters.

Figure 3. The SFBOFS grid resolution structures are depicted. The element length sizes range from order 400-1700 m along the ocean boundary to order $200 \mathrm{~m}$ at the Bay Entrance as shown in the top panel. Within the Bay region the element lengths are reasonably uniform of order $150 \mathrm{~m}$ as shown in the lower panel with finer resolution around a few small islands of order $50 \mathrm{~m}$.

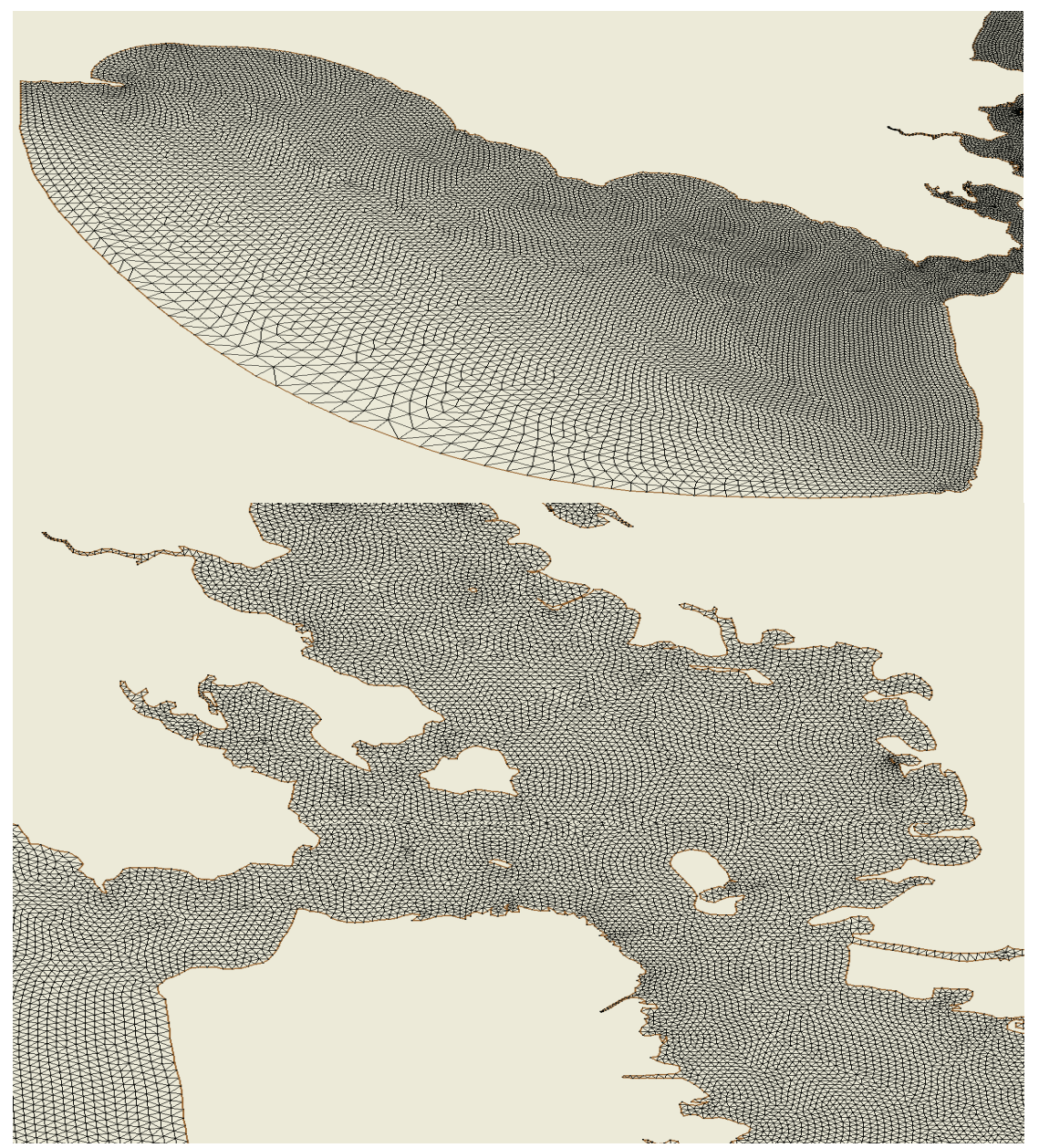

The bottom stress formulation in shallow water for wetting and drying has received continuing interest. Research by Xue and Due [27], Uchiyama [28], Oey [29,30], and Oey et al. [31] has indicated that the bottom drag coefficient must be adjusted if the water depth approaches the bottom roughness height. How to perform this adjustment is an area for further consideration. In the present version of FVCOM, the effective water depth used in the bottom friction formulation is limited to $3 \mathrm{~m}$; e.g., when the actual water depth is less than $3 \mathrm{~m}$, the depth used in the bottom friction formulation is set to $3 \mathrm{~m}$. 


\section{Model Setup}

Basically, the model needs reasonable specifications of the following four items to obtain skillful predictability. They are (1) River boundary forcing conditions, (2) open ocean boundary conditions, (3) initial conditions, and (4) surface forcings. Each of these model elements is discussed below.

\subsection{River Boundary Forcing Condition Specification}

There are seven rivers considered in the model. Traditional river discharge condition is used for the five small rivers that are not in the delta (the rivers with names in blue in Figures 2 and 3) area. These five rivers are the Petaluma River $\left(2 \mathrm{~m}^{3} / \mathrm{s}\right)$, Alameda Creek $\left(3 \mathrm{~m}^{3} / \mathrm{s}\right)$, Napa River $\left(100 \mathrm{~m}^{3} / \mathrm{s}\right)$, Coyote Creek $\left(2 \mathrm{~m}^{3} / \mathrm{s}\right)$ and Guadalupe River $\left(3 \mathrm{~m}^{3} / \mathrm{s}\right)$ with approximate mean annual flows in parentheses. The two rivers in the delta are Sacramento River at Rio Vista $\left(1000 \mathrm{~m}^{3} / \mathrm{s}\right)$ and San Joaquin River at Antioch $\left(100 \mathrm{~m}^{3} / \mathrm{s}\right)$ with approximate mean annual flows in parentheses. Two different upstream boundary condition types were considered for the Sacramento and San Joaquin Rivers forcing specification.

In type one, the average daily flow of Sacramento River was used to specify the flow at Rio Vista (RIO), while the San Joaquin River flow was estimated as the total delta outflow (OUT) minus the Rio Vista flow (RIO). The measured data are from the California Department of Natural Resources' DAYFLOW [32]. The average daily flows (note: negative flow indicates flow into the Delta from the Bay) are used only for the hindcast scenario testing. Minimum inflow and zero salinity were set up for the two rivers in low flow period when DAYFLOW's estimates may be suspect as noted by Oltmann [33]. In type two, the water level surface elevations (stage) were specified at Rio Vista and Antioch for Sacramento River and San Joaquin River, respectively, similar to the previous work in this region by MacWilliams et al. [16].

Both flow and stage river boundary conditions were used in the hindcast for comparison purposes. Please see Schmalz [22] for details. However, in the nowcast/forecast system we only use a river stage forcing for these two rivers. This is because NOCMP's top priority is to support PORTS for navigation safety, and water level prediction is paramount. Previous studies and personal communication with Michael MacWilliams [34] have found that flow boundary condition may be more suitable if the focus is on salinity prediction. However, our major concern is surface water level as in PORTS, and the stage boundary condition is more suitable.

\subsection{Open Ocean Boundary Condition Specification}

The open ocean boundary of the grid (see Figures 2 and 3) is forced with a superposition of the subtidal water levels and predicted tides. The harmonic constants of $\mathrm{M}_{2}, \mathrm{~S}_{2}, \mathrm{~N}_{2}, \mathrm{~K}_{2}, \mathrm{~K}_{1}, \mathrm{O}_{1}, \mathrm{P}_{1}$, and $\mathrm{Q}_{1}$ that are used to predict tide are derived from the Oregon State University Tidal Inversion Software (OTIS) for the West Coast (WC2010 1/30) [35].

In the hindcast scenario, the subtidal water level signal at Point Reyes (see Figure 1 for its location) is used to prescribe the subtidal water level along the outer boundary. A revised sponge layer treatment at the open ocean boundary was considered. The salinity and temperature at the open 
boundaries were determined, with nudging, from NOAA's World Ocean Atlas 2001 [36]. No velocities are prescribed along the open ocean boundary.

In the nowcast and forecast scenarios, subtidal water level open boundary conditions are generated from the NCEP's (National Centers for Environmental Prediction) G-RTOFS (Global Real-Time Ocean Forecast System) gridded operational products. The temperature, salinity and baroclinic current open boundary conditions are also generated from G-RTOFS. The most recently available products for the given time period are searched and used for adjustments of the open boundary conditions using the COMF-HPC. Several horizontal interpolation methods are implemented, and a linear method is used for vertical interpolation from G-RTOFS vertical coordinates to model vertical coordinates. Measured real time sea surface elevation data at Point Reyes are used for the subtidal water level adjustment along the open boundary. Similarly, measured temperature data at San Francisco (see Figure 1 for its location) are used for boundary temperature adjustment. The adjustment is the difference between the observation and the G-RTOFS prediction at the start of the nowcast/forecast cycle and is discussed in greater detail in Section 6.1.

\subsection{Initial Condition Specification}

For the 19-month hindcast initial condition specification, the salinity and temperature fields were developed for 1 April 1979 using the joint NOS and USGS historical circulation survey conductivity-temperature-depth (CTD) datasets and the model was started from rest. The quasi-operational nowcast/forecast system started in the middle of March 2013 when a climatological temperature and salinity file (with adjustment from observation) was used as the very first initial condition. For each nowcast/forecast cycle, the COMF-HPC will automatically find the most recent restart file as this cycle's initial condition (SFBOFS has four cycles a day). The details of the HPC-COMF can be found in Zhang et al. [17].

\subsection{Surface Forcing Specification}

For hindcast scenario, the North American Regional Reanalysis (NARR) 2007 datasets with 32 $\mathrm{km}$ spatial and $3 \mathrm{~h}$ temporal resolution were interpolated to the model grid to provide $10 \mathrm{~m}$ winds, sea level atmospheric pressure, and $2 \mathrm{~m}$ fluxes of downward shortwave radiation and net total heat flux. For the nowcast and forecast, the COMF-HPC will automatically find the most recent NAM4 (North American Mesoscale Model 4 km resolution) results in NCEP's data tank to get the necessary input surface forcings.

\section{Tidal Simulation}

The tide scenario simulation is the standard first step for all OFS' development. This is due in good measure to the fact that water level is the first priority for safe navigation, and tide and tidal current are the dominant dynamic processes in most coastal waters. For the tide scenario, the model setup for the four forcing specifications as mentioned in the previous section is similar to that for hindcast scenario. The slight differences can be found below. 


\subsection{Short Term Experiment: 1-15 April 1979}

A three-dimensional simulation approach including baroclinics was used to capture the influence of internal waves on the tidal dynamics following [37,38]. The slight model setup difference from hindcast scenario is: winds were set to zero and the sea level atmospheric pressure set to $1013 \mathrm{mb}$. River flow conditions are used for all rivers. The April 1979 NOS and USGS historical circulation survey data were used to compare the model results with the observation.

To develop initial salinity and temperature conditions on 1 April 1979 (and on 1 September 1980 for the later extended experiment case), the available CTD and CT time series data were placed on a coarse unstructured grid of order 50 elements. An interpolation program was developed in which each FVCOM grid node was assigned a given element and the salinity/temperature value interpolated from the node values at the appropriate depths. This program allows the initial density condition to be developed for the tidal and hindcast simulations.

To calibrate the bottom roughness, the approach of Cheng et al. [15] was used, in which the bottom roughness is made a function of water depth as in Table 1. To reduce the amplitude of the simulated water level response at Port Chicago, the bottom friction was further increased above Carquinez Strait as noted in Table 1. The water level response with respect to MLLW at Port Chicago for Experiments 1 and 2 is similar (See Figure 4). Results for Experiments 5 and 7 show very minor improvement in the agreement with water level observations at Port Chicago in the order of a $2 \mathrm{~cm}$ reduction in RMSE. Experiments 3, 4, and 6 were unstable, due to large horizontal gradients in bottom roughness during the wetting/drying cycle.

Table 1. Delta Inflow Bottom Friction Experiment Summary. The scale factor was used to multiply bottom roughness in model domain above Carquinez Strait. The tapered scale factor ranges from 1 to the full value in a linear fashion from Carquinez Strait to the river inflows based on longitude. The bottom roughness sets are given in the second table. The HA amplitude reduction corresponds to reducing the amplitudes of the offshore boundary harmonic constants.

\begin{tabular}{|c|c|c|c|c|}
\hline Experiment & Scale Factor & \multicolumn{3}{|c|}{ HA Amplitude Reduction (\%) } \\
\hline Exp1 & 2 & 1 & & 0 \\
\hline Exp2 & 5 & 1 & & 0 \\
\hline Exp3 & 10 tapered & 1 & & 0 \\
\hline Exp4 & 10 & 1 & & 0 \\
\hline Exp5 & 5 & 1 & & 5 \\
\hline Exp6 & 5 & 2 & & 10 \\
\hline Exp7 & 1.2 & 2 & & 10 \\
\hline $\begin{array}{c}\text { Roughness Zone } \\
\text { Number }\end{array}$ & $\begin{array}{l}\text { Lower Depth } \\
\text { (m) }\end{array}$ & $\begin{array}{l}\text { Upper Depth } \\
(\mathrm{m})\end{array}$ & $\begin{array}{c}\text { Set } 1 \text { Bottom Roughness } \\
\mathrm{z}_{0}(\mathrm{~mm})\end{array}$ & $\begin{array}{c}\text { Set } 2 \text { Bottom Roughness } \\
\mathrm{z}_{0}(\mathrm{~mm})\end{array}$ \\
\hline 1 & 0 & 1 & 30 & 40 \\
\hline 2 & 1 & 3 & 20 & 30 \\
\hline 3 & 3 & 10 & 10 & 20 \\
\hline 4 & 10 & 50 & 7 & 17 \\
\hline 5 & 50 & 1000 & 5 & 15 \\
\hline
\end{tabular}


Three additional Experiments 8-10 were conducted in which the river stage at Rio Vista and at Antioch was reconstructed from NOS harmonic constituents. Experiment 8 used the Experiment 7 bottom roughness specification. Experiment 9 included a $20 \mathrm{~cm}$ offset for the San Joaquin River and a $22 \mathrm{~cm}$ offset for the Sacramento River. In Experiment 10, the Experiment 9 offsets were retained and the Set 1 Bottom Roughness zo values were used. Note in these stage experiments the Oregon State University Tidal Data Inversion, OTIS Regional Tide Solutions [35] harmonic analysis results were reduced by $5 \%$ for the four ocean open boundary stations. Note the Sa and Ssa harmonic constituents derived from San Francisco water level analysis were used at these stations. All other open boundary node water levels were derived via linear interpolation of values from two of the stations surrounding the node.

Figure 4. Comparison of modeled versus predicted water level at Port Chicago with flow boundary condition over the period 1-15 April 1979.

\section{San Francisco Bay Tidal Simulation 941-5144 Port Chicago \\ Elevation - MLLW (M)}

RMSE $=0.19 \mathrm{~cm} \quad$ Flow River Condition

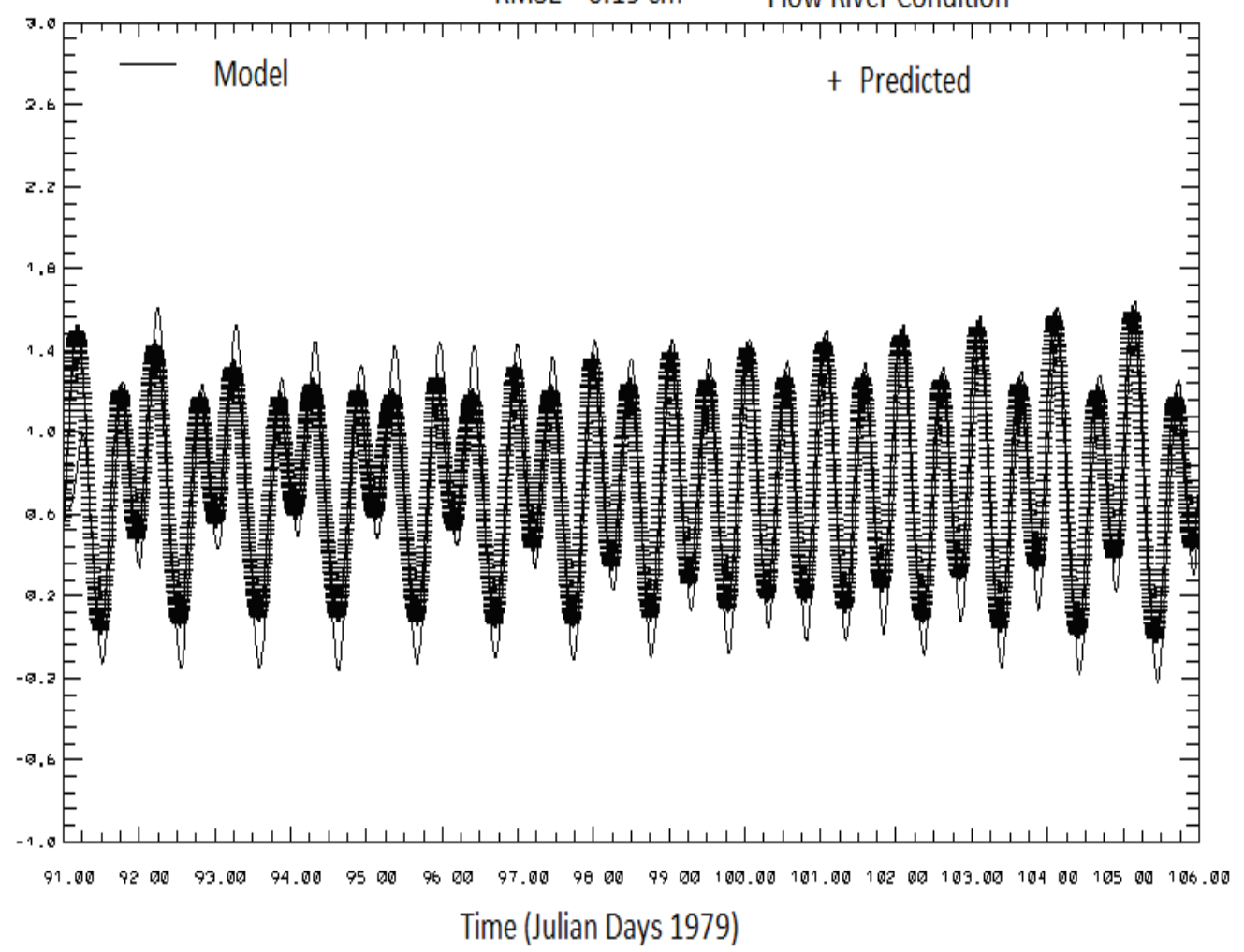

In SFBOFS, we assume that the model datum is equal to the North American Vertical Datum of 1988 (NAVD88) minus $0.955 \mathrm{~m}$ (this resultant level is close to the MSL at open ocean boundary). Therefore, an additional field, model datum minus mean sea level, was developed. In San Francisco Bay, NAVD88 data were available from Point Reyes up to the river inflow locations. 
A program was developed to access the VDATUM database and to interpolate onto the SFBOFS grid the following four datum fields: MLLW to MSL, MLW to MSL, MHHW to MSL, and MHW to MSL. In addition, the specification of the model datum (MD) to MSL allows the model predicted water level results to be presented with respect to all of the tidal datums. MSL, MLLW, NAVD88 and MSL-MD of key stations are listed in Table 2.

Table 2. Water Level Vertical Datums. Note tidal datums and NAVD88 are with respect to gage zero. Model Datum (MD) is given with respect to MSL. Note at the up estuary stations, MSL is above the model datum, while at the entrance to the Bay, MSL and the model datum are coincident. Using the table, it is possible to determine MLLW with respect to $\mathrm{MD}$.

\begin{tabular}{cccccc}
\hline Station Number & Station Name & MSL & MLLW & NAVD88 & MSL-MD \\
\hline $941-5020$ & Point Reyes & 2.152 & 1.206 & 1.214 & -0.017 \\
$941-4290$ & San Francisco & 2.773 & 1.822 & 1.804 & 0.014 \\
$941-4523$ & Redwood City & 3.378 & 2.033 & $\mathrm{n} / \mathrm{a}$ & 0.026 \\
$941-4575$ & Coyote Creek & 1.388 & -0.112 & $\mathrm{n} / \mathrm{a}$ & 0.026 \\
$941-4750$ & Alameda & 2.067 & 1.016 & 1.086 & 0.026 \\
$941-4863$ & Richmond & 4.520 & 3.528 & 3.530 & 0.035 \\
$941-5218$ & Mare Island & 1.864 & 0.922 & 0.784 & 0.125 \\
$941-5144$ & Port Chicago & 1.996 & 1.215 & 0.880 & 0.161 \\
\hline
\end{tabular}

Note that MSL-MD difference increases from the Bay entrance to Antioch and Rio Vista. The MSL at Antioch and Rio Vista are 0.20 and $0.22 \mathrm{~m}$ above model datum, respectfully. The digital relationships among the different tidal datums, the model datum and NAVD88 are helpful in correctly comparing model results with measured water level data. The Experiment 10 water level response at Port Chicago with respect to MLLW is shown in Figure 5. Note by using the stage boundary condition with the offsets in Experiment 10, the agreement with observations is reduced from $19 \mathrm{~cm}$ in Figure 4 with the flow boundary condition to $9 \mathrm{~cm}$ RMSE. This is due in large measure to the improvement in the simulated tidal range.

\subsection{Extensive Tidal Calibration}

For further calibration, the model setup used for the short term tidal experiment was used over an extended 19-month simulation from April 1979 through October 1980. Meteorological forcings were specified by setting the wind speed to zero and the sea level atmospheric pressure to $1013 \mathrm{mb}$ over the entire model domain. A nudging of both salinity and temperature to specified climatological values was used along the open ocean boundary. The nineteen month simulation was completed in 38 segments of approximately 15 days' duration each, with each segment restarted from the previous segment's final fields. 
Figure 5. Comparison of modeled versus predicted water level at Port Chicago with stage boundary condition and 5\% harmonic amplitude reduction over the period 1-15 April 1979.

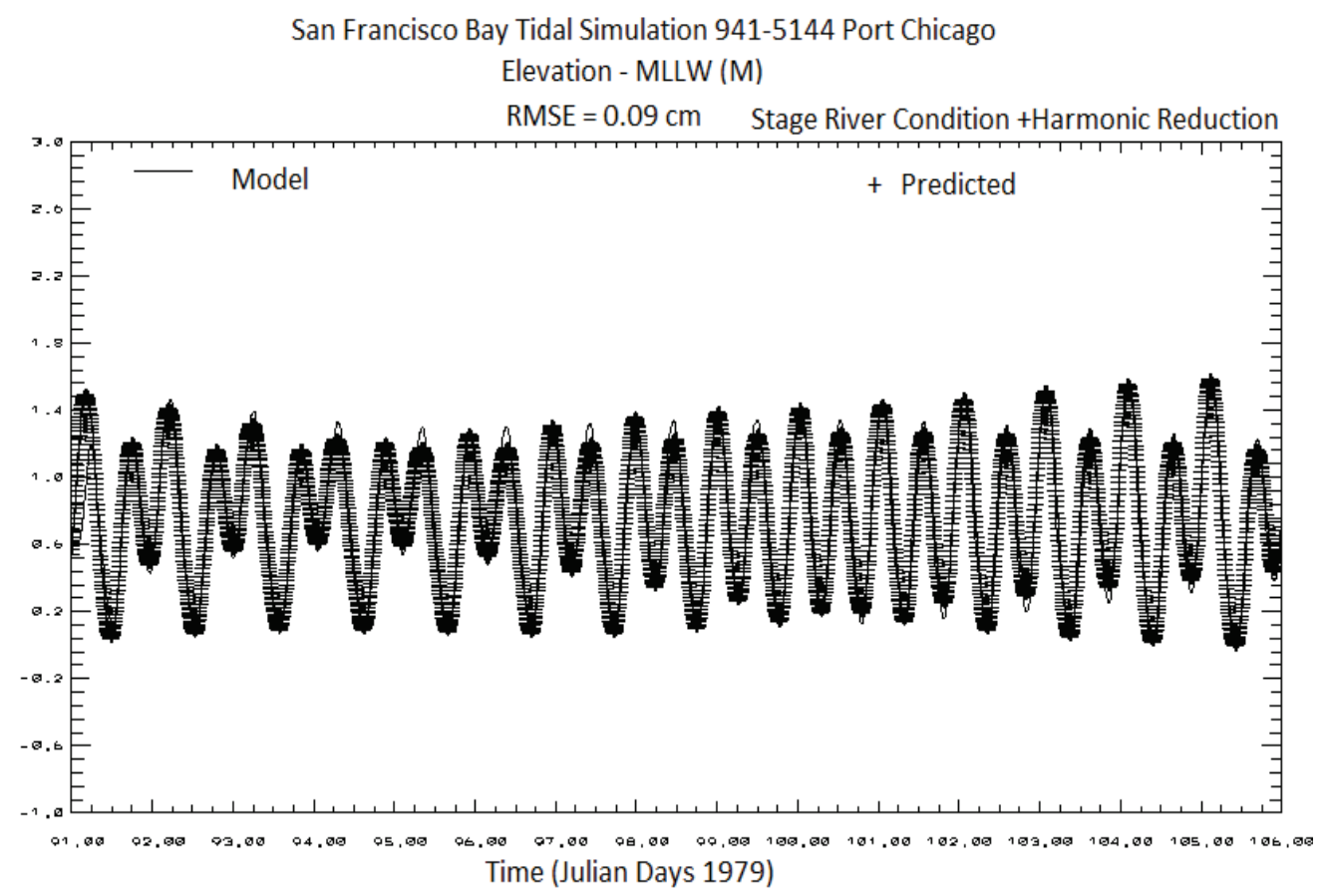

In Table 3, simulation segment results for water surface elevation are compared respectively to harmonic predictions in terms of RMS error and Willmott relative error [39], which is given by $<(a b s(Y-X))^{2}>/<(a b s(Y-<X>)+a b s(X-<X>))^{2}>$, with $Y$ the model prediction and $X$ the observation. Station locations can be found in Figure 6. In addition, model and predicted means are compared with respect to station MLLW. In general, the water level RMS errors do not exceed $15 \mathrm{~cm}$ and are consistent from month to month from Port Chicago in Suisun Bay through San Pablo and mid-Bay regions, as well as in the offshore and southern regions of San Francisco Bay. At Coyote Creek, at the southern end of South Bay, while the means are in close agreement, the RMS errors range from 13 to $22 \mathrm{~cm}$ and often exceed $15 \mathrm{~cm}$. The adjustment of the bottom friction over salt marsh regions undergoing wetting and drying may need further consideration. In Table 4, principal component direction currents at mid layer $(\mathrm{k}=10)$ are compared respectively to harmonic predictions in terms of RMS error and Willmott relative error. In addition, model and predicted mean currents are given. Current amplitude RMS errors are consistent from month to month and are generally less than 35 $\mathrm{cm} / \mathrm{s}$. Willmott relative errors are less than $10 \%$ except at C-33.

A more formal skill assessment has been performed in two parts. In part one, harmonic analysis was used to compare water level and principal component current strengths for the $\mathrm{M}_{2}, \mathrm{~S}_{2}, \mathrm{~N}_{2}, \mathrm{O}_{1}$, and $\mathrm{K}_{1}$ tidal constituents. NOS accepted harmonic constants are compared with tidal simulation results in Table 5. Favorable comparisons were obtained for all constituents at all stations. In Table 6, model principal component current strengths are compared with NOS harmonic constants. 
Again, comparisons are favorable for both amplitude and phase at most stations except at Station $\mathrm{C}-18$ for the $\mathrm{M}_{2}$ amplitude. In part two, model and predicted means, root mean square error, standard deviation of the error, and central frequency (at reference levels of $15 \mathrm{~cm}$ for water level and $26 \mathrm{~cm} / \mathrm{s}$ for current) were considered. In Table 7, water level skill assessment results are given with favorable comparisons exhibited for means and RMSE at all stations with the exception of Coyote Creek, where the water level error exceeded $15 \mathrm{~cm} \mathrm{33.9 \%} \mathrm{of} \mathrm{the} \mathrm{time.} \mathrm{In} \mathrm{Table} \mathrm{8,} \mathrm{principal} \mathrm{component}$ current strength skill assessment results are shown with favorable results observed at most stations except again at Station C-18.

Figure 6. NOS and USGS Historical Circulation Survey Water Level, Current, Salinity, and Temperature Stations. Note current meters were collocated with conductivity-temperature sensors. Note the location of Point Reyes is shown in Figure 1.

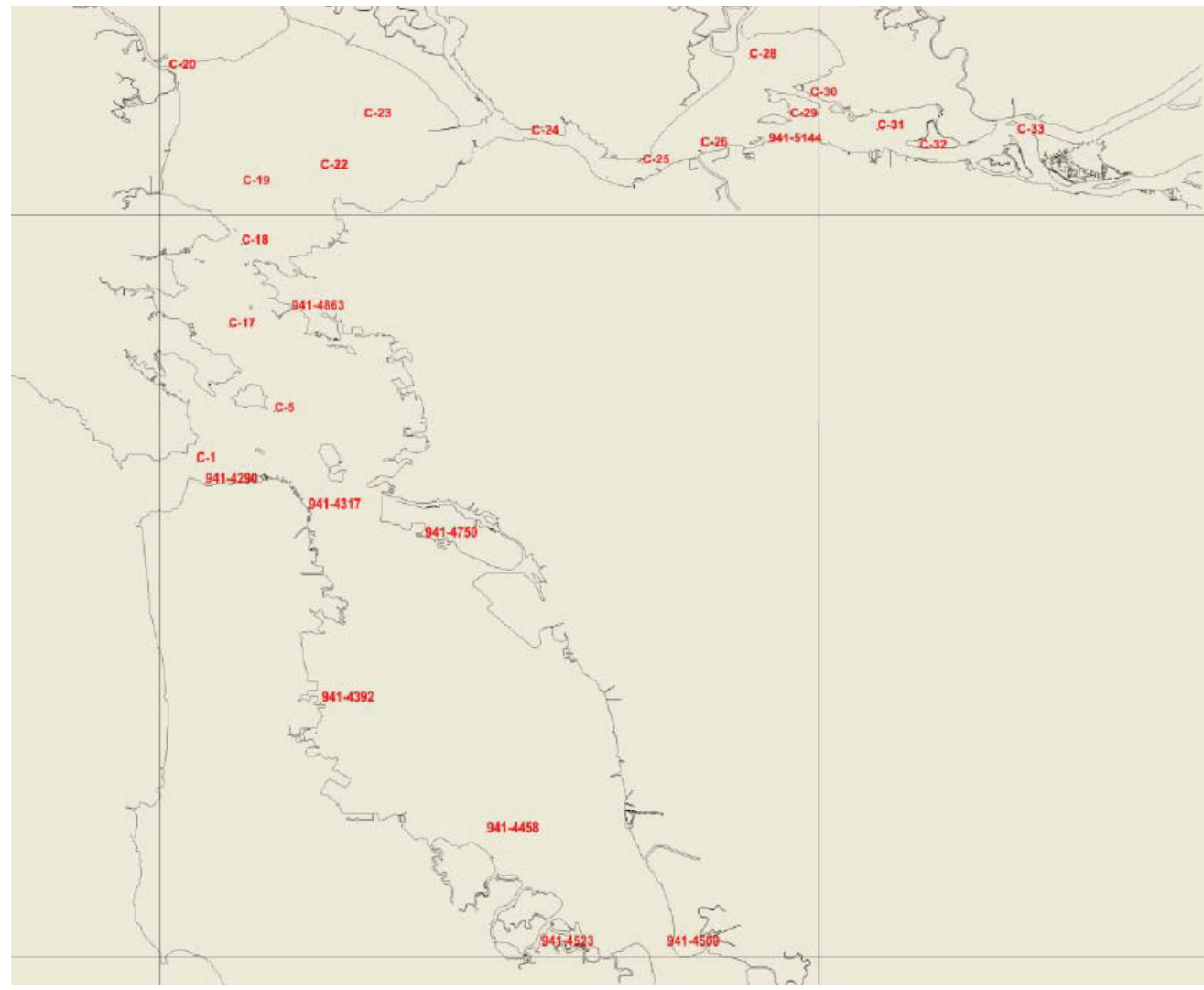

The heat flux algorithm generates no excessive temperatures and produces accurate seasonal heating and cooling [22]. No comparisons with observed salinity are made, since meteorological forcings are not included. However, the simulated salinity gradients are reasonable and a density front is present with the inclusion of the freshwater inflows [22]. The salinity structures through the entrance are in line with climatological values. In the next section, all forcings will be turned on for the hindcast simulation and the model skill assessment will be conducted for further validation. 


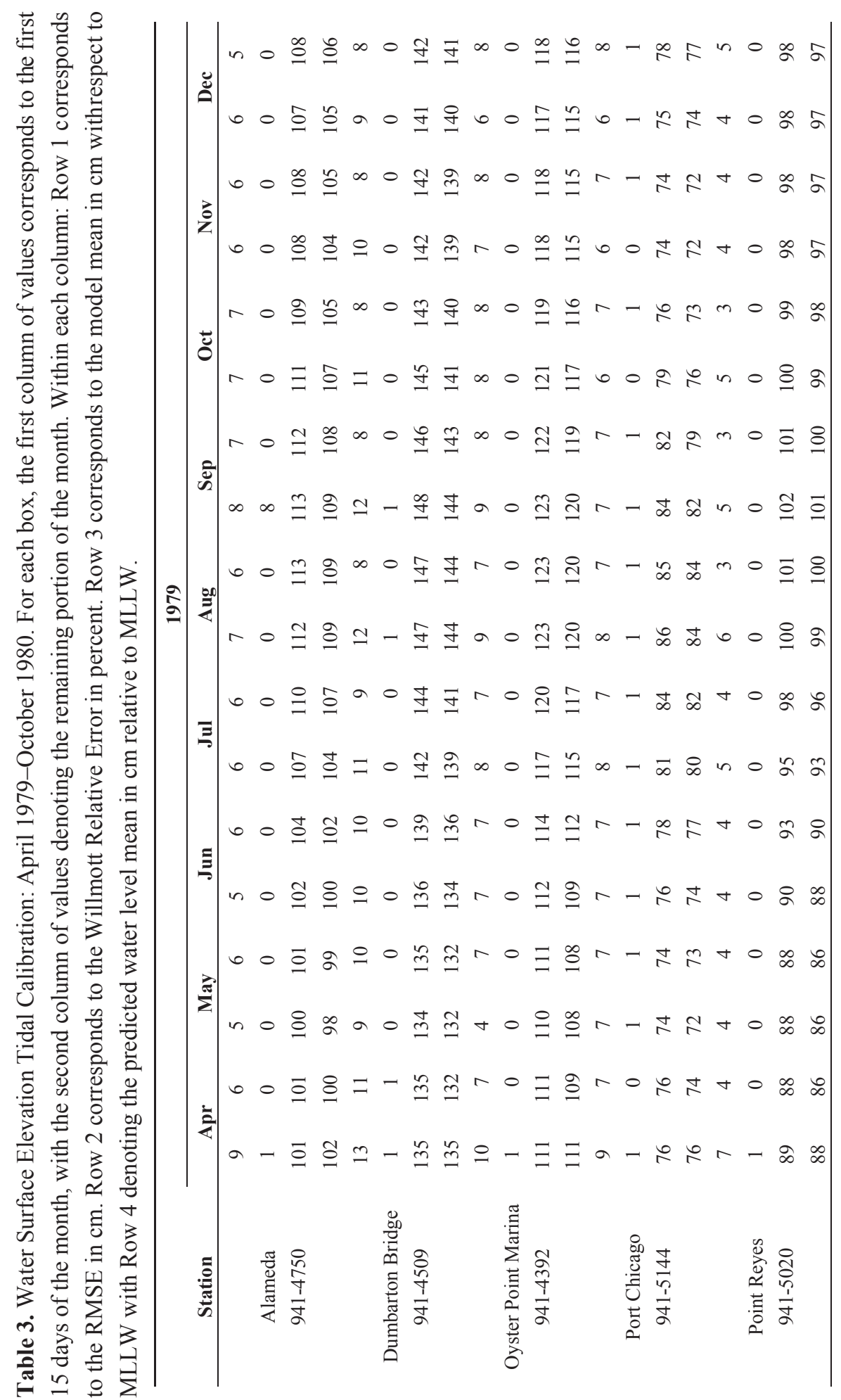




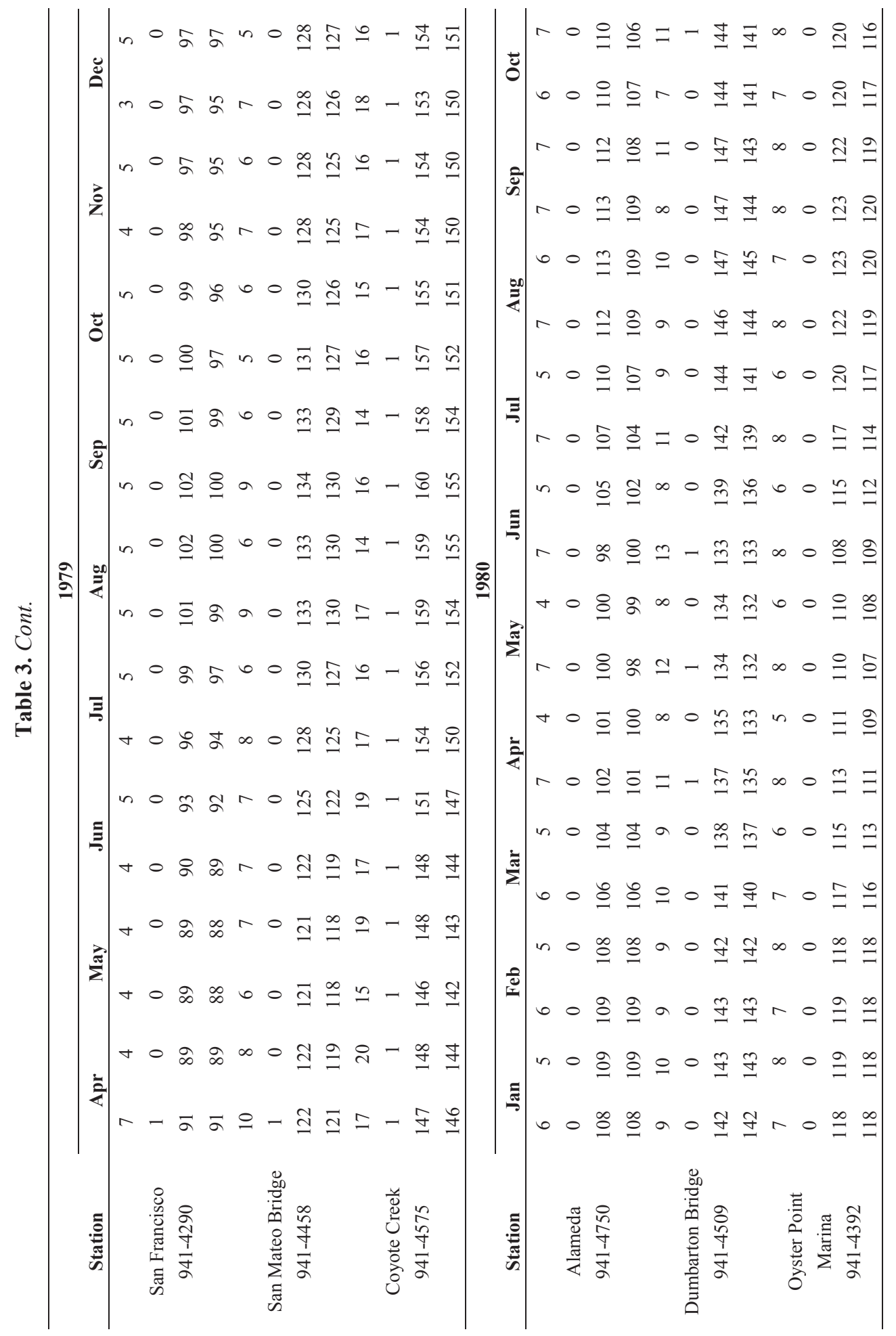




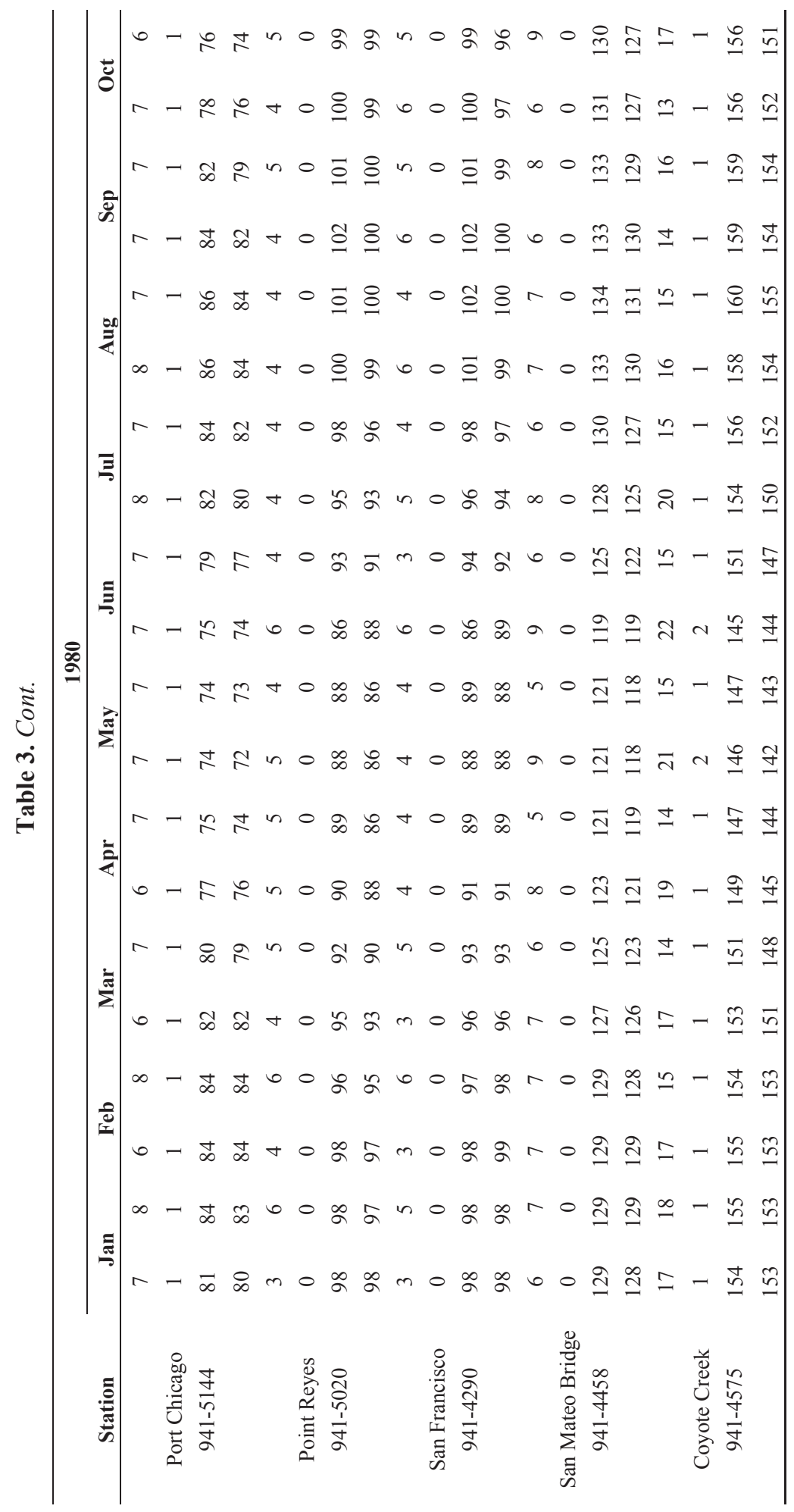




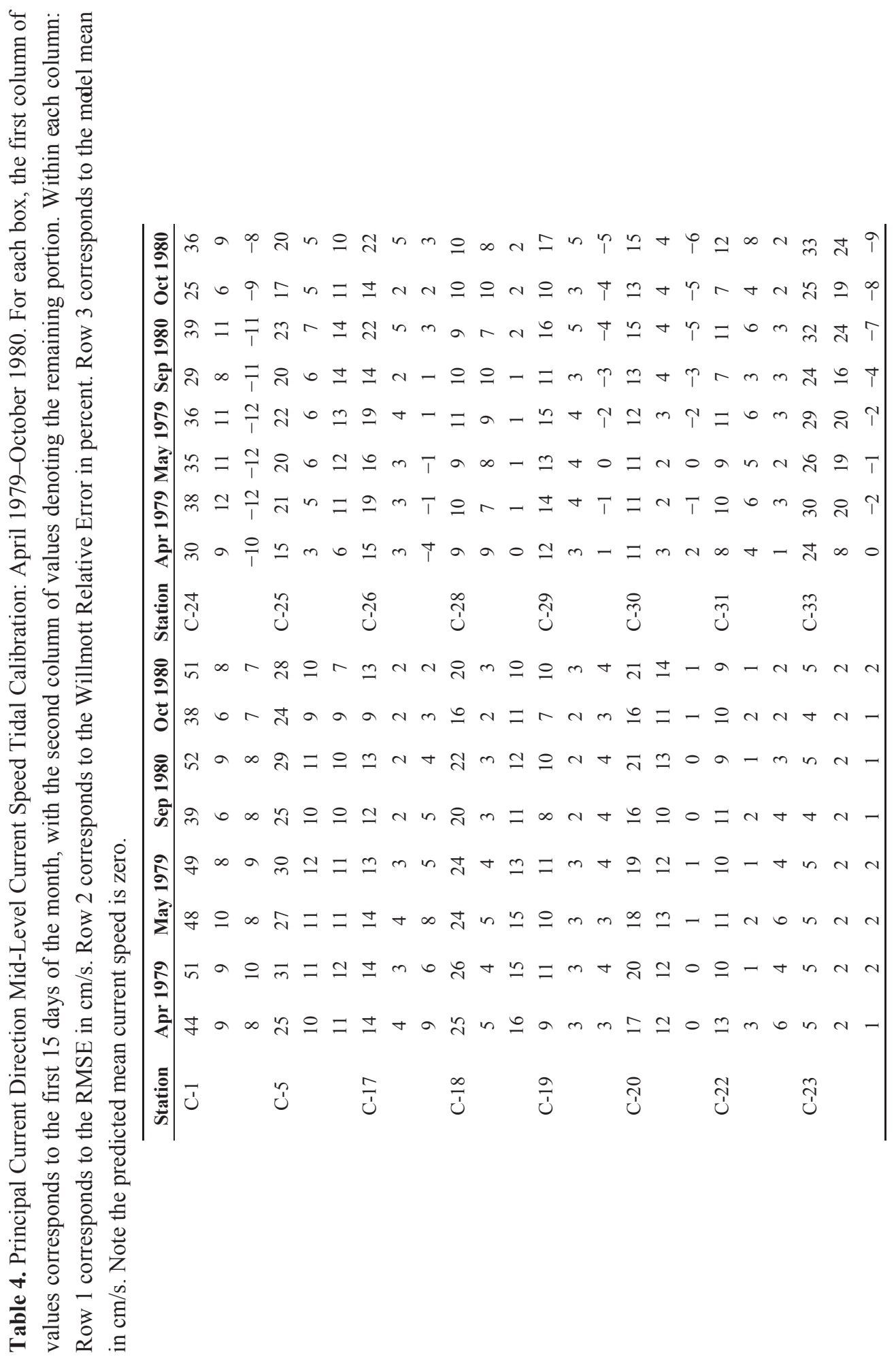




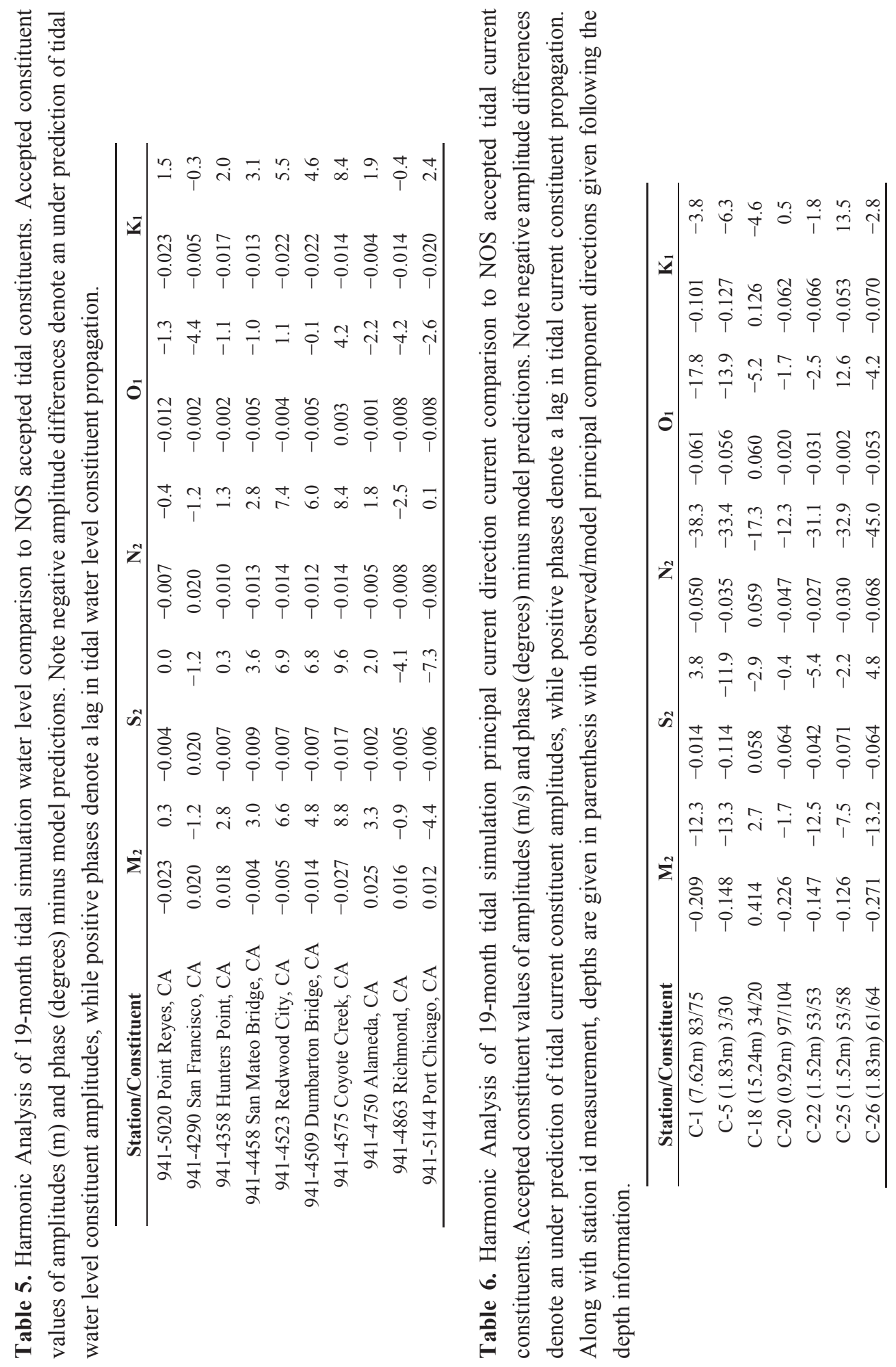




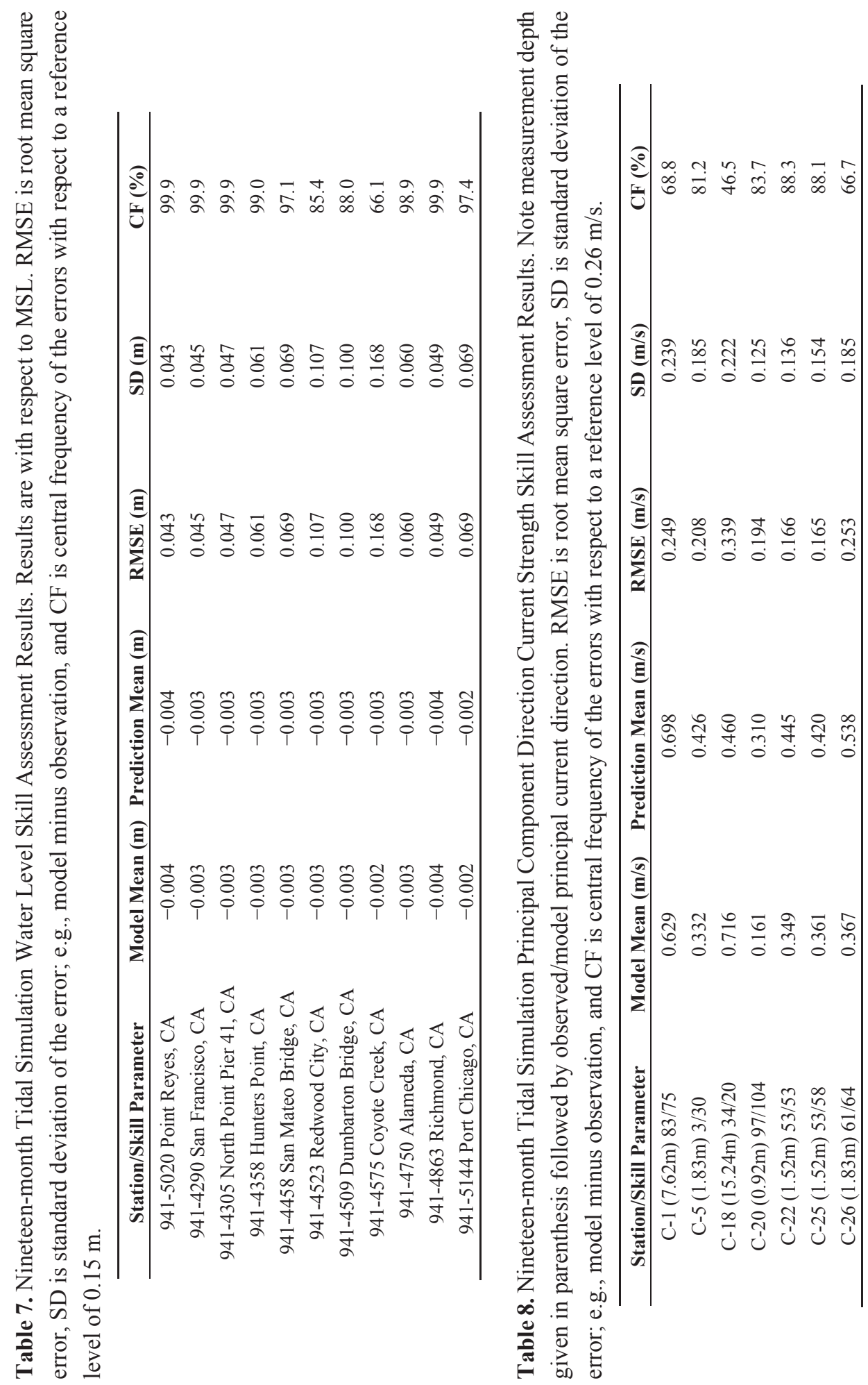




\section{Hindcast Validation}

An extended 19-month hindcast model validation was performed with complete meteorological forcings. The details of the model setup can be found in Section 3. During the simulation period, RMS wind speed errors are less than $5 \mathrm{~m} / \mathrm{s}$ with direction RMS errors order 50 degrees. For sea level atmospheric pressure, the RMS errors are near $2 \mathrm{mb}$. For the offshore temperature and salinity, a zero gradient boundary condition is used. Since the meteorological forcings are at $3 \mathrm{~h}$ intervals, the effect of the sea breeze may not be completely captured.

The results are presented in 15 day increments in Table 9 for water levels. There are fewer stations available with measured data for comparison than for the tidal calibration. In addition, there are gauge datum issues at several water level stations. Generally, the water level RMS errors do not exceed $15 \mathrm{~cm}$ and are consistent from month to month in almost all regions. At Point Reyes, there are issues with the data, which cause errors in the subtidal water level forcings for several months indicated as blanks.

As shown in Table 10, current amplitude RMS errors are consistent throughout the period and are generally less than $35 \mathrm{~cm} / \mathrm{s}$. The salinity response is summarized in Table 11. Generally, the model salinity was in agreement with the observations at most of the stations. However, it was overestimated in the northern portion of San Pablo Bay and throughout Suisun Bay. This is believed to be due to the fact that the river subtidal water levels were not included since no measured river stage data were available. As a result, the model results could not correctly reflect the freshwater runoff during the high flow months when substantial river subtidal levels were present. This in effect, limited the amount of freshwater entering the Bay through the Delta. The temperature response is summarized in Table 12 and exhibited a normal seasonal response, but in October 1980 there was some evidence of overheating by about $2{ }^{\circ} \mathrm{C}$ in Suisun Bay.

In addition to the validation in terms of RMS errors, the NOS skill assessment criteria [40,41] are also applied to the hindcast. We show in Table 13 the results at some of the major water level stations. Additional model skill assessment results for currents, salinity, and temperature are given in [22]. Generally, the skill assessment indicates that most water-level related statistical parameters pass the NOS skill assessment criteria for different scenarios, and that amplitudes and epochs of major harmonic constituents such as $\mathrm{M}_{2}, \mathrm{~S}_{2}, \mathrm{~N}_{2}, \mathrm{~K}_{2}, \mathrm{~K}_{1}, \mathrm{O}_{1}, \mathrm{P}_{1}$, and $\mathrm{Q}_{1}$ from the tide-only scenario simulation are very close to the observed values at almost all stations.

Most of CF (Central Frequency), NOF (Negative Outlier Frequency), POF (Positive Outlier Frequency), MDNO (Maximum Duration of Positive Outliers), and MDPO (Maximum Duration of Positive Outliers) either pass or are close to the criteria at the Bay current stations for not only the tide-only scenario but also the hindcast scenario, since tidal current dominates the signal in San Francisco Bay region. See Schmalz [22] for more complete definitions of the skill assessment parameters.

The tidal and hindcast simulations indicate that the SFBOFS runs robustly and that the results are in acceptable agreement with the measurements. The model package was therefore loaded into the COMF-HPC on NCEP's high performance computers to perform semi-operational nowcast/forecasts. 


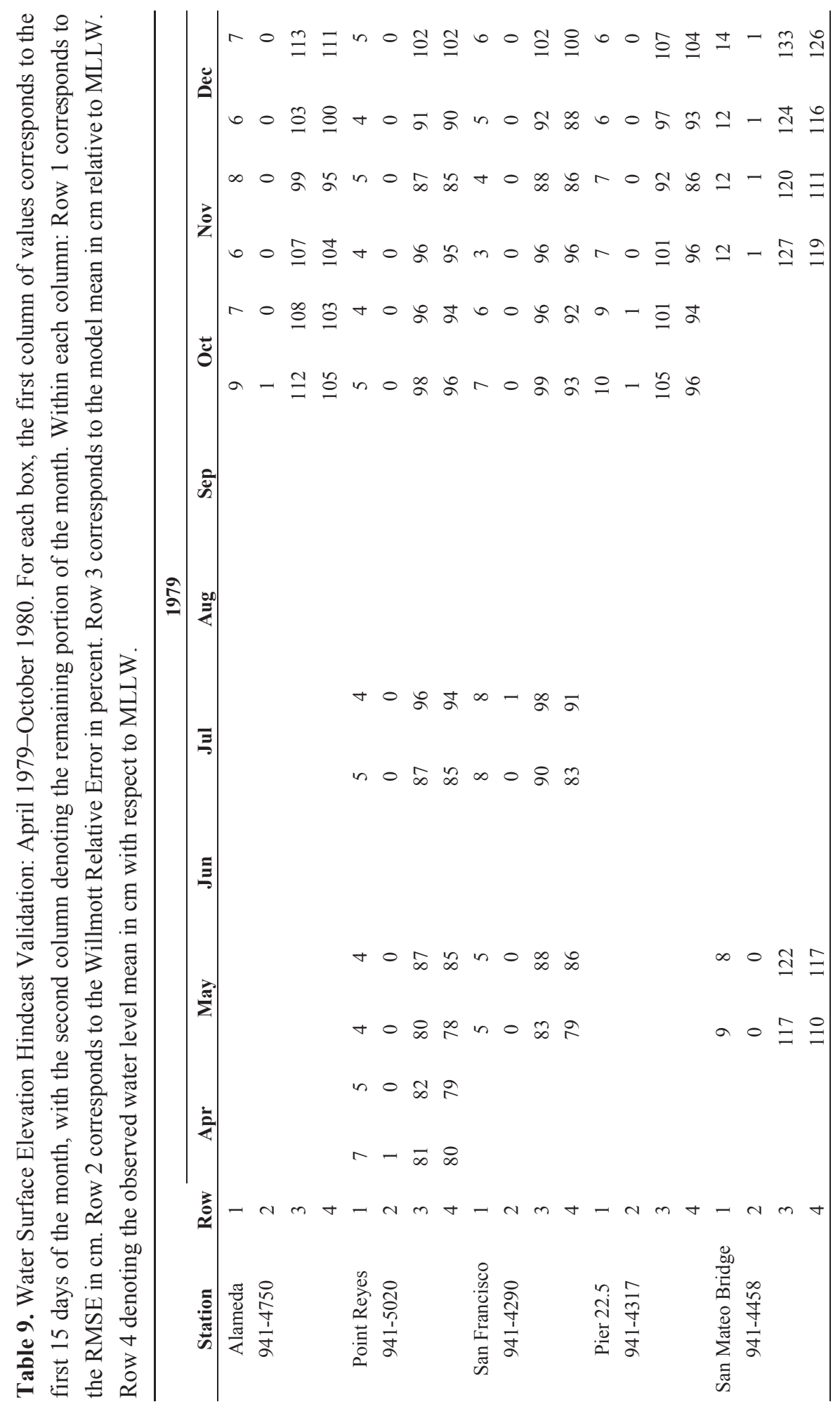




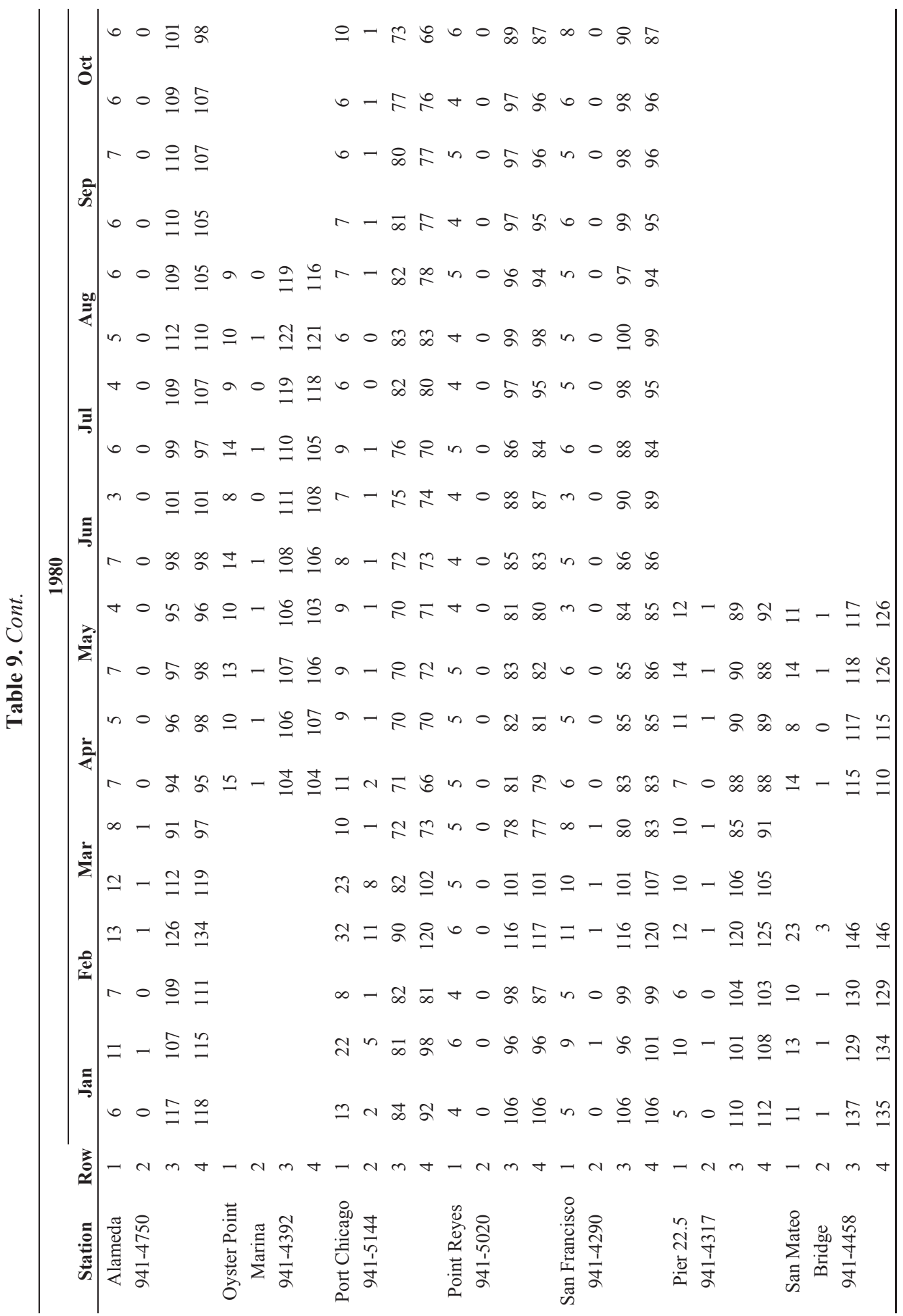




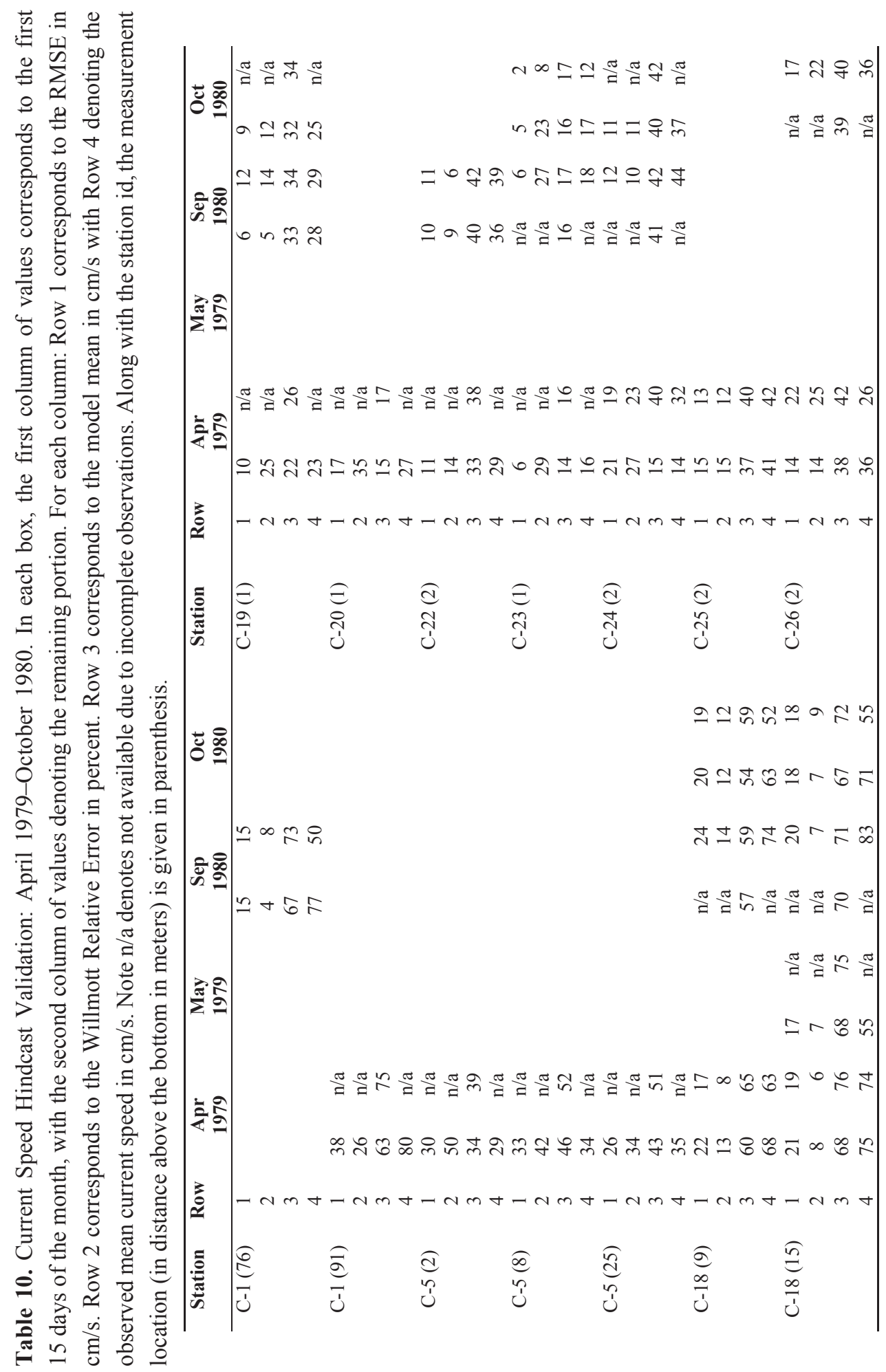




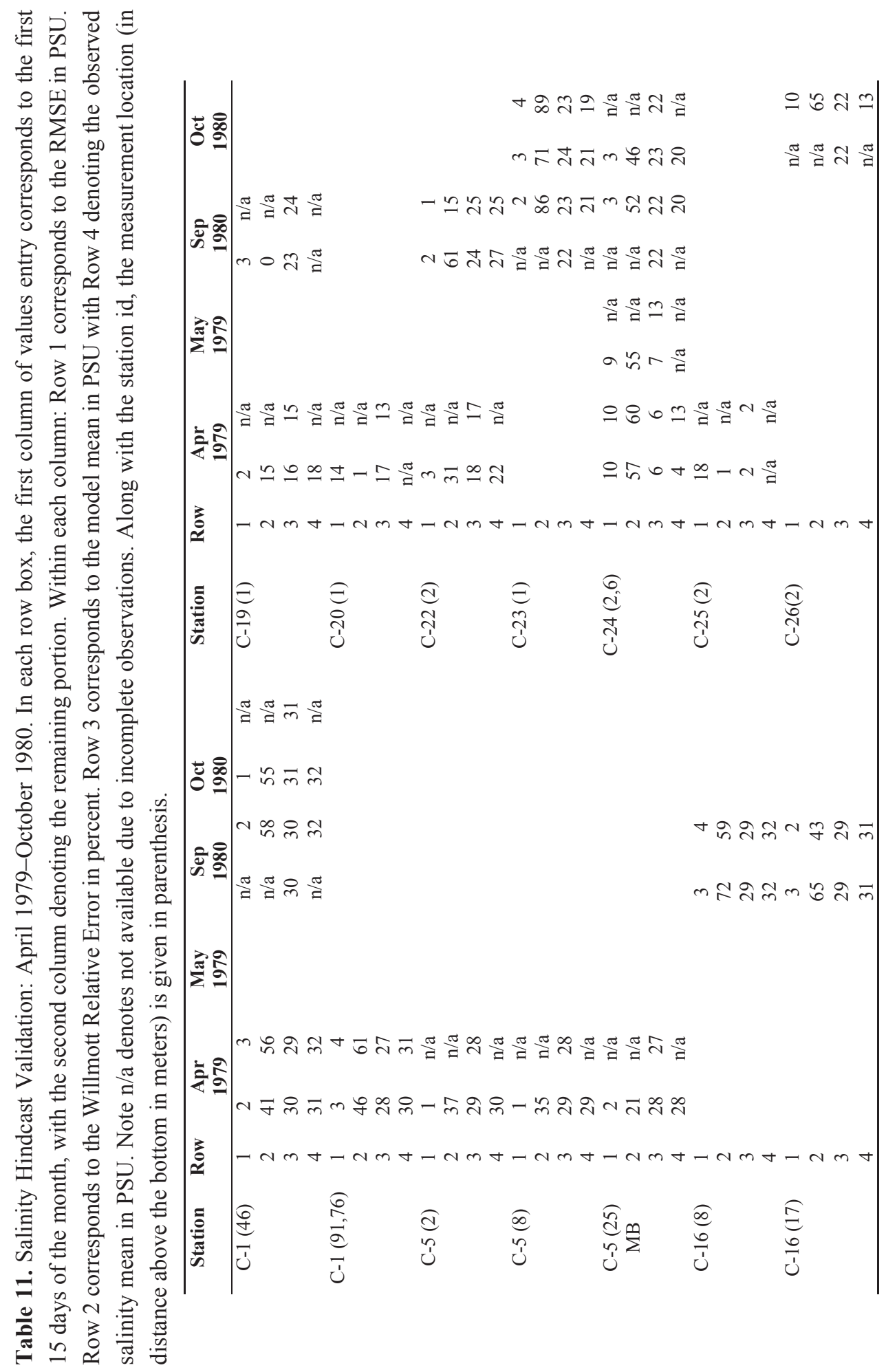




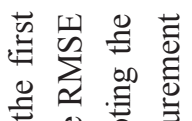

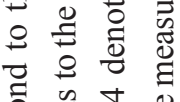

تृ:

के ठ․

仓

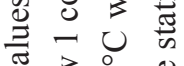

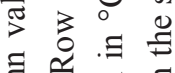

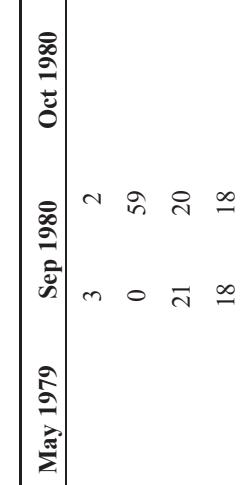

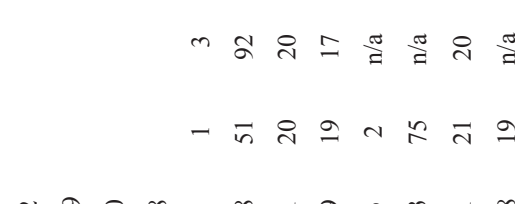

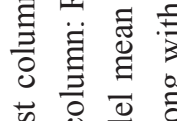

苟

¿

$\Xi \Xi$

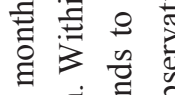

ㅎํㅇ ठํㅇㅇ

0 氙

ฮี

$\Xi$ 的矛

¿

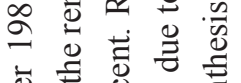

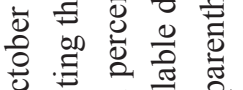

ช

유 흘

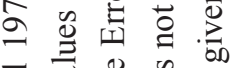

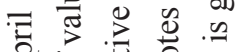

远范焉

范吉

苞

㲔

范

용

ลิำ $-\infty \simeq$ ก

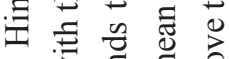

๖

壳吾营

范

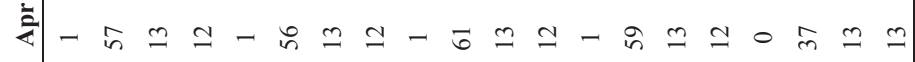

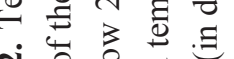

$\frac{\pi}{a}-4 m+-4 m+-4 m+-4 m+t h m+4$

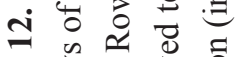

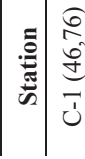

a $\quad$ d

$\overbrace{0}^{2} \quad \frac{\infty}{n}$

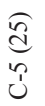

离 


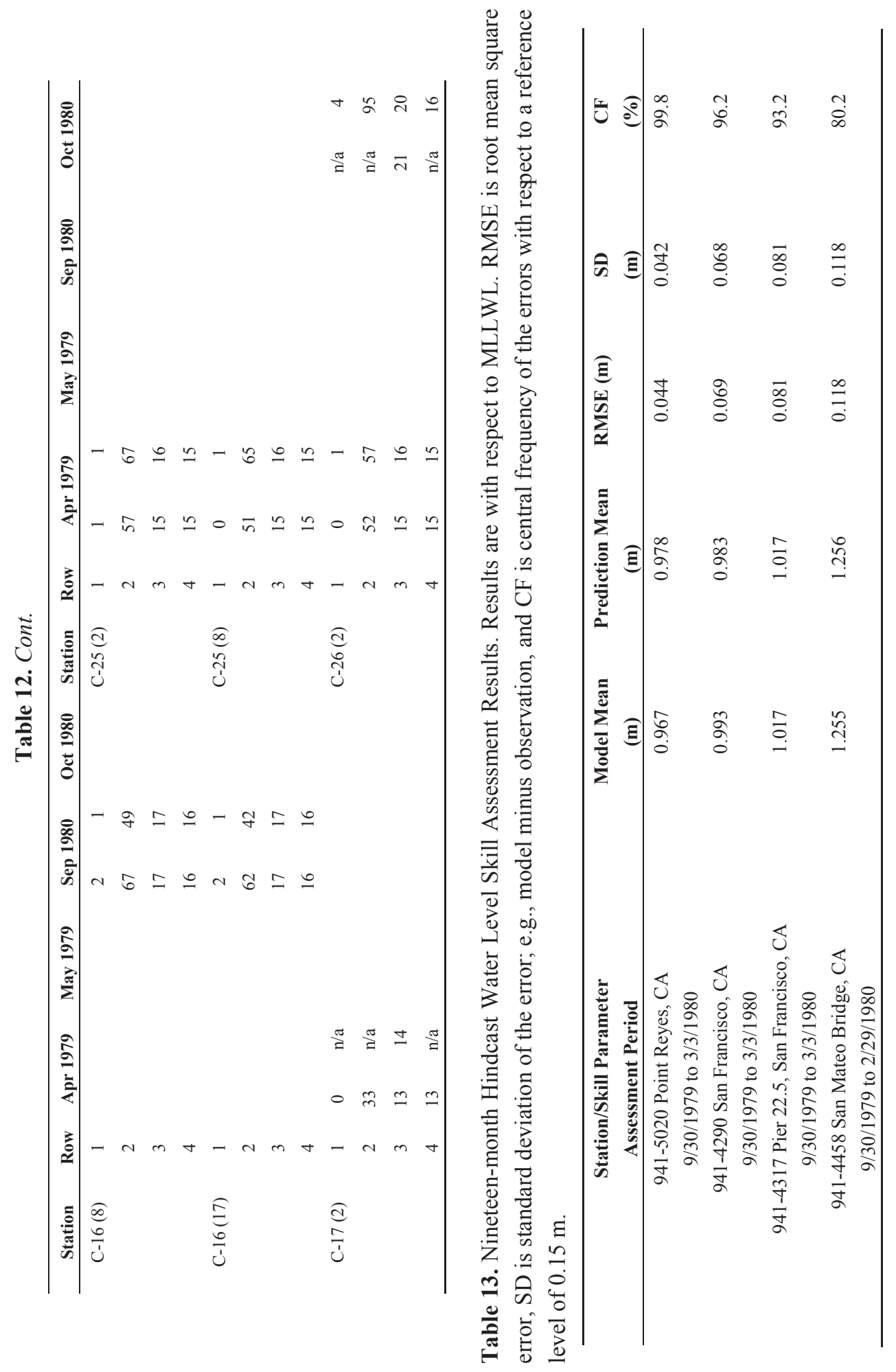




\section{Semi-Operational Nowcast/Forecast Simulation}

The SFBOFS runs four cycles each day. In each cycle, the model performs a six hour nowcast followed by a $48 \mathrm{~h}$ forecast. During the model preparation process, the COMF-HPC automatically searches for and obtains the necessary observed data and other model (e.g., NAM4 and RTOFS) generated data to obtain the required forcings.

\subsection{COMF-HPC Generated Input Forcings}

For the nowcast, the subtidal water levels along the open ocean boundary are determined using an adjustment of the Global RTOFS (G-RTOFS) latest hourly subtidal forecast guidance. The adjustment is determined by averaging the hourly subtidal anomalies at Point Reyes (NOAA gauge) over the previous six-hour nowcast period and ramping the forecast subtidal values to the adjustment. The astronomical tide is determined from the tidal constituent netCDF file and the application of the latest node factor and equilibrium argument values at six-minute intervals. The total open ocean boundary six-minute water level values are the sum of the adjusted subtidal levels and the predicted tidal values at each boundary grid point. Salinity and temperature along the open ocean boundary are obtained from the adjusted G-RTOFS forecast guidance. The adjustment is determined by averaging the salinity and temperature anomalies at San Francisco (NOAA gauge) over the previous six-hour nowcast period and ramping the nowcast values to the adjustment.

For the forecast, along the open ocean boundary, water levels are specified as a superposition of the tide predictions and the subtidal water level forecast. Note the nowcast adjustments are maintained for the forecast period for water level, salinity and temperature open boundary conditions.

For both nowcast and forecast, the most recent NAM4 results in NCEP's data tank are input into COMF-HPC to get the necessary input surface forcings.

The methodology to treat the Sacramento and San Joaquin River forcings in nowcast and forecast scenarios is different because no river stage subtidal signals are available in the forecast period. Even during the nowcast, stage data are not necessarily available. COMF-HPC uses the following approach to handle this.

Subtidal river stage data adjustment is performed on the boundary nodes of the two rivers. Real-time observed stage height data from USGS 11337190 Station are taken for the San Joaquin River nodes adjustment and the data from USGS 11455420 are used for the Sacramento River nodes. The real challenge though is how to determine the subtidal water level time series for the whole nowcast and forecast time window.

As shown in Figure 7, the green curves indicate the subtidal stage height time series, which is computed as the direct water level measurement minus the tidal prediction. The vertical black time line is the current run cycle time, for example 12Z. Since the cron job is launched after the cycle time (after the NAM4 and RTOFS forcings of the same cycle are obtained), the USGS river stage reading end time, $R T$ (end), is always on the right side of the black time line. The reading start time $R T(I)$, however, can be on either side of the nowcast start time, ZetaT(I). 
The ultimate goal is to obtain the subtidal stage height for the whole nowcast and forecast period, the time between ZetaT(I) and ZetaT(end). For the upper case in Figure 7, when $R T(I)$ is later than $\operatorname{ZetaT}(I)$, we assume that stage height between ZetaT(I) and $R T(I)$ equals the height at $R T(I)$. For model stability, the subtidal stage height from $R T(I)$ to $R T($ end $)$ is decomposed into "mean" and "fluctuating" parts. The "mean" is indicated by the horizontal black line in Figure 7, and the "fluctuating" part is in green. The "fluctuating" part at $R T$ (end) is ramped off lineally to zero in the next six hours. The "fluctuating" part in the rest of forecast time period is therefore taken as zero. In other words, the subtidal stage height in this period is the "mean" from $R T(I)$ to $R T$ (end).

Figure 7. Diagram on how measured river stage height is used in COMF.

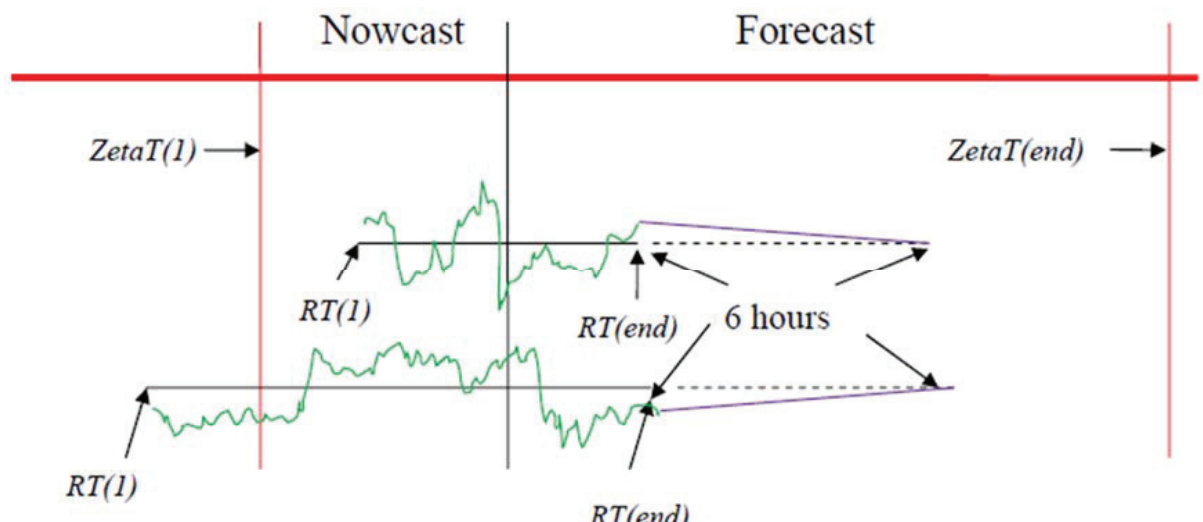

As water temperatures are not available for the two USGS stations, the real-time temperature measurement data are obtained from Port Chicago, a NOAA Gauge Station with NOS_ID of 9415144. When no real-time stage non-tidal data are available from the NCEP data tank, the climatological stage height and temperature data are automatically input into the model.

\subsection{Semi-Nowcast/Forecast Results}

The SFBOFS semi-operational nowcast and forecast model assessment period started from 10 March 2013 and continued to 10 June 2013. The results from these simulations were concatenated into continuous time series for analysis using the NOS skill assessment software [17]. The model ran robustly in the whole assessment period. Generally, the results of water level, current, temperature and salinity agree well with observations, and CF, NOF, POF, MDNO, MDPO, WOF and other statistical variables pass the criteria in both nowcast and forecast scenarios. Figure 8, as an example, shows the agreement of model results and observation of water level at three major stations. Refer to Peng and Zhang [42] for complete model skill assessment results at all stations for the water level, current, salinity, and water temperature. 
Figure 8. The comparison of modeled versus observed sea levels at three stations in April 2013. The station locations can be found in Figure 1.

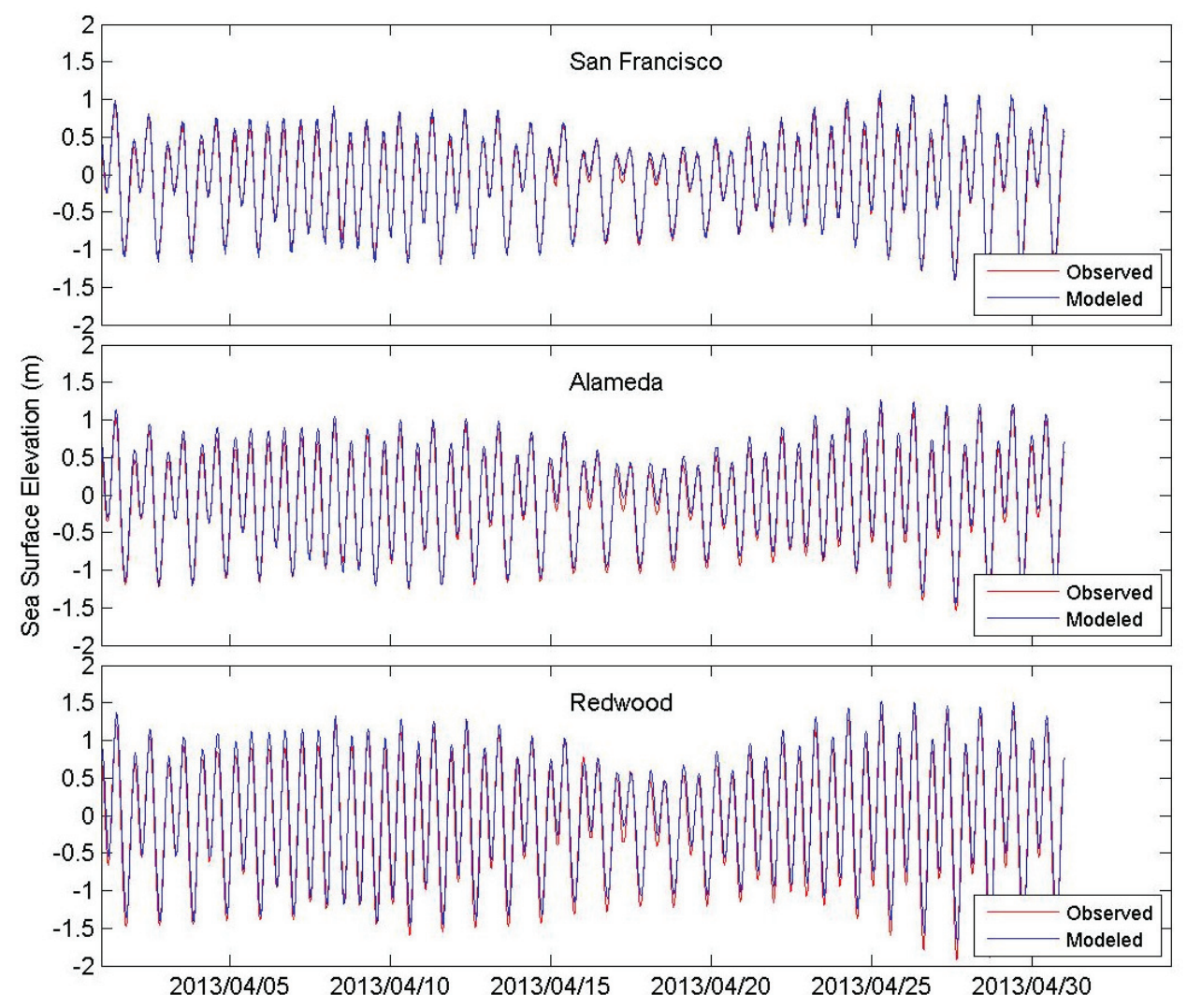

Semi-nowcast/forecast model performance is statistically shown in Figure 9. The Taylor diagrams [43] indicate that the water level results are better than the water temperature and salinity. Water level correlation coefficients at all stations are higher than 0.98 , while the salinity correlation coefficient at $\mathrm{S} 1$ is only about 0.50 for both nowcast and forecast scenarios. The normalized modeled standard deviation at all stations is close to 1.0 for water level, but it is higher than 2.0 for some stations for salinity. Similar to the hindcast scenarios, as mentioned previously, the water level performs the best followed by water temperature and salinity. One should note that the RMSD value shown in these normalized Taylor diagrams needs to be multiplied by its corresponding measured standard deviation as listed in Tables 14-16 to get its real value. 
Figure 9. Normalized Taylor diagrams of water level, surface temperature and surface salinity for nowcast and forecast scenarios. S1, S2, S3, etc. are station series numbers. Si of water level, temperature and salinity does not necessarily indicate the same station. The modeled standard deviation of each variable at each station is normalized by its corresponding observed standard deviation. The data are from October 2013.
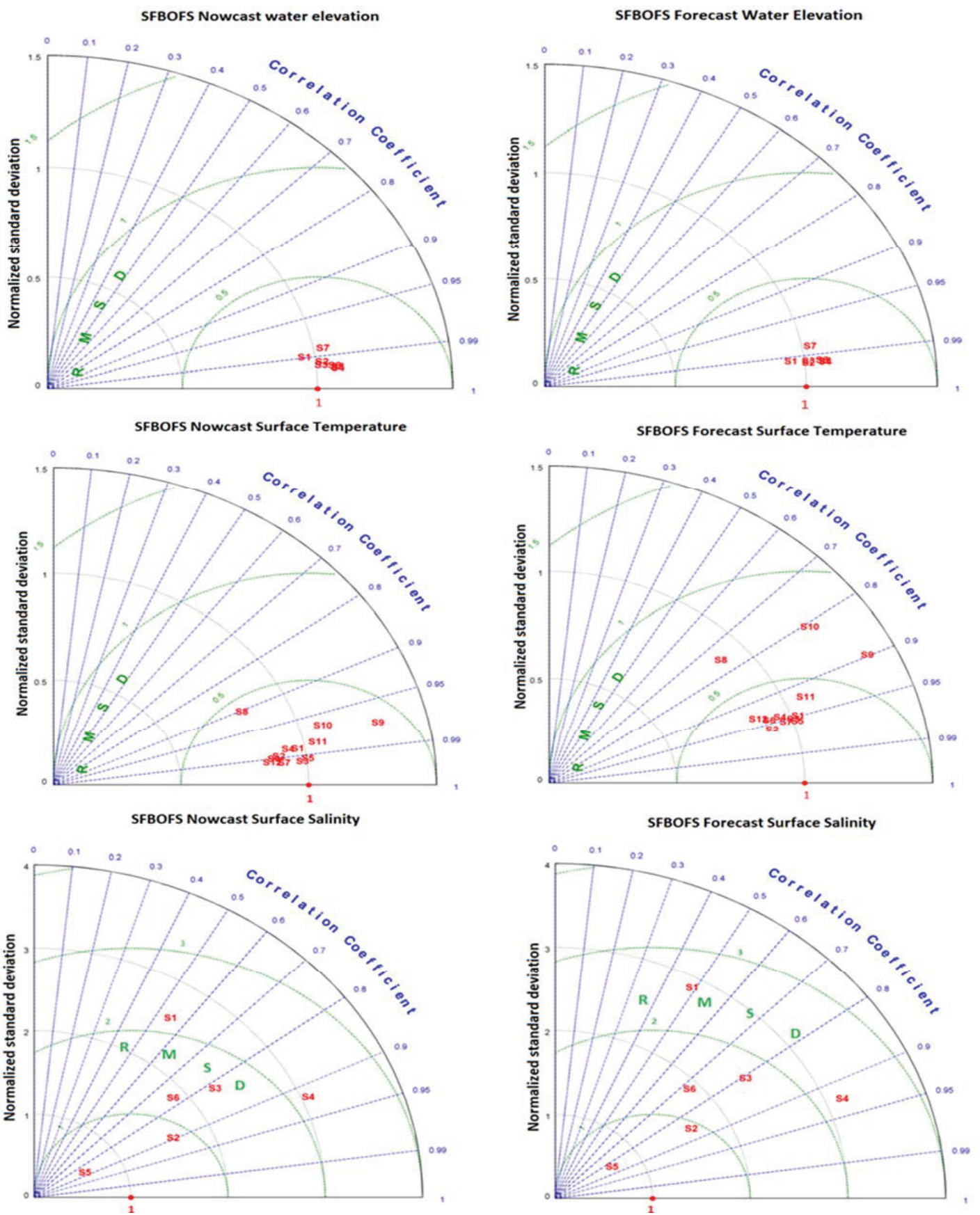
Table 14. Observed water level standard deviations (m) at selected stations in nowcast and forecast scenarios.

\begin{tabular}{cccccccc}
\hline Station \# & S1 & S2 & S3 & S4 & S5 & S6 & S7 \\
\hline Station names & Port Chicago & Martinez & Point Reyes & Richmond & San Francisco & Alameda & Redwood City \\
Nowcast & 0.44 & 0.47 & 0.53 & 0.56 & 0.55 & 0.61 & 0.75 \\
Forecast & 0.44 & 0.48 & 0.55 & 0.57 & 0.55 & 0.62 & 0.76 \\
\hline
\end{tabular}

Table 15. Observed temperature standard deviations $\left({ }^{\circ} \mathrm{C}\right)$ at selected stations in nowcast and forecast scenarios.

\begin{tabular}{ccccccc}
\hline Station \# & S1 & S2 & S3 & S4 & S5 & S6 \\
\hline Station Names & Rio Vista & Suisun Slough & Collinsville & Port Chicago & Mallard Island & Martinez \\
Nowcast & 1.52 & 1.87 & 1.48 & 1.48 & 1.42 & 1.43 \\
Forecast & 1.72 & 2.13 & 1.65 & 1.66 & 1.59 & 1.63 \\
Station\# & S7 & S8 & S9 & S10 & S11 & S12 \\
Station Names & Antioch & Point Reyes & Richmond & San Francisco & Alameda & Redwood City \\
Nowcast & 1.57 & 0.92 & 0.82 & 0.63 & 1.25 & 1.54 \\
Forecast & 1.66 & 1.06 & 0.95 & 0.73 & 1.46 & 1.83 \\
\hline
\end{tabular}

Table 16. Observed salinity standard deviations (PSU) at selected stations in nowcast and forecast scenarios.

\begin{tabular}{ccccccc}
\hline Station \# & S1 & S2 & S3 & S4 & S5 & S6 \\
\hline Station Names & Suisun Slough & Collinsville & Port Chicago & Mallard Island & Martinez & Antioch \\
Nowcast & 0.40 & 1.10 & 1.56 & 1.35 & 2.18 & 0.95 \\
Forecast & 0.41 & 1.12 & 1.58 & 1.37 & 2.19 & 0.97 \\
\hline
\end{tabular}

The semi-nowcast/forecast results can be found on the SFBOFS web page [44]. To serve the San Francisco Bay maritime community, the SFBOFS provides users with nowcast and forecast guidance for water levels, currents, water temperature, and salinity out to $48 \mathrm{~h}$, four times per day. The SFBOFS model domain on the web is divided into two separate subdomains (the San Francisco Bay and the San Francisco Bay Entrance), allowing users to focus on their area of interest. Nowcast/forecast animations of each of the two subdomains as well as time series at over 50 locations are available for winds, water levels, currents, temperature, and salinity.

Figure 10 is a snapshot from nowcast salinity animation of the larger subdomain at 0600 PST of 2 December 2013. Figure 11 illustrates that model salinity results agree well with the measurement at locations where Sacramento and San Joaquin Rivers have noticeable effect on salinity distributions. Meanwhile the available measurement at Port Chicago indicates, as shown in Figure 12 , that the water level nowcast is also in good agreement with observations. The satisfying model results for both water level and water salinity near the two rivers are largely due to the fact that river stage boundary conditions have been employed.

The SFBOFS webpage offers not only the latest model output graphics as shown in Figures 10-12, but also links where users can get access and download one-year historic output files (in NetCDF format) through CO-OPS's OPenDAP and THREDDS servers. 
Figure 10. Nowcast salinity distribution for San Francisco Bay (12/02/13 0600 PST).
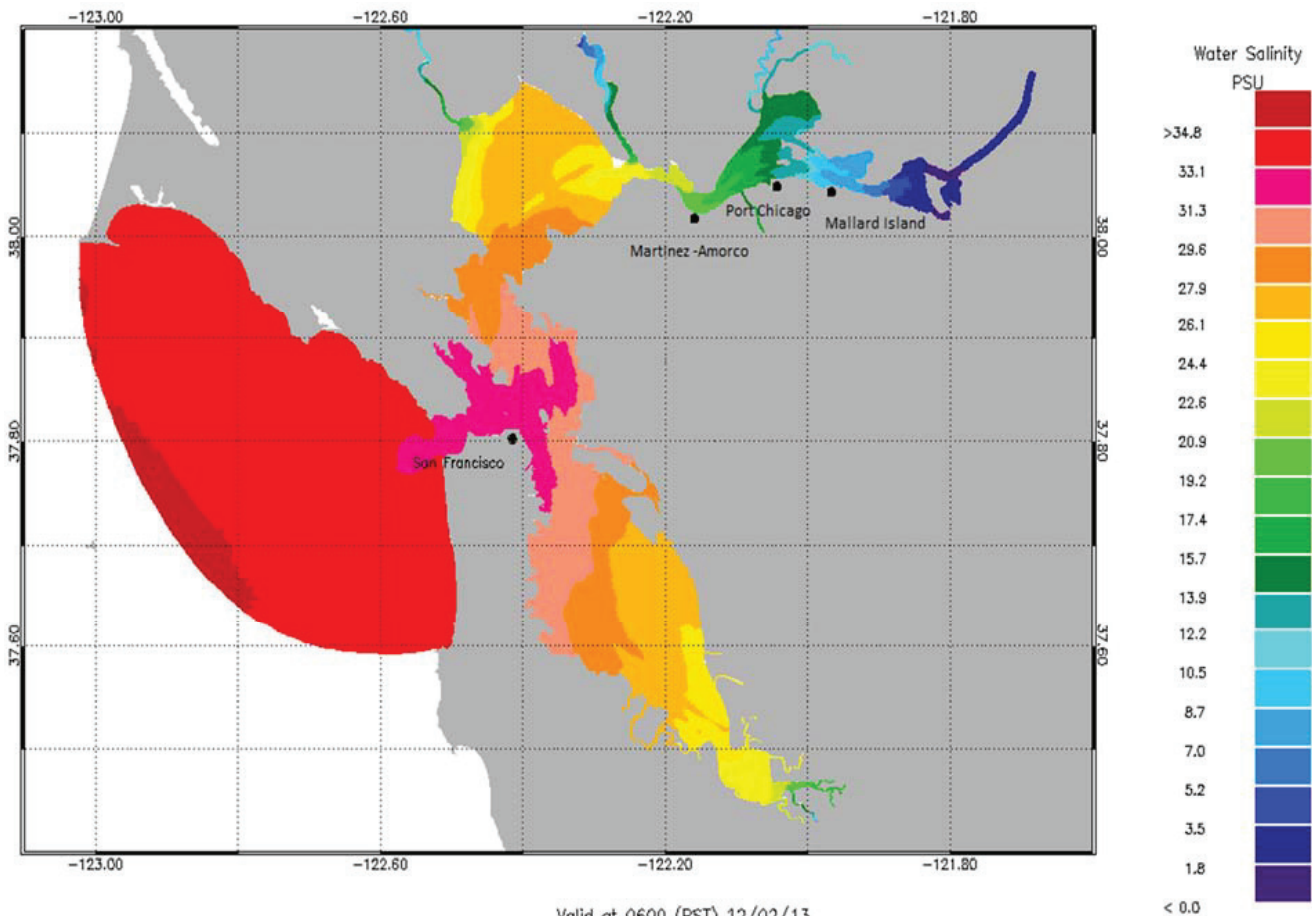

Valid at 0600 (PST) 12/02/13

Figure 11. The nowcast/forecast water surface salinity versus measurement at stations where the Sacramento and San Joaquin Rivers have noticeable effects on salinity distrubution.
NOAA/National Ocean Service
Observation: $\quad$ xxxxxxxxxxx
San Francisco Bay
Operational Forecast System (SFBOFS)

Nowcast: $\quad$ (-..-.-.
Forecast Guidance:

MALLARD ISLAND Water Salinity

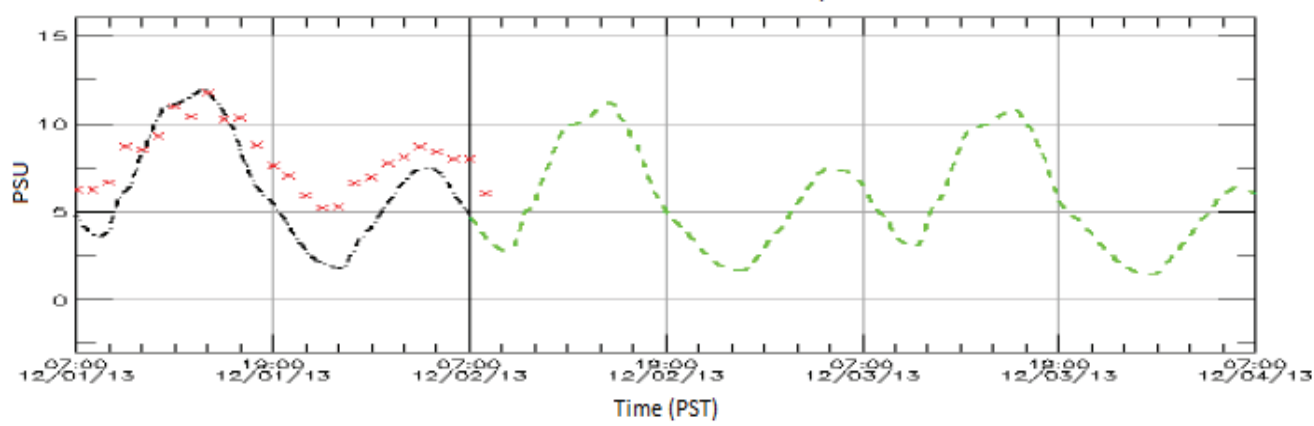


Figure 11. Cont.

NOAA/National Ocean Service San Francisco Bay Operational Forecast System (SFBOFS)

Observation: $\quad$ xxxxxxxxxxx

Nowcast:

Forecast Guidance:

PORT CHICAGO Water Salinity

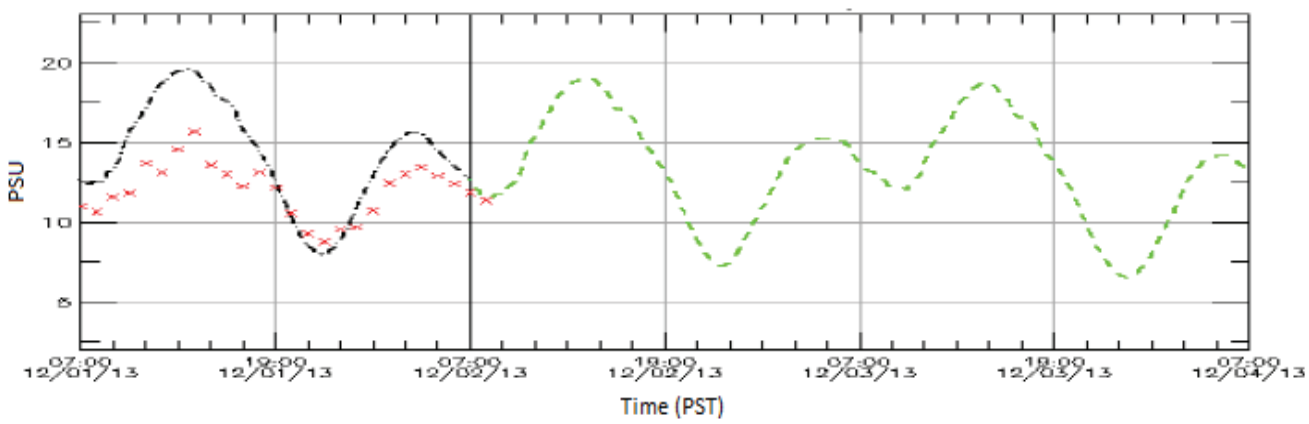

NOAA/National Ocean Service

San Francisco Bay

Operational Forecast System (SFBOFS)

MARTINEZ - AMORCO Water Salinity

Observation: $\quad$ xxxxxxxxxxx

Nowcast:

Forecast Guidance:

$-\cdots$

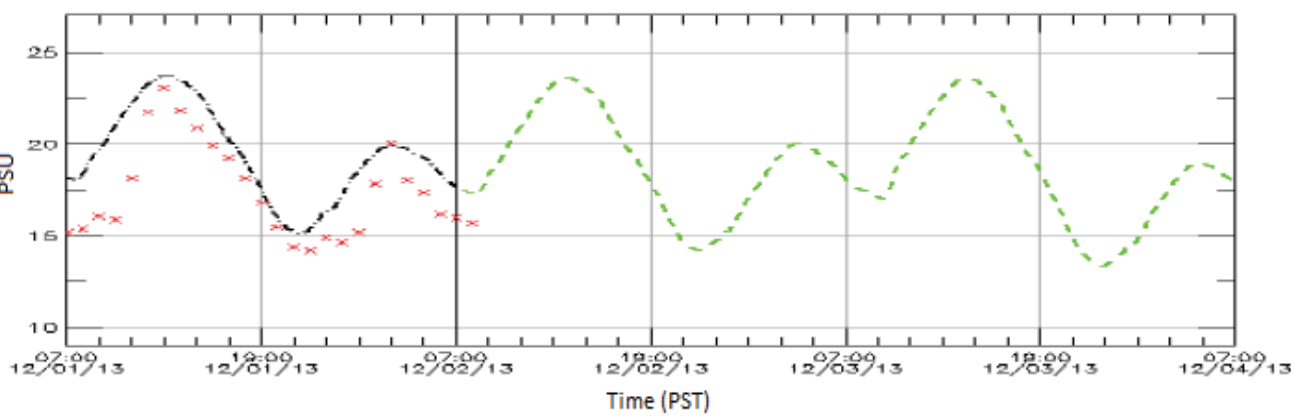

Figure 12. The nowcast/forecast versus observed water levels at Port Chicago.

NOAA/National Ocean Service San Francisco Bay

Observation:

Tidal Prediction:

Noweast:

Operational Forecast System (SFBOFS)

Forecast Guidance:

$\infty \infty \infty \infty$

$-\cdot-\cdot-$

PORT CHICAGO Water Levels

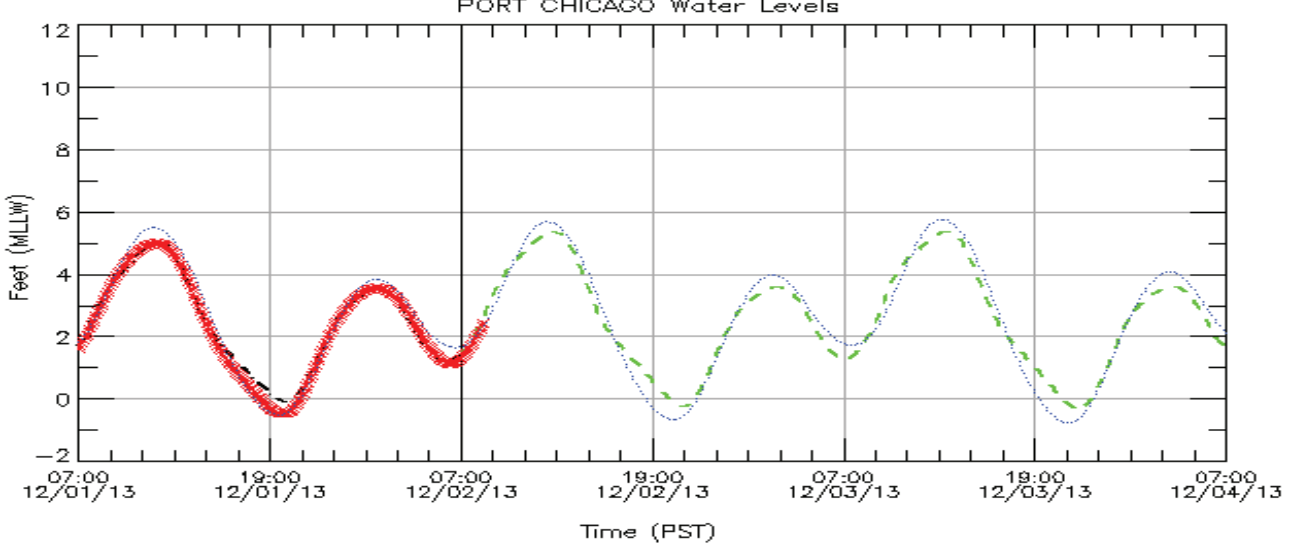




\section{Conclusion and Discussion}

This paper details how the SFBOFS was setup, tested and extensively validated in tidal and hindcast scenarios. The performance of the model package during the three-month semi-operational nowcast and forecast using the NOS COMF-HPC is discussed. FVCOM, the core of SFBOFS, ran robustly during the trial. Amplitudes and epochs of the $\mathrm{M}_{2} \mathrm{~S}_{2}, \mathrm{~N}_{2}, \mathrm{~K}_{2}, \mathrm{~K}_{1}, \mathrm{O}_{1}, \mathrm{P}_{1}$, and $\mathrm{Q}_{1}$ constituents from the tide scenario simulation are very close to the observed values at all stations. NOS skill assessment and RMS errors of all variables indicate that most statistical parameters pass the assessment criteria for both hindcast and nowcast/forecast scenarios and model outputs have good agreements with the measurement. We have to note that OTIS Regional Tide Solutions harmonic analysis results were reduced by $5 \%$ on the open boundary. Though this ad hoc treatment ensures very good water level results, more work needs to be done to understand the dynamics behind the adjustment.

Modeled water level and salinity from Martinez to Mallard Island (see Figure 10 for locations) showed strong disagreement with measurement during hindcast period when flow river boundary conditions were employed for the Sacramento and San Joaquin Rivers. The model water level results after using stage river boundary for the two rivers were greatly improved. However, salinity disagreement still existed, though in very low occurrence, during the past ten months after the semi-operational nowcast/forecast trial period. As shown in Figure 13, the model predicted salinity at Port Chicago was in agreement with the observations from October 15-October 25. However, on October 26 and 27, the model salinity predictions at Port Chicago abruptly deviated from the observations. On the $10 / 27 / 18 \mathrm{Z}$ cycle, the model under predicted the salinity by up to 8 PSU in the nowcast time window. A comparison of the model river forcing water surface elevation to the USGS stage data at the two rivers showed no indication that the model stage was in error.

The location of the river boundaries is still within the tidal domain and either a stage or flow boundary condition is not entirely appropriate. In effect, the boundary location is not at the head of tide and is a tidal river with flow in both directions. In the case of a stage boundary condition, no unique stage discharge relationship exists. The stage is a function of both the discharge and the offshore subtidal water level. The imposition of the stage boundary condition yields accurate water level prediction, but is problematic for salinity, since the appropriate discharge cannot always be specified. For a flow boundary condition, since the boundary is not at the head of tide, tidal wave reflections will occur and will lead to inaccurate stage predictions in the lower delta and even at Port Chicago.

In addition, the model grid cannot represent the complex water channel system in the delta region. One can compare the real delta system in Figure 1 and the model grid in Figure 2. While previous work [15] has used a $20 \mathrm{~m}$ deep rectangular "false delta" to produce the appropriate tidal prism of the unresolved area, this approach was not used in the present SFBOFS, since it was felt that the entire delta region may need to be represented as discussed by MacWilliams et al. [45]. This further effort initially considered outside the scope of the SFBOFS is now being considered to improve the salinity prediction in the lower delta and to also potentially provide additional navigation guidance to the Ports of Stockton and Rio Vista. As an interim measure, a data assimilation scheme is being considered within the present SFBOFS, to correct the model salinity predictions from Martinez to 
Rio Vista on the Sacramento River and Antioch on the San Joaquin River at the start of each nowcast/forecast cycle. Future work will also consider the extension of the offshore boundary to include the Farallon Islands, which will allow for a more accurate specification of the offshore water level and current boundary conditions.

Figure 13. Modeled salinity strays away from observation with time.
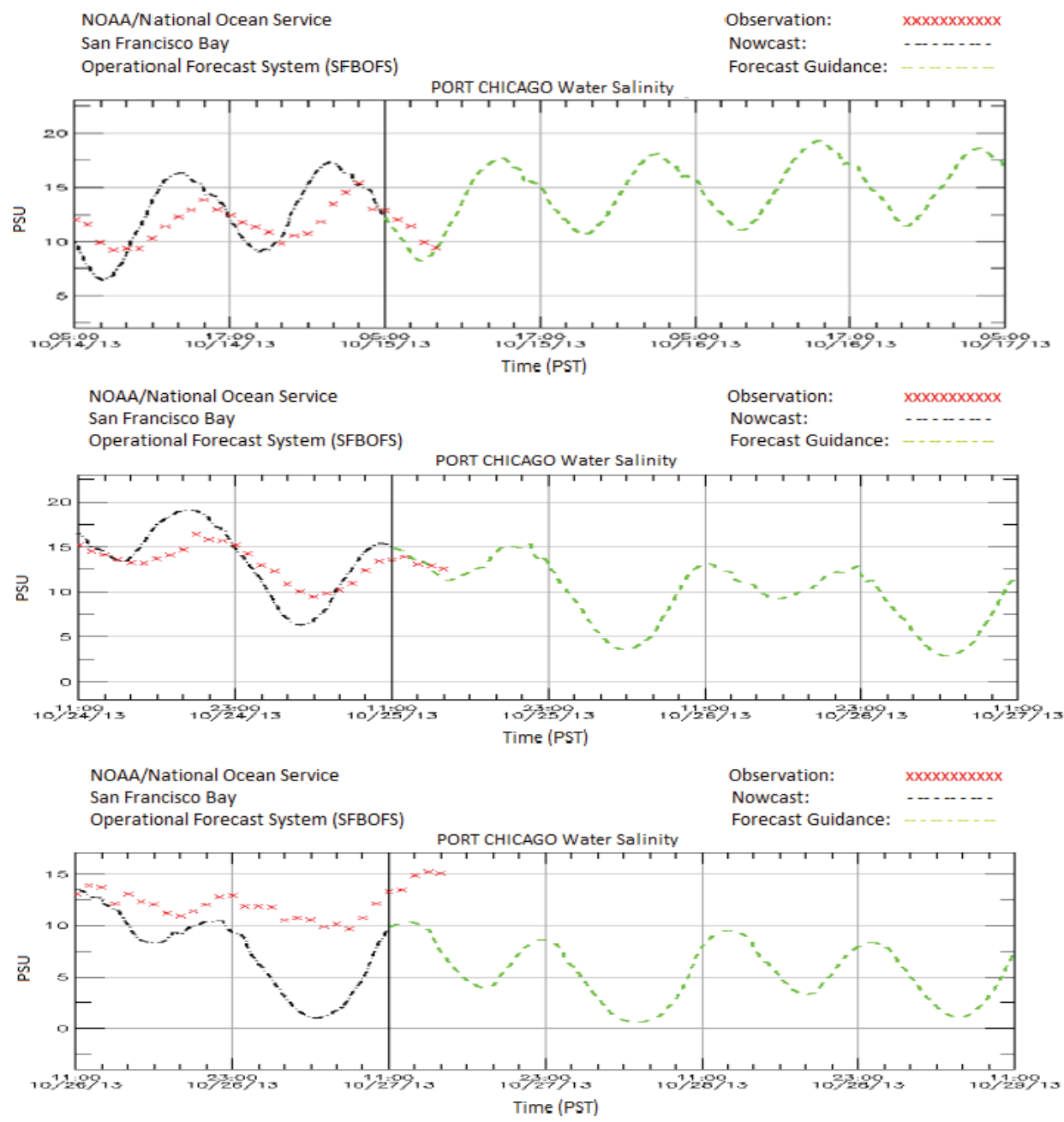

\section{Acknowledgments}

Richard Patchen, Chief Science Officer (retired) of the CSDL provided several insights on model grid development. Jiangtao Xu, CSDL, provided valuable assistance with the development of multiple grids and with the use of the SMS software. Philip Richardson, CSDL, assisted with the hindcast initial condition specification, validation data preparation, and the skill assessment. Special thanks to the two anonymous reviewers, who provided many insights and suggestions, which greatly improved the paper. 


\section{Author Contributions}

R. A. Schmalz and M. Peng conducted hindcast, nowcast and forecast development and are the key authors for the manuscript writing. A. Zhang developed COMF for the operational modeling and supervised the nowcast and forecast development. F. Aikman supervised the hindcast development.

\section{Conflicts of Interest}

The authors declare no conflict of interest.

\section{References}

1. NOAA, National Ocean Service, Center for Operational Oceanographic Products and Services, San Francisco Bay PORTS. Available online: http://tidesandcurrents.noaa.gov/ports/index. html?port=sf (accessed on 15 October 2013).

2. Cassuli, V. Semi-Implicit Finite Difference Methods for the Two-Dimensional Shallow Water Equations. J. Comput. Phys. 1990, 86, 56-74.

3. Casulli, V.; Cattani, E. Stability, Accuracy and Efficiency of A Semi-Implicit Method for Three-Dimensional Shallow Water Flow. Appl. Math. Comput. 1994, 27, 99-112.

4. Casulli, V.; Walters, R.A. An Unstructured Grid, Three-Dimensional Model Based on the Shallow Water Equations. Int. J. Numer. Meth. Fluids 2000, 32, 331-348.

5. Cheng, R.T.; Smith, R.E. A Nowcast Model for Tides and Tidal Currents in San Francisco Bay, California. In Proceedings of Ocean Community Conference, Baltimore, MD, USA, 15-19 November 1998; pp. 537-543.

6. Gross, E.S.; MacWilliams, M.L.; Kimmerer, W.J. Three-Dimensional Modeling of Tidal Hydrodynamics in the San Francisco Estuary. San Franc. Estuary Watershed Sci. 2010, 7, $1-37$.

7. MacWilliams, M.L.; Cheng, R.T. Three-Dimensional Hydrodynamic Modeling of San Pablo Bay on an Unstructured Grid. In Proceedings of the 7th International Conference on Hydroscience and Engineering, (ICHE-2006), Philadelphia, PA, USA, 10-13 September 2006.

8. Barnard, P.L.; Hanes, D.M.; Rubin, D.M.; Kvitek, R.G. Giant Sand Waves at the Mouth of San Francisco Bay. EOS Trans. Am. Geophys. Union 2006, 87, 285-289.

9. Barnard, P.L.; Eshleman, J.L.; Erikson, L.H.; Hanes, D.M. Coastal Processes Study at Ocean Beach, San Francisco, CA: Summary of Data Collection 2004-2006; Open File Report 2007-1217; U. S. Geological Survey: Reston, VA, USA, 2007.

10. Barnard, P.L.; O’Reilly, B.; van Ormondt, M.; Elias, E.; Ruggiero, P.; Erikson, L.H.; Hapke, C.; Collins, B.D.; Guza, R.T.; Adams, P.N.; et al. The Framework of a Coastal Hazards Model-A Tool for Predicting the Impact of Severe Storms; Open File Report 2009-1073; U. S. Geological Survey: Reston, VA, USA, 2009.

11. Deltares. Delft3D-FLOW User Manual; Deltares Rotterdamseweg: Delft, The Netherlands, 2014; p. 684. 
12. Uslu, B.; Arcas, D.; Titov, V.V.; Venturato, A.J. PMEL Tsunami Forecast Series: Vol. 3. A Tsunami Forecast Model for San Francisco, California; NOAA/OAR Special Report, NOAA/PMEL Contribution No. 3342; NOAA/PMEL Center for Tsunami Research: Seattle, WA, USA, 2010.

13. Fringer, O.B.; Gerritsen, M.; Street, R.L. An Unstructured-Grid, Finite Volume, Nonhydrostatic, Parallel Coastal Ocean Simulator. Ocean Model. 2006, 14, 139-173.

14. Chua, V.P.; Fringer, O.B. Sensitivity Analysis of Three-Dimensional Salinity Simulations in North San Francisco Bay Using the Unstructured-Grid SUNTANS Model. Ocean Model. 2011, 39, 332-350.

15. Cheng, R.T.; Casulli, V.; Gartner, J.W. Tidal Residual Intertidal Mudflat (TRIM) Model and its Applications to San Francisco Bay, California. Estuar. Coast. Shelf Sci. 1993, 36, 235-280.

16. MacWilliams, M.L.; Gross, E.S.; DeGeorge, J.F.; Rachielle, R.R. Three-Dimensional Hydrodynamic Modeling of the San Francisco Estuary on an Unstructured Grid. In Proceedings of the 32nd International Association for Hydraulic Research Congress, Venice, Italy, 1-6 July 2007.

17. Zhang, A.; Yang, Z. Coastal Ocean Modeling Framework on NOAA's High Performance Computer (COMF-HPC); NOAA Technical Report NOS CO-OPS 039; National Oceanic and Atmospheric Administration: Silver Spring, MD, USA, 2014; p. 70.

18. Chen, C.; Liu, H.; Beardsley, R.C. An Unstructured, Finite-Volume, Three-Dimensional, Primitive Equation Ocean Model: Application to Coastal Ocean and Estuaries. J. Atmos. Ocean. Technol. 2003, 20, 159-186.

19. Chen, C.; Beardsley, R.C.; Cowles, G.W. An Unstructured Grid, Finite-Volume Coastal Ocean Model (FVCOM) System. Oceanography 2006, 19, 78-89.

20. Chen, C.; Beardsley, R.C.; Cowles, G.W. An Unstructured Grid, Finite-Volume Coastal Ocean Model FVCOM User Manual; Technical Report SMAST/UMASSD-06-0602; University of Massachusetts-Dartmouth: New Bedford, MA, USA, 2006.

21. Xu, J.; Myers, E.P.; White, S.A. VDATUM for the Coastal Waters of North/Central California, Oregon and Western Washington: Tidal Datums and Sea Surface Topography; NOAA Technical Memorandum, NOS CS 22; National Oceanic and Atmospheric Administration: Silver Spring, MD, USA, 2009.

22. Schmalz, R.A. Hydrodynamic Model Development for the San Francisco Bay Operational Forecast System (SFBOFS); NOAA Technical Report NOS CS 34; National Oceanic and Atmospheric Administration: Silver Spring, MD, USA, 2014.

23. Warner, J. Re: Problem with ROMS Wetting/Drying and Turbulence Model(s); ROMS Discussion Group. Available online: http://www.myroms.org (accessed on 6 February 2012).

24. Lettman, K. University of Oldenburg, Oldenburg, Germany. Personal Communication, 2012.

25. Fang, X.; Stefan, H.G. Dynamics of Heat Exchange between Sediment and Water in a Lake. Water Resour. Res. 1996, 32, 1719-1727.

26. Smith, N. Observations and Simulations of Water-Sediment Heat Exchange in a Shallow Coastal Lagoon. Estuaries 2002, 25, 483-487. 
27. Xue, H.; Due, Y. Implementation of a Wetting-and-Drying Model in Simulating the Kennebec-Androscoggin Plume and the Circulation in Casco Bay. Ocean Dyn. 2010, 60, 341-357.

28. Uchiyama, Y. Modeling Three-Dimensional Cohesive Sediment Transport and Associated Morphological Variation in Estuarine Intertidal Mudflats; Port and Airport Research Institute: Yokosuka, Japan, 2005.

29. Oey, L. A Wetting-Drying Scheme for POM. Ocean Model. 2005, 9, 133-150.

30. Oey, L. An OGCM with Movable Land-Sea Boundaries. Ocean Model. 2006, 13, 176-195.

31. Oey, L.; Ezer, T.; Hu, C.; Muller-Karger, F.E. Baroclinic Tidal Flow and Inundation Processes in Cook Inlet, Alaska: Numerical Modeling and Satellite Observations. Ocean Dyn. 2007, 57, 205-221.

32. California Department of Natural Resources, DAYFLOW program. Available online: http://www.water.ca.gov/dayflow/documentation/dayflowDoc.cfm\#Introduction (accessed on 15 October 2010).

33. Oltmann, R.N. Indirect Measurement of Delta Outflow using Ultrasonic Velocity Meters and Comparison with Mass-Balance Calculated Outflow; Interagency Ecological Program (IEP) for the Sacramento-San Joaquin Estuary Newsletter: San Francisco, CA, USA, 1998.

34. MacWilliams, M. Delta Modeling Associates, San Francisco, CA, USA. Personal Communication, 2013.

35. Oregon State University Tidal Data Inversion, OTIS Regional Tide Solutions, 2010: West Coast of the USA. Available online: http://volkov.oce.orst.edu/tides/WC.html (accessed on 15 June 2011).

36. Conkright, M.E.; Boyer, T.P.; Antonov, J.I.; Baranova, O.K.; Garcia, H.E.; Gelfeld, R.; Johnson, D.; Locarnini, R.A.; Murphy, P.P.; O’Brien, T.D.; et al. World Ocean Database 2001, Volume 5: Temporal Distribution of Nutrient Profiles; Levitus, S., Ed.; NOAA Atlas NESDIS 46, U.S. Government Printing Office: Washington, DC, USA, 2002; p. 286.

37. Carter, G.S. Barotropic and Baroclinic $\mathrm{M}_{2}$ Tides in the Monterey Bay Region. J. Phys. Oceanogr. 2010, 40, 1766-1783.

38. Carter, G.S.; Fringer, O.B.; Zaron, E.D. Regional Models of Internal Tides. Oceanography 2012, 25, 56-65.

39. Willmott, C.J.; Ackleson, S.G.; Davis, R.E.; Feddema, J.J.; Klink, K.M.; Legates, D.R.; O'Donnell, J.; Rowe, C.M. Statistics for the Evaluation and Comparison of Models. J. Geophys. Res. 1985, 90, 8995-9005.

40. Hess, K.W.; Gross, T.F.; Schmalz, R.A.; Kelley, J.G.W.; Aikman, F.; Wei, E.; Vincent, M.S. NOS Standards for Evaluating Operational Nowcast and Forecast Hydrodynamic Model Systems; NOAA Technical Report NOS CS 17; National Oceanic and Atmospheric Administration: Silver Spring, MD, USA, 2003.

41. Zhang, A.; Hess, K.W.; Wei, E.; Myers, E. Implementation of Model Skill Assessment Software for Water Level and Current in Tidal Regions; NOAA Technical Report NOS CS 24; National Oceanic and Atmospheric Administration: Silver Spring, MD, USA, 2006. 
42. Peng, M.; Zhang, A. San Francisco Bay Operational Nowcast and Forecast System Development and its Skill Assessment; NOAA Technical Report (unpublished work); National Oceanic and Atmospheric Administration: Silver Spring, MD, USA, 2013.

43. Taylor, K.E. Summarizing Multiple Aspects of Model Performance in a Single Diagram. J. Geophys. Res. 2001, 106, 7183-7192.

44. NOAA, National Ocean Service, Center for Operational Oceanographic Products and Services, San Francisco Bay OFS. Available online: http://tidesandcurrents.noaa.gov/ofs/sfbofs/ sfbofs.html (accessed on 2 December 2013).

45. MacWilliams, M.L; Salcedo, F.G.; Gross, E.S. San Francisco Bay-Delta UnTRIM Model Calibration Report, POD 3-D Particle Tracking Modeling Study; California Department of Water Resources: Sacramento, CA, USA, 2008. 


\title{
Strengthening the Resiliency of a Coastal Transportation System through Integrated Simulation of Storm Surge, Inundation, and Nonrecurrent Congestion in Northeast Florida
}

\author{
Justin R. Davis, Vladimir A. Paramygin, Chrysafis Vogiatzis, Y. Peter Sheng, \\ Panos M. Pardalos and Renato J. Figueiredo
}

\begin{abstract}
The Multimodal Transportation Educational Virtual Appliance (MTEVA) is an application developed within the framework of the broader Coastal Science Educational Virtual Appliance (CSEVA) to enhance coastal resiliency through the integration of coastal science and transportation congestion models for emergency situations. The first generation MTEVA enabled users to perform and visualize simulations using an integrated storm surge and inundation model (CH3D-SSMS) and transportation evacuation/return modeling system that supports contraflow in a simple synthetic domain (order of tens of intersections/roads) under tropical storm conditions. In this study, the second generation MTEVA has been advanced to apply storm surge and evacuation models to the greater Jacksonville area of Northeast Florida (order tens of thousands of transportation intersections/roads). To support solving the evacuation problem with a significantly larger transportation network, new models have been developed, including a heuristic capable of efficiently solving large-scale problems. After initial testing on several smaller stand-alone transportation networks (e.g., Anaheim, Winnipeg), the heuristic is applied to the Jacksonville area transportation network. Results presented show the heuristic produces a nearly optimal (average optimality gap $<0.5 \%$ ) solution in $90 \%$ less wall clock time than needed by the exact solver. The MTEVA's new capabilities are then demonstrated through the simulation of a Hurricane Katrina-sized storm impacting the region and studying how the evacuation patterns are affected by the closing of roads due to flooding and bridges due to high winds. To ensure residents are able to leave the area, evacuations are shown to need to have begun at least $36 \mathrm{~h}$ prior to landfall. Additionally it was shown that large numbers of residents would be left behind if evacuation does not begin within $18 \mathrm{~h}$ of landfall and $\sim 97 \%$ would not escape if evacuation did not begin until landfall, when areas of the coast that are the most prone to flooding are already cut off from the "safe" nodes of the transportation network.
\end{abstract}

Reprinted from J. Mar. Sci. Eng. Cite as: Davis, J.R.; Paramygin, V.A.; Vogiatzis, C.; Sheng, Y.P.; Pardalos, P.M.; Figueiredo, R.J. Strengthening the Resiliency of a Coastal Transportation System through Integrated Simulation of Storm Surge, Inundation, and Nonrecurrent Congestion in Northeast Florida. J. Mar. Sci. Eng. 2014, 2, 287-305.

\section{Introduction}

Hurricanes, earthquakes, industrial accidents, terrorist attacks and other such emergency situations pose great dangers to lives and property. Efficient evacuation during these events is one way to increase safety and avoid escalation of damages. The penalties incurred when Hurricane 
Katrina caught the nation off guard were severe. It is estimated that Hurricane Katrina displaced more than 1.5 million people and caused economic damages of \$40-120 billion [1]. Over the past decade, evacuation problems have been given a heightened attention and there are numerous studies available in the literature on evacuation strategies [2-7].

The evacuation problem has attracted significant scientific interest over the years, and mathematical models and approaches have been devised to solve it, based on network flow optimization techniques [8]. The problem is formally stated as follows. Given a transportation network $G(V, E)$, where each node (intersection) $i \in V$ has a set demand $d_{i}$ and each arc (road) has a capacity of $u_{i j}$, and a set of safe nodes $S$ (destinations), find the optimal routes to safety. Optimality here can be defined in different ways: number of evacuees that reach safety, smallest overall time to safety, average time to safety. In this effort, we aim to maximize the number of people that are safely evacuated to one of the nodes in set $\mathrm{S}$.

Maximizing the number of people that are safely evacuated to secure areas is often modeled as a quickest transshipment problem [9]. Models for solving the problem were proposed in [10], while a summary of recent results can be found in [11]. In the context of evacuation, contraflow can be defined as the flow that traverses an arc in the reverse way. That is, if an arc $(i, j)$ is reversed, then flow can travel from node $\mathrm{j}$ to node $\mathrm{i}$. However, when we consider contraflow, the problem becomes NP-hard [12], and as such it is inherently more difficult to solve. Hence, in large-scale, realistic transportation networks, the size of the problem renders exact approaches impractical, as significant computational time and power would be required. Decomposition schemes [13] and heuristics are thus preferred for practical reasons.

A comprehensive survey was carried out to identify and evaluate the existing techniques for solving large-scale evacuation problems available in literature [14]. Recognizing a reasonable level of insufficiencies in multimodal transportation, alternate evacuation routes in case of accidents and congestion, and heuristic exploration of difficult optimization problems, this survey helped explain the deficiencies in current techniques and also identified the features that significantly affect evacuation efficiency. At this moment, key approaches to solving evacuation problems (as defined previously) are optimization and simulation. In both cases, the factors that come into play are origin-destination assignments (i.e., people that need to reach specific safe zones), arc capacities (static or dynamic, contraflow), and priorities (for sensitive groups of people or areas).

The type of optimization or simulation technique can also be used to classify the problem. The most widely used approach (and the approach adopted herein) is the maximum dynamic flow problem [15]. Other approaches include, but are not limited to, the Dynamic Traffic Assignment Problem [16], Macroscopic Simulation Techniques (NETVAC [17] and MASSVAC [18]), and techniques that utilize both optimization and simulation, as in the cell based formulation of $[19,20]$. For more information on these techniques, see [20], where 22 evacuation models are compared.

Evacuation (and return) planning and disaster management are a vital necessity to the coastal areas of Florida where tropical storms are an ever present threat. In particular, to better understand how tropical storms impact evacuation patterns in coastal areas and to assist in coastal science, transportation, and cyberinfrastructure education, research and outreach, the Multimodal Transportation 
Educational Virtual Appliance (MTEVA), has been developed [21]. The MTEVA is an application developed within the framework of the broader Coastal Science Educational Virtual Appliance (CSEVA).

The CSEVA [22] is a unique, self-contained software environment designed to support interdisciplinary coastal science education and outreach activities, enabling active, hands-on numerical modeling experiments by researchers, stakeholders and the general public. Contained within the "virtualized" environment of the CSEVA, are the applications that cover a variety of coastal science topics. Integration of these applications into a single appliance enhances the user experience (less storage requirements, easier to install, linked application scenarios, etc.) and provides a single collection of applications that can serve as practical and educational tools to scientists, educators and students, alike. In addition to the MTEVA, the CSEVA contains CI-TEAM [23] and SCOOP [24] applications as well as built-in and ready to use models and tools such as the atmospheric model WRF (Weather Research and Forecasting model) and a fully functional THREDDS Data Server (TDS) [25]. The CI-TEAM application simulates the release of a tracer into the waters of the Indian River Lagoon estuarine system (Northeast Florida). While, the SCOOP application simulates storm surge and inundation in two different domains: a simple domain being impacted by a synthetic storm and Charlotte Harbor (southwest Florida) being impacted by various different wind forecasts for Hurricane Charley (2004).

The first generation MTEVA enabled users to perform and visualize simulations using an integrated storm surge and inundation model (CH3D-SSMS) and transportation evacuation/return modeling system that supports contraflow in a simple synthetic domain (order of tens of transportation nodes/arcs) under tropical storm conditions. In this study, the second generation MTEVA has been advanced to apply storm surge and evacuation models to the greater Jacksonville area of Northeast Florida (order tens of thousands of transportation nodes/arcs). To support solving the evacuation problem with the significantly larger transportation network, several new algorithms have been developed including a heuristic. After initial testing on several smaller stand-alone transportation networks (e.g., Anaheim, Winnipeg), the heuristic is shown to be near optimal network (average optimality gap $<0.5 \%$ ) for the Jacksonville transportation, while the wall clock time necessary to reach a solution decreased more than $90 \%$, compared to the time needed to obtain a solution solving the optimization problem using an exact solver. The MTEVA's new capability to simulate the transportation network response to a significantly larger network is demonstrated through the simulation of a Hurricane Katrina-sized storm impacting the region and studying how the evacuation patterns are affected by the closing of roads due to flooding and bridges due to high winds.

The paper is outlined as follows. First, we give a description of the Storm Surge and Inundation Modeling part within the MTEVA, and provide information on its main component, the CH3D-SSMS. Further, in Section 3, we introduce notation and provide optimization models to describe the problem. We then describe three different methods to tackle the large-scale problem, and compare them in terms of solution quality and computational efficiency. In Section 4, a demonstration application is presented in which a synthetic storm is bearing down on the Jacksonville area. Finally, Section 5 summarizes the findings of this effort and aims to give further insight in future work and approaches on the field. 


\section{Storm Surge and Inundation Modeling within the MTEVA}

The core of the MTEVA is a coupled storm surge and transportation network modeling system. These models, the optimization engine used to solve the network optimization problem, and all of the associated pre- and post-processing utilities are then packaged into the MTEVA. The main driver of the coupled modeling system is the storm surge modeling system, CH3D-SSMS (e.g., [26]). It includes a high-resolution coastal surge model CH3D, developed by [27,28], which is coupled to a coastal wave model SWAN [29] and large scale surge and wave models. Both models can receive open boundary conditions from a number of large-scale surge and wave models. Finally, a synthetic hurricane wind [30] model is also incorporated into the system that provides wind and barometric pressure forcing in the domain. CH3D-SSMS is validated using many recent Atlantic Basin hurricanes (e.g., [26]) and is used to produce a FIRM (Flood Insurance Rate Map) for Pinellas County, FL. CH3D-SSMS was also used to produce surge atlas which was compared with the SLOSH (the model used by the National Hurricane Center) surge atlas. Since 2004, CH3D-SSMS has been advanced to provide real-time forecast of hurricane wind, storm surge, wave, and coastal inundation for various parts of FL and Gulf coasts during hurricane seasons [26,31].

Also, given that the issue of sea level rise (SLR) has garnered attention recently, an option to simulate the effect of SLR is included. The SLR values chosen are: the 100-year projections derived from a continuation of the approximate local linear trend $(+21 \mathrm{~cm})$, the value in between of the nearby Mayport (2.40 mm/year) and Fernandina (2.02 mm/year) tide stations through 2006 [32]; the value developed for the Intergovernmental Panel on Climate Change (IPCC) mid-range scenario A1B $(+50 \mathrm{~cm})$ [33]; and an estimate near the upper SLR limits found for several IPCC scenarios in [34] $(+150 \mathrm{~cm})$. Two algorithms for implementing the SLR physics on storm surge and inundation are included. In the first algorithm ("ad-hoc"), SLR is simply added onto the final simulated water level. In the second algorithm ("integrated"), SLR is added onto the water level boundary and initial conditions used in the model such that the model simulates the end effect of the SLR providing a much more realistic estimate of flooding due to SLR as it takes into consideration the hydrodynamics.

For a given storm surge and inundation simulation, CH3D-SSMS either sends the entire simulated response at the completion of the simulation or it sends the response periodically (e.g., once every $15 \mathrm{~min}$ of simulated time) including the current pattern of storm surge and inundation as well as the state (all roads passable, certain roads flooded, etc.) of the transportation network. The state of roads (arcs) and intersections (nodes) are based on inundation and wind conditions. Exceeding threshold inundation values will mark a road (arc or a node) as impassable and unavailable to be used in evacuation. The transportation network optimization model then reads in the state of the network along with a set of capacities, demands, etc. and determines the optimal traffic flow either using an exact solver or a heuristic approach.

During a simulation, potential nodes fall into several possible categories: (1) The node is connected to one or more other nodes via an arc; (2) The node is isolated and no longer has any connections (e.g., due to flooded roads), but may reconnect in the future; or (3) The node has been 
destroyed and will never again be connected to any other nodes (node becomes permanently flooded for the duration of the evacuation, so that for the remainder of the evacuation event it cannot be used). Nodes are considered destroyed if flooding exceeds some critical value, $H_{N c r}$.

Each arc within the network is defined as either a "road" (considered indestructible) or a "bridge". Roads are assumed at some height, $R_{A}$, above (or below) the surrounding topography and become unusable if, during the course of a simulation, the water level at any location on the road exceeds some critical height, $H_{A c r}$, above the road. If, at any point of time later the water level retreats, the road becomes usable again. Each bridge has its own elevation relative to the simulation vertical datum (e.g., NAVD88), $B_{A}$. If, during the course of a simulation the water reaches the bridge, it is considered "destroyed" and permanently unusable. Additionally, regardless of water level, bridges are also assumed to be impassable during periods of high wind when the wind speed exceeds some critical value, $W_{\text {Acr }}$. For practical purposes $\mathrm{H}_{\mathrm{Ncr}}$ is set to $30 \mathrm{~cm}$ (about one foot of flooding) and $\mathrm{W}_{\text {Acr }}$ to $45 \mathrm{mph}$. In reality these number can vary depending on location, but they are in line with actual values used by authorities. Critical values can be customized in the system, but not directly in the user interface.

Finally, for the optimization phase, we consider the transportation network as a graph G(V,E), where $\mathrm{V}$ is the set of nodes and $\mathrm{E}$ the set of roads. We further define two costs for the roads, namely $c_{i j}$ and $h_{i j}$. The first represents the time/cost to use arc $(\mathrm{i}, \mathrm{j}) \in \mathrm{E}$, while the latter the cost to reverse it, in order to allow the contraflow. It is easy to see that in order to reverse a road, some actions are necessary; police officers should be employed to control traffic, proper traffic signs should be used, etc. For simplicity, we treat every arc the same way, hence $c_{i j}=h_{i j}=1$.

\section{The Transportation Network Assignment (aka Evacuation) Model}

Within the MTEVA, three algorithms are now available to solve the transportation network assignment (aka evacuation) problem: (1) Time Static — a fast algorithm that works with a single time instance attempting to move as many people as possible to safety (any node in the set $\mathrm{S}$ ) and is then iterated for multiple time steps; (2) Time Dynamic - attempts a planned evacuation, however, adding the time dimension to the problem increases its size and thus takes significantly longer to solve; (3) Heuristic - a compromise between the computational time and problem complexity. Coupled to the surge model - the transportation model operates based on knowledge about flooding extents and dynamics. The mathematical models that arise within the time static, time dynamic heuristic, along with the model of the time dynamic version (exact) are all solved using the GNU Linear Programming Kit (GLPK) contained within the MTEVA.

\subsection{Algorithms and Implementation}

In this section, we first give the notation (Table 1) and the necessary information we need, and then proceed to formulate the problem as a mixed-integer linear program. We also propose two heuristic approaches, and evaluate their efficiency in synthetic and real transportation networks. The two heuristic approaches can be summarized as: (1) Iteratively solve each discrete time step, updating each node's demand and status (Time Static); (2) Heuristically solve the time dynamic 
version (NP-Hard) of the problem, after smartly selecting the arcs to be reversed (Time Dynamic Heuristic). Solving the NP-hard problem provides an optimal solution as to the routes that each vehicle needs to use, and the routes that need to be reversed in order to achieve maximum efficiency. On the other hand, both Time Static and Time Dynamic Heuristics provide approximate solutions that can be significantly faster to compute. The results show that the heuristics developed produce solutions within reasonable optimality gaps, and are significantly faster to compute.

Table 1. Notation used to describe the transportation network, $\boldsymbol{G}(\boldsymbol{V}, \boldsymbol{E})$, of a region and the mathematical model.

\begin{tabular}{cl}
\hline Sets & \\
\hline $\mathbf{V}$ & The set of all nodes (intersections) in the network. \\
$\mathbf{E}$ & The set of all arcs (roads) in the network \\
$\boldsymbol{S}$ & The set of nodes that are considered safe \\
\hline Input Parameters \\
\hline $\boldsymbol{u}_{\boldsymbol{i} \boldsymbol{i}}$ & The capacity of arc $(\boldsymbol{i}, \boldsymbol{j}) \in \boldsymbol{E}$. For any two nodes $(\boldsymbol{i}, \boldsymbol{j}) \notin \boldsymbol{E}, \boldsymbol{u}_{\boldsymbol{i} \boldsymbol{j}}=\mathbf{0}$. \\
$\boldsymbol{\xi}_{\boldsymbol{i}}^{t}$ & A binary input parameter that is equal to 0 if node $\boldsymbol{i}$ is destroyed at time $\boldsymbol{t}$, or 1 otherwise. \\
$\boldsymbol{\zeta}_{\boldsymbol{i} \boldsymbol{i}}^{t}$ & A binary input parameter that is equal to 0 if arc $(\boldsymbol{i}, \boldsymbol{j})$ is destroyed at time $\boldsymbol{t}$, or 1 otherwise. \\
$\boldsymbol{K}$ & The budget of arcs that can be reversed during the evacuation process. \\
\hline $\mathbf{V a r i a b l e s}$ to be Optimized \\
\hline $\boldsymbol{d}_{\boldsymbol{i}}^{\boldsymbol{t}} \quad$ The demand of node $i \in V$ at time $t \in T . d_{i}^{0}$ is the initial demand of node $i$ and is given. \\
$\boldsymbol{x}_{\boldsymbol{i} \boldsymbol{t}}^{t} \quad$ The flow on arc $(i, j) \in E$ at time $t \in T$. \\
$\boldsymbol{y}_{\boldsymbol{i} \boldsymbol{i}}$ A binary variable that is equal to 1 if arc $(\boldsymbol{i}, \boldsymbol{j}) \in \boldsymbol{E}$ is reversed, or 0 otherwise. \\
\hline
\end{tabular}

The first approach, Time Static [21], involves the decomposition of the big, time dynamic, problem into smaller problems, each considered as one discrete time step. The final solution is essentially the collection of all partial solutions, obtained after each step. However, this approach is myopic as it does not consider future consequences. For example, evacuations are performed without any consideration of which areas are physically closer to being flooded and thus, need to be evacuated first.

On the other hand, the second approach (Time Dynamic Heuristic) considers future consequences, and selects routes and road reversals that are going to maximize the number of people that reach safety in the end, rather than at each time step. The heuristic uses model information to locate the arcs that seem to be bottlenecks for the evacuation process. This approach is based on the "shadow prices" of the capacity constraint set of the original problem. In mathematical programming, every linear program has its dual, which is typically used to extract information on the model and the solution. The capacity constraints state that the flow on any road at any time has to satisfy the capacity of the road $\left(x_{i j}^{t} \leq u_{i j}\right)$ without consideration of contraflow. The dual multiplier of this set of constraints represents the increase in the number of evacuees, if the capacity of the arcs were bigger. However, this assumes that the number of evacuees is much bigger (which might not be the case). Now, let $\lambda_{i j}$ be the dual multipliers of the relaxed constraint. Selecting the $K$ arcs with the biggest $\lambda_{i j} * u_{j i}$ gives a greedy approach on the $K$ arcs that should be reversed.

After the arcs have been reversed, the remaining problem is a large-scale, time-dynamic evacuation problem that can be solved as a quickest transshipment problem [9]. We, instead, 
dualize the capacity constraints, and augment them, based on an Augmented Lagrange duality iterative scheme.

The two heuristic approaches can be summarized as follows:

- Time Static [21]

- Everyone evacuates simultaneously. Future events (congestion/flooding) not considered.

○ Decomposition into discrete, smaller problems, each considering only one time step.

- Time Dynamic Heuristic (Present Study)

- Evacuation is phased. Future events (congestion/flooding) are considered.

- Relaxation involves the selection of the arcs to be reversed.

- Locates the arcs that would benefit evacuation the most (if equal demand everywhere).

- Resulting formulation of a dynamic network flow problem is solved using the Augmented Lagrange relaxation approach.

The formulation can be given as

$$
\begin{array}{ll}
\max \sum_{t \in T} \sum_{i \in N \backslash S} \sum_{j \in S} x_{i j}^{t} & \\
\text { s.t. } d_{i}^{t+1}=d_{i}^{t}+\sum_{j \in N:(j, i) \in E} x_{j i}^{t}-\sum_{j \in N:(j, i) \in E} x_{i j,}^{t} & \forall i \in V, \forall t \in T: \xi_{i}^{t}=1 \\
x_{i j}^{t} \leq u_{i j}+y_{i j} u_{j j} & \forall(i, j) \in E, \forall t \in T: \zeta_{i j}^{t}=1 \\
\sum_{(i, j) \in E} y_{i j} \leq K & \\
x_{i j}^{t} \geq 0, & \forall(i, j) \in E, \forall t \in T \\
d_{i}^{t} \geq 0, & \forall i \in V, \forall t \in T \\
y_{i j} \in\{0,1\}, & \forall(i, j) \in E
\end{array}
$$

The objective function in (1) ensures that the number of people exiting the "unsafe" areas of the network and entering a secure location (safe zone) is maximized. Constraint (2) is the time-dynamic counterpart of the well-known flow conservation constraint in network flow problems. Then, the capacity of the arcs is set in constraint (3). Observe that when an arc is reversed, its capacity is added to the one of the opposite direction. For simplicity, we assume that for a one-way road $(\mathrm{i}, \mathrm{j})$, there exists a reverse direction road (j,i) as well with a capacity of $u_{i j}=0$. Equation (4) is a typical budget constraint that ensures no more than $\mathrm{K}$ arcs can be reversed. The reason for that limitation is logistical; reversing a road takes time and needs to be done carefully. Hence, it is realistic to assume a limit on that number. Last, constraints (5)-(7) define the restrictions on the variable values.

Observe that in an optimal solution, no road $(\mathrm{i}, \mathrm{j})$ can have positive values for the flows $\mathrm{x}_{\mathrm{ij}}$ and $\mathrm{x}_{\mathrm{ji}}$. The proof, which is done by contradiction, can be found in Lemma 1 of [13].

\subsection{Computational Results}

The key advantage of the heuristics developed herein are that they are computationally efficient. This is particularly important as events which lead to mass evacuations can be unpredictable. For example, Hurricane Charley (2004) was forecast to make landfall in Tampa Bay, FL. Within $24 \mathrm{~h}$ 
of making landfall, the storm made an abrupt turn to the right and residents of the Charlotte Harbor area (several hundred miles to the South of Tampa Bay) had little time to evacuate. In this section, we present the results of a computational study using the MTEVA to show how the heuristic performs on both synthetic and real transportation networks and show the heuristics feasibility for potential use in real-time evacuation planning. Three algorithms are compared: (1) the exact method (i.e., optimizing using GLPK); (2) the time static heuristic; and (3) the time dynamic heuristic. Findings are reported in terms of "optimality gaps" (difference between the estimated values calculated by the heuristic and the exact values) and the computational time required to reach a solution. In our approach, we measure the objective function by the number of evacuees that reached a safe node within the time horizon. Each algorithm is written in $\mathrm{C}++$, and the numerical experiments were performed on a server with two AMD Opteron 6128 Eight-Core CPUs and 12 GB of RAM, running Linux x86_64, CentOS 5.9. Even though the server supports parallelization, at the moment the algorithms are not implemented in parallel.

The computational experiments were designed as follows. First, 5 synthetic networks of different sizes ranging from 20 to 10,000 nodes were created, where $5 \%-10 \%$ of the nodes were, at random, selected to serve as safe areas. Then, the three approaches (exact, time static, and heuristic) were tested, reporting their respective optimality gaps and computational time. In addition, real transportation networks from a set of well-known transportation network test problems (Anaheim, Austin, Philadelphia, Sioux Falls, and Winnipeg) [35] were optimized. The safety nodes for the real networks were randomly selected and the optimization process was repeated 10 times for each network. On the other hand, for the Jacksonville transportation network, the set of safe nodes was known in advance, and hence, only one experiment was performed.

From the results of the numerical experiments, it can be seen that the optimality gap is small and the computational time was reduced significantly as compared to the exact solver. For example, for large network (10,000 nodes) simulations performed using synthetic transportation networks (Tables 2 and 3), the time static heuristics is shown to decrease simulation time on average by $89 \%$ while providing a result on average within $8.11 \%$ of being optimal. For the more realistic time dynamic heuristic, simulation time is cut by $87 \%$ and optimality is within $1.99 \%$. Similar results can be seen when simulating real transportation networks (Tables 4 and 5).

Table 2. Time Static Heuristic Statistics on Synthetic Networks.

\begin{tabular}{ccccc}
\hline $\begin{array}{c}\text { Network Size } \\
\text { (nodes) }\end{array}$ & $\begin{array}{c}\text { Average Optimality } \\
\text { Gap (\%) }\end{array}$ & $\begin{array}{c}\text { Maximum } \\
\text { Optimality Gap (\%) }\end{array}$ & $\begin{array}{c}\text { Average Time } \\
\text { Decrease (\%) }\end{array}$ & $\begin{array}{c}\text { Maximum Time } \\
\text { Decrease (\%) }\end{array}$ \\
\hline 20 & 0.28 & 1.27 & 81 & 89 \\
100 & 0.41 & 3.89 & 85 & 92 \\
500 & 0.80 & 8.02 & 87 & 93 \\
1000 & 2.54 & 14.47 & 87 & 94 \\
10,000 & 8.11 & 31.12 & 89 & 97 \\
\hline
\end{tabular}


Table 3. Time Dynamic Heuristic Statistics on Synthetic Networks.

\begin{tabular}{ccccc}
\hline $\begin{array}{c}\text { Network Size } \\
\text { (nodes) }\end{array}$ & $\begin{array}{c}\text { Average Optimality } \\
\text { Gap (\%) }\end{array}$ & $\begin{array}{c}\text { Maximum } \\
\text { Optimality Gap (\%) }\end{array}$ & $\begin{array}{c}\text { Average Time } \\
\text { Decrease (\%) }\end{array}$ & $\begin{array}{c}\text { Maximum Time } \\
\text { Decrease (\%) }\end{array}$ \\
\hline 20 & 0.19 & 1.01 & 79 & 85 \\
100 & 0.24 & 1.15 & 85 & 89 \\
500 & 0.55 & 2.01 & 86 & 90 \\
1000 & 1.54 & 3.60 & 87 & 90 \\
10,000 & 1.99 & 4.41 & 87 & 91 \\
\hline
\end{tabular}

Table 4. Time Static Heuristic Statistics on Real Networks. $|\mathrm{V}|$ indicates the number of nodes.

\begin{tabular}{ccccc}
\hline Network (nodes) & $\begin{array}{c}\text { Average Optimality } \\
\text { Gap (\%) }\end{array}$ & $\begin{array}{c}\text { Maximum } \\
\text { Optimality Gap (\%) }\end{array}$ & $\begin{array}{c}\text { Average Time } \\
\text { Decrease (\%) }\end{array}$ & $\begin{array}{c}\text { Maximum Time } \\
\text { Decrease (\%) }\end{array}$ \\
\hline $\begin{array}{c}\text { Sioux Falls } \\
(|\mathrm{V}|=24)\end{array}$ & 0.00 & 0.00 & 75 & 90 \\
$\begin{array}{c}\text { Anaheim } \\
(|\mathrm{V}|=416)\end{array}$ & 1.08 & 1.17 & 85 & 90 \\
$\begin{array}{c}\text { Winnipeg } \\
(|\mathrm{V}|=1057) \\
\text { Austin }\end{array}$ & 3.02 & 3.66 & 86 & 92 \\
$(|\mathrm{~V}|=7388)$ & & & & 94 \\
$\begin{array}{c}\text { Philadelphia } \\
(|\mathrm{V}|=13,389)\end{array}$ & 6.97 & 7.11 & 86 & 97 \\
\hline
\end{tabular}

Table 5. Time Dynamic Heuristic Statistics on Real Networks. $|\mathrm{V}|$ indicates the number of nodes.

\begin{tabular}{ccccc}
\hline Network (nodes) & $\begin{array}{c}\text { Average Optimality } \\
\text { Gap (\%) }\end{array}$ & $\begin{array}{c}\text { Maximum } \\
\text { Optimality Gap } \\
\mathbf{( \% )}\end{array}$ & $\begin{array}{c}\text { Average Time } \\
\text { Decrease (\%) }\end{array}$ & $\begin{array}{c}\text { Maximum Time } \\
\text { Decrease (\%) }\end{array}$ \\
\hline Sioux Falls $(|\mathrm{V}|=24)$ & 0.00 & 0.00 & 72 & 86 \\
Anaheim $(|\mathrm{V}|=416)$ & 0.00 & 0.00 & 76 & 88 \\
Winnipeg $(|\mathrm{V}|=1057)$ & 0.00 & 0.00 & 76 & 88 \\
Austin $(|\mathrm{V}|=7388)$ & 0.98 & 2.11 & 77 & 92 \\
Philadelphia $(|\mathrm{V}|=13389)$ & 3.25 & 3.89 & 82 & 92 \\
\hline
\end{tabular}

\subsection{Virtual Appliance Performance}

Virtual machines, as can be used in the MTEVA, do not provide the same computation efficiency as native hardware due to $\mathrm{I} / \mathrm{O}$ overhead, etc. However, test simulations indicate (Table 6) that this overhead is fairly small and is more than compensated for by the computational efficiently improvements of the heuristics. 
Table 6. Computational overhead due to performing simulations in the virtual MTEVA environment.

\begin{tabular}{cc}
\hline Algorithm & Computational Overhead \\
\hline Time Static & $+4.2 \%$ \\
Time Dynamic & $+4.8 \%$ \\
Heuristic & $+6.2 \%$ \\
\hline
\end{tabular}

\section{Demonstration Application to the NE Florida Coast}

The MTEVA's enhanced ability to simulate the evacuation patterns in significantly larger transportation networks (in a reasonable amount of time) using a heuristic are demonstrated through the simulation of a Hurricane Katrina-sized storm impacting the Northeast Florida coastal region and studying how the evacuation patterns are affected by the closing of roads due to flooding and bridges due to high winds. Results within the MTEVA are presented using high-level, standards-compliant, GUI-driven interfaces. Specifically, CH3D-SSMS output is written as NetCDF compliant with CF (climate forecasting) conventions, which enables the use of a TDS to provide access to data and simplify visualization. OpenLayers is then used to bring together the mapping of storm surge and transportation results. As part of the second generation MTEVA, the interactive interface is now developed using AJAX and PHP (Figure 1 shows the simulation setup and Figure 2 shows visualization of results as examples of the first generation interface).

Storm surge and inundation in the Northeast Florida region is simulated using a high resolution (100 m) CH3D-SSMS model for Northeast Florida $(255 \times 1201$ cells $)$, which domain spans from West Palm Beach to the Florida/Georgia border and extends $\sim 40 \mathrm{~km}$ offshore. This model is then coupled with the transportation network that is based on the newest NERPM4 (NorthEast Regional Planning Model version 4, created for Northeast Florida (Figure 3) "2005 base" MTEVA configuration. The network includes 28,585 nodes and 57,814 links. Demands at the nodes are obtained by combining different types of demands (various types of cars, public transportation, etc.) data from the NERPM4 as the current network optimization model does not differentiate between different transportation modes.

Figure 1. User interface for the simple network MTEVA configuration featuring a synthetic tropical storm making landfall in an idealized domain with a bay.

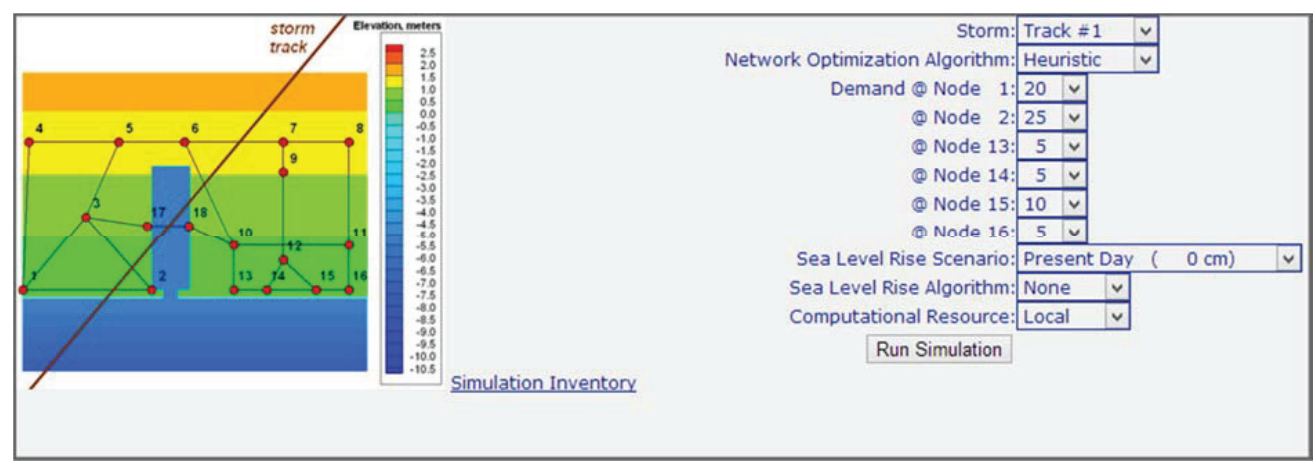


Figure 2. Simulated transportation network response to the synthetic storm making landfall in an idealized domain. The initial configuration of the transportation network is shown on the left while the simulated network assignment and storm surge and inundation as the storm approaches is shown on the right.
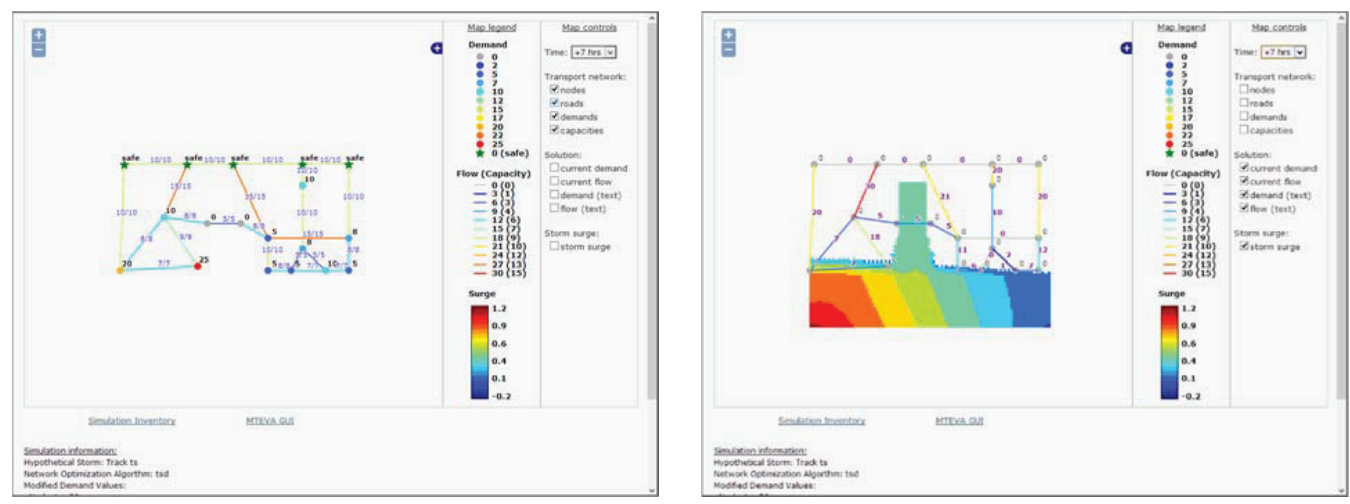

Figure 3. NERPM4 road capacities (left) and demands (right).
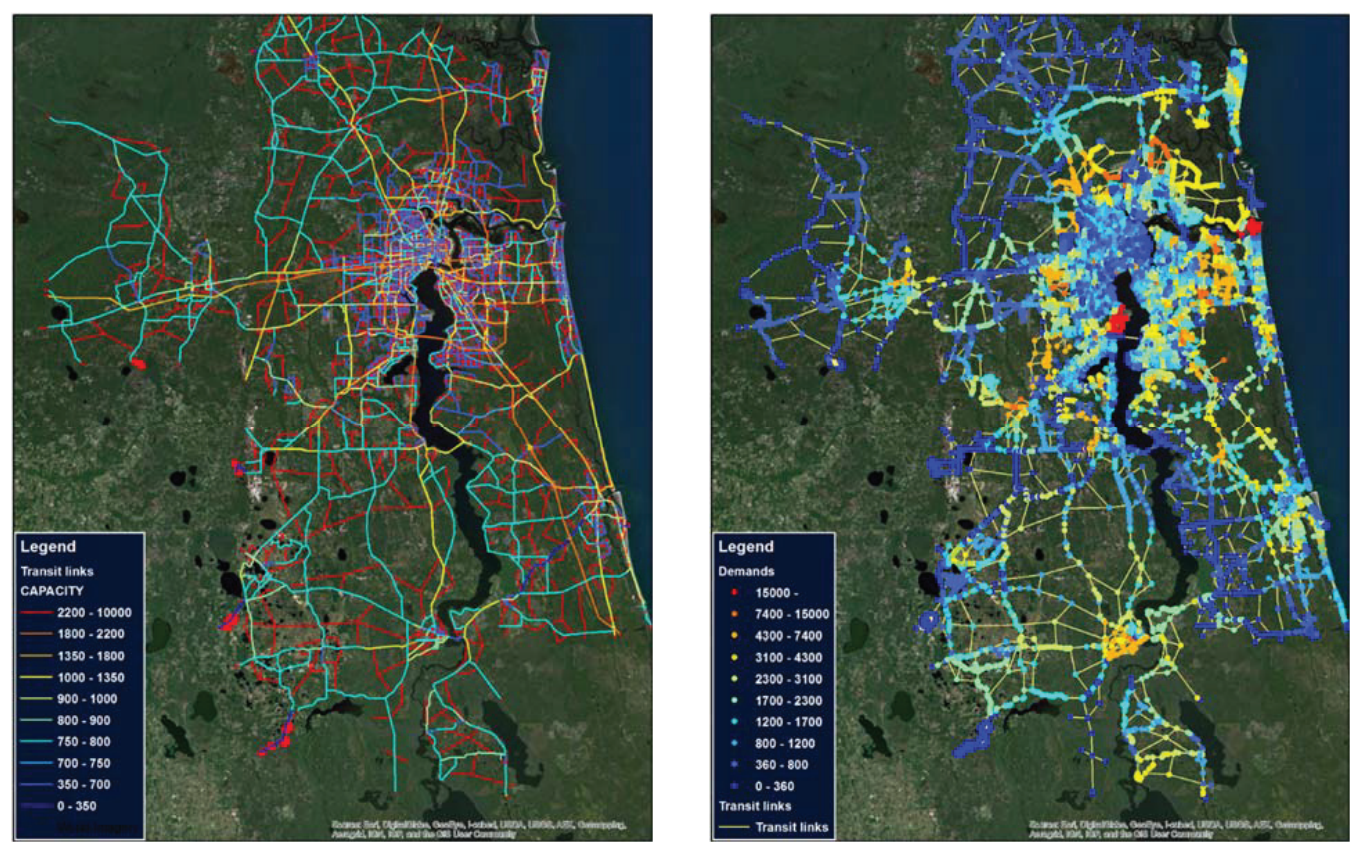

To assess the efficiency of the newly developed heuristic for the Northeast Florida transportation network, another set of computational experiments was performed (Table 7). As with the experiments presented earlier, both the original and newly developed heuristics are shown to significantly improve the speed at which the evacuation problem can be solved. 
Table 7. Efficiency of the heuristics for the Northeast Florida network.

\begin{tabular}{ccccc}
\hline Heuristic & $\begin{array}{c}\text { Average Optimality } \\
\text { Gap (\%) }\end{array}$ & $\begin{array}{c}\text { Maximum Optimality } \\
\text { Gap (\%) }\end{array}$ & $\begin{array}{c}\text { Average Time } \\
\text { Decrease (\%) }\end{array}$ & $\begin{array}{c}\text { Maximum Time } \\
\text { Decrease (\%) }\end{array}$ \\
\hline Static & 14.51 & 14.51 & 88 & 88 \\
Dynamic & 4.33 & 4.33 & 80 & 80 \\
\hline
\end{tabular}

The simulation of several different Northeast Florida scenarios can be performed within the MTEVA based on a synthetic storm, similar in size to Hurricane Katrina, making landfall on the east coast of Florida in presence of varying amounts of SLR (Figure 4). Inputs are provided through a simple interface which allows for variation of network assignment algorithm, amount of SLR, SLR algorithm, etc. The atmospheric storm wind and pressure gradient forcing is supplied by an analytic wind model [30] which uses a synthetic Katrina-like (size/intensity) storm track that makes landfall in the region. After completion, simulated storm surge and inundation are displayed in an interface (Figure 5) which allows map navigation along with the ability to toggle display layers (surge and inundation, transportation network, background layers, etc.). For reference, using relatively modern computational hardware, the evacuation model building and optimization phase, using a commercial solver, takes $\sim 25 \mathrm{~h}$ to compute using the exact solver, due in part to the largescale model and inherent difficulty of the problem.

The Northeast Florida MTEVA configuration provides an opportunity to study how timing of evacuation affects the ability to do it as well as how SLR may potentially impact evacuation plans. As a demonstration application under present day conditions (no SLR), Figure 6 shows the use of evacuation routes at different times ( 5 and $2 \mathrm{~h}$ until landfall, respectively, with evacuation starting $48 \mathrm{~h}$ before landfall) and how traffic patterns change as a bridge closes due to high wind intensity and Figure 7 shows changes in local traffic routes due to flooding of roads (snapshots of traffic 3 and $2 \mathrm{~h}$ until landfall are shown).

Figure 4. Interface for the Northeast Florida MTEVA configuration showing the track and intensity of the synthetic storm.

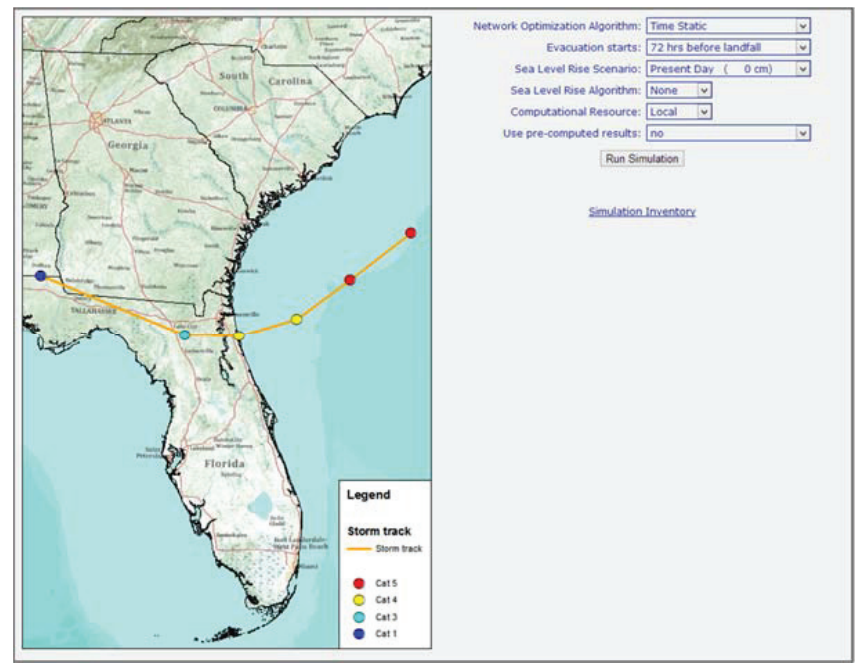


Figure 5. Visualization of model simulation results.

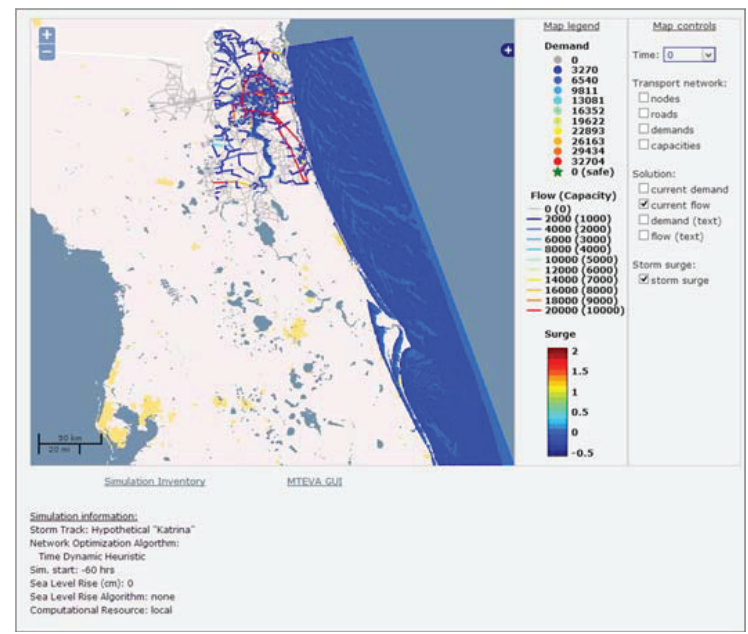

Figure 6. Comparison of evacuation routes at different time instances three hours apart. In the second case the evacuees are forced to take Acosta Bridge (right) because of the inaccessibility of the Fuller Warren Bridge (which is otherwise the preferred route, left) due to high wind intensity.

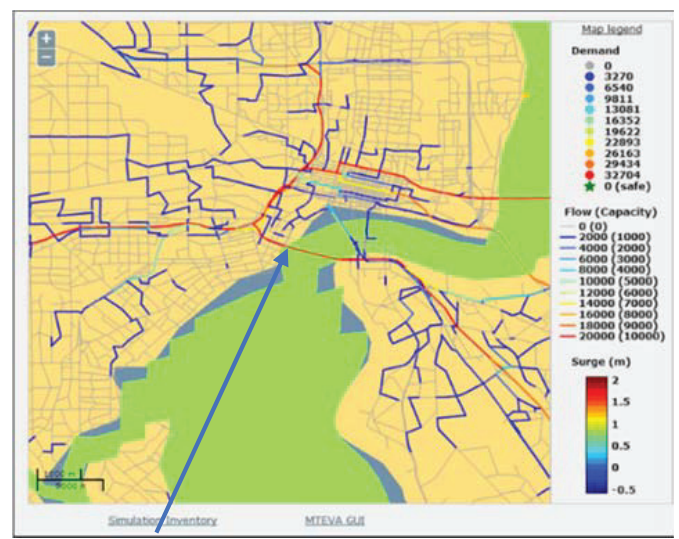

Full Warren Bridge

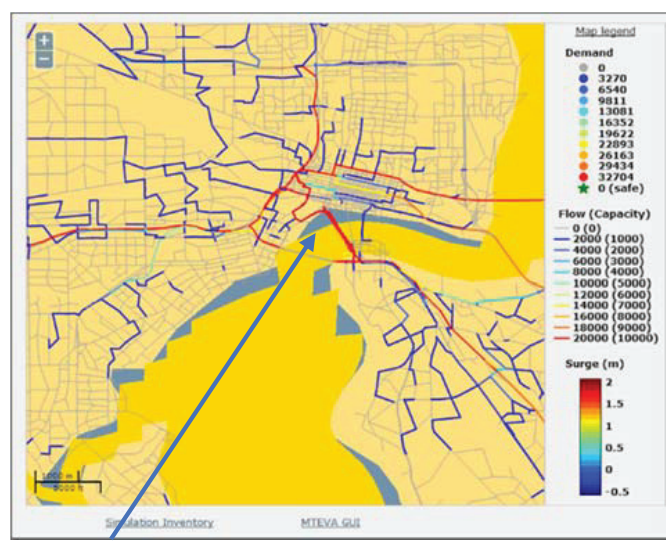

Acosta Bridge

To determine the optimal time to begin an evacuation, a series of simulations were performed using different evacuation times. Figure 8 illustrates the number of people located in areas that flood that will not have enough time to evacuate as a function of evacuation start time. For the particular demonstration application presented, all evacuations that start at least $36 \mathrm{~h}$ prior to hurricane landfall are $100 \%$ successful in evacuating flooded areas. However, the number of people unable to escape increases dramatically if an evacuation has not begun at least $18 \mathrm{~h}$ prior to landfall with about $97 \%$ loss if evacuation starts at landfall. This is not surprising as areas near the coast that are the most prone to flooding are already cut off from the "safe" nodes of the transportation network. 
Figure 7. Raised water level alters local traffic patterns due to flooding of roads and intersections.
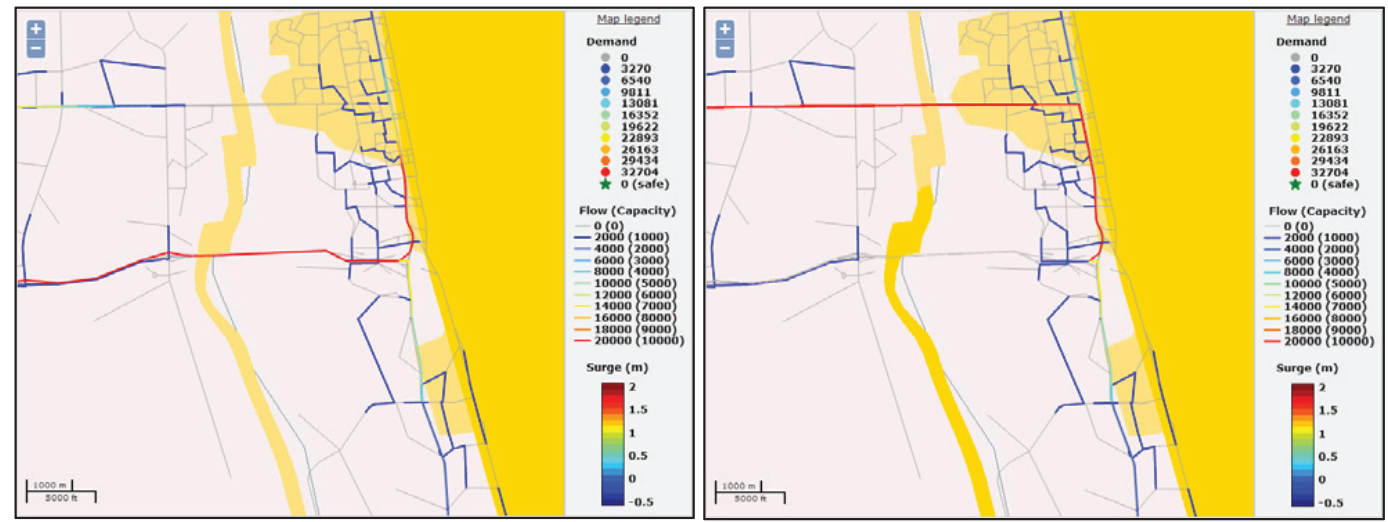

Figure 8. Estimated percentage of the number of people in flooded areas unable to evacuate (loss) as a function of evacuation start time.

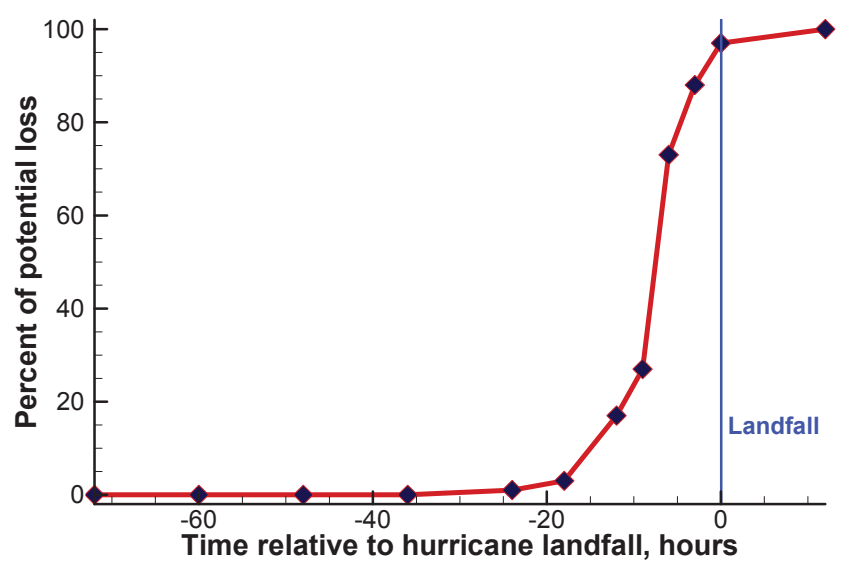

\section{Summary and Conclusions}

Enhancements to a unique, self-contained, software environment, the MTEVA, have been presented. The MTEVA seeks to assist in coastal science, transportation and cyberinfrastructure research, education and outreach by creating a coupled modeling system capable of simulating the transportation network response in synthetic and real physical domains to a system subject to high winds, storm surge, and inundation. The MTEVA allows individual science components to be brought together in a simple-to-use infrastructure where users can focus on learning the science instead of trying to setup and perform simulations.

While there are countless possible uses of the MTEVA, three will be highlighted. First, the MTEVA would be well suited for use by planners and organizers of emergency preparedness exercises who need to develop (in an easy-to-use fashion) realistic scenarios of conditions and transportation network conditions before (evacuation), during, and after (return) a storm. Second, the MTEVA is now, thanks to the inclusion of a heuristic, well suited towards "real-time" use in an 
Emergency Operations Center (EOC) (i.e., after evacuation has occurred) to assist first responders in predicting specific transportation infrastructure which may be impassable. Finally, the MTEVA is ideally suited for deployment in educational environments where students of all skill levels can learn, through hands-on activities, about: storm surge and inundation, transportation engineering and optimization.

In summary, the MTEVA:

- contains a storm surge and inundation modeling system coupled with a transportation network optimization model capable of simulating lane reversal. The coupled modeling system is then applied to both synthetic and real domains.

- demonstrates and promotes interoperability through its use of a THREDDS Data Server (TDS) for distribution and visualization of results. At the most basic level, users can access the MTEVA through the web-based GUI. However, more advanced users are able to setup and perform simulations using the scheduling interfaces directly (e.g., using the "condor_submit" command).

- is completely configurable, customizable and expandable. Because the tools, scripts, web interfaces, etc. are located within the MTEVA; any individual component can be altered to meet an individual user's needs. For example, locations of nodes modified, additional network nodes/arcs can be added, or demands and capacities changed.

- provides an educational environment useful for students of coastal science, cyberinfrastructure, and transportation engineering. For example, coastal science students can better understand how storm surge impacts a domain given storm strength, domain shape, etc. Cyberinfrastructure students can focus on the technical details of the MTEVA itself along with its web interfaces, databases and scripting technologies used behind the scenes. Transportation engineering students could investigate how the use of lane reversal can be optimized during a storm event. Finally, transportation practitioners in Northeast Florida could use the MTEVA to investigate how their domain responds to different synthetic tropical storms.

As part of this study, the MTEVA has been enhanced to includes three algorithms for solving the transportation network optimization problem for evacuation: (1) Time Static - a fast algorithm that works with a single time instance attempting to move as many people of possible to safety and is then iterated for multiple time steps; (2) Time Dynamic - attempts a planned evacuation, however, adding the time dimension to the problem increases its size and thus takes significantly longer to solve; (3) Heuristic - a compromise between the computational time and problem complexity.

The heuristic was shown to be able to successfully simulate large scale transportation networks with only a small optimality gap but a large decrease in computational time. For example, when using the realistic time dynamic heuristic, simulation time is cut by $87 \%$ ( $~ 3 \mathrm{~h}$ to obtain a heuristic solution, compared to $\sim 25 \mathrm{~h}$ to solve the problem exactly) and optimality is within $1.99 \%$, making the heuristic highly suitable for simulation of the large Northeast Florida MTEVA configuration (also implemented as part of this study) which is based on the NERPM transportation network.

Finally, a demonstration application was presented which illustrates how the MTEVA can be used to better understand how storm surge and inundation impacts key evacuation travel routes and leads to an increase in non-recurrent congestion. Through better understanding of such 
impacts, emergency managers and planners can better optimize evacuation/return routes increasing coastal resiliency.

\section{Acknowledgments}

This work was funded by the UF Center for Multimodal Solutions for Congestion Mitigation (CMS) (2009-010 and 2011-017) and the University of Florida.

\section{Author Contributions}

J.R.D. led the integration of the coastal science with the transportation models for emergency situations. V.A.P. and Y. P. S. performed the simulations of storm surge and inundation and developed the visualization and interfaces for the MTEVA. C.V. and P.M.M. developed and performed the computational analysis on the enhanced transportation evacuation/return modeling system. R.J.F., one of the original developers of the underlying Virtual Appliance software, assisted with its use by the MTEVA.

\section{Conflicts of Interest}

The authors declare no conflict of interest.

\section{References}

1. Hurricane Katrina: Performance of Transportation Systems. In Technical Council on Lifeline Earthquake Engineering Monograph; DesRoches, R., Ed.; American Society of Civil Engineers: Reston, VA, USA, 2006.

2. Wolshon, B.; Urbina Hamilton, E.; Levitan, M.; Wilmot, C. Review of Policies and Practices for Hurricane Evacuation. II: Traffic Operations, Management, and Control. Nat. Hazards Rev. 2005, 6, 143-161.

3. Gwynne, S.; Galea, E.R.; Owen, M.; Lawrence, P.J.; Filippidis, L. A review of the methodologies used in the computer simulation of evacuation from the built environment. Build. Environ. 1999, 34, 741-749.

4. Kuligowski, E.D.; Peacock, R.D. A Review of Building Evacuation Models; National Institute of Standards and Technology, Technology Administration, U.S. Department of Commerce: Washington, DC, USA, 2005; p. 156.

5. Radwan, E.; Mollaghasemi, M.; Mitchell, S.; Yildirim, G. Framework for Modeling Emergency Evacuation; Center for Advanced Transportation Systems Simulation, University of Central Florida: Orlando, FL, USA, 2005; p. 47.

6. The Volpe National Transportation Systems Center. Improving Regional Transportation Planning for Catastrophic Events (FHWA); Volpe Center Highlights: Cambridge, MA, USA, 2002.

7. Howe, D. Planning Scenarios: Executive Summaries; Homeland Security Council: Washington, DC, USA, 2004. 
8. Ahuja, R.K. Network Flows: Theory, Algorithms, and Applications; Prentice Hall: Englewood Cliffs, NJ, USA, 1993.

9. Hoppe, B.; Tardos, É. The Quickest Transshipment Problem. Math. Oper. Res. 2000, 25, 36-62.

10. Yamada, T. A network flow approach to a city emergency evacuation planning. Int. J. Syst. Sci. 1996, 27, 931-936.

11. Lu, Q.; George, B.; Shekhar, S. Capacity Constrained Routing Algorithms for Evacuation Planning: A Summary of Results. In Advances in Spatial and Temporal Databases; Bauzer Medeiros, C., Egenhofer, M.J., Bertino, E., Eds.; Springer Berlin Heidelberg: Berlin, Heidelberg, Germany, 2005; Volume 3633, pp. 291-307.

12. Rebennack, S.; Arulselvan, A.; Elefteriadou, L.; Pardalos, P.M. Complexity analysis for maximum flow problems with arc reversals. J. Comb. Optim. 2010, 19, 200-216.

13. Vogiatzis, C.; Walteros, J.L.; Pardalos, P.M. Evacuation Through Clustering Techniques. In Models, Algorithms, and Technologies for Network Analysis; Goldengorin, B., Kalyagin, V.A., Pardalos, P.M., Eds.; Springer New York: New York, NY, USA, 2013; Volume 32, pp. 185-198.

14. Pardalos, P.M.; Arulselvan, A. Multimodal Solutions for Large Scale Evacuations; University of Florida: Gainesville, FL, USA, 2009; p. 53.

15. Ford, L.R. Flows in Networks. In Princeton Landmarks in Mathematics; Princeton University Press: Princeton, NJ, USA, 2010.

16. Merchant, D.K.; Nemhauser, G.L. A Model and an Algorithm for the Dynamic Traffic Assignment Problem. In Traffic Equilibrium Methods; Florian, M.A., Ed.; Springer Berlin Heidelberg: Berlin, Heidelberg, Germany, 1976; Volume 118, pp. 265-273.

17. Sheffi, Y.; Mahmassani, H.S.; Powell, W.B. NETVAC1: A Transportation Network Evacuation Model; Center for Transportation Studies, Massachusetts Institute of Technology: Cambridge, MA, USA, 1980.

18. Radwan, A.E.; Hobeika, A.G.; Sivasailam, D. A computer simulation model for rural network evacuation under natural disasters. Inst. Transp. Eng. J. 1985, 55, 25-30.

19. Zou, N.; Yeh, S.-T.; Chang, G.-L.; Marquess, A.; Zezeski, M. Simulation-Based Emergency Evacuation System for Ocean City, Maryland, During Hurricanes. Transp. Res. Rec. 2005, 1922, 138-148.

20. Liu, Y.; Lai, X.; Chang, G.-L. Cell-Based Network Optimization Model for Staged Evacuation Planning Under Emergencies. Transp. Res. Rec. 2006, 1964, 127-135.

21. Davis, J.R.; Paramygin, V.A.; Tutak, B.; Sheng, Y.P.; Zheng, Q.P.; Pardalos, P.M.; Figueiredo, R.J. Development of a Multimodal Transportation Educational Virtual Appliance (MTEVA) to study congestion during extreme tropical events. In Proceedings of the Transportation Research Board 91st Annual Meeting, Washington, DC, USA, 22-26 January 2012.

22. Davis, J.R.; Paramygin, V.A.; Figueiredo, R.J.; Sheng, Y.P.; Vogiatzis, C.; Pardalos, P.M. The Coastal Science Educational Virtual Appliance (CSEVA). In Proceedings of the 12th International Conference on Estuarine and Coastal Modeling, St. Augustine, FL, USA, 7-9 November 2011; Spaulding, M.L., Ed.; American Society of Civil Engineers: Reston, VA, USA, 2012; pp. 359-377. 
23. Davis, J.R.; Figueiredo, R.J.; Sheng, Y.P.; Fortes, J.A.; Ganguly, A.; Paramygin, V.A.; Wolinsky, D.I.; Zhang, J.; Tutak, B. Application of emerging cyberinfrastructure technologies to aid in the education and training of coastal and estuarine scientists. J. Ocean Technol. 2010, 5, 56-80.

24. Davis, J.R.; Paramygin, V.; Tutak, B.; Juste, P.S.; Figueiredo, R.J.; Sheng, Y.P. Advancing Educational Capacity: Using the SCOOP Educational Virtual Appliance. In Proceedings of the 11th International Conference on Estuarine and Coastal Modeling, Seattle, WA, USA, 4-6 November 2009; Spaulding, M.L., Ed.; American Society of Civil Engineers: Reston, VA, USA, 2010; pp. 201-220.

25. Davis, J.R.; Paramygin, V.A.; Figueiredo, R.J.; Sheng, Y.P. Using Virtualization to Integrate Weather, Climate, and Coastal Science Education. In Proceedings of the American Geophysical Union Fall Meeting, San Francisco, CA, USA, 3-7 December 2012.

26. Sheng, Y.P.; Alymov, V.; Paramygin, V.A. Simulation of storm surge, wave, currents, and inundation in the Outer Banks and Chesapeake Bay during Hurricane Isabel in 2003: The importance of waves. J. Geophys. Res. 2010, 115, C04008; doi:10.1029/2009JC005402.

27. Sheng, Y.P. On modeling three-dimensional estuarine and marine hydrodynamics. In Three-Dimensional Models of Marine and Estuarine Dynamics; Nihoul, J.C.J., Jamart, B.M., Eds.; Elsevier: Amsterdam, The Netherlands, 1987; pp. 35-54.

28. Sheng, Y.P. Evolution of a three-dimensional curvilinear-grid hydrodynamic model for estuaries, lakes and coastal waters: CH3D. In Proceedings of the Estuarine and Coastal Circulation and Pollution Transport Model Data Comparison Specialty Conference on Estuarine and Coastal Modeling; Spaulding, M.L., Ed.; American Society of Civil Engineers: Reston, VA, USA, 1990; pp. 40-49.

29. Booij, N.; Ris, R.C.; Holthuijsen, L.H. A third-generation wave model for coastal regions: 1. Model description and validation. J. Geophys. Res. 1999, 104, 7649-7666.

30. Holland, G.J. An Analytic Model of the Wind and Pressure Profiles in Hurricanes. Mon. Weather Rev. 1980, 108, 1212-1218.

31. Sheng, Y.P.; Paramygin, V.A.; Alymov, V.; Davis, J.R. A Real-Time Forecasting System for Hurricane Induced Storm Surge and Coastal Flooding. In Proceedings of the Ninth International Conference on Estuarine and Coastal Modeling, Charleston, SC, USA, 31 October-2 September 2005; Spaulding, M.L., Ed.; American Society of Civil Engineers: Reston, VA, USA, 2006; pp. 585-602.

32. Zervas, C. Sea Level Variations of the United States: 1854-2006; Center for Operational Oceanographic Products and Services, National Oceanic and Atmospheric Administration: Silver Spring, MD, USA, 2009; p. 194.

33. Meehl, G.A.; Stocker, T.F.; Collins, W.D.; Friedlingstein, P.; Gaye, A.T.; Gregory, J.M.; Kitoh, A.; Knutti, R.; Murphy, J.M.; Noda, A.; et al. Global Climate Projections. In Climate Change 2007: The Physical Science Basis. Contribution of Working Group I to the Fourth Assessment Report of the Intergovernmental Panel on Climate Change; Solomon, S., Qin, D., Manning, M., Chen, Z., Marquis, M., Averyt, K.B., Tignor, M., Miller, H.L., Eds.; Cambridge University Press: Cambridge, UK; New York, NY, USA, 2007. 
34. Vermeer, M.; Rahmstorf, S. Global sea level linked to global temperature. Proc. Natl. Acad. Sci. USA 2009, 106, 21527-21532.

35. Bar-Gera, H. Transportation Network Test Problems. Available online: http://www.bgu.ac.il/ $\sim$ bargera/tntp/ (accessed on 5 May 2013). 


\title{
Evaluation of the Zone of Influence and Entrainment Impacts for an Intake Using a 3-Dimensional Hydrodynamic and Transport Model
}

\section{Shwet Prakash, Venkat Kolluru and Carol Young}

\begin{abstract}
Ballast water systems in large LNG carriers are essential for proper operations and stability. Water withdrawn from the surrounding environment to supply to the ballast can pose entrainment and impingement risk to the resident fish population. Quantification of these risks and the net effect on population is usually quite challenging and complex. Various methods over the last several decades have been developed and are available in the literature for quantification of entrainment of mobile and immobile lifestages of resident fish. In this study, a detailed 3-dimensional model was developed to estimate the entrainment of ichthyoplankton (fish eggs and larvae) and fish from an estuarine environment during the repeated short-term operation of a ballast water intake for an LNG carrier. It was also used to develop a zone of influence to determine the ability of mobile life stages to avoid impingement. The ichthyoplankton model is an Equivalent Adult Model (EAM) and assesses the number of breeding adults lost to the population. The EAM incorporates four different methods developed between 1978 and 2005. The study also considers the uncertainty in estimates for the lifestage data and, as such, performs sensitivity analyses to evaluate the confidence level achievable in such quantitative estimates for entrainment.
\end{abstract}

Reprinted from J. Mar. Sci. Eng. Cite as: Prakash, S.; Kolluru, V.; Young, C. Evaluation of the Zone of Influence and Entrainment Impacts for an Intake Using a 3-Dimensional Hydrodynamic and Transport Model. J. Mar. Sci. Eng. 2014, 2, 306-325.

\section{Introduction}

Intake systems are used throughout the world for a variety of reasons including: ballast water systems, cooling water systems, drinking water systems and industrial use systems. In all of these intake systems, water is withdrawn from the surrounding surface waters and can entrain ichthyoplankton (IP) and other life stages. Quantification of entrainment and the resulting effect on a population is usually quite challenging and complex. Various methods over the last several decades have been developed and are available in the literature for quantification of entrainment of mobile and immobile lifestages of resident fish. However, accurate estimation relies heavily on field sampling, understanding of the fish population and the choice of appropriate methodologies. Due to the differences in volitional movement, planktonic stages must be evaluated differently than swimming life stages.

Typically the risks to fishes associated with intake operations can be categorized into the following main impacts:

- Change in local circulation

- Entrainment of planktonic organisms 
- Entrainment and impingement of mobile organisms

- Mortality of entrained or impinged organisms

- Effects on the population

Figure 1 shows a conceptual model of the various capture zones.

Figure 1. Conceptual model of capture zones for planktonic and mobile life stages.

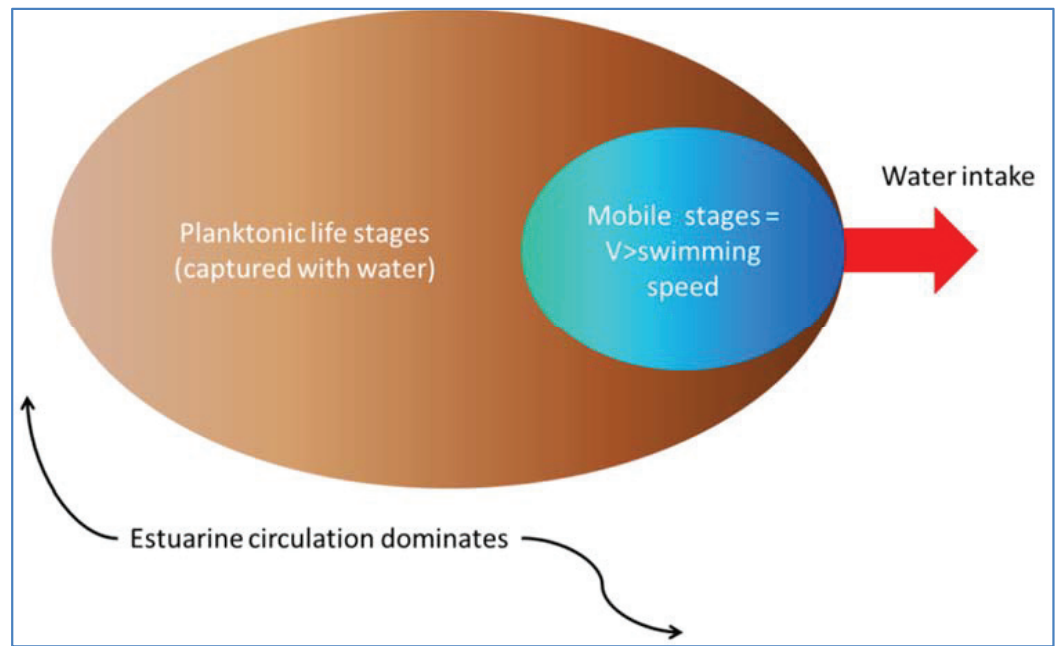

\section{Objectives}

Environmental impacts from the operations of intakes have been studied throughout the literature. The literature, however, does not include a comparison of the impact assessment methods. The objectives of this paper are:

- evaluation of intake zones of influence using a hydrodynamic model;

- comparison of literature methods for fish population impact assessment; and

- development of tools that will:

- assist with design of intakes

- delineate zone of influences

- quantify impacts

While impingement risk was assessed for the case study discussed here, this paper focuses on the entrainment element. Entrainment was considered in two different contexts: (1) entrainment of non-mobile IP based on concentrations in the water column and (2) entrainment of mobile life stages based on a zone of influence and burst swimming speeds. Since the ballast water along with any entrained organisms is removed from the area by the vessel, entrainment mortality was assumed to be $100 \%$.

To accomplish these objectives, two 3-dimensional models were used. The first 3-dimensional model was used to develop the flow fields and was based on Delft3D [1,2]. The second model was based on Generalized Environmental Modeling System for surface waters [3-5] and was used to 
estimate the entrainment of IP from an estuarine environment during the short-term operation of a ballast water intake for an LNG carrier. The equivalent adult model (GEMSS-EAM) assesses the equivalent adults lost through entrainment of ichthyoplankton using the modeled flow fields and incorporates four different methods developed between 1978 and 2005. These methods stem from the same approach of considering lifestages, lifestage durations, natural mortalities related to planktonic lifestages and entrainment mortalities attributable to the intake operations. The study also considers the potential for juveniles and adults to become entrained based on their swimming ability relative to the zone of influence at the intake. The study also considers the uncertainty in estimates for the lifestage data and, as such, performs sensitivity analyses to evaluate the confidence level achievable in such quantitative estimates for entrainment.

For mobile life stages, the focus was on the endangered shortnose sturgeon (Acipenser brevirostrum) and the protected (due to its similar appearance) Atlantic sturgeon (Acipenser oxyrhynchus). The second element of the analysis considered the burst swimming speeds of adults and juveniles and their ability to escape either impingement (larger adults) or entrainment (smaller adults and juveniles).

All entrainment calculations relied on a hydrodynamic model for the estuary that simulates a 3-dimensional near-field zone of influence in a tidal environment. The 3-dimensional hydrodynamic model was run to predict baseline (no intake operation) hydrodynamic conditions which were contrasted against the conditions during the intake operations. The two modeled conditions were quantitatively compared and the resulting changes in the hydrodynamic conditions were calculated. For plankton, the model was used to predict the number of each species group and planktonic life stage entrained as a function of the volume of water and concentration of IP by species group and life stage. This analysis was then introduced to an Equivalent Adult Model (EAM) to project the number of adults lost to the population. For mobile life stages, the changes were quantitatively compared against swimming speeds for shortnose sturgeon (Acipenser brevirostrum) and Atlantic sturgeon (Acipenser oxyrhynchus). Sustained, prolonged and burst speeds were considered during evaluation of effects of the intake zone of influence on these species and their ability to escape entrainment.

\section{Equivalent Adult Model (EAM)}

The GEMSS-EAM model was developed by extending the Equivalent Adult Model (EAM) formulation described in Horst [6] and Goodyear [7] to include the entrainment estimates from near field regions of a surface water intake. The Goodyear EAM [7] estimates the numbers of adult fish that would result based on the early life-stage population. EAM estimates the loss of IP vulnerable to intake system withdrawals based on the fraction of water volume drawn from various areas throughout the range of vulnerability multiplied by the density of vulnerable IP in those areas. The analysis allows direct comparison of what mortality occurs as a result of fish losses due to entrainment and impingement, compared to populations in the area. From this point, the IP losses are projected to equivalent adults using four methods available in the literature: 
Method 1. Extension of the Horst [6] and Goodyear [7] methods to near-field entrainment estimates;

Method 2. Adjustment of the Horst [6] and Goodyear [7] based estimates to consider natural mortality;

Method 3. Adjustment using a survival function developed by EPRI [8]; and

Method 4. Adjustment using a survival function published by Exponent [9].

These methods provide a range of projected equivalent losses which can be used to assess the impacts of intake operations.

The hydrodynamic and entrainment modeling is used as input densities of IP from the field sampling data from the sampling regions. The density of a species for a given life-stage " $\mathrm{j}$ " at the intake during week " $i$ " is defined mathematically as $\mathrm{DW}_{\mathrm{i}, \mathrm{j}}$. If $\mathrm{D}_{\mathrm{i}, \mathrm{j}, \mathrm{k}}$ is the density of the same species for life stage " $\mathrm{j}$ " and in region " $k$ " during week " $i$ ", then its density at the intake becomes:

$$
D W_{i, j}=\sum_{k} D_{i, j, k} E_{i, k} / E_{o i, k}
$$

Where $\mathrm{E}_{\mathrm{i}, \mathrm{k}} / \mathrm{E}_{\mathrm{Oi}, \mathrm{k}}$ is the fraction of density entrained from a sampling region to the initial sampling region density. The sampling density is population density which is the number of organisms per $1000 \mathrm{ft}^{3}$ of water and is defined individually for each species, lifestage, region and week. Thus, using the parameters computed from the hydrodynamic and transport model, the intake density required for performing the entrainment analysis leading to the EAM evaluation, $\mathrm{DW}_{\mathrm{i}, \mathrm{j}}$ can be estimated from the observed densities, $\mathrm{D}_{\mathrm{i}, \mathrm{j}, \mathrm{k}}$ in all sampling regions, weighted by the fractional entrainment from that region.

\subsection{EAM Modeling from Biological Sampling Region Data}

Placing the fractional loss of IP data into context is difficult, largely due to incomplete knowledge of the total population of vulnerable life stages available, their period of vulnerability within each age class or life stage (to the point where they are mobile and can avoid the effects of entrainment or impingement), or their mortality through the system (assumed to be 100\%: all entrained IP are lost). The model calculates the portion lost due to entrainment based on the hydrodynamic modeling and the population of vulnerable IP throughout the area potentially affected by the water withdrawals. The identification of vulnerable IP population was based on the extent of the withdrawal modeled by the hydrodynamic model.

Having calculated the number of IP lost, the next task is to place that loss into some context, such as the equivalent number of adults lost to the system, as a result of losses at each life stage (day-age-class, cohort, etc.). There are two methods to complete that analysis, either estimating the population of adults that loss would have represented by forecasting the numbers of adults that would have resulted from the population of earlier lifestages by cascading throughout successive lifestages to the adult stage, or estimating the stock size from which those numbers derived in the first place by hind-casting losses of IP into adults that would have produced that number of those life stages or age-classes of fish. Forecasting the loss of adults applies some estimate of survival to adulthood for each life stage, which itself is subject to debate. We address the former, using the EAM tool. 
For a species, the number of equivalent adults entrained can be expressed mathematically as:

$$
N a=\sum_{j=1}^{n} N_{j} S_{j}^{n}
$$

where $N_{j}$ is the number of individuals at life stage (or age class) " $\mathrm{j}$ ” that have been entrained, $S^{n_{j}}$ is the survival probability from the $j$ th life stage class to adulthood, and " $n$ " is the total number of life stages before reaching adulthood. Equation (2) can be expanded to give the number of organisms entrained from each sampling region for each weekly set of observed densities, or $N_{i, j, k}$. It can be computed as:

$$
N_{i, j, k}=D_{i, j, k} S_{j}^{n} V_{i, k} F E_{i, k}
$$

where $F E_{i, k}$ is the fraction entrained from region "k", and is computed from the hydrodynamic and transport model as:

$$
F E_{i, k}=E_{i, k} / E_{o i, k}
$$

The net equivalent adults entrained, $N a$, from all the regions and over the entire simulation period, then, is:

$$
N a=\sum_{i} \sum_{j} \sum_{k} N_{i, j, k}
$$

Expanding Equation (5) using Equations (3) and (4) gives:

$$
\text { Method 1: } N a=\sum_{i} \sum_{k}\left\{\sum_{j} D_{i, j, k} S_{j}^{n}\right\} F E_{i, k} V_{i, k}
$$

This formulation of the EAM, with application over several sampling regions, using weekly density data and results from the hydrodynamic model provides a necessary and important refinement to its computation as recommended by Horst [6].

\subsection{Determination of the Probability of Survival $S_{j}$}

An important part of the EAM model is the estimation of natural survival rate, $\mathrm{Sj}$. The original Goodyear [7] paper uses a complex method based on fecundity and cumulative catch data segregated into separate length classes. Others have segregated the data into day-age classes, cohorts (groups of fish spawned within a similar time frame or of like age) or life stages (yolk-sac or prolarvae, post yolk-sac larvae, juveniles, etc.).

Another method, and one used locally in the Salem PSEG 316(b) demonstration as part of their NPDES permit application report [10], is to compute $S_{j}$ from the mortality rate of each successive life stage through to the adult stage. A limitation of this approach is the varying efficiencies of sampling used to estimate populations of successive lifestages of species, but the survival through an individual life stage can be computed as:

$$
f_{l}=\exp ^{-z_{l} T_{l}}
$$


where $f_{l}$ is the probability of survival through life stage $l$ (fraction survived at the end of the life stage), and $l=$ an index for the individual life stage; e.g., $l=1$ is eggs, $l=2$ is larvae, $l=3$ is juveniles etc. The $z_{l}$ is the natural mortality rate (1/day) for life stage $l$, and $T_{l}$ is the length (days) of life stage $l . S_{j}^{n}$ the product of the probability of survival from life stage $l$ through all successive life stages to the adult life stage, then can be given by:

$$
S_{j}^{n}=\prod_{l=j}^{n} f_{l}
$$

where " $n$ " is the final life stage. Equation (8) can also be written as:

$$
S_{j}^{n}=\exp ^{\sum_{l=j}^{n}-z_{l} T_{l}}
$$

The sum within Equation (9) goes from life stage $\mathrm{j}$ through all life stages to the adult stage, $\mathrm{n}$, even though entrainment does not take place beyond a certain life stage. This varies by species, but was assumed to be through the post-yolk larval stage. For the computations in Equation (6) only the densities up through the entrainable life stages should be used.

\subsection{Percent of Population Entrained}

Entrainment impact assessment compares the number of fishes entrained through and lost to the intake against the population at risk. A common limitation in extrapolating the IP losses to equivalent adults in many of these analyses is the lack of good fisheries data for the broader system feeding IP into the region potentially affected by the intake. In fact, locally, comments made in the Salem report [10] were that the EAM was not used extensively because there were no fishery data or other information available for comparative purposes. This limitation can be overcome, in part, using the extended model with weekly regional sampling. Examination of Equation (6) shows that the adult population within the sampled regions that could have survived in the absence of the entrainment from the ballast intake over the different life stages is:

$$
N a_{T}=\sum_{i} \sum_{k}\left\{\sum_{j} D_{i, j, k} S_{j}^{n}\right\} V_{i, k}
$$

Thus, the percent entrainment of equivalent adults from the full population of adults that might have been entrained from those regions becomes:

$$
\% \text { Entrained }=\mathrm{Na} / \mathrm{Na}_{\mathrm{T}} * 100
$$

The percent entrained is determined only from the potential adults that could have been entrained from the surveyed regions, and not to the total fisheries population produced for the whole waterbody that may include un-sampled regions. Thus, in that case, Equation (11) will give a larger percentage entrained than if the total fisheries of the whole waterbody (entire waterbody sampled) population were known. 


\subsection{Entrainment Mortality}

The above formulation includes the implicit assumption that all the species are entrained at the beginning of the life stage, in that it does not account for natural mortality that occurs on that life stage. This assumption, however, is invalid per se, as both the natural mortality and entrainment mortality occur simultaneously. The assumption of all the entrainment occurring at the beginning of the life stage is therefore conservative; it overestimates the effect of entrainment mortality on the population by not accounting for the natural mortality that would have reduced that same population over the period for which they were entrained. To decrease this overestimate, an entrainment function is required. This entrainment function depends on the entrainment mortality.

Entrainment mortality is defined as the rate of entrainment from each region due to the intake operations and is treated similar to the natural mortality. For instance, if there is no natural mortality, then the survival rate for species can be estimated by a formula similar to the one given by Equation (9). Equation (12) below shows the entrainment mortality which depends only on the intake operations and the regional hydrodynamics.

$$
\text { Entrainment Mortality }=\frac{Q_{I n}}{V_{T}}
$$

where $Q_{I n}$ is the intake flow rate and $V_{T}$ is the total volume of the waterbody disturbed. In cases where the waterbody is divided in to " $\mathrm{k}$ " regions, the entrainment mortality is given by Equation (13).

$$
\text { Entrainmen } t \text { Mortality }=\frac{Q_{I n}}{V_{k}} * F_{i, k}=m_{i, k}
$$

where $F_{i, k}$ is defined as the ratio of the number of individuals entrained at the intake from region " $\mathrm{k}$ " during week $\mathrm{i}$ to the total number of individuals entrained from all regions and is shown in Equation (14).

$$
F_{i, k}=\frac{E_{i, k}}{E_{T i}}
$$

The survival function due to the entrainment is then given by Equation (15).

$$
S_{i, j, k}^{m}=\exp ^{\sum_{l=j}^{n}-m_{i, k} T_{l}}
$$

The number of equivalent adults entrained then can be expressed by Equation (16).

$$
\text { Method 2: } N a=\sum_{i} \sum_{k}\left\{\sum_{j} D_{i, j, k} S_{j}^{m}\left(1-S_{j}^{m}\right)\right\} F E_{i, k} V_{i, k}
$$

\subsection{EPRI Adjusted Entrainment Survival Function}

The above formulation applies the entrainment mortality at the end of the life stage, and thus has tendency to under-predict the entrained population. When day-age class population size and survival functions by day-age class are unavailable, the Electric Power Research Institute [8] suggests that the entrainment mortality should be applied assuming that half the natural mortality 
has occurred (e.g., the middle of the life stage). At this point, the IP population at each life stage has decreased due to the natural mortality and thus more accurately attributes losses due to entrainment. When the entrainment mortality is applied at this half-life-stage, the survival function due to entrainment is given by EPRI [8]:

$$
S_{i, k}^{*}=2 * S_{j}^{n} * \exp ^{-\left(1+\ln \left(S_{j}^{n}\right)\right)}
$$

The number of equivalent adults entrained then can be expressed by Equation (18).

$$
\text { Method 3: } N a=\sum_{i} \sum_{k}\left\{\sum_{j} D_{i, j, k} S_{j}^{n}\left(1-S^{*}{ }_{j}\right)\right\} F E_{i, k} V_{i, k}
$$

\subsection{Exponent, Inc.-Adjusted Entrainment Survival Function}

Exponent, Inc. was commissioned by the Center for Liquefied Natural Gas (CLNG) to investigate and critique the technical work adopted to estimate the entrainment impacts in Open Loop Vaporization (OLV) systems, which were commonly proposed in warmer open water (offshore) LNG revaporization designs. Exponent, Inc. found that the assumption of half natural mortality used in EPRI's method still makes the entrainment mortality conservative since the natural mortality survival function is an exponentially decreasing term. This results in an overestimation of the entrainment impacts. To further improve the entrainment survival function, Exponent, Inc. suggested an alternate relationship which defines the survival function at the end of each life stage as given by Equation (19) [9]:

$$
S_{i, k}^{* *}=\frac{S_{j}^{n}\left\{\frac{S_{i, k}^{m}}{m}+T_{l}-\frac{1}{m}\right\}}{S_{j}^{n} * S_{i, k}^{m}\left\{\frac{1}{k+m}-\frac{1}{k^{*} S_{j}^{n}}\right\}-\left\{\frac{1}{k+m}-\frac{1}{k}\right\}}
$$

The survival function is continuous within each stage as opposed to at the half-life stage. This further corrects the estimate of survivability by discretizing the continuous effects of natural and entrainment mortality into smaller steps (life stages). The number of equivalent adults entrained then can be expressed by Equation (20).

$$
\text { Method 4: } N a=\sum_{i} \sum_{k}\left\{\sum_{j} D_{i, j, k} S_{j}^{n}\left(1-S^{* *}{ }_{j}\right)\right\} F E_{i, k} V_{i, k}
$$

\section{Case Study}

The case study used to demonstrate the entrainment computations and study the possible fish population-level impacts is vessel ballasting in an estuarine system. The site is located in the Delaware River Estuary where concerns were raised about the potential negative effects on the population of ichthyoplankton from entrainment during ballast water intake at the terminal berth and also the entrainment risk to sturgeon presented by the ballast intake. A $138,000 \mathrm{~m}^{3} \mathrm{LNG}$ carrier, the design vessel for this study, will withdraw approximately 8 million gallons [11] of 
ballast water while at berth. The operations assume that one LNG carrier will call at the project every two to three days, resulting in approximately 150 ship calls per year or 12 per month. For the purposes of this study, the design intake rate of 660,430 gallons per hour and the design reballasting period of $12 \mathrm{~h}$ were selected. Figure 2 shows the site location in New Jersey near the state lines of Pennsylvania and Delaware.

Figure 2. Site location.

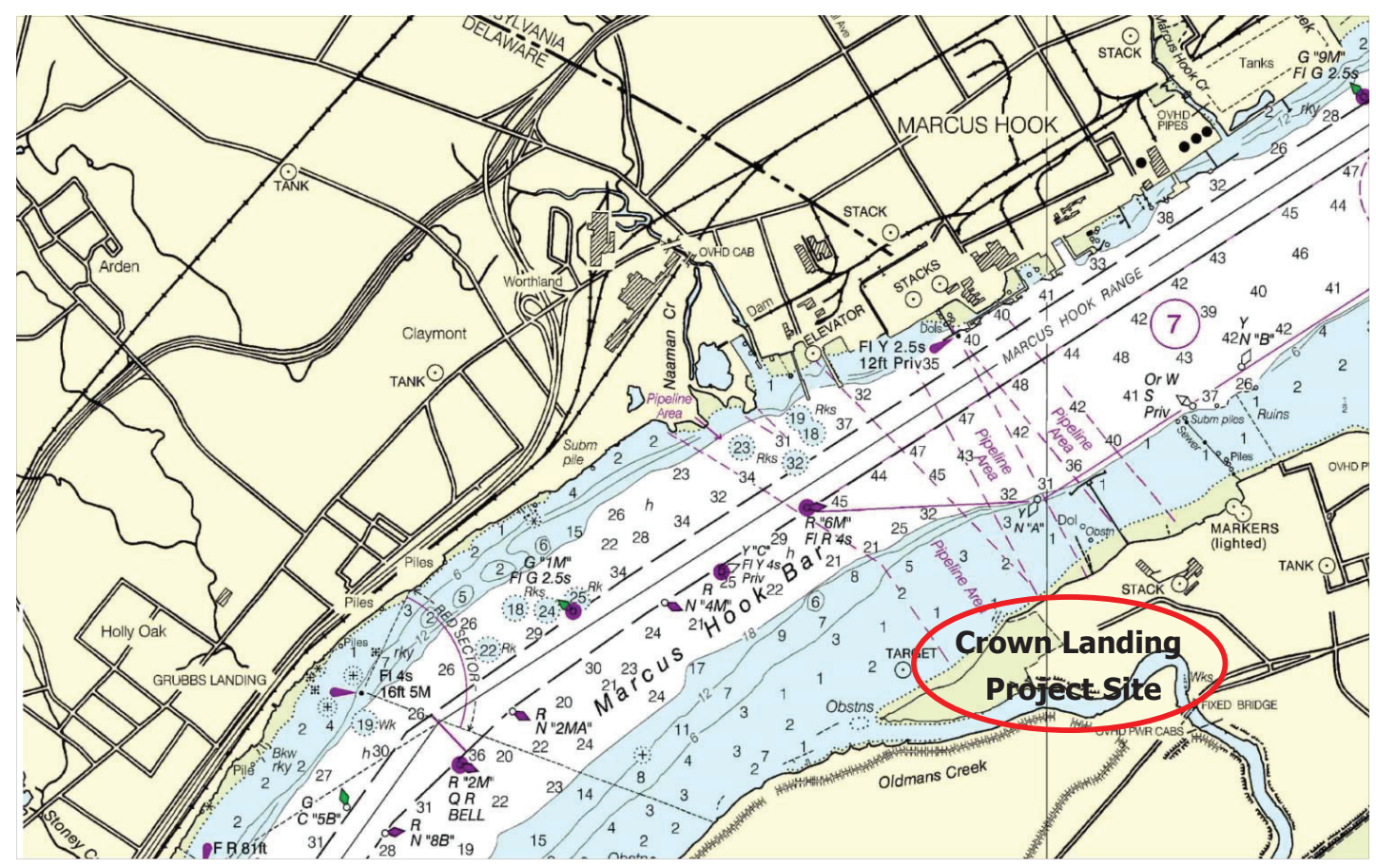

\subsection{Ichthyoplankton}

Striped bass, white perch, clupeidae (river herring and American shad), and bay anchovy were the species and groups of concern since they consistently dominate the IP population in the project area. Mean IP densities between the months of April and July were available for the Delaware River in the project area. These density data were collected by PSEG during the springs of 2002 [12] and 2003 [13]. The density data were separated into different zones along the length of the Delaware River and, for purposes of this case study, it was assumed that these densities did not vary vertically and were composites of all trawls in each zone; however, the hydrodynamic model was divided into three vertical zones: epilimnion, metalimnion and hypolimnion. Only four zones (8-11) around the import terminal were considered as they covered a region of 25 miles downstream and 30 miles upstream (see Figure 3). The entrainable population within these four zones is shown in Table 1. IP is assumed to be present only during the months of April through July, so annual losses are calculated as a sum of these four months. 
Figure 3. Project location and IP data zones.

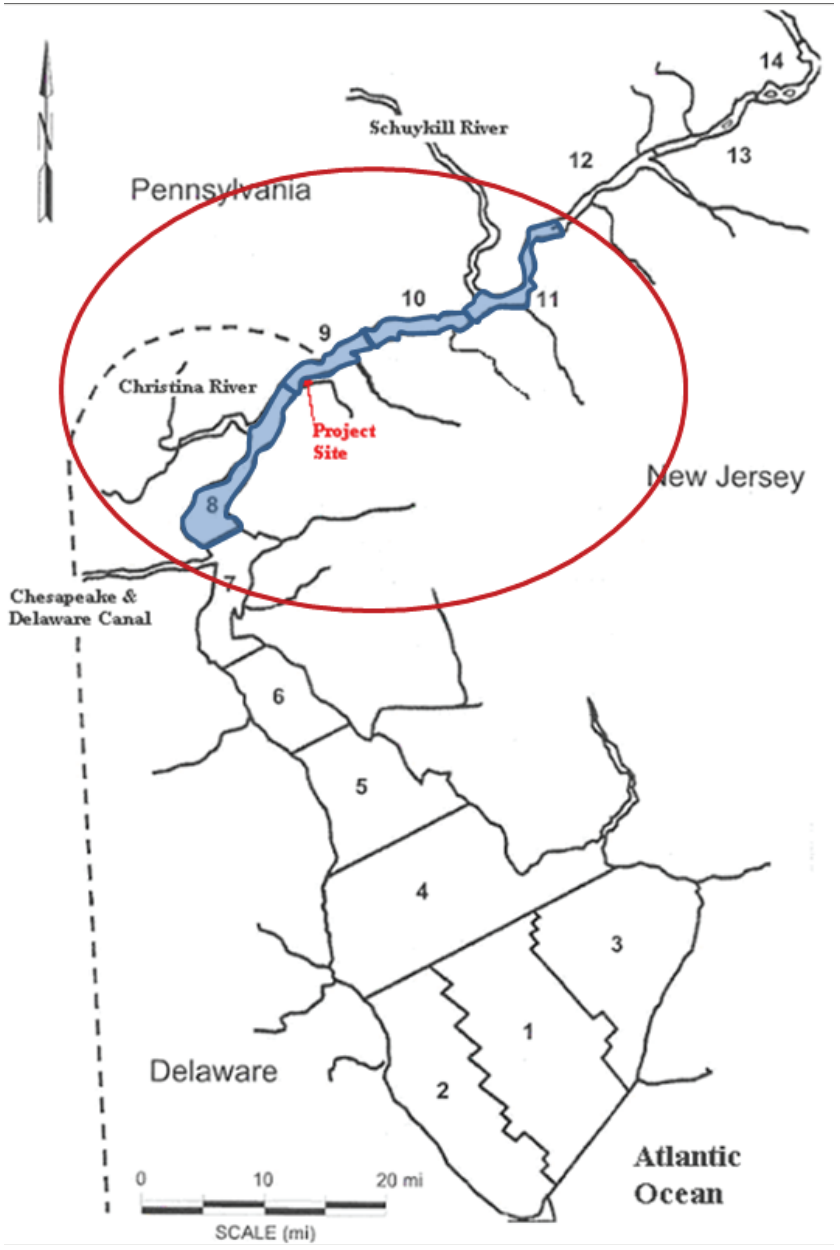

Table 1. Entrainable IP by PSEG zone (number of organisms per $1000 \mathrm{ft}^{3}$ of water).

\begin{tabular}{cccccc}
\hline Species/Group & Life Stage & Zone 8 & Zone 9 & Zone 10 & Zone 11 \\
\hline Clupeidae & Egg & 0.00 & 0.06 & 0.14 & 1.39 \\
(American Shad & Prolarvae & 0.00 & 0.51 & 1.64 & 8.92 \\
and River Herring) & Postlarvae & 5.18 & 8.61 & 9.86 & 12.57 \\
& Egg & 0.00 & 0.00 & 0.00 & 0.00 \\
Bay Anchovy & Prolarvae & 0.00 & 0.00 & 0.00 & 0.00 \\
& Postlarvae & 72.13 & 0.57 & 0.03 & 0.00 \\
& Egg & 0.03 & 1.16 & 0.91 & 1.36 \\
White Perch & Prolarvae & 0.65 & 0.76 & 1.19 & 3.34 \\
& Postlarvae & 156.87 & 10.17 & 16.17 & 23.25 \\
& Egg & 31.44 & 41.4 & 1.05 & 0.54 \\
Striped Bass & Prolarvae & 27.90 & 21.75 & 0.88 & 0.17 \\
& Postlarvae & 938.00 & 5.8 & 7.1 & 0.86 \\
\hline
\end{tabular}


Figure 4. Ballast intake extent of influence.

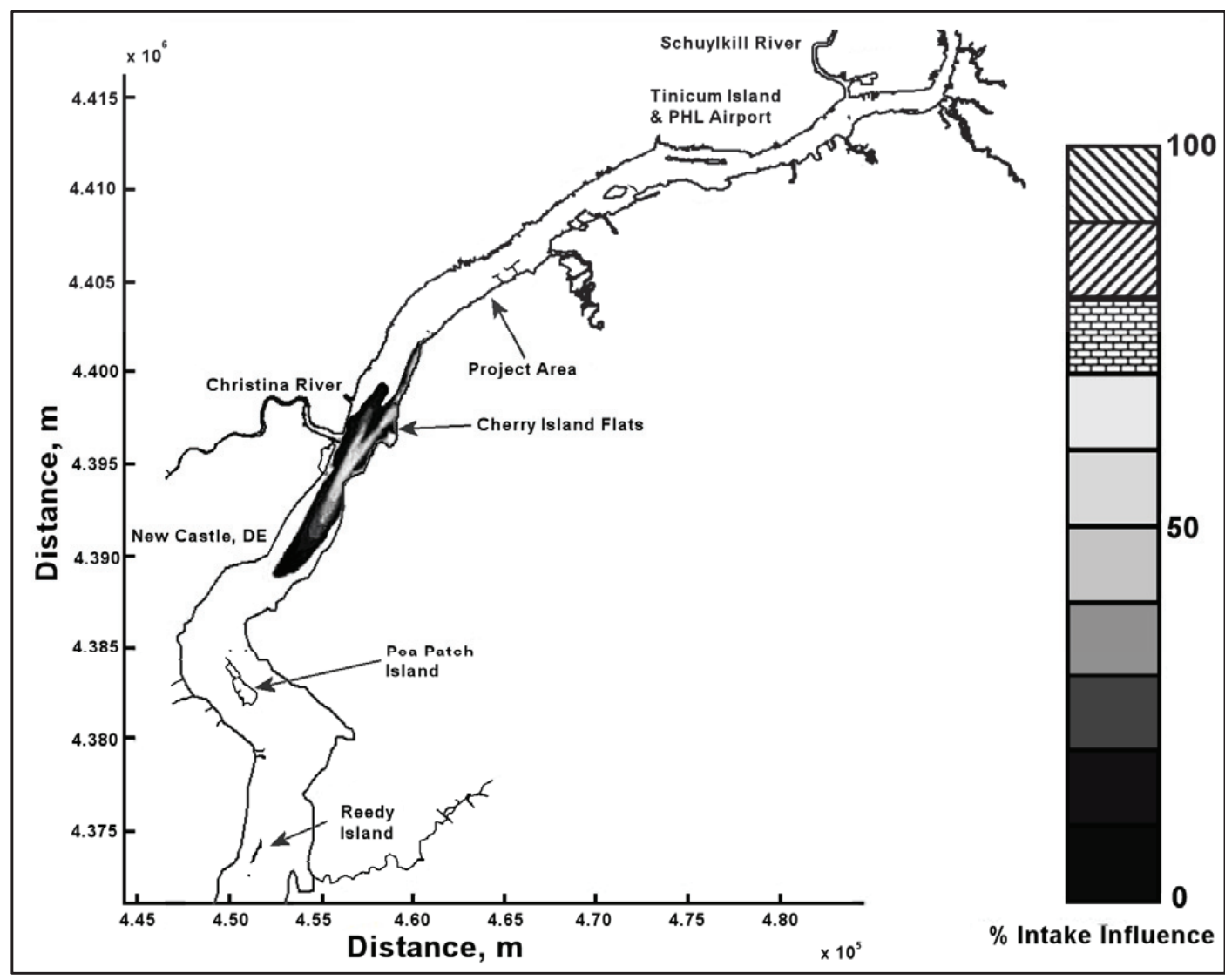

A hydrodynamic model and a water quality transport model were developed to evaluate the percentage of water entrained during a single ballast water intake at the project location. The numerical modeling protocol established in Edinger and Kolluru [14] to estimate the entrainment of ichthyoplankton due to power plant cooling water intakes along a body of water was used as the basis for this study. Edinger and Kolluru divided the domain into several regions and used a numerical hydrodynamic model and a numerical transport model to simulate the entrainment of dye from each of these regions. The dye does not react or decay. The percentage of the dye entrained is used as a proxy to represent the amount of ichthyoplankton entrained. The model was based on the Delft3D [1,2] modeling system. The grid was created around the LNG terminal with grid sizes varying between $50 \mathrm{~m}$ and $200 \mathrm{~m}$ in the $x$-direction (along the river) and $65 \mathrm{~m}$ and $100 \mathrm{~m}$ in the $y$-direction (across the river). The grid extends all the way down to the Delaware Bay on the southern side and to Philadelphia on the northern side with 21,669 surface cells. The vertical resolution of the grid is chosen as $1 \mathrm{~m}$. The model was run under flood and ebb conditions at the import terminal. Figure 4 shows the extent of influence of the ballast intake as modeled.

The percentage of water entrained during each ballast water intake cycle during the flood condition is shown in Table 2. 
Table 2. Percent of each water layer entrained by ballasting - flood condition.

\begin{tabular}{|c|c|c|c|}
\hline Zone/Month & $\begin{array}{l}\text { Percent Entrained } \\
\text { from Epilimnion }\end{array}$ & $\begin{array}{l}\text { Percent Entrained } \\
\text { from Metalimnion }\end{array}$ & $\begin{array}{l}\text { Percent Entrained } \\
\text { from Hypolimnion }\end{array}$ \\
\hline \multicolumn{4}{|c|}{ April } \\
\hline Zone 8 & $0.000 \%$ & $0.000 \%$ & $0.000 \%$ \\
\hline Zone 9 & $0.033 \%$ & $0.012 \%$ & $0.017 \%$ \\
\hline Zone 10 & $0.002 \%$ & $0.002 \%$ & $0.002 \%$ \\
\hline Zone 11 & $0.000 \%$ & $0.000 \%$ & $0.000 \%$ \\
\hline \multicolumn{4}{|c|}{ May } \\
\hline Zone 8 & $0.000 \%$ & $0.000 \%$ & $0.000 \%$ \\
\hline Zone 9 & $0.034 \%$ & $0.012 \%$ & $0.018 \%$ \\
\hline Zone 10 & $0.002 \%$ & $0.001 \%$ & $0.001 \%$ \\
\hline Zone 11 & $0.000 \%$ & $0.000 \%$ & $0.000 \%$ \\
\hline \multicolumn{4}{|c|}{ June } \\
\hline Zone 8 & $0.000 \%$ & $0.000 \%$ & $0.000 \%$ \\
\hline Zone 9 & $0.034 \%$ & $0.012 \%$ & $0.017 \%$ \\
\hline Zone 10 & $0.001 \%$ & $0.001 \%$ & $0.001 \%$ \\
\hline Zone 11 & $0.000 \%$ & $0.000 \%$ & $0.000 \%$ \\
\hline \multicolumn{4}{|c|}{ July } \\
\hline Zone 8 & $0.000 \%$ & $0.000 \%$ & $0.000 \%$ \\
\hline Zone 9 & $0.035 \%$ & $0.012 \%$ & $0.017 \%$ \\
\hline Zone 10 & $0.001 \%$ & $0.001 \%$ & $0.001 \%$ \\
\hline Zone 11 & $0.000 \%$ & $0.000 \%$ & $0.000 \%$ \\
\hline
\end{tabular}

These percentages were further used to estimate the entrainment potential for the four species based on their lifestage duration and natural mortality as shown in Tables 3 and 4.

Table 3. IP stage durations.

\begin{tabular}{cccc}
\hline Species/Group & \multicolumn{3}{c}{ Lifespan in Each Life Stage (Days) } \\
\cline { 2 - 4 } & Egg & Yolk Sac Larvae & Post-Yolk Sac Larvae \\
\hline White Perch & 3 & 30 & 332 \\
Clupeidae & 6 & 53 & 306 \\
Striped Bass & 2 & 52 & 311 \\
Bay Anchovy & 1 & 34 & 330 \\
\hline
\end{tabular}

Table 4. Natural mortality rates.

\begin{tabular}{cccc}
\hline Species/Group & \multicolumn{3}{c}{ Natural Mortality in Each Life Stage (Day ${ }^{-1}$ ) } \\
\cline { 2 - 4 } & Egg & Yolk Sac Larvae & Post-Yolk Sac Larvae \\
\hline White Perch & 0.601 & 0.164 & 0.005 \\
Clupeidae & 0.088 & 0.065 & 0.020 \\
Striped Bass & 0.601 & 0.164 & 0.005 \\
Bay Anchovy & 0.648 & 0.202 & 0.004 \\
\hline
\end{tabular}

Overlaying the water capture fraction with the IP densities, life stage durations and natural mortality, the EAM model can calculate the effective entrainment. All four methods described 
previously were examined to compare the predictions of the different methods. Table 5 summarizes the results and shows the predicted number of equivalent adults lost annually due to the intake operations. Methods 1 and 2 provide estimates of the likely upper and lower bound of the adults lost, while Methods 3 and 4 tend to give results reflective of the actual numbers likely to be lost. Table 6 shows the equivalent number of adults lost as a percentage of total equivalent adults available within the entrainable zone. The projected number of adults lost are very small (maximum of $0.12 \%$ ) and thus suggest that the intake operations will likely have very little effect on the regional fish populations, if any.

Table 5. Total number of equivalent adults lost annually during flood and ebb condition ballast water intake operations using the four equivalent adult methods available in GEMSS-EAM.

\begin{tabular}{ccccc}
\hline Species/Group & Method 1 & Method 2 & Method 3 & Method 4 \\
\hline & \multicolumn{4}{c}{ Flood Condition } \\
Clupeidae & 478 & 89 & 476 & 459 \\
Bay anchovy & 7472 & 1133 & 4245 & 2869 \\
White perch & 13,706 & 1325 & 9485 & 6618 \\
Striped bass & 30,671 & 5725 & 20,324 & 14,120 \\
& & Ebb Condition & & \\
Clupeidae & 360 & 55 & 357 & 344 \\
Bay anchovy & 16,425 & 994 & 9330 & 6270 \\
White perch & 15,454 & 1817 & 10,695 & 7473 \\
Striped bass & 110,427 & 3594 & 73,166 & 50,327 \\
\hline
\end{tabular}

Table 6. Total number of equivalent adults lost annually as percentage of total equivalent adults available in the entrainable zone (average of flood and ebb condition).

\begin{tabular}{ccccc}
\hline Species/Group & Method 1 & Method 2 & Method 3 & Method 4 \\
\hline Clupeidae & $0.01 \%$ & $0.00 \%$ & $0.01 \%$ & $0.01 \%$ \\
Bay anchovy & $0.00 \%$ & $0.00 \%$ & $0.00 \%$ & $0.00 \%$ \\
White perch & $0.00 \%$ & $0.00 \%$ & $0.00 \%$ & $0.00 \%$ \\
Striped bass & $0.12 \%$ & $0.02 \%$ & $0.08 \%$ & $0.05 \%$ \\
\hline
\end{tabular}

The Methods 1 and 2 are clearly bounding approaches because Method 1 applies the entrainment mortality at the beginning of the life stage (largest population size within the life stage) whereas Method 2 applies entrainment mortality at the end of the life stage (smallest population size within the life stage). These two assumptions lead to Method 1 over predicting and Method 2 under predicting the actual losses. The remaining two models attempt to apply the entrainment mortality at a more reasonable point (within the life stage). Method 3 uses the midpoint of the life stage whereas Method 4 applies it continuously along with the entrainment mortality (net mortality which is a result of exponentially decaying population from entrainment and natural mortality individually). It is therefore important to bind the estimated impacts using these approaches along with considering the Method 4 as a more realistic estimate. 


\subsection{Zone of Influence-Sturgeon Effects}

To address sturgeon entrainment, the zone of influence from the operation of the ballast water intake was studied using a second hydrodynamic model, GEMSS (Generalized Environmental Modeling System for Surface waters). A second model was applied to capture the level of detail required to evaluate the active swimming of fish as opposed to the passive entrainment of IP. The first step of the modeling was to create a high resolution near field grid around the ballast intake. The high resolution grid was created around this intake location with grid sizes varying between $10 \mathrm{~m}$ and $250 \mathrm{~m}$ in the $x$-direction (along the river) and $15 \mathrm{~m}$ and $300 \mathrm{~m}$ in the $y$-direction (across the river). The grid extends about $1 \mathrm{~km}$ on either side of the terminal along the river and covers the entire cross section with 1850 surface cells. The vertical resolution of the grid is chosen as $0.5 \mathrm{~m}$. Based on the design information, the ballast intake of diameter $0.6 \mathrm{~m}(600 \mathrm{~mm})$ and location of $3.7 \mathrm{~m}$ above the keel and $57 \mathrm{~m}$ forward of the stern was assumed. The high resolution model did not separate the two tidal cases as with the low resolution model earlier. The entire tidal cycle was combined into one model simulation to obtain cumulative effects. Some adults are long enough to become impinged if captured sidelong across the intake. Other mobile stages (adults and juveniles) can become entrained due to size or body orientation when they encounter the intake. These intake dimensions were closely followed in setting up the LNG carrier in the model domain as shown in Figure 5.

Figure 5. Carrier representation on the model domain.

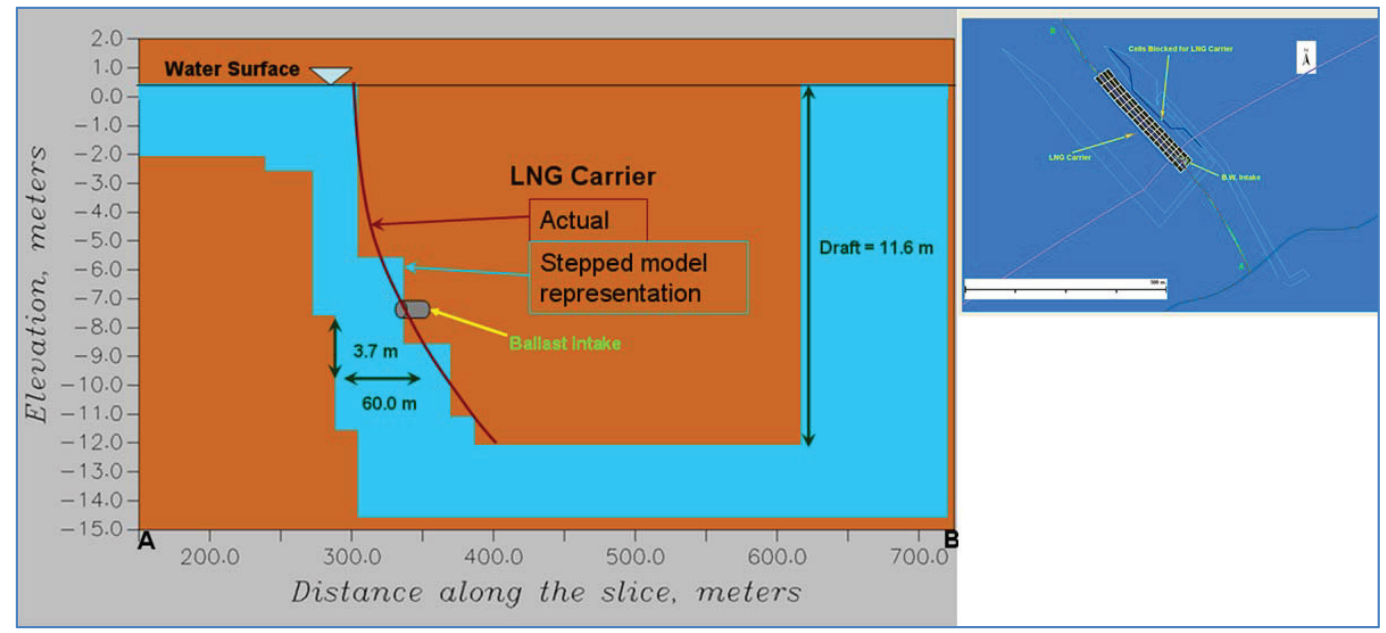

Shortnose sturgeon have typical mean swimming speeds of $8.1 \mathrm{~cm} / \mathrm{s}$ to $34.0 \mathrm{~cm} / \mathrm{s}$. These swimming speeds (and also burst speeds) are size dependent [15]. McCleave [16] found that the mean swimming speeds for shortnose sturgeon vary between 0.07 and 0.37 body lengths/s. Limited information is available about the swimming speeds for Atlantic sturgeon. Shortnose sturgeons are endangered species due the historical fishing and Atlantic sturgeon are similarly protected due to their resemblance to the shortnose. Entrainment of these sturgeons due to intake operations in the Delaware River is of concern. Sturgeons, and other species, as well can attain peak swimming 
speeds of up to 10-22 lengths/s [15] under increased opposing flows. However, during these increased swimming speeds (burst speed), respiration increases which results in exhaustion decreasing the distance traveled. Thus, they are expected to escape high flow conditions if the zone of this high flow is less than their endurance. The swimming speeds for these sturgeons were obtained from Amaral and Sullivan [17] and are summarized in Table 7.

Table 7. Swimming speeds.

\begin{tabular}{cccc}
\hline Swimming/Speed Type & Sustained Duration & Speed & Fish Length \\
\hline Maximum Sustained & $>200 \mathrm{~min}$ & $4 \mathrm{~cm} / \mathrm{s}$ & $15 \mathrm{~cm}$ \\
Speeds & & $84 \mathrm{~cm} / \mathrm{s}$ & $120 \mathrm{~cm}$ \\
Prolonged Speeds & $20 \mathrm{~s}-200 \mathrm{~min}$ & $39 \mathrm{~cm} / \mathrm{s}$ & $16 \mathrm{~cm}$ \\
& & $90 \mathrm{~cm} / \mathrm{s}$ & $120 \mathrm{~cm}$ \\
Burst Speeds & & $90 \mathrm{~cm} / \mathrm{s}$ & $45 \mathrm{~cm}$ \\
& $<20 \mathrm{~s}$ & Same as Prolonged & Same as Prolonged \\
\hline
\end{tabular}

The ballast water intake was located at a depth as shown in Figure 5. The high resolution model was run for two cases. Case 01 was run with the intake turned on whereas the Case 02 was run without the intake. These two cases were needed to determine the change in hydrodynamic conditions attributable to the intake operations. At this depth, in the near field, the horizontal velocity was predominantly towards the intake. There is a drastic difference in the horizontal velocities between the two cases. To better understand the effects due to the intake operation alone, consider Figure 6, which shows the velocity difference (with intake-without intake). The difference was very high close to the intake $(\sim 35 \mathrm{~cm} / \mathrm{s})$ but this difference rapidly decreased with distance from the intake.

A northwest-southeast plane (Slice AB) passing through the ballast water intake, as shown in Figures 5 and 6 , was chosen to study the vertical and northwest-southeast directional flow and zone of influence. The hydrodynamics of the region close to the intake is mostly dominated by the intake momentum as compared to the tidal influence. As we move slightly away from this region a small tidal variation in the circulation is seen under different tidal phases. The difference in the flow conditions between the two cases is shown in Figure 7. The flows are high and directed towards the intake with a defined circulatory flow pattern. The effects of the intake, though smaller, can be seen even close to the bottom ( $\sim 6 \mathrm{~m}$ below the intake). The difference in the velocity magnitude between the two cases is as high as $50 \mathrm{~cm} / \mathrm{s}$ (Figure 7). The differential velocity vectors clearly show a new eddy type circulation pattern introduced during the up estuary flow condition. The incremental velocity magnitude close to the bottom ranges between $0.5 \mathrm{~cm} / \mathrm{s}$ and $6 \mathrm{~cm} / \mathrm{s}$. The zone of influence is about $5 \mathrm{~m}-6 \mathrm{~m}$ in the vertical direction and about $50 \mathrm{~m}$ in the horizontal direction. After around $50 \mathrm{~m}$ in the horizontal direction at the intake level, the difference in net velocity magnitude drops to $0.1 \%(<0.5 \mathrm{~cm} / \mathrm{s}$ as compared to $50 \mathrm{~cm} / \mathrm{s}$ at the intake cell). 
Figure 6. Horizontal velocities at intake for each case.

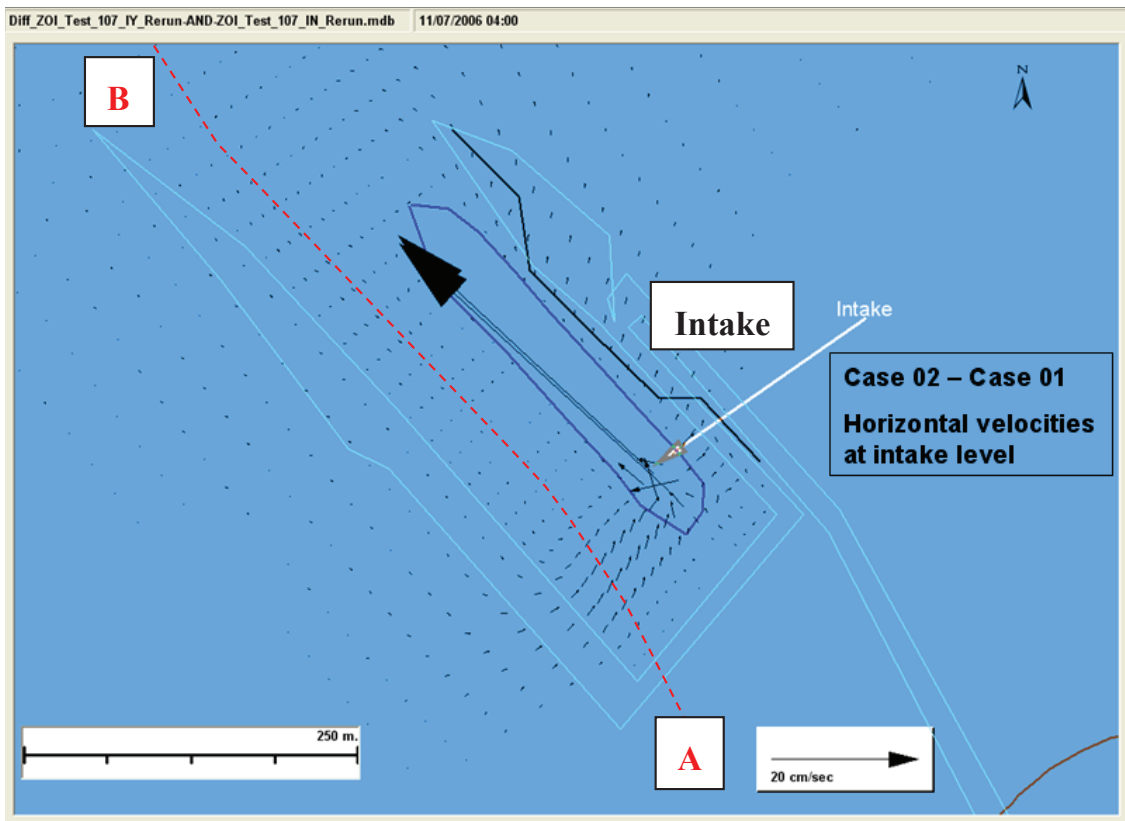

Figure 7. Differential velocities.

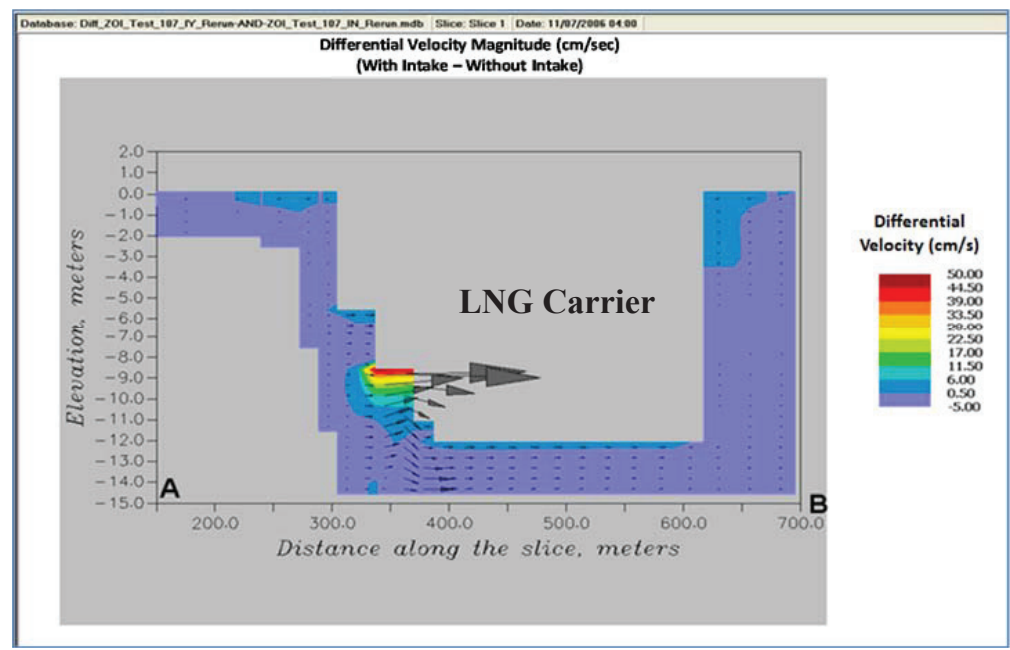

The mouth of the intake experiences the maximum increased flow (increase of $30-50 \mathrm{~cm} / \mathrm{s}$ ) which results in similar intake velocities of $30-50 \mathrm{~cm} / \mathrm{s}$ (Figure 8 ). These velocities at the intake when the ballast water intake is active are within the mean swimming speeds of both Atlantic and shortnose sturgeon. The burst speeds are much higher than the intake velocities and thus can allow them to escape the zone of influence. The burst swimming speeds cannot be sustained for a long duration (Table 7). However, at these speeds (e.g., $90 \mathrm{~cm} / \mathrm{s})$ fish can move up to $18 \mathrm{~m}(90 \mathrm{~cm} / \mathrm{s} \times$ 
$20 \mathrm{~s})$ to $54 \mathrm{~m}(90 \mathrm{~cm} / \mathrm{s} \times 60 \mathrm{~s})$ which will move them out of the zone of influence $(50 \mathrm{~m})$. Even though the burst swimming speeds are not sustainable, the extent of the zone of influence is small to allow the fish to quickly escape. However, there may be instances when the fish are close to the intake and may be entrained due to the smaller net velocity (swimming speed-velocity towards intake). Only a volume of $13 \mathrm{~m}^{3}$ was above the lowest burst swimming speed of $40 \mathrm{~cm} / \mathrm{s}$, a very small region.

Figure 8. Velocity magnitude when intake is active.

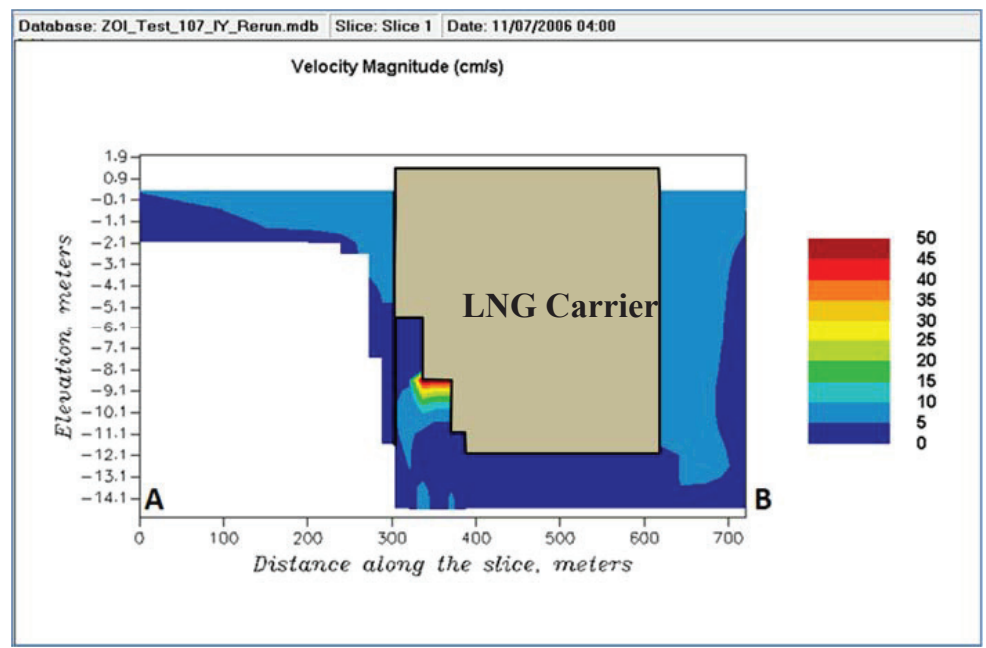

\section{Summary and Conclusions}

\subsection{Ichthyoplankton and Equivalent Adults}

Using these data, the GEMSS-EAM was run for each of the four months in question (April, May, June and July), assuming all ballast intake occurs while the ship is at berth. Methods 1 and 2 provide estimates of the likely upper and lower bound of the adults lost, while Methods 3 and 4 tend to give results reflective of the actual numbers likely to be lost. The projected numbers of adults lost are very small (maximum of $0.12 \%$ ) and thus suggest that the intake operations will likely have very little effect on the regional fish populations. Use of all four methods provides confirmation bounds for these quantifications that rely heavily on lifestage information which is hard to predict. A range of equivalent adults lost, therefore, is an appropriate choice. Additionally, sensitivity analysis should be performed to assess the uncertainty potential of these estimates.

It should be noted that there is always some risk associated with the withdrawal of ballast water by the ship intake. An expectation of no risk should not be a criterion for evaluating such impacts as the ecosystem, under natural conditions, has the ability to recover from small impacts. The risk evaluation completed as part of the study shows that the impacts are minimal, and within the ecosystem's ability to recover from. 


\subsection{Sturgeon Effects}

The velocity at the mouth of the intake was calculated as $30-50 \mathrm{~cm} / \mathrm{s}$. These velocities are within the mean swimming speeds of both Atlantic and shortnose sturgeon. The burst speeds are much higher than the intake velocities and thus can allow them to escape the zone of influence. At these speeds (e.g., $90 \mathrm{~cm} / \mathrm{s}$ ), fish can swim up to $18-54 \mathrm{~m}$, which will move them out of the zone of influence $(50 \mathrm{~m})$. Even though the burst swimming speeds are not sustainable, the extent of the zone of influence is small to allow the fish to quickly escape. Only a volume of $13 \mathrm{~m}^{3}$ was above the lowest burst swimming speed of $40 \mathrm{~cm} / \mathrm{s}$.

\section{Acknowledgments}

The authors would like to thank BP America for providing the necessary funding for this study. Authors also acknowledge the resources and encouragement provided by Environmental Resource Management (ERM) to develop these formulations.

\section{Author Contributions}

Shwet Prakash, Venkat S. Kolluru and Carol Young conceptualized the model formulations and development. Shwet Prakash developed coding for various formulations; Venkat Kolluru developed the hydrodynamic model and provided technical direction throughout the project. Carol Young managed the overall project.

\section{Conflicts of Interest}

The authors declare no conflict of interest.

\section{References and Notes}

1. Delft. Delft3D-FLOW: Simulation of Multi-Dimensional Hydrodynamic Flows and Transport Phenomena, Including Sediments; WL | Delft Hydraulics: Delft, The Netherlands, 2004.

2. Delft. Delft3D-RGFGRID: Generation and Manipulation of Curvilinear Grids for FLOW and WAVE User Manual; WL | Delft Hydraulics: Delft, The Netherlands, 2004.

3. Edinger, J.E.; Buchak, E.M. Numerical Hydrodynamics of Estuaries in Estuarine and Wetland Processes with Emphasis on Modeling; Hamilton, P., Macdonald, K.B., Eds.; Plenum Press: New York, NY, USA, 1980; pp. 115-146.

4. Kolluru, V.S.; Buchak, E.M.; Edinger, J.E. Integrated Model to Simulate the Transport and Fate of Mine Tailings in Deep Waters. In Proceedings of the Tailings and Mine Waste '98 Conference, Fort Collins, CO, USA, 26-29 January 1998.

5. Prakash, S.; Kolluru, V.S. Implementation of Higher Order Transport Schemes with Explicit and Implicit Formulations in a 3-D Hydrodynamic and Transport Model. In Proceedings of 7th International Conference on Hydroscience and Engineering, Philadelphia, PA, USA, 10-13 September 2006. 
6. Horst, T.J. The Equivalent Adult Model: A General Model for Fisheries Impact Assessment; Environmental Division, Stone \& Webster Engineering Corporation: Boston, MA, USA, 1977.

7. Goodyear, C.P. Entrainment Impact Estimates Using the Equivalent Adult Approach; Department of Interior, Fish and Wildlife Service, Office of Biological Services, Power Plant Project: Minneapolis and Saint Paul, MN, USA, 1978.

8. Electric Power Research Institute (EPRI). Extrapolating Impingement and Entrainment Losses to Equivalent Adults and Production Foregone; Document No. 1008471; EPRI: Palo Alto, CA, USA, 2004.

9. Nielsen, R.D.; Ginn, T.C.; Ziccardi, L.M.; Boehm, P.D. An Evaluation of the Approaches Used to Predict Potential Impacts of Open Loop LNG Vaporization Systems on Fishery Resources of the Gulf of Mexico; Document No. BN02922.001 01F1 1005 DN21; Centre for liquefied natural Gas, Seawater Usage Technology Committee: Washington, DC, USA, November 2005.

10. Public Service Electric and Gas Company (PSEG). Salem Generating Station Permit Application to New Jersey Department of Environmental Protection; PSEG: Salem, NJ, USA, 1999.

11. The value was provided by BP and relates to different density between LNG $\left(450 \mathrm{~kg} / \mathrm{m}^{3}\right)$ and seawater density $\left(1027 \mathrm{~kg} / \mathrm{m}^{3}\right)$ and the remaining ballast water would be taken on as the vessel departs and after exiting the most sensitive habitat area. In consultation with both vessel captains and resource agencies, $8 \mathrm{mg}$ of ballast was selected as the ballast volume for this analysis.

12. Public Service Electric and Gas Company. Ichthyoplankton Sampling Study Data Report for 2002; PSEG: Salem, NJ, USA, 2002.

13. Public Service Electric and Gas Company. Ichthyoplankton Sampling Study Data Report for 2003; PSEG: Salem, NJ, USA, 2003.

14. Edinger, J.E.; Kolluru, V.S. Power Plant Intake Entrainment Analysis. J. Energy Eng. 2000, $126,1-14$.

15. Castro-Santos, T.; Haro, A. Sprinting Performance of Upstream Migratory Fishes; Conte Anadromous Fish Research Center/USGS-BRD: Turners Falls, MA, USA, 2000.

16. McCleave, J.D.; Fried, S.M.; Towt, A.K. Daily movements of shortnose sturgeon, Acipenser brevirostrum, in a Maine estuary. Copeia 1977, 1977, 149-157.

17. Amaral, S.; Sullivan, T. Downstream Fish Passage from Sturgeon. In Proceedings of Great Lakes Sturgeon Coordination Meeting, Sault Ste. Marie, MI, USA, 9-10 November 2004. 


\title{
Bed Scouring During the Release of an Ice Jam
}

\section{Michail Manolidis and Nikolaos Katopodes}

\begin{abstract}
A model is developed for simulating changes in river bed morphology as a result of bed scouring during the release of an ice jam. The model couples a non-hydrostatic hydrodynamic model with the processes of erosion and deposition through a grid expansion technique. The actual movement of bed load is implemented by reconstructing the river bed in piecewise linear elements in order to bypass the limitations of the step-like approximation that the hydrodynamic model uses to capture the bed bathymetry. Initially, an ice jam is modeled as a rigid body of water near the free surface that constricts the flow. The ice jam does not exchange mass or momentum with the stream, but the ice body can have a realistic shape and offer resistance to the flow of water through the constriction. An ice jam release is modeled by suddenly enabling the ice to flow and exchange mass and momentum with the water. The resulting release resembles a dam break wave accelerating and causing flow velocities to rise rapidly. The model is used to simulate the 1984 ice jam in the St. Clair River, which is part of the Huron-Erie Corridor. The jam had a duration of 24 days, and its release was accompanied by high flow velocities. It is speculated that high flow velocities during the release of the jam caused scouring of the river bed. This led to an increase in the river's conveyance that is partly responsible for the persistence of low water levels in the upper Great Lakes. The simulations confirm that an event similar to the 1984 ice jam will indeed cause scouring of the St. Clair River bed.
\end{abstract}

Reprinted from J. Mar. Sci. Eng. Cite as: Manolidis, M.; Katopodes, N. Bed Scouring During the Release of an Ice Jam. J. Mar. Sci. Eng. 2014, 2, 370-385.

\section{Introduction}

The Great Lakes account for $20 \%$ of the Earth's surface freshwater and for $90 \%$ of North America's surface freshwater [1]. These figures indicate the importance of these lakes as a freshwater reservoir. Furthermore, the Great Lakes have great importance as an ecosystem. With respect to human activities, they are a source of food, they encompass commercial routes for industry, they offer tourist attractions and entire communities and recreational facilities are built around the Great Lakes. A general map of the Great Lakes System can be seen in Figure 1.

Between 1963 and 2006, there has been a lake-to-lake head fall between Lakes Michigan-Huron and Lake Erie of approximately $23 \mathrm{~cm}$. A drop of the water level in the Great Lakes, in addition to translating to a loss of colossal amounts of freshwater, can affect and change the shoreline and the communities that have been built around the Lakes. It may affect the entire ecosystem and can also cause disruptions to human activities, such as creating impediments for the passing of ships. Bathymetric studies indicate that St. Clair River's conveyance increased during the 1980s; four hydrodynamic models were used during the development of a joint commission report, and all indicated an increase in conveyance [2]. Namely, the models that were used were HEC-RAS (Hydrologic Engineering Centers River Analysis System), RMA-2, HydroSed2D (2D 
Hydrodynamics and Sediment transport model) and TELEMAC-2D. It is speculated that the increase in conveyance was caused by a deepening of the river related to a major ice jam in 1984 [3]. From the HydroSed2D model, it was estimated that under normal flow conditions, the stresses at the bottom of the St. Clair River would not suffice to induce any bed erosion, considering the bed composition. However, during episodic events, as in ice jam releases, high flow velocities may induce scouring of the bed.

Figure 1. Map of the Great Lakes System [2].

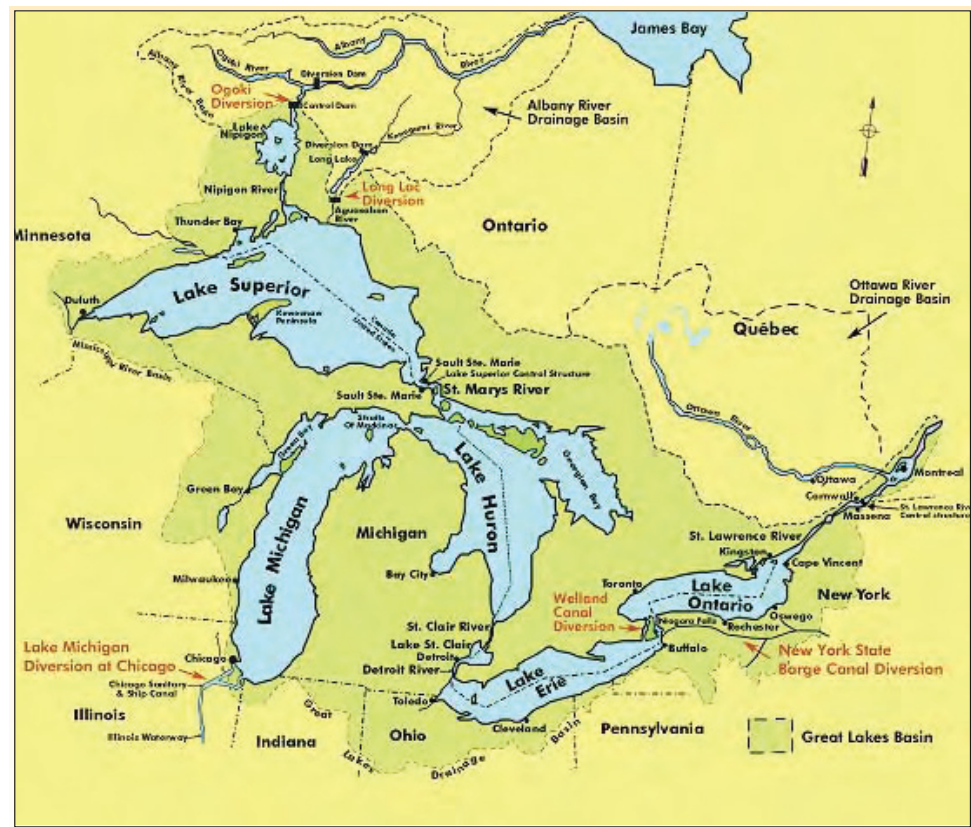

In this work, flow in the St. Clair River is simulated during the presence and the release of an ice jam similar to the one in 1984. A hydrodynamic model is modified in such a way as to simulate the presence of a jam and its subsequent release. A bedload transport model is developed and combined with the hydrodynamic model, and a simulation of the 1984 ice jam release is carried out. The hydrodynamic model is based on the Stanford Unstructured Non-hydrostatic Terrain-following Adaptive Navier-Stokes Simulator (SUNTANS) project [4] and implements the finite volume method to solve the non-hydrostatic Reynolds-averaged Navier-Stokes (RANS) equations on an unstructured $\mathrm{z}$-coordinate grid. The free surface is handled by depth-integration of the continuity equation. Recent ice jam models are based on the St. Venant equations [5,6]. Liu [5] developed a 2D finite element model that treated ice as a separate viscous-plastic continuum. Ice jam release simulations were run with and without the inclusion of ice, and the authors concluded that the presence of ice has a dampening effect on the surge that follows the release of an ice jam, but leads to higher flow velocities after the initial surge. Later, She [6] modified the 1D finite element model by Hicks [7] to account for ice implicitly by adding a resistance term to the momentum equation. Their results were similar to those of Liu [5]. This work marks the first time a fully 3D, non-hydrostatic model was 
implemented for simulating the presence and release of an ice jam. Complex turbulent structures and non-hydrostatic gradients may affect the stresses on the river bed during the stay and release of an ice jam, and their capture is important in assessing the possible effects on river bed scouring. Furthermore, the hydrodynamic model is computationally efficient at large scales, which is essential in being able to run meaningful simulations in the physical domain involved. The ice jam is modeled as a foreign rigid object in the flow field by setting all fluxes within the ice jam to zero. A drag law is enforced on the underside of the jam to account for flow-induced friction. The ice jam release is simulated by simply removing the zero-flux condition and releasing the initially still body of water in the flow. Several bed scouring models have been developed recently, and all employ a non-hydrostatic RANS solver and all, with the exception of one [8], employ adaptive gridding with continuous meshing [9-13]; the exception being the model by Khosronejad [8] that uses the immersed boundary method.

The scouring model developed in this work is unique in that it employs adaptive gridding without the need for continuous re-meshing. It achieves this by adding or removing cells from the computational domain and the flow field. Unlike the case of the immersed boundary method, the approach followed in this work does not require interpolation for computing boundary flow velocities, since those are readily computed in the finite volume scheme. The hydrodynamic model employs a z-coordinate grid, and the bed is modeled with a step-like approximation. As such, angles of inclination are not readily available for the bed, which are required in order to be able to solve the constitutive relations that give the bedload fluxes. Two different methods for geometric modeling of the river bed are developed and successfully implemented. The methods provide an approach for finding angles of inclination, as well as discretizing the boundary domain in order to solve the Exner equation. Once the bed morphology is modeled, the approach by Roulund [10] is followed to compute the bedload fluxes. In this approach, the equations of motion are solved for a representative bed particle, taking into account not only all the forces involved, but also that the particle may be moving at an angle with the flow. Once the bedload fluxes are computed, the Exner equation is solved numerically, so the approach is contingent upon the geometric modeling methodology for the river bed.

A computational grid is constructed of the St. Clair River, and appropriate bathymetric data are used, as obtained from the Great Lakes Environmental Research Laboratory of the National Oceanic and Atmospheric Administration (NOAA). Boundary conditions are set appropriately, and an ice jam similar to the one in 1984 is modeled. The jam geometric parameters are adjusted so that flow conditions agree with recorded values. Normal flow conditions are also simulated. Finally, flow conditions are simulated with the ice jam in place. Once the steady state is achieved, the stresses on the bed are computed. Then, the ice jam is released, and the bed stresses are computed again.

\section{The Hydrodynamic Model}

The hydrodynamic model used in this work is a non-hydrostatic, RANS solver that uses the finite volume method on a triangular, z-coordinate staggered grid. It is based on SUNTANS, originally developed by Fringer [4]. A typical cell comprising the grid can be seen in Figure 2. 
Figure 2. Description of a 3D prismatic grid cell.

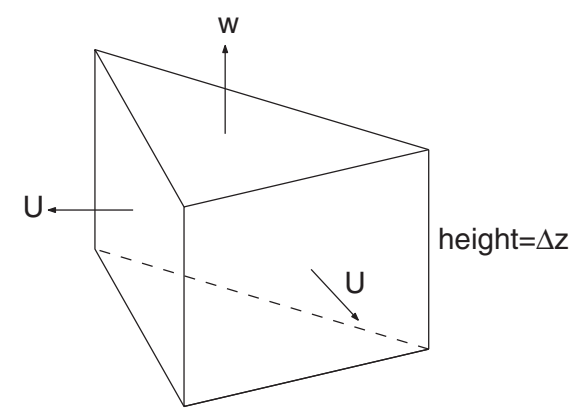

The solver computes the horizontal velocity at each vertical face, the vertical velocity at each horizontal face, as well as the free surface height and the non-hydrostatic pressure. The two horizontal momentum equations can be written as follows:

$$
\frac{\partial u}{\partial t}+\nabla \cdot(\vec{u} u)=-\frac{1}{\rho_{o}} \frac{\partial p}{\partial x}-g \frac{\partial h}{\partial x}+\nabla_{H} \cdot\left(\nu_{H} \nabla_{H} u\right)+\frac{\partial}{\partial z}\left(\nu_{V} \frac{\partial u}{\partial z}\right)
$$

and:

$$
\frac{\partial v}{\partial t}+\nabla \cdot(\vec{u} v)=-\frac{1}{\rho_{o}} \frac{\partial p}{\partial y}-g \frac{\partial h}{\partial y}+\nabla_{H} \cdot\left(\nu_{H} \nabla_{H} v\right)+\frac{\partial}{\partial z}\left(\nu_{V} \frac{\partial v}{\partial z}\right)
$$

where $u$ and $v$ are the horizontal $x$ and $y$ velocity components, $p$ is the non-hydrostatic pressure, $g$ is the acceleration of gravity and $h$ is the free surface height. $\nu_{H}$ and $\nu_{V}$ are the horizontal and vertical eddy viscosities, following the Boussinesq approximation. Combining the two horizontal momentum equations and taking the dot product with the face normal, $\vec{n}$, results in:

$$
\frac{\partial U}{\partial t}+\vec{n} \cdot \nabla \cdot(\vec{u} \vec{u})=-\frac{1}{\rho_{o}} \frac{\partial p}{\partial n}-g \frac{\partial h}{\partial n}+\nabla_{H} \cdot\left(\nu_{H} \nabla_{H} U\right)+\frac{\partial}{\partial z}\left(\nu_{V} \frac{\partial U}{\partial z}\right)
$$

where $\frac{\partial}{\partial n}$ is the derivative in the direction of the normal and $\vec{u}$ is the flow velocity vector. The vertical momentum equation is given by:

$$
\frac{\partial w}{\partial t}+\nabla \cdot(\vec{u} w)=-\frac{1}{\rho_{o}} \frac{\partial p}{\partial z}+\nabla_{H} \cdot\left(\nu_{H} \nabla_{H} w\right)+\frac{\partial}{\partial z}\left(\nu_{V} \frac{\partial w}{\partial z}\right)
$$

In addition, the incompressibility condition is written as follows:

$$
\nabla \cdot \vec{u}=0
$$

The free surface is computed by depth-integrating the continuity equation. After enforcement of the kinematic condition at the free surface, an evolution equation for the total depth of flow is obtained, as follows:

$$
\frac{\partial h}{\partial t}+\frac{\partial}{\partial x}\left(\int_{-d}^{h} u \mathrm{~d} z\right)+\frac{\partial}{\partial y}\left(\int_{-d}^{h} v \mathrm{~d} z\right)=0
$$


where $d$ is the depth measured from the undisturbed free surface. The two momentum equations, the depth-integrated continuity equation and the incompressibility constraint form a set of four equations in four unknowns, namely the face-normal velocity, $U$, the vertical velocity, $w$, the free surface height, $h$, and the non-hydrostatic pressure, $q$. The velocities at the cell centers are found by interpolation.

The boundary condition at the river bed determines the flow resistance using the law of the wall and can be written as follows:

$$
\left.\nu_{V} \frac{\partial U}{\partial z}\right|_{z=h}=C_{d, B}|U| U
$$

where $C_{d, B}$ is the drag coefficient for the bed.

In the numerical scheme for the momentum equations, the convection and horizontal diffusion terms are discretized explicitly. Vertical diffusion terms are discretized semi-implicitly with the theta method. The semi-implicit treatment of vertical diffusion terms, as opposed to the explicit treatment of other diffusion and convection terms, allows for the use of smaller discretization scales in the vertical direction, while keeping a relatively large time step. This makes SUNTANS suitable for simulations in estuaries, rivers and oceans, where horizontal scales are much bigger than vertical ones.

The non-hydrostatic solver uses a predictor-corrector method. The velocity field is predicted based on the non-hydrostatic pressure of the previous time step. The momentum equations are solved jointly with the depth-integrated continuity equation, where the predicted horizontal velocity is used, to give the predicted velocity field, as well as the free surface height at the next time step. The predicted velocity field is then inserted into the local continuity equation, and a Poisson equation is solved for the non-hydrostatic pressure correction term at the next time step. Once the correction term is computed, the velocity and pressure fields are updated to those of the next time step.

\subsection{The Turbulence Model}

Closure to the RANS equations is achieved with the Mellor and Yamada 2.5 model. The key characteristic of the model is that it applies to situations where the horizontal scales are much bigger than the vertical scales, and as such, it is assumed that turbulence is resolved only in the latter. Only the vertical eddy viscosity is solved for, while the horizontal eddy viscosity is set to a constant in order to preserve stability. The vertical eddy viscosity is given by:

$$
\nu_{V}=-l q S_{M}
$$

where $l$ is a length scale, $q$ is the turbulent kinetic energy and $S_{M}$ is an algebraic function of the vertical horizontal velocity gradients. The Mellor and Yamada model is a two-equation model. The equation for the turbulent kinetic energy is given by:

$$
\frac{D\left(q^{2} / 2\right)}{D t}-\frac{\partial}{\partial z}\left(l q S_{q} \frac{\partial}{\partial}\left(\frac{q^{2}}{2}\right)=P_{s}-\epsilon\right.
$$

where $S_{q}$ is a constant and $\epsilon$ is the turbulent kinetic energy dissipation rate given by: 


$$
\epsilon=\frac{q^{3}}{B_{1} l}
$$

The dissipation rate is inversely proportional to the length scale, since the latter represents an average distance that a turbulent eddy travels before it is dissipated. The equation for the length scale is given by:

$$
\frac{D}{D t}\left(q^{2} l\right)-\frac{\partial}{\partial z}\left[q l S_{l} \frac{\partial}{\partial z}\left(q^{2} l\right)\right]=l E_{1} P_{s}-\frac{q^{3}}{B_{1}}\left[1+E_{2}\left(\frac{l}{\kappa L}\right)^{2}\right]
$$

where $S_{l}, E_{1}$ and $E_{2}$ are constants, $\kappa$ is the von Karman constant and $L$ is the distance from the wall.

\section{The Bed Scouring Model}

The boundary condition that the hydrodynamic model uses for the bed is given by Equation (7) and is based on the law of the wall. It can be shown that the drag coefficient, $C_{d, B}$, is given by:

$$
C_{d, B}=\left(\frac{1}{\kappa} \ln \frac{z}{z_{o}}\right)^{-2}
$$

where $z$ is the distance from the bed at which the velocity is measured and $z_{0}$ is the theoretical distance from the bed at which the velocity becomes zero. For rough boundaries, $z_{o}$ is given by:

$$
z_{o}=\frac{k_{s}}{30}
$$

where $k_{s}$ is the equivalent roughness height. For typical river beds, $k_{s}$ can be taken as [14]:

$$
k_{s} \approx 3.5 d_{85}
$$

where $d_{85}$ is the the 85 th percentile grain diameter. Generally, $d_{85}$ can be taken to be 1.5 times the median grain diameter, $d_{50}$, of the bed [15]. If the sediment size and type are known, the shear velocity can be computed by measuring the flow velocity some distance $z$ above the bed and taking:

$$
u_{*}=\sqrt{\left(\frac{1}{\kappa} \ln \frac{z}{\frac{3.5 * 1.5 * d_{50}}{30}}\right)^{-2}}|U|
$$

The dimensionless Shields stress, $\theta$, can then be calculated using the formula:

$$
\theta=\frac{u_{*}^{2}}{(s-1) g d_{50}}
$$

where $s$ is the specific gravity of the sediment. In the model, both the median sediment grain size, $d_{50}$, and the specific gravity can vary along the bed, with the resolution of the field distribution being limited only by the resolution of the horizontal mesh.

The constitutive relations that couple the flow field with sediment movement at some point along the bed require that the local angle of inclination of the bed at that location be known. SUNTANS implements a step-like approximation of the bed, and as such, local angles of inclination are not readily available. Two different approaches were developed in order to estimate the angle of 
inclination. In both methods, the bathymetry is approximated by projecting the horizontal triangular mesh on the plane of the bed. In the first method, each vertex of a triangle is assigned a depth equal to the weighted average of the depths of the Voronoi points of triangles that share that vertex. Figure 3 shows a schematic of the two-dimensional equivalent case.

Figure 3. Reconstructing the bed geometry: the $2 \mathrm{D}$ case. The red dotted line is the reconstructed continuous surface.

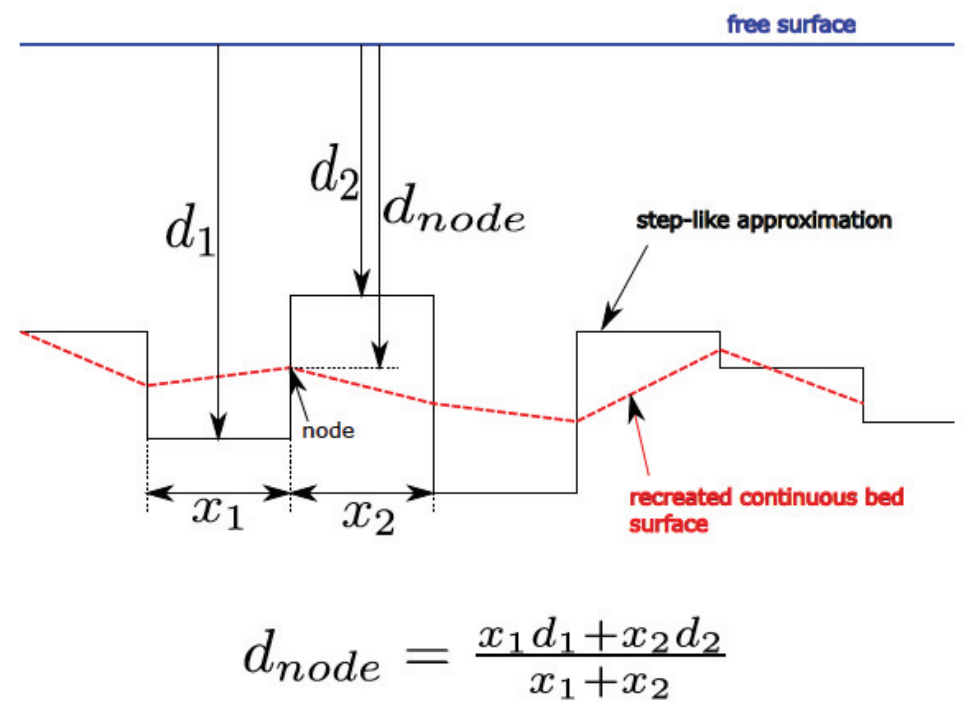

As shown in Figure 4, the angle of inclination is just the inverse cosine of the z-component $\left(n_{z}\right)$ of the normal vector, $\vec{n}$. The direction of maximum slope, given by the vector, $\vec{b}$, along which the weight component acts, is given by:

$$
\vec{b}=\frac{\left(\hat{e}_{z} \times \vec{n}\right) \times \vec{n}}{\left|\left(\hat{e}_{z} \times \vec{n}\right) \times \vec{n}\right|}
$$

where $\hat{e}_{z}$ is the unit vector in the z-direction. Once these important geometric parameters are known, i.e., the angle of inclination and the direction of maximum slope, the flow field can be coupled with sediment transport. The key coupling factor is the shear velocity, which is essentially a measure of the stress on the bed. The application of the constitutive relations follow the approach by Roulund [10], where a force balance is applied to a representative sediment particle. The schematic shown in Figure 5 shows the forces involved, as well as their geometric relationships. 
Figure 4. Finding the bed inclination.

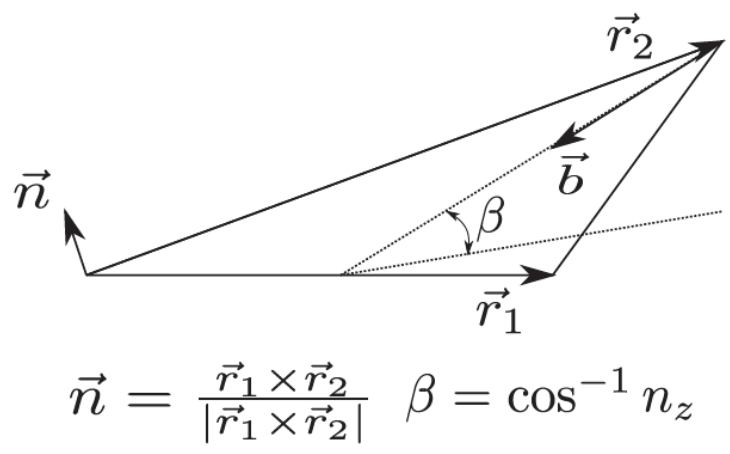

Figure 5. Forces on a bed particle and their geometric relationships.

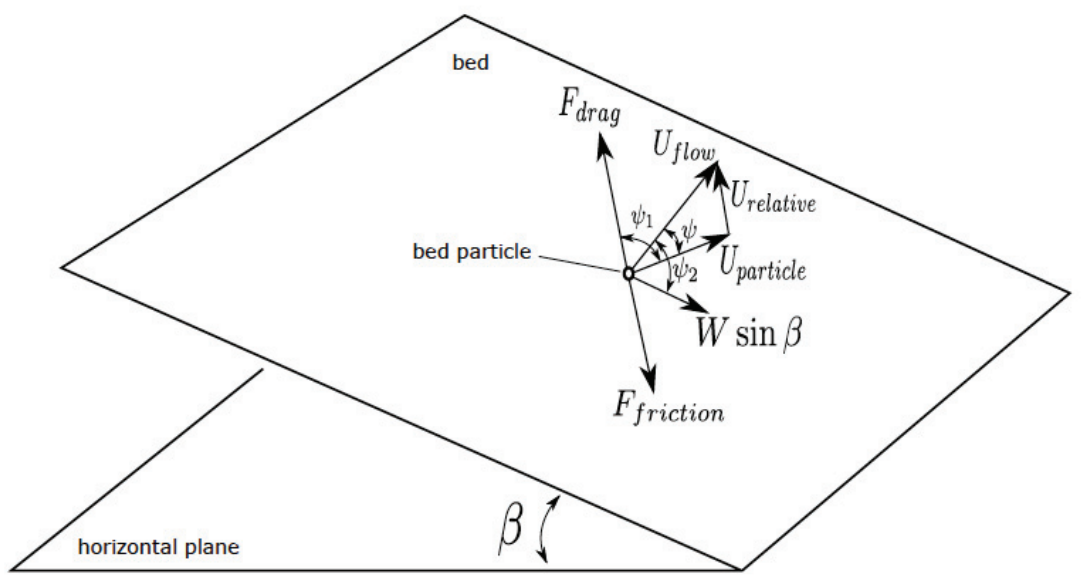

A set of dynamic and kinematic non-linear algebraic relations are produced and solved in our model by the Newton-Raphson method. The solution to the system of equations provides the velocity of the representative particle, which is then extrapolated to compute the bed load fluxes along the bed. Once the fluxes are known, a bed evolution equation is solved, also known as the Exner equation, given below:

$$
\frac{\partial \eta}{\partial t}=-\frac{1}{1-n} \nabla \cdot \vec{q}_{b}
$$

where $\eta$ is the bed elevation, $n$ is the sediment porosity and $\vec{q}_{b}$ are the $2 \mathrm{D}$ fluxes. Integrating over an element and applying the divergence theorem gives:

$$
A \frac{\partial \eta}{\partial t}=-\frac{1}{1-n} \int_{\partial A} \overrightarrow{q_{b}} \cdot \vec{n}
$$


where $\vec{n}$ is the outward normal and $A$ is the projected area of an element. Discretization of the last equation yields:

$$
\frac{\Delta \eta_{i}}{\Delta t}=-\frac{1}{1-n} \frac{1}{A_{i}} \sum_{j=1}^{3} \vec{q}_{j} \cdot \vec{n}_{j} l_{j}
$$

where the index, $i$, refers to the cell number and the index, $j$, refers to the number of the side of the cell. $l_{j}$ is the length of side $j$. In this method of geometric modeling of the bed, the fluxes are initially computed at the cell centers. The fluxes at the sides are computed by simple interpolation.

The aforementioned model was used to simulate the scouring downstream of a sluice gate. The specifics of the computational setup are given by [16]. The computed bed surface is shown in Figure 6. While the results are qualitatively correct, a noticeable irregularity is present. The errors are a direct result of the averaging process proposed above for the computation of the local angels of inclination. Although artificial diffusion has been added to the Exner equation, the erratic bed scouring persists.

Figure 6. Scouring under a sluice gate.

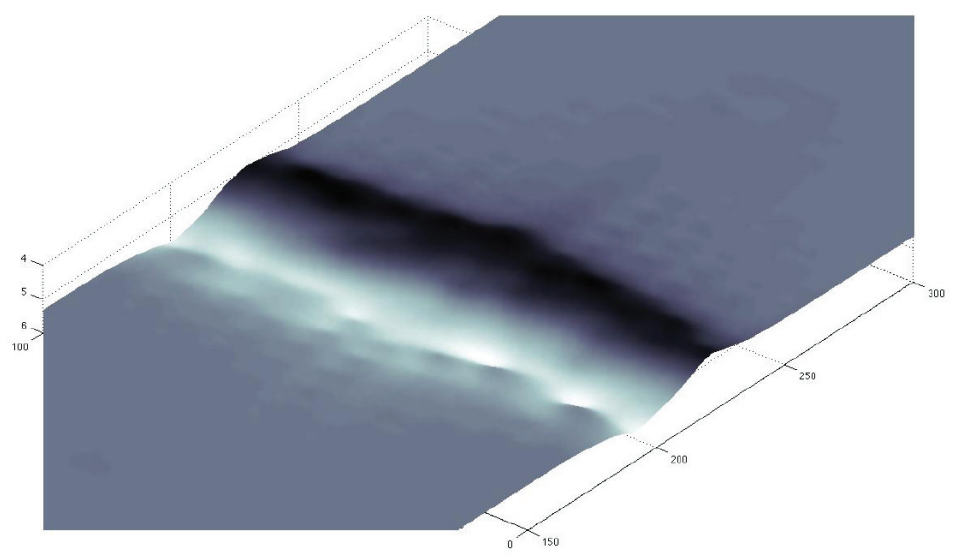

To avoid the irregularities that result from the geometric modeling technique, an alternative method was developed and used in the simulations. Figure 7 explains schematically the proposed method. It involves the division of each element in three parts and the assignment of a different angle of inclination to each part. The angle is shared by the corresponding part of the adjacent cell, depending on the depth difference between the two cells.

The constitutive relations are then solved separately for each part of the cell, but always using the shear velocity derived at the center of the cell. Therefore, each part of the cell has a different flux assigned to it. Fluxes at the edges are computed by simple interpolation, and the Exner equation is solved accordingly, following the procedure presented above.

Figure 8 depicts scouring under a sluice gate, under the same flow conditions, i.e., those used to produce the results in Figure 6. The superiority of the alternative method is obvious, as no irregularities appear in the solution of the Exner equation, and no artificial diffusion is needed. 
Figure 7. The geometric scheme followed in order to find the bed inclination.

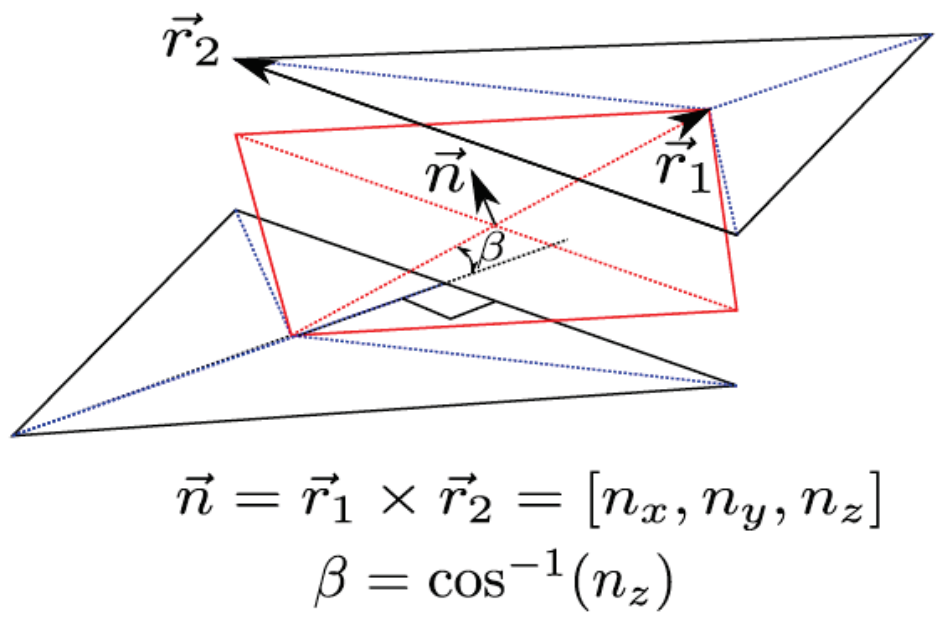

Figure 8. Scouring under a sluice gate (not shown) with the latter modeling scheme. No irregularities are present.

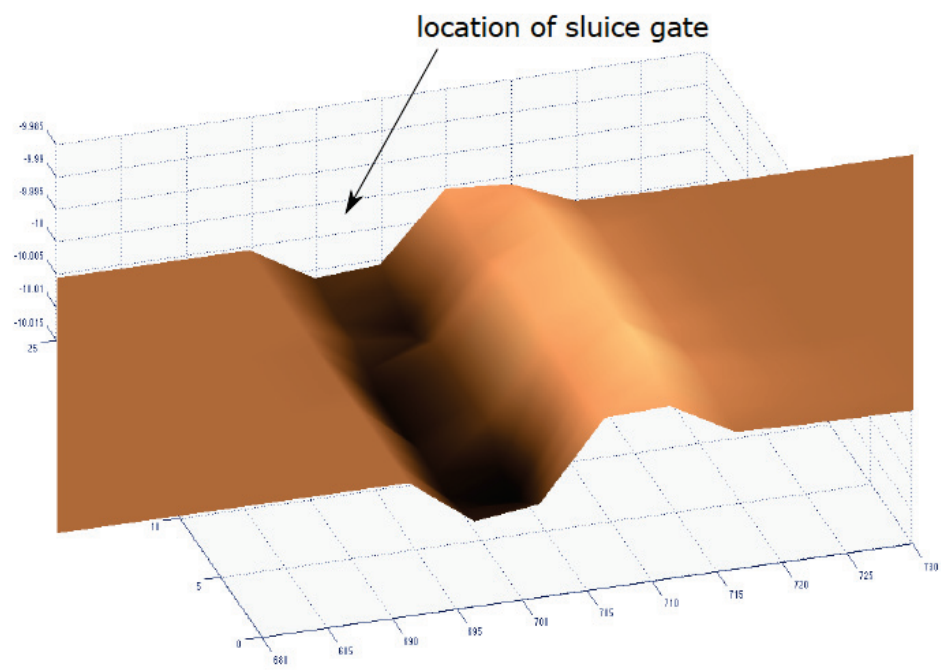

While the bed morphology used for bed scouring is not exactly interpreted by the hydrodynamic model, since it implements step-like approximation, the z-coordinate meshing offers an advantage over other existing models. An algorithm was developed and implemented, whereby the grid adapts to the changing bed by shrinking or elongating the cells nearest to the bottom when the change in bed elevation is small. However, when the change in bed elevation exceeds a certain threshold, cells are added or removed from the computational grid. This allows the grid to adapt to any change in bed 
morphology, however great that may be, by not having to re-mesh the entire domain and by avoiding any grid distortions if the change is significant. At the same time, velocities at the center of cells are readily available from the hydrodynamic model, which allows for easy computing of the shear velocity without the need for any interpolation, as would be the case in an immersed boundary method. Overall, with the hydrodynamic model being well-suited for large-scale flows and the scouring model being able to accommodate for changing bathymetry without significant computational cost, the combined model is well suited for scouring simulations in rivers.

\section{Ice Jam Release Scenario}

The 1984 ice jam in the St. Clair River was chosen as a case scenario. Simulations were first run under conditions where an ice jam was not present. The boundary conditions used were fixed stage elevations at the entrance and exit of the river, no slip at the banks and the law of the wall for the bed. The effect of wind-induced stresses was neglected. The entrance and exit of the river were constructed to be very wide in our grid, as can be seen in Figure 9, and the flow velocities at the cells forming the boundaries of the entrance and exit were set to zero. Weak boundary conditions were enforced at the entrance and exit to allow for mass flow, as dictated by the difference in stage elevations.

Figure 9. Grid used for our simulations.

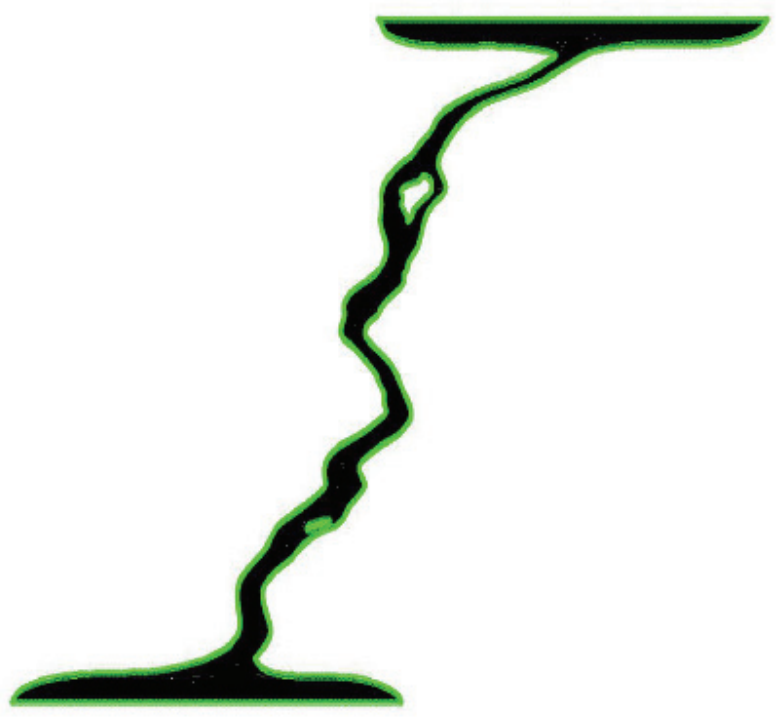

The bathymetry was determined from data obtained from NOAA, along with the sediment size distribution in the river [17]. The bathymetric data had a resolution of approximately $60 \mathrm{~m}$, which was comparable to the resolution of the grid(s) used. Varying the size of the sediment along the river bed allowed for variation in the bed drag coefficient. The stage elevation difference between 
the entrance of the St. Clair River and its estuary remains almost constant over the seasons and equal to approximately $1.4 \mathrm{~m}$. The seasonal variation in flow rates is due to the water level in the river. The bathymetric data obtained from NOAA were adjusted by adding approximately $15 \mathrm{~cm}$ uniformly to the depth of the river in order to achieve a flow rate of approximately $4800 \mathrm{~m}^{3} / \mathrm{sec}$, which is a reasonable estimate for the month of April. The flow rates obtained from NOAA were based on year-averaged values. Furthermore, it was found that varying the depth of the river in our model within the limits of measured average seasonal variations caused flow rates to vary within the range of reported seasonal values with a $95 \%$ approximate accuracy; this agreement added credibility to the hydrodynamic model, as well as the bed roughness values used, dependent on the sediment size distribution. Under average flow conditions, it was found that there are three regions of elevated stresses along the river, as can be seen in Figure 10.

Figure 10. Stress distribution (Shields stress values) in the St. Clair River under average flow conditions. There are three regions of elevated stresses on the bed (yellow and red colors).

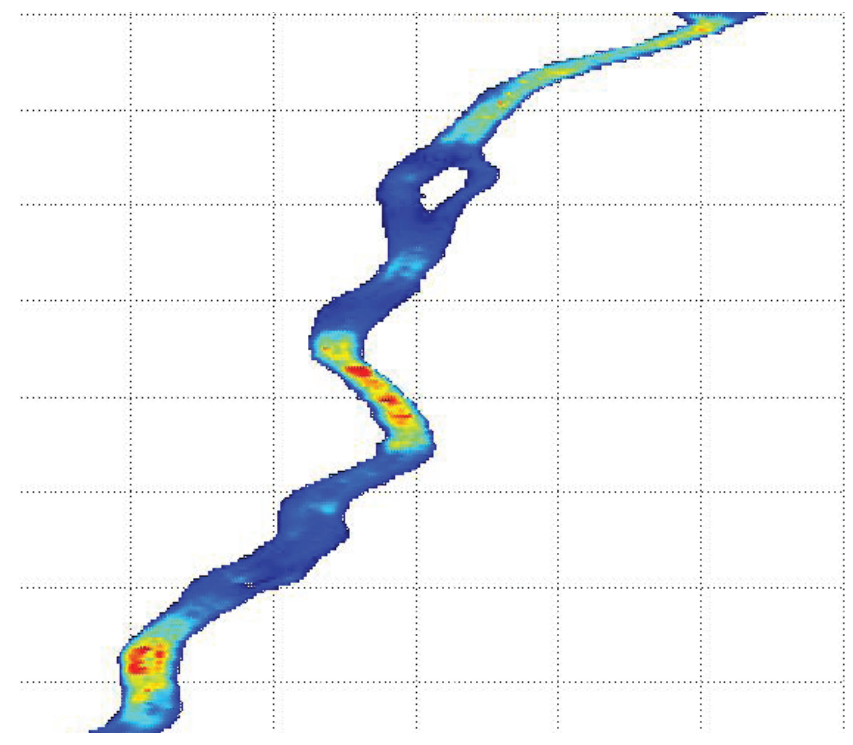

The ice jam was simulated by setting all fluxes to zero in the flow field region occupied by the jam. The size of the zero-flux region was adjusted so that flow conditions agree with the recorded values during the 1984 ice jam. In the final days of the jam, the water flow through the river was reduced by approximately $65 \%$ and the water level in Lake St. Clair dropped by approximately 0.6 $\mathrm{m}$. In our model, the stage elevation at the exit of the river was reduced by $0.6 \mathrm{~m}$ and the size and the thickness of the jam was adjusted so that the flow rate become approximately $1700 \mathrm{~m}^{3} / \mathrm{s}$. The adjusted ice jam configuration and the resulting flow rate served as an initial condition for the ice jam release simulation. The ice jam in our model, in its final form, had a head thickness of $2 \mathrm{~m}$ and gradually thickened to reach a thickness of $4 \mathrm{~m}$ at its toe, which is a shape similar to that of an actual ice jam. Detailed information on the shape of the 1984 ice jam is lacking. The length of the 
ice jam was in accordance to field observations of the 1984 ice jam [3]. In its final days, the ice jam covered about a third of the river, its upstream end starting a little below St. Clair and its downstream end reaching Algonac. A drag law was imposed on the under side of the ice jam, to account for friction between the flow and the ice. A friction coefficient in accordance with published data was chosen [18]. It was found that the stresses on the bed under the still ice jam were lower than those when an ice jam was not present. This is in disagreement with the assertion that scouring would happen under the toe of the fully developed ice jam.

The ice jam was released by removing the zero-flux condition. Figure 11 shows the stress evolution on the river bed following the release.

Figure 11. Evolution of stresses on the river bed following the release of a jam.

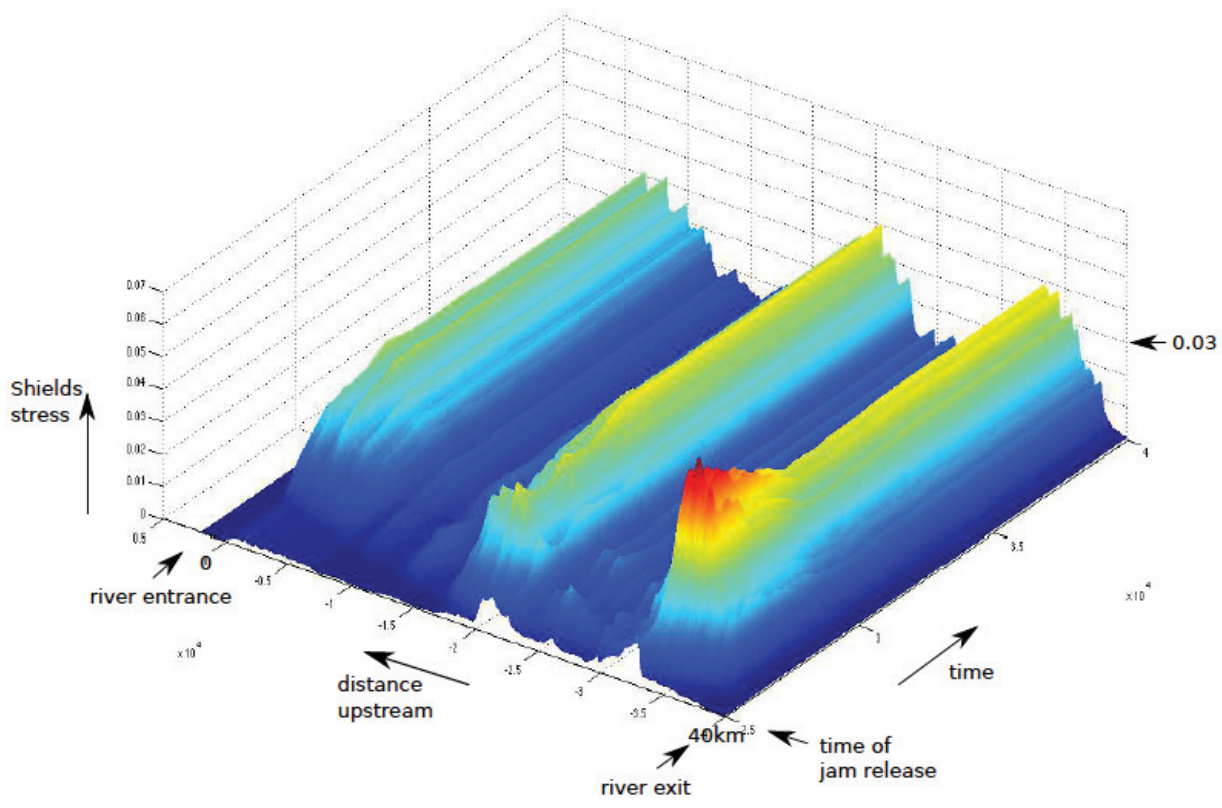

It can be seen from the figure that the stresses in three regions are particularly high. These are the regions that experience high stresses when an ice jam is absent, according to the model. A critical Shields stress value of 0.03 was chosen. The critical Shields stress value varies depending on the kind of sediment that comprises the surface layer of the bed. For a bed with a uniform grain size, the nominal value of 0.047 is given [19,20]. However, based on experimental studies and field observations of bedload transport in rivers, for beds with mixed grain composition, a value of 0.03 is more accurate [21-23]. The critical Shields stress was adjusted for the local angle of inclination at each computational cell. It was found that critical stress values were exceeded in the three regions of elevated stresses on the river bed, with ensuing scouring. Most scouring occurred near the exit of the river. Figure 12 depicts the depth change caused by scouring during the first $1.4 \mathrm{~h}$ following the release. 
Figure 12. The change in depth along the river caused by scouring.

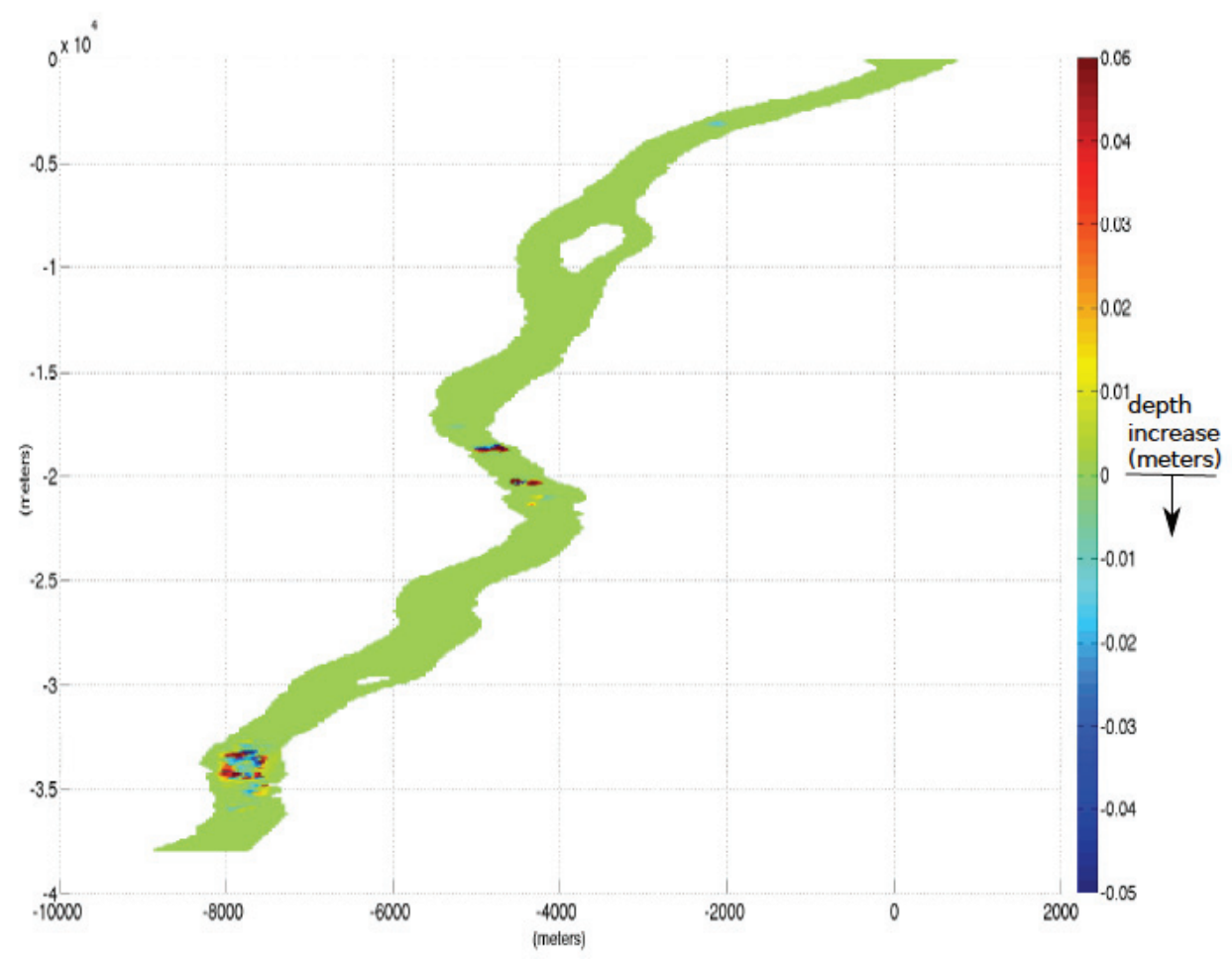

The net amount of sediment displaced during that period was approximately 10,000 cubic meters. Most of the scouring occurred near the estuary in Lake St. Clair, at the exit of the river. It is concluded that in the case of an ice jam similar to the one in 1984, scouring is highly probable following the release of the ice jam. While our results do not constitute proof that scouring of such an extent will happen, they provide a strong indication. The results are based on a particular hydrodynamic model and a particular turbulence model; other hydrodynamic and turbulence models should be implemented before drawing final conclusions. Three different grids were used as part of grid refinement studies: One with approximately 600,000 cells, one with approximately one million cells and the most refined, which had approximately two million cells. The three grids had a horizontal spacing of approximately 55, 45 and $35 \mathrm{~m}$, respectively, while the vertical grid spacing ranged from $1 \mathrm{~m}$ to $75 \mathrm{~cm}$. The results in terms of scouring were similar for all three grids.

\section{Conclusions}

A bed scouring model was developed and incorporated in a hydrodynamic model that implements a z-coordinate grid with step-like approximation of the river bed. An algorithm that expands or contracts the grid to follow changes in bed morphology without the need for re-meshing the entire grid was also developed. Ice jams were modeled by creating a rigid body of water in the flow field 
by ignoring the fluxes in the cells that comprise the region of the ice jam. The release was simulated by removing the zero-flux condition and releasing the initially stationary body of water into the flow field. The 1984 ice jam in the St. Clair River was simulated by adopting flow and boundary conditions that replicate the conditions during the jam. It was found that in the scenario of a jam like the one in 1984, scouring occurs that amounts to significant net amounts of displaced sediment, especially near the river exit. The effect of such a change in bed morphology on the river's conveyance needs to be ascertained, and the sensitivity of the system to changes in depth in the locations affected by the ice jam release remains a subject of future research. The present model provides a framework for the prediction of extreme events in the Huron-Erie Corridor and for designing mitigation measures.

\section{Acknowledgments}

The authors are grateful to Oliver Fringer for providing SUNTANS and for his guidance during this study. The authors also express their thanks to Krzysztof Fidkowski for his insightful advice on technical matters.

\section{Conflicts of Interest}

The authors declare no conflict of interest.

\section{References}

1. Great Lakes Information Network. Available online: http://www.great-lakes.net (accessed on 30 September 2013).

2. International Joint Commission. Impacts on Upper Great Lakes Water Levels: St. Clair River; International Upper Great Lakes Study: Ottawa, ON, Canada, 2009.

3. Derecki, J.A.; Quinn, F.H. Record St. Clair River ice jam of 1984. J. Hydraul. Eng. 1986, 112, 1182-1194.

4. Fringer, O.B.; Gerritsen, M.; Street, R.L. An unstructured-grid, finite-volume, nonhydrostatic, parallel coastal ocean simulator. J. Ocean. Model. 2006, 14, 139-173.

5. Liu, L.W.; Shen, H.T. Dynamics of ice jam release surges. In Proceedings of the 17th International Symposium on Ice, St. Petersburg, Russia, 21-25 June 2004.

6. She, Y.; Hicks, F. Incorporating ice effects in ice jam release surge models. In Proceedings of the 13th Workshop on the Hydraulics of Ice Covered Rivers, Hanover, ON, Canada, 15-16 September 2005.

7. Hicks, F.; Steffler, P.M. Characteristic dissipative Galerkin scheme for open channel flow. J. Hydraul. Eng. 1992, 118, 337-352.

8. Khosronejad, A.; Seokkoo, K.; Borazjani, I.; Sotiropoulos, F. Curvilinear immersed boundary method for simulating coupled flow and bed morphodynamic interactions due to sediment transport phenomena. Adv. Water Resour. 2011, 34, 829-843. 
9. Nagata, N.; Hosoda, T.; Nakato, T.; Muramoto, Y. Three-dimensional numerical model for flow and bed deformation around river hydraulic structures. J. Hydraul. Eng. 2005, 131, 1074-1087.

10. Roulund, A.; Sumer, B.M.; Fredsoe, J.; Michelsen, J. Numerical and experimental investigation of flow and scour around a circular pile. J. Fluid Mech. 2005, 534, 351-401.

11. Khosronejad, A.; Rennie, C.D.; Salehi, S.A.A.; Townsend, R.D. 3D numerical modeling of flow and sediment transport in laboratory channel bends. J. Hydraul. Eng. 2007, 133, 1123-1134.

12. Liu, X.; Garcia, H.M. Three-dimensional numerical model with free water surface and mesh deformation for local sediment scour. J. Waterw. Port Coast. Ocean Eng. 2008, 134, 203-217.

13. Apsley, D.D.; Stansby, P. Bed-load sediment transport on large slopes: Model formulation and implementation within a RANS solver. J. Hydraul. Eng. 2008, 134, 1440-1451.

14. Haws, B.B. Ability of ADV Measurements to Detect Turbulence Differences Between Angular and Rounded Gravel Beds of Intermediate-Roughness Scale. Master's Thesis; Brigham Young University, Provo, UT, USA, 2008.

15. Raudviki, A.J. Loose Boundary Hydraulics; Balkema: Rotterdam, The Netherlands, 1998.

16. Manolidis, M. Modeling the Release of River Ice Jams and their Impact on River Bed Scouring. Ph.D. Thesis; University of Michigan-Ann Arbor, Ann Arbor, MI, USA, 2013.

17. Krishnappan, B.G. Sediment transport regime of St. Clair River. In Sediment Studies in St. Clair River; International Upper Great Lakes Study Board of the International Joint Commission: Ottawa, ON, Canada, 2009.

18. Attar, S.; Li, S.S. Momentum, Energy and Drag Coefficients for Ice-Covered Rivers. River Res. Appl. 2012, doi:10.1002/rra.2611.

19. Meyer-Peter, E.; Muller, R. Formulation for Bed Load Transport. In Proceedings of the 2nd Congress, International Association of Hydraulic Research, Stockholm, Sweden, 7-9 June 1948.

20. Einstein, H.A. The Bed Load Function for Sediment Transportation in Open Channel Flows; Technical Bulletin of U.S. Department of Agriculture: Washington, DC, USA, 1950.

21. Parker, G. Surface-Based Bedload Transport Relation for Gravel Rivers. J. Hydraul. Res. 1990, 28, 417-436.

22. Duan, J.G.; Scott, S. Selective Bed Load Transport in Las Vegas Wash, a Gravel-Bed Stream. J. Hydrol. 2007, 342, 320-330.

23. Wilcock, P.R.; Kenworthy, S.T.; Crowe, J.C. Experimental Study of the Transport of Mixed Sand and Gravel. Water Resour. Res. 2001, 37, 3349-3358. 


\title{
Exploring Localized Mixing Dynamics during Wet Weather in a Tidal Fresh Water System
}

\section{Ramona Stammermann and Philip Duzinski}

\begin{abstract}
A recently validated 3-dimensional implementation of the Environmental Fluid Dynamic Code (EFDC) for the tidal-fresh portions of the Delaware Estuary was exercised against the results of a dye release from a sewer outfall during a storm. The influence on dye distribution in the estuary resulting from variations in wind and local storm water discharges in an urban area is investigated. The modeled domain stretches $116 \mathrm{~km}$ from the head of tide and includes hydrologic input from 33 streams and a number of municipal and industrial discharges. Bottom roughness was parameterized from sedimentological and geophysical surveys. Model validation to-date relies upon field observations and tidal harmonics for sea level and currents derived from the NOAANOS 1984-1985 circulation survey and a current survey conducted by the Philadelphia Water Department (PWD). Model representation of dye distribution compared favorably for observations of concentrations in the dye plume from 10 cross-sections spanning the extent of the plume over seven tidal cycles. The dye distribution was characterized by an initial period of high local storm water and stream inflows with low wind conditions, lasting for several tidal cycles, followed by a period of reduced fresh water input and increasing wind stress. The dye experiment provided a unique opportunity to observe the performance of the model through the transition between these two very different meteorological periods, and to explore the physical conditions driving the hydrodynamics through both observations and numerical experiments. The influences of local meteorological forcing and channel morphology on lateral mixing, dispersion and longitudinal dynamics are characterized.
\end{abstract}

Reprinted from J. Mar. Sci. Eng. Cite as: Stammermann, R.; Duzinski, P. Exploring Localized Mixing Dynamics during Wet Weather in a Tidal Fresh Water System. J. Mar. Sci. Eng. 2014, 2, 386-399.

\section{Introduction}

During the City of Philadelphia's development in the 19th and 20th centuries, a combined sewer system was built, which conveys stormwater runoff and sewage together in the same pipe network [1]. Today about $60 \%$ of the City's sewered area is still served by combined sewers, especially in the older sections of the city. The remaining $40 \%$ is served by separate sewers for sewage and stormwater respectively [2]. High intensity rainfall within the City causes the combined sewers to reach their maximum capacity, and a mixture of stormwater and untreated sewage is released into rivers and tributaries.

The City of Philadelphia is regulated by the Pennsylvania Department of Environmental Protection for discharges from combined sewer overflows and storm water outfalls to the Delaware and Schuylkill Rivers. The Philadelphia Water Department (PWD) is developing a water quality model 
of the tidal Delaware and Schuylkill Rivers to quantify the effects of City of Philadelphia discharges on these waterbodies and meet regulatory requirements.

For this purpose a 3-dimensional hydrodynamic numerical model was developed using the Environmental Fluid Dynamics Code (EFDC) [3]. It was hydrodynamically validated against observations from the 1984 NOAA-NOS circulation survey and contemporary ongoing long term current surveys conducted by the PWD that started in August 2012. The following study shows a first attempt on assessing the model's transport capabilities by exercising it against a dye study conducted by Ocean Surveys, Inc. (OSI) for the Delaware River Basin Commission (DRBC) [4].

\section{Methods}

\subsection{Study Area}

The Delaware Estuary is located on the East Coast of the United States between Washington, D.C. and New York, NY, USA (Figure 1). The estuary spans $215 \mathrm{~km}$ from its mouth between Cape May, NJ, USA and Lewes, DE, USA to the head of tide at Trenton, NJ, USA. The City of Philadelphia is situated at River 147-180 km. The model domain includes the Delaware River section from 99 to $215 \mathrm{~km}$ and the tidal Schuylkill River. The model area begins north of the Chesapeake and Delaware Canal confluence, where a tidal gauge at Delaware City, DE, USA provides observed water levels for model forcing. The turbidity maximum zone of the Delaware Estuary reaches from 50 to $120 \mathrm{~km}$. With the mean salt intrusion reaching $97 \mathrm{~km}$, the model domain is generally considered to be tidal fresh water. Significant levels of salinity are only reached within the model domain during severe drought conditions when upstream river discharges are low.

Within the City of Philadelphia, there are $4800 \mathrm{~km}$ of sewer pipe, 455 storm water outfalls and 164 combined sewer outfalls (CSO). Most outfalls discharge directly into the Delaware and Schuylkill Rivers. Some are located along smaller non-tidal tributaries in the city area, the Cobbs, Frankford and Pennypack Creeks, which are connected as boundary conditions to the tidal model.

\subsection{CSO Mixing Zone Study}

The aim of the mixing zone study was to characterize a CSO discharge during a wet weather event, to identify initial dilution and mixing, and to determine the far-field impact of CSOs [4]. The study was conducted by OSI on behalf of DRBC and HydroQual, Inc. (HQI) during the period of 21-25 November 1997. Rhodamine WT dye was injected over a period of $3.5 \mathrm{~h}$ into a trunk sewer upstream of CSO D-39 shortly after midnight on 22 November 1997, while the CSO was actively overflowing due to a 1.1 inch storm in the region. Dye tracer concentrations were recorded during six plume mappings on the following days that coincided with either high or low slack tides (Figure 2). Contour lines of the plume during each mapping were determined by interpolation of the measured track lines.

Mappings of the observed dye data showing the interpolated dye plume projections were created by OSI. The dye concentration quickly declined with the beginning of a strong local wind event that led to a setdown of the mean sea level as can be seen in Figure 2 during 24 November 1997. 
Figure 1. Overview over Delaware River Estuary.

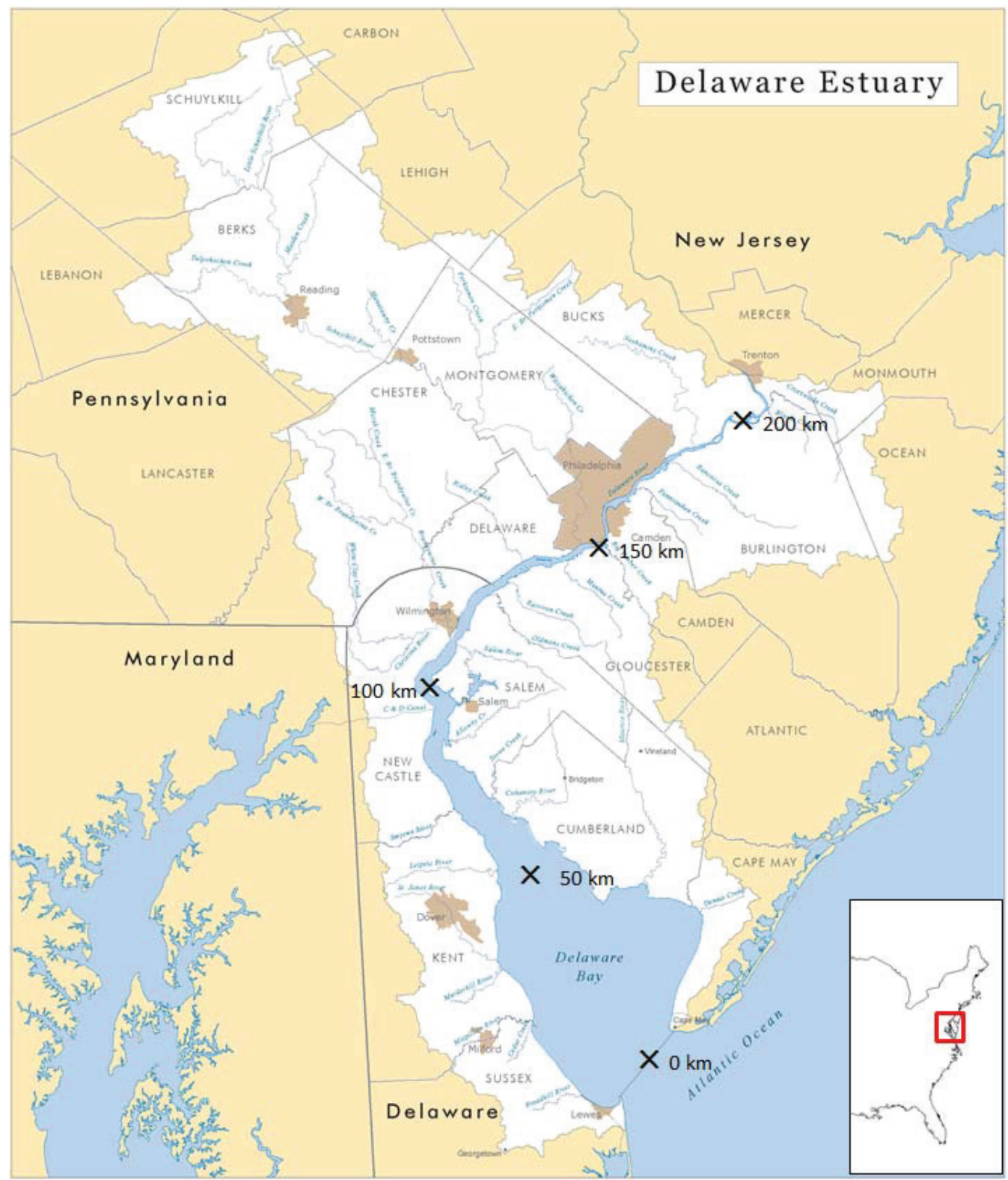


Figure 2. Wind conditions and time table of dye injection and mapping events (shaded areas).

Local wind stress

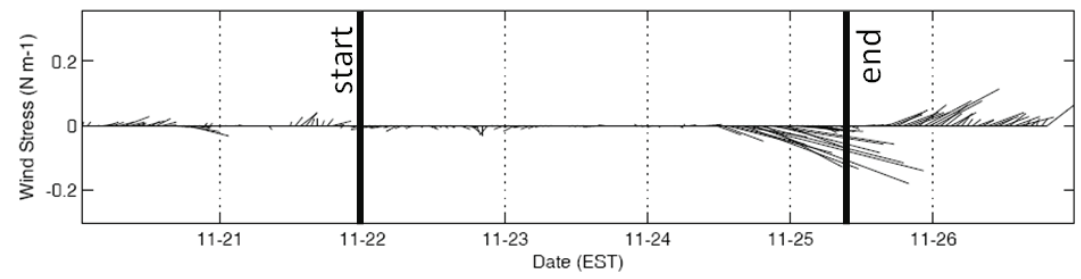

Remote wind stress

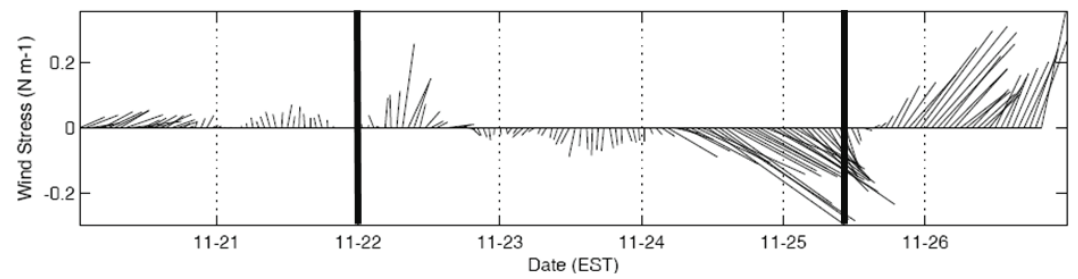

Philadelphia Water Level and Mapping events

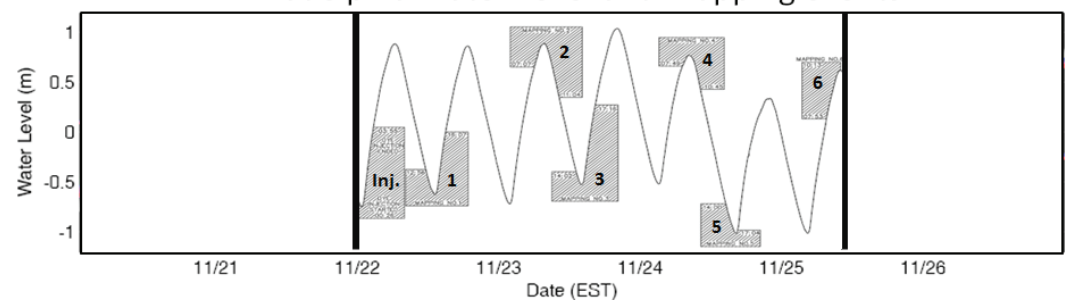

\subsection{Model Setup}

The EFDC model used for this study was developed at the Virginia Institute of Marine Science and has been applied for a wide range of environmental studies. The EFDC model solves the 3dimensional, vertically hydrostatic, free surface, turbulent averaged equations of motion using stretched or sigma vertical coordinates and Cartesian or curvilinear, orthogonal horizontal coordinates. It solves the equations using a combination of finite volume and finite difference techniques, and allows for wetting and drying in shallow areas. Dynamically coupled transport equations for turbulent kinetic energy, turbulent length scale, salinity and temperature are also solved. Additionally, an arbitrary number of Eulerian transport-transformation equations for dissolved and suspended materials can be solved simultaneously [3,5].

The model and the dye study were used to characterize the hydrodynamics of the tidal Delaware River and the impact of stormwater and CSO discharges. A strong wind event at the end of the dye study period appeared to have considerable influence on the rate of dilution. Three model scenarios were performed to analyze the impact of wind on dye transport in the model:

(i) tidal only: forcing with predicted water level at the open boundary, no wind field;

(ii) no wind: forcing with observed water level at the open boundary, no wind field;

(iii) wind: forcing with observed water level at the open boundary and wind field inside the model domain. 


\subsubsection{Model Grid}

The model grid was generated using RGFgrid from the Delft3D software package [6] (Figure 3). The domain spans $116 \mathrm{~km}$ of the tidal Delaware River from the downstream water level open boundary at Delaware City, DE, USA to the head of tide at Trenton, NJ, USA. The tidal extents of the Schuylkill River and three tributaries (Cobbs Creek, Frankford Creek, Pennypack Creek) that receive City of Philadelphia CSO discharges are represented in the model. The grid contains 9746 elements with lengths ranging from $17 \mathrm{~m}$ in the lateral direction in small tributaries to $650 \mathrm{~m}$ longitudinally in the Delaware River, and has five vertical sigma layers that follow the bottom geometry.

Figure 3. Model domain and grid.

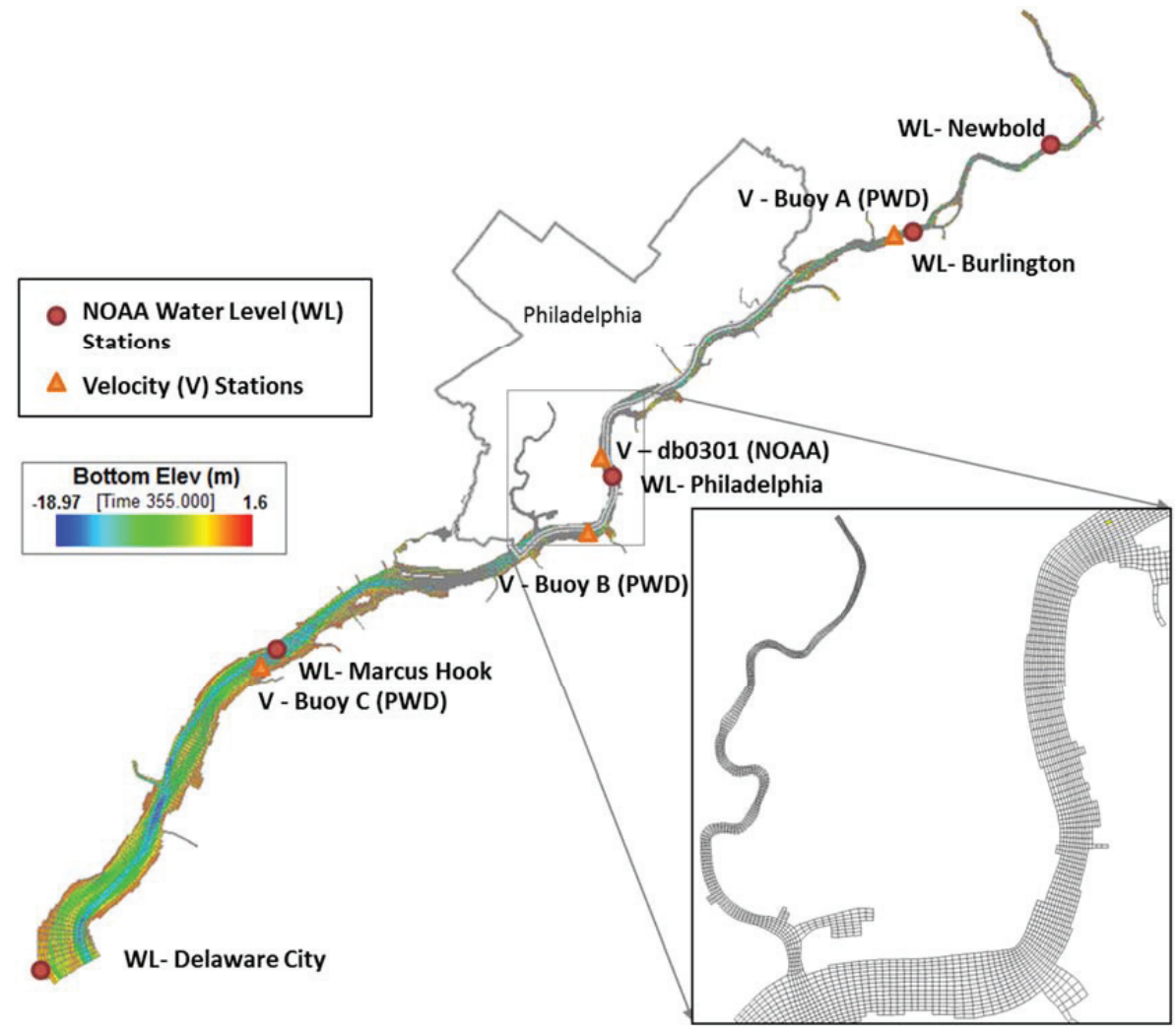

\subsubsection{Initial and Boundary Conditions}

\subsubsection{Model Validation}

Initial model calibration and validation were performed using data from the NOAA-NOS 1984-1985 circulation survey [7]. An "astronomical tides only" scenario was used to assess the model's capability of accurately representing the tidal dynamics. The model was further calibrated using observed data from 1984 to 2012 for model forcing and comparison. Roughness calibration was performed based on information from a sedimentological survey of the upper Delaware 
Estuary [8], leading to local roughness parameters ranging from $0.001 \mathrm{~m}$ in the downstream section of the model to $0.015 \mathrm{~m}$ in the coarser upstream section.

\section{NOAA/NOS Survey 1984}

The National Oceanic and Atmospheric Administration and National Ocean Service (NOAA/NOS) conducted a Delaware Bay and River circulation survey in 1984/1985. Stations within the model domain upstream of the Chesapeake and Delaware Canal were used for this study. The majority of measurements were conducted from February through April 1984. Five water level stations and seven current stations were available for model forcing, as reference, and to develop tidal constituents. In the tidal-only scenario the downstream open boundary was forced using the predicted water level for Delaware City based on 37 tidal constituents from contemporary water level data. The flow boundaries were forced using annual mean discharge from 23 USGS river gauges.

No observed water level was available for Delaware City in 1984 to force the hindcast scenario, thus the water level time series from the nearby Reedy Point station was shifted in phase to match the timing at Delaware City. Observed discharge from 23 USGS stations provided data for the flow boundaries. The bathymetry used for grid generation was assembled from individual sounding datasets downloaded from the NOAA National Geophysical Data Center, Digital Elevation Model Discovery Portal [9] and converted to NAVD88 using VDATUM [10]. Additional soundings of smaller tributaries of interest were conducted by PWD and integrated into the bathymetry data set.

\section{PWD Long Term Current Survey 2012/13}

In May 2012 PWD installed three buoy mounted ADCPs within the model domain to collect long term current measurements for additional model calibration and validation. The NOAA Physical Oceanographic Real-time System (PORTS) for the Delaware Bay provided current data at a station near Philadelphia (db0301) and water levels at five stations within the domain [11] (Figure 3). Observed water level data for Delaware City and discharge data from all gauged tributaries along the model domain were used to force the open boundaries. An area ratio based approach was used to estimate discharge for ungauged tributaries and for run off areas downstream of USGS gauges and along the Delaware River. Wind forcing data were generated from measurements at five stations within the domain obtained from the National Climatic Data Center [12].

\subsubsection{Dye Study 1997}

The dye study was conducted in November 1997. Observed water levels were available for stations at Reedy Point and Philadelphia at this time. Reedy Point water level data was shifted in phase to be used as open boundary forcing and the Philadelphia water level data was compared to model results for validation. Observed discharge from USGS gauges were used as available and discharge for ungauged tributaries and runoff areas were estimated using an area ratio based approach. Since the dye study's main goal was to observe a wet weather event, all Philadelphia CSO inputs were included in the model forcing. The PWD Hydrologic and Hydraulic (H\&H) modeling group maintains a validated Stormwater Management Model (SWMM) of each of 
Philadelphia's three wastewater plant drainage districts. The SWMM model utilizes precipitation data, geospatial data of the land cover of the contributing service area, and numeric representation of the combined sewer system to simulate CSO flows. A range of flow estimates for each of the City's 164 CSO regulators and reported flows from the three wastewater treatment plants were provided for the dye study simulation exercise.

For the study, dye was injected into the sewer line $180 \mathrm{~m}$ back from the end of pipe. An average dye concentration of 236 parts-per-billion ( $\mathrm{ppb}$ ) was measured downstream of the injection point at the end of the pipe. The dye was injected upstream of a regulator that directs flow to a treatment plant during dry weather and allows for overflows into the river during storms. Thus, a considerable amount of dye was likely redirected to the plant and did not reach the outflow where the concentration was measured. The reported discharge was back calculated based on the measured concentration and the total amount of dye injected. Application of the reported discharge resulted in overprediction of dye concentrations in the river. As an alternative, the modeled CSO discharge for this sewer line was used, which resulted in good agreement with observed dye concentrations in the river. Wind fields were generated from observed data of three NCDC stations within the model domain.

\section{Results and Discussion}

\subsection{Model Validation}

For the astronomic tidal-only simulation in February through April 1984, water level results at Philadelphia showed good agreement with predicted time series as shown in Table 1 below. Amplitude errors range from 0 to $6 \mathrm{~cm}$ for water level. A slight shift in phase exists compared to observed data, which explains higher values for the RMSE. The RMSE and Skill by Willmott [13] are $12 \mathrm{~cm}$ and 0.98 , respectively. Results for all water level stations range from 9 to $15 \mathrm{~cm}$ for RMSE and 0.98 to 0.99 for Skill.

Table 1. Tidal-only harmonic constituents: predicted vs. model for water level and major velocity at Philadelphia NOAA stations 8545530 and C51.

\begin{tabular}{cccccccccccccc}
\hline \multicolumn{4}{c}{ Water Level-Amplitude (m) Phase (h) } & \multicolumn{4}{c}{ Major Velocity-Amplitude (m/s) Phase (h) } \\
\hline Tidal & Amp & Amp & Amp & Phase & Phase & Phase & Amp & Amp & Amp & Phase & Phase & Phase \\
Const & Pred & Mod & Err & Pred & Mod & Err & Pred & Mod & Err & Pred & Mod & Err \\
\hline M2 & 0.86 & 0.86 & 0.00 & 6.42 & 6.47 & 0.05 & 0.94 & 0.86 & -0.07 & 4.14 & 3.91 & -0.23 \\
S2 & 0.10 & 0.12 & 0.02 & 7.56 & 8.07 & 0.51 & 0.07 & 0.12 & 0.05 & 5.33 & 5.67 & 0.33 \\
N2 & 0.15 & 0.19 & 0.04 & 5.99 & 5.90 & -0.09 & 0.11 & 0.18 & 0.07 & 3.48 & 3.28 & -0.19 \\
K1 & 0.11 & 0.06 & -0.06 & 18.70 & 19.34 & 0.65 & 0.07 & 0.03 & -0.05 & 13.22 & 13.68 & 0.46 \\
M4 & 0.09 & 0.07 & -0.02 & 4.57 & 4.71 & 0.14 & 0.15 & 0.13 & -0.02 & 4.11 & 4.07 & -0.03 \\
O1 & 0.09 & 0.07 & -0.02 & 18.86 & 18.52 & -0.34 & 0.05 & 0.03 & -0.01 & 13.86 & 12.44 & -1.41 \\
M6 & 0.06 & 0.05 & -0.01 & 2.88 & 2.80 & -0.08 & 0.10 & 0.08 & -0.02 & 2.52 & 2.33 & -0.19 \\
\hline
\end{tabular}

Velocity results also showed good agreement with predicted time series at Philadelphia station C51 from the NOS Delaware River and Bay Circulation Survey. Velocity data were measured 
$8.5 \mathrm{~m}$ above bottom corresponding to model results from the second layer below surface. Amplitude errors ranged from 1 to $7 \mathrm{~cm} / \mathrm{s}$ as shown in Table 1 . The RMSE and Skill are $11 \mathrm{~cm} / \mathrm{s}$ and 0.98 respectively. Results for currents range from 7 to $17 \mathrm{~cm} / \mathrm{s}$ for RMSE and 0.42 to 0.98 for Skill at all stations.

For the hindcast simulation in August through September 2012, water level results showed good agreement with predicted time series with amplitude errors smaller than $3 \mathrm{~cm}$ as shown in Table 2 below. The RMSE and Skill are $7.7 \mathrm{~cm}$ and 0.99 .

Velocity results also showed good agreement with predicted time series as shown in Table 2 below. Amplitude errors range from 0 to $7 \mathrm{~cm} / \mathrm{s}$. The RMSE and Skill are $8.5 \mathrm{~cm} / \mathrm{s}$ and 0.98 .

Table 2. Hindcast harmonic constituents, August-September 2012: observed vs. model for water level and major velocity at Philadelphia NOAA stations 8545240 and PWD Buoy B, layer 4.

\begin{tabular}{cccccccccccccc}
\hline \multicolumn{4}{c}{ Water Level-Amplitude (m) Phase (h) } & \multicolumn{4}{c}{ Major Velocity-Amplitude (m/s) Phase (h) } \\
\hline Tidal & Amp & Amp & Amp & Phase & Phase & Phase & Amp & Amp & Amp & Phase & Phase & Phase \\
Const & Pred & Mod & Err & Pred & Mod & Err & Pred & Mod & Err & Pred & Mod & Err \\
\hline M2 & 0.84 & 0.87 & 0.03 & 1.41 & 1.27 & -0.14 & 0.64 & 0.58 & 0.07 & 11.13 & 11.10 & 0.04 \\
S2 & 0.09 & 0.11 & 0.02 & 2.52 & 2.49 & -0.03 & 0.09 & 0.08 & 0.01 & 0.20 & 0.13 & 0.07 \\
N2 & 0.15 & 0.12 & -0.02 & 0.93 & 1.52 & 0.59 & 0.09 & 0.08 & 0.01 & 11.69 & 11.63 & 0.05 \\
K1 & 0.10 & 0.10 & 0.00 & 13.86 & 14.11 & 0.26 & 0.05 & 0.03 & 0.02 & 9.33 & 8.21 & 1.12 \\
M4 & 0.08 & 0.09 & 0.01 & 5.63 & 5.78 & 0.15 & 0.07 & 0.08 & -0.01 & 5.41 & 5.06 & 0.36 \\
O1 & 0.08 & 0.11 & 0.03 & 13.91 & 13.04 & -0.87 & 0.04 & 0.03 & 0.01 & 5.60 & 6.79 & -1.19 \\
M6 & 0.05 & 0.04 & -0.01 & 2.00 & 1.82 & -0.18 & 0.06 & 0.06 & 0.00 & 3.33 & 1.17 & 2.15 \\
\hline
\end{tabular}

\subsection{Dye Study 1997}

Dye simulation results were compared to in-situ fluoroscopy observations that were converted to ppb by weight. The most fully-developed plume is represented by Mapping 3, which is comprised of survey observations interpolated over the $3.5 \mathrm{~h}$ of Day 2, low-slack tide (Figure 4). Figure 5 below shows contour plot visualizations of simulated dye results for the corresponding Mapping 3time, which successfully characterized the observed plume. The extent of the $0.01 \mathrm{ppb}$ contour line, thus the total detectable plume, matched the observed extent very well.

Transect plots of the dye results are shown in Figure 6 in which generally good agreement with observed concentrations are shown. Less dye was transported in the downstream extent of the plume in the model simulation than was measured in the survey as seen at profile P2, but this result is within an acceptable range.

A strong wind co-aligned with the Delaware Bay longitudinal axis led to a setdown throughout the estuary, which is visible at the Philadelphia NOAA water level station as a drop in mean water level of approximately $0.6 \mathrm{~m}$. This resulted in a barotropic emptying of the upper estuary that transported much of the dye mass out of the domain of the original study. The model response to this setdown showed good agreement by matching the outflow of volume as seen in a plot of the subtidal water level at Philadelphia (see Figure 7). 
Figure 4. Mapping 3 contour plot of low-slack, Day 2 survey results. Inset shows location of dye-injection point. Model results of profiles P2, P3, P4 and P5 are shown in Figure 6.

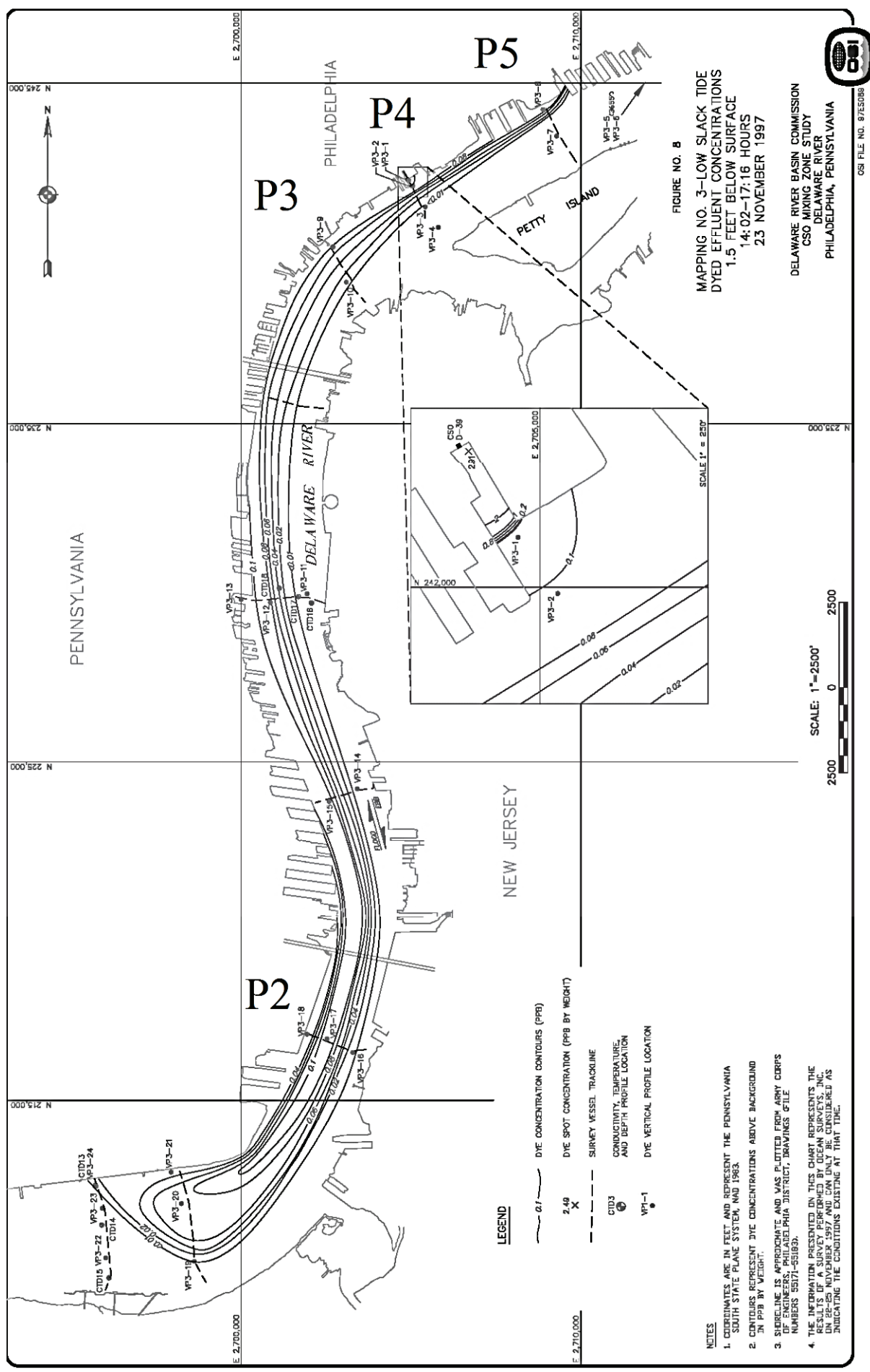


Figure 5. Contour plots of simulated dye injection, at time of Mapping 3. Axes in kilometer, dye in ppb, and time in Julian days.
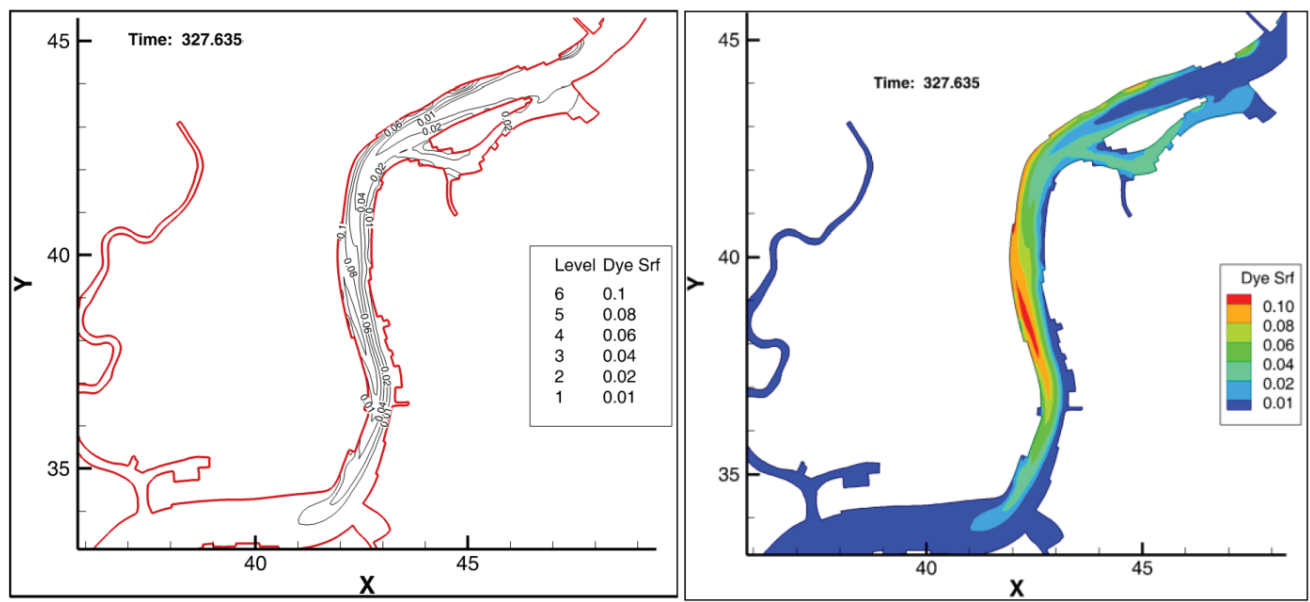

Figure 6. Model results vs. observed concentrations for profiles P2, P3, P4 and P5.
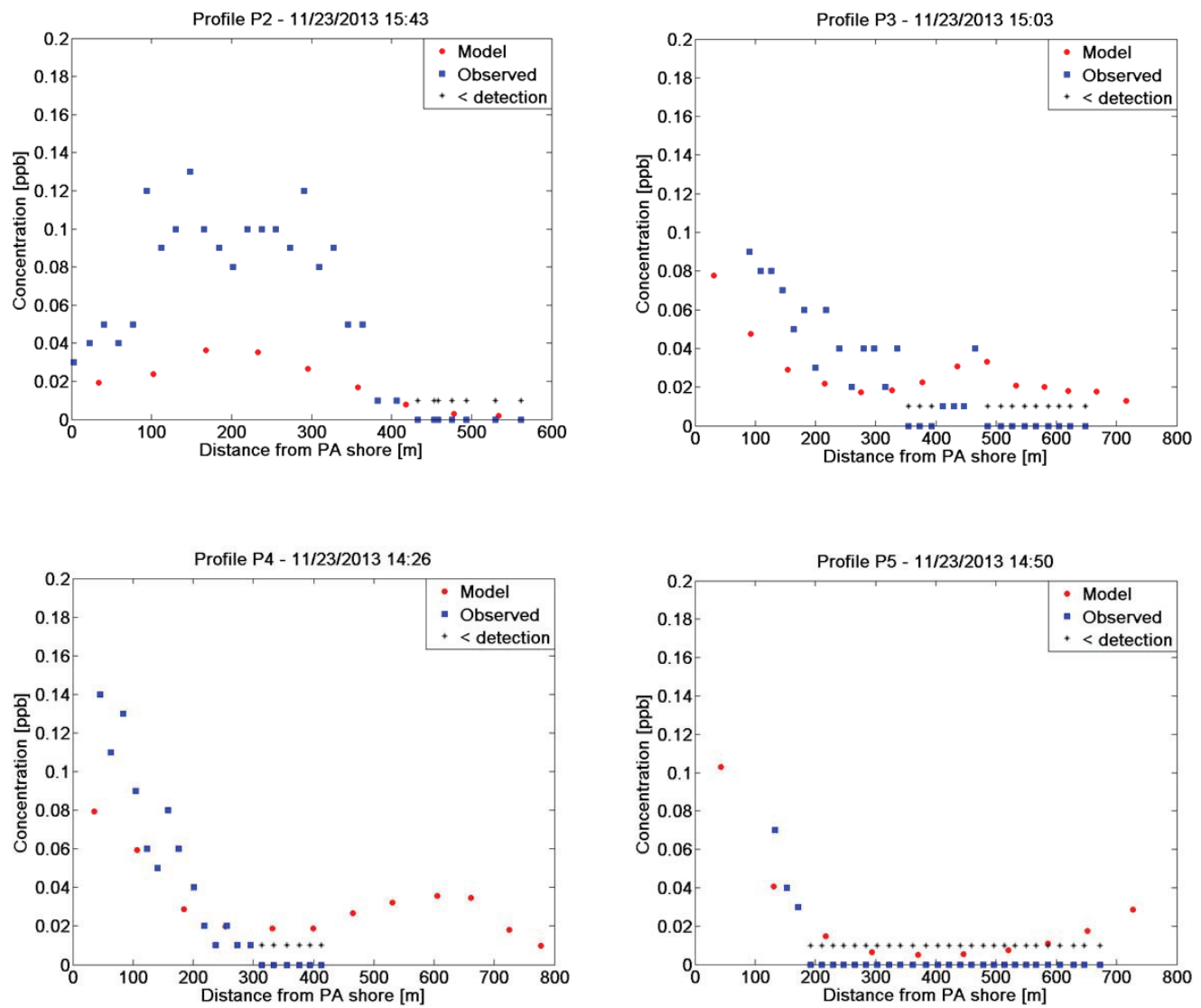
Figure 7. Water level and subtidal water level scenarios: (1) tidal-only boundary forcing with no local wind (solid gray); (2) observed boundary forcing with no local wind (red); and (3) observed boundary forcing with local wind (blue).

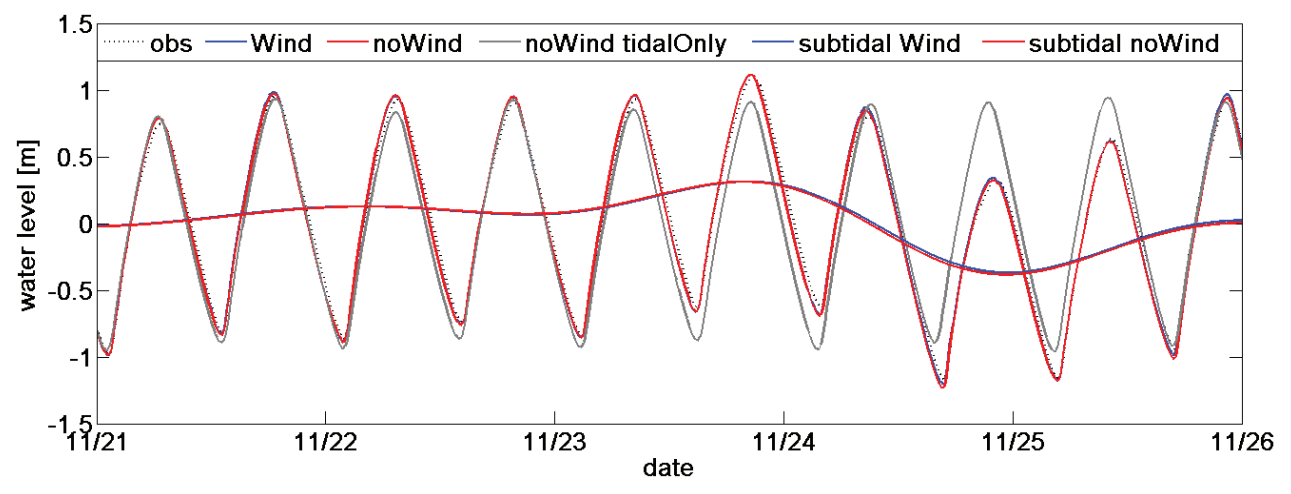

To demonstrate the impact of meteorological forcing on dye transport, three scenarios were simulated: (1) tidal-only boundary forcing comprised of harmonic constituents from the NOAA Delaware City station with no local wind; (2) observed water level that contained the down-bay setdown as a subtidal signal was applied at the lower model open boundary without a local wind field; and (3) the same observed boundary forcing was applied but along with a composite local wind field.

Comparison of the water level and subtidal plots between Scenarios 2 and 3 demonstrated the dominance of the down-bay subtidal set-down in both cases, but show only a very small impact on water levels from local wind within the model domain (Figure 7). This influence of along-estuary wind stress on subtidal fluctuations in the Delaware Estuary is consistent with the findings of Janzen and Wong [14].

Figure 8. Model dye results vs. observed: Scenario 1 and Scenario 3 showing impact of barotropic setdown on dye transport.
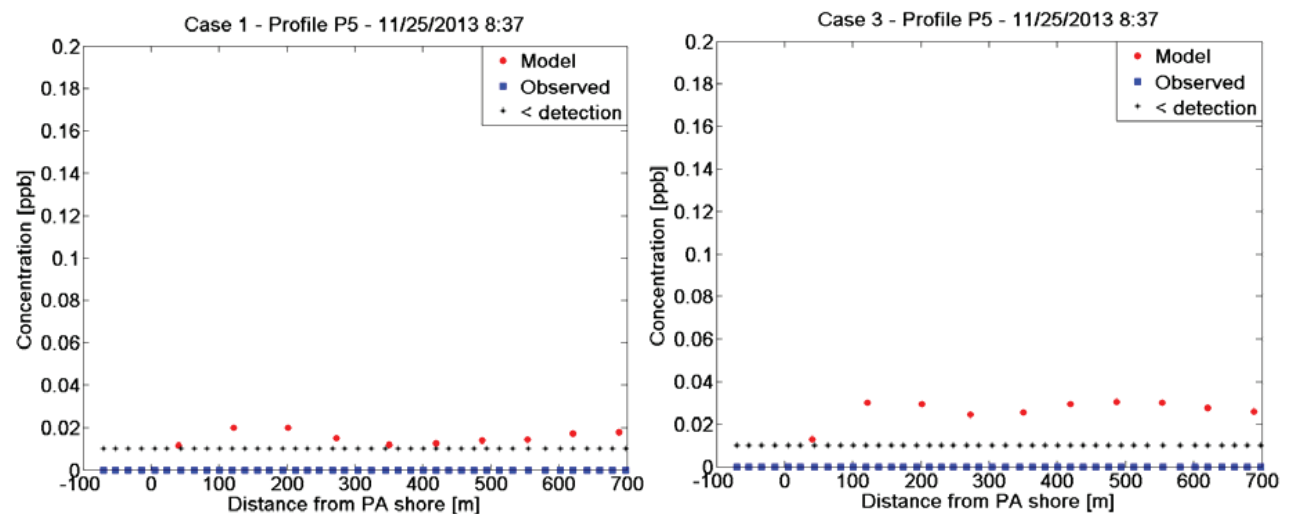

Comparison of observed and simulated dye concentrations in Scenario 3 during the setdown event also showed good agreement (see Figure 8). Results from Scenario 1 with tidal-only boundary 
forcing shows the range of error that would be experienced without simulating the effects of the estuarine setdown.

The influence of bathymetry on dye distribution can be seen in the extent of the plume. The mixing length, the length after which full lateral mixing can be expected in a channel, was previously estimated to be on the same order of magnitude as the tidal excursion in this area [15]. Thus, full lateral mixing could be expected within the first day of the dye study. Instead, the plume largely moved along the Pennsylvania shoreline, with its center of mass following the navigation channel (Figure 5). In areas where the navigation channel shifted between shores (Figure 9) or where the entire river cross section was deeper (Figure 10) the plume followed as well, further confirming bathymetrical steering induced by the presence of the navigation channel.

Figure 9. Modeled plume extent with shifting navigation channel. Bed elevation in meters, dye in ppb.

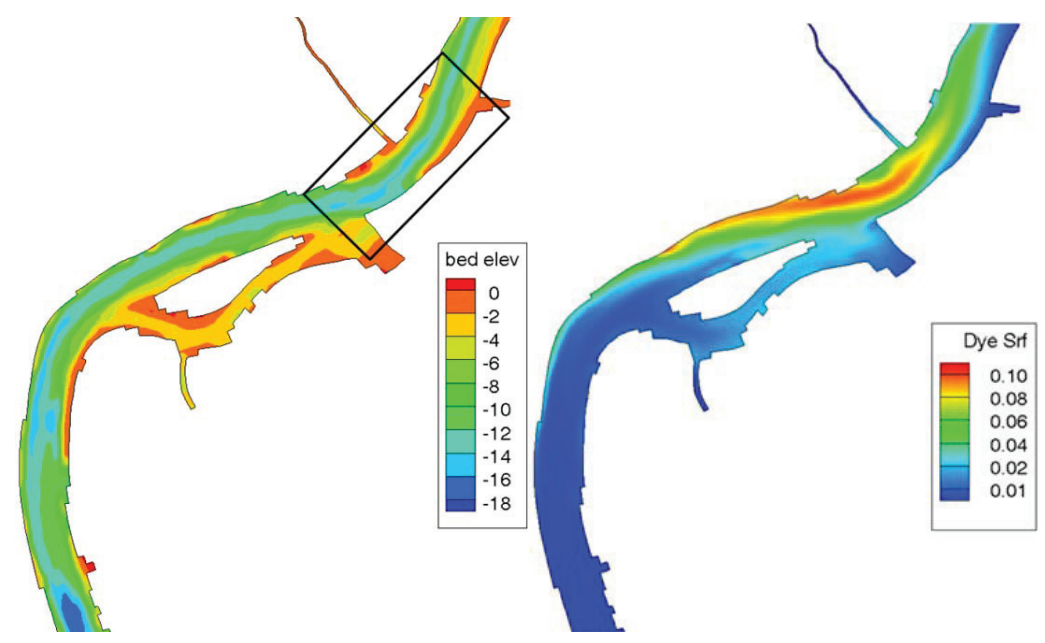

Figure 10. Modeled plume extent in deep river section.

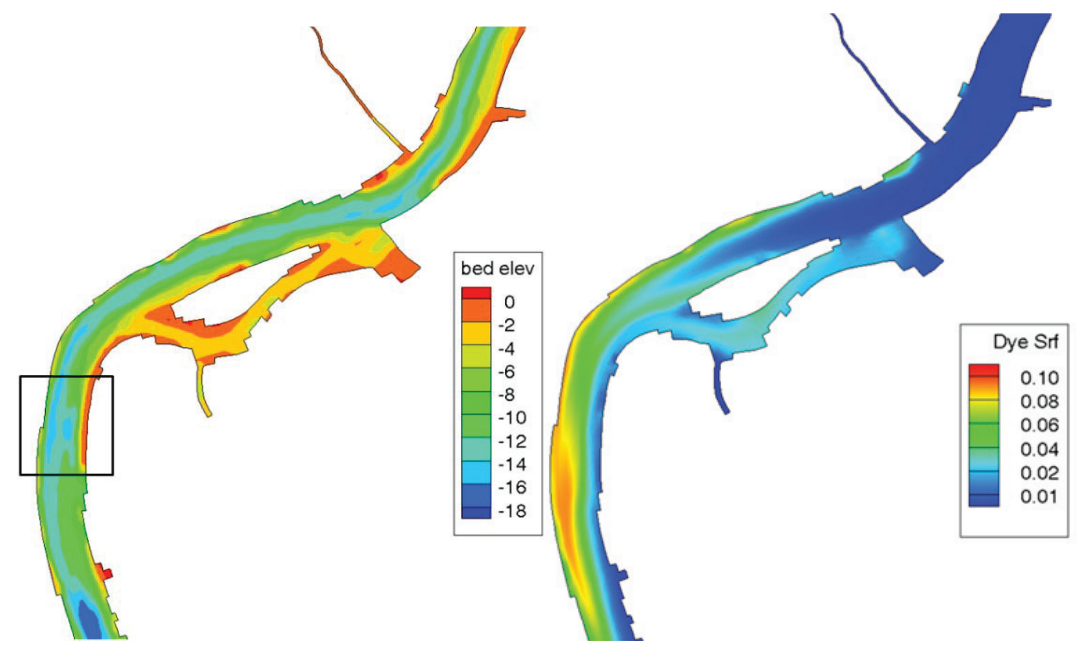




\section{Conclusions}

To meet its regulatory obligations for combined sewer overflow control, the City of Philadelphia Water Department is developing a hydrodynamic and water quality model to determine if changes made to the stormwater infrastructure will result in improvements in receiving stream water quality. Validation of an EFDC hydrodynamic model was successfully completed as demonstrated through model skill metrics.

Exercising the model against the results of a dye study demonstrated that this tidal fresh water riverine system model, using a detailed and bathymetrically accurate grid, and forced at the downstream boundary with observed water levels, successfully represents the dynamics of the advection and dispersion of dye transport. The selected model domain proved to be appropriate with the observed water level forcing at Delaware City driving the model to adequately represent the tidal and subtidal (meteorologically-induced) effects, including those that originated down-bay, from the Chesapeake and Delaware Canal, and remotely from the continental shelf. Numerical experiments conducted with and without the application of wind showed that the model responded as expected to meteorological forcing through a local, down-bay stress and yielded results consistent with findings of other Delaware Estuary researchers. That is, large-scale wind stress forcing on the lower Delaware Bay caused a setdown at the model lower boundary, resulting in a barotropic response observed in both the dye study and the model. Local wind forcing internal to the model domain was shown to exert little influence on the hydrodynamics driving the dye advection and dispersion.

Bathymetric interactions play an important role in lateral mixing. With an estimated mixing length on the order of the local tidal excursion, full lateral mixing could theoretically be possible over the course of the dye study. Comparison of the dye plume to the bathymetry suggested that bathymetric steering forces the major part of the dye into the deep navigational channel preventing it from fully distributing laterally.

These validation and dye study exercises demonstrate that our model is a reliable tool for a broad range of applications for the City of Philadelphia. Future use of the model will include exploring more advanced mixing dynamics through a new dye study that includes a more complete plume coverage. Other applications include scenarios for early response to pollutant spills and strategic planning related to climate change impacts on infrastructure vulnerability and salt intrusion on the City's drinking water source.

\section{Acknowledgments}

We want to acknowledge the assistance of James Smullen, CDM Smith, a consultant to the Office of Watersheds of the PWD, as well as support from our PWD colleagues.

\section{Authors Contributions}

The authors contributed equally to research and manuscript writing. 


\section{Conflicts of Interest}

The authors declare no conflict of interest.

\section{References}

1. Phillyriverinfo History of CSOs in Philadelphia. Available online: http://www. phillyriverinfo.org/CSOLTCPU/Home/History_Of_CSO.aspx (accessed on 21 November 2013).

2. PWD Stormwater Management. Available online: http://www.phillywatersheds.org/ watershed_issues/stormwater_management/faq (accessed on 21 November 2013).

3. Hamrick, J.M. A Three-Dimensional Environmental Fluid Dynamics Computer Code: Theoretical and Computational Aspects; College of William and Mary, Virginia Institute of Marine Science: Gloucester Point, VA, USA, 1992.

4. OceanSurveys. Delaware River Basin Commision Combined Sewer Overflow Mixing Zone Study-Final Report; OSI JOB NO. 97ES089; HydroQual Inc. and Delaware River Basin Comission (DRBC): Mahwah, NJ, USA, 1998.

5. TetraTech-Inc. The Environmental Fluid Dynamics Code-User Manual-US EPA Version 1.01; Tertra Tech Inc.: Fairfax, VA, USA, 2007.

6. Deltares. Available online: http://www.deltaressystems.com/hydro/product/621497/delft3dsuite (accessed on 21 November 2013).

7. Klavans, A.S.; Stone, P.J.; Stoney, G.A. Delaware River and Bay Circulation Survey: 1984-1985; U.S. Department of Commerce: Rockville, MD, USA, 1986.

8. Sommerfield, C.K.; Madsen, J.A. Sedimentological and Geophysical Survey of the Upper Delaware Eastuary; University of Delaware: Newark, DE, USA, 2003.

9. NOAA. National Geophysical Data Center (NGDC). Available online: http://www.ngdc.noaa.gov/ (accessed on 21 November 2013).

10. NOAA. Vertical Datum Transformation (VDATUM). Available online: http://vdatum.noaa.gov/ (accessed on 4 March 2013).

11. NOAA. Delaware Bay Physical Oceanographic Real-Time System (PORTS). Available online: http://tidesandcurrents.noaa.gov/ports/index.html?port=db (accessed on 21 November 2013).

12. NOAA. National CLimatic Data Center (NCDC). Available online: http://www.ncdc.noaa.gov/ (accessed on 21 November 2013).

13. Warner, J.C.; Geyer, W.R.; Lerczak, J.A. Numerical modeling of an estuary: A comprehensive skill assessment. J. Geophys. Res. Ocean. 2005, 110, C05001; doi:10.1029/2004JC002691.

14. Janzen, C.D.; Wong, K.C. Wind-forced dynamics at the estuary-shelf interface of a large coastal plain estuary. J. Geophys. Res. Ocean. 2002, 107, 3138; doi:10.1029/2001JC000959.

15. Fischer, H.; List, J.; Koh, R.; Imberger, J.; Brooks, N. Mixing in Inland and Coastal Waters; Academic Press: San Diego, CA, USA, 1979. 


\title{
Effluent Mixing Modeling for Liquefied Natural Gas Outfalls in a Coastal Ecosystem
}

\section{Mustafa Samad and Karim El-Kheiashy}

\begin{abstract}
Liquid Natural Gas (LNG) processing facilities typically are located on ocean shores for easy transport of LNG by marine vessels. These plants use large quantities of water for various process streams. The combined wastewater effluents from the LNG plants are discharged to the coastal and marine environments typically through submarine outfalls. Proper disposal of effluents from an LNG plant is essential to retain local and regional environmental values and to ensure regulatory and permit compliance for industrial effluents. Typical outfall designs involve multi-port diffuser systems where the design forms a part of the overall environmental impact assessment for the plant. The design approach needs to ensure that both near-field plume dispersion and far-field effluent circulation meets the specified mixing zone criteria. This paper describes typical wastewater process streams from an LNG plant and presents a diffuser system design case study (for an undisclosed project location) in a meso-tidal coast to meet the effluent mixing zone criteria. The outfall is located in a coastal and marine ecosystem where the large tidal range and persistent surface wind govern conditions for the diffuser design. Physical environmental attributes and permit compliance criteria are discussed in a generic format. The paper describes the design approach, conceptualization of numerical model schemes for near- and far-field effluent mixing zones, and the selected diffuser design.
\end{abstract}

Reprinted from J. Mar. Sci. Eng. Cite as: Samad, M.; El-Kheiashy, K. Effluent Mixing Modeling for Liquefied Natural Gas Outfalls in a Coastal Ecosystem. J. Mar. Sci. Eng. 2014, 2, 493-505.

\section{Introduction}

Total global demand for liquefied natural gas (LNG), which is one of the cleanest fossil fuels, is estimated to have grown by approximately seven percent per year since 2000 [1,2]. Driven by national environmental preference for lower carbon fuels, economic impacts of carbon emission costs and low shale gas prices, desire to diversify energy supply sources, geopolitics, and heightened popular opposition to post-Fukushima nuclear energy, the LNG production capacity is set to experience unprecedented growth by 2018 [2,3]. The number of new construction and operation of LNG plants also heightened environmental awareness in the plant permitting process. The LNG is primarily composed of methane, $\mathrm{CH}_{4}$, which is converted to a liquid form for adequate storage and transport. In a typical LNG process the natural gas is first extracted from a deep on- or offshore gas exploration site, pre-treated and transported to an onshore or near shore processing plant where it is purified by removing condensates such as water, oil, mud, and other gases. An LNG process train would also typically be designed to remove trace amounts of mercury from the gas stream. The gas is then cooled down in stages until it is liquefied at approximately $-260^{\circ} \mathrm{F}$ at atmospheric pressure [4]. 
The LNG processing plants use large quantities of water for various process and wastewater streams. Plant wastewater is treated to meet required regulatory standards before wastewater effluents are discharged to the coastal and marine environments. Onshore LNG plants also support desalination of seawater to meet the large water demand of the LNG process and potable use during construction and operation of the LNG plant. Proper disposal of effluents from an LNG facility is essential to retain regional environmental values and ensure regulatory and permit compliance. The combined wastewater effluents are discharged through appropriately designed outfalls that commonly adopt a multi-port diffuser system in sufficiently deep waters. The diffuser system design accounts for the mixing characteristics in the near field and far field regions and generally forms a part of the plant overall environmental impact assessment.

In this paper, a diffuser system design case study is presented to meet the regulatory effluent mixing zone criteria. Although the project location is not specified, it is located on a meso-tidal coast with frequent storm surge impacts. The outfall is located in a coastal and marine ecosystem where large tidal range and persistent surface wind govern conditions for the diffuser design. Physical environmental attributes and permit compliance criteria for the case study are discussed in a generic format. The paper describes major LNG process wastewater streams, the diffuser system design approach, conceptualization of numerical model schemes for near- and far-field effluent mixing zones, and the selected diffuser design with particular emphasis on the modeling of the near-field mixing process.

\section{LNG Process and Outfall Wastewater Streams}

Onshore LNG plants support desalination of seawater to meet the large water demand of the LNG process and potable use during construction and operation of the LNG plant. Treated effluents from LNG plants may include several wastewater streams, for example, desalination plant brines, treated wastewater from LNG process streams, and treated sanitary wastewater.

Figure 1 shows a typical schematic description of the LNG plant wastewater process streams including outfall to natural environment. The figure shows one desalination (seawater reverse osmosis, SWRO) plant to supply SWRO product water to the LNG plant and SWRO filtration water and brines as wastewater to the equalizer tank. Treated wastewater from two sanitary wastewater streams, one from the LNG train areas and other from site facilities, are also pumped to the same equalizer tank. The final treated wastewaters from these streams are equalized in the combined equalizer tank before discharging to the outfall. The projected combined effluent flow rate from this system is estimated as approximately $750 \mathrm{~m}^{3} / \mathrm{h}$. 
Figure 1. Schematics of a typical LNG plant wastewater process streams.

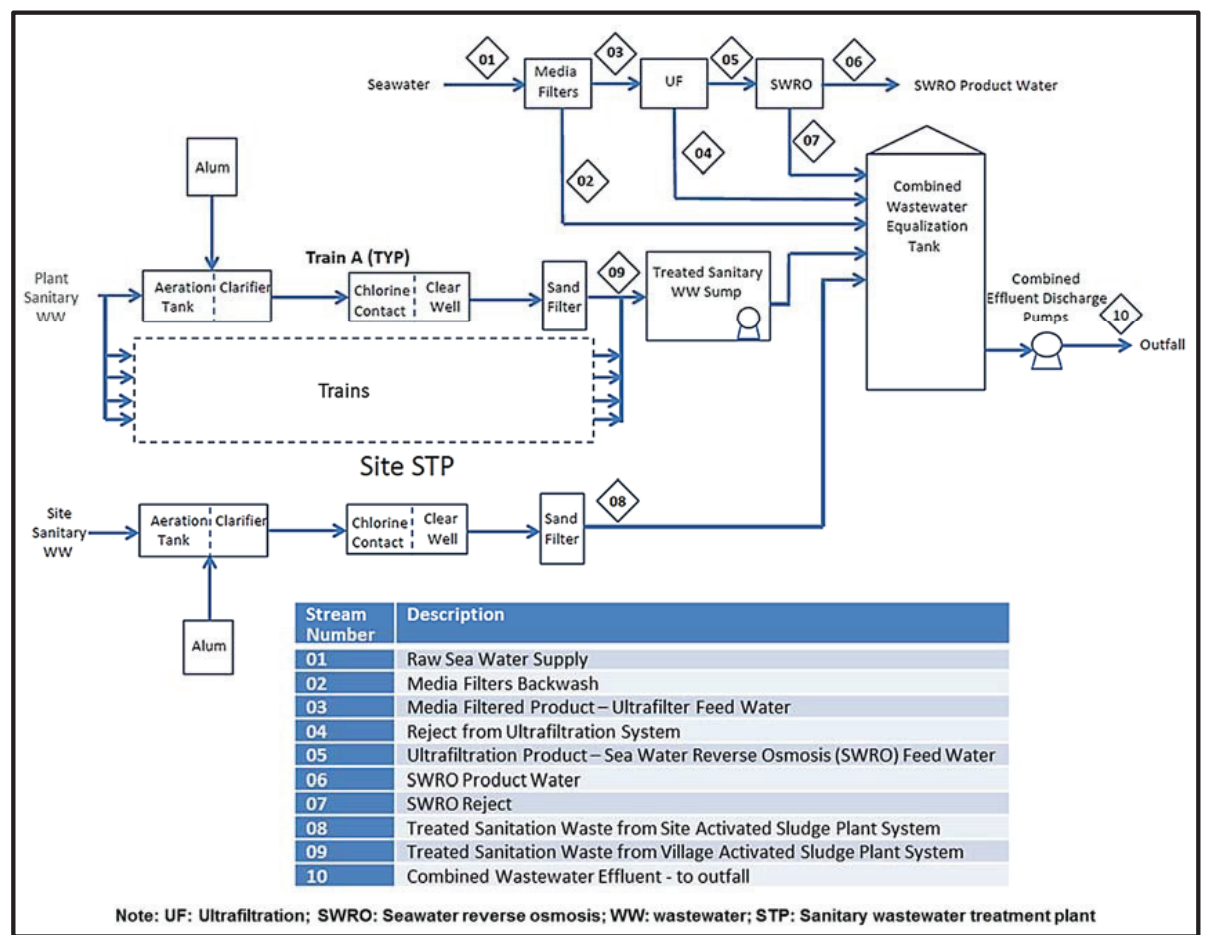

\section{Effluent Diffuser Design Approach}

Environmental impacts from wastewater discharges are often evaluated based on the characteristics of effluent outfall plumes including mixing, dispersion and dilution, and ambient hydraulic characteristics such as currents, winds, temperature and density. Detailed evaluation of effluent outfall plumes is also important for meeting regulatory mixing zone criteria. Such effluent evaluation studies are performed employing numerical models that account for diffuser system design and resolve flow dynamics for the near field and far field regions. The near field region is characterized by small scales near the discharge location where flows are governed by diffuser designs, discharge properties and strong turbulent and jet mixing. On the other hand, the far field region is defined by large scales in the ambient receiving water where buoyant spreading motions and passive diffusion governs effluent dilution. Combination of these models is routinely used for mixing zone evaluation and wastewater disposal designs [5-8]. Several models are available for each flow types (near- and far-fields) focusing on the specific scales, resolutions and processes for each flow fields [9-12]. Plume models, which provide average plume characteristics in the near field zone, use spatial and temporal averaging of the flow field using equivalent diffuser characteristics. Consequently, the plume models simplify the processes using empirical techniques and analytical solutions based on the simplified geometry $[9,10,13,14]$. Hydrodynamic circulation models resolves the flow, density and temperature fields in three-dimensions solving the unsteady, baroclinic, shallow water equations $[15,16]$. 
In addition models that combine the near-field and far-field mixing processes are also proposed $[17,18]$ to dynamically couple information exchanges between the models of varying time and space scales. Numerical fluid dynamic simulations, which are computationally very demanding, have also been performed to resolve the mixing process [19].

Present study uses a combination of near- and far-field models to evaluate outfall discharge configuration and mixing zone behavior. This paper presents results from both near- and far-field analyses with particular emphasis on the near-field mixing process. Effluent near-field mixing is evaluated by employing the Cornell Mixing Zone Expert System (CORMIX) modeling tool $[9,10,13,14]$. CORMIX is a steady-state mixing zone model for single or multi-port discharges particularly suitable for near-field mixing. CORMIX has the capability to analyse negatively buoyant effluents such as effluents from desalination plants that have higher density than the receiving water body. This is simulated in CORMIX such that the effluent flow from a submerged discharge port provides a velocity discontinuity between the discharged fluid and the ambient fluid causing an intense shearing action which breaks down into turbulent motion. This turbulent intensity progresses in the direction of the flow by entraining more of the ambient less turbulent fluid [9].

The far-field effluent mixing process is studied using the three-dimensional numerical model, Delft3D-FLOW [15]. The study investigates the far-field dispersion of the outfall discharge, the potentials for re-circulation of the effluent discharge as well as the dredged bathymetry impact on the extent of the mixing zone. Delft3D-FLOW is a three-dimensional hydrodynamic and transport process model, which simulates unsteady flow and transport phenomena that result from tidal and meteorological forcing. Delft3D-FLOW solves the governing flow equations for an incompressible fluid, under the shallow water assumptions and solves the equations on a rectilinear or a curvilinear boundary fitted grid system. The far-field model primarily was used to confirm the selected diffuser design from the near-field model.

\section{Model Setup}

The shoreline and layout of the proposed outfall is shown in Figure 2. The outfall is located approximately $2.2 \mathrm{~km}$ from the shoreline at water depth of $5 \mathrm{~m}$ with respect to the lowest astronomical tide (LAT). For this analysis tidal water level variation is considered and the corresponding water depth and current velocity are used for each studied tidal conditions.

\subsection{Physical Environment}

Ambient conditions of the receiving water body of the coastal environment where the effluent discharges are described below.

\subsubsection{Bathymetry}

The bathymetry input comprises of bathymetry data (below water surface) and topography data (above water surface) from several data sources. A navigation channel is planned at the project site with a water depth of approximately $14.8 \mathrm{~m}$ relative to mean sea level (MSL). Figure 3 shows the 
pre-development bathymetry of the area. The diffuser system would be placed approximately at elevation $5 \mathrm{~m}$ below the lowest astronomical tide (LAT) (see Figure 2), which is considered as the uniform bottom elevation of the offshore-ward unbounded near-field model (CORMIX). The difference between MSL and LAT is approximately $1.5 \mathrm{~m}$.

Figure 2. Outfall diffuser location and receiving water body.

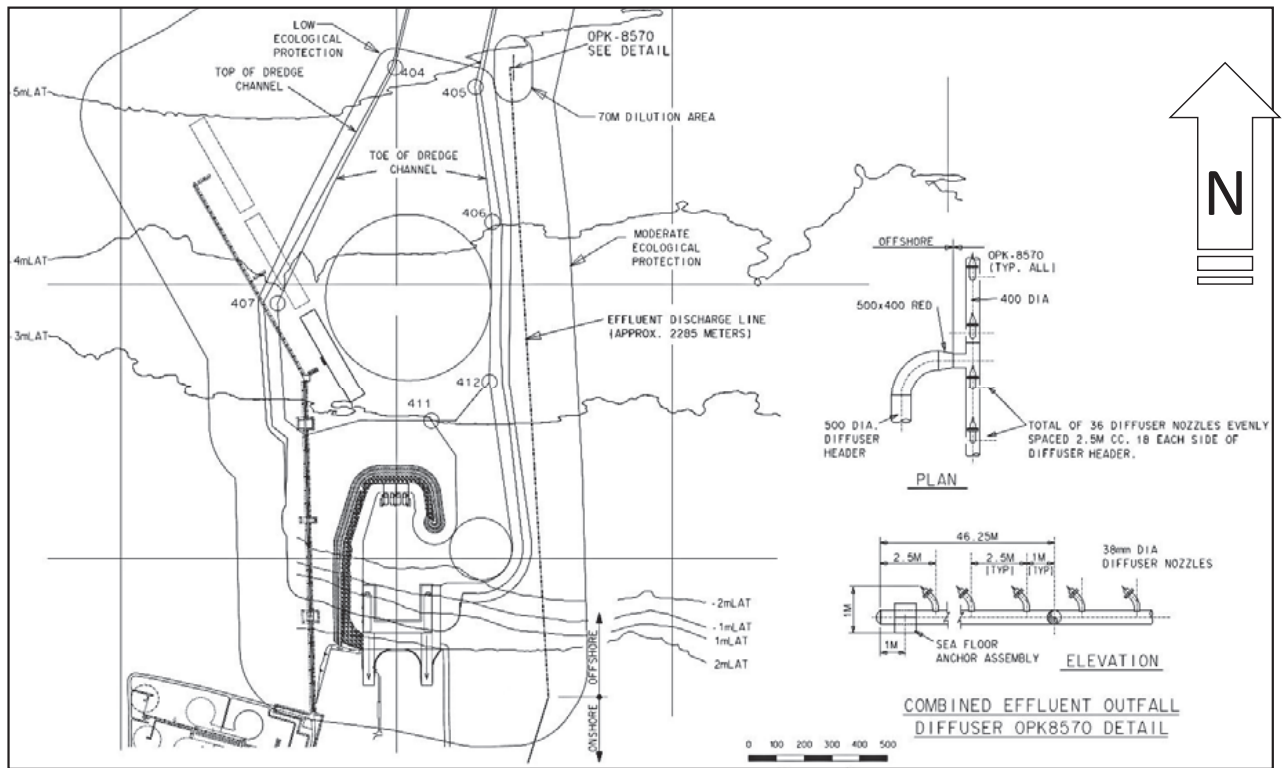

Figure 3. Bathymetry near the outfall location (depths are in meter relative to MSL).

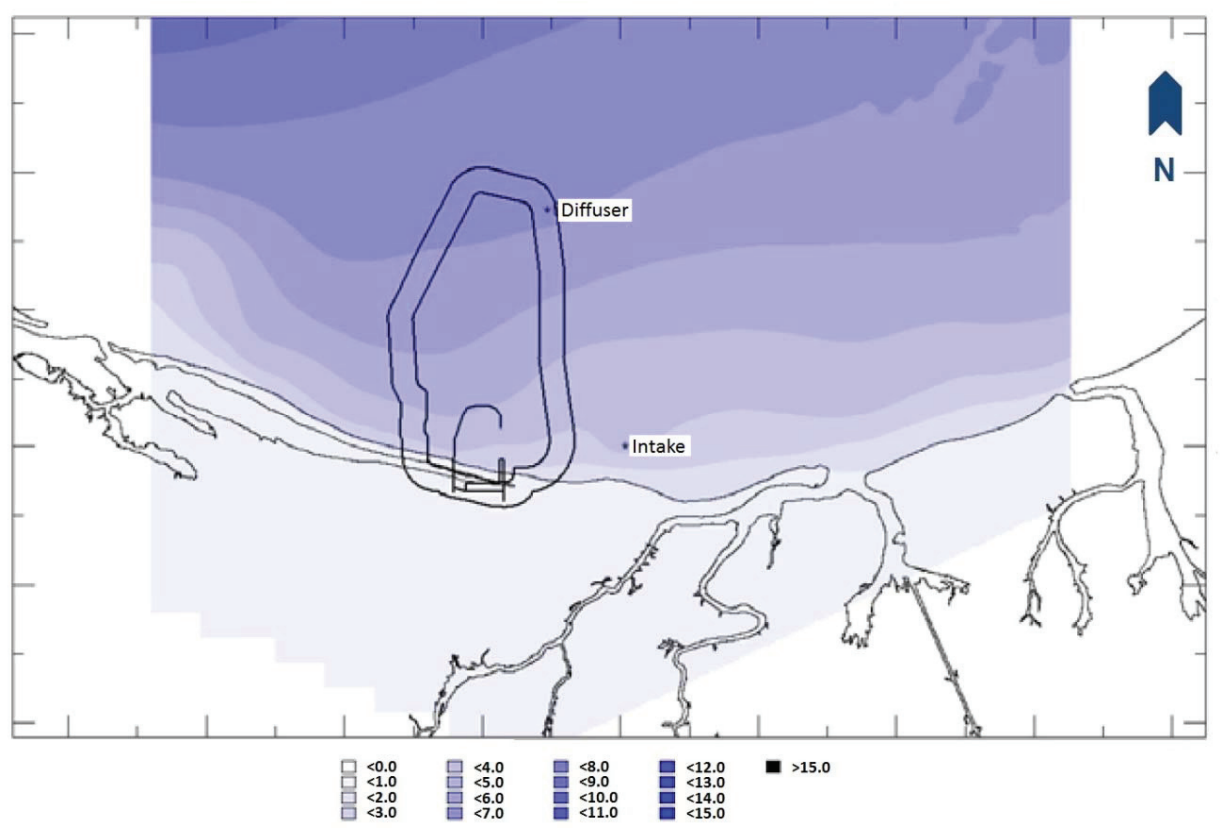




\subsubsection{Wind Speed}

Wind speeds of $3 \mathrm{~m} / \mathrm{s}$ (breeze) were assumed in the direction towards the shore for the near-field simulation to represent a conservative design condition [8]. Although wind impacts are unimportant for near-field mixing [10], higher wind conditions likely would result in more dilution to the effluent plume.

\subsubsection{Tide}

Figure 4 shows tidal water level and current variation over a neap-spring tidal cycle near the site. Note that all current magnitudes are presented as positive. As the outfall location experiences tidal reversals, near-field dilution analysis is performed at the tidal phase when current velocities are at or near slack tide. The following 20 tide phases were considered for the analysis:

- Four tidal conditions - high and low water slack under neap and spring tides.

- Five tidal phases - at slack tide, and one and two hours before and after slack tides.

\subsubsection{Salinity, Temperature and Density}

The average seawater salinity and temperature at the outfall area are 35 parts per thousand (ppt) and $25^{\circ} \mathrm{C}\left(77^{\circ} \mathrm{F}\right)$, respectively. No density stratification due to salinity is indicated for the coastal area near the outfall. The ambient density of the seawater was estimated based on the ambient total dissolved solids (TDS) concentration and temperature. Based on the methodology outlined in the UNESCO equation of state [20], TDS concentration of $37,600 \mathrm{mg} / \mathrm{L}\left(37.6 \mathrm{~kg} / \mathrm{m}^{3}\right)$ and temperature of $25^{\circ} \mathrm{C}\left(77^{\circ} \mathrm{F}\right)$, the seawater density is estimated as $1025.31 \mathrm{~kg} / \mathrm{m}^{3}$.

\subsubsection{Ambient Constituent Concentrations}

The ambient TDS concentration of $37,600 \mathrm{mg} / \mathrm{L}$ corresponds to Stream Number 1, as shown in Figure 1, under maximum flow conditions. The ambient TSS (Total Suspended Solids) concentration was obtained as $5.3 \mathrm{mg} / \mathrm{L}$ corresponds to Stream Number 1 under average flow conditions. The ambient phosphorus concentration was obtained from measured data as $0.0135 \mathrm{mg} / \mathrm{L}$, which was taken as a conservative value. The ambient nitrogen concentration was obtained as $0.15 \mathrm{mg} / \mathrm{L}$ corresponding to Stream Number 1. This value is estimated as an average of measured data close to the site.

\subsection{Diffuser Geometry}

A Staged Fanned diffuser type of arrangement is selected to discharge the combined effluent to the marine environment. Sketch of the diffuser is given in Figure 5. The staged fanned type produces a net horizontal momentum flux parallel to the diffuser line and gave the maximum possible dilution when compared to other diffuser types. 
Figure 4. Variation of tidal water level and current near the site over a neap-spring cycle.

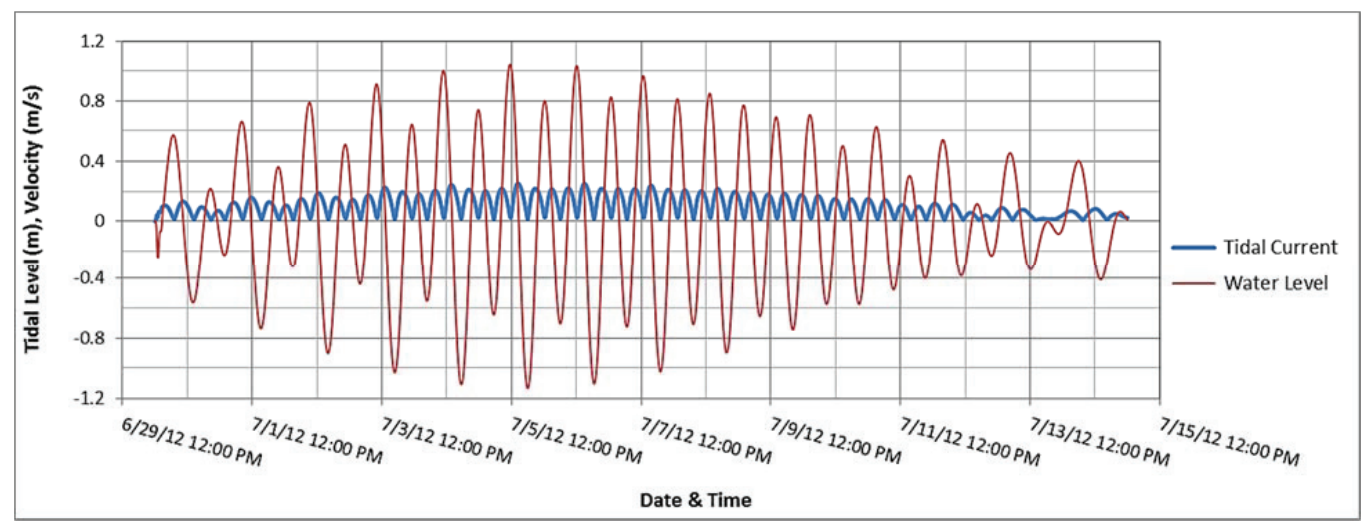

Figure 5. Schematic of staged fan diffuser.

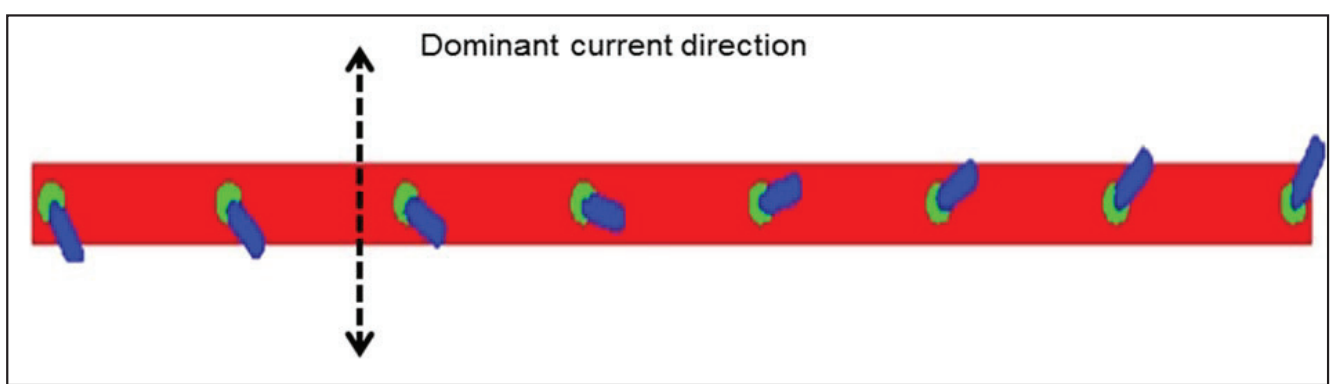

The number of ports (36) was selected based on the duckbill exit velocity. For this analysis, the exit velocity was used to determine the number of ports based on the discharge rate of approximately $750 \mathrm{~m}^{3} / \mathrm{h}$. The flow per nozzle is then calculated as total flow divided by the number of ports (36), which equals to about $21 \mathrm{~m}^{3} / \mathrm{h}$. The staged fanned design type was selected to ensure adequate dilution is attained during different flow directions as well as eliminate any effluent plume hitting the surface. In CORMIX, the duckbill type check valves are modelled with steady flow effluent discharge at the design flow rate.

\subsection{Effluent Discharge Conditions}

For this analysis, the required dilution values for the following constituents were evaluated: TDS, Total Nitrogen (Ntot), Total Phosphorous (Ptot), Total Suspended Solids (TSS), and Aluminum $(\mathrm{Al}+)$.

\section{Mixing Criteria}

The criteria for effluent constituents are based on regulatory requirements at the edge of the defined mixing zone (70 $\mathrm{m}$ from the outfall location). The TDS and salinity values are typically correlated and the mixing zone criterion adopted was +5 percent of ambient for both. The criterion 
for TDS was then estimated as $39,480 \mathrm{mg} / \mathrm{L}(+5$ percent of $37,600 \mathrm{mg} / \mathrm{L})$. As the background concentrations of Ntot are above the regulatory guideline of $0.1 \mathrm{mg} / \mathrm{L}$, the 80 th percentile of the background concentrations was used as the site specific standard, which was estimate to be 0.187 $\mathrm{mg} / \mathrm{L}$. The Ptot, TSS and AL+ criteria were taken as $0.015 \mathrm{mg} / \mathrm{L}, 8 \mathrm{mg} / \mathrm{L}$ and $0.32 \mathrm{mg} / \mathrm{L}$, respectively, following regulatory guidelines.

The geometric characteristics of the diffuser includes a diffuser length of $92.5 \mathrm{~m}$ with an orientation of $90^{\circ}$ to current direction, 36 Duckbill valve type ports each with an area of 0.00082 $\mathrm{m}^{2}$ with equivalent diameter of $0.03231 \mathrm{~m}$ at $45^{\circ}$ vertical angle from horizontal. A spacing of $2.5 \mathrm{~m}$ between ports is assumed with the port height of $1.0 \mathrm{~m}$ above seabed. The seabed slope at the diffuser is assumed horizontal. Based on the flow rate $\left(750 \mathrm{~m}^{3} / \mathrm{h}\right)$ and port opening $\left(0.00082 \mathrm{~m}^{2}\right)$, the exit velocity at the port/duckbill valve is $7.16 \mathrm{~m} / \mathrm{s}$.

\subsection{Model Simulation Cases}

Two cases of effluent composition are evaluated, as can be seen in Table 1. Case 1 represents effluent discharge condition with high TDS and Case 2 with low TDS magnitudes. The two cases represent various stages of the plant construction and operation to bind the expected range of effluent properties and expected environmental impacts. A number of CORMIX simulations were performed for the two cases to arrive at a suitable diffuser design meeting the following restrictions:

(a) Sufficient effluent dilution is reached that would meet the required constituents' concentrations at the end of the mixing zone as specified before.

(b) The port vertical angle is $45^{\circ}$ for ease of construction.

(c) The diffuser type, orientation and alignment minimize any effluent plume hitting the water surface.

(d) The diffuser design consistently meets the required dilution during tidal reversals and tide phases close to reversals at the outfall location and over the range of neap-spring tide cycle.

Table 1. Outfall discharge evaluation cases.

\begin{tabular}{ccc}
\hline Parameters & Case 1 & Case 2 \\
\hline Intake Seawater Flow Rate $\left(\mathrm{m}^{3} / \mathrm{h}\right)$ & 966 & 0.0 \\
Outfall Discharge Flow Rate $\left(\mathrm{m}^{3} / \mathrm{h}\right)$ & 750 & 750 \\
Total Dissolved Solids $(\mathrm{TDS})(\mathrm{mg} / \mathrm{L})$ & 49,706 & 600 \\
Total Nitrogen (Ntot) $(\mathrm{mg} / \mathrm{L})$ & 6.8 & 35 \\
Total Phosphorus $($ Ptot $)(\mathrm{mg} / \mathrm{L})$ & 0.78 & 4 \\
Total Suspended Solids $(\mathrm{TSS})(\mathrm{mg} / \mathrm{L})$ & 24.2 & 10 \\
Al+ $(\mathrm{mg} / \mathrm{L})$ & 0.0 & 0.08 \\
\hline
\end{tabular}

Slack tide is typically the most conservative conditions for dilution analysis as ambient velocity becomes at or near stagnation conditions producing the lowest dilutions. 


\section{Model Results}

Table 2 shows the results of the near-field dilution simulation cases for the spring and neap tides for Case 1 and Case 2. The variation of dilution for various tidal phases for Case 1 is also shown in Figure 6 along with tidal currents. As can be seen from the table and the figure, dilution has a strong correlation with tidal current with higher current magnitude providing higher dilution. The lowest dilution can be observed at slack phases, which is only active for a short period of time. Based on the variation of dilution over the tidal phases, the minimum dilution one hour after the slack tide over the neap-spring cycle for each case was selected for applying the mixing zone criteria.

Table 2. Results of dilution analysis.

\begin{tabular}{|c|c|c|c|c|c|}
\hline \multirow{2}{*}{ Description } & \multirow{2}{*}{ Tidal Phases } & \multirow{2}{*}{ Current (m/s) } & \multicolumn{2}{|c|}{ Dilution at the End of Mix Zone } & \multirow{2}{*}{ Comments } \\
\hline & & & Case 1 & Case 2 & \\
\hline \multirow{5}{*}{ HW_-Spring } & $2 \mathrm{~h}$ before slack & 0.17 & 521 & 525 & \multirow{5}{*}{ At $81 \mathrm{~m}$} \\
\hline & $1 \mathrm{~h}$ before slack & 0.1 & 348 & 355 & \\
\hline & Slack & 0.02 & 85 & 84 & \\
\hline & $1 \mathrm{~h}$ after slack & 0.13 & 360 & 365 & \\
\hline & $2 \mathrm{~h}$ after slack & 0.22 & 570 & 575 & \\
\hline \multirow{5}{*}{ LW_-Spring } & $2 \mathrm{~h}$ before slack & 0.19 & 479 & 483 & \multirow{5}{*}{ At $103 \mathrm{~m}$} \\
\hline & $1 \mathrm{~h}$ before slack & 0.12 & 294 & 302 & \\
\hline & Slack & 0.02 & 76 & 76 & \\
\hline & $1 \mathrm{~h}$ after slack & 0.11 & 226 & 235 & \\
\hline & $2 \mathrm{~h}$ after slack & 0.19 & 410 & 412 & \\
\hline \multirow{5}{*}{ LW-Neap } & $2 \mathrm{~h}$ before slack & 0.13 & 344 & 352 & \multirow{5}{*}{ At $94 \mathrm{~m}$} \\
\hline & $1 \mathrm{~h}$ before slack & 0.07 & 206 & 219 & \\
\hline & Slack & 0.01 & 78 & 78 & \\
\hline & $1 \mathrm{~h}$ after slack & 0.09 & 221 & 230 & \\
\hline & $2 \mathrm{~h}$ after slack & 0.14 & 345 & 353 & \\
\hline \multirow{5}{*}{ HW-Neap } & $2 \mathrm{~h}$ before slack & 0.12 & 360 & 368 & \multirow{5}{*}{$\begin{array}{c}\text { At } 86 \mathrm{~m} \\
\text { Selected dilution }\end{array}$} \\
\hline & $1 \mathrm{~h}$ before slack & 0.07 & 239 & 249 & \\
\hline & Slack & 0.02 & 83 & 83 & \\
\hline & $1 \mathrm{~h}$ after slack & 0.07 & 212 & 218 & \\
\hline & $2 \mathrm{~h}$ after slack & 0.13 & 344 & 352 & \\
\hline
\end{tabular}

Note: HW: High water; LW: Low water.

The selected dilution for each case was then applied to calculate the equivalent effluent constituent concentrations at the end of the mixing zone for comparisons with the effluent criteria as in Table 3.

\section{Discussion on Model Results}

Model results for near-field simulations in Tables 2 and 3 show that the criteria for all constituents are met except for Ptot in Case 1 and Ntot and Ptot for Case 2. With the current dilution factor for Case 1 and an ambient concentration of $0.01 \mathrm{mg} / \mathrm{L}$, the Ptot effluent criteria could be met with an effluent concentration of $0.0135 \mathrm{mg} / \mathrm{L}$. Ptot effluent concentration should not exceed 0.34 
$\mathrm{mg} / \mathrm{L}$ (instead of $0.78 \mathrm{mg} / \mathrm{L}$ ) if the standard is to be met through the tidal signal. It should be noted that the criteria for Ptot could be met several hours from slack tide when stronger tidal currents exist in the outfall location.

Figure 6. Variation of dilution over the spring-neap tidal cycle for Case 1.

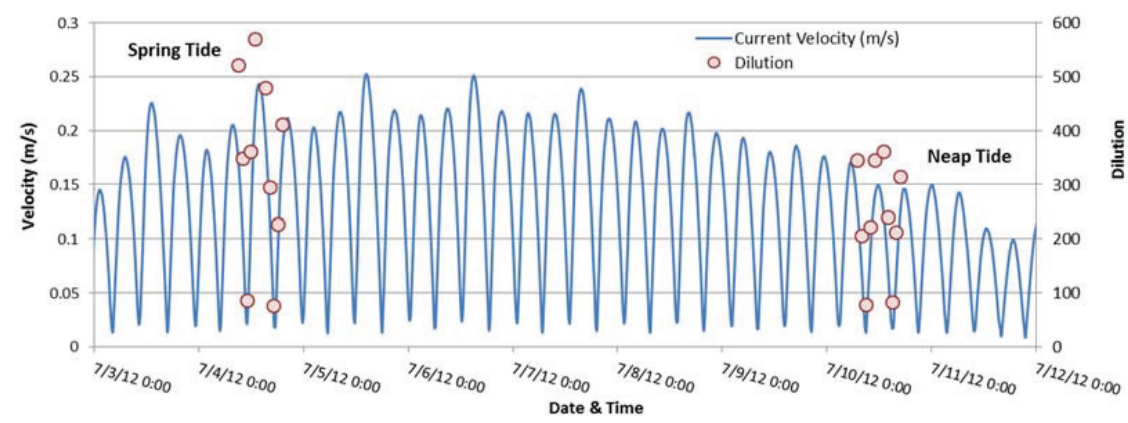

Table 3. Effluent constituent concentration at the end of mixing zone.

\begin{tabular}{|c|c|c|c|c|c|c|c|c|c|c|}
\hline \multirow[b]{2}{*}{ Constituent } & \multirow[b]{2}{*}{ Unit } & \multirow[b]{2}{*}{ Ambient } & \multirow[b]{2}{*}{ Effluent } & \multirow[b]{2}{*}{ Criteria } & \multicolumn{3}{|c|}{ Case 1} & \multicolumn{3}{|c|}{ Case 2} \\
\hline & & & & & $\begin{array}{c}\text { Required } \\
\text { Dilution }\end{array}$ & $\begin{array}{l}\text { Selected } \\
\text { Dilution }\end{array}$ & Conc. & $\begin{array}{c}\text { Required } \\
\text { Dilution }\end{array}$ & $\begin{array}{l}\text { Selected } \\
\text { Dilution }\end{array}$ & Conc. \\
\hline TDS & $\mathrm{mg} / \mathrm{L}$ & 37,600 & 49,706 & 39,480 & 6 & & 37,655 & N/A & & 37,425 \\
\hline Ntot & $\mathrm{mg} / \mathrm{L}$ & 0.15 & 6.8 & 0.187 & 180 & & 0.1804 & 942 & & 0.3144 \\
\hline Ptot & $\mathrm{mg} / \mathrm{L}$ & 0.0135 & 0.78 & 0.015 & 511 & 212 & 0.017 & 2658 & 218 & 0.0323 \\
\hline TSS & $\mathrm{mg} / \mathrm{L}$ & 5.3 & 24.2 & 8 & 7 & & 5.3863 & 2 & & 5.3222 \\
\hline $\mathrm{Al}+$ & $\mathrm{mg} / \mathrm{L}$ & 0 & 0 & 0.32 & 0 & & - & 0 & & 0.0004 \\
\hline
\end{tabular}

Note: The effluent TDS concentration for Case 2 is smaller than the ambient concentration.

For Ntot, the effluent criteria would be met in Case 1. However, for Case 2, the high effluent concentration $(35 \mathrm{mg} / \mathrm{L})$ would exceed the mixing zone criteria for some tidal phases. Ntot effluent concentration should not exceed $8 \mathrm{mg} / \mathrm{L}$ if the standard is to be met through the tidal cycle.

Delft3D model simulations were performed with CORMIX results as input to the model for design verification in the far field. The far-field Delft3D model employs a nested rectilinear grid model with horizontal grid spacing varying as $180 \mathrm{~m}, 60 \mathrm{~m}$ and $20 \mathrm{~m}$. The fine mesh grid covers the diffuser region with the effluent concentrations from CORMIX lumped over one Delft3D grid to represent the near field mixing. A sigma grid vertical coordinate system is selected for the model with the coarse, medium and fine grid domains represented with 1, 3 and 6 layers, respectively. The model results show that, in general, the impact of the effluent discharge on the intake is insignificant for all cases considered. For the high TDS case, the dredged bathymetry appears to guide the effluent toward the intake area. The time-series of the TDS concentration shows above ambient at the intake area; however, the maximum above ambient concentration is shown to be far below the near-field criteria for the TDS constituent. As noted before, the far-field model only provides a confirmation of the near filed mixing analysis, which governed the diffuser design including the type, size and number of diffuser ports, port discharge angle and spacing. 
It should be noted that the approach to combine the results of near field simulations into the far field model is not dynamic and treated as one-way offline input. Changes in ambient conditions as a result of the near field mixing after each tidal phase are not accounted for in the far field model. Also, quasi transient treatment of the tidal cycle in the near field model only to a limited extent accounts for the accumulation of constituent concentration during tidal reversal [10]. The design of the diffuser system therefore is dependent on the conservatively selected dilution factor in the near-field model. Also, after each tidal phase the near-field model did not update he ambient flow field from the far-field model results. Therefore, accumulation of concentration built-up during tidal reversal over several tidal cycles has not been accurately modeled in the in the near-field CORMIX model.

\section{Conclusions}

This paper describes typical wastewater process streams from an LNG plant and presents a diffuser system design case study in a meso-tidal coast to meet the effluent mixing zone criteria. CORMIX mixing model is employed to evaluate the near field mixing process of the combined plant effluent in marine environment. Three dimensional Delft3D model is used for the far field mixing only as a confirmatory analysis taking input from the near-field model. The neap-spring tidal cycle is discretized on a quasi-steady approach to evaluate dilution in the Cormix model. A staged fanned diffuser with 36 ports and $2.5 \mathrm{~m}$ spacing was used to achieve significant dilution within the mixing zone boundary. The length of the diffuser is $92.5 \mathrm{~m}$.

The dilution factor at the boundary of the mixing zone was obtained by taken the lowest possible dilution around various slack tide conditions for neap and spring tides from the CORMIX simulations. The analysis showed that although not all effluent constituents would meet the regulatory mixing zone criteria for all tidal phases for the selected diffuser design and marine environment, the dilution criteria would be met for all constituents for most tidal phases. Also, the large tidal range and persistent surface wind govern the conditions for the diffuser design.

\section{Author Contributions}

Conceived and developed concepts: KTE MAS. Performed model simulations and analyzed results: KTE MAS. Wrote the paper: MAS KTE.

\section{Conflicts of Interest}

The authors declare no conflict of interest.

\section{References}

1. Sankey, P.; Hermann, L.; Clark, D.T.; Micheloto, S.; Nip, W. Gorgon \& the Global LNG Monster, Deutsche Bank Markets Research: Global LNG; Deutsche Bank Securities Inc.: New York, NY, USA, 2012; p. 82. 
2. International Energy Agency. World Energy Outlook 2012. Available online: http://www.worldenergyoutlook.org/pressmedia/recentpresentations/PresentationWEO2012lau nch.pdf (accessed on 12 December 2013).

3. Morgan Cazanove, J.P. Global LNG: Full Steam Ahead, but Cross-basin Arbitrageurs beware Henry Hub Price Diffusion; Global Equity Research, J.P. Morgan Chase \& Co.: London, UK, 2012; p. 248.

4. LNG Technology Licensing, ConocoPhilips: Liquefied Natural Gas. Available online: http://lnglicensing.conocophillips.com/EN/Pages/index.aspx (accessed on 13 December 2013).

5. Doneker, R.L.; Ramachandran, A.; Opila, F. CORMIX modeling of sediment plumes for the oil and gas industry. In Proceedings of the International Symposium on Outfall Systems, Mar del Plata, Argentina, 15-18 May 2011.

6. Chopakatla, S.; Khangaonkar, T.; Sorenson, T. A detailed study of the zone of initial dilution to evaluate exposure and fish entrainment-Fort James operating company's Wauna outfall. In Proceedings of the Engineering, Pulping and Environmental Conference, Atlanta, GA, USA, 5-8 November 2006; Curran Associates, Inc.: Red Hook, NY, USA, 2007; pp. 440-454.

7. Maia, L.P.; Bezerra, M.O.; Pinheiro, L.; Redondo, J.M. Application of the Cormix model to assess environmental impact in the coastal area: An example of the ocean disposal system for sanitary sewers in the city of Fortaleza (Ceara, Brazil). J. Coast. Res. 2011, 64, 922-925.

8. Nigam, S.; Rao, B.P.S.; Srivastava, A. Effect of thermal discharge of cool water outfall from liquefied natural gas (LNG) plant into sea using Cormix. J. Comput. Commun. Sci. Res. 2013, 1, 9-13.

9. Akar, P.J.; Jirka, G.H. Cormix2: An Expert System for Hydrodynamic Mixing Zone Analysis of Conventional and Toxic Multiport Diffuser Discharges; Technical Report EPA/600/3-91/073; U.S. Environmental Research Laboratory: Athens, Georgia, 1991.

10. Jirka, G.H.; Doneker, R.L.; Hinton, S.W. User's Manual for CORMIX: A Hydrodynamic Mixing Zone Model and Decision Support System for Pollutant Discharge into Surface Waters; U.S. Environmental Protection Agency: Ithaca, NY, USA, 1996; p. 152.

11. Wood, I.R.; Bell, R.G.; Wilkinson, D.L. Ocean Disposal of Wasterwater. Advanced Series on Ocean Engineering_Volume 8; World Scientific: Singapore, 1993; p. 425.

12. Fischer, H.B.; List, E.J.; Koh, R.C.Y.; Imberger, J.; Brooks, N.H. Mixing in Inland and Coastal Waters; Academic Press: Oxford, UK, 1979; p. 483.

13. Doneker, R.L.; Jirka, G.H. CORMIX1: An Expert System for Mixing Zone Analysis of Conventional and Toxic Single Port Aquatic Discharges; U.S. EPA, Environmental Research Laboratory: Athens, GA, USA, 1990; EPA-600/600/3-90/012.

14. Jirka, G.H. Use of mixing zone models in estuarine waste load allocation. In Part III of Technical Guidance Manual for Performing Waste Load Allocations, Book III: Estuaries; Ambrose, R.A., Discharges, J., Martin, J.L., Eds.; U.S. EPA: Washington, DC, USA, 1992; EPA-823-R-92-004.

15. Deltares. Delft3D-FLOW, Simulation of Multi-Dimensional Hydrodynamic Flows and Transport Phenomena, including Sediments, User Manual, Version: 3.14, Revision: 9772, 4 December 2009; Deltares: Delft, The Netherland, 2009. 
16. Danish Hydraulic Institute. MIKE21 Flow Model: Hydrodynamic Module, Scientific Documentation; Danish Hydraulic Institute: Hørsholm, Denmark, 2010.

17. Morelissen, R.; Kaaij, T.V.D; Bleninger, T. Waste water discharge modelling with dynamically coupled near field and far field models. In Proceedings of the International Symposium on Outfall Systems, Mar del Plata, Argentina, 15-18 May 2011.

18. Choi, K.W.; LEE, J.H.W. A new approach to effluent plume modelling in the intermediate field. In Proceedings of the XXXI IAHR Congress, Seoul, Korea, 11-16 September 2005.

19. De Wit, L. Near field 3D CFD modelling of overflow plumes. In Proceedings of the 19th World Dredging Conference (WODCON XIX), Beijing, China, 9-14 September 2010.

20. UNESCO. Background Papers and Supporting Data on the International Equation of State of Seawater 1980; Technical Papers in Marine Science; UNESCO: Paris, France, 1981; p. 192. 


\title{
Hydrologic and Water Quality Model Development Using Simulink
}

\section{James D. Bowen, David N. Perry and Colin D. Bell}

\begin{abstract}
A stormwater runoff model based on the Soil Conservation Service (SCS) method and a finite-volume based water quality model have been developed to investigate the use of Simulink for use in teaching and research. Simulink, a MATLAB extension, is a graphically based model development environment for system modeling and simulation. Widely used for mechanical and electrical systems, Simulink has had less use for modeling of hydrologic systems. The watershed model is being considered for use in teaching graduate-level courses in hydrology and/or stormwater modeling. Simulink's block (data process) and arrow (data transfer) object model, the copy and paste user interface, the large number of existing blocks, and the absence of computer code allows students to become model developers almost immediately. The visual depiction of systems, their component subsystems, and the flow of data through the systems are ideal attributes for hands-on teaching of hydrologic and mass balance processes to today's computer-savvy visual learners. Model development with Simulink for research purposes is also investigated. A finite volume, multi-layer pond model using the water quality kinetics present in CE-QUAL-W2 has been developed using Simulink. The model is one of the first uses of Simulink for modeling eutrophication dynamics in stratified natural systems. The model structure and a test case are presented. One use of the model for teaching a graduate-level water quality modeling class is also described.
\end{abstract}

Reprinted from J. Mar. Sci. Eng. Cite as: Bowen, J.D.; Perry, D.N.; Bell, C.D. Hydrologic and Water Quality Model Development Using Simulink. J. Mar. Sci. Eng. 2014, 2, 616-632.

\section{Introduction}

Mechanistic models of water quality have long been used for predicting the impact of wastewaters on natural water bodies. While the first use of models relied on analytical solutions to problems of point or distributed sources of conventional pollutants (e.g., biochemical oxygen demand (BOD), suspended solids) into rivers, most of the water quality modeling applications these days rely on very large computer codes written with a high-level programming language such as FORTRAN or C++.

Many of the most used water quality models were originally developed in the 1980s and 1990s using FORTRAN as the high-level programming language. FORTRAN is still widely used; for instance, in recent a review of fifteen lake ecosystem models [1], five were written in FORTRAN and another five were written in $\mathrm{C}++$, with the remainder written in other high level languages. These models are similar in concept and execution in that they are capable of modeling the dynamics in multi-dimensional physical systems of water quality properties, nutrients, dissolved oxygen, organic matter, and biota by simultaneously solving conservation equations for heat, momentum, and constituent mass in numerous water volumes. Examples of these sorts of models include the Water Analysis Simulation Program (WASP) [2], the Environmental Fluid Dynamics Code (EFDC) [3] with the water quality formulations described in HEM-3D [4], Qual2E [5], CE-QUAL-ICM [6], and 
CE-QUAL-W2 [7]. These models are very commonly used in regulatory water quality management (e.g., $[8,9])$ or to investigate the dynamics of water quality indicators as influenced by dynamic anthropogenic pollutant loading (e.g., [10]).

All of the above referenced models are essentially very large, complex computer codes that are maintained, modified, and manipulated by only a very small group of expert model developers. Manipulation of the code for site-specific or research purposes is not practical for the vast majority of users. There are circumstances, however, when model development is warranted, either when new model state variables are needed, when a special set of water quality processes are appropriate, or when prediction accuracy could be improved by assimilating monitoring data rather than modeling it. Water quality model development is also an important part of education in the field. Making these powerful models more flexible in their formulation through user development could greatly improve their overall utility.

MATLAB/Simulink has been adopted in other fields of engineering as a means for modeling and simulating complex systems without the need to write thousands of lines of computer code during model development. Simulink systems are drawn using a graphical user interface as "block and arrow" diagrams. The Simulink block library is very large and includes math and logic functions, signal generation and processing, visualization, plus many specialized toolboxes (e.g., fuzzy logic, DSP, control systems, neural networks). Lines connecting the blocks represent data signals. Signals can be bundled into buses and selectively unbundled as input into "downstream" blocks. Simulink systems are often operated in a time stepping mode to model the dynamic behavior of the system. As an extension of the MATLAB environment, Simulink models can be easily integrated to read and write data from the workspace and to interact with scripts written with its own high-level programming language.

Simulink has been utilized previously to model the dynamics of engineered systems in a variety of disciplines. Examples of its use in non-environmental systems analysis include process modeling in the sugar industry [11] and building systems modeling [12]. In the area of environmental engineering, Simulink has been used for simulating wastewater treatment plants, either as individual unit processes $[13,14]$, as benchmark simulations of an entire wastewater treatment plant $[15,16]$, for simulation of stormwater systems [17,18], or for integrated models that include both engineered and natural surface water systems $[19,20]$. Simulink has also been used to model the hydrodynamics and water quality of a few surface water natural systems [21-23].

In this article we explore the benefits of Simulink for water quality model development in teaching and research. Of particular interest is how the graphical modeling environment of Simulink can assist new model developers without programming experience as they are introduced to mass-balanced based water quality simulation in a graduate-level course that intentionally includes both instruction and collaborative model development by students. Simulink has been frequently used in engineering education for situations where construction of powerful computational tools for system simulation is an integral part of the pedagogy. For example, Simulink has been used as a teaching aid in courses on digital and analog modulation [24], multiphase electric machines [25], river water quality [26], and wastewater treatment plant operation and control [27]. It has been recognized in the engineering education community that use of tools such as Simulink can provide a "learner-centered" 
environment whereby students are able to create simulation tools that allow personal experimentation of system behavior (e.g., [28]). Courses structured to include such features can positively affect student interactivity, participation, and course satisfaction [29].

As a case study of water quality modeling instruction and model development with Simulink, we present three examples that were developed either for use in the classroom and/or in research. The first model was developed as an alternative to a spreadsheet solution of conservative flushing and transport through a pond and channel. The second application is a Simulink version of a widely used stormwater runoff hydrology model. The third example describes the finite volume implementation in Simulink of the water quality model CE-QUAL-W2. This application represents one of the first uses of Simulink for modeling dynamic, spatially varying water quality in natural systems.

\section{Models of Pollutant Transport for Teaching Water Quality Modeling}

Many environmental engineering curricula include a course on mass-balance based surface water quality modeling. These courses build and expand upon the steady-state, one-dimensional dissolved oxygen/BOD modeling that is usually taught at the undergraduate level. The courses rely on process-based descriptions of fate and transport of constituents in surface water systems that are analyzed by solving mass balance equations for one or more of the constituents. The assignments in the courses typically are computationally intensive in keeping with the subject matter. A number of textbooks are available to teach such a course [30-34]; here we examine the use of Simulink in a graduate-level course that has been taught several times using the Chapra text.

An example problem from the Chapra text is used here to illustrate alternative means of model development for quantitative problem solving. In this particular problem (Problem 10.3), conservative dye is being flushed from a completely mixed pond into a channel by a river diversion (Figure 1). The dye exits the pond as an exponentially decaying source of mass to a downstream channel. No mixing occurs in the channel. After a travel period downstream in the channel, the diverted river water containing the dye is conservatively mixed back into the river. The student is asked to calculate the concentration time history at the pond exit, the channel exit, and after mixing into the river.

Figure 1. Diagram of a representative problem (Chapra, Problem 10.3) where mass passes from a pond to a channel and is conservatively mixed into a river.

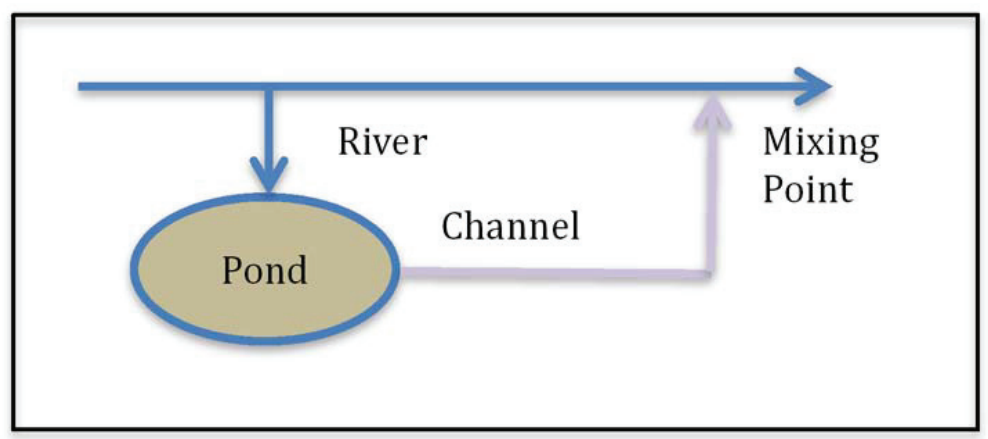


Students have typically solved this problem with a spreadsheet solution created using Microsoft Excel (Figure 2). Spreadsheet equations are used to calculate the three needed time histories; Excel charts are created to visualize the results. While not an onerous problem for the students, use of these spreadsheet solutions in the class can present several problems. Students generally know Excel, but they vary widely in their expertise with it. Complex problems can overwhelm their capabilities and their patience with cut and paste solutions, even when problem specific parameter names are used. Solutions often involve long complex equations that are difficult to impossible to debug. Solutions typically have no common look and feel and are therefore time consuming to grade. Finally, there is often little opportunity to reuse spreadsheet solutions from problem to problem.

The use of Simulink as a model development tool for problem solving in the graduate-level water quality modeling course was first piloted in an independent study version of the course. Two students who had previously taken the modeling course were offered an independent study to learn Simulink and demonstrate its use through problem-based model development. After a successful pilot program, Simulink was used as the primary means for student problem solving when the water quality modeling course was offered the following year. The course included one week of training in Simulink followed by another week in the computer lab solving some simple example problems from the Chapra text. Over the remainder of the semester, approximately two Simulink problems were assigned each week over the remainder of the fourteen-week semester. While not all textbook problems were amenable to Simulink solutions, there were sufficient problems available in all sections of the course that could be solved with a Simulink model.

Figure 2. Solution to pond-channel-river problem (Chapra 10.3) created in Excel.

\begin{tabular}{|c|c|c|c|c|c|c|c|c|c|c|c|c|}
\hline \multicolumn{3}{|c|}{ SUM } & $\otimes 0$ & $-f x$ & $=S I S 4^{\circ}$ EXP & SBS9*1 & $0 / 5$ & & & & & \multirow{3}{*}{ L } \\
\hline & \multirow[t]{2}{*}{ A } & B & $\mathrm{C}$ & I D & \begin{tabular}{|l|l|} 
& $\mathbf{E}$ \\
\end{tabular} & \begin{tabular}{l|l}
$F$ & \\
\end{tabular} & G & $\mathrm{H}$ & I & J & K & \\
\hline 1 & & \multicolumn{2}{|c|}{ Chapra, Surface Wate } & \multirow{2}{*}{\multicolumn{4}{|c|}{$\begin{array}{l}\text { Quality Moceling. Problem } 10.3 \\
\text { Note: } 1 \mathrm{ppb}=1 \mathrm{mg} / \mathrm{m} 3\end{array}$}} & \multirow[b]{3}{*}{ Timo (d) } & & & & \\
\hline 2 & Parameter & Value & Unit & & & & & & & \\
\hline 3 & Spill Mass & 10000 & $\frac{\text { nit }}{\mathrm{mg}}$ & & \multicolumn{3}{|c|}{ Note: $1 \mathrm{ppb}=1 \mathrm{mg} / \mathrm{m} 3$} & & \multicolumn{2}{|c|}{$\begin{array}{c}\text { Concentration (ppb) } \\
\end{array}$} & PL.C & \\
\hline 4 & Pond & 2500 & $\mathrm{~m} 3$ & & & & & 0.00 & 4.00 & 0.00 & 0.00 & \\
\hline 5 & Channel & 2 & $\mathrm{~m}$ & & & & & 0.10 & 3.69 & 0.00 & 0.00 & \\
\hline 6 & Channel & 1 & m & & & & & 0.20 & 3.41 & 0.00 & 0.00 & \\
\hline 7 & Channel & 500 & $\mathrm{~m}$ & & & & & 0.30 & 3.15 & 0.00 & 0.00 & \\
\hline 8 & River Flow & 20000 & $\mathrm{~m} 3 / \mathrm{d}$ & & & & & 0.40 & 2.90 & 0.00 & 0.00 & \\
\hline 9 & $\begin{array}{l}\text { Channel } \\
\text { Flow }\end{array}$ & 2000 & $\mathrm{~m} 3 / \mathrm{d}$ & & & & & 0.50 & 2.68 & 4.00 & 0.40 & \\
\hline 10 & Channel & 1000 & m/d & & & & & 0.60 & SBS4) & 3.69 & 0.37 & \\
\hline 11 & \multirow{2}{*}{$\begin{array}{l}\text { Travel Time } \\
\text { Time Incr }\end{array}$} & 0.5 & d & & & & & 0.70 & 2.28 & 3.41 & 0.34 & \\
\hline 12 & & 0.1 & d & & & & & 0.80 & 2.11 & 3.15 & 0.31 & \\
\hline 13 & Time incr & & & & & & & 0.90 & 1.95 & 2.90 & 0.29 & \\
\hline 14 & \multirow{16}{*}{$\begin{array}{l}\text { 음 } \\
\text { 음 } \\
\text { 흐 }\end{array}$} & & & & & & & 1.00 & 1.80 & 2.68 & 0.27 & \\
\hline 15 & & & & & & & & 1.10 & 1.66 & 2.48 & 0.25 & \\
\hline 16 & & $4.00 t$ & II & & -PL.A & & & 1.20 & 1.53 & 2.28 & 0.23 & \\
\hline 17 & & $3.50 t$ & 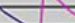 & & -PL.B & & & 1.30 & 1.41 & 2.11 & 0.21 & \\
\hline 18 & & $3.00 t$ & & & & & & 1.40 & 1.31 & 1.95 & 0.19 & \\
\hline 19 & & $2.50 t$ & $\Delta$ & $\longrightarrow$ & PLC & & & 1.50 & 1.20 & 1.80 & 0.18 & \\
\hline 20 & & $2.00 t$ & 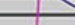 & 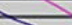 & & & & 1.60 & 1.11 & 1.66 & 0.17 & \\
\hline 21 & & $1.50 t$ & & $\longrightarrow$ & $\mathrm{P}$ & & & 1.70 & 1.03 & 1.53 & 0.15 & \\
\hline 22 & & $1.00 t$ & & & $\mathrm{P}$ & & & 1.80 & 0.95 & 1.41 & 0.14 & \\
\hline 23 & & 0.507 & & & 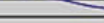 & 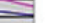 & & 1.90 & 0.87 & 1.31 & 0.13 & \\
\hline 24 & & 0.001 & & & & & & 2.00 & 0.81 & 1.20 & 0.12 & \\
\hline 25 & & & & & & & & 2.10 & 0.75 & 1.11 & 0.11 & \\
\hline 26 & & 0.00 & 0.50 & 1.00 & 1.50 & 2.50 & & 2.20 & 0.69 & 1.03 & 0.10 & \\
\hline 27 & & & & Time & (d) & & & 2.30 & 0.64 & 0.95 & 0.09 & \\
\hline 28 & & & & & & & & 2.40 & 0.59 & 0.87 & 0.09 & \\
\hline 29 & & & & & & & & 2.50 & 0.54 & 0.81 & 0.08 & \\
\hline
\end{tabular}

As an example, the corresponding Simulink solution created by one of the students for the problem described earlier is shown in Figure 3. The Simulink solution couples constituent mass-balance based solutions for the pond, channel, and river. The model also includes a separate subsystem for the volume balance in the pond (Figure 3). Simulink "scope" blocks are used to visualize the 
concentration time histories at the three locations. The system parameters and concentration time histories are bundled into data buses and passed between the subsystems that need the particular data.

Figure 3. Solution to pond-channel-river problem (Chapra 10.3) created in Simulink.

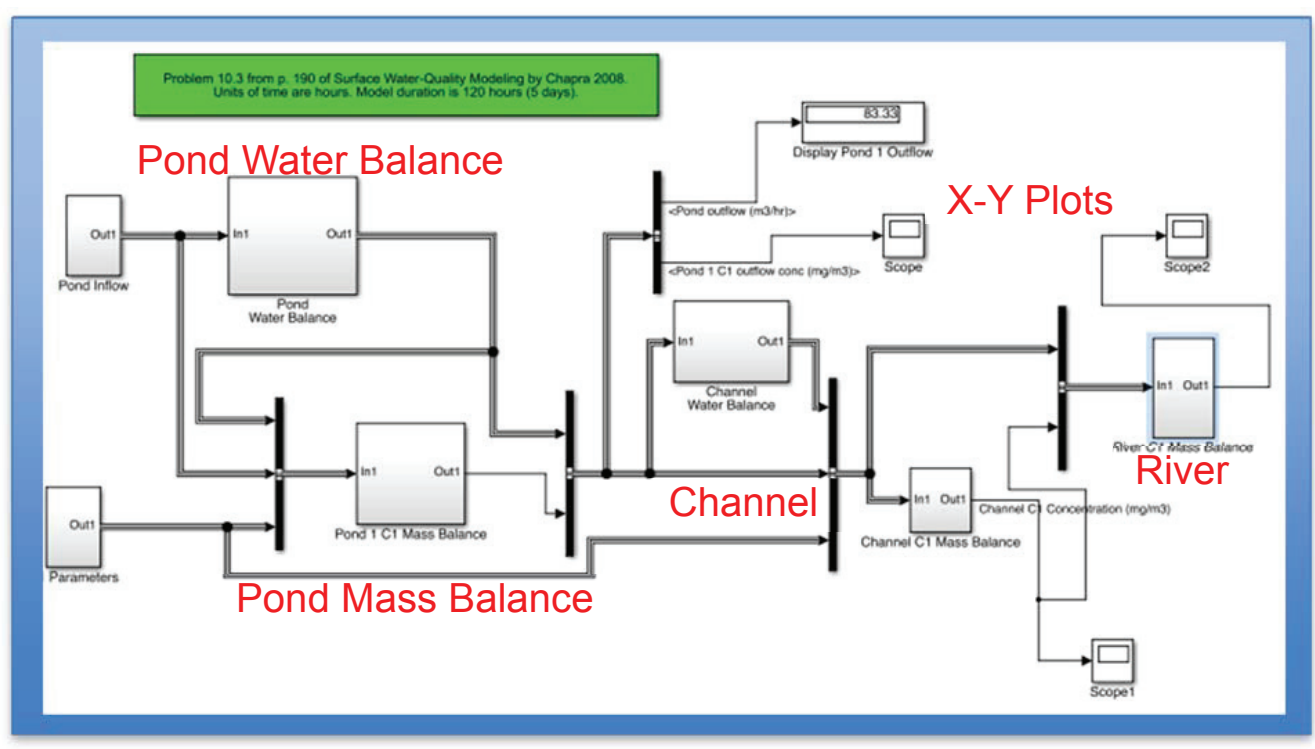

Solution of the constituent mass balance in the pond uses a continuous time integration of the mass balance equation for a completely mixed reactor:

$$
\frac{d(V C)}{d t}=\boldsymbol{W}+\boldsymbol{Q}_{\text {in }} \boldsymbol{C}_{\text {in }}-\boldsymbol{Q}_{\text {out }} \boldsymbol{C} \pm \boldsymbol{X}
$$

where $C$ and $C_{\text {in }}\left(\mathrm{g} / \mathrm{m}^{3}\right)$ represent the constituent concentrations in the reactor and its inflow, $W$ (g/day) is a mass load to the reactor, $X$ (g/day) is the reaction term in the reactor, and $Q_{\text {in }}$ and $Q_{\text {out }}$ $\left(\mathrm{m}^{3} /\right.$ day) are the inflow and outflow of the reactor, which has a volume $\mathrm{V}$. The pond constituent mass balance uses a solution to Equation (1) that has as its basis a solution for an earlier problem having only a single completely stirred reactor (Figure 4). As compared with previous years where students used either handwritten analytical solutions or Excel spreadsheets, student solutions created in Simulink were found to be much easier to grade. Similarity between student solutions was aided by including with the problem assignment example figures showing a recommended overall model structure and some example $x-y$ plots. Students liked the ability to use components from previous problems in their solution and in general caught on quickly to creating solutions in Simulink. Reuse of the mass balance solution for later problems was found to be straightforward. The solution served as the basis of several problems later in the course. 
Figure 4. Simulink model of pond mass balance for a constituent.

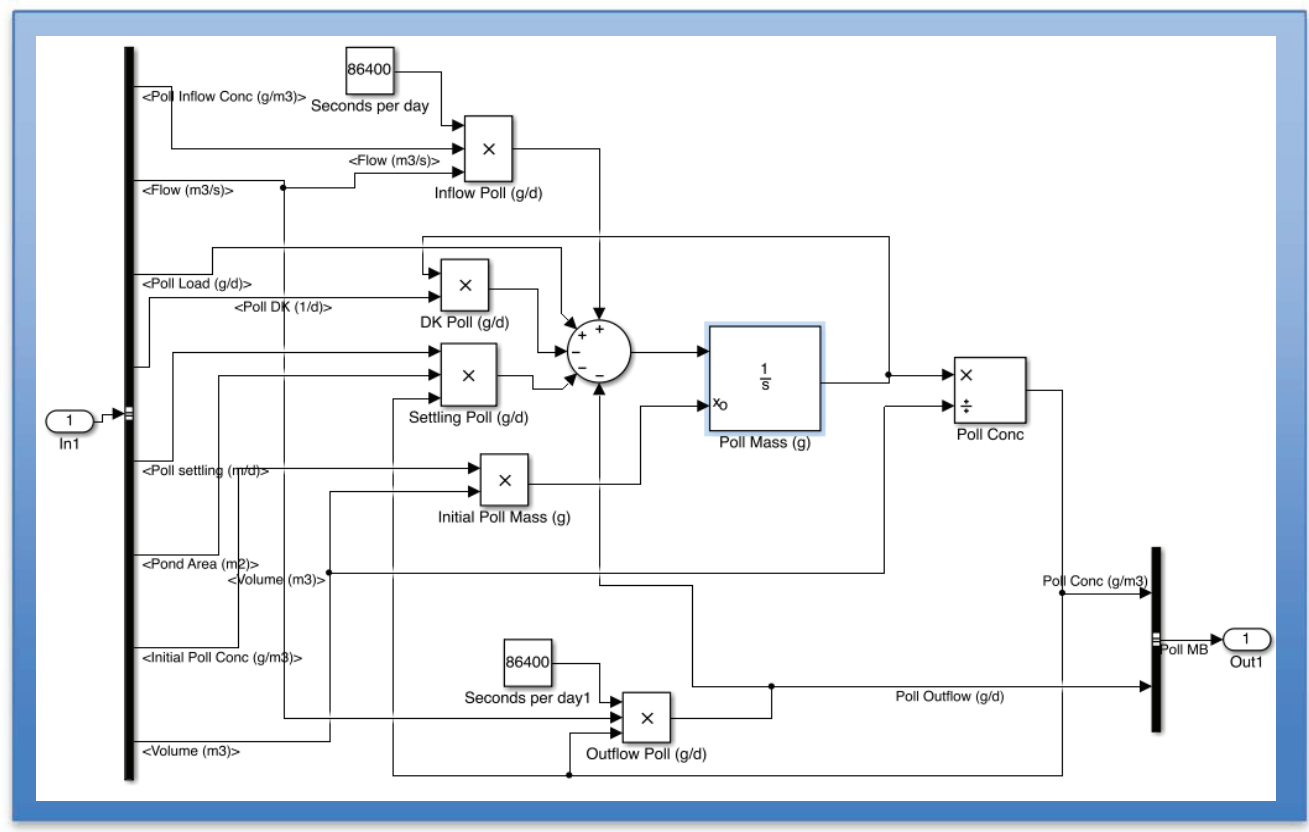

\section{A Simple Hydrologic Model Using Simulink}

During the initial pilot test of the course, students also investigated the use of Simulink modeling for hydrologic simulation. As part of this work, one student created a Simulink version of the Soil Conservation Service (SCS) runoff model that makes up part of the TR55 model [35]. The method is based upon the unit hydrograph approach that convolutes a unit hydrograph with an incremental runoff time history. The student found that creating a Simulink version of the SCS runoff model was challenging, as separate models were needed to generate the unit hydrograph and calculate the runoff hydrograph (Figure 5). The level of Simulink knowledge needed to create the model was likely beyond what reasonably could be expected in the introductory modeling course. To accomplish the runoff calculation, the unit hydrograph generation model was first called, executed, and its data passed to the MATLAB workspace (Figure 5a) before the runoff generation model was executed. The runoff model then read the unit hydrograph data from the workspace and generated the incremental runoff based upon precipitation and land cover (Figure 5b). Creation of the runoff hydrograph utilized two specialized data processing blocks (memory, digital filter) from the Simulink library that had not previously been used in the course. 
Figure 5. Soil Conservation Service (SCS) Method Runoff Calculation Model Using Simulink. Unit hydrograph generation model (a) is run first with output passed to workspace. Runoff calculation (b) reads unit hydrograph from workspace and convolutes signal with incremental runoff time history.

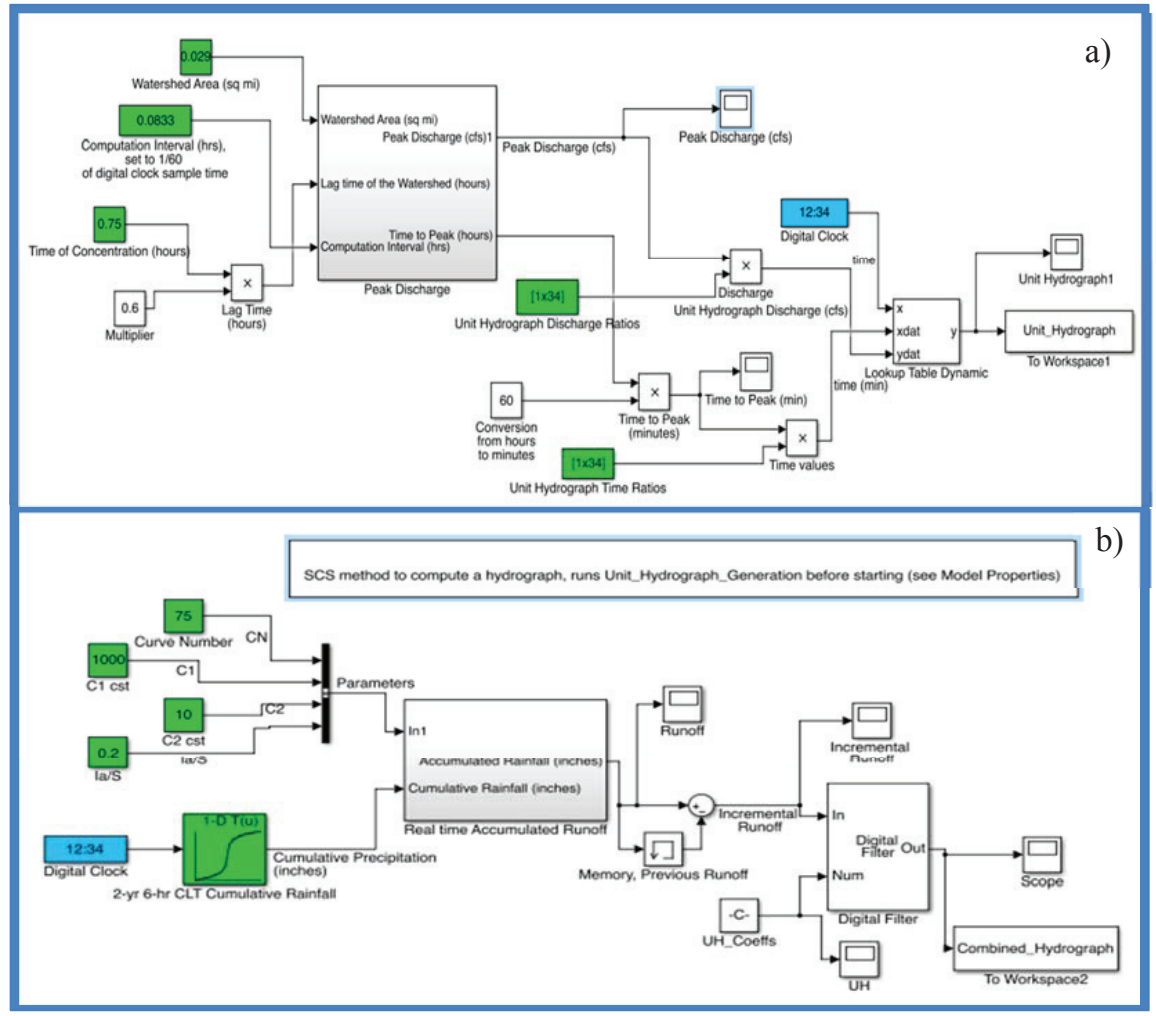

\section{A Multi-Constituent Water Quality Model Created with Simulink}

As a further test of Simulink's capabilities, a Simulink model suitable for modeling water quality conditions in lakes and ponds was developed. The model uses the same finite volume formulation described earlier and the kinetic formulations of CE-QUAL-W2 [7]. This Simulink based version of CE-QUAL-W2 is currently able to simulate and output all but five of the twenty-nine possible CE-QUAL-W2 constituents that are available in version 3.6 of the model. Total inorganic carbon, alkalinity, iron, epiphyton, and zooplankton are not currently modeled, and only one phytoplankton state variable can be currently modeled in Simulink. For this initial trial version, the Simulink implementation is also limited to a one-dimensional volume balance based hydrodynamic model with a spillway outlet. Even with these limitations, the model is useful for simulating temporal and vertical eutrophication dynamics in lakes and ponds. Its utility was investigated for both teaching and research purposes.

The overall organization of the water quality model that was created for this purpose (called W2_SL) relies on a hierarchical arrangement of subsystems that is an essential part of Simulink 
models. The uppermost system (Figure 6) contains subsystems for input of model kinetic parameters, initial conditions, and physical characteristics of the system. The model has a single horizontal segment, with three vertical layers. A display subsystem allows for visualization of the concentration time histories for each layer of the segment (Figure 6).

Figure 6. Uppermost system in the one-segment 3-layer water quality (W2SL3) model executed in Simulink. Each box is a separate subsystem for setting inputs and parameters (left) or solving volume, heat, and mass balances (right). Lines and arrows indicate data transfers between subsystems.

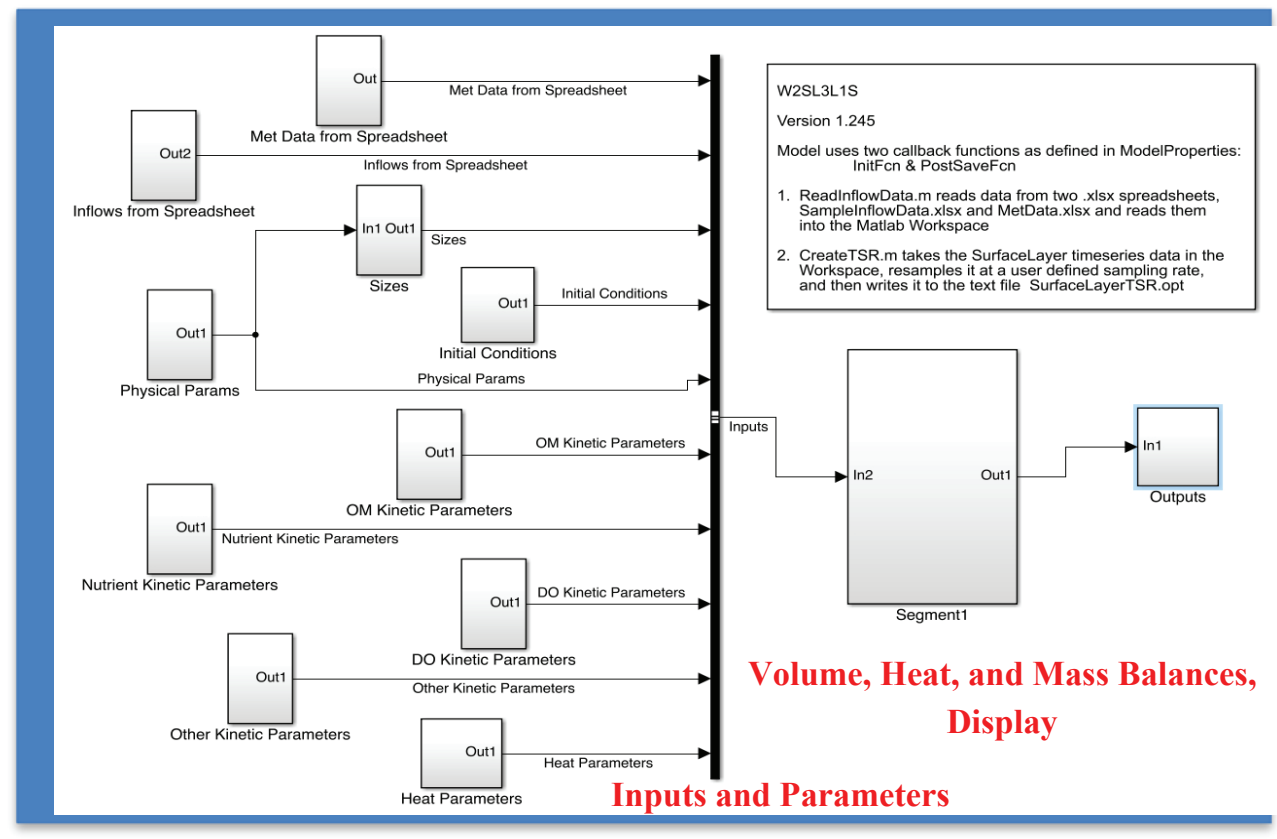

For this application, the water column of the segment is vertically separated into three layers (Figure 7). As implemented in CE-QUAL-W2 [7], layers can be of variable width and the top layer can have a time-varying elevation. A volume balance for the segment is performed to determine the time-varying elevation of the upper layer. Within the three layer subsystems are heat balance and mass balance subsystems. Each layer can exchange heat and mass with adjoining layers. The bottom layer exchanges heat and mass with the sediment layer. The surface layer exchanges heat with the air above (Figure 7). 
Figure 7. W2_SL model of segment 1. Separate subsystems (shown with boxes) calculate the heat and mass balances for each layer or the volume balance for all three layers. Lines and arrows indicate data transfers between subsystems.

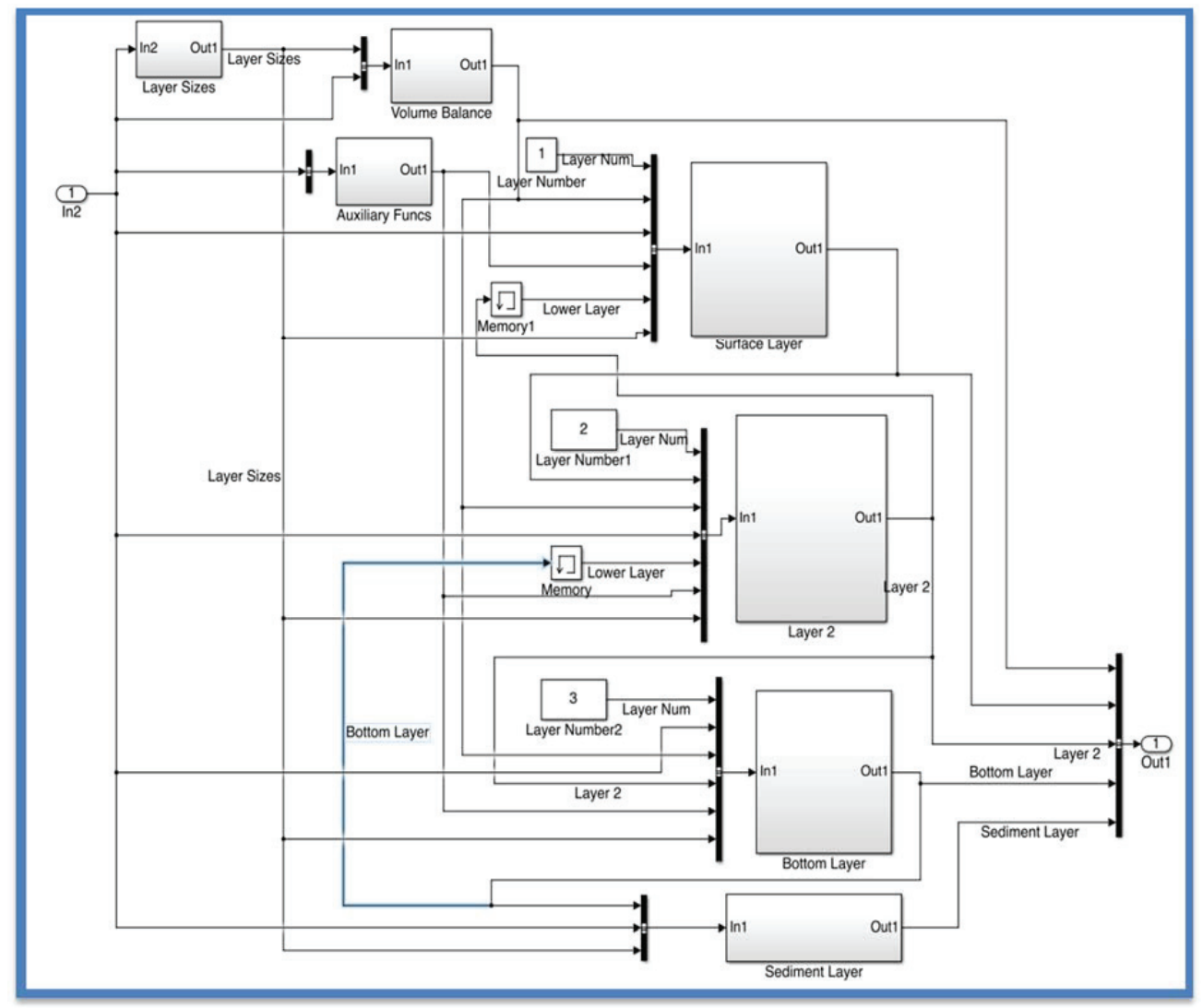

Subsystems for heat and mass balances are found in each of the vertical layers within a segment. The set of constituents follows that of CE-QUAL-W2 [7], although at present only a single algal group is considered, and some other state variables are not included as described earlier. The mass balance subsystem (Figure 8) is further divided into subsystems that contain organic matter mass balances (labile and refractory dissolved and particulate matter plus algal organic matter), nutrient mass balances (nitrogen, phosphorus, silica), dissolved oxygen, and assorted other constituents (salinity, total dissolved solids, residence time, fecal coliform). Input data signals (e.g., meteorological data, water temperature) are used to calculate temperature-varying organic matter process rates (Figure 8).

The labile particulate organic matter (LPOM) constituent is used as an example as to how conceptual process descriptions are translated into a mass balance subsystem in Simulink. The process description block diagram (Figure 9) as specified in the CE-QUAL-W2 user's manual includes inputs to the LPOM from mortality of algal organic matter, ephiphytes, and macrophytes. Sinks of LPOM include sinking and decay that produce either RPOM or inorganic C, N, and P. Production of inorganic C, N, and P also consumes oxygen (Figure 9). 
Figure 8. W2_SL model of the mass balances for the surface layer of segment 1 as implemented in Simulink. Separate subsystems (shown with boxes) calculate the organic matter, nutrient, dissolved oxygen and other mass balances for each the layer. Lines and arrows indicate data transfers between subsystems.

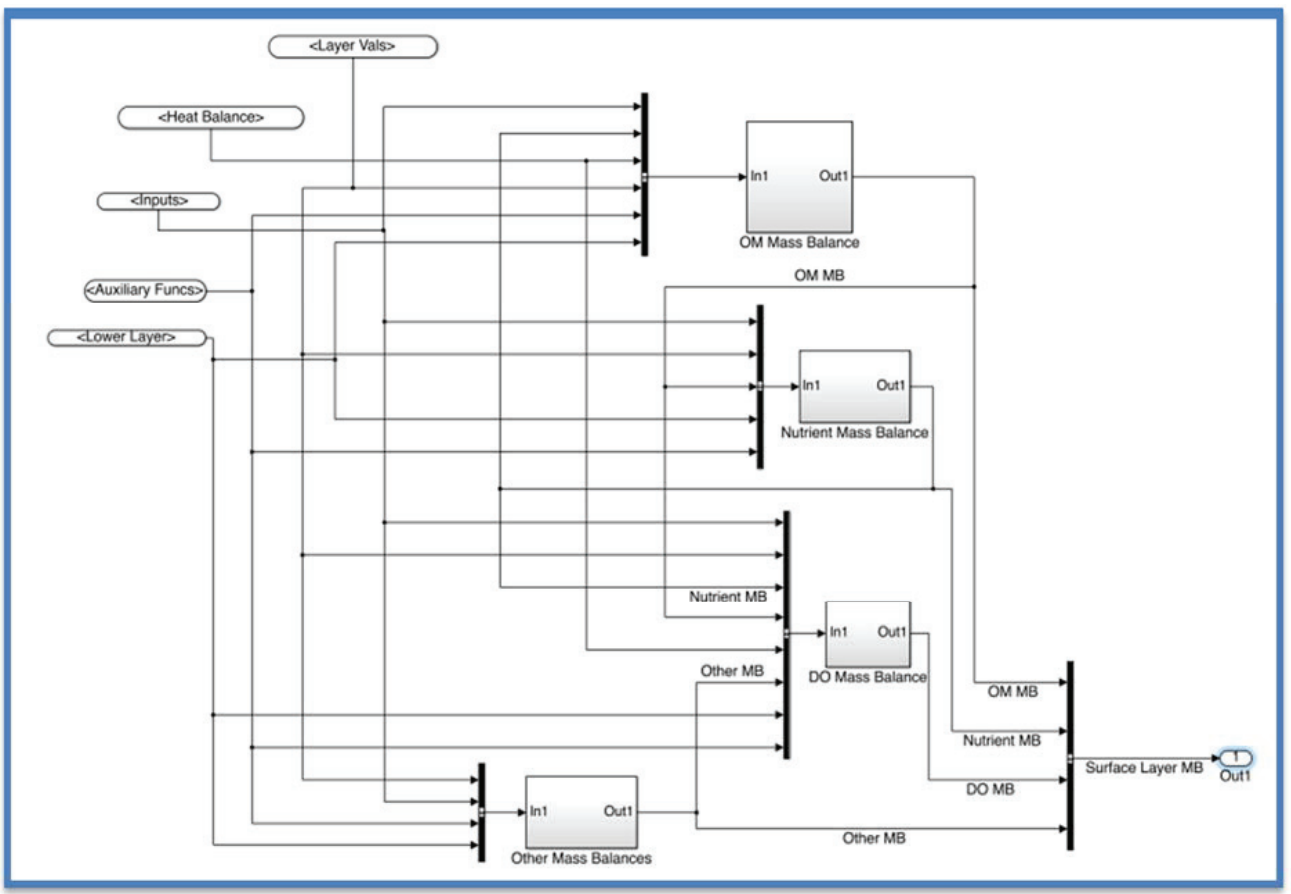

Figure 9. CE-QUAL-W2 mass balance processes internal to a volume for labile particulate organic matter (LPOM).

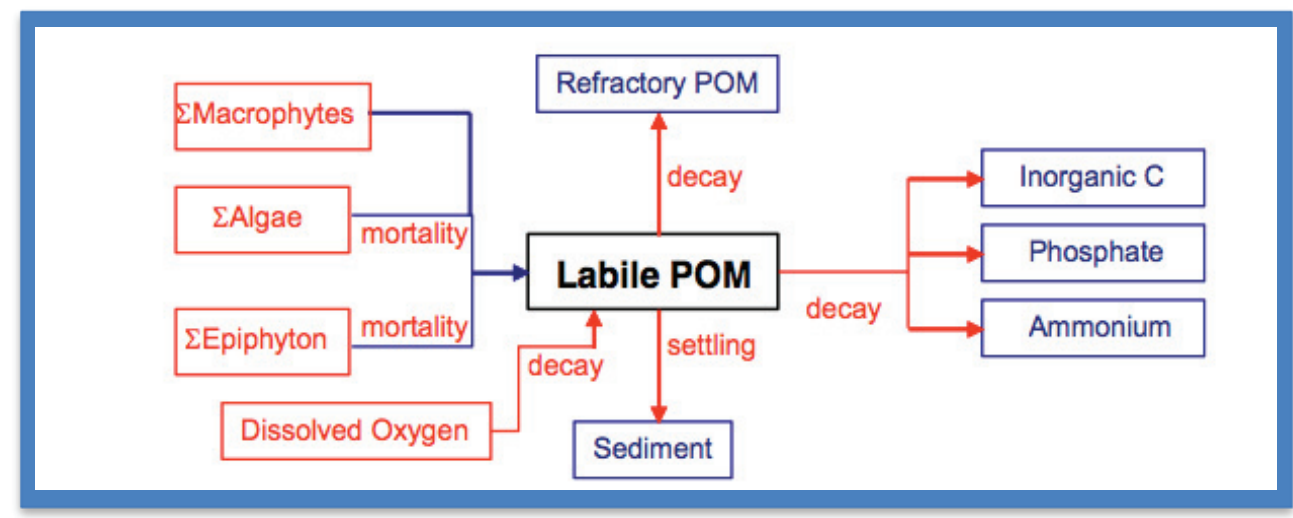

The Simulink model's LPOM subsystem (Figure 10) includes additional transport processes not present in the box and arrow diagram of the CE-QUAL-W2 manual (Figure 9, [7]). As with the tracer mass balance shown earlier (Figure 4), a continuous time integration block takes input from a summation block. The summation block inputs represent each mass input or mass output term in the 
mass balance. For LPOM in the surface layer there are seven terms in the summation block, three of which are sources (AOM to LPOM via mortality, loading, diffusion from the layer below), while four are mass sinks (settling to the lower layer, LPOM decay, LPOM to RPOM, LPOM outflow). Labeling of input and output signals was found to make it relatively easy to use the block and arrow diagram as a process descriptor. The overall visual layout of the subsystem is similar to the conservative tracer subsystem shown earlier (Figure 4), which is not surprising since this subsystem, and in fact all the mass balance subsystems were created by cutting and pasting of other subsystems, using the tracer mass balance as the starting point.

Figure 10. Labile particulate organic matter (LPOM) constituent found with the nutrient mass balance subsystem within each segment and layer as executed in Simulink.

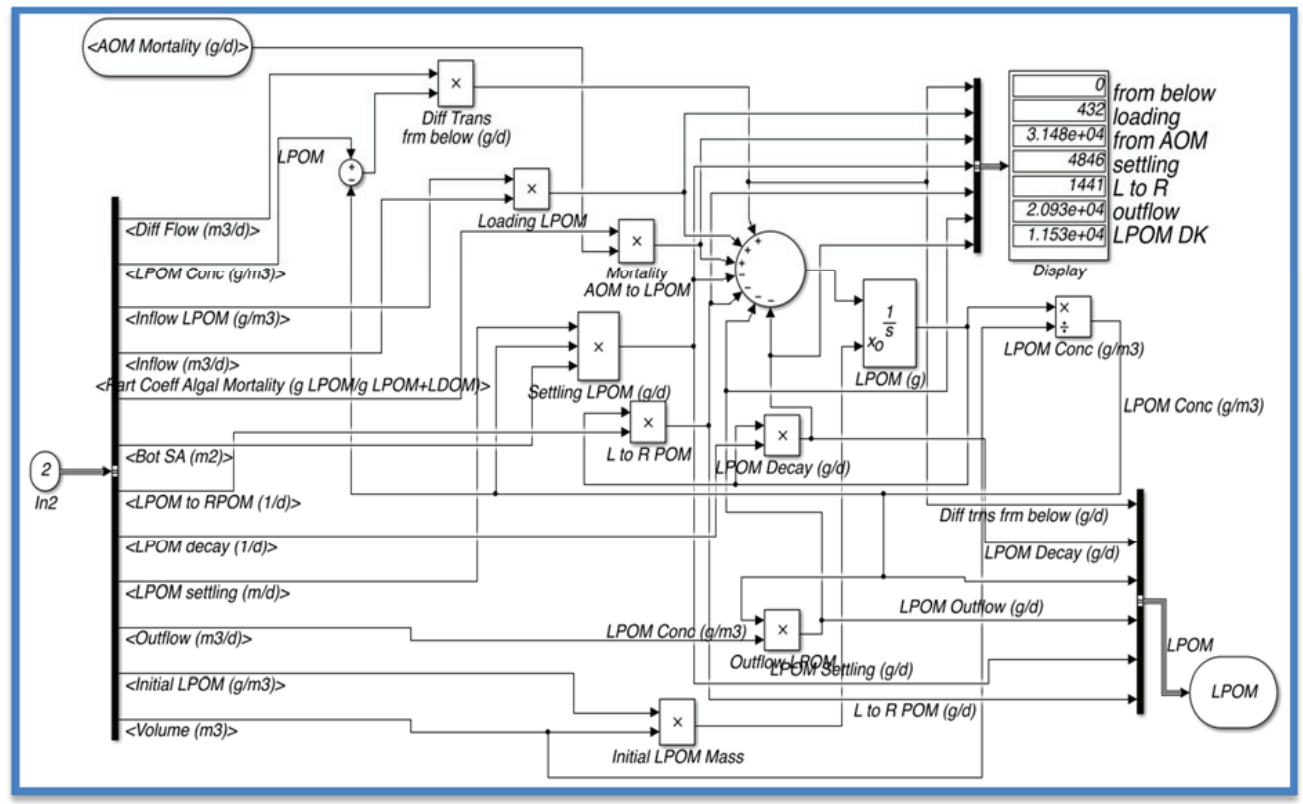

As part of model verification, several model tests were performed to confirm that the model was correctly implementing the mass balances and water quality kinetics described by CE-QUAL-W2. One such test was a comparison of corresponding predictions for the two models for a case with a steady input (both inflow and concentrations held steady) of water and nutrients (N, P, Si) into the surface layer of a pond with a spillway outlet. Identical forcings (inflows, inflow concentrations, meteorological forcings) were specified in the two model applications. All kinetic parameters were set to the same set of default values for CE-QUAL-W2. There were some unavoidable differences in the physical setup, as the minimum number of horizontal segments for CE-QUAL-W2 is two, while the Simulink version had only one horizontal segment. Total pond length and width were the same, and each model application had three layers of identical thickness. The pond temperature was set via setting inflow temperatures and meteorological forcings so that the temperature did not limit algal growth. Initial conditions for nutrients were specified such that there was a brief phytoplankton bloom that occurred when growth was not limited by either light or nutrient conditions. Light 
conditions were set such that growth limitation due to self-shading occurred only early in the simulation once algal abundances increased to sufficient levels but before nutrient depletion became the growth limiting factor. Eventually the nutrient limited algal growth rate $\left(\mathrm{PO}_{4}\right.$ was the limiting nutrient) exactly balanced biomass losses through flushing, sinking, mortality, and respiration. Recycling of algal organic matter serves as a source of particulate and dissolved organic matter. As expected, an equilibrium condition was finally established where each water quality constituent asymptotically approached a constant concentration.

Figure 11. Comparison of model predictions in the surface layer for orthophosphate ( $\mathrm{PO}_{4}$, top panel), labile particulate organic matter (LPOM, middle panel), and algal organic matter (AOM, bottom panel) for a test case of a pond modeled as one (Simulink) or two (CE-QUAL-W2) horizontal segments. For the CE-QUAL-W2 case, the most downstream of the two horizontal segments is shown.
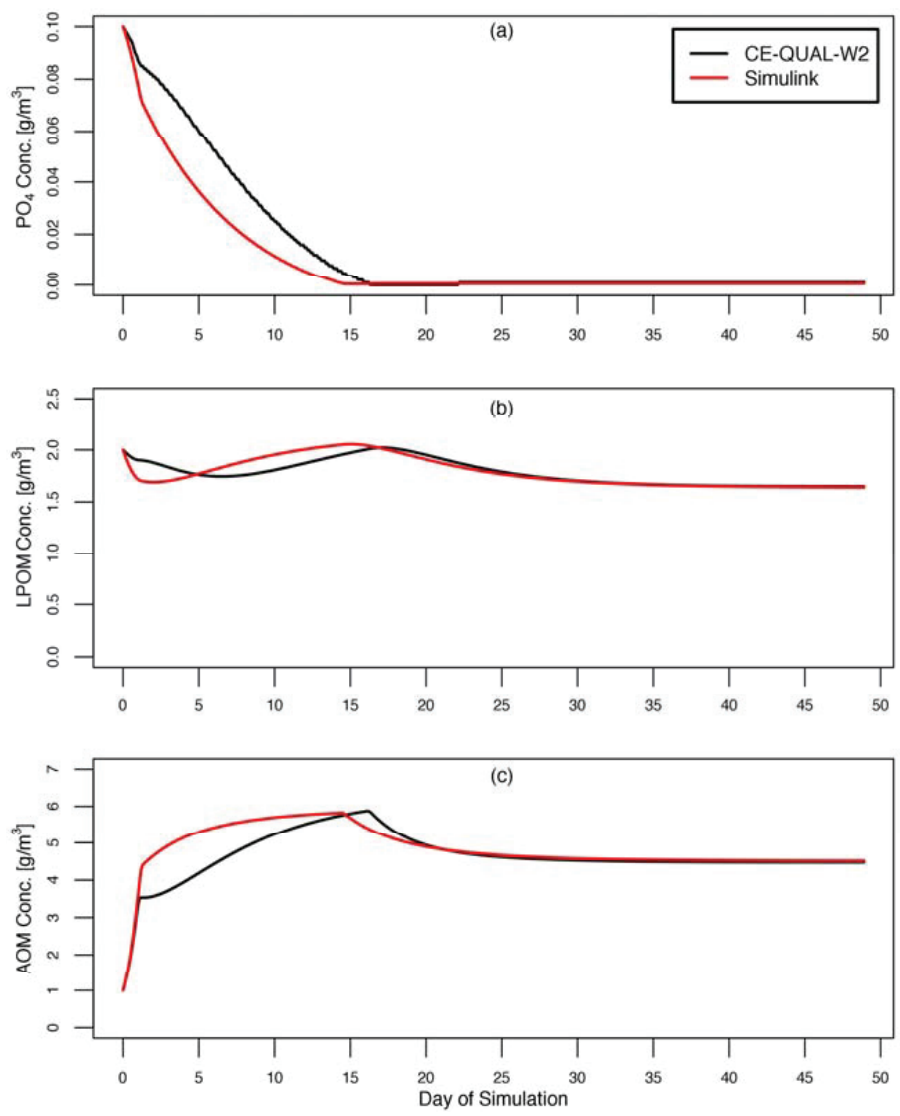

Concentration time histories for three representative constituents (orthophosphate- $\mathrm{PO}_{4}$, labile particulate organic matter-LPOM, and algal organic matter-AOM) as predicted by CE-QUAL-W2 and W2_SL (Figure 11), show nearly identical values for the asymptotic concentrations, but some transient differences in the concentrations in the first few days of the simulations. The final 
concentrations for the three constituents varied between 0.0 percent $\left(\mathrm{PO}_{4}\right)$ and 0.87 percent $(\mathrm{AOM})$. The $\mathrm{PO}_{4}$ concentration declined more rapidly in the Simulink case, reaching 10 percent of the initial concentration in 10.5 rather than 13.1 days (Table 1). Smaller relative differences were observed between the corresponding LPOM and AOM peak concentrations (1.63 and 0.88 percent) and the times to peak AOM concentration (11.1 percent, Table 1). These differences are thought to be due to the different physical configuration of the two systems and not to model errors or limitations of the modeling approach. We are currently developing a Simulink model having two horizontal segments that will allow for a better comparison test between the two models.

Table 1. Comparison of representative statistics for predictions of orthophosphate $\left(\mathrm{PO}_{4}\right)$, labile particulate organic matter (LPOM), and algal organic matter (AOM, bottom panel) for a test case of a pond modeled as one (Simulink) or two (CE-QUAL-W2) horizontal segments.

\begin{tabular}{cccc}
\hline Statistic & $\begin{array}{c}\text { Simulink } \\
\text { Value }\end{array}$ & CE-QUAL-W2 & $\begin{array}{c}\text { Percent } \\
\text { Difference }\end{array}$ \\
\hline $\mathrm{PO}_{4}$, time to $10 \%$ of initial concentration (days) & 10.5 & 13.1 & 19.9 \\
$\mathrm{PO}_{4}$, final concentration $\left(\mathrm{g} / \mathrm{m}^{3}\right)$ & 0.001 & 0.001 & 0.0 \\
$\mathrm{LPOM}$, peak concentration $\left(\mathrm{g} / \mathrm{m}^{3}\right)$ & 2.054 & 2.021 & 1.63 \\
LPOM, final concentration $\left(\mathrm{g} / \mathrm{m}^{3}\right)$ & 1.640 & 1.648 & 0.49 \\
$\mathrm{AOM}$, peak concentration $\left(\mathrm{g} / \mathrm{m}^{3}\right)$ & 5.826 & 5.878 & 0.88 \\
$\mathrm{AOM}$, time to peak $($ days $)$ & 14.4 & 16.2 & 11.1 \\
$\mathrm{AOM}$, final concentration $\left(\mathrm{g} / \mathrm{m}^{3}\right)$ & 4.514 & 4.475 & 0.87 \\
\hline
\end{tabular}

For teaching purposes, a working but not completely functional version of the model was given to students who were working cooperatively as part of a final project for the water quality modeling course. The project task assigned was to add the necessary functionality and then use the model to predict dissolved oxygen concentrations for a system receiving pollutant inputs of organic matter and ammonia. Small groups of students were assigned responsibility for creating submodels of individual constituents such as ammonia, dissolved oxygen, or BOD. Other students were responsible for connecting the submodels together and generating model solutions for the group.

The students successfully used the single segment three-layer water quality model based upon CE-QUAL-W2 as the basis for a final project in the water quality modeling course. During the project students were able to work together to combine their individual contributions into a single model. It was necessary to provide at the start of the project a working, but not fully functional version of the model to the students. In particular, several constituents (e.g., ammonia, nitrate, dissolved oxygen) and several process calculations (e.g., dissolved oxygen reaeration, sediment oxygen demand) were left out of the model that served as the project's starting point. Despite the fact that students differed quite significantly in their numerical problem solving ability and in their experience with high-level programming languages, they each were able to contribute to the group's efforts, and collectively they did complete the model development part of the project. Overall both the students and the instructor found the model development project to be successful. 


\section{Discussion and Conclusions}

Our investigation of Simulink has shown that it is possible to create multi-dimensional, multi-constituent finite-volume based water quality models without the use of a high-level programming language. A version of the model with the complete set of CE-QUAL-W2 kinetics is being tested for research use. Currently the model is being tested with the data sets included with CE-QUAL-W2. Simulation times for a 400-day run are approximately 5 minutes. Significantly faster run times are expected once a fully compiled version of the model is created. Once the model has been thoroughly tested, we plan to use it as part of a study investigating toxic byproducts of algal production that have been observed in agricultural ponds in the Limousin region of France. This novel Simulink-based multi-dimensional water quality model seems like a particularly good choice for this application because additional constituents may be needed to simulate the processes that lead to toxin accumulation in the pond. The Simulink model environment has been found to be quite convenient for adding and deleting of constituents in the model depending upon project need.

The model as currently written could be applied for systems with a reasonably small number (1-5) of segments and layers. Additional development is focused on creating a model that can conveniently be applied to systems with many segments and many layers, as these models are commonly used. The model as shown in this article requires manual construction of data links between any new segments and layers, which makes expansion to many segments and layers difficult. In testing now is a procedure that uses the "for each subsystem" Simulink construct that allows for specification of a single set of subsystems (e.g., mass, heat, volume balances) that can simultaneously be applied to all segments and layers of the physical system. Use of this new construct should make the model much easier to expand to multiple horizontal segments and vertical layers.

Our experience with Simulink in the classroom is also promising. Students involved in the pilot test class and the first-time use in the regular course, report that problem solutions created with Simulink take approximately the same time as those earlier made with Excel and are much less tedious to debug and grade. Students report that the copy and paste feature for subsystems and objects makes reuse from problem to problem relatively simple. Overall they had a positive experience in using Simulink as a model development environment in the water quality model course. Based upon these experiences, Simulink will be used for model development the next time the course is taught.

\section{Acknowledgments}

This material is based on work supported by the National Science Foundation/National Institutes of Health joint program in ecology and evolution of infectious diseases under grant no. OCE-0813147.

\section{Conflicts of Interest}

The authors declare no conflict of interest. 


\section{References}

1. Mooij, W.M.; Trolle, D.; Jeppesen, E.; Arhonditsis, G.; Belolipetsky, P.V.; Chitamwebwa, D.B.; Degermendzhy, A.G.; DeAngelis, D.L.; Domis, L.N.D.S.; Downing, A.S. Challenges and opportunities for integrating lake ecosystem modelling approaches. Aquat. Ecol. 2010, 44, 633-667.

2. Ambrose, R.B.; Wool, T.A.; Martin, J.L. The Water Quality Analysis Simulation Program, Wasp5, Part A: Model Documentation; Environmental Research Laboratory, US Environmental Protection Agency: Athens, GA, USA, 1993.

3. Hamrick, J.M. A Three-Dimensional Environmental Fluid Dynamics Computer Code: Theoretical and Computational Aspects; Virginia Institute of Marine Science and College of William and Mary: Williamsburg, VA, USA, 1992.

4. Park, K.; Kuo, A.Y.; Shen, J.; Hamrick, J.M. A Three-Dimensional Hydrodynamic-Eutrophication Model (Hem-3d): Description of Water Quality and Sediment Process Submodels; Virginia Institute of Marine Science: Gloucester Point, VA, USA, 1995.

5. Brown, L.C.; Barnwell, T.O. The Enhanced Stream Water Quality Models Qual2e and Qual2e-Uncas: Documentation and User Manual; Environmental Research Laboratory, Office of Research and Development, US Environmental Protection Agency: Athens, GA, USA, 1987.

6. Cerco, C.F.; Cole, T. Three-dimensional eutrophication model of chesapeake bay. J. Environ. Eng. 1993, 119, 1006-1025.

7. Cole, T.M.; Buchak, E.M. CE-Qual-W2: A Two-Dimensional, Laterally Averaged, Hydrodynamic and Water Quality Model, Version 2.0, User Manual; Instruction Report EL-951; U.S. Army Corps of Engineers: Washington, DC, USA, 1995.

8. Bowen, J.D.; Hieronymus, J.W. A ce-qual-w2 model of neuse estuary for total maximum daily load development. J. Water Resour. Plann. Manag. 2003, 129, 283-294.

9. Bowen, J.D.; Rajbhandari, N. Estimating dissolved oxygen depletion from anthropogenic and riverine loadings using a three-dimensional water quality model. In Estuarine and Coastal Modeling, Proceedings of the Twelfth International Conference, St. Augustine, FL, USA, 7-9 November 2011; ASCE Publications: Reston, VA, USA, 2012; p. 274.

10. Froelich, B.; Bowen, J.; Gonzalez, R.; Snedeker, A.; Noble, R. Mechanistic and statistical models of total Vibrio abundance in the neuse river estuary. Water Res. 2013, 47, 5783-5793.

11. Peacock, S. The use of Simulink for process modelling in the sugar industry. Proc. S. Afr. Sug. Technol. Ass. 2002, 76, 444-455.

12. Kalagasidis, A.S.; Weitzmann, P.; Nielsen, T.R.; Peuhkuri, R.; Hagentoft, C.-E.; Rode, C. The international building physics toolbox in Simulink. Energy Build. 2007, 39, 665-674.

13. Smets, I.Y.; Haegebaert, J.V.; Carrette, R.; Van Impe, J.F. Linearization of the activated sludge model asm1 for fast and reliable predictions. Water Res. 2003, 37, 1831-1851.

14. Rosen, C.; Vrecko, D.; Gernaey, K.; Pons, M.-N.; Jeppsson, U. Implementing ADM1 for plant-wide benchmark simulations in Matlab/Simulink. Water Sci. Technol. 2006, 54, 11-19. 
15. Vrecko, D.; Gernaey, K.; Rosen, C.; Jeppsson, U. Benchmark simulation model no 2 in Matlab-Simulink: Towards plant-wide wwtp control strategy evaluation. Water Sci. Technol. 2006, 54, 65-72.

16. Åmand, L.; Carlsson, B. Optimal aeration control in a nitrifying activated sludge process. Water Res. 2012, 46, 2101-2110.

17. Achleitner, S.; Möderl, M.; Rauch, W. City drain ${ }^{\circ}$ - an open source approach for simulation of integrated urban drainage systems. Environ. Model. Softw. 2007, 22, 1184-1195.

18. Ahlman, S.; Svensson, G. Modelling substance flows in urban sewer systems using Matlab/Simulink. Bridges 2002, 10, 101.

19. Astaraie-Imani, M.; Kapelan, Z.; Fu, G.; Butler, D. Assessing the combined effects of urbanisation and climate change on the river water quality in an integrated urban wastewater system in the UK. J. Environ. Manag. 2012, 112, 1-9.

20. Fu, G.; Butler, D.; Khu, S.-T. The impact of new developments on river water quality from an integrated system modelling perspective. Sci. Total Environ. 2009, 407, 1257-1267.

21. Giusti, E.; Marsili-Libelli, S.; Gualchieri, A. Modelling a coastal lake for flood and quality management. In Watermatex 2011, Proceedings of the 8th IWA Symposium on Systems Analysis and Integrated Assessment, San Sebastian, Spain, 20-22 June 2011; International Water Association: London, UK, 2011; pp. 396-403.

22. Gnauck, A.; Luther, B.; Krug, W. Using a commercial optimisation tool for fine tuning of parameters of an eutrophication model. In Environmental Software Systems: Frameworks of Environment; Springer: Heidelberg, Germany, 2011; pp. 618-624.

23. Mitreski, K.; Naumoski, A. Dynamic model and estimation of the future eutrophication for the Lake Prespa. In Proceedings of the 2nd IASME/WSEAS International Conference on Energy and Environment, Portoroz, Slovenia, 15-17 May 2007; World Scientific and Engineering Academy and Society (WSEAS): Portoroz, Slovenia, 2007; pp. 44-49.

24. Boulmalf, M.; Semmar, Y.; Lakas, A.; Shuaib, K. Teaching Digital and Analog Modulation to Undergradute Information Technology Students Using Matlab and Simulink. In Proceedings of IEEE EDUCON Education Engineering 2010-The Future of Global Learning Engineering Education, Madrid, Spain, 14-16 April 2010; IEEE: Piscatway, NJ, USA, 2010; pp. 685-691.

25. Tessarolo, A. Modeling and simulation of multiphase machines in the Matlab/Simulink environment. In Engineering Education and Research Using MATLAB; Assi, A.H., Ed.; InTech: Rijeka, Croatia, 2011; Chapter 1.

26. Cathers, B.; Boyd, M.; Craig, E.; Chadwick, M. Modelling for environmental engineering students using Matlab and Simulink. In Proceedings of IEEE International Conference on Multi Media Engineering Education, Melbourne, Australia, 3-5 July 1996; IEEE: Piscatway, NJ, USA, 1996; pp. 261-268.

27. Morgenroth, E.; Arvin, E.; Vanrolleghem, P. The use of mathematical models in teaching wastewater treatment engineering. Water Sci. Technol. 2002, 45, 229-233.

28. Bayrakceken, M.K.; Arisoy, A. An educational setup for nonlinear control systems: Enhancing the motivation and learning in a targeted curriculum by experimental practices [focus on education]. Control Systems IEEE 2013, 33, 64-81. 
29. Durán, M.J.; Gallardo, S.; Toral, S.L.; Martínez-Torres, R.; Barrero, F.J. A learning methodology using Matlab/Simulink for undergraduate electrical engineering courses attending to learner satisfaction outcomes. Int. J. Technol. Des. Educ. 2007, 17, 55-73.

30. Schnoor, J.L. Environmental Modeling: Fate and Transport of Pollutants in Water, Air, and Soil; John Wiley and Sons: Hoboken, NJ, USA, 1996.

31. Thomann, R.V.; Mueller, J.A. Principles of Surface Water Quality Modeling and Control; Harper \& Row, Publishers: New York, NY, USA, 1987.

32. Martin, J.L.; McCutcheon, S.C. Hydrodynamics and Transport for Water Quality Modeling; CRC Press: Boca Raton, FL, USA, 1998.

33. Chapra, S.C. Surface Water-Quality Modeling; Waveland Press: Salem, WI, USA, 2008.

34. Chin, D.A. Water-Quality Engineering in Natural Systems: Fate and Transport Processes in the Water Environment; John Wiley \& Sons: Hoboken, NJ, USA, 2012.

35. USDA. Urban Hydrology for Small Watersheds; Technical Release 55; Conservation Engineering Division, Natural Resources Conservation Service, United States Department of Agriculture: Washington, DC, USA, 1986; pp. 2-6. 


\title{
Analysis of Hurricane Irene's Wind Field Using the Advanced Research Weather Research and Forecast (WRF-ARW) Model
}

\section{Alfred M. Klausmann}

\begin{abstract}
Hurricane Irene caused widespread and significant impacts along the U.S. east coast during 27-29 August 2011. During this period, the storm moved across eastern North Carolina and then tracked northward crossing into Long Island and western New England. Impacts included severe flooding from the mid-Atlantic states into eastern New York and western New England, widespread wind damage and power outages across a large portion of southern and central New England, and a major storm surge along portions of the Long Island coast. The objective of this study was to conduct retrospective simulations using the Advanced Research Weather Research and Forecast (WRF-ARW) model in an effort to reconstruct the storm's surface wind field during the period of 27-29 August 2011. The goal was to evaluate how to use the WRF modeling system as a tool for reconstructing the surface wind field from historical storm events to support storm surge studies. The results suggest that, with even modest data assimilation applied to these simulations, the model was able to resolve the detailed structure of the storm, the storm track, and the spatial surface wind field pattern very well. The WRF model shows real potential for being used as a tool to analyze historical storm events to support storm surge studies.
\end{abstract}

Reprinted from J. Mar. Sci. Eng. Cite as: Klausmann, A.M. Analysis of Hurricane Irene's Wind Field Using the Advanced Research Weather Research and Forecast (WRF-ARW) Model. J. Mar. Sci. Eng. 2014, 2, 33-45.

\section{Introduction}

During the period when Hurricane Irene was moving northward along the U.S. east coast, the storm was encountering increasing wind shear and cooler sea surface temperatures and was slowly weakening as it tracked from the Carolinas to New England. Despite this, Irene brought widespread and significant impacts along the east coast, causing severe flooding from the mid-Atlantic states into eastern New York and western New England, widespread wind damage and power outages across a large portion of southern and central New England, and a major storm surge along portions of the Long Island coast. The objective of this study was to perform retrospective numerical simulations with the Advanced Research Weather Research and Forecast model (WRF-ARW) and evaluate how to use the WRF modeling system [1] as a tool for reconstructing the surface wind field for historical storm events to support storm surge studies. The WRF wind and pressure fields can be used to drive a storm surge model such as the Advanced Circulation model (ADCIRC) as part of a storm surge analysis. WRF output may represent a potential source of data for storm surge analysis especially for regions with limited or no observational data.

Storm surge studies typically use a variety of approaches to re-analyze historical storms. These include parametric wind models [2,3] to develop a radial profile of the storm winds based on 
available data typically issued in National Hurricane Center advisories, including storm central pressure, maximum wind speed, and radius of maximum wind. These parametric-based approaches have been modified recently to account for storm asymmetries by allowing for storm quadrant specific profiles, again using data from available advisories that contain information about wind radii in each quadrant of the storm. Other approaches include hurricane boundary layer models [4] and objective analysis systems such as the Interactive Objective Kinematic Analysis (IOKA) system from Ocean Weather [5] and the HWIND analysis (also denoted as H*WIND) from the National Oceanic and Atmospheric Administration's (NOAA's) Hurricane Research Division [6]. Data from the HWIND product is dependent on the density and quality of observational data, and to some extent relies on wind speeds extrapolated from flight level observations or dropsonde measurements, so the quality of the analysis may vary throughout a storm's history. Typically, a hurricane's inner core region is well sampled through reconnaissance flights and dropsonde data, while observational data may be more sparse at large distances from the center. Finally, use of nonsteady state dynamic models such as WRF offers another approach to storm reanalysis. There has been some work already done to study the use of the WRF model to drive the ADCIRC model for purposes of providing an improved storm surge prediction system [7]. However, to this author's knowledge, there have been no further applications of WRF as a tool to reanalyze historical storms events specifically for storm surge modeling studies.

WRF has a number of advantages over steady state and objective analysis approaches. The model simulates the evolution of atmospheric systems including tropical cyclones using full physics. It employs a range of physics options to account for cloud microphysics, atmospheric radiation processes, planetary boundary layer and surface layer processes, and parameterization of sub-grid scale moist convection. These capabilities allow WRF to simulate far field winds, spiral rainband structures, and supergradient flow in the inner core region [7], structures generally not resolved by other approaches. The WRF model also has full data assimilation capabilities including four-dimensional data assimilation (FDDA) and three-dimensional variational (3DVAR) approaches for blending the model fields with a diverse set of observational data [8,9]. Other more advanced data assimilation techniques such as four-dimensional variational (4DVAR) and Ensemble Kalman Filter (EnKF) techniques can also be applied to improve the analysis. Unlike HWIND or IOKA, the WRF model is not reliant on observations alone to simulate a storm event, but can use observations when available to help refine the model solutions by adjusting the model fields towards the observed data. The data assimilation process helps to constrain the model fields while preserving important structural features of the storm. Additionally, the model can output wind and pressure fields at both high spatial and temporal resolutions, thus eliminating the need for interpolating between analysis periods. Finally, the application of the WRF model is not limited to tropical cyclones but can also be used to simulate extra-tropical cyclones and hybrid type events such as Superstorm Sandy, where use of parametric modeling approaches are extremely limited. This study presents some results of an ongoing effort to optimize the WRF model for storm surge modeling applications. The focus of the work in this study was on WRF simulations of Hurricane Irene during the period 27-29 August 2011. 


\section{Methodology}

The WRF model configuration consisted of a $12-\mathrm{km}$ resolution parent domain and a $4-\mathrm{km}$ nested grid with 40 vertical levels from the surface to 100 millibars. The model was configured with a Lambert Conformal (LCC) projection, NWS-84 datum centered at $38.5 \mathrm{~N}, 83.0 \mathrm{~W}$, and with standard parallels of $28.5 \mathrm{~N}$ and $48.5 \mathrm{~N}$. A third nest was used for Advanced Hurricane WRF (WRF-AHW) simulations at a spatial resolution of $2 \mathrm{~km}$. Figure 1 shows the modeling domains for the WRF simulations with the inner nested domains focused over the northeastern United States and over the North Carolina region. The Kain-Fritsch cumulus parameterization scheme was used on the 12-km domain only, while convection was explicitly simulated on the 4-km and 2-km nested domains. The WSM5 microphysics scheme, the Yonsei University (YSU) PBL scheme, and the NOAH land surface model were implemented on all domains. The National Centers for Environmental Prediction (NCEP) 1-degree final analysis (FNL) data was used for the initial and lateral boundary conditions along with the NCEP Real Time Gridded 1/12 degree sea surface temperature data. Four-dimensional data assimilation was applied in all simulations. There are two types of FDDA available in the WRF modeling system: Analysis nudging and observation nudging. In these WRF simulations, analysis nudging was performed on the 12-km domain only using the FNL gridded analysis data. Several sensitivity simulations were also conducted with just the 4-km nested domain to examine the sensitivity of the model to the PBL and cumulus parameterization schemes. The schemes tested were based in part on previous WRF modeling studies [10,11]. In addition, simulations were conducted using three different initialization times at both 0000 and 1200 Universal Coordinated Time (UTC) on 27 August 2011, and another at 1200 UTC on 26 August 2011.

Figure 1. Weather Research and Forecast (WRF) modeling domains. Note the inner domains over the northeast United States and the North Carolina Region. Domain 2 uses a spatial resolution of $4 \mathrm{~km}$ while Domain 3 uses a spatial resolution of $2 \mathrm{~km}$.
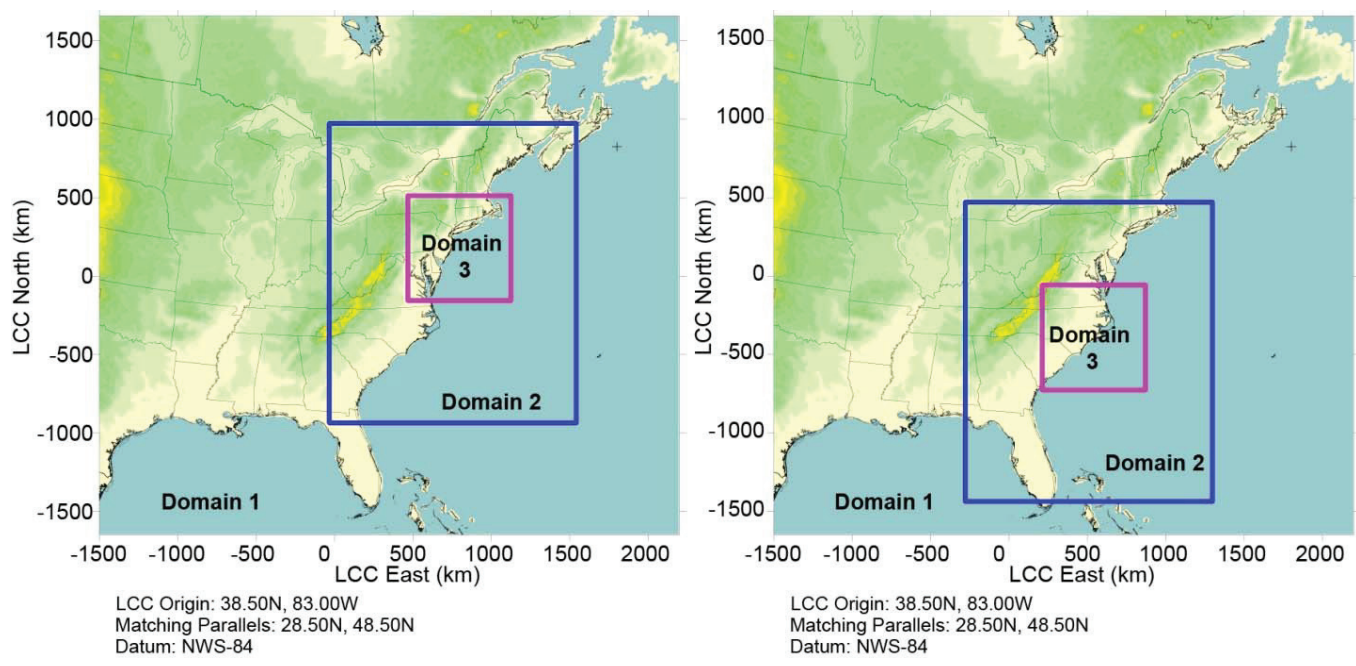
After some initial evaluation of the 4-km resolution WRF simulations, two new sets of simulations were conducted with the WRF-AHW settings with the introduction of a $2-\mathrm{km}$ resolution nested domain. One WRF-AHW simulation focused over the northeast United States and the other simulation was conducted with the $4-\mathrm{km}$ and $2-\mathrm{km}$ nested domains centered on the North Carolina region. These WRF-AHW simulations used a specific selection of data and physics options that were designed to improve the WRF model's performance specifically for hurricanes. The WRFAHW configuration consists of initializing the model with HYCOM ocean model data and selecting the surface ocean physics option. This allows the model to evolve the sea surface temperature in response to the storm. The Donelan surface flux option was selected for handling surface fluxes and surface drag. For the WRF-AHW simulations, available surface observations and upper air soundings from the National Centers for Environmental Predictions Automated Data Processing (ADP) data were blended with the FNL analysis data and used for the analysis nudging. The ADP surface and upper air data consist of land-based surface observations, buoy data, and ship reports as well as radiosonde measurements, data from pibals, and aircraft reports. For the WRF-AHW simulations, the WSM5 microphysics, Kain-Fritsch cumulus parameterization, YSU planetary boundary layer scheme, and NOAH land surface model were used. The microphysics, cumulus parameterization, and surface and planetary boundary layer schemes used in the WRF-AHW simulations were the same as the initial WRF simulations conducted on the 4-km nested domain.

Figure 2. Plot of surface meteorological stations.

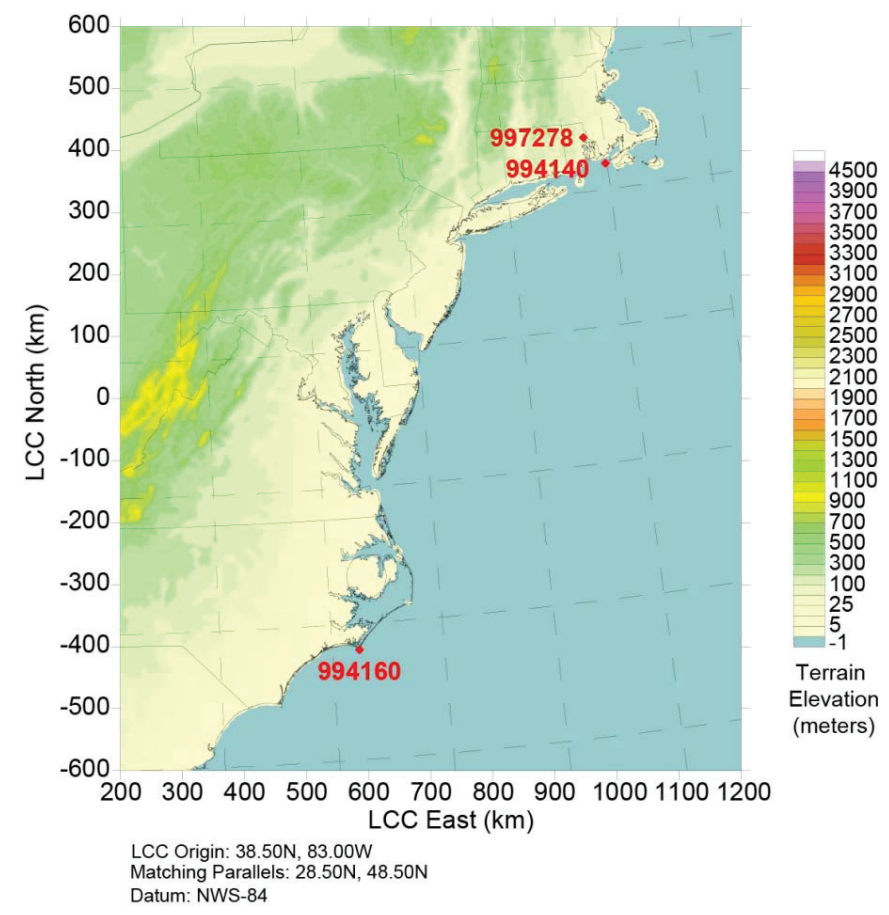

Figure 2 shows a plot of the surface stations used for validation. They include Cape Lookout, North Carolina (Station 994160), Buzzards Bay, Massachusetts (Station 994140), and Providence 
Rhode Island (Station 997278). For comparisons with direct observations, time series plots were constructed from the observations and compared against time series from the WRF simulation at the observation locations.

\section{Results}

Figure 3 shows wind vector plots from the 4-km modeling domain from the initial WRF simulation which are compared to the National Hurricane Center Best Track data. This figure shows that the WRF track of Irene fits quite well with the best track data. At 1200 UTC on August 28 (right plot of Figure 3), there is a small southwestward displacement by about $30 \mathrm{~km}$ compared to the best track data suggesting the model storm was slightly slower than indicated by the observed data.

Figure 3. WRF $10-\mathrm{m}$ wind vectors on the 4-km domain over the northeast United States (see left plot in Figure 1) at 0000 UTC (left) and 1200 Universal Coordinated Time (UTC) (right) 28 August 2011. The red line shows the observed track of Hurricane Irene.
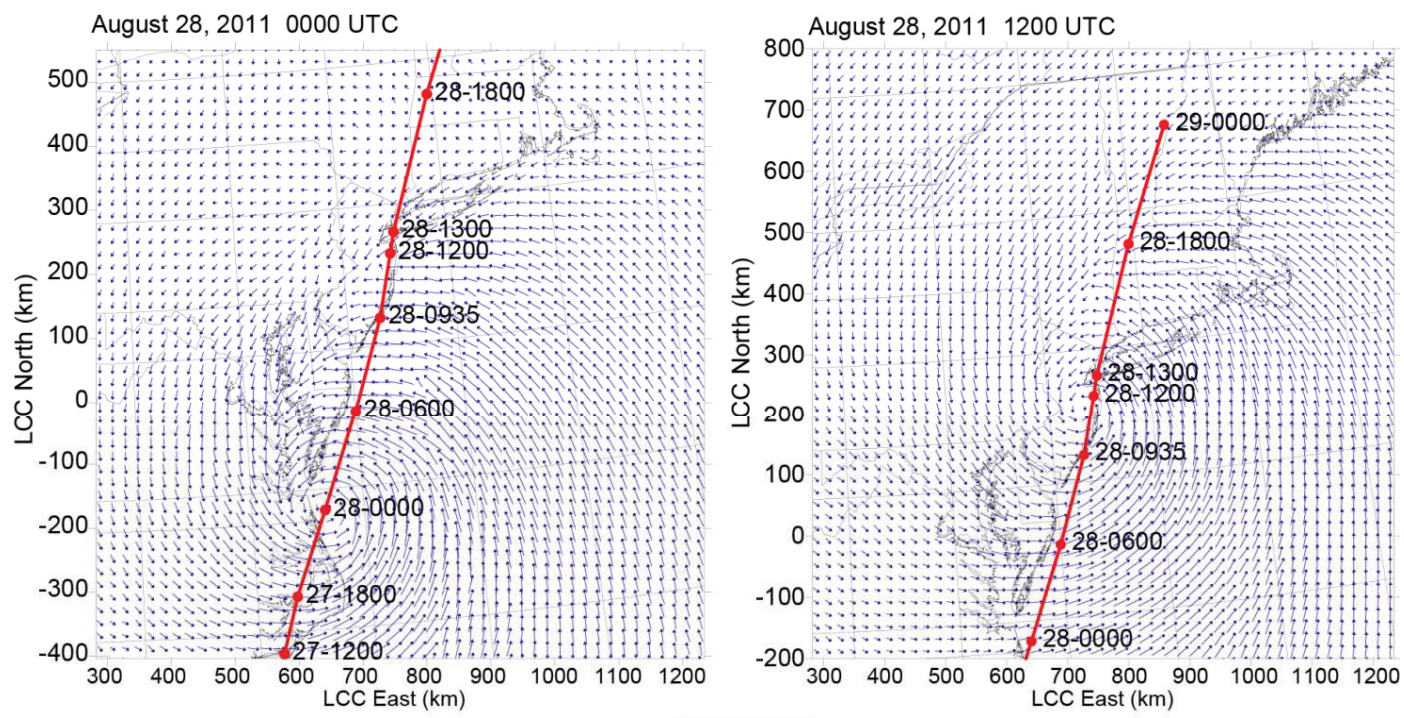
\begin{aligned} \hline Wind Speed $(\mathrm{m} / \mathrm{s}) \\ \rightarrow \\ \rightarrow \\ \rightarrow \\ \rightarrow 10 \\ \end{aligned}$

Figure 4 shows the WRF 10-m wind speed plots on the 4-km resolution modeling domains from the initial WRF simulations and compares these to the HWIND 10-m wind speed analysis. This indicates that at a resolution of $4 \mathrm{~km}$, the shape and orientation of the surface wind field agreed well with HWIND, but the WRF wind speeds were larger overall compared to the HWIND analysis. At this resolution, the WRF model was able to resolve key structural aspects of Hurricane Irene. For modeling classic hurricanes with a compact and well developed inner core, grid resolutions of at least $2 \mathrm{~km}$ would be needed to properly resolve the inner core structure. 
In order to assess how well the WRF simulations reproduced the overall storm structure and dynamics, a plot of total precipitation from the WRF simulation was compared against the NOAA Advanced Hydrologic Prediction System (AHPS) multi-sensor precipitation analysis product. Figure 5 shows the total rainfall for the 24-h period ending on 28 August 2011, from the WRF simulation for the 4-km resolution domain compared to the AHPS analysis for the same period. The results show that the spatial pattern of total storm rainfall along the U.S. east coast was well simulated by WRF. This plot shows a distinct southwest to northeast axis of 6- to 8-in. rainfall totals extending from the Carolinas into western New England and eastern New York in both the WRF simulation and the observed rainfall analysis. Pockets of rainfall greater than 10 in. are evident both in the WRF simulation and the observed data. This suggests the WRF model properly simulated the storm structure and dynamics.

Figure 4. WRF 10-m wind speed analysis on the 4-km resolution domain (A) at 0400 UTC and (C) at 1300 UTC compared to the HWIND 10-m wind speed analysis (B) 0430 UTC and (D) at 1330 UTC on 28 August 2011 (Courtesy of the Hurricane Research Division).
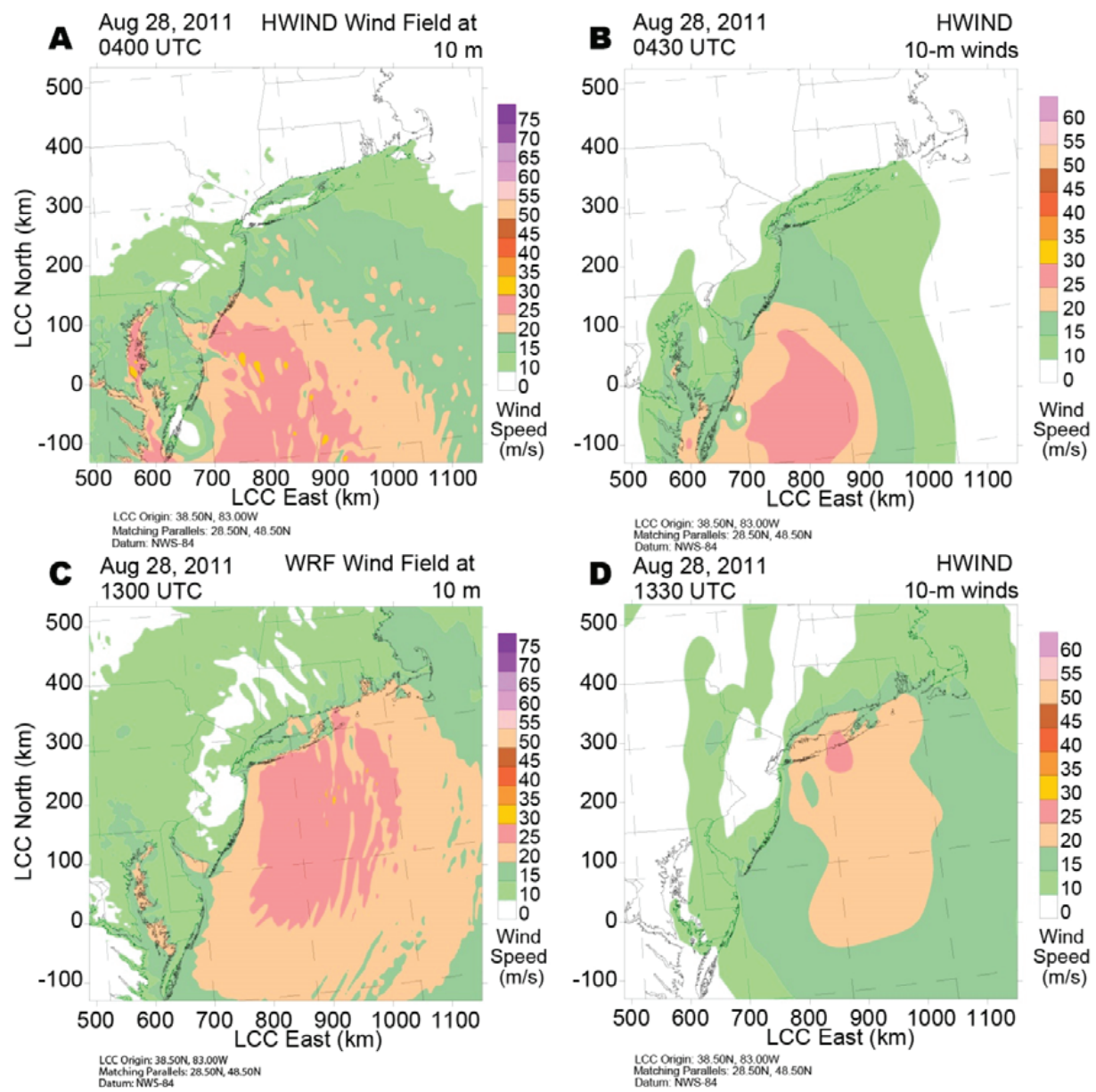
Figure 5. Twenty four-hour total rainfall ending on 28 August 2011, at 1200 UTC from WRF simulation on the 4-km domain (left) and observed rainfall from the National Oceanic and Atmospheric Administration (NOAA) Advanced Hydrologic Prediction System (AHPS) Multi-Sensor Precipitation Analysis (right).
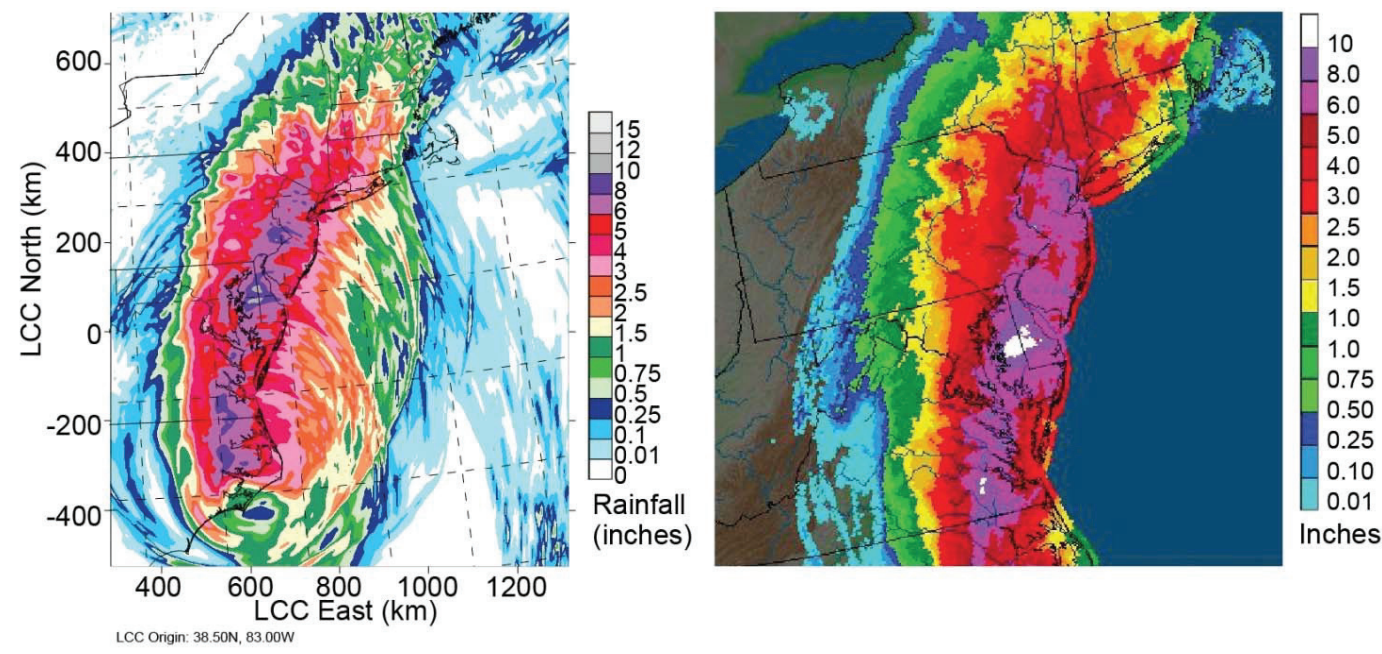

Time series plots of 10-m wind speed for several of the initial WRF sensitivity simulations on the 4-km nested domain only are compared to time series of the observed wind speeds and are provided in Figure 6. The time series at Cape Lookout shows that the WRF simulations captured the wind speed signature of the storm's eye as it passed over Cape Lookout. The WRF simulations were a little slower, bringing the eye into Cape Lookout later by a couple of hours compared to the observed data. The peak wind speeds were higher than the observed winds at Cape Lookout, but as a whole, the time evolution of the WRF wind speeds was in general agreement with the observed data. Note that after about $36 \mathrm{~h}$, when the eye region is northeast of Cape Lookout, the WRF wind speeds are higher for all simulations compared to the observed data. The time series at Providence and Buzzards Bay both show the WRF wind speeds in close agreement with the observed winds. Overall there is some variability between the different simulations, but all the simulations show wind speeds that cluster near the observed values. Computed root mean square error (RMSE) values were on the order of about $2 \mathrm{~m} / \mathrm{s}$ for Providence and Buzzards Bay and about $4 \mathrm{~m} / \mathrm{s}$ at Cape Lookout. The larger error at Cape Lookout is likely due to the tighter gradients near the storm core at a period when the storm had a more well-defined inner core structure. Thus, small timing errors in the WRF simulation can result in increased RMSE values.

Figure 7 shows both wind vectors and color-filled, 10-m wind speed contours for the two WRF-AHW simulations on the 2-km resolution domain, one for the North Carolina region (top) and the other for the Northeast region (bottom). Figure 7 shows that the $2-\mathrm{km}$ resolution WRF model presents a realistic representation of Hurricane Irene's spatial wind field structure. While the storm was evolving south of the North Carolina coast, the WRF model shows a more well defined but still asymmetric wind field structure. The asymmetry was more pronounced as the storm moved northward along the Northeast coast and into western New England on 28 August 2011. Most of 
the strong surface winds were east of the center and covered a larger spatial region. Note that the WRF-AHW simulations on the 2-km nested domain show a somewhat stronger storm (compared to the 4-km resolution simulations shown in Figure 4). This is, at least in part, due to the increased grid resolution.

Figure 6. Time series plots of WRF 10-m wind speeds compared to observed data for several WRF simulations using different physics, cumulus parameterization, and initialization times for Cape Lookout, North Carolina (top), Buzzards Bay, Massachusetts (middle), and Providence, Rhode Island (bottom).
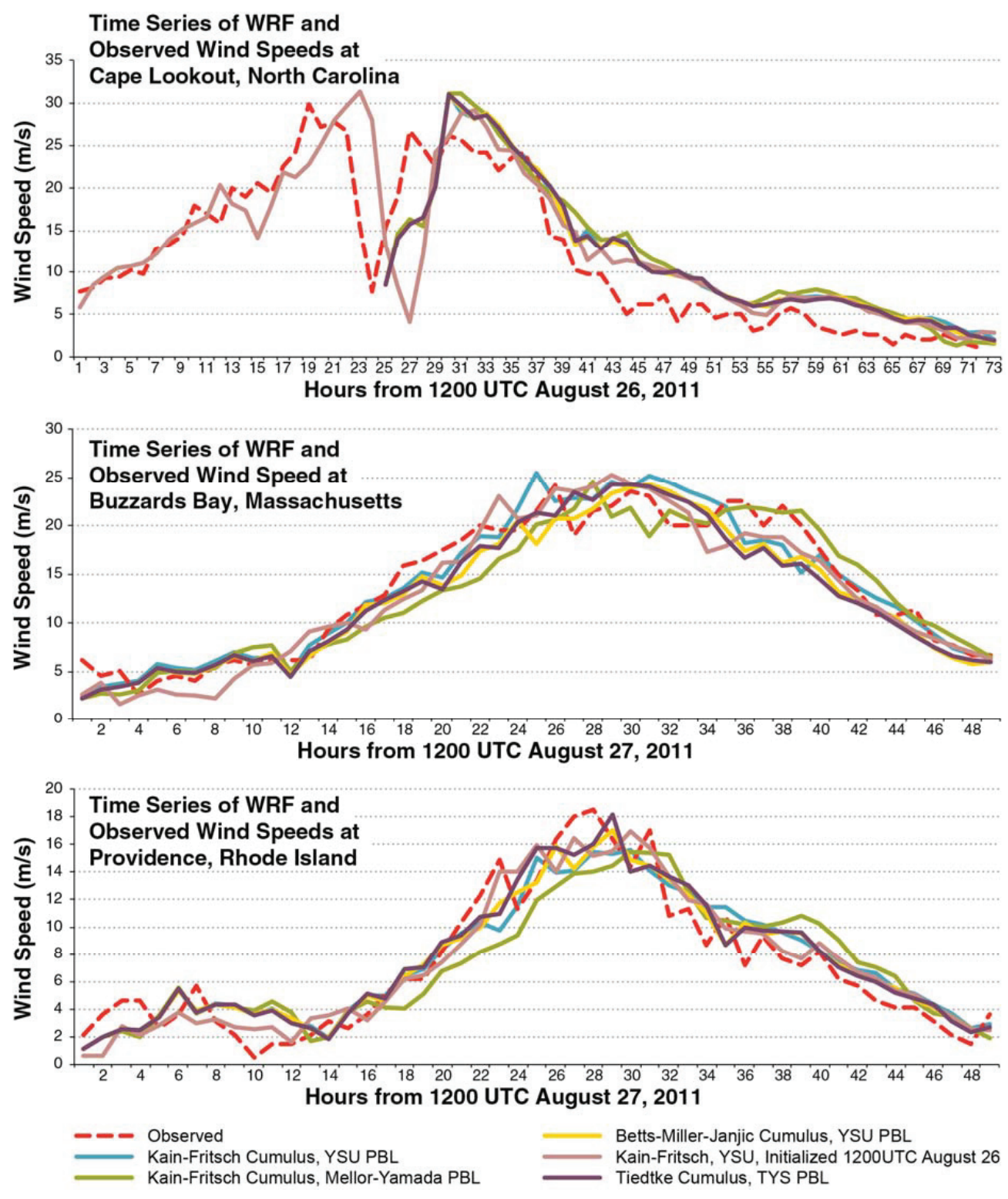
Figure 7. WRF-AHW wind vectors and 10-m wind speed analysis on the 2-km resolution domain (A) at 1200 UTC on 27 August 2011, (B) at 1600 UTC on 27 August 2011, (C) 0400 UTC on 28 August 2011, and (D) at 1200 UTC on 28 August 2011.
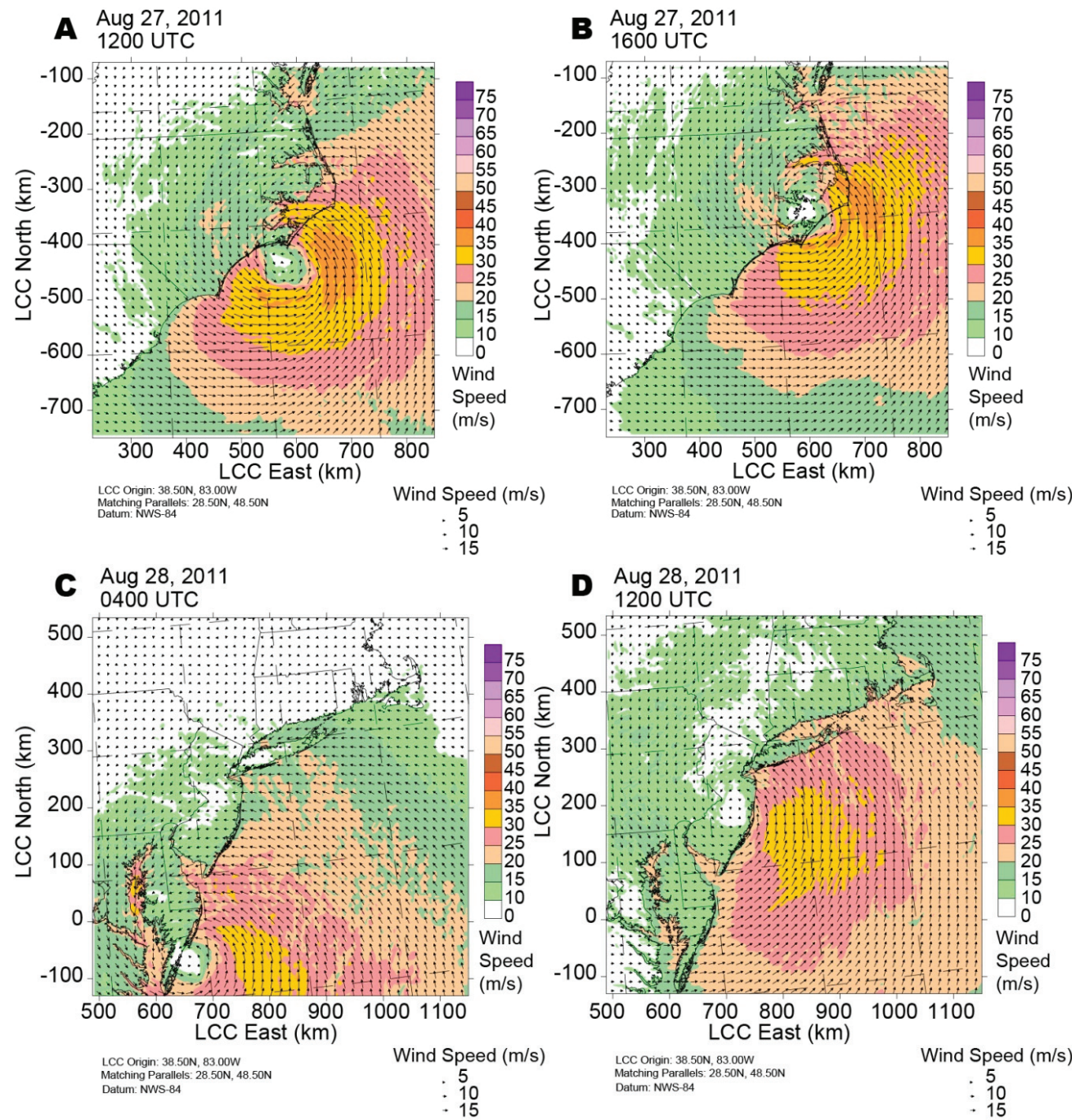

Figure 8 shows the WRF-AHW simulation 10-m wind speed analysis (2-km resolution domain) compared to the HWIND analysis product. These results show close agreement with the shape and location of the maximum wind speed axis depicted by the HWIND analysis. The WRF wind speeds were higher in both the inner core and outer regions relative to HWIND. Some preliminary analysis (not shown) suggests that the higher wind speeds are due to the central pressures being too low in WRF compared to the observed data. Further sensitivity simulations are being explored to understand this issue. 
Figure 8. WRF-AHW 10-m wind speed analysis on the 2-km resolution domain (A) at 1000 UTC compared to the HWIND 10-m wind speed analysis (B) at 1030 UTC on 27 August 2011, (C) WRF at 1300 UTC, and (D) HWIND at 1330 UTC on 28 August 2011 (HWIND data Courtesy of the Hurricane Research Division).
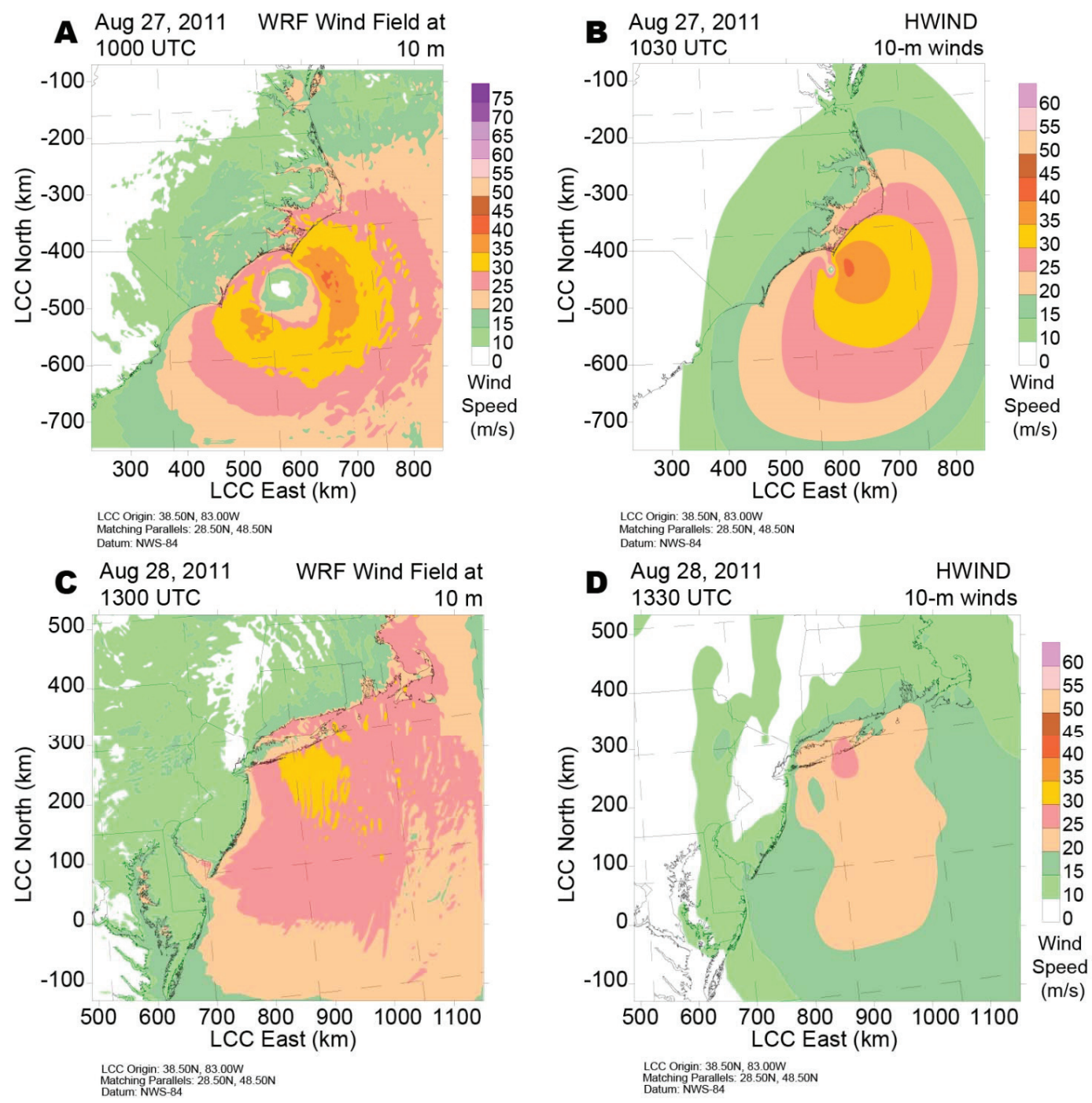

Figure 9 shows a comparison of the WRF-AHW simulated radar reflectivity run with the Special Sensor Microwave Imager Sounder (SSMIS) microwave image from the Defense Meteorological Satellite Programs F-16 satellite obtained from the U.S. Naval Research Laboratory. The SSMIS imagery is sensitive to precipitation particles rather than cloud top temperature and as a result has some similarities to a radar image. The simulated WRF-AHW reflectivity is from the 2-km resolution nested grid. These plots show excellent agreement between the WRF reflectivity field and the SSMIS imagery. Note that the WRF simulation correctly resolved the large intense 
precipitation region north and northwest of the storm center as well as the cyclonically curved rainband structures to the east and southeast of the center of Irene.

Figure 9. Simulated radar reflectivity from WRF-AHW simulation on the 2-km resolution domain for 28 August 2011, at 1200 UTC (left) and the special sensor microwave imager Sounder (SSMIS) photo (right) for 28 August 2011, at 1136 UTC from the Defense Meteorological Satellite Programs F-16 Satellite (SSMIS image courtesy of the U.S. Naval Research Laboratory).
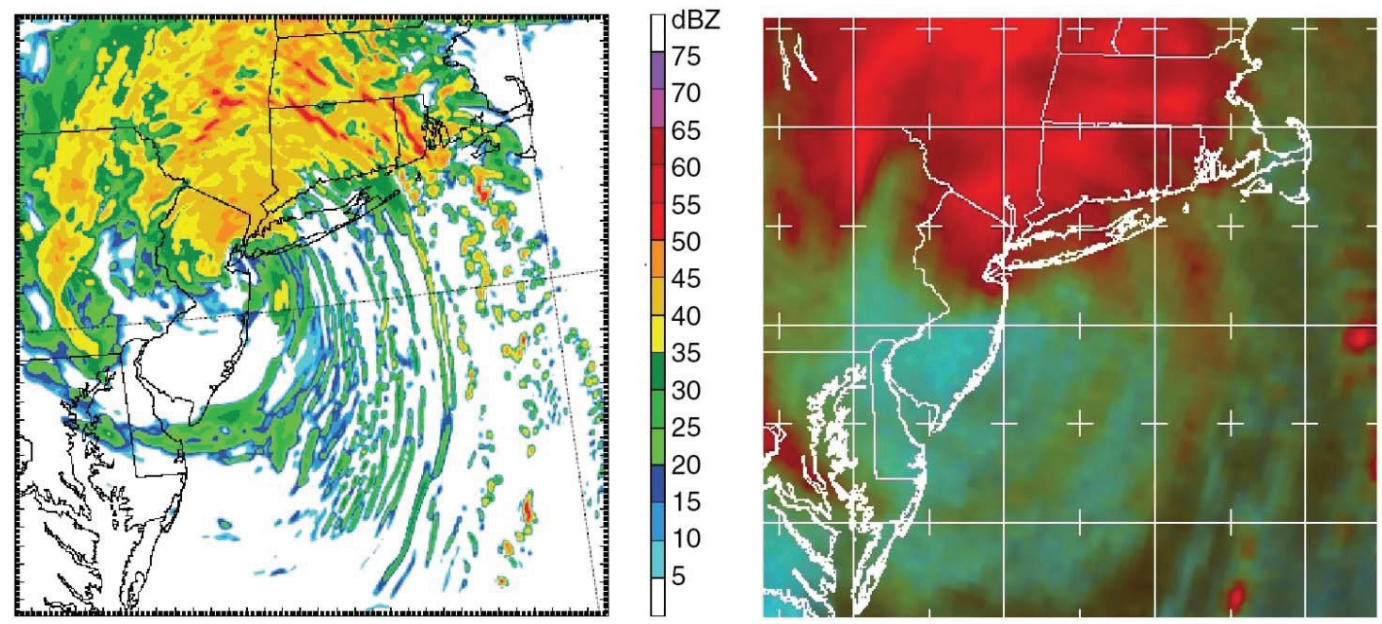

The results of both the initial WRF simulations on the 4-km resolution nested domain and the WRF-AHW simulations on the 2-km nested domain suggest that with even modest data assimilation applied to these simulations, the model was able to resolve the detailed structure of the storm, the storm track, and the spatial surface wind field pattern very well.

\section{Concluding Remarks}

The WRF simulations showed that the WRF model realistically simulated the overall structure and movement of Hurricane Irene. The WRF simulations presented here show that the spatial surface wind field pattern and the shape and location of maximum winds compared well with the Hurricane Research Division's HWIND analysis product. The WRF 10-m wind speed analysis showed higher wind speeds relative to the HWIND analysis. Comparisons of the WRF simulated 24-h total rainfall with the NOAA observed rainfall analysis showed close agreement, while simulated radar reflectivity compared to satellite imagery showed that WRF correctly resolved the rainfall patterns as well as rainband structures east of the storm center.

These results suggest that with even modest data assimilation applied to these simulations, the model was able to resolve the detailed structure of the storm, the storm track, and the spatial surface wind field pattern very well. The WRF model shows real potential for being used as a tool to analyze historical storm events to support storm surge studies. 
Improved data assimilation strategies and more comprehensive sensitivity testing to examine different physics options and their interaction should help to improve the model's performance. Work is currently underway to assimilate dropsonde data directly into the high resolution WRF domains to help improve the WRF analysis. Future efforts will explore assimilating more observational data directly, testing various data assimilation methods, performing sensitivity tests with different physics schemes, and evaluating the use of different data sets for initial and lateral boundary conditions, as well as assimilating selected grid point data from the HWIND analysis data sets. Finally, a more comprehensive model performance evaluation is needed, incorporating more observational data to better quantify the accuracy of the model results relative to observed data. This should also include a more detailed evaluation of the HWIND analysis to determine how well this product is capturing key features of the storm's wind field.

\section{Acknowledgments}

I would like to thank Christopher DesAutels, Christelle Escoffier, and Zhong Wu of Exponent for their assistance with data processing and their helpful comments. I would also like to thank Christopher Davis and Jimy Dudhia from the National Center for Atmospheric Research for their helpful suggestions, Mark Powell of the Hurricane Research Division for providing technical information on the HWIND data, and the Hurricane Research Division for making the HWIND data and dropsonde data available.

\section{Conflicts of Interest}

The authors declare no conflict of interest.

\section{References}

1. Skamarock, W.C.; Klemp, J.B.; Dudhia, J.; Gill, D.O.; Barker, D.M.; Duda, M.G.; Huang, X.-Y.; Wang, W.; Powers, J.G. A Description of the Advanced Research WRF Version 3; NCAR Technical Note: NCAR/TN-4751+STR; National Center for Atmospheric Research: Boulder, CO, USA, 2008.

2. Holland, G.J. An analytic model of the wind and pressure profiles in hurricanes. Mon. Weather Rev. 1980, 108, 1212-1218.

3. Holland, G.J. A revised model for radial profiles of hurricane winds. Mon. Weather Rev. 2010, 138, 4393-4401.

4. Vickory, P.J.; Wadhera, D.; Powell, M.D.; Chen, Y. A hurricane boundary layer and wind field model for use in engineering applications. J. Appl. Meteorol. Climatol. 2009, 48, 381-405.

5. Cox, A.T.; Greenwood, J.A.; Cardone, V.J.; Swail, V.R. An interactive objective kinematic analysis system. In Proceedings of 4th International Workshop on Wave Hindcasting and Forecasting, Banff, Alberta, Canada, 16-20 October 1995.

6. Powell, M.D.; Houston, S.H.; Amat, L.R.; Morrisseau-Leroy, N. The HRD real-time wind analysis system. J. Wind Eng. Ind. Aerodyn. 1998, 77\&78, 53-64. 
7. Mattocks, C.A.; Forbes, C.; Jedlovec, G.; Case, J.; LaFontaine, F. Adaptation of the advanced hurricane WRF for driving a storm surge prediction model. In Proceedings of the 29th Conference on Hurricanes and Tropical Meteorology, Tucson, AZ, USA, 10-14 May 2010.

8. Xiao, Q.; Zhang, X.; Davis, C.; Tuttle, J.; Holland, G.; Fitzpatrick, P.F. Experiments of hurricane initialization with airborne Doppler radar data for the advanced-research hurricane WRF(ARW) model. Mon. Weather Rev. 2009, 137, 2758-2777.

9. Xiao, Q.; Chen, L.; Zhang, X. Evaluations of BDA scheme using the Advanced Research WRF (ARW) model. J. Appl. Meteorol. Climatol. 2009, 48, 680-689.

10. Davis, C.; Wang, W.; Chen, S.S.; Chen, Y.; Corbosiero, K.; DeMaria, M.; Dudhia, J.; Holland, G.; Klemp, J.; Michalakes, J.; et al. Prediction of landfalling hurricanes with the advanced hurricane WRF Model. Mon. Weather Rev. 2008, 136, 1990-2005.

11. Li, X.; Pu, Z. Sensitivity of numerical simulations of the early rapid intensification of Hurricane Emily to cumulus parameterization schemes in difference model horizontal resolutions. J. Meteorol. Soc. Jpn. 2009, 87, 403-421. 
MDPI AG

Klybeckstrasse 64

4057 Basel, Switzerland

Tel. +41 616837734

Fax +41 613028918

http://www.mdpi.com/

JMSE Editorial Office

E-mail: jmse@mdpi.com

http://www.mdpi.com/journal/jmse 


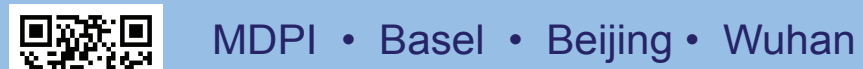
ISBN 978-3-03842-047-7 www.mdpi.com 